\title{
Europäisierung deutscher Migrationspolitik
}

\author{
Dissertation \\ zur Erlangung des sozialwissenschaftlichen Doktorgrades der \\ Sozialwissenschaftlichen Fakultät \\ der Georg-August-Universität Göttingen \\ vorgelegt \\ von
}

Nam-Eun Lee

aus Tanyang, Korea

Göttingen 2012 
1. Gutachterin : Prof. Dr. Ilona Ostner

2. Gutachter : Prof. Dr. Ernst Kuper

3. Gutachterin : Prof. Dr. Claudia Diehl

Tag der mündlichen Prüfung : 17. Oktober 2011 


\section{Inhaltsverzeichnis}

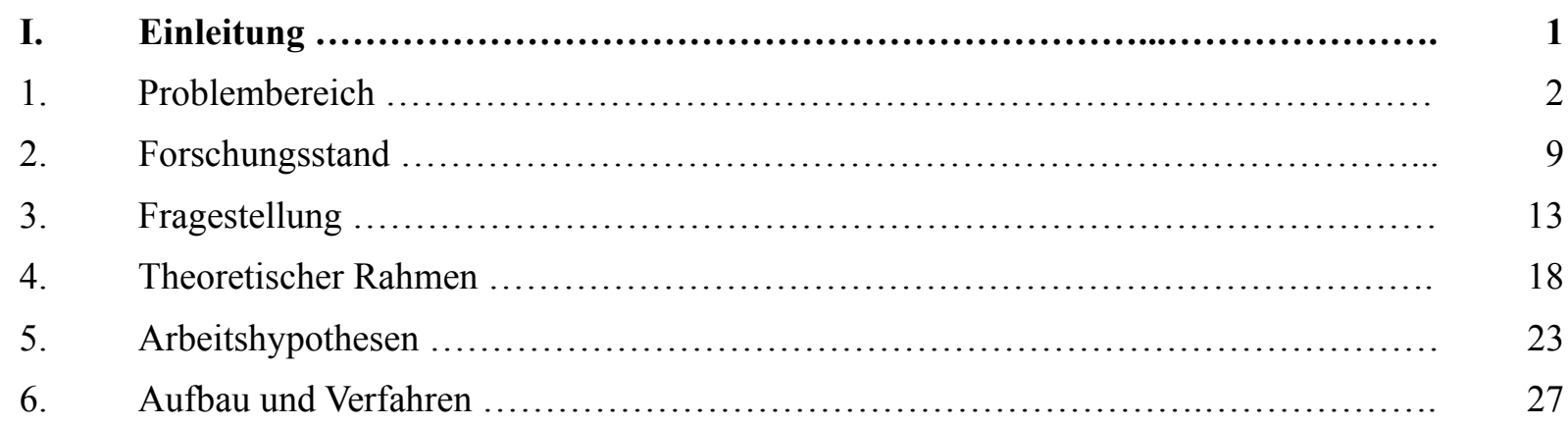

II. Migration und die historische Entwicklung der Migrationspolitik in Deutschland 30

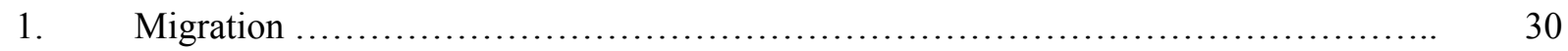

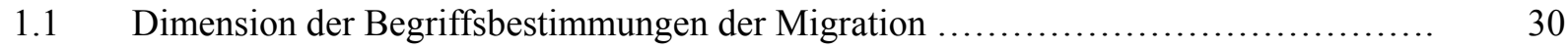

1.2 Dimension der Ursachen, Motive von Migration und Push-Pull-Modell ............... 32

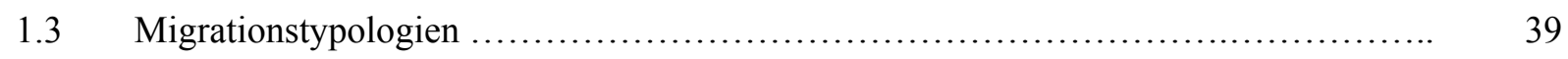

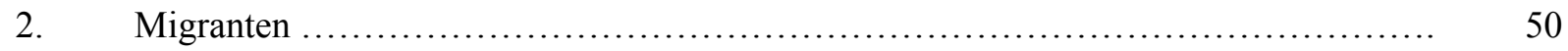

2.1 Dimension der geografischen und demografischen Entwicklungen in der EU ........... 50

2.2 Dimension der geografischen und demografischen Entwicklungen in Deutschland ...... 62

3. Migrationspolitik : Historische Dimension der deutschen Migrationspolitik ............. 76

3.1 Phase 1 : Nachkriegsdeutschland und die dreifache Zuwanderung 1945-1954 ........... 78

3.2 Phase 2 : Anwerbepolitik zu Gastarbeiter und Anwerbestopp 1955-1973 ............... 83

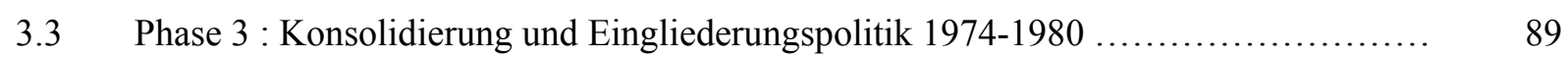

3.4 Phase 4 : Begrenzungspolitik als Wende der Migrationspolitik 1981-1990 ............. 92

3.5 Phase 5 : Fokussierung auf die Asylpolitik 1991-1997 ........................... 97

3.6 Phase 6 : Staatsangehörigkeitsreform und Zuwanderungsgesetz 1998-2004 ............ 102

3.7 Phase 7 : Neue Zuwanderungs- und Integrationspolitik 2005-2012 .................. 108

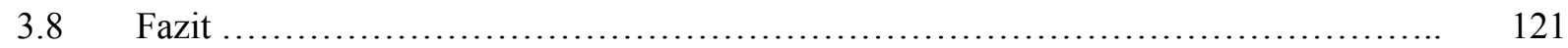

III. Migrationspolitik der Europäischen Union .................................. 124

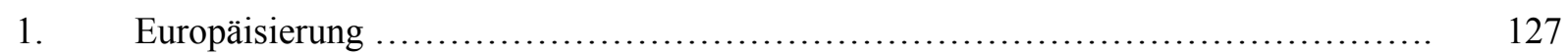

2. Europäisierung durch die vertragliche Institutionalisierung auf EU-Ebene ............. 134

$2.1 \quad$ Die Schengener Abkommen .................................................. 137

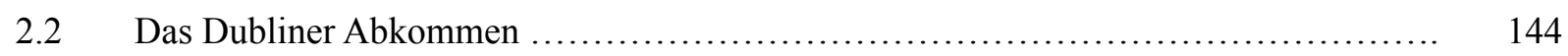

$2.3 \quad$ Londoner Entschließungen .................................................. 149 


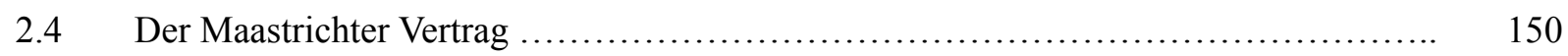

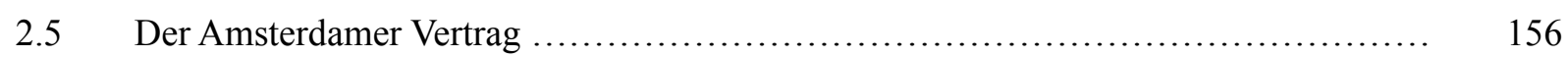

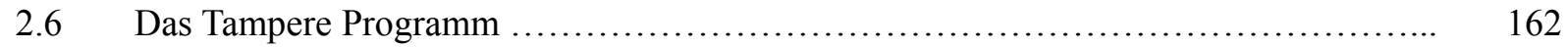

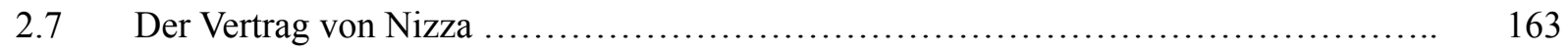

$2.8 \quad$ Das Haager Programm ....................................................... 166

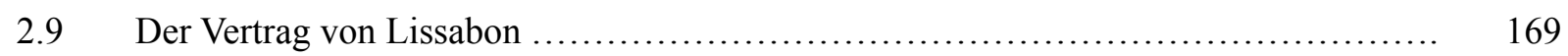

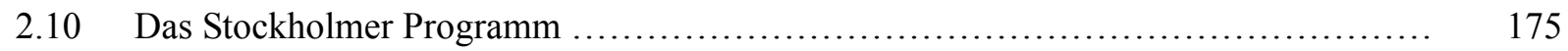

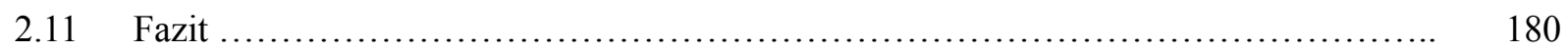

3. Europäisierung des Politikfeldes Migration im europäischen Integrationsprozess ........ 184

$3.1 \quad$ Asyl- und Flüchtlingspolitik der EU ......................................... 184

3.1.1 Bürgerkriegsflüchtlinge aus dem ehemaligen Jugoslawien ......................... 185

3.1.2 Innere Sicherheit durch EUROPOL in der EU ................................. 196

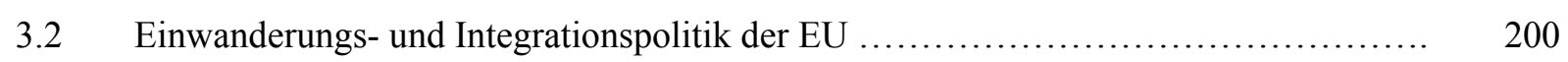

3.2.1 Die Antidiskriminierungsrichtlinie .......................................... 201

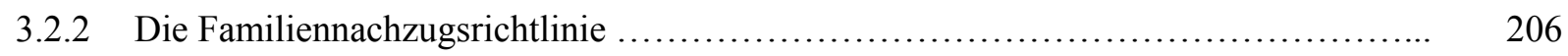

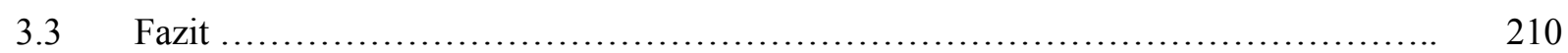

IV. Europäisierung durch Einbindung des deutschen Migrationssystems .............. 212

1. Das Akteursfeld im Kontext der deutschen institutionellen Rahmenbedingungen ........ 213

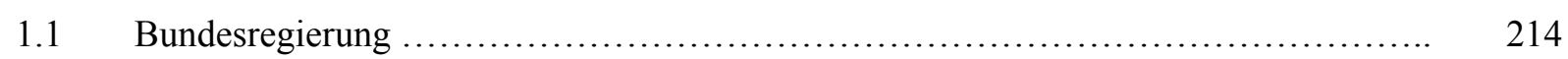

1.1.1 Bundeskanzler und Bundeskanzleramt (BK) .................................. 220

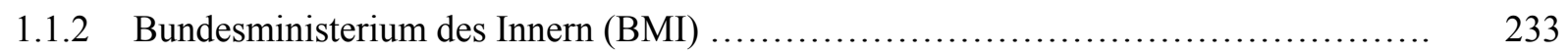

1.1.3 Bundesamt für Migration und Flüchtlinge (BAMF) ............................. 234

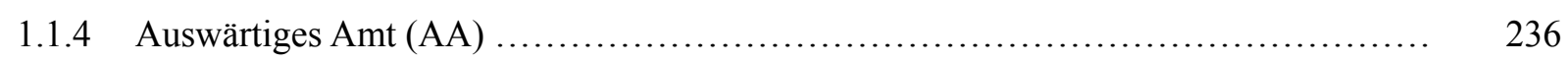

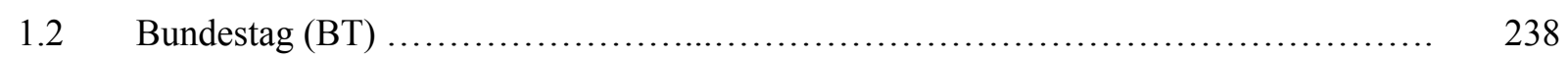

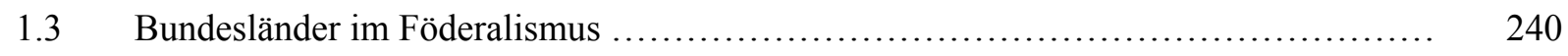

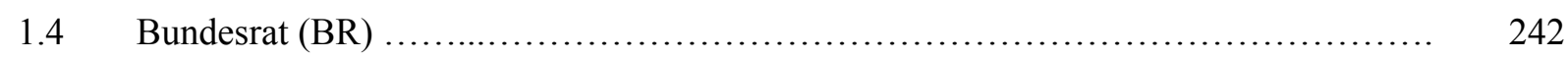

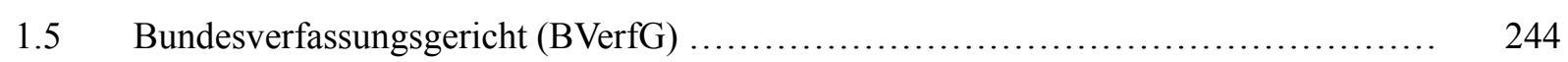

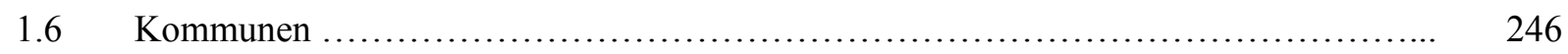

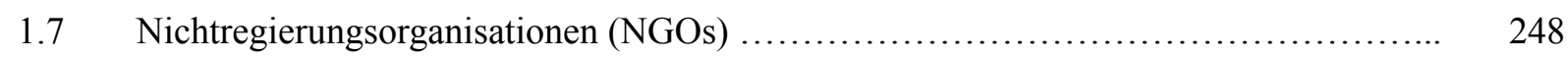

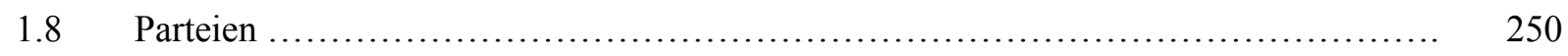

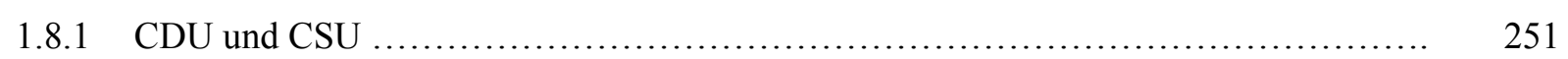

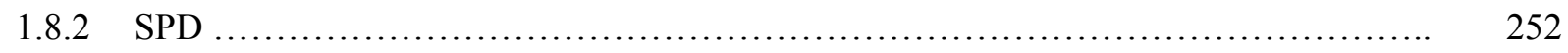

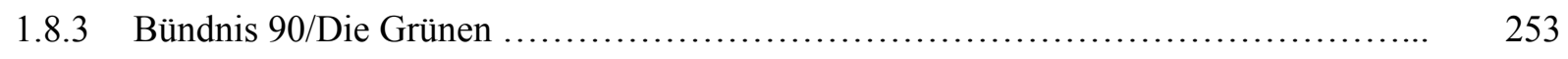

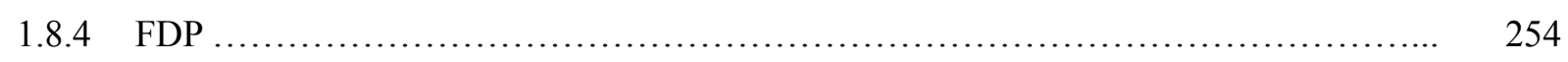

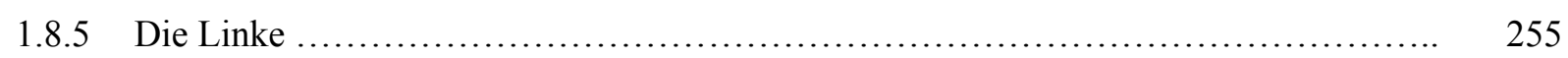




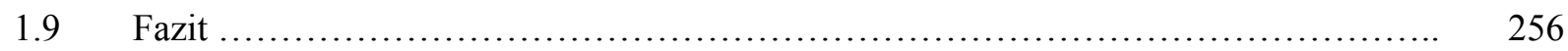

2. Deutsche Interessen im Europäisierungsprozess der Hochqualifizierten ................ 260

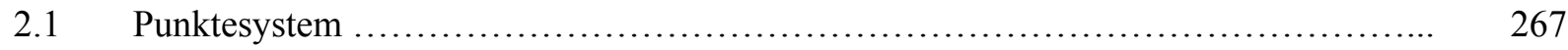

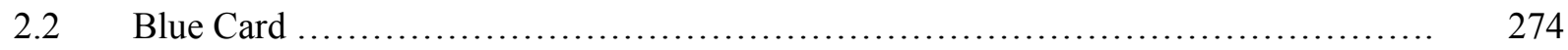

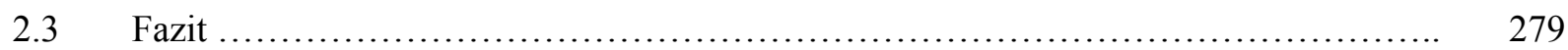

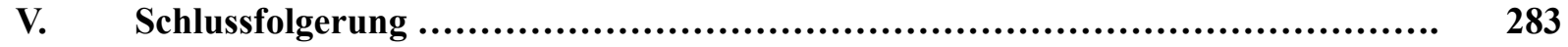

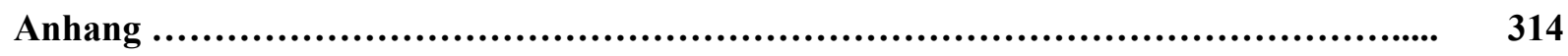

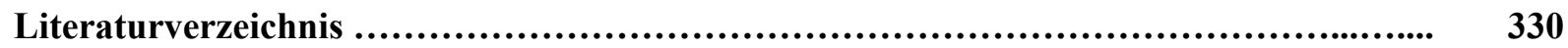





\section{Einleitung}

Deutschland zählt in Europa zu den Staaten, die in der Zeit des wirtschaftlichen Aufschwungs nach dem Zweiten Weltkrieg besonders intensiv Anwerbepolitik betrieben haben, und wird bereits als Teil „Kern-Europas“ mit den Benelux-Ländern und Frankreich das Potenzial zugeschrieben, die Politik der EU maßgeblich beeinflussen oder letztendlich sogar formulieren zu können. ${ }^{1}$ Nach der deutschen Wiedervereinigung und dem Zusammenbruch der kommunistischen Herrschaft in Osteuropa sowie ferner der Öffnung der Grenzen zu Osteuropa hat sich die wirtschaftliche und politische Position der Bundesrepublik Deutschland in Europa erheblich verändert. Die politischen Veränderungen der Jahre 1989/90 haben zusätzlich einen entscheidenden Anteil daran, dass die Bundesrepublik Deutschland seitdem bei dem Thema Ausländerzuwanderung neue Aufgaben bewältigen muss (vgl. Abschnitt I.1).

Heute kann angesichts weltweiter Migrationsbewegungen kein Zweifel mehr darüber bestehen, dass die Bundesrepublik zu einem Einwanderungsland geworden ist. Im Hinblick auf die globale Dimension der Migration wird somit schon von einem „age of migration“ 2 gesprochen, wobei von einer Globalisierung, Beschleunigung, Differenzierung und Feminisierung der Migrationsbewegungen ausgegangen werden kann. Vor diesem Hintergrund möchte die vorliegende Arbeit mit dem Thema der „Europäisierung deutscher Migrationspolitik“ eine neue Perspektive eröffnen.

\footnotetext{
${ }^{1}$ Birsl, Ursula et. al. 2003: Migration und Interkulturalität in Großbritannien, Deutschland und Spanien: Fallstudien aus der Arbeitswelt. Opladen, S. 20.; Tomei, Verònica 2001: Europäisierung nationaler Migrationspolitik: Eine Studie zur Veränderung von Regieren in Europa, Stuttgart, S. 20.; vgl. Woyke, Wichard 2000: Deutsch-französische Beziehungen seit der Wiederverreinigung: Das Tandem faßt wieder Tritt. Opladen, S. 56.; vgl. Faist, Thomas 1998: Immigration, Integration und Wohlfahrtsstaaten. Die Bundesrepublik Deutschland in vergleichender Perspektive. In: Bommes, Michael und Halfmann, Jost (Hrsg.) 1998: Migration in nationalen Wohlfahrtsstaaten: Theoretische und vergleichende Untersuchungen. Osnabrück, S. 147-170, hier S. 152.; vgl. auch Baldwin-Edwards, Martin 1991: Immigration after 1992. In: Policy and Politics, 19. Nr. 3/1991, S. 199-211.

${ }^{2}$ Castles, Stephen / Miller, Mark J. 1998: The Age of Migration. International Population Movements in the Modern World. London, S. 3-8 f.
} 


\section{Problembereich}

Zwischen den Staaten der Europäischen Union $(\mathrm{EU})^{3}$ lässt sich in den vergangenen Jahren zunehmend die Entstehung eines gemeinsamen Migrationsraums beobachten. Aufgrund der geografischen Nähe und des hohen Verflechtungsgrades untereinander sind die EU-Mitgliedstaaten von den jeweiligen nationalen migrationspolitischen Maßnahmen wechselseitig sehr abhängig. Diese gegenseitige Abhängigkeit ist besonders durch die Wanderungsgeschichte Europas ${ }^{4}$ in den über fünf Jahrzehnten zwischen Ende des Zweiten Weltkrieges und Ende des Kalten Krieges zu erklären. Der Bereich der Migrationspolitik, wie man ihn heute im EU-Kontext versteht - nämlich als Politik gegenüber Bürgern von Staaten, die nicht Mitglied der EU sind (sog. Drittausländer bzw. Drittstaatsangehörige $)^{5}$ - ist im historischen, vertraglichen Ablauf von Schengen (1985) aufgeführt.

Im Hinblick auf die Entwicklung der europäischen Migrationspolitik können bis zum heutigen Zeitpunkt vier Phasen ("four phases of european migration") unterschieden werden: "the first begins immediately after the Second World War and ends in the beginning of the 1960s, the second phase lasts until the first oil price crisis 1973/74, the third starts with the end of full-employment in the mid 1970s and ends in 1989, and the fourth begins with the collapse of central planning in 1989. The first phase is characterized by the absorption of large migrations flows caused by the disruptions of the Second World War and decolonization, the second by conventional economic migration, the third by restrained migration after the end of full-employment, and the fourth by the consequences of the dissolution of socialism." 6 Dies stand in unmittelbarem Zusammenhang mit dem Prozess der europäischen Integration. Die

\footnotetext{
${ }^{3}$ Die Erwähnung Europas im Folgenden zielt nicht auf den europäischen Teil des Kontinents Eurasien, sondern die politische Konfiguration, deren ursprüngliches Zentrum die westeuropäischen Staaten darstellen. Mittlerweile gehören zur Europäischen Union (EU), der Nachfolgerin der Europäischen Wirtschaftsgemeinschaft (EWG), auch die südeuropäischen und nordeuropäischen Staaten sowie nach dem Osterweiterung die baltischen und osteuropäischen Staaten. Vgl. Treibel, Annette 2003: Migration in modernen Gesellschaften: Soziale Folgen von Einwanderung, Gastarbeit und Flucht. München, S. 68.

${ }^{4}$ Vgl. Zum historischen Überblick über die Wanderungsbewegungen in und nach Europa: Fassmann, Heinz / Münz, Rainer 1996: Europäische Migration - ein Überblick. In: Fassmann, Heinz / Münz, Rainer (Hrsg.) 1996: Migration in Europa. Historische Entwicklung, aktuelle Trends, politische Reaktionen. Frankfurt a. M., S. 13-52.; vgl. auch. Bade, Klaus J. / Emmer, Pieter C. / Lucassen, Leo / Oltmer, Jochen (Hrsg.) 2010: Enzyklopädie Migration in Europa, Vom 17. Jahrhundert bis zur Gegenwart. Paderborn.

${ }^{5}$ Vgl. Treibel, Annette 2003: Migration in modernen Gesellschaften: a.a.O., S. 72-73.

${ }^{6}$ Boeri, Tito / Hanson, Gordon / McCormick, Barry (Ed.) 2002: Immigration Policy and the Welfare System. Oxford, S. 10-12.
} 
Europäische Gemeinschaft war bereits seit ihrer Gründung in den Römischen Verträgen von $1957^{7}$ auf ein gemeinsames Migrationsregime, und zwar bezüglich der Binnenmigration ausgerichtet. Von Beginn an ging es bei der Schaffung des gemeinsamen Arbeitsmarktes in Europa auch um die Freizügigkeit der EUArbeitnehmer, die ,die Abschaffung jeder auf der Staatsangehörigkeit beruhenden unterschiedlichen Behandlung der Arbeitnehmer der Mitgliedstaaten in Bezug auf Beschäftigung, Entlohnung und sonstige Arbeitsbedingungen“" umfasst (Art. 48 EGVertrag). ${ }^{8}$ Zur Umsetzung dieses Ziels hat die Europäische Gemeinschaft auf der Grundlage der Art. 49 ff. des EG-Vertrags zahlreiche Richtlinien und Verordnungen erlassen, sodass die nationale Politik der EU-Staaten gegenüber EU-Bürgern nahezu vollständig durch sekundäres Gemeinschaftsrecht geregelt ist. Als ein Beispiel hierfür setzt das deutsche Gesetz über Einreise und Aufenthalt von Staatsangehörigen der Mitgliedstaaten der Europäischen Wirtschaftsgemeinschaft teilweise deklaratorisch EGRichtlinien und Verordnungen in deutsches Recht um. ${ }^{9}$ Das gemeinsame Migrationsregime der EU-Staaten hat folglich normative Vorgaben auch für den Umgang mit Drittausländern entwickelt, im Falle von Familienangehörigen von Arbeitnehmern mit der Staatsangehörigkeit eines der Mitgliedstaaten.

Die europäische Migrationspolitik wurde mittlerweile jedoch vor dem Maastrichter Vertrag (1993), vor allem bis 1985, als rein nationale Angelegenheit betrachtet und daher wurde eine graduelle Verschiebung der Handlungsmotivationen erkennbar: ${ }^{10}$ Von einer ausschließlichen Instrumentalisierung der Migrationspolitik für die europäische Einigung zu diversen Merkmalen eines umgekehrten Prozesses, insbesondere einer Instrumentalisierung der europäischen Ebene für die Bewältigung nationaler Migrationsprobleme. Es wurde dann ein völkerrechtlicher, zwischenstaatlicher Rechtsakt erlassen, wenn eine Maßnahme auf europäischer Ebene für erforderlich gehalten wurde. Beispiele hierfür sind die zwei Schengener Abkommen über den

\footnotetext{
${ }^{7}$ In Rom wurden am 25. März 1957 die Verträge zur Gründung der Europäischen Wirtschaftsgemeinschaft (EWG) und der Europäischen Atomgemeinschaft (EAG) von den sechs Gründerstaaten (Belgien, Deutschland, Frankreich, Italien, Luxemburg und die Niederlande) unterzeichnet. Das Inkrafttreten dieser Römischen Verträge erfolgte am 1. Januar 1958. Hierdurch wurde der europäische Einigungsprozess, der sich bis dahin auf den Kohle- und Stahlbereich (Montanunion) begrenzt hatte, auf die gesamte Wirtschaft Westeuropas ausgedehnt. In: Han, Petrus 2005: Soziologie der Migration: Erklärungsmodelle. Fakten. Politische Konsequenzen. Perspektiven. Stuttgart, S. 200.

8 Oppermann, Thomas 1999: Europarecht. München, S. 630 ff.; vgl. Tomei, Verònica 1997: Europäische Migrationspolitik: zwischen Kooperationszwang und Souveränitätsansprüchen. Bamberg, S. 13.

9 Hailbronner, Kai 1995: Ausländerrecht: Kommentar. Heidelberg, D1.

10 Tomei, Verònica 1997: Europäische Migrationspolitik: zwischen Kooperationszwang und Souveränitätsansprüchen. Bamberg, S. 59.
} 
schrittweisen Abbau von Binnengrenzkontrollen hinsichtlich des Bedarfs der gemeinsamen Außengrenzkontrolle (Schengen I vom 14.6.1985 und Schengen II vom 19.6.1990) sowie das Dubliner Abkommen über die Bestimmung des für die Prüfung eines Asylantrags zuständigen Staates. Diese Motivationskette bzw. gegenseitige Abhängigkeit entspringt somit der Sachlogik innerhalb des europäischen Integrationsprozesses, die vor allem zur institutionellen Aufwertung der gemeinsamen migrationspolitischen Bemühungen im Maastricht-Vertrag (1993) und fortwährend zur Vergemeinschaftung im Amsterdamer Vertrag (1999) herangezogen wurde. Seit Mitte der achtziger Jahre wuchs somit die Bedeutung der Migrationspolitik als Teil der auf EU-Ebene verhandelten Politiken.

Der Übergang von den 1980er zu den 1990er Jahren zieht auf dem Gebiet der migrationspolitischen Zusammenarbeit in Europa eine entscheidende Veränderung nach sich: ${ }^{11}$ Der epochale Umschwung der Nachkriegsordnung hat auch auf diesen Bereich. Auswirkungen. Die Wanderungsbewegung wurde durch den Wegfall der restriktiven Feizügigkeitsbeschränkungen im Osten Europas nach dem Ende des kommunistischen Herrschaftssystems verstärkt. Diese Entwicklung, zusammen mit gestiegenen Asylbewerberzahlen und zunehmender illegaler Einwanderung, bewirkte Anfang der neunziger Jahre eine Krisensituation, die sich in den Staaten der Europäischen Union in einer sicherheitspolitischen Perzeption transnationaler Wanderungsprozesse niederschlug. So erlebte der Westen Europas einerseits als mitauslösender Faktor, andererseits als Folgeerscheinung des Regimewechsels im Osten Europas eine massive Erhöhung der Zuwanderungszahlen aus den östlichen Gebieten. Europa war und ist vor diesem Hintergrund durch eine restriktiv orientierte Migrationspolitik in Bezug auf das Sicherheitsproblem gekennzeichnet. ${ }^{12}$ Zur migrationspolitischen Situation der EUStaaten Anfang der neunziger Jahre ist demgemäß ein Schwerpunkt der migrationspolitischen Problematik vor allem im Asylbereich ersichtlich geworden. Die hohen Asylbewerberzahlen in dieser Zeit haben die westeuropäischen Aufnahmestaaten unter anderem deshalb unter starken Handlungsdruck gesetzt, da die Anwendung der aufwendigen Verfahren der Genfer Flüchtlingskonvention (GFK) nicht für große Zahlen von Asylbewerbern, sondern nur für die Maßnahme der Einzelfallprüfung angelegt worden war. Dies führte schnell zu einer Überlastung des gesamten Asylsystems, durch den Bearbeitungsrückstau erfolgte eine Verzögerung der Verfahren über Jahre. Dies verursachte insbesondere in den Ländern, die Asylbewerber in ihr Sozialleistungssystem

${ }^{11}$ Vgl. Tomei, Verònica 1997: Europäische Migrationspolitik: a.a.O., S. 24, 36.

12 Vgl. Huysmans, Jef 2000: The European Union and the Securitization of Migration. In: Journal of Common Market Studies (JCMS), Vol. 38, No. 5. December 2000, S. 751-777. 
integrierten, hohe Kosten. ${ }^{13}$ Die EU-Mitgliedstaaten, die die meisten Asylbewerber zu verzeichnen hatten, waren Deutschland (256.100), Frankreich (47.400), das Vereinigte Königreich (67.000) und die Niederlande (21.600). Weitere wichtige europäische Asylländer waren Schweden (26.500) und die Schweiz (41.600). ${ }^{14}$ Anhand dieser Daten zu Asylsuchenden plädierte vor allem Deutschland Anfang der neunziger Jahre für eine Gemeinschaftszuständigkeit in der Asylpolitik. Diese Sichtweise kam folglich in den Diskussion zu dem Vertrag über die Europäische Union zum Tragen. In der Folge setzten sich die für Einwanderungsfragen zuständigen Minister demnach in ihrem dem Maastrichter Gipfel (Dezember 1991) vorgelegten Bericht mit dem migrationspolitischen Problem auseinander, dass der in den meisten Mitgliedsländern ersichtliche drastische Anstieg des Einwanderungsdruckes eine gemeinsame Beantwortung benötige und die Migration als ein den EU-Staaten gemeinsames Sicherheitsproblem zu begreifen sei: „Es ist nämlich weder vernünftig noch politisch wünschenswert, Zuwanderungsströme aus einem Mitgliedstaat in einen anderen umzuleiten: Man muss das Problem für die gesamte Gemeinschaft in den Griff bekommen. Hierfür werden Instrumente benötigt, die auf einer umfassenden Zusammenarbeit zwischen den Mitgliedstaaten beruhen und die gleichzeitig verhindern, dass sich die Politik eines Mitgliedstaates negativ auf die Politik eines anderen Mitgliedstaates auswirkt.“'15 Der externe Wanderungsdruck auf die EU-Mitgliedstaaten in den 1990er Jahren, dem auf nationaler Ebene nicht effektiv begegnet werden konnte, förderte somit die binnengemeinschaftliche Solidarität und führte zu dem Wunsch nach Lastenteilung, was wiederum das Bemühen um gemeinsame Aufnahmestandards nach sich zog. Demzufolge fand sukzessive in nahezu allen EU-Staaten eine Verschärfung nationaler Aufnahmeregelungen statt, wobei sich Westeuropa zugleich durch „seine koordinierte Visa-Politik von der ,Dritten Welt' abgeschottet und dadurch die meisten Flüchtlinge aus diesen Staaten daran gehindert hat, überhaupt Asyl zu beantragen.“16

Schließlich dringt somit die EU-Ebene - als mögliche zusätzliche Problemlösungsebene

13 Loescher, Gil 1992: Refugee Movements and International Security. Adelphi Papers 268. London:Brassey's, S. 18.

14 Zum Vergleich der Daten zur Zuwanderung von Asylbewerbern siehe Santel, Bernhard 1995: Migration in und nach Europa: Erfahrungen. Strukturen. Politik. Opladen, S. 71; vgl. auch OECD: SOPEMI 1994: Continuous reporting system on migration. Jahresberichte 1989-1994. Paris, S. 188.

15 Ad-hoc-Gruppe Einwanderung (AHE) 1991: Bericht der für Einwanderungsfragen zuständigen Minister an den Europäischen Rat (Maastricht) über die Einwanderungs- und Asylpolitik. Brüssel, WGI 930. S. 13; vgl. auch Tomei, Verònica 1997: Europäische Migrationspolitik: zwischen Kooperationszwang und Souveränitätsansprüchen. Bamberg, S. 24.

16 Thränhardt, Dietrich 1997: Zuwanderungspolitik im europäischen Vergleich. In: Angenendt, Steffen (Hrsg.) 1997: Migration und Flucht: Aufgaben und Strategien für Deutschland, Europa und die internationale Gemeinschaft. Bonn, S. 147. 
für die Herausforderung durch die internationale Migration, die alle EU-Staaten anbelangt - zunehmend in das Bewusstsein der handelnden Akteure. Die Entwicklung dieser Motivationslagen und ihr Niederschlag in einschlägigen Vertragswerken auf EUEbene soll in Kapitel III dieser Arbeit in Bezug auf Europäisierungsprozesse nachgezeichnet werden. Eine gemeinsame Migrationspolitik kann in einem zusammenwachsenden Europa aus einer funktionalen Sicht deshalb somit als wichtig angesehen werden. In dem Migrationsgeschehen in der EU existieren Geddes zufolge Kettenwirkungen (Chain Effects) und Interdependenzen, welche die Mitgliedstaaten miteinander, aber auch mit Drittstaaten, mit Herkunftsländern von Migranten, verbinden. ${ }^{17}$ Migration nach Europa wird diesbezüglich bis heute als ein europaweites, auch humanitäres Problem und nicht (mehr) als einzelstaatlich handhabbar betrachtet. ${ }^{18}$

Hiervon ausgehend lässt sich die migrationspolitische Zusammenarbeit in dem „Mehrebenensystem (multilevel governance)“19 im Rahmen der EU erklären, wobei der innenpolitische Handlungsdruck der einzelnen EU-Mitgliedstaaten aufgrund der verschiedenen geografischen Lage und der Migrationsgeschichte unterschiedlich groß ist. Es liegt daher zwischen den EU-Staaten eine Interessenkongruenz im Hinblick auf das Ziel der Vermeidung weiterer Zuwanderung vor. Aus europapolitischer Sicht besteht auch eine Interessenkongruenz bezüglich der Verhinderung innergemeinschaftlicher Konflikte. Hierbei lässt sich, wie schon erwähnt, seit Anfang der 1990er Jahre für nahezu alle EU-Staaten eine Phase der intensiven Suche nach einer Neukonzeption der Migrationspolitik ersehen. ${ }^{20}$ Die „Migrationskontrolle“ gehört seitdem zu den fundamentalen Interessen der EU, wobei zunächst auf die grundsätzliche Bedeutung der Wanderungskontrolle für den Nationalstaat einzugehen ist: Der Nationalstaat umfasst nicht nur die territoriale Dimension des europäischen Nationalstaats, sondern auch seine personale Dimension. Die Migrationsprobleme verweisen folglich auf die kollektive Identität und auf Inklusions- und Exklusionsregeln. Hierbei wird die „Staatsangehörigkeit“ bzw. „Staatsbürgerschaft“ als Anknüpfungspunkt für die Grenzen

17 Vgl. Geddes, Andrew 2003: The EU Migration Regime's Effects on European Welfare States. In: Lavenex, Sandra / Ucarer, Emek M. (Ed.) 2003: Migration and the Externalities of European Integration. New York, S. 201-202.

18 Argument dazu vgl. auch Maurer, Andreas / Parkes, Roderick 2006: Asylum Policy and Democracy in the European Union from Amsterdam to the Hague Programme. In: SWP-Working Paper Nr. 16. Berlin: Stiftung Wissenschaft und Politik.

19 Zur politikwissenschaftlichen Diskussion und Forschung über „Mehrebenensystemen (multilevel governance)“vgl. Benz, Arthur 2009: Politik in Mehrebenensystemen. Wiesbaden.

20 Dies bezieht sich auf die Mehrzahl der heute geltenden gesetzlichen Zugangsregelungen der EUStaaten datiert nach 1990. In: Tomei, Verònica 2001: Europäisierung nationaler Migrationspolitik: Eine Studie zur Veränderung von Regieren in Europa, Stuttgart, S. 24, Fußnote 21. 
zwischen Bürgern und Fremden bzw. zwischen Inländern und Ausländern aufgefasst ${ }^{21}$ (hierauf wird in der Fragestellung in Abschnitt I.3. näher eingegangen). Dieser Unterschied ist konstitutiv für die Sensibilität des Politikfeldes Migration. ${ }^{22}$ Hintergrund dieser Grundspannung auf dem Gebiet der Migrationspolitik ist die Tatsache, dass internationale Zuwanderung quer zur geltenden Ordnung der Welt in territorial und personal voneinander abgegrenzten Ländern stattfindet. ${ }^{23}$ Migrationspolitik gehört damit zum Kernbereich nationaler Autonomie und zum Ausdruck ihrer Inklusions- und Exklusionsregeln, die die jeweiligen mentalen Bilder des Staats operationalisieren. ${ }^{24}$ Die hohe Souveränitätsrelevanz des Politikfeldes Migration bestimmt demgemäß die Suche nach einer Kooperationsform, folglich ist die migrationspolitische Kooperation der EU-Staaten nur insofern möglich, als dass sie das Interesse an einer Erhöhung nationalstaatlicher Steuerungskompetenz in diesem Bereich mit der Bewahrung nationalstaatlicher Handlungsautonomie verbindet.

In diesen grundlegenden Vorausetzungen wird die Europäisierung ${ }^{25}$ nationaler Migrationspolitik bislang aber nicht genügend berücksichtigt. Die Europäisierung deutscher Migrationspolitik könnte jedoch das komplizierte Projekt der voranschreitenden europäischen Integration darstellen. Diese Aufgabe ist nicht nur eine Herausforderung, weil die Kontrolle über die Aufnahme von Zuwanderern bislang als Kernbereich souveräner Nationalstaaten galt. Vor diesem Hintergrund hervorgehoben werden soll nun die Veränderung des politischen Bezugssystems des Nationalstaates Deutschland in einem Bereich, der traditionell diesem Kernbereich nationalstaatlicher Souveränität zugerechnet wurde. In diesem Verständnis lässt sich die Analyse

${ }^{21}$ Vgl. Eder, Klaus 1998: Warum ist Migration ein soziales Problem? Von einer politischen Ökonomie zu einer politischen Soziologie der Migration. In: Bommes, Michael / Halfmann, Jost (Hrsg.) 1998: Migration in nationalen Wohlfahrtsstaaten: Theoretische und vergleichende Untersuchungen. IMISSchriften Bd. 6. Osnabrück, S. 64.; vgl. Ipsen, Knut 1999: Völkerrecht: Ein Studienbuch. S. 291-295.; vgl. Schulze, Hagen 1994: Staat und Nation in der europäischen Geschichte. München; vgl. auch Brubaker, Rosers 1994: Staats-Bürger: Deutschland und Frankreich im historischen Vergleich. Hamburg, S. 79.

${ }^{22}$ Vgl. Baldwin-Edwards, Martin 1997: The Emerging European Immigration Regime: Some Reflections on Implications for Southern Europe. In: Journal of Common Market Studies (JCMS) 1997. Vol. 35, No. 4. December 1997, S. 497-519, hier S. 497.

${ }^{23}$ Zolberg, Aristide R. 1981: International Migrations in Political Perspektive. In: Kritz, Mary M. / Keely, Charles B. / Tomasi, Silvano M. (Ed.) 1981: Global Trends in Migration. Theory and Research on International Population Movements. New York:Center for Migration Studies, S. 3-27, hier S. 7.; vgl. Tomei, Verònica 2001: Europäisierung nationaler Migrationspolitik: Eine Studie zur Veränderung von Regieren in Europa, Stuttgart, S. 24.

${ }^{24}$ Bauböck, Rainer 1996: Nation, Migration und Staatsbürgerschaft. In: Beyme, Klaus von / Offe, Claus (Hrsg.) 1996: Politische Theorien in der Ära der Transformation. PVS-Sonderheft Nr. 26/1995. Opladen, S. 325-348, hier S. 330-332.

${ }^{25}$ Zum Begriff der "Europäisierung (Europeanization)" bzw. " Europäisierungsprozess" wird in Kapitel III. 1. dieser Arbeit näher betrachtet. 
angesichts der migrationspolitischen Probleme vor allem bezogen auf Akteurskonstellationen sowie nationalstaatliche Interessen nicht einfach als „Inputs“ in ein undifferenziertes politisches System, also im Sinne von Eastons Systemmodell fast ausschließlich auf „demands and support“ des politischen Systems betrachten, das diese dann zu „Outputs“ in „decisions and actions“ umwandelt; vielmehr soll die Analyse der vorliegenden Arbeit zeigen, wie bestimmte politische Akteure mit bestimmten Handlungsorientierungen und Fähigkeiten diese nationalstaatlichen Interessen in ihre eigenen Handlungsorientierungen einfließen lassen bzw. diese nicht berücksichtigen. ${ }^{26}$

Wie bereits erwähnt, nehmen internationale Wanderungsbewegungen bis heute einen wachsenden Stellenwert in der deutschen und europäischen Politik ein und sind von weltpolitischer Bedeutung. Dabei sind die sozialen, wirtschaftlichen und arbeitsmarktpolitischen Probleme von Migration in vielfältiger Weise mit Gesichtspunkten der inneren Sicherheit und der Steuerbarkeit bzw. der Steuerungsfähigkeit der staatlichen Akteure $^{27}$ in der EU verknüpft. Es ist demgemäß sinnvoll, auf die vergangenen Jahrzehnte zurückzublicken und zu bewerten, ob die bisher erzielten Ergebnisse einen politischen Willen der Mitgliedstaaten - hier insbesondere im Fall Deutschland - erkennen lassen, Fortschritte auf diesem Gebiet zu erreichen.

Aus diesem Grund wird nun dem Forschungsziel dieser Arbeit nachgegangen, die deutsche Migrationspolitik seit den 1990er Jahren bei der Entwicklung einer gemeinsamen Migrationspolitik in der EU unter den Bedingungen der „Europäisierung“ näher zu ergründen und folglich die Eigendynamik der Europäisierungsprozesse auf nationaler- und EU-Ebene systematisch herauszuarbeiten.

\footnotetext{
${ }^{26}$ Vgl. Scharpf, Fritz W. 2000: Interaktionsformen: Akteurzentrierter Institutionalismus in der Politikforschung. Opladen, S. 128.; vgl. auch Jann, Werner / Wegrich, Kai 2009: Phasenmodelle und Politikprozesse: Der Policy Cycle. In: Schubert, Klaus / Bandelow, Nils C. (Hrsg.) 2009: Lehrbuch der Politikfeldanalyse 2.0, München, S. 76.

27 Vgl. Luft, Stefan 2009: Staat und Migration: Zur Steuerbarkeit von Zuwanderung und Integration. Frankfurt a. M.
} 


\section{Forschungsstand}

Die vorliegende Arbeit verfolgt den Prozess der Europäisierung der Migrationspolitik seit den neunziger Jahren, wobei die Untersuchung der Europäisierung der Migrationspolitik ein vergleichsweise junger Forschungsgegenstand ist. Hierbei wird zunächst versucht, die drei untersuchten Ebenen miteinander zu verknüpfen: Es gibt zum einen Beiträgen, welche die Politikprozesse auf EU-Ebene untersuchen (Angenendt (Ed.) 1999/2002; Angenendt/Parkes 2010; Bendel 2006; Bendel 2009; Boeri/Hanson/McCormick (Ed.) 2002; Caestecker 2006; Geddes 2000; Geddes 2003; Kohler-Koch/Conzelmann/Knodt (Hrsg.) 2004; Maurer/Parkes 2006; Maurer/Parkes 2007; Niemann 2008; Schulte 2002; Schwarz 2008; Wolter (Hrsg.) 1999). Zum anderen lässt sich Migration auf nationaler Ebene (darunter u. a. Deutschland) erforschen (Angenendt 2008; Bommes 1996/2000/2001; Butterwegge 2009; Currle/Wunderlich (Hrsg.) 2001; Currle 2004; Davy/Weber (Hrsg.) 2006; Faist 1998; Ireland 2004; Kühne 2009; Luft 2009; Meyer 2002; Münz/Seifert/Ulrich 1997; Münz 2001; Schulte/Treichler 2010; Thränhardt/Hunger (Hrsg.) 2003; Weber 1997; Wilp 2007). Darüber hinaus ist eine geringere Zahl an Publikationen zu nennen, die die beiden Ebenen von Europäisierungsprozess und Migration miteinander verbinden (Birsl 2005; Geddes 2000; Geddes 2005; Hunger/Aybek/Ette/Michalowski (Hrsg.) 2008; Lavenex 2001; Lavenex/Ucarer (Ed.) 2003; Märker 2001/2002; Santel 1995; Tomei/Heckmann 1999; Tomei 2001; Treichler 2002).

Die bisherigen migrationspolitischen Untersuchungen auf EU-Ebene beschäftigen sich vorwiegend mit Gemeinschaftskompetenz und supranationalen Entscheidungsmechanismen (Brasche 2003; Jachtenfuchs/Kohler-Koch 1996; KohlerKoch 1998b; Tömmel 2008). Die weitere Forschung über die europäische Migrationspolitik ist insbesondere durch die gemeinsame Asylpolitik und die EUStrategien zur Bekämpfung der illegalen Einwanderung geprägt (Alt/Bommes (Hrsg.) 2006; Bigo 2001; Koslowski 2001; Lavenex 2001). Für die Erforschung der nationalen Ebene in Deutschland findet sich ein entwickelndes Migrationssystem, in dem nationale Entscheidungsprozesse, Strukturen und die rechtlichen Regelungen und Debatten miteinander verflochten werden (Groß 2006; Parusel/Schneider 2010; Santel/Weber 2000; Schönwälder 2004/2006). Der Forschungsstand eröffnet jedoch den Blick auf eine Legitimationslücke der Europäisierung nationaler Migrationspolitik (Kielmansegg 1996; Beyers/Kerremans 2005). Trotz des wachsenden Interesses ist die Forschung von 
Migrationsprozessen in der Politikwissenschaft der Bundesrepublik bislang nicht in gleichem Ausmaß etabliert wie etwa in den Vereinigten Staaten, Australien oder Frankreich. Ein Grund für die vergleichsweise geringe Resonanz liegt in dem kollektiven deutschen Selbstverständnis begründet, dass sich Deutschland im Unterschied $\mathrm{zu}$ den genannten klassischen Einwanderungsländern nie als Einwanderungsland definiert bzw. akzeptiert hat. ${ }^{28}$ Diese Haltung findet einerseits ihren besonderen Ausdruck im bisherigen Abstammungsprinzip (Ius sanguinis) der Staatsbürgerschaft (Brubaker 1992/1994), neben der im Januar 2000 das Territorial- bzw. Geburtsortprinzip (Ius soli) in Bezug auf eine neue Staatsangehörigkeitsrechtsreform in Kraft trat. Andererseits werden Einwanderer auch bei einem Aufenthalt und vollzogener Integration weiterhin als Ausländer bzw. Gastarbeiter betrachtet. Hierdurch liegen die Stärken der noch relativ jungen politikwissenschaftlichen Migrationsforschung in Deutschland eher in der Analyse politischer Debatten und Konflikte und der Grundlinien staatlicher Migrationspolitik. Untersucht wurden z. B. Parteienkonkurrenz hinsichtlich des Einwanderungskonflikts (Hunger/Kolb 2001; Tietze 2008), Entwicklung und Besonderheiten des deutschen Staatsangehörigkeitsrechts (Brubaker (Hrsg.) 1994: Hagedorn 2001), Asylpolitik und Debatten um das bundesdeutsche Asylrecht (Münch 1992; Süssmuth 2006), kommunale Integrationspolitik in Deutschland (Häußermann/Kapphan 2008; Gesemann/Roth (Hrsg.) 2009), Konzeption und Umsetzung politischer Interventionen gegen Diskriminierung (Fereidooni 2011; Schulte/Treichler 2010), die Minderheitenpolitik (Heckmann 1992; Schönhuth 2008), die Entwicklung der deutschen und europäischen Migrationspolitik (Baringhorst/Hunger/Schönwälder (Hrsg.) 2006; Nuscheler 2004; Geddes 2005) sowie Arbeit und Einfluss von Migrantenorganisationen bzw. organisierte nicht-staatliche Akteure (z. B. NGOs) (Angenendt 2003; Eising/Kohler-Koch 2005; Seifer 2009). Des Weiteren liegt ein Schwerpunkt der Migrationsforschung in der Bundesrepublik Deutschland, vor allem zur juristischen Diskussion der Aufenthalts- bzw. Anerkennungs- und sozialrechtlichen Aspekte, auf den sozial-integrativen Fragestellungen der Migrationspolitik, vornehmlich der Bildungs- und Arbeitsplatzsituation und den Mechanismen sozialer Stratifikation sowie dem Familiennachzug (vgl. Franz 2006; Keskin 2005; Kluth/Hund/Maaßen (Hrsg.) 2008; Kühne 2009; Lederer 2006; Luft 2009). Daneben beziehen einige Autoren von neueren Sammelbänden, in denen nationale Migrationspolitiken verglichen werden, auch zunehmend Beiträge zu den Entwicklungen auf europäischer Ebene mit ein (z. B. Birs1 et al. 2003; Baringhorst/Hunger/Schönwälder (Hrsg.) 2006; Bommes/Halfmann (Hrsg.)

${ }^{28}$ Santel, Bernhard 1995: Migration in und nach Europa:Erfahrungen. Strukturen. Politik. Opladen, S. 17. 
1998; Bommes/Geddes (Ed.) 2000; Butterwegge/Hentges (Hrsg.) 2009; Hentges/Hinnenkamp/Zwengel (Hrsg.) 2008; Heinelt (Hrsg.) 1994; Thränhardt (Ed.) 1996; Treichler (Hrsg.) 2002). Es gibt jedoch parallele Länderstudien, die eine europäische Perspektive berücksichtigen, dies allerdings mehr in inhaltlicher Richtung und weniger im Hinblick auf die Frage nach den sich entwickelnden institutionellen, europäisierten Veränderungen (Bade (Hrsg.) 2001; Bade/Münz (Hrsg.) 2000; Bommes/Halfmann (Hrsg.) 1998; Düvell 2006; Seifert 2000; Treichler (Hrsg.) 2002; Weber (Hrsg.) 1997). Zudem trat und tritt nunmehr die Rolle der einzelnen institutionellen Akteure zwischen den beiden Ebenen EU und Mitgliedstaaten, wie im Fall der Bundesrepublik Deutschland, stärker in den Vordergrund (vgl. Angenendt 1999a; Baumann 2006; Bendiek 2004; Kohler-Koch u. a. 1998; Parusel 2010; Santel 1995; Schneider 2010). Auch hat in den letzten 20 Jahren der Historiker Klaus Bade einen wesentlichen Beitrag zur deutschen Migrationsforschung geleistet. In seinem kulturhistorischern Forschungsansatz beschreibt er in Deutschland die Tendenz einer Veränderung, d. h., er geht davon aus, dass sich die Bundesrepublik mit der Zeit von einem Gastarbeiterland $\mathrm{zu}$ einem Einwanderungsland entwickeln wird (Bade 1983/2004). Unter seiner Herausgabe sind auch zahlreiche Aufsatzsammlungen zum Thema entstanden (2001/Bade et al. 2010). Außerdem schreiben Bade (2000/2004), Münz (1997), Treibel (2003), Han (2005) ausführlich über die Geschichte der Migrationsbewegungen.

Die europäische Zusammenarbeit in der Migrationspolitik befindet sich daher seit Anfang der neunziger Jahre zunehmend im Fokus des wissenschaftlichen Forschungsinteresses. Während vor und in den achtziger Jahren das Migrationsphänomen und soziale Folgen des Migrationsprozesses die beherrschenden Themen der Migrationsforschung waren, richtet sich das wissenschaftliche Interesse seit Mitte der achtziger Jahre vorrangig auf staatliche Steuerungsversuche in diesem Bereich der Migrationspolitik (Hammar 1985; Angenendt 1992). Dementsprechend sind die migrationspolitischen Interessen vielschichtiger geworden: Heute, im 21. Jahrhundert, wird - im Gegensatz zum Überwiegen von Abschottungs- und Sicherheitsinteressen in den 1990er Jahren - Zuwanderung in deutlich breiter angelegten Zusammenhängen betrachtet. Gleichzeitig werden in wachsendem Maße Differenzierungen zwischen der Wirtschaft förderlichen und nicht willkommenen Migranten vorgenommen und die Thematik der Zuwanderung wandelt sich in diesem Zusammenhang zu einer wirtschaftspolitischen sowie arbeitsmarktpolitischen Fragestellung (Angenendt/Parkes 2010; Nohl/Schittenhelm/Schmidtke/Weiß 2010). 
Vor diesem Hintergrund richtet sich das Untersuchungsinteresse dieser Arbeit sowohl auf Veränderungen einzelner Politikinstrumente als auch auf Prozesse, in denen nationalstaatliche Migrationspolitik gestaltet wird. Die Bedeutsamkeit dieses Interesses liegt jedoch nicht in einem unmittelbaren „Anpassungsdruck“ an die nationale Politik, sondern in der Ausbildung der Reproduktionsmechanismen der nationalstaatlichen Institutionen. Darüber hinaus sind der klare neo-institutionentheoretische Bezug und Institutionalisierungsprozesse sowie die Anschlussfähigkeit an die parallele Kompetenzausübung im Politikfeld der Migratrionspolitik von Bedeutung. Mit diesem Verständnis versucht die vorliegende Arbeit auch in Bezug auf die Europäisierungsforschung eine neue Perspektive mit der Vorstellung der ,parallelen Institutionalisierung in der Migrationspolitik ${ }^{\text {‘29 }}$ aufzuzeigen: $^{30}$ Die Migrationspolitik der EU ist zwar breit erforscht, allerdings noch nicht ausreichend unter dem Gesichtspunkt der aktuellen Debatte um die „Europäisierung“. Bezüglich der Europäisierung wird hierbei sowohl die Bottom-up-Perspektive - etwa in der Untersuchung des Einflusses der Mitgliedstaaten auf europäische Regulierung und Politikgestaltung (Hèritier et al. 1994) - als auch die Top-down-Perspektive eingenommen, die sich bislang überwiegend einseitig auf die Implementierung europäischer Policies konzentrierte (Börzel/Risse 2000; Cowles et al. 2001; Knill 2001; Featherstone/Radaelli 2003). Die Forschungseinrichtung wird demnach eine Koordination nationaler Migrationspolitik auf der supranationalen Ebene der EU vornehmen und folglich diesen zweifachen Prozeß der Europäisierung systematisch herausarbeiten. Parallel werden die Wechselwirkungen und beziehungen im europäischen Mehrebenensystem bzw. in den spezifischen Akteurskonstellationen thematisiert (Grande 1996; Hèritier 1999; Schmidt 1998; Tömmel 1994). Darüber hinaus gibt es auch weiteren Forschungsbedarf hinsichtlich der Interaktion der Mitgliedstaaten, hier im Fall der deutschen Akteure, und der Funktionsweisen der EUAkteure, vor allem Kommission, Rat und Europäisches Parlament im Wettstreit der Interessen über die Ausgestaltung der gemeinsamen Migrationspolitik und der Politiken zur Steuerung der Migration. In diesem Kontext wäre mit Blick auf die Forschungslücke der Frage nachzugehen, inwieweit die Europäisierung der Migrationspolitik durch die Systemstruktur und die Interaktion zwischen den institutionellen Akteuren bzw. Akteursinteressen der EU und Deutschland konkret ausgestaltet wird.

\footnotetext{
29 Vgl. Conzelmann, Thomas 2002: Große Räume, kleine Räume: Europäisierte Regionalpolitik in Deutschland und Großbritannien. Baden-Baden.

30 Vgl. Tömmel, Ingeborg (Hrsg.) 2008: Die Europäische Union: Governance und Policy-Making. S. 15.
} 


\section{Fragestellung}

Vor dem Hintergrund des beschriebenen Forschungsstands zu diesem Thema ist es das Ziel der vorliegenden Arbeit, die deutsche Migrationspolitik im Hinblick auf die Entwicklung einer gemeinsamen Migrationspolitik unter den Bedingungen der „Europäisierung“ näher zu ergründen. Angesichts dieses Forschungsziels ist zunächst in der Betrachtung der migrationspolitischen Interessen der Tatsache Rechnung zu tragen, dass das Politikfeld Migration einen Kernbereich nationalstaatlicher Souveränität darstellt (vgl. Abschnitt I.1.): Es ist unstrittig, dass Nationalstaaten das souveräne Recht haben, über den Zugang zum Staatsgebiet und zum Staatsvolk zu bestimmen. Der Staat übt jedoch nicht nur Gebietshoheit ${ }^{31}$ aus, sondern auch Personalhoheit ${ }^{32}$ über die zu seinem Staat gehörenden Personen. Das Recht, diese Zugehörigkeit zu definieren, ist unmittelbarer Ausfluss der Personalhoheit. Fraglich ist jedoch, inwieweit die Personalhoheit des Staates auch diejenigen Staatsangehörigen betrifft, die sich außerhalb seines Territoriums aufhalten. Migrationspolitik, die die Regelung vom Zugang Fremder zum Staatsgebiet und den Aufenthalt von diesen auf dem Territorium vornimmt, ist damit Kernbereich staatlicher Hoheitsrechte. Dies stellt auch klar, dass die nationalstaatliche Migrationspolitik ihre Entstehung im Zusammenhang mit der Frage der Staatsangehörigkeit ${ }^{33}$ hat: In Deutschland werden die formale state-membership, die partizipatorische citizenship und die ethnisch-kulturelle nation-membership durch verschiedene Begriffe beschrieben: Staatsangehörigkeit, Staatsbürgerschaft und Nationalität beziehungsweise Volkszugehörigkeit. ${ }^{34}$ Die Staatsangehörigkeit unterscheidet zwischen Fremden und Nicht-Fremden im modernen Nationalstaat. Sie ist nicht nur als ein Instrument der Schließung, als eine Basis für den Genuss bestimmter

31 „Die Gebietshoheit wirkt in zweierlei Hinsicht: Zum einen über das ihr unterliegende Territorium, über das der Staat verfügen kann. Darüber hinaus erstreckt sich die Gebietshoheit auch auf alle Personen und Sachen, welche sich auf dem Territorium eines Staates befinden. Hieraus ergibt sich zugleich, dass aus der Gebietshoheit des Staates die Befugnis folgt, den auf seinem Territorium befindlichen Einzelpersonen bindende Befehle für ihr Verhalten vorzuschreiben und diese Anordnungen durchzusetzen.“ In: Ipsen, Knut 1999: Völkerrecht: Ein Studienbuch. S. 291.

32 „Ein Staat ist aber in erster Linie ein Personenverband und basiert insofern auf einer „persönlichen“ Grundlage, als er ein Treueverhältnis zwischen dem Staat und seinem Staatsvolk voraussetzt. Dies drückt sich grenzüberschreitend in der Personalhoheit aus.“ In: Ipsen, Knut 1999: Völkerrecht: Ein Studienbuch. München, S. 291.

33 Die Staatsangehörigkeit eröffnet als ,Mitgliedschaftsrecht den Zugang zu einer Vielzahl von Rechtspositionen [...], die nicht universal jedem Menschen, sondern nur den Angehörigen des eigenen Staates eingeräumt sind [...].“ Preuß, Ulrich 1993: Zum verfassungstheoretischen Begriff des Staatsbürgers in der modernen Gesellschaft. In: Preuß, Ulrich (Hrsg. ) 1993: Staatsbürgerschaft und Zuwanderung. Bremen: Zentrum für Europäische Rechtspolitik. S. 23.

34 Brubaker, Rosers 1994: Staats-Bürger: Deutschland und Frankreich im historischen Vergleich. Hamburg (amerikanische Originalausgabe von 1992), S. 79. 
Rechte oder für die Teilnahme an bestimmten Interaktionsarten zu verstehen. Sie ist vielmehr in sich selbst, als Status mit beschränktem Zugang, - Gegenstand der Schließung. ${ }^{35}$ Die politische Seite der Staatsangehörigkeit betrifft folglich politische Bürgerrechte und -pflichten. Bedenkt man hierzu, in welchem Maße die Kopplung moderner Nationalstaaten das Interesse der Aufnahmeländer an einer Zuwanderungskontrolle fördert, so ist nicht anzunehmen, dass die Nationalstaaten vollständig auf ihre migrationspolitischen Befugnisse verzichten werden. ${ }^{36}$ Als Grundlagen der Migrationspolitik sind somit die Grenzkontrolle und die Staatsangehörigkeit als Hauptinstrumente sozialer und territorialer Schließung zu sehen. ${ }^{37}$ Vor diesem Hintergrund erscheint supranationale Migrationspolitik also auf EU-Ebene nahezu unmöglich, zumindest dann, wenn sie eine Politik jenseits der nationalstaatlichen Souveränität impliziert. Daher liegt ein besonderes Interesse in der Frage, wie unter diesen Bedingungen Kooperation gestaltet wird und inwiefern es demnach möglich ist, dieses kooperationsbedürftige und zugleich souveränitätsrelevante Gebiet im Rahmen einer Mehrebenenpolitik umfassend zu europäisieren. Mit diesen Fragen soll insbesondere auch auf das Verhältnis zwischen nationalstaatlicher Handlungsautonomie und auf die Einbindung in die europäische Handlungsebene bzw. auf das Interesse an erweiterter Problemlösungskompetenz näher eingegangen werden.

Zusätzlich zu der allgemeinen politischen Bedeutung, vor allem in Bezug auf die oben angesprochene Souveränitätsrelevanz der Migrationspolitik in Nationalstaaten, ist es schließlich von besonderem Interesse zu untersuchen, wie sich traditionell nach innen ausgerichtete institutionelle Strukturen des Nationalstaates an die Herausforderungen zunehmender Interdependenz anpassen. ${ }^{38}$ Das zentrale Erkenntnisinteresse ist demzufolge die Veränderung des Migrationssystems in Deutschland. Deutschland ist bereits weltweit als ein spezifisches Wohlfahrtsstaatsregime gekennzeichnet, das in der Studie Baldwin-Edwards ${ }^{39}$ als das kontinentaleuropäisches Regime oder nach dem Schengener Modell darauf ausgerichtet ist, mit relativ starker Kontrolle der

${ }^{35}$ Brubaker, Rosers 1994: Staats-Bürger: Deutschland und Frankreich im historischen Vergleich. S. 57.

${ }^{36}$ Tomei, Verònica / Heckmann, Friedrich 1999: Europäisierung und nationalstaatliche Souveränität Das Beispiel Migrationspolitik. In: Wenzel, Heinz-Dieter (Hrsg.) 1999: Integration und Transformation in Europa. Forschungsform Heft 9/1999. Berichte aus der Otto-Friedrich-Universität Bamberg, S. 117.

37 Tomei, Verònica 2001: Europäisierung nationaler Migrationspolitik: Eine Studie zur Veränderung von Regieren in Europa, Stuttgart, S. 40.

38 Tomei, Verònica 2001: Europäisierung nationaler Migrationspolitik: a.a.O., S. 14.

39 Baldwin-Edwards, Martin 1991: Immigration after 1992. In: Policy and Politics, 19. Nr. 3/1991, S. 199-211; vgl auch Faist, Thomas 1998: Immigration, Integration und Wohlfahrtsstaaten. Die Bundesrepublik Deutschland in vergleichender Perspektive. In: Bommes, Michael und Halfmann, Jost (Hrsg.) 1998: Migration in nationalen Wohlfahrtsstaaten: a.a.O., S. 147-170, hier S. 152. 
Zuwanderung im Ganzen, Einwanderungsmöglichkeiten nur für ökonomisch notwendige „Gastarbeiter“ zu bieten. Ein Wohlfahrtsstaatsregime erklärt sich hierbei als "the specific institutional arrangement adopted by societies in the pursuit of work and welfare." ${ }^{40}$ Somit können Immigrations- und Integrationsregime als das spezifische institutionelle Arrangement von nationalen Wohlfahrtsstaaten zur Regulierung der Aufnahme und Integration von Zuwanderern definiert werden. In diesem Zusammenhang ordnet Esping-Andersen Deutschland als konservativ-korporatistisches (bezüglich der kontinental-europäischen Länder) Wohlfahrtsstaatsregime in seinen „The Three Worlds of Welfare Capitalism“411 ein. Die Variablen zur Unterscheidung dieser Typen bezeichnen den jeweiligen Grad der De-Kommodifizierung ${ }^{42}$ der Arbeitskraft bzw. das erreichte Niveau sozialer Rechte. ${ }^{43}$ Es wäre dann die Frage zu stellen, ob das Migrationssystem Deutschlands durch die Kriterien „Niveau sozialer Rechte“ und „Grad der Arbeitsmarktregulierung“ beschreibbar ist. In diesem Verständnis ist auch auf eine Forschungslücke hinzuweisen: Bislang wurde einer Re-Kommodifizierung der Arbeitskraft in Bezug auf die Integrationspolitik der Migranten zu geringe Aufmerksamkeit zuteil. ${ }^{44}$ Insofern ist die Forschungsfrage auf Implikationen des Verhältnisses von Migration, Nationalstaat und Wohlfahrtsstaat angewiesen, die die Problemstellungen der Migrationsforschung, Ungleichheit bzw. die institutionalisierte Ungleichheit und Integration im Kern anbelangen. Als eine der entscheidenden Fragen ist in diesem Zusammenhang $\mathrm{zu}$ sehen, welche kollektiven Akteure innerhalb der Nationalstaaten und der EU institutionelle Lösungen der Integration oder NichtIntegration in Bezug auf ein wahrgenommenes Kosten-Nutzen-Verhältnis favorisieren.

${ }^{40}$ Esping-Andersen, Gosta 1987: The Comparison of Policy Regimes: An Introduction. In: Rein, Martin / Esping-Andersen, Gosta / Rainwater, Lee (Hrsg.) 1987: Stagnation and Renewal. The Rise and Fall of Policy Regimes. Armonk/New York, S. 3-13, hier S. 6.

${ }^{41}$ Esping-Andersen, Gosta 1993: The Three Worlds of Welfare Capitalism. Princeton, S. $21 \mathrm{f}$.

${ }^{42}$ Der Begriff der De-Kommodifizierung bezieht sich darauf, in welchem Ausmaß soziale Leistungen als Rechte gewährt werden und Personen ihren Lebensunterhalt eventuell auch ohne direkte Abhängigkeit vom Arbeitsmarkt bestreiten können. Vgl. dazu Esping-Andersen, Gosta 1993: The Three Worlds of Welfare Capitalism. Princeton, S. 21f.; mit „Re-Kommodifizierung“ ist dann die umgekehrte Bewegung gemeint, d. h. eine tendenzielle und partielle Zurücknahme von einem in Wohlfahrtsstaaten erreichten Niveau sozialer Rechte. Zitiert in Faist, Thomas 1998: Immigration, Integration und Wohlfahrtsstaaten. Die Bundesrepublik Deutschland in vergleichender Perspektive. In: Bommes, Michael und Halfmann, Jost (Hrsg.) 1998: Migration in nationalen Wohlfahrtsstaaten: a.a.O., S. 150: Fußnote 8.

43 „In welchem Umfang ein bestimmtes Niveau formaler sozialer Rechte konkret zur Geltung kommt, hängt von der Verteilung der sozialpolitischen Aufgaben in den drei Institutionen Markt, Staat und Familie ab." In: Faist, Thomas 1998: Immigration, Integration und Wohlfahrtsstaaten. Die Bundesrepublik Deutschland in vergleichender Perspektive. A.a.O., S. 151.

${ }^{44}$ Faist, Thomas 1998: Immigration, Integration und Wohlfahrtsstaaten. Die Bundesrepublik Deutschland in vergleichender Perspektive. In: Bommes, Michael und Halfmann, Jost (Hrsg.) 1998: Migration in nationalen Wohlfahrtsstaaten: a.a.O., S. 147-170, hier S. 170. 
Mit dem Forschungsziel der vorliegenden Arbeit soll die Untersuchung, wie an anderer Stelle bereits erwähnt, indes auch darauf verweisen, dass die Arbeit auf einer neoinsitutionalistischen Perspektive basiert, die Anknüpfungspunkte zwischen unterschiedlichen Erklärungsansätzen zur Europäisierung der Migrationspolitik gestattet und die an Institutionen gekoppelte Prozesshaftigkeit der Interessenvertretung hervorheben soll. Diesbezüglich ist ein Trend zur Europäisierung von Politik bemerkenswert, sobald und soweit sich das Handeln einer kritischen Menge von Akteuren an der auf den europäischen Raum bezogenen Institutionenordnung zu orientieren beginnt bzw. dieser Institutionenordnung durch neu in das Politikfeld eintretende, einflussreiche Akteure Gewicht zukommt. Arbeiten hinsichtlich der Analysen zur Europäisierung von Politik in den EU-Mitgliedstaaten haben somit immer wieder auf die Bedeutsamkeit politikfeldübergreifender Institutionenordnungen hingewiesen. ${ }^{45}$ Das Forschungsinteresse dieser Arbeiten richtet sich demnach auf die Frage nach der Orientierungsleistung institutioneller Arrangements und institutioneller Leitideen für politische Akteure. Dabei gehen allerdings politische Strukturentscheidungen und Leitideen auf europäischer Ebene einerseits und institutionell relevante Einstellungs- und Handlungsmuster auf der nationalen Akteursund Adressatenebene andererseits auseinander. ${ }^{46}$

Mit diesem Verständnis besteht ein Schwerpunkt der vorliegenden Analyse darin, die von den Akteuren in der deutschen Migrationspolitik vertretenen Interessen zu untersuchen (dies wird in Kapitel IV.1 näher betrachtet). Welche politischen Interessen werden dabei von den deutschen Akteuren vertreten? Welche Interessen sind ausdrücklich für die Europäisierung bzw. die gemeinsame Migrationspolitik einzuführen und folglich zu schaffen? Die Frage kann indes jedoch nicht völlig losgelöst von der EU-Migrationspolitik betrachtet werden. Daher wird in dieser Arbeit die Entwicklung der gemeinsamen Interessen im Rahmen der EU ebenfalls beleuchtet. Das Forschungsinteresse richtet sich somit zunächst auf Fragen der Motive, Formen und Dynamisierungsfaktoren sowie Auswirkungen migrationspolitischer Kooperation im Rahmen der institutionellen Einordnung der Europäischen Union: Warum sollte die EU-

45 Vgl. Kohler-Koch, Beate (Hrsg.) 1998: Europäisierung der Regionen. Institutioneller Wandel als sozialer Prozeß. In: Kohler-Koch, Beate u. a. 1998: Interaktive Politik in Europa. Regionen im Netzwerk der Integration. Opladen, S. 13-31; Schmidt, Vivien A. 2001: Europeanization and the Mechanics of Economic Policy Adjustment. In: European Integration Online Papers (EIoP) 5(6); http://eiop.or.at/eiop/texte/2001-006a.htm

46 Vgl. Sturm, Roland / Pehle, Heinrich 2001: Das neue deutsche Regierungssystem. Die Europäisierung von Institutionen, Entscheidungsprozessen und Politikfeldern in der Bundesrepublik Deutschland. Opladen. 
Ebene offen sein? In welcher Form ist die europäische Zusammenarbeit der Migrationspolitik entwickelt worden und welche Veränderungen sind im Laufe der Zeit $\mathrm{zu}$ verfolgen? Welche Dynamisierungsfaktoren sind dabei von Bedeutung gewesen? Welche Auswirkungen inhaltlicher und institutioneller Art sind auf nationaler Ebene zu beobachten? Inwiefern wird das Spannungsverhältnis zwischen den nationalen Souveränitätsansprüchen und dem Kooperationszwang aufgelöst? Welche Blockaden stehen der weiteren Vergemeinschaftung im europäischen Mehrebenensystem entgegen? Darauf aufbauend sollen folgende Fragen die Untersuchung der Europäisierung deutscher Migrationspolitik näher strukturieren: Inwiefern kann deutsche Migrationspolitik innerhalb der EU ausgeführt bzw. vertieft und infolgedessen zur Europäisierung entwickelt werden? Hierbei wird gefragt, mit welchen Herausforderungen die deutsche Migrationspolitik hinsichtlich der EU konfrontiert wird und wie die Reaktionen darauf ausfallen werden. Von welchen innen- und außenpolitischen Faktoren werden die migrationspolitischen Entscheidungen beeinflusst? Vor diesem Hintergrund schließt sich die Frage an, welche Ergebnisse und Perspektiven die bisherigen Europäisierungsschritte für den künftigen Umgang Deutschlands mit Flüchtlingen und Migranten ${ }^{47}$ bieten.

${ }^{47}$ Bezüglich der begrifflichen Unterscheidung zwischen Flüchtlingen und Migranten lässt sich mit den Worten von Bernhard Santel erklären: „Bei der freiwilligen Migration sind es überwiegend ökonomische Motive, also der Wunsch nach verbesserten sozialen Lebensbedingungen, nach höherem Einkommen, sicherer Arbeit und besseren individuellen Entfaltungsmöglichkeiten, die als auslösende Faktoren zu betrachten sind. Idealtypisch geht der freiwilligen Migration ein Entscheidungsprozeß voraus, in dem Vor- und Nachteile der Abwanderung rational gegeneinander abgewogen werden [...]. Von der freiwilligen Wanderung ist die Zwangswanderung zu unterscheiden. Hier gibt es [...] keine Entscheidungsalternative. Der Flüchtling ist vielmehr aufgrund unmittelbar ausgeübter (acute refugee) oder sicher zu erwartender (anticipatory refugee), sein Leben und seine Freiheit gefährdender Gewalthandlungen zur Flucht gezwungen." In: Santel, Bernhard 1995: Migration in und nach Europa: Erfahrungen. Strukturen. Politik. Opladen, S. 22, 24.; vgl. auch Treibel, Annette 2003: Migration in modernen Gesellschaften: Soziale Folgen von Einwanderung, Gastarbeit und Flucht. München, S. 157-163; vgl. Pries, Ludger 2001: Internationale Migration. Bielefeld.; vgl. Schoenemann, Peter 1994: Das Asylrecht in europäischen Staaten. Eine vergleichende Betrachtung. In: Heinelt, Hubert (Hrsg.) 1994: Zuwanderungspolitik in Europa: Nationale Politiken - Gemeinsamkeiten und Unterschiede. Opladen, S. 68-69. 


\section{Theoretischer Rahmen}

Die Arbeit erhebt den Anspruch, den komplexen Europäisierungsprozessen in der Entwicklung deutscher Migrationspolitik durch eine auf verschiedenen Ansätzen des Neo-Institutionalismus (NI) ${ }^{48}$ basierenden Analyse gerecht $\mathrm{zu}$ werden: „Europeanization as a political process may be understood in terms of both the creation of a European polity and the adaptation of national polities to European integration.(...) Drawing on a new institutionalist analytical framework, it is shown that these differential patterns of national adaptation correspond to more general models of incremental institutional change and, as such, are likely to be a persisting feature of European integration." 49 Von diesen NI-Ansätzen werden in der vorliegenden Arbeit zunächst der Rational-Choice-Institutionalismus (RC: ,Logik der Konsequenz') einerseits und der soziologische (SI: ,Logik der Angemessenheit') und historische Institutionalismus (HI: ,Logik der Sequenz') andererseits betrachtet. Alle drei Richtungen beschäftigen sich damit, warum politische Akteure sich so verhalten, wie sie es tun, welche Wahlhandlungen sie vornehmen, und insbesondere, wie diese Wahlhandlungen von Institutionen beeinflusst oder bestimmt werden. ${ }^{50}$ Der Schwerpunkt der Auseinandersetzungen des Neo-Institutionalismus liegt damit in dem jeweils unterstellten Handlungsmodell, d. h. der Annahme unterschiedlicher Formen

${ }^{48}$ Für die theoretische Überlegung des Neo-Institutionalismus (NI) vgl. Hall, Peter A. / Taylor, Rosemary C. R. 1996: Poitical Science and the Three New Institutionalism. In: Political Studies 44 (5), S. 936957; vgl. auch Immergut, Ellen M. 1998: The Theoretical Core of the New Institutionalism. In: Politics \& Society (26) 1, S. 5-34; March, James G / Olsen, Johan P. 1989: Rediscovering Institutions: The Organizational Basis of Politics. New York; vgl. March, James G / Olsen, Johan P. 1998: The Institutional Dynamics of International Political Orders. International Organization 52 (4), S. 943-969; vgl. Pierson, Paul 2000: Increasing Returns, Path Dependence, and the Study of Politics. In: American Political Science Review 94 (2), S. 251-267; vgl. auch Berg-Schlosser, Dirk / Quenter, Sven (Hrsg.) 1999: Literaturführer Politikwissenschaft: Eine kritische Einführung in Standardwerke und „Klassiker“ der Gegenwart. Stuttgart, S. 152 f.; vgl. Harmsen, Robert 2000: Europeanzation and Governance: A New Institutionalist Perspektive. In: Harmsen, Robert / Wilson, Thomas M. (Ed.) 2000: Europeanization: Institution, Identities and Citizenship. Amsterdam-Atlanta, S. 51-81; vgl. Van Waarden, Frans 2009: Institutionen zur Zentralisierung und Kontrolle politischer Macht. In: Schubert, Klaus / Bandelow, Nils C. (Hrsg.) 2009: Lehrbuch der Politikfeldanalyse 2.0. München, S. 273-312, hier S. 284-291; vgl. auch Scharpf, Fritz W. 2006: Interaktionsformen. Akteuerszentrierter Institutionalismus in der Politikforschung. Opladen; vgl. Parusel, Bernd 2010: Abschottungs- und Anwerbungsstrategien: EU-Institutionen und Arbeitsmigration. Wiesbaden, S. 58.; vgl. Katzenstein, Peter J. 2000: Gezähmte Macht: Deutschland in Europa. In: Knodt, Michèle / Kohler Koch, Beate (Hrsg) 2000: Deutschland zwischen Europäisierung und Selbstbehauptung. S. 58.

${ }^{49}$ Harmsen, Robert 2000: Europeanzation and Governance: A New Institutionalist Perspektive. In: Harmsen, Robert / Wilson, Thomas M. (Ed.) 2000: Europeanization: Institution, Identities and Citizenship. Amsterdam-Atlanta, S. 51-81, hier S. 51.

${ }^{50}$ Van Waarden, Frans 2009: Institutionen zur Zentralisierung und Kontrolle politischer Macht. In: Schubert, Klaus / Bandelow, Nils C. (Hrsg.) 2009: Lehrbuch der Politikfeldanalyse 2.0. S. 283. 
und Gründe der Verhaltensstrukturierung durch Institutionen: „Most importantly, the new institutionalism is based on a markedly more extensive understanding of the term 'institution'. The new institutionalism looks not only at core political institutions (such as executives, legislatures, and parties), but casts its net much wider so as to bring in a range of other politically significant institutions." ${ }^{51}$ Hierdurch lassen sich politische Instituionen verstehen als „Regelsysteme der Herstellung und Durchführung verbindlicher, gesamtgesellschaftlich relevanter Entscheidungen und Instanzen der symbolischen Darstellung von Orientierungsleistungen einer Gesellschaft. Der erste Halbsatz formuliert den Steuerungsaspekt, der zweite den Integrationsaspekt. " 52 Institutionen haben demgemäß neben der regulierenden Funktion auch eine orientierende Funktion, als dass sie symbolisch bestimmte Wertbezüge und Leitideen offenbaren. ${ }^{53}$ Dergestalt verdeutlicht die Auslegung Göhlers, dass sich auf supranationaler Ebene in zunehmendem Maße ebenfalls institutionelle Ordnungen entwickeln, welche regulierende und orientierende Leistungen erzielen, wobei jedoch der Einfluss der nationalstaatlichen Bezugsräume konstant bleibt. ${ }^{54}$

Im Folgenden lassen sich die oben genannten drei Zweige des politikwissenschaftlichen Neo-Institutionalismus (NI), indem die Behauptung einer strukturierenden Wirkung von Institutionen auf den Politikverlauf aufgestellt wird, näher definieren (vgl. hierzu den theoretischen Überblick in Abbildung 1).

51 Harmsen, Robert 2000: Europeanzation and Governance: A New Institutionalist Perspektive. In: Harmsen, Robert / Wilson, Thomas M. (Ed.) 2000: Europeanization: a.a.O., S. 58.

52 Göhler, Gerhard 1997: Wie verändern sich Institutionen? Revolutionärer und schleichender Institutionenwandel. In: Göhler, Gerhard (Hrsg.) 1997: Institutionenwandel. Leviathan, Sonderheft 16/1997. Opladen, S. 21-56, hier S. 29.

53 Vgl. Lepsius, M. Rainer 1995: Institutionenanalyse und Institutionenpolitik. In: Nedelmann, Birgitta (Hrsg.) 1995: Politische Institutionen im Wandel. Opladen:Kölner Zeitschrift für Soziologie und Sozialphychologie (KZfSS), Sonderheft 35, S. 392-403.

54 Conzelmann, Thomas 2002: Große Räume, kleine Räume: Europäisierte Regionalpolitik in Deutschland und Großbritannien. Baden-Baden, S. 35. 


\section{Abbildung 1}

\section{Neo-Institutionalismus : Main features of the three institutionalist approaches ${ }^{55}$}

\begin{tabular}{|c|c|c|c|}
\hline & $\begin{array}{l}\text { Soziologischer } \\
\text { Institutionalismus (SI) }\end{array}$ & $\begin{array}{l}\text { Historischer } \\
\text { Institutionalismus (HI) }\end{array}$ & $\begin{array}{l}\text { Rationalistischer } \\
\text { Institutionalismus (RC) }\end{array}$ \\
\hline Wissenschaftsverständnis & $\begin{array}{l}\text { Konstruktivistisch, } \\
\text { Identitäten, geteilte } \\
\text { Erfahrungen, } \\
\text { Kultur. }\end{array}$ & $\begin{array}{l}\text { Eigeninteressen der } \\
\text { Akteure werden } \\
\text { eingeschränkt. }\end{array}$ & $\begin{array}{l}\text { Methodologischer } \\
\text { Individualismus, } \\
\text { nutzenmaximierendes } \\
\text { und strategisches } \\
\text { Verhalten. }\end{array}$ \\
\hline Forschungsfragen & $\begin{array}{l}\text { Fallstudien: } \\
\text { „kulturelle/ } \\
\text { kognitive Links“. }\end{array}$ & $\begin{array}{l}\text { Fallstudien/Zeitge- } \\
\text { schichtlich. }\end{array}$ & $\begin{array}{l}\text { Kausale Illustrationen } \\
\text { von Hypothesen, } \\
\text { quantitative Tests. }\end{array}$ \\
\hline Zeitliche Ausrichtung & langfristig. & langfristig. & kurzfristig. \\
\hline Wirkung von & Entscheidende & Intervenierende & Intervenierende \\
\hline $\begin{array}{l}\text { Institutionen auf } \\
\text { menschliches Verhalten }\end{array}$ & $\begin{array}{l}\text { unabhängige } \\
\text { Variable; kulturelle } \\
\text { Einschränkung }\end{array}$ & $\begin{array}{l}\text { Variable; gewachsene } \\
\text { Einschränkung }\end{array}$ & $\begin{array}{l}\text { Variable; situative } \\
\text { Einschränkung }\end{array}$ \\
\hline Präferenzbildung & $\begin{array}{l}\text { Endogen: } \\
\text { Institutionen } \\
\text { formen Akteure }\end{array}$ & $\begin{array}{l}\text { Endogen: } \\
\text { Institutionen } \\
\text { wirken sich auf } \\
\text { Akteure aus. }\end{array}$ & $\begin{array}{l}\text { Exogen: unabhängig } \\
\text { vom } \\
\text { Entscheidungsverlauf }\end{array}$ \\
\hline $\begin{array}{l}\text { Wie entstehen } \\
\text { Institutionen? }\end{array}$ & Evolutionär & aus Delegation & $\begin{array}{l}\text { Verteilungsfrage } \\
\text { (Reduzierung von } \\
\text { Transaktionskosten). }\end{array}$ \\
\hline $\begin{array}{l}\text { Entwicklung von } \\
\text { Institutionen }\end{array}$ & $\begin{array}{l}\text { Kognitiver Prozess, } \\
\text { Ereignisse } \\
\text { werden mythologisiert }\end{array}$ & $\begin{array}{l}\text { Fortlaufender Prozess, } \\
\text { pfadabhängig }\end{array}$ & $\begin{array}{l}\text { Verhandlungsergebnis; } \\
\text { evolutionär/Wettbewerb }\end{array}$ \\
\hline
\end{tabular}

${ }^{55}$ Quelle: Aspinwall, Mark D. / Schneider, Gerald 2000: Same menu, separate tables: The institutionalist turn in political science and the study of European integration. In: European Journal of Political Research, Volume 38, No. 1 (August 2000). Netherlands, S. 1-36, hier S. 7 (englisches Original siehe Anhang: Übersicht 1); zentrale Autoren des ,NI': Geoffrey Garret, George Tsebelis, Paul Pierson, Mark Pollack, John Zysman. 


\section{A. Rational-Choice-Institutionalismus (RC)}

Entsprechend dem Rational-Choice-Ansatz (RC: Logik der Konsequenz), welcher im Grunde auf mikroökonomischen Hypothesen sowie auf der rationalen Kosten-NutzenVariante basiert, besteht das Interesse der politischen Akteure darin, mit anderen Akteuren im Hinblick auf das strategische Verhalten bzw. den Wettbewerb zusammenzuarbeiten. Ziel der Akteure ist demgemäß eine Maximierung der Eigeninteressen, wobei sie ihre Bestrebungen auf eine rationale Art umsetzen, indem sie alternative Wahlmöglichkeiten vergleichen und jene Alternative aussuchen, die ihnen den maximalen Nutzen bei der Reduzierung von Transaktionskosten ${ }^{56}$ bringt. Das RCModell setzt in diesem Sinn voraus, dass politische Akteure ihren Interessen und Präferenzen folgen, weil sie es so wollen. ${ }^{57}$ An dieser Stelle beinhaltet die Europäisierung als Einbindung in vielseitige Kooperationen und Institutionen mannigfache Möglichkeiten der Selbstbehauptung der unterschiedlichen Akteure. Dabei bleibt zu beachten, dass die Handlungspräferenzen der einzelnen Akteure exogen, also von außen vorgegeben sind, d. h. die Form und der Wandel der Institutionen ist als das Resultat individueller Entscheidungen vorgegeben und somit nicht von sozialer Interaktion abhängig. Das RC-Modell nimmt demgemäß eine Abstraktion vom sozialen Zusammenhang vor. Die Betonung liegt auf den Wahlhandlungen methodologischer Individuen, die von ihrem sozialen Kontext losgelöst betrachtet werden.

\section{B. Soziologischer Institutionalismus (SI)}

Der soziologische Institutionalismus (SI: Logik der Angemessenheit) nimmt an, dass Akteure „handeln, weil sie denken dass es von anderen sozialen Akteuren so von ihnen erwartet wird und dass es sich so gehört. ${ }^{\text {(58 }}$ Soziale Akteure definieren somit ihre Präferenzen und Präferenzrangordnung nicht isoliert, sondern in sozialen Interaktionen. Solche Präferenzen können sich dabei auch während der sozialen Interaktion, d. h. im Laufe des Spiels ständig verändern. Damit sind die Spielregeln endogen vorgegeben und im Modell variabel. ${ }^{59}$ Des Weiteren wird nach diesem SI-Ansatz das Verhältnis von

\footnotetext{
56 Schubert, Klaus / Bandelow, Nils C. 2009: Lehrbuch der Politikfeldanalyse 2.0. Oldenbourg, S. 284.

57 Van Waarden, Frans 2009: Institutionen zur Zentralisierung und Kontrolle politischer Macht. S. 290.

58 Van Waarden, Frans 2009: Institutionen zur Zentralisierung und Kontrolle politischer Macht. S. 290.

59 Harmsen, Robert 2000: Europeanzation and Governance: A New Institutionalist Perspektive. S. 59.
} 
Akteuren und Institutionen als integrativ betrachtet: Die Handlungen von Akteuren werden von Institutionen beeinflusst, die die Akteure formen. ${ }^{60}$ Kennzeichnend für die Normen und Identitäten der Akteure sind die zwei wesentlichen Auswirkungen: Die Institutionen setzen Akteure ein und beeinflussen ihre Interessen, sie beschränken sich somit auf Akteurspräferenzen. ${ }^{61}$ Die „Wirkung von Institutionen auf Akteursinteressen beruht nicht nur auf Nutzenkalkül, sondern auch auf der bewussten oder unbewussten Befolgung von Normen. “62 Folglich wird jede Entscheidung eines Akteurs immer in einem institutionellen Rahmen gefällt. Die politischen Handlungsoptionen können somit nicht nur über den Rechtsweg vermittelt werden. Sie finden vielmehr auch parallel anhand eines Prozesses der sozialen Anerkennung Verbreitung.

\section{Historischer Institutionalismus (HI)}

Der historische Institutionalismus (HI: Logik der Sequenz) fokussiert auf die Rolle der Vergangenheit, des Vorangegangenen für politische Entscheidungsfindung, der Geschichte. Der HI-Ansatz unterstreicht vor allem die „Pfadabhängigkeit“ (d. h. „frühere Wahlhandlungen beeinflussen spätere“). Diesbezüglich erklärt der HI-Ansatz, warum Akteure der Tradition folgen. Demzufolge werden die Akteure erläutern: „Ich handle, weil ich es immer so getan habe, weil Veränderung teuer ist. “63 Die Akteure hängen insofern der Tradition an, wobei Institutionen diese Tradition repräsentieren. In dieser Hinsicht lässt sich somit eindeutig erkennen, dass die Veränderungen in KostenNutzen-Relationen zu teuer sein kann oder mit den geltenden Normen nicht im Einklang stehen. ${ }^{64}$ Vor diesem Hintergrund bezieht sich der HI-Ansatz auf die „Zeitdimension“ oder die „historische Prozesshaftigkeit des Verhältnisses zwischen Insitutionen und Akteuren." ${ }^{65}$ Hierbei ist die Pfadabhängigkeit insbesondere für die Entwicklung von Institutionen bedeutend. In diesem Zusammenhang wirken bestehende politische Institutionen auf nachfolgende Wahlhandlungen ein; dies umfasst dabei auch die Wahl, diese Insitutionen zu verändern. ${ }^{66}$ Nach diesem Verständnis fällt es den politischen Akteuren schwer, sich von den einmal entwickelten Modellen und Regeln freizumachen und gegebenfalls einen neuen Pfad einzuschlagen.

\footnotetext{
60 Parusel, Bernd 2010: Abschottungs- und Anwerbungsstrategien: a.a.O., S. 58.

61 Katzenstein, Peter J. 2000: Gezähmte Macht: Deutschland in Europa. A.a.O., S. 58.

62 Parusel, Bernd 2010: Abschottungs- und Anwerbungsstrategien: a.a.O., S. 58.

63 Van Waarden, Frans 2009: Institutionen zur Zentralisierung und Kontrolle politischer Macht. S. 287.

${ }^{64}$ Van Waarden, Frans 2009: Institutionen zur Zentralisierung und Kontrolle politischer Macht. S. 287 f.

65 Parusel, Bernd 2010: Abschottungs- und Anwerbungsstrategien: a.a.O., S. 58.

${ }^{66}$ Van Waarden, Frans 2009: Institutionen zur Zentralisierung und Kontrolle politischer Macht. S. 287.
} 


\section{Arbeitshypothesen}

Vor dem Hintergrund der unterschiedlichen theoretischen Ansätze des NeoInstitutionalismus (NI) wird weiter unten die zentrale These entwickelt, dass eine Europäisierung deutscher Migrationspolitik insbesondere dann zu erwarten ist, wenn die Europäisierung zunächst nicht mehr auf einem Anpassungsdruck angesichts von EUVorgaben auf nationaler Ebene basiert bzw. verstanden und kommuniziert wird. Die Europäisierung deutscher Migrationspolitik wird in zunehmendem Maße ermöglicht, wenn der Prozess der Europäisierung verstärkt im Zusammenhang mit der wesentlichen Übertragung aktiver deutscher Interessenpolitik von Akteuren auf die Europäische Union betrachtet wird, und dieser vor allem in Bezug auf die parallele Institutionalisierung der Kompetenzausübung verschiedener nationaler und supranationaler Akteure der EU und Deutschland zum Tragen kommt. Ich gehe nun von folgenden zentralen Arbeitshypothesen aus:

Erstens: Die Migrationspolitik des Nationalstaats Deutschland wird im Kernbereich nationalstaatlicher Souveränität durch die supranationale Institutionalisierung noch nicht penetriert.

Die erste These bezieht sich auf die von Radaelli ${ }^{67}$ erwähnte „Penetration“ mitgliedstaatlichen Regierens in der EU. Die Veränderung mitgliedstaatlicher Politik basiert dabei einerseits auf der von Kohler-Koch unter Bezugnahme auf Rosenaus 68 genannten Befestigung ,legitimer Einmischung“ europäischer Akteure in die Ausgestaltung nationaler Politik, andererseits auf der schrittweisen Institutionalisierung regulativer, kognitiver und normativer Bezugspunkte politischen Handelns, welche auf den europäischen EU-Raum bezogen sind und sich im Wettbewerb mit den etablierten Institutionenordnungen der Mitgliedstaaten darstellen: „Der Prozess der Vergemeinschaftung stellt die nationale Souveränität zur Disposition und induziert eine Neukonstruktion des politischen Raums.

${ }^{67}$ Radaelli, Claudio M. 2000: Whither Europeanization? Concept Stretching and Substantive Change. In: European Integration Online Papers (EIoP) Vol. 4 (2000) Nr. 8, S. 3. Abrufbar unter: http://www.eiop.or.at/eiop/texte/2000-008.htm (Stand: 17.07.2000).

68 „A penetrated political system is one in which non-members of a national society participate directly and authoritatively, through actions taken jointly with the society's members, in either the allocation of its values or the mobilization of support on behalf of its goals". In: Rosenau, James N. (Hrsg.) 1969: Linkage Politics. Essays on the Convergence of National and international Systems. New York/London, S. 65.; vgl. Conzelmann, Thomas 2002: Große Räume, kleine Räume: Europäisierte Regionalpolitik in Deutschland und Großbritannien. Baden-Baden, S. 32 (Fußnote 31.). 
Das Besondere daran ist, dass dabei das Prinzip der territorialen Herrschaft in Frage gestellt wird. [...]. Es ist ein Mehrebenensystem im Entstehen, in dem Regionen ebenso wie Nationalstaaten zu Bestandteilen eines ,penetrated system' (Rosenau 1969) werden; d. h. eines Systems, in dem ,äußere Einmischung' institutionell verankert und als legitim anerkannt ist. [...]. Vor allem in Politikfeldern, in denen sich europäische und nationale bzw. regionale Kompetenzen überschneiden, geraten konkurrierende institutionelle Regelungsmechanismen unter Druck“. ${ }^{69}$ Eingedenk des ,penetrated systems" ist somit zu den zentralen Bestandteilen der Europäisierungsprozesse zu sagen, dass die Neukonstruktion des politischen Raums, die institutionelle Verankerung und Legitimität von äußerer Einmischung und die Beeinflussung nationaler Politikfelder durch europäisch begründete Institutionen bewirkt wird. ${ }^{70}$ Die diesem System eigenen Verhandlungszwänge und die vielfältigen Zugangskanäle in den politischen Prozessen können auch von einzelnen Akteuren instrumentalisiert werden, um deren jeweilige Interessen durchzusetzen.

Zweitens: Wenn Deutschland seine Kompetenzausübung mit den EU-Vorgaben als quasi parallele Institutionalisierung ${ }^{71}$ auf nationaler- und europäischer Ebene integrieren kann, dann ist eine Europäisierung deutscher Migrationspolitik wahrscheinlicher.

Eine Verdeutlichung dieser parallelen Institutionalisierung veranschaulichte die Arbeit von Kohler-Koch/Edler: ${ }^{72}$ Die parallel europäisch und mitgliedstaatlich vermittelte Institutionalisierung von Regeln, Normen und Prinzipien erzeugt ein transparentes System des Regierens. Eine Überschneidung mitgliedstaatlicher Institutionenordnungen durch parallele europäische Steuerungs- und Orientierungsangebote kann in eine Europäisierung mitgliedstaatlicher Politik münden. Triebkraft dieser Europäisierung ist die von der Europäischen Kommission aktiv betriebene Institutionenpolitik, durch die bestimmte soziale und ordnungspolitische Leitbilder verbreitet und in bestimmten

${ }^{69}$ Kohler-Koch, Beate 1998: Europäisierung der Regionen: Institutioneller Wandel als sozialer Prozeß. In: Kohler-Koch, Beate, u. a. (Hrsg.) 1998: Interaktive Politik in Europa. Regionen im Netzwerk der Integration. Opladen, S. 15, 22.

${ }^{70}$ Vgl. Kohler-Koch, Beate 2000: Europäisierung: Plädoyer für eine Horizonterweiterung. In: KohlerKoch, Beate / Knodt, Michèle (Hrsg.) 2000: Deutschland zwischen Europäisierung und Selbstbehauptung. Frankfurt a. M., S. 19-27.

71 Zur These der ,parallelen Institutionalisierung“ vgl. auch Conzelmann, Thomas 2002b: Große Räume, kleine Räume: Europäisierte Regionalpolitik in Deutschland und Großbritannien. S. 48-51.

72 Kohler-Koch, Beate / Edler, Jakob 1998: Ideendiskurs und Vergemeinschaftung: Erschließung transnationaler Räume durch europäisches Regieren. In: Kohler-Koch, Beate (Hrsg.) 1998: Regieren in entgrenzten Räumen. PVS-Sonderheft 29/1998. Opladen, S. 169-206. 
Politik-Paradigmen und darauf bezogenen Instrumenten konkretisiert werden. Die parallele Kompetenzausübung bedingt jedoch das Fehlen eines Drucks zur Anpassung der mitgliedstaatlichen Politik. Mitgliedstaatliche Politik bezeichnet bislang nicht nur eine Restgröße in dem von gemeinschaftlicher Regelung noch nicht erfassten Raum, sondern wird als eine vom Durchgriff des Gemeinschaftsrechts geschützte Sphäre betrachtet. $^{73}$

Drittens: Anpassungsdruck, der im Zuge der Europäisierung vor allem von der europäischen Ebene ausgeht (also die Top-down-Perspektive), und im Wesentlichen in der Rechtsordnung angesichts des supranationalen Prinzips des Vorrangs von Gemeinschaftsrecht vor nationalem Recht begründet ist, stellt keine notwendige Bedingung dar, um eine Veränderung nationalstaatlicher Politik in Deutschland voranzutreiben. Stattdessen wird die Europäisierung vorrangig durch die Einbindung des nationalen Migrationssystems in das europäische Mehrebenensystem vorangetrieben, wobei Legitimationsdefizite der EU-Vorgaben überbrückt werden und langfristig Veränderungen nationalstaatlicher Politik zu erwarten sind.

Bislang hat sich die zahlreiche Europäisierungsforschung überwiegend mit der Implementierung von Sekundärrecht beschäftigt und sich diesbezüglich damit befasst, wie von europäischer Ebene auf die Politik der Mitgliedstaaten durch direkte, sekundärrechtliche Vorgaben - Richtlinien und Verordnungen - eingewirkt wird. ${ }^{74}$ Versteht man aber den Prozess der Europäisierung zuzüglich der Erfordernis zu analysieren, welche Veränderungen auf der nationalen Ebene mit der EU-Mitgliedschaft einhergehen, wird deutlich, dass eine Umsetzungsperspektive nicht umfassend genug ist. Auch hierbei unterliegt nationale Politik in vielen Bereichen erheblichem auf europäischer Ebene erzeugtem Anpassungsdruck: „Europäisierung wird in vielfältiger Weise als Vehikel der Modernisierung eingesetzt. Der Verweis auf die Anpassungszwänge an einen europäischen „mainstream“ dient immer wieder zur Legitimierung von Reformen, die binnengesellschaftlich auf anhaltenden Widerstand stoßen. [...]. Europäisierung ist nicht, wie die Forschung zur EU-Europäisierung manchmal nahe legt, die Anpassung an Vorgaben, sondern eröffnet Angebote, die eine Auswahl erlauben und deren Aufnahme davon abhängt, ob sie auf Interesse und

\footnotetext{
73 Streinz, Rudolf 1999: Europarecht. Heidelberg, S. 49.

74 Vgl. Schmidt, Susanne K. / Blauberger, Michael / van den Nouland, Wendelmoet 2008: Jenseits von Implementierung und Compliance - Die Europäisierung der Mitgliedstaaten. In: Tömmel, Ingeborg (Hrsg.) 2008: Die Europäische Union: Governance und Policy-Making. PVS-40/2007, S. 292-293.
} 
„kaufkräftige“ Nachfrage stoßen.“75 Die Bedeutsamkeit des Europäisierungsprozesses liegt somit zunächst nicht in einem unmittelbaren „Anpassungsdruck“ auf die nationale Politik, sondern eher vorrangig in der demokratischen Legitimation der Europäisierung nationaler Migrationspolitik. Darüber hinaus ist jedoch die Anschlussfähigkeit an die Besonderheit der parallelen Kompetenzausübung im Politikfeld der Migrationspolitik von Relevanz. Vor diesem Hintergrund lässt sich die Veränderung nationalstaatlicher Politikinstrumente bzw. der diese stützenden Institutionenordnungen innerhalb des nationalstaatlichen Migrationssystems, das vor allem durch ein verändertes Handeln bzw. Interessen der nationalstaatlichen Akteure angetrieben wird, beobachten. Demgemäß muss die besondere Prägung des Europäisierungsprozesses vielmehr im „Politik-Paradigma“ 76 der mitgliedstaatlichen Institutionen versteh- und kommunizierbar bleiben.

75 Kohler-Koch, Beate 2000: Europäisierung: Plädoyer für eine Horizonterweiterung. In: Kohler-Koch, Beate / Knodt, Michèle (Hrsg.) 2000: Deutschland zwischen Europäisierung und Selbstbehauptung. Frankfurt a. M., S. 23-24.

76 Zum Begriff des policy paradigm vgl. Hall, Peter 1993: Policy Paradigms, Social Learning and the State: The Case of Economic Policymaking in Britain. In:Comparative Politics, 25 (3). Jg., S. 275-296. 


\section{Aufbau und Verfahren}

\section{A. Aufbau}

Die Untersuchung gliedert sich in insgesamt fünf größere Teile. Am Anfang (Kapitel I) steht ein einleitender theoretischer und methodischer Teil, in dem zunächst das dieser Arbeit zugrundeliegende Verständnis des Problembereichs, der Forschungsstand und die Fragestellungen sowie die Arbeitshypothese erläutert werden. Das zweiten Kapitel beschäftigt sich mit der Findung geeigneter Dimensionen für die Analyse der migrationspolitischen Situation in Deutschland. Vor diesem Hintergrund wird zudem die historische Dimension deutscher Migrationspolitik in den sieben Phasen dargestellt. Besonders aufmerksam sind dabei die Wandlungsprozesse bzw. der Politikwandel deutscher Migrationspolitik in der Geschichte zu betrachten. Die beiden Hauptkapitel III und IV behandeln die Veränderung der europäischen und deutschen Migrationspolitik im Kontext des europäischen Mehrebenensystems. In beiden Teilen werden zunächst die wichtigsten Merkmale der jeweiligen europäischen und deutschen Migrationspolitik und der in ihr institutionalisierten Politik-Paradigmen 77 herausgearbeitet: In der Untersuchung der EU-Migrationspolitik in Kapitel III geht es vorab um die allgemeinere Diskussion zur „Europäisierung“ von Politik (Kapitel III.1.). Darüber hinaus wird zunächst die Europäisierung durch die vertragliche Institutionalisierung auf EU-Ebene (Kapitel III.2.) und die Einbindung des Politikfeldes Migration in den europäischen Integrationsprozess (Kapitel III.3.) näher untersucht. Ebenso werden hierbei die daraus resultierenden Pfade in der europäischen Migrationspolitik betrachtet und hernach verfolgt, wie sich auf der europäischen Ebene schrittweise eine neue Leitidee in den Verträgen und in den europäischen Integrationsprozessen entwickelt, die sich mit den Begriffen des nationalstaatlichen Souveränitätsbeharrens und verstärkten Kooperationsbedarfs im Migrationsbereich in Verbindung bringen lässt. Es wird damit aufgezeigt, wie sich die Gemeinschaftspolitik in diesen Bereichen herausgebildet hat, seit wann sich die zuständigen Institutionen mit der Migrationsthematik befassen, welche Kompetenzen tatsächlich vorhanden sind und welche Konzepte umgesetzt wurden. Es erfolgt dann eine genauere Betrachtung der Europäisierungsprozesse. Um die Analyse der Europäisierungsprozesse vertiefen zu 77 Vgl. Hall, Peter A. 1993: Policy Paradigms, Social Learning and the State. The Case of Economic
Policymaking in Britain. In: Comparative Politics 25 Jg. (3), 1993, S. 275-296. 
können, wurde Deutschland als Fallbeispiel ausgewählt, welches im westeuropäischen Kontext bereits als ein Muster eines Einwanderungslandes, d. h. als sogenanntes „Anwerbeland von ausländischen Arbeitskräften“78 ${ }^{678}$ gesehen wird. Dem schließt sich zunächst in Kapitel IV.1. die Untersuchung des Akteursfelds im Bereich der Migrationspolitik unter den institutionellen Rahmenbedingungen der organisatorischen Einbettung der Bundesrepublik Deutschland seit den 1990er Jahren bis heute an. Auch vor dem Hintergrund der Entwicklung einer gemeinsamen Migrationspolitik zur Steuerung der Arbeitsmigration aus Drittstaaten werden ferner die deutschen Interessen im Europäisierungsprozess der Hochqualifizierten betrachtet (Kapitel IV.2.). In der Zusammenfassung der Ergebnisse im abschließenden Kapitel V werden zunächst die unterschiedlichen Facetten der Europäisierung von Politik auf den europäischen und deutschen Ebenen diskutiert. Hierbei zeigt sich ein klarer Einfluss auf die Prozesse der Europäisierung politikfeldspezifischer und politikfeldübergreifender Institutionenordnungen auf diesen beiden Ebenen. Auch wird ein „paralleles“ Vorhandensein von europäischer und deutscher Migrationspolitik deutlich sowie teilweise schwerwiegende Kontroversen zwischen EU-Akteuren und deutschen Akteuren. Im Anschluss werden die Interessen der Akteure und ihre Entwicklung unter Rückgriff auf die eingangs vorgestellte theoretische Perspektive des NeoInstitutionalismus (NI) zusammengefasst und diskutiert. Des Weiteren wird vor dem Hintergrund der Interessenveränderung in der deutschen und europäischen Migrationspolitik ein kritischer Ausblick auf zu erwartende Entwicklungen gegeben.

${ }^{78}$ Birsl, Ursula 2005: Migration und Migrationspolitik im Prozess der europäischen Integration?. Opladen, S. 15. 


\section{B. Verfahren}

Der Untersuchungszeitraum wird den Zeitraum seit den 1990er Jahren bis in die Gegenwart im Bereich der Migrationspolitik umfassen, wobei aber insbesondere zur Erklärung der EU-Kooperation auch auf die zweite Hälfte der achtziger Jahre eingegangen wird. Der Prozess der Europäisierung ist hierbei vornehmlich in die permanente Interaktion zwischen europäischer und deutscher nationaler Institutionenordnung eingebunden. Auch unter Migrationspolitik wird hier allgemein die Regelung des Zugangs und Aufenthalts von Nicht-Staatsangehörigen, in der Regel Nicht-EU-Bürgern (sogenannte Drittausländern), verstanden. Migrationspolitik wird daher in einem Sinne aufgefasst, der auch die Asyl- und Flüchtlingspolitik mit umfasst.

Die wichtigsten Arbeitsmethoden werden die Auswertung von Primärliteratur wie Gesetzestexte, Verträge, Gerichtsentscheidungen und Parlamentsprotokolle, Pressemitteilungen des Rates der Europäischen Union, der Bundesregierung sowie der deutschen Parteien sein und es wird sich darüber hinaus auf eine umfangreiche Sekundärliteratur gestützt. Des Weiteren werden statische Daten analysiert. Ein Teil der verwendeten Forschungsliteratur ist dem Internet entnommen. 


\section{Migration und die historische Entwicklung der Migrationspolitik in Deutschland}

\section{Migration}

\subsection{Dimension der Begriffsbestimmungen der Migration}

Der Begriff „Migration“79 wird bisher uneinheitlich verwandt, sodass sich zahlreiche Definitionen gegenüberstehen. ${ }^{80}$ Allgemein ist Migration bzw. Wanderung ${ }^{81}$ nach Everett S. Lee $(1966)^{82}$ definiert als ein permanenter oder semipermanenter Wechsel des Wohnsitzes (,a permanent or semipermanent change of residence“). Je nach theoretischem Hintergrund oder beschreibendem Interesse werden jedoch bei den Begriffsbestimmungen der Migration unterschiedliche Ansichten des vielschichtigen Phänomens betrachtet. ${ }^{83}$ Ernst George Ravenstein $(1885)^{84}$, der der Begründer der modernen Migrationsforschung ist, verstand Migration als sozialen Prozess, in dem sich Gruppen, politisch und ökonomisch beeinflusst, entlang von Ketten bewegen. ${ }^{85}$ Migration ist also bereits Ende des 19. Jahrhunderts als ein komplexer Vorgang geschildert worden, der von einer Vielzahl von Verhaltensweisen und Randbedingungen bestimmt wird. Auch laut dem Bundesministerium des Innern (BMI) findet Migration statt, wenn „Personen („Migranten“) [...] zu unterschiedlichen Aufenthaltszwecken

79 Der Begriff Migration leitet sich von dem lateinischen „migrare bzw. migratio“ (wandern, wegziehen, Wanderung) ab. In: Han, Petrus 2005: Soziologie der Migration: Erklärungsmodelle Fakten Politische Konsequenzen Perspektiven. Stuttgart, S. 7.

80 Treibel trägt hierbei insgesamt zehn verschiedene Definitionsansätze zusammen. Vgl. Treibel, Annette 2003: Migration in modernen Gesellschaften. Soziale Folgen von Einwanderung, Gastarbeit und Flucht. München, S. 19.

${ }^{81}$ Nach Treibel sind die beiden Begriffe „Migration“ und „Wanderung“ synonym zu verwenden. Vgl. Treibel, Annette 2003: a.a.O., S. 18.

82 Lee, Everett S. 1966: A Theory of Migration. In: Demography. Vol. 3, 1966/I. Washington, S. 47-57; Deutsche Übersetzung siehe Lee, Everett S. 1972: Eine Theorie der Wanderung. In: Szèll, György (Hrsg.) 1972: Regionale Mobilität. Elf Aufsätze. München, S. 115-129, hier S. 117.; vgl. auch Lee, Everett S. 1996: A Theory of Migration. In: Cohen, Robin (Ed.) 1996: Theories of Migration. Cheltenham/Brookfield, S. 14-24, hier S. 16.

83 Vgl. hierzu Santel, Bernhard. 1995: Migration in und nach Europa: a.a.O., S. 17-27.

84 „Vor über 100 Jahren, in den achtziger Jahren des 19. Jahrhunderts, hielt der Demograph und Kartograph Ernest George Ravenstein vor der Royal Statistical Society seinen Vortrag über die „Gesetze der Wanderung“ (The Laws of Migration). Dieser Vortrag, den die Gesellschaft in zwei Folgen in ihrem Journal abdruckte (Ravenstein 1885/1889; deutsche Übersetzung siehe Ravenstein 1972), gilt als Beginn der Migrationsforschung.“ Zitiert in: Treibel, Annette 2003: Migration in modernen Gesellschaften. a.a.O., S. 25; vgl. Szèll, György (Hrsg.) 1972: Regionale Mobilität. Elf Aufsätze. München, S. 41-94.

85 Vgl. Blaschke, Jochen 1997: Migration-Ein Bericht über den Forschungsstand unter besonderer Berücksichtigung internationaler Publikationen zur Arbeitsmigration seit 1991 (Materialien zur Bewölkerungswissenschaft, Sonderheft 28). Wiesbaden, S. 11. 
mittel- oder längerfristig ihren Aufenthaltsort oder Lebensmittelpunkt über Grenzen hinweg in einen anderen Staat [verlegen]““. ${ }^{86}$ Einige Wissenschaftler definieren jedoch Migration als ,jede längerfristige, räumliche Verlagerung des Lebensschwerpunktes über eine größere Distanz, die ein Verlassen des sozialen Aktionsraumes zur Folge hat. “87 Oder „Migration ist der auf Dauer angelegte bzw. dauerhaft werdende Wechsel in eine andere Gesellschaft bzw. in eine andere Region von einzelnen oder mehreren Menschen. “88 Ebenso sind nach der revidierten Empfehlung der Vereinten Nationen (UN) zur statistischen Erfassung der internationalen Migranten von 1998 diejenigen Menschen als Migranten zu begreifen, die zumindest für den Zeitraum von einem Jahr (for a periode of at least a year) den ständigen Wohnsitz (usual residence) von ihrem Herkunftsland in ein anderes Land verlegen. ${ }^{89}$

Aus deskriptiver Perspektive bzw. fachspezifischer Perspektive können die jeweiligen Definitionen vor allem auf Unterschiede der räumlichen wie zeitlichen Dimension von Migration zurückgeführt werden. ${ }^{90}$ So begreift man in den Sozialwissenschaften unter dem Begriff der Migration generell solche Bewegungen von Personen und Personengruppen im Raum (spatial movement), die einen dauerhaften Wohnortwechsel (permanent change of residence) herbeiführen. ${ }^{91}$ Für die Politikwissenschaft stehen überdies die ausländerrechtlichen und ausländerpolitischen Entwicklungen im Mittelpunkt. ${ }^{92}$ Politisch unumstritten ist dabei, dass Migration als eine Wanderungsbewegung über nationalstaatliche Grenzen hinweg aufgefasst werden kann. Die größten Diskrepanzen in der politischen Auslegung von Migration werden demgemäß bei der Fragestellung deutlich, von welchem Zeitpunkt an tatsächlich eine Aus- oder Abwanderung aus einem Staat oder eine Einwanderung in einen anderen Staat festgestellt werden kann. ${ }^{93}$ Darüber hinaus liegen als wichtige Impulse Untersuchungen etwa zur Staatsbürgerschaft oder zum europäischen Vergleich von Einwanderungs- und Asylpolitiken vor. ${ }^{94}$

\footnotetext{
${ }^{86}$ Bundesministerium des Innern (Hrsg.) 2006: Zuwanderungsrecht und Zuwanderungspolitik. S. 89.

87 Hansen, Georg / Wennig, Norbert 1991: Migration in Vergangenheit und Zukunft. Hagen, S. 17.

88 Treibel, Annette 2003: Migration in modernen Gesellschaften. a.a.O., S. 21.

89 Han, Petrus 2005: Soziologie der Migration: a.a.O., S. 7.

90 Santel, Bernhard 1995: Migration in und nach Europa: Erfahrungen. Strukturen. Politik, S. 18.

91 Han, Petrus 2005: Soziologie der Migration: a.a.O., S. 7.

92 Zahlreiche weitere wissenschaftliche Disziplinen bezüglich Migration sind erfasst in Treibel, Annette 2003: Migration in modernen Gesellschaften. a.a.O., S. 17-18.

93 Birsl, Ursula 2005: a.a.O., S. 19.

94 Vgl. Brubaker, Rogers 1994: Staats-Bürger. a.a.O.; Heinelt, Hubert (Hrsg.) 1994: Zuwanderungspolitik in Europa. Nationale Politiken. Gemeinsamkeiten und Unterschiede. Opladen.
} 


\subsection{Dimension der Ursachen, Motive von Migration und Push-Pull-Modell}

Migration bzw. Wanderung kann politisch, ökonomisch, ökologisch, demografisch, sozial oder kulturell motiviert sein; vorwiegend entstammen die jeweiligen Migrationsentscheidungen jedoch einem multifaktoriellen Ursachengeflecht. ${ }^{95}$ Als einige allgemeine Ursachen für Migration lassen sich die Suche nach neuen sowie besseren Lebensbedingungen bzw. die Suche nach Arbeit und der Schutz vor Verfolgung nennen. ${ }^{96}$ Vor allem aber sind die Migranten bestrebt, ihre eigene Situation nach dem Prinzip eines ,ökonomischen Rationalismus“97 zu handhaben.

Ernest George Ravenstein (1885/1889) ${ }^{98}$ legte bereits in seiner „The Laws of Migration“ (Wanderungsgesetze) jeder Wanderung hauptsächlich strukturellökonomische Ursachen und ein damit korrespondierendes Motiv der Wanderungen zugrunde. Er formulierte somit, wie oben angesprochen, die Prämisse, dass der entscheidende Migrationsgrund der Menschen darin besteht, ihre materiellen Lebensbedingungen zu verbessern. Vor diesem Hintergrund befasste sich Ravenstein ausschließlich mit Arbeitsmigration. Die Menschen zogen diesbezüglich in die neuen Industriestädte, wobei maßgebliche Gründe für den Zuzug der Menschen die besseren Lebensbedingungen waren. Infolgedessen war die Migration der überschüssigen Bevölkerung (,surplus population“) von den unterentwickelten zu den besser entwickelten Gebieten mit florierendem Handel und Industrieansiedlung für Ravenstein normal. $\mathrm{Zu}$ diesen ökonomischen und demografischen Faktoren zählen etwa Arbeitsmarktsituation, Lohnniveau, Bevölkerungsentwicklung etc. 99 Das Zusammenwirken dieser Faktoren in dem Herkunftsort und dem Zielort wird als „PushPull-Modell“ bezeichnet. ${ }^{100}$ Ausgangspunkt dieses Push-Pull-Modells ist abermals die

95 Mühlum, Albert 1993: Armutswanderung, Asyl und Abwehrverhalten: Globale und nationale Dilemmata. In: Aus Politik und Zeitgeschichte (APuZ), 43 Jahrgang, B7/1993, S. 3-15, hier S. 5.

96 Vgl. Treibel, Annette 2003: Migration in modernen Gesellschaften. a.a.O., S. 21.; vgl. Ravenstein, Ernest George 1972: Die Gesetze der Wanderung I und II. In: Szèll, György (Hrsg.) 1972: Regionale Mobilität. Elf Aufsätze. München, S. 41-94 (vgl. englisches Original von 1885 und 1889), hier S. 43.

97 Ewers, Ruth 1931: Die soziologische und ökonomische Bedeutung der Einwanderung. Untersucht am Beispiel der Vereinigten Staaten von Nord-Amerika. Heidelberg (Diss.), S. 39.; vgl. auch Winchie, Diana B. / Carment, David W. 1989: Migration and Motivation: The Migrant's Perspective. In: International Migration Review (IMR) 1989, Volume 23, No. 1. New York, S. 96-104.

98 Siehe hierzu Ravenstein, Ernest George 1972: Die Gesetze der Wanderung I und II. In: Szèll, György (Hrsg.) 1972: Regionale Mobilität. Elf Aufsätze, München, S. 41-94 (deutsche Übersetzungen der englischen Texte von 1885 und 1889).

99 Vgl. Treibel, Annette 2003: Migration in modernen Gesellschaften. a.a.O., S. 40.

100 Treibel, Annette 2003: Migration in modernen Gesellschaften. a.a.O., S. 40. 
in „The Laws of Migration“ von Ravenstein aufgestellte Ansicht, die er selbst zu einem „Gravitationsmodell“ ${ }^{101}$ ausformulierte: Dieses Gravitationsmodell geht von der These aus, „dass ein inverser Zusammenhang zwischen Migrationshäufigkeit und geographischer Entfernung besteht"“. ${ }^{102}$ Ravenstein hatte hierbei festgestellt, dass mit zunehmender Entfernung vom Zuwanderungsgebiet die Zahl der Migranten abnahm. ${ }^{103}$ Zwischen Nachbarländern ist Migration somit denkbarer als zwischen weiter entfernten Orten oder Gebieten. Der Strom von Migranten, die aus Mexiko in die USA übersiedeln, könnte hierfür als Anhaltspunkt genannt werden. ${ }^{104}$ Allerdings ist diese Gravitationsannahme aus heutiger Sicht nicht bestätigt, ,weil die Migrationshäufigkeit heute mehr von den restriktiven politischen und legislativen Bestimmungen der Aufnahmeländer abhängt und weniger von der geographischen Entfernung. “" ${ }^{105}$ Später stellte Everett S. Lee (1966) ${ }^{106}$ darüber hinaus die Bedeutung der „Push- und PullFaktoren“ der Migration in seiner Migrationstheorie (,A Theory of Migration“) differenziert dar: Unter den „Push-Faktoren“ (Druckfaktoren) werden all die Faktoren des Herkunftsgebietes der Migranten zusammengefasst, die diese zur Auswanderung („Emigration“ bzw. „Vertreibung“) veranlassen. Es kann sich dabei „um politische und religiöse Verfolgung, wirtschaftliche Krisen, zwischenstaatliche Kriege, Bürgerkriege, Umwelt- und Naturkatastrophen usw.“ 107 oder „um geringes Lohnniveau sowie schlechte Arbeits- und Berufschancen für bestimmte soziale Schichten oder in bestimmten wirtschaftlichen Räumen“ 108 handeln. Unter den „PullFaktoren“ (Sogfaktoren bzw. Anziehungsfaktoren) lassen sich dagegen all die Faktoren des Zielgebietes bzw. Aufnahmeortes der Migranten zusammenfassen, die diese zur Einwanderung (,Immigration“) motivieren. Als Sogfaktoren können etwa ,politische Stabilität, demokratische Sozialstruktur, religiöse Glaubensfreiheit, wirtschaftliche

${ }^{101}$ Zum theoretischen Überblick über die "Gravitationsmodelle" vgl. Wachinger, Hans-Albrecht 1979: Erklärungen und Vorausschätzungen von Wanderungen: Entscheidungs- und systemtheoretische Ansätze und Analysen. Göttingen, S. 16-18.; vgl. Ravenstein, Ernest George 1972: Die Gesetze der Wanderung I und II. In: Szèll, György (Hrsg.) 1972: a.a.O., S. 41-94.; vgl. auch Han, Petrus 2005: Soziologie der Migration: a.a.O., S. 14-15.

102 Han, Petrus 2005: Soziologie der Migration: a.a.O., S. 15.; vgl. auch Feithen, Rosemarie 1985: Arbeitskräftewanderungen in der Europäischen Gemeinschaft. Bestimmungsgründe und regionalpolitische Implikationen. Frankfurt/New York, S. 53.

${ }^{103}$ Ravenstein untersuchte jedoch nur Binnenmigration innerhalb des Vereinigten Königreiches. Vgl. Ravenstein, Ernest George 1972: a.a.O., S. 44.; vgl. Wachinger, Hans-Albrecht 1979: a.a.O., S. 16.

104 Seifert, Wolfgang 2000: Geschlossene Grenzen - offene Gesellschaften?: Migrations- und Integrationsprozesse in westlichen Industrienationen. Frankfurt/New York, S. $28 \mathrm{f}$.

${ }^{105}$ Han, Petrus 2005: Soziologie der Migration: a.a.O., S. 15.

${ }^{106}$ Lee, Everett S. 1966: A Theory of Migration. In: Demography. Vol. 3, 1966/I. Washington, S. 47-57; Deutsche Übersetzung siehe Lee, Everett S. 1972: Eine Theorie der Wanderung. In: Szèll, György (Hrsg.) 1972: Regionale Mobilität. Elf Aufsätze. München, S. 115-129, hier S. 118.

107 Han, Petrus 2005: Soziologie der Migration: a.a.O., S. 15.

${ }^{108}$ Birsl, Ursula 2005: Migration und Migrationspolitik: a.a.O., S. 33. 
Prosperität und bessere Ausbildungs- und Verdienstmöglichkeiten“ gezählt werden. ${ }^{109}$

Kennzeichnend für zentrale Push- wie Pull-Faktoren kann, wie oben erwähnt, generell die Situation auf dem Arbeitsmarkt sein, die in dem Herkunftsort der Migranten unzulänglich und in dem Zielort erstrebenswerter ist. Hierbei sind drei spezifische Parameter bezüglich der Migrationsursachen ausschlaggebend: ${ }^{110} 1$. Bestehende Unterschiede im Hinblick auf die Beschäftigungssituation (job-vacancy-Hypothese). Beispiele sind diesbezüglich Arbeitslosigkeit in dem Herkunftsgebiet versus Arbeitsplatzangebote in dem Zielgebiet. 2. Bestehende Unterschiede hinsichtlich der Einkommenssituation (income-differentials-Hypothese), wie etwa höhere Löhne in den Zielregionen. 3. Persönliche Beziehungen zu Verwandten oder Bekannten, die schon ausgewandert sind, und „Informationskanäle“ über die Zielregion, die entscheidend zum Migrationsentschluss beitragen. Dieser dritter Faktor wird als Informationshypothese (migrant-stock-Variable) bezeichnet und stellt die erste Erweiterung des Push-PullModells dar.

Hierbei spielt ebenso das Vorhandensein von Migrationsnetzwerken (,migration networks") ${ }^{111}$ im Sinne einer praktischen Unterstützung neuer Migranten durch bereits etablierte Einwanderer eine wichtige Rolle: „Je mehr Landsleute schon im Gastland sind, desto leichter lassen sich persönliche Kenntnisse und Fähigkeiten, die mit der eigenen Nationalität bzw. Kultur verbunden sind, transferieren und nutzbar machen. “112 Die Ursachen und die Motive von Migration sind somit nicht immer an dem rational zu erwartenden ökonomischen Vorteil, sondern oft mehr an den sozialen und emotionalen Bindungen orientiert. ${ }^{113}$ Bestätigt wurde diese relativ neue Bilanz der „Migrationsnetzwerke“ durch eine Studie von Thomas Faist (1997) ${ }^{114}$ anhand der Fragestellung, warum es ,relativ wenige internationale Migranten“ gebe und auch „warum trotz teilweise günstiger Gelegenheiten zur internationalen Wanderung sich viele potentielle Migranten dazu entscheiden, ihre Zukunft im Herkunftsland zu gestalten." Hier wird davon ausgegangen, dass die Ursachen für die Entscheidung

${ }^{109}$ Han, Petrus 2005: Soziologie der Migration: a.a.O., S. 15.

110 Treibel, Annette 2003: Migration in modernen Gesellschaften: a.a.O., S. 40.

${ }^{111}$ Han, Petrus 2005: Soziologie der Migration: a.a.O., S. 16.

112 Straubhaar, Thomas / Wolter, Achim 1999: Migration in Europa - Neue Dimensionen, neue Fragen, neue Antworten In: Wolter, Achim (Hrsg.) 1999: Migration in Europa: Neue Dimensionen, neue Fragen, neue Antworten. Baden-Baden, S. 12.

113 Vgl. Han, Petrus 2005: Soziologie der Migration: a.a.O., S. 16.

114 Ausführlich hierzu siehe Faist, Thomas 1997: Migration und der Transfer sozialen Kapitals oder: Warum gibt es relativ wenige internationale Migranten?. In: Pries, Ludger (Hrsg.) 1997: Transnationale Migration. Baden-Baden (Soziale Welt;Sonderband. 12), S. 63-83, hier S. 63-64. 
potenzieller Migranten, am Herkunftsort zu bleiben oder auszuwandern, vor allem in den starken (z. B. Familien, Haushalte), schwachen (z. B. Nachbarschaften, Makler) sowie symbolischen (z. B. religiöse Gemeinschaften) sozialen Bindungen und dem sozialen Kapital zu sehen sind. So betonte Faist ein „Meso-Bindeglied“ zwischen der sogenannten Mikroebene der Individuen und der Makroebene übergeordneter Strukturen (vgl. hierzu Anhang: Übersicht 2). ${ }^{115}$ Das Meso-Bindeglied verknüpft dabei das in Migrationsnetzwerken inkorporierte soziale Kapital in Anlehnung an Bourdieu (1983). ${ }^{116}$ Der Begriff „,Soziales Kapital“ findet sich bei Faist wieder: ,all diejenigen Ressourcen, die Akteuren erlauben, mit Hilfe sozialer Bindungen innerhalb von Gruppen bzw. Partizipation in Netzwerken ihre individuelle bzw. kollektiven Ziele zu verwirklichen. Solche potentiellen oder faktischen Ressourcen hinsichtlich möglicher Migration umfassen z. B. Informationen über Arbeitsplätze in einem potentiellen Bestimmungsland oder über Reisemöglichkeiten, aber auch die Existenz von Normen wie Reziprozität.“117 Soziales Kapital in sozialen Beziehungsnetzwerken hat somit zwei Wirkungen bzw. Funktionen: Es hat vor allem eine „adaptive Funktion“, indem es die Eingliederung von Migranten erleichtert, und auch eine „selektive Funktion“, indem es nur bestimmten Gruppen (z. B. Angehörigen, Freunden) die Unterstützungsoption ermöglicht. ${ }^{118}$ Bei der Analyse von Migrationsprozessen differenzierte Faist demgemäß folgende drei Dimensionen genauer: „die makrostrukturelle Ebene (politische, ökonomische und kulturelle Faktoren, einmal in den Sende- und Empfängerstaaten und zum anderen im internationalen Kontext), die individuelle Ebene (Grad individueller Autonomie potentieller Migranten, deren Pläne und Ressourcen); verbunden durch die relationale Ebene (soziale Bindungen und soziales Kapital potentieller Migranten). “119

$115 \mathrm{Zu}$ makro- und mikrotheoretischen Ansätzen in der Migrationsforschung vgl. Faist, Thomas 1997: a.a.O., S. 65-70.; vgl. Seifert, Wolfgang 2000: a.a.O., S. 27-46.; vgl. auch Wolter, Achim 1999: Von der unternehmensinternen zur unternehmensinduzierten Migration Höherqualifizierter in Europa. In: Wolter, Achim (Hrsg.) 1999: Migration in Europa: a.a.O., S. 38-55.

116 Bourdieu schrieb: „das Sozialkapital ist die Gesamtheit der aktuellen und potentiellen Ressourcen, die mit dem Besitz eines dauerhaften Netzes von mehr oder weniger institutionalisierten Beziehungen gegenseitigen Kennens oder Anerkennens verbunden sind.“; oder anders angedrückt, ,es handelt sich dabei um Ressourcen, die auf der Zugehörigkeit zu einer Gruppe beruhen. Das Gesamtkapital, das die einzelnen Gruppenmitglieder besitzen, dient ihnen allen gemeinsam als Sicherheit und verleiht ihnen - im weitesten Sinne des Wortes - Kreditwürdigkeit. [...]. Der Umfang des Sozialkapitals, das der einzelne besitzt, hängt demnach sowohl von der Ausdehnung des Netzes von Beziehungen ab, die er tatsächlich mobilisieren kann, als auch von dem Umfang des (ökonomischen, kulturellen oder symbolischen) Kapitals, das diejenigen besitzen, mit denen er in Beziehung steht.“ Bourdieu, Pierre 1983: Ökonomisches Kapital, kulturelles Kapital, soziales Kapital. In: Kreckel, Reinhard (Hrsg.) 1983: Soziale Ungleichheiten. Göttingen (Soziale Welt: Sonderband 2), S. 183-198, hier S. 191.

117 Faist, Thomas 1997: Migration und der Transfer sozialen Kapitals oder: a.a.O., S. 74.

118 Vgl. Faist, Thomas 1997: a.a.O., S. 74.; vgl. Seifert, Wolfgang 2000: a.a.O., S. 38.

119 Faist, Thomas 1997: Migration und der Transfer sozialen Kapitals oder: a.a.O., S. 65. 
Migration wird somit nicht als Einbahnstraße angesehen, sondern als ein relationales Netz von Individuen in einem ,transnationalen sozialen Raum“. ${ }^{120}$ Im Kontext dieses transnationalen sozialen Raumes werden nicht nur dauerhafte Umsiedlungen sondern auch Pendelmigration denkbar. Daraus folgend ist die Bedeutung der sogenannten „Pioniermigration“ und der ihr nachfolgenden Kettenmigration (,chain migration“") als besonders groß anzusehen, wobei sich diese Netzwerkmigration weitgehend der Steuerung oder Regulierung durch Migrationspolitik entzieht. ${ }^{122}$ Mit dem Konzept des Meso-Bindeglieds von Faist im Rahmen von Migrationsnetzwerken des sozialen Kapitals können folglich manche Migrationseffekte erklärt werden, wie etwa, warum beispielsweise BewohnerInnen der Dörfer A, B in der Türkei sich für unterschiedliche bzw. bestimmte Zielländer (etwa Deutschland, Frankreich usw.) entscheiden und in diese abwandern. ${ }^{123}$ Als Erklärung dafür könnte dienen, dass in diesen Ländern schon seit mehreren Jahrzehnten umfangreichere ethnische Communities ${ }^{124}$ existieren, welche sich im Zuge der Anwerbung von Arbeitskräften aus diesen Dörfern etabliert haben. Dabei besteht weiterhin eine aktive Kommunikation mit den Herkunftsdörfern. ${ }^{125}$ Demzufolge wird auch deutlich, warum jedoch keine internationale Migration von BewohnerInnen aus dem anderen türkischen Dorf $\mathrm{C}$ erfolgte: ${ }^{126}$ Denn die BewohnerInnen aus dem Dorf $\mathrm{C}$ verfügen über kein Migrationsnetzwerk und kein entsprechendes soziales Kapital für Migrationsdynamiken, wie etwa deren Einfluss auf Kettenmigration. ${ }^{127}$ Festzuhalten bleibt hierbei allerdings, dass es ,aufgrund des schwierigen Transfers von sozialem Kapital nicht zu internationaler Migration aus bestimmten Dörfern kommt und sich so Prozesse der Kettenmigration gar nicht entwickeln“ 128 bzw. durchaus brüchig werden und sogar zum Herkunftsort zurückführen können. Soziale Beziehungsnetzwerke zwischen Herkunfts- und Zielregion haben folglich auf Migrationsentscheidungen, Wanderungsziele sowie den Umfang und die Dynamik des Wanderungsprozesses ganz erheblichen Einfluss und scheinen jüngeren Forschungen zufolge sogar wichtiger zu sein als nur ökonomische Faktoren. $^{129}$

\footnotetext{
120 Pries, Ludger 1997: Neue Migration im transnationalen Raum. In: Pries, Ludger 1997: a.a.O., S. 17.

121 Han, Petrus 2005: a.a.O., S. 12; vgl. Birsl, Ursula 2005: Migration und Migrationspolitik: a.a.O., S. 35.

122 Straubhaar, Thomas / Wolter, Achim 1999: Migration in Europa - a.a.O., S. 12.

123 Faist, Thomas 1997: Migration und der Transfer sozialen Kapitals oder: a.a.O., S. 64.

124 Vgl. Fawcett, James T. 1989: Networks, Linkages, and Migration Systems. In: International Migration Review (IMR) 1989, Volume 23, No. 3. New York, S. 671-680.

125 Birsl, Ursula 2005: Migration und Migrationspolitik: a.a.O., S. 36.

126 Faist, Thomas 1997: Migration und der Transfer sozialen Kapitals oder: a.a.O., S. 64.

127 Vgl. Birsl, Ursula 2005: Migration und Migrationspolitik: a.a.O., S. 39.

128 Faist, Thomas 1997: Migration und der Transfer sozialen Kapitals oder: a.a.O., S. 80 f.

129 Vgl. Oswald, Ingrid 2007: Migrationssoziologie. Konstanz, S. 73.
} 
Durch bestehende Migrationsnetzwerke im transnationalen sozialen Raum kommt außerdem der Migrationspolitik sowie dem Migrationssystem im Aufnahmeland vor allem in Bezug auf den Migrationsverlauf und die Bekämpfung der Migrationsursachen große Bedeutung zu. Daher hat sich „Selektivität" in Migrationsprozessen als wichtiger Punkt erwiesen: „Selektiv ist dabei nicht nur die staatliche Migrationspolitik, auch auf der individuellen Ebene lassen sich Selektionsprozesse beobachten, beispielsweise durch ausgeprägte Netzwerkstrukturen. Entsprechend selektive Migrationsprozesse führen dazu, dass verschiedene Länder unterschiedliche Migrationsmuster aufweisen. Durch institutionelle Selektivität wird ein erheblicher Einfluß auf die Integrationschancen von Immigranten ausgeübt. “130 Viele Empfängerländer betreiben somit eine ,selektive Migrationspolitik“, das heißt, die Zielländer eröffnen Zuwanderungsmöglichkeiten bzw. Zulassungsregularien etwa anhand von bestimmten Kategorien wie Nationalität, Religion, Ethnizität, Sprache sowie Beruf (so z. B. Flüchtlinge aus bestimmten Staaten, spezielle Berufsgruppen usw.) und schaffen daraus neue Pull-Faktoren, die jedoch für andere Migranten zu Ausschlusskriterien werden. ${ }^{131}$ So werden beispielsweise das „Punktesystem“ und die „Blue Card“ als Strategien der selektiven Migrationspolitik in Europa durchgeführt, wobei die Rekrutierung von hoch qualifizierten Wissenschaftlern und Arbeitskräften aus Drittstaaten, also aus Nicht-EUStaaten, somit zu einem flexibel angewandten, arbeitsmarktpolitischen Instrument gehört (auf dieses Thema wird in Kapitel IV. 2 näher eingegangen). Auch dürfte in diesem Kontext die Verwertbarkeit von Qualifikationen der MigrantInnen auf dem Zielarbeitsmarkt die Migrationsentscheidung beeinflussen. ${ }^{132}$ Der Selektionsprozess im Sinne der Arbeitsmigration gilt weiterhin als ein Gewinn des „Humankapitals“ für die Aufnahmeländer und umgekehrt stellt das Problem des schmerzlichen „Brain Drain“ also einen Verlust der „man-power-resource“ für die Herkunftsländer dar. ${ }^{133}$ Migrationsentscheidungen werden somit auch durch die selektiven und restriktiven Aufnahmekriterien der bevorzugten Zielländer vorgegeben. Diese gates of entry filtern die Zuwanderung und ermöglichen in einem gewissen Maß eine Kontrolle durch die Aufnahmeländer. ${ }^{134}$

Anschließend wird nun darauf hingewiesen, dass die bisher beschriebenen Migrationsursachen und Motive einen zentralen Punkt bei den Push- und Pull-Modellen

130 Seifert, Wolfgang 2000: Geschlossene Grenzen - offene Gesellschaften?: a.a.O., S. 46.

131 Vgl. Oswald, Ingrid 2007: Migrationssoziologie. Konstanz, S. 72.; vgl. auch Faist, Thomas 1997:

Migration und der Transfer sozialen Kapitals oder: a.a.O., S. 78.

132 Seifert, Wolfgang 2000: Geschlossene Grenzen - offene Gesellschaften?: a.a.O., S. 36.

133 Vgl. Han, Petrus 2005: Soziologie der Migration: a.a.O., S. 31-41, hier S. 34.

134 Vgl. Oswald, Ingrid 2007: Migrationssoziologie. Konstanz, S. 72. 
bzw. -Faktoren bezeichnen. Denn eine Migrationsentscheidung lässt sich teils mit den Migrationsnetzwerken erklären, wie die Kettenmigration belegt, jedoch nicht ausschließlich durch eine rationale bzw. gewinnmaximierende Abwägung des Individuums von Kosten und Nutzen sowie vom größten Vorteil einer Abwanderung in ein bestimmtes Zielland. ${ }^{135}$ Weiterhin bleibt das Push-Pull-Modell in der Migrationsforschung umstritten ${ }^{136}$ und es wird indes generell angenommen, dass die Push- und Pull-Faktoren im Kontext der modernen Informations-, Kommunikationsund Transportmöglichkeiten und des wachsenden Globalisierungseffekts zunehmend an Relevanz für die individuellen Migrationsentscheidungen gewinnen. ${ }^{137}$ Außerdem können sich die Ursachen, Motive und der Verlauf von Migration über die Zeit verändern. So ist es heute durchaus denkbar, dass durch staatliche Interventionen, wie etwa die Wahrnehmung von Migranten als „Humankapital“ in den Selektionsprozessen, einerseits die Migrationsanreize der Migranten zugenommen haben, andererseits allerdings eine zunehmend restriktive Migrationspolitik für die Aufnahmeländer bevorzugt werden kann. Folglich besteht hier auch ein enger Zusammenhang zwischen Herkunfts- und Zielgebiet oder vielmehr vor allem ,zwischen äußerer und innerer Offenheit bzw. Geschlossenheit" ${ }^{\text {(138 }}$ der Aufnahmegebiete.

${ }^{135}$ Lee, Everett S. 1972: Eine Theorie der Wanderung. In: Szèll, György (Hrsg.) 1972: Regionale Mobilität. Elf Aufsätze. München, S. 115-129, hier S. 120 (vgl. amerikanisches Original von Lee, Everett S. 1966: A Theory of Migration. In: Demography. Vol. 3, 1966/I. Washington, S. 47-57).; vgl. Han, Petrus 2005: Soziologie der Migration: a.a.O., S. 16-17.; vgl. Birsl, Ursula 2005: Migration und Migrationspolitik: a.a.O., S. 35.; vgl. Oswald, Ingrid 2007: Migrationssoziologie. Konstanz, S. 71.; vgl. auch Sjaastad, Larry A. 1962: The costs and returns of human migration. In: The Journal of Political Economy (70/1962), Volume LXX, Number 5, Part 2. Chicago, S. 80-93.

136 Vgl. Portes, Alejandro / Böröcz, József 1996: Contemporary Immigration: Theoretical Perspectives on its Determinants and Modes of Incorporation. In: Cohen, Robin (Ed.) 1996: Theories of Migration. Cheltenham/Brookfield, S. 156-180.

137 Vgl. Han, Petrus 2005: Soziologie der Migration: a.a.O., S. 15 f.

138 Seifert, Wolfgang 2000: Geschlossene Grenzen - offene Gesellschaften?: a.a.O., S. 46. 


\subsection{Migrationstypologien}

Kennzeichnend für die verschiedenen Migrationsbegriffe bzw. alle Definitionen der vielschichtigen und komplexen Ursachen sind Versuche, Migration typologisch zu konkretisieren und zu differenzieren: Ernst George Ravenstein typologisiert in seinen „Gesetzen der Wanderung“ (The Laws of Migration) Migration etwa nach der jeweils zurückgelegten Distanz und der Dauer der Wanderung. Hierbei unterscheidet Ravenstein fünf Migrantentypen: ${ }^{139}$ 1. Die lokalen Wanderer (,local migrants“), die in derselben Stadt oder Gemeinde bleiben, in der sie geboren sind. 2. Die Nahwanderer (,short-journey migrants“), die nur eine sehr kurze Strecke wandern. Diese Wanderer stellen nach Ravenstein den Haupttyp dar. 3. Die Fernwanderer (,long-journey migrants"), die aus ihrer Heimat wegziehen, um sich an einem entfernten Ort des Landes niederzulassen. 4. Die Etappenwanderer (,,migration in stages“), womit eine in mehreren kürzeren Schritten vollzogene Wohnsitzverlagerung über eine längere Distanz bezeichnet wird. 5. Die temporären Wanderer („temporary migrants“), die nur vorübergehend ihren Wohnsitz verlagern und deren Migration zeitlich begrenzt ist (z. B. Saisonarbeiter, Seefahrer, Studenten, Urlauber oder Gefängnisinsassen). Henry Pratt Fairchild (1925) ${ }^{140}$ ergänzte Ravensteins „Distanzmodelle“ um den Aspekte des jeweiligen „Kulturniveaus“ im Ausgangs- und Zielgebiet der Migration und differenziert kriegerische (zu denen er „Invasion, Conquest, Colonization“ zählt) und friedliche (zu denen er „Immigration“ rechnet) Wanderungsbewegungen im Rahmen einer Typologie. An dieser Typologie der Migration von Fairchild kritisierte der USamerikanische Soziologie und Bevölkerungswissenschaftler William Petersen zwei Kriterien. Erstens, dass Fairchild mit seinem ersten Kriterium „Kulturniveau“ faktisch die Gefahr des Ethnozentrismus bewirke. Außerdem übte Petersen Kritik an der undeutlichen und missverständlichen Begriffsverwendung „kriegerisch bzw. friedlich“. ${ }^{141}$ William Petersen (1958) ${ }^{142}$ ging dagegen vielmehr unter

139 Ravenstein, Ernest George 1972: Die Gesetze der Wanderung I und II. In: Szèll, György (Hrsg.) 1972: Regionale Mobilität. Elf Aufsätze, München, S. 41-94, hier S. 43-46; vgl. Gormsen, Erdmann 1993: Internationale Migration. Begriffe - Hintergründe - Folgen. Ein weltweiter Vergleich. In: Gormsen, Erdmann / Thimm, Andreas (Hrsg.) 1993: Migration in der Dritten Welt. Mainz, S. 7-55, hier S. 11 f.; vgl. Treibel, Annette 2003: Migration in modernen Gesellschaften. a.a.O., S. 26-27.; vgl. Han, Petrus 2005: a.a.O., S. 42-43.; vgl. Oswald, Ingrid 2007: Migrationssoziologie. Konstanz, S. 66-67.

140 Vgl. Fairchild, Henry Pratt 1925: Immigration: A World Movement and its American Significance. New York:Macmillan, S. 13 ff.; vgl. Petersen, William 1972: Eine allgemeine Typologie der Wanderung. In: Szèll, György (Hrsg.) 1972: Regionale Mobilität. Elf Aufsätze. München, S. 95-96 (englisches Original von 1958); Petersen, William 1958: A General Typology of Migration. In: American Sociological Review (ASR), Vol. 23 (1/1958), S. 257.; vgl. Han, Petrus 2005: a.a.O., S. 26.

${ }^{141}$ Vgl. Petersen, William 1972: Eine allgemeine Typologie der Wanderung. In: Szèll, György (Hrsg.) 
Berücksichtigung der individuellen Wunschvorstellungen (migrants level of aspiration) auf die Frage ein, warum bestimmte Menschen (bzw. Völker) wandern und bestimmte nicht wandern. ${ }^{143} \mathrm{Zu}$ diesem Zweck unterschied Petersen ergänzend zwei Charakterisierungen der Migrationsziele, er differenzierte zwischen konservativer und innovativer Migration: ${ }^{144}$ a) ,Innovating': „Einige Menschen wandern mit der Absicht, das Neue zu erlangen. Diese Art der Wanderung bezeichnen wir als innovative.“: „Some persons migrate as a means of achieving the new. Let us term such migration innovating. “ b) ,Conservative’: „Andere wandern in Reaktion auf eine Änderung der Bedingungen, um das zu bewahren, was sie hatten; sie wandern in ähnliche Landschaften, um in gewohnter Umgebung zu bleiben. Diese Art der Wanderung nennen wir konservativ”: „Others migrate in responce to a change in conditions, in order to retain what they have had. " Diese Klassifizierung ist die Grundlage für die von ihm vorgenommene Einteilung von Migration in fünf Hauptarten (siehe Abbildung 2): ${ }^{145}$ 1. Primitive migration (ursprüngliche Wanderung). 2. Forced migration (gewaltsame Wanderung). 3. Impelled migration (zwangsweise Wanderung). 4. Free migration (freiwillige Wanderung). 5. Mass migration (massenhafte Wanderung). Die Besonderheit seiner Typologie ist darin zu sehen, dass Petersen zwischen zwei Formen der Zwangsmigration differenziert: Bei der „zwangsweisen (impelled) Wanderung“ besteht ein Rest an Entscheidungsfreiheit für die Wandernden, bei der „gewaltsamen (forced) Wanderung“ nicht, im letztgenannten Fall kommt den Migranten keine Entscheidungsmacht zu. ${ }^{146}$ Es existieren für ihn auch bei der Zwangsmigration eine konservative und eine innovative Form. ${ }^{147}$ Unter diesem Typus sind vor allem diejenigen Migranten aufmerksam zu betrachten, die die ,gewaltsame bzw.

1972: Regionale Mobilität. a.a.O., S. 96.; vgl. Han, Petrus 2005: a.a.O., S. 26.

142 Vgl. Petersen, William 1958: A general typology of migration. In: American Sociological Review (ASR), Vol. 23 (1/1958).

143 Petersen, William 1972: Eine allgemeine Typologie der Wanderung. In: Szèll, György (Hrsg.) 1972: Regionale Mobilität. Elf Aufsätze. München, S. 97.; vgl. auch Faist, Thomas 1997: Migration und der Transfer sozialen Kapitals oder: Warum gibt es relativ wenige internationale Migranten?. In: Pries, Ludger (Hrsg.) 1997: Transnationale Migration. Baden-Baden (Soziale Welt: Sonderband. 12), S. 6383, hier S. 63.; vgl. Hammar, Tomas / Brochmann, Grete / Tamas, Kristof / Faist, Thomas (Ed.) 1997: International Migration Immobility and Development. A Multidisciplinary Perspective. Oxford:Berg.

144 Petersen, William 1972: Eine allgemeine Typologie der Wanderung. In: Szèll, György (Hrsg.) 1972: Regionale Mobilität. Elf Aufsätze. München, S. 97 (vgl. englisches Original von 1958, S. 258.).

145 Petersen, William 1972: Eine allgemeine Typologie der Wanderung. In: Szèll, György: a.a.O., S. 109; Petersen, William 1958: a.a.O., S. 266.; vgl. Han, Petrus 2005: Soziologie der Migration. a.a.O., S. 27-30.; vgl. Treibel, Annette 2003: Migration in modernen Gesellschaften. a.a.O., S. 165.

146 „Als historisches Beispiel werden die durch antisemitische Gesetze und Aktivitäten veranlasste Emigration der Juden aus Nazideutschland in den Jahren 1933 bis 1938 sowie ihre erzwungene Deportation in die Konzentrationslager in den Jahren 1938 bis 1945 angeführt." In: Han, Petrus 2005: Soziologie der Migration. Stuttgart, S. 28.

147 Treibel, Annette 2003: Migration in modernen Gesellschaften. a.a.O., S. 165. 
erzwungene“ (forced) Migration überlebt haben; diese werden wegen ihrer passiven Rolle als „,displaced persons“ (DPs) bezeichnet. ${ }^{148}$ Flüchtlinge, so nach Petersen, sind von Emigranten dadurch klar $\mathrm{zu}$ unterscheiden, dass sie ihren Aufenthalt im Aufnahmeland als vorübergehend ansehen. ${ }^{149}$

\section{Abbildung 2: ,A General Typology of Migration' nach William Petersen}

\begin{tabular}{|c|c|c|c|c|}
\hline Beziehung & Ursache der & Art (Klasse) der & \multicolumn{2}{|c|}{ Wanderungstypus } \\
& Wanderung & Wanderung & konservativ & innovierend \\
\cline { 4 - 5 } & & & Wanderung \\
Natur und Mensch & Ökologischer & ursprünglich & Landflucht \\
& Druck & & Verschleppung & Sklavenhandel \\
\hline $\begin{array}{c}\text { Mensch und Staat } \\
\text { (od. Äquivalent) }\end{array}$ & Wanderungspolitik & gewaltsam & Flucht & Kuli-Handel \\
\hline Mensch und seine & Streben nach & freiwillig & Gruppen- & Pioniere \\
Normen & Besserem & & wanderung & \\
\hline Kollektives & Soziale & massenhaft & Besiedlung & Verstädterung \\
Verhalten & Verhältnisse & & & \\
\hline
\end{tabular}

Quelle: Petersen, William 1972: Eine allgemeine Typologie der Wanderung. In: Szèll, György (Hrsg.) 1972: Regionale Mobilität. Elf Aufsätze. München, S. 109 (deutsche Übersetzung des englischen Texts von 1958); Petersen, William 1958: A General Typology of Migration. In: American Sociological Review (ASR), Vol. 23 (1/1958), S. 266 (englisches Original von 1958; siehe Anhang Übersicht 3).

${ }^{148}$ Es existierten im Jahr 1944, nach dem Ende des zweiten Weltkrieges, insgesamt 10,5 - 11,7 Mio. DPs mit etwa 20 Nationalitäten und mehr als 35 Verschiedenen Sprachen, die ohne alliierte Unterstützung nicht zurückkehren oder eine neue Heimat finden konnten. In: Han, Petrus 2005: Soziologie der Migration. a.a.O., S. 28.; vgl. Jacobmeyer, Wolfgang 1992: Ortslos am Ende des Grauens: „Displaced Persons“ in der Nachkriegszeit. In: Bade, Klaus (Hrsg.) 1992: Deutsche im Ausland - Fremde in Deutschland. Migration in Geschichte und Gegenwart. München, S. 367-373, hier S. 368.

149 Treibel, Annette 2003: Migration in modernen Gesellschaften: a.a.O., S. 165.

150 Unter "ranging" versteht man hier "umherstreifen", "durchziehen". In: Treibel, Annette 2003: Migration in modernen Gesellschaften: a.a.O., S. 165, Fußnote 67.

151 „Unter dem ,Kuli-System' versteht man die - manchmal auch gewaltsame - Rekrutierung von Arbeitskräften, die in der zweiten Hälfte des 19. Jahrhunderts die Arbeit von Sklaven auf den Plantagen ersetzten." In: Treibel, Annette 2003: a.a.O., S. 165, Fußnote 68. 
Insgesamt kann davon ausgegangen werden, dass die Typologie der Migration von William Petersen trotz einiger Kritik ${ }^{152}$ eine gute Zusammenfassung der unterschiedlichen Interaktionstypen und bestimmten Ursachenkomplexen der Migration seit 1945 darstellt. Allerdings ist die von Petersen aufgestellte klassifikatorische Einteilung nicht ausreichend.

Der Züricher Soziologe Hans-Joachim Hoffmann-Nowotny (1973) ${ }^{153}$ knüpft weiterhin ferner an folgende Typologisierung an: Er setzt als Ausgangspunkt seiner Analyse der Migration das Bestehen „struktureller und anomischer Spannungen“ im Rahmen sozietaler Systeme und unterscheidet Migration zusätzlich nach ihrem Stellenwert für die soziale Schichtung im Ausgangs- und Zielgebiet. Im Mittelpunkt seiner Schichtungstheorie stehen die Macht- und Prestigebeziehungen einzelner Gesellschaften und der Weltgesellschaft insgesamt. ${ }^{154}$ Hoffmann-Nowotny versteht demgemäß Auswanderung als Prestige-Export und Einwanderung als Prestige-Import. Migration ist „die Folge eines Spannungsunterschiedes“, eines „Entwicklungsgefälles zwischen dem Immigrations- und dem Emigrationssystem“. ${ }^{155}$ Die Weltgesellschaft unterliegt folglich nach Hoffmann-Nowotnys Auffassung einem Prozess der Verwestlichung auf struktureller wie auf kultureller Ebene. ${ }^{156}$ Des Weiteren interpretiert Hartmut Esser $(1980)^{157}$ in seinem handlungstheoretischen Ansatz „Push (Druck)“- und „Pull (Sog)““Faktoren als individuelle Entscheidungskriterien, die den in verschiedenen Stufen ablaufenden Assimilationsprozess bestimmen. Esser analysiert daher die Gesamtheit der Beziehungen der Immigranten zum Aufnahmesystem unter drei Grundaspekten der Eingliederung: Akkulturation (der Prozess der Angleichung), Assimilation (der Zustand der Ähnlichkeit) und Integration (der Zustand des Gleichgewichts). ${ }^{158}$ Dagegen differenziert Blaschke $(1997)^{159}$, dass Migrationen bzw. Wanderungsbewegungen kaum handlungstheoretisch zu erklären sind, vielmehr sind sie stets in konkrete historische

${ }^{152}$ Vgl. Hoffmann-Nowotny, Hans-Joachim 1970: Migration. Ein Beitrag zu einer soziologischen Erklärung. Stuttgart (Diss.), S. 60-64.; vgl. auch Albrecht, Günther 1972: Soziologie der geographischen Mobilität. Zugleich ein Beitrag zur Soziologie des sozialen Wandels. Stuttgart, S. 29.

153 Hoffmann-Nowotny, Hans-Joachim 1973: Soziologie des Fremdarbeiterproblems: Eine theoretische und empirische Analyse am Beispiel der Schweiz. Stuttgart.; vgl. Han, Petrus 2005: a.a.O., S. 59.; vgl. Treibel, Annette 2003: Migration in modernen Gesellschaften: a.a.O., S. 176-186, hier S. 177-178.

154 Ausführlich siehe die Dissertation Hoffmann-Nowotny, Hans-Joachim 1970: Migration. a.a.O.

155 Hoffmann-Nowotny, Hans-Joachim 1973: Soziologie des Fremdarbeiterproblems: a.a.O., S. 21.

156 Vgl. Treibel, Annette 2003: Migration in modernen Gesellschaften: a.a.O., S. 178.

157 Esser, Hartmut 1980: Aspekte der Wanderungssoziologie. Assimilation und Integration von Wanderern, ethnischen Gruppen und Minderheiten. Eine handlungstheoretische Analyse. Darmstadt/Neuwied, S. 20.; vgl. Han, Petrus 2005: a.a.O., S. 63-69, hier S. 64.

158 Zur „Begriffliche Dimensionen der Eingliederung von Wanderern“ siehe Esser, Hartmut 1980: S. 25.

159 Blaschke, Jochen 1997: Migration - Ein Bericht über den Forschungsstand unter besonderer Berücksichtigung internationaler Publikationen zur Arbeitsmigration seit 1991. Wiesbaden. 
und politische Strukturen eingebunden, die das Geschehen wesentlich beeinflussen. Hierzu ist eine europaspezifische Typologisierung von Fassmann/Münz (1996) mit Interesse zu betrachten. Fassmann/Münz teilen dabei die in Europa seit dem Zweiten Weltkrieg unterschiedlich stark vertretenen Migranten in fünf verschiedene Gruppen ein: „1. Koloniale und postkoloniale Wanderer, worunter Zuwanderer gleicher und anderer Nationalität aus ehemaligen Kolonien zu verstehen sind. 2. Ethnische Wanderer, die Zuwanderer gleicher ethnischer Zugehörigkeit bezeichnen. 3. Arbeitsmigranten und deren Angehörige. 4. Flüchtlingswanderung, die sowohl anerkannte als auch de-factoFlüchtlinge und geduldete Kriegsopfer umfasst. 5. Sonstige Zuwanderer (etwa Elitenund Rentnerwanderung). “160 Anschließend entwickelt Treibel (2003) noch eine feinere Typologisierung der Migration, wobei meist folgende vier Aspekte unterschieden werden: „1. Räumliche Aspekte: Binnenmigration oder interne Migration (vom Land in die Stadt) versus internationale oder externe Migration (kontinentale oder interkontinentale Wanderungen). 2. Zeitliche Aspekte: begrenzte oder temporäre Migration (z. B. der Saisonarbeiter) versus dauerhafte oder permanente Migration (der Aus- bzw. Einwanderung und Niederlassung). 3. Aspekte der Wanderungsentscheidung und Wanderungsursache: freiwillige Migration (Arbeitsmigration) von der erzwungenen Migration (Vertreibung, Fluchtmigration). 4. Aspekt des Umfanges der Migration: Einzelner versus Gruppen- oder Kollektivmigration und Massenmigration. “ 161

Zusammenfassend kann Migration bzw. Wanderung danach typologisiert werden, ob sie kollektiv oder individuell, intern oder extern, freiwillig oder erzwungen sowie temporär oder dauerhaft erfolgt.

Vor diesem Hintergrund der Typologisierung nach den Migrationsursachen, Motivation und auch der geografischen Herkunft der MigrantInnen lassen sich schließlich die wichtigsten Migrationsgruppen als Migrationstypen in Europa bezüglich der alten 15EU-Länder (siehe Abbildung 3) und in der Bundesrepublik Deutschland (siehe Abbildung 4) unterscheiden.

\footnotetext{
${ }^{160}$ Fassmann, Heinz / Münz, Rainer 1996: Europäische Migration - Ein Überblick. In: Fassmann, Heinz / Münz, Rainer (Hrsg.) 1996: Migration in Europa. Historische Entwicklung, aktuelle Trends und politische Reaktionen. Frankfurt a. M./New York, S. 13-52, hier S. 18-28.

161 Treibel, Annette 2003: Migration in modernen Gesellschaften. Soziale Folgen von Einwanderung, Gastarbeit und Flucht. München, S. 20.
} 
Abbildung 3: Migrationstypen in den alten 15-EU-Ländern

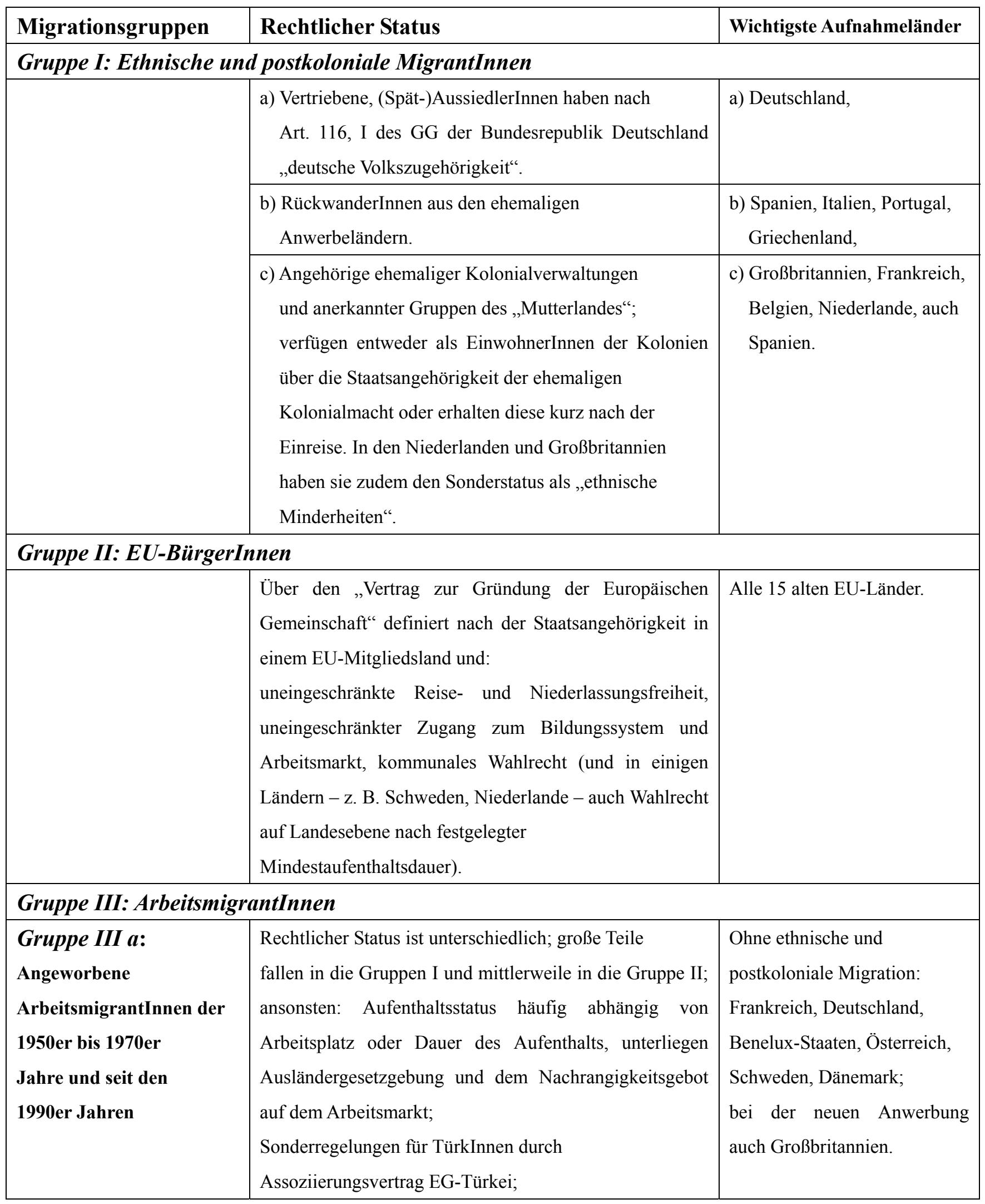




\begin{tabular}{|c|c|c|}
\hline $\begin{array}{l}\text { Gruppe III a: } \\
\text { Angeworbene } \\
\text { ArbeitsmigrantInnen der } \\
\text { 1950er bis 1970er } \\
\text { Jahre und seit den } \\
\text { 1990er Jahren }\end{array}$ & $\begin{array}{l}\text { Gleichstellung mit Gruppe I oder II für Nicht-EU- } \\
\text { BürgerInnen nur über Einbürgerung, die in den Ländern } \\
\text { unterschiedlich offen beziehungsweise restriktiv } \\
\text { gehandhabt wird (und in einigen Ländern - z. B. } \\
\text { Schweden, Niederlande - auch Wahlrecht auf } \\
\text { Landesebene nach festgelegter Mindestaufenthaltsdauer). } \\
\text { Anwerbung von Geringqualifizierten fällt in die beiden } \\
\text { Kategorien von III b und III c. }\end{array}$ & \\
\hline $\begin{array}{l}\text { Gruppe III a: } \\
\text { Blue-Card-InhaberInnen }\end{array}$ & $\begin{array}{l}\text { Die neue Anwerbung von Hochqualifizierten aus } \\
\text { Drittstaaten, also Nicht-EU-Staaten, die mit der } \\
\text { Aufenthaltsdauer für zunächst vier Jahre in der EU } \\
\text { ausgestattet sind; die im Juni } 2009 \text { verabschiedete, } \\
\text { sogenannte „Blue-Card-Richtlinie“ } 162 \text { zur einheitlichen } \\
\text { Arbeitsgenehmigung für hochqualifizierte Fachkräfte } \\
\text { muss bis } 2011 \text { von den Mitgliedstaaten umgesetzt werden } \\
\text { (abgesehen von Dänemark, Irland und Großbritannien). } \\
\text { Zuständigkeit: Bei den einzelnen EU-Mitgliedstaaten. }\end{array}$ & $\begin{array}{l}12 \text { alte EU-Länder } \\
\text { (abgesehen von allen } 15 \text { alten } \\
\text { EU-Ländern). }\end{array}$ \\
\hline $\begin{array}{l}\text { Gruppe III b: } \\
\text { SaisonarbeiterInnen }\end{array}$ & $\begin{array}{l}\text { Kurzzeitig befristete Aufenthalts- und Arbeitserlaubnisse } \\
\text { in eingeschränkten Berufsfeldern und regionalen } \\
\text { Geltungsbereichen (zumeist Landwirtschaft und } \\
\text { Baugewerbe). }\end{array}$ & $\begin{array}{l}\text { Deutschland, Spanien, } \\
\text { Frankreich. }\end{array}$ \\
\hline $\begin{array}{l}\text { Gruppe III c: } \\
\text { WerkvertragsarbeiterInnen }\end{array}$ & $\begin{array}{l}\text { Bilaterale Werkvertragsabkommen mit Nicht-EU- } \\
\text { Ländern, danach können „heimische“ Unternehmen über } \\
\text { Werkverträge mit ausländischen Betrieben Arbeitskräfte } \\
\text { für den eigenen Bedarf entsenden lassen. Für die } \\
\text { Arbeitskräfte gelten die Verträge und Bedingungen des } \\
\text { Entsendebetriebs und -landes. }\end{array}$ & $\begin{array}{l}\text { Alle } 15 \text { alten EU-Länder, } \\
\text { besonders Deutschland. }\end{array}$ \\
\hline
\end{tabular}

${ }^{162}$ Richtlinie 2009/50/EG des Rates vom 25. Mai 2009 über die Bedingungen für die Einreise und den Aufenthalt von Drittstaatsangehörigen zur Ausübung einer hochqualifizierten Beschäftigung. In: Amtsblatt der Europäischen Union, L 155 vom 18. 06. 2009, S. 17-29. Auch im Internet: http://www.aufenthaltstitel.de/rl_2009_50_eg.html; vgl. Angenendt, Steffen / Parkes, Roderick 2010: Blue Card - (noch) kein Erfolg?: Perspektiven der EU-Migrationspolitik für hochqualifizierte Arbeitskräfte. In: SWP-Aktuell 34, April 2010. Berlin, S. 2.; vgl. hierzu Kapitel IV. 2 in dieser Arbeit. 


\begin{tabular}{|c|c|c|}
\hline \multicolumn{3}{|c|}{ Gruppe IV: Asylsuchende } \\
\hline & $\begin{array}{l}\text { Individuelles Recht auf Asyl aufgrund politischer } \\
\text { Verfolgung; Definition von Verfolgung ist } \\
\text { unterschiedlich, gesetzliche Regelungen; } \\
\text { Ausnahme Deutschland: Grundrecht auf Asyl nach Art. } \\
\text { 16 GG; häufig nur eingeschränkte soziale Rechte und } \\
\text { abgesenkte Sozialleistungen, widerrufbarer Status. }\end{array}$ & $\begin{array}{l}\text { Alle } 15 \text { alten EU-Länder, } \\
\text { besonders Deutschland, } \\
\text { Großbritannien, } \\
\text { Niederlande, Belgien. }\end{array}$ \\
\hline \multicolumn{3}{|c|}{$\begin{array}{l}\text { Gruppe V: Flüchtlinge, Kontingentflüchtlinge, Kriegs- und Bürgerkriegsflüchtlinge, } \\
\text { Konventionsflüchtlinge }\end{array}$} \\
\hline & $\begin{array}{l}\text { Definiert u. a. im Rahmen humanitärer Hilfsaktionen } \\
\text { oder nach dem sog. Non-Refoulement Grundsatz der } \\
\text { Genfer Flüchtlingskonvention (GFK); } \\
\text { sowohl individualrechtliche Ansprüche als auch nach } \\
\text { ethnischer oder religiöser Zugehörigkeit; } \\
\text { in einigen Ländern befristetes Arbeitsverbot, } \\
\text { abgesenkte Sozialleistungen. }\end{array}$ & $\begin{array}{l}\text { Alle } 15 \text { alten EU-Länder, } \\
\text { besonders Deutschland, } \\
\text { Großbritannien, } \\
\text { Niederlande, Belgien. }\end{array}$ \\
\hline \multicolumn{3}{|c|}{$\begin{array}{l}\text { Quelle: Birsl, Ursula 2005: Migration und Migrationspolitik im Prozess der europäischen Integration?. Opladen, S. 93-94.; vgl. } \\
\text { Mintzel, Alf 1997: Multikulturelle Gesellschaften in Europa und Nordamerika: Konzepte, Streitfragen, Analysen, Befunde. Passau, S. } \\
\text { 467-470.; vgl. auch Thränhardt, Dietrich 1997: Zuwanderungspolitik im europäischen Vergleich. In: Angenendt, Steffen (Hrsg.) 1997: } \\
\text { Migration und Flucht: Aufgaben und Strategien für Deutschland, Europa und die internationale Gemeinschaft. Bonn, S. 137-153.; } \\
\text { Richtlinie 2009/50/EG des Rates vom 25. Mai } 2009 \text { über die Bedingungen für die Einreise und den Aufenthalt von } \\
\text { Drittstaatsangehörigen zur Ausübung einer hochqualifizierten Beschäftigung. In: Amtsblatt der Europäischen Union, L } 155 \text { vom 18. } 06 \text {. } \\
\text { 2009, S. 17-29.; Angenendt, Steffen / Parkes, Roderick 2010: Blue Card - (noch) kein Erfolg?: Perspektiven der EU-Migrationspolitik } \\
\text { für hochqualifizierte Arbeitskräfte. In: SWP-Aktuell 34, April 2010. Berlin, S. 2. Online Verfügbar unter: http://www.swp- } \\
\text { berlin.org/common/get_document.php?asset_id=6963 }\end{array}$} \\
\hline
\end{tabular}




\section{Abbildung 4: Migrationstypen in der Bundesrepublik Deutschland}

\begin{tabular}{|c|c|}
\hline Typen an Migrationsgruppen & Rechtliche Regelungen / Stellung \\
\hline $\begin{array}{l}\text { Gruppe I: } \\
\text { ethnische/deutschstämmige } \\
\text { MigrantInnen }\end{array}$ & $\begin{array}{l}\text { Gelten als Deutsche, definiert nach „,deutscher Volkszugehörigkeit“ im } \\
\text { Art. 116, I GG. Bis } 1990 \text { freie Einreise, mit dem AAG von } 1990 \text { u. dem } \\
1993 \text { novellierten BVFG v. } 1953 \text { eingeschränkt. }\end{array}$ \\
\hline $\begin{array}{l}\text { Gruppe II: } \\
\text { EU-AusländerInnen }\end{array}$ & $\begin{array}{l}\text { Einreise- und Niederlassungsfreiheit zunächst in den Ländern der sog. } \\
\text { „Schengen-Gruppe“ (zuletzt } 13 \text { EU-Mitgliedsländer außer } \\
\text { Großbritannien und Irland), mittlerweile durch den Amsterdamer } \\
\text { Vertrag der EU seit } 1999 \text { gewährleistet. }\end{array}$ \\
\hline Gruppe III: ArbeitsmigrantInnen & $\begin{array}{l}\text { Generell gilt hier noch der Anwerbestopp von 1973, der nur noch auf } \\
\text { Angehörige von Drittstaaten außerhalb der EU Anwendung findet, } \\
\text { jedoch sind Ausnahmen möglich. }\end{array}$ \\
\hline „GastarbeiterInnen“ & $\begin{array}{l}\text { Ausländische Arbeitskräfte, die vor dem Anwerbestopp von } 1973 \text { durch } \\
\text { bilaterale Abkommen zwischen 1955/1960 und } 1968 \text { angeworben } \\
\text { wurden sowie deren Familienangehörige. }\end{array}$ \\
\hline Green-Card-InhaberInnen & $\begin{array}{l}\text { Anwerbung von IT-ExpertInnen mit Studienabschluss oder } \\
\text { garantiertem Brutto-Mindesteinkommen von 100.000/Jahr für eine } \\
\text { Aufenthaltsdauer von } 5 \text { Jahren; Verordnung am 1. August } 2000 \text { in Kraft } \\
\text { getreten; Zuständigkeit: Arbeitsamt. }\end{array}$ \\
\hline SaisonarbeitnehmerInnen & $\begin{array}{l}\text { Seit 1991; Vermittlung dieser sog. „Kurzzeitgebundenen } \\
\text { Beschäftigung“ erfolgt über das AFG und die ZAV; Grundlage sind } \\
\text { bilaterale Vereinbarungen mit ost- und südosteuropäischen Ländern. } \\
\text { Anwerbung erfolgt saisonal für drei Monate und dies ausschließlich in } \\
\text { der Forst- u. Landwirtschaft, im Hotel- u. Gaststättengewerbe, in der } \\
\text { Obst- und Gemüseverarbeitung, im Schaustellergewerbe, in } \\
\text { Sägewerken u. bis } 1993 \text { im Baugewerbe. }\end{array}$ \\
\hline WerkvertragsarbeitnehmerInnen & $\begin{array}{l}\text { Ausnahme vom Anwerbestopp durch einen Beschluss des } \\
\text { Bundeskabinetts von } 1981 \text { und durch die „Anwerbestoppausnahme- } \\
\text { Verordnung von 1990: deutsche Firmen können über Werkverträge mit } \\
\text { ausländischen Firmen von diesen Arbeitskräfte rekrutieren. }\end{array}$ \\
\hline $\begin{array}{l}\text { Gruppe IV: } \\
\text { Asylberechtigte als politisch Verfolgte }\end{array}$ & $\begin{array}{l}\text { Individuelles Grundrecht auf Asyl nach Art. 16a, I und II GG. } \\
\text { Asylrecht greift nur bei staatlicher Verfolgung. }\end{array}$ \\
\hline Asylbewerber & $\begin{array}{l}\text { Ausländer, die Schutz als politisch Verfolgte nach Artikel 16a Absatz } 1 \\
\text { des Grundgesetzes (GG) oder Schutz vor Abschiebung nach § } 51 \text { Abs. } \\
1 \text { des Ausländergesetzes (AuslG) oder einer sonstigen Rückführung in }\end{array}$ \\
\hline
\end{tabular}




\begin{tabular}{|c|c|}
\hline $\begin{array}{l}\text { Gruppe IV: } \\
\text { Asylbewerber }\end{array}$ & $\begin{array}{l}\text { einen Staat beantragen bzw. deren Verfahren noch nicht bestands- oder } \\
\text { rechtskräftig abgeschlossen ist, in dem ihr Leben oder ihre Freiheit } \\
\text { wegen ihrer Rasse, Religion, Staatsangehörigkeit, ihrer Zugehörigkeit } \\
\text { zu einer bestimmten sozialen Gruppe oder wegen ihrer politischen } \\
\text { Überzeugung bedroht ist. Auf Artikel 16a Absatz } 1 \text { des Grundgesetzes } \\
\text { kann sich nicht berufen, wer aus einem sicheren Drittstaat im Sinne des } \\
\text { Paragrafen } 26 \text { a Absatz } 2 \text { des Asylverfahrensgesetzes einreist. }\end{array}$ \\
\hline \multicolumn{2}{|l|}{ Gruppe V: Andere Flüchtlinge } \\
\hline Konventionsflüchtlinge & $\begin{array}{l}\text { Entsprechend Art. 1a Nr. } 2 \text { GFK (Genfer Flüchtlingskonvention vom } \\
\text { 28.07.1951) „politisch Verfolgte“, denen jedoch kein Asyl gemäß Art. } \\
\text { 16a GG zuerkannt wurde. Unterliegen einem Abschiebeschutz nach § } \\
\text { 51, I AuslG, auch „kleines Asyl“ genannt. }\end{array}$ \\
\hline Kontingentflüchtlinge & $\begin{array}{l}\text { Kontingentflüchtlinge sind Flüchtlinge aus Krisenregionen, die im } \\
\text { Rahmen internationaler humanitärer Hilfsaktionen aufgenommen } \\
\text { werden. Ihr Status richtet sich nach dem Gesetz über Maßnahmen für } \\
\text { im Rahmen von humanitären Hilfsaktionen aufgenommene Flüchtlinge } \\
\text { vom 22. Juli } 1980 \text { (BGB1. I. S. 1057). Ihnen wird ein dauerhaftes } \\
\text { Bleiberecht in der Bundesrepublik Deutschland gewährt, ohne dass sie } \\
\text { sich zuvor einem Anerkennungsverfahren unterziehen mussten. } \\
\text { Deutschland hat seit } 1973 \text { in großer Zahl unter anderem Flüchtlinge aus } \\
\text { Indochina (insbesondere Vietnam, sogenannte Boat-people) und aus } \\
\text { Chile aufgenommen. Die Aufnahme jüdischer Zuwanderer aus der } \\
\text { ehemaligen Sowjetunion erfolgte aufgrund des Beschlusses der } \\
\text { Regierungschefs des Bundes und der Länder vom 9. Januar } 1991 \text { in } \\
\text { entsprechender Anwendung des Gesetzes. }\end{array}$ \\
\hline De-Facto-Flüchtlinge & $\begin{array}{l}\text { De-facto-Flüchtlinge sind Personen, die keinen Asylantrag gestellt } \\
\text { haben oder deren Asylantrag abgelehnt worden ist, denen aber aus } \\
\text { humanitären oder politischen Gründen die Rückkehr in ihr Heimatland } \\
\text { nicht zumutbar ist, sowie Personen, die ursprünglich aus diesen } \\
\text { Gründen Aufnahme gefunden haben und sich immer noch im } \\
\text { Bundesgebiet aufhalten. Diese De-facto-Flüchtlinge stellen die größte } \\
\text { Flüchtingsgruppe in der Bundesrepublik Deutschland dar. }\end{array}$ \\
\hline $\begin{array}{l}\text { Kriegs- und Bürgerkriegsflüchtlinge } \\
\text { (Bosnien und Herzegowina, Kosovo) }\end{array}$ & $\begin{array}{l}\text { Personen, die wegen der Kriegsereignisse ihre Heimat aus Furcht } \\
\text { vor den Auswirkungen kriegerischer Auseinandersetzungen (direkte } \\
\text { Auswirkungen der Kampfhandlungen, Übergriffe der Kriegsparteien, } \\
\text { gezielte Vertreibung oder Ähnliches) verlassen. }\end{array}$ \\
\hline
\end{tabular}




\begin{tabular}{|c|c|}
\hline $\begin{array}{l}\text { Gruppe } V \text { : } \\
\text { Kriegs- und Bürgerkriegsflüchtlinge } \\
\text { (Bosnien und Herzegowina, Kosovo) }\end{array}$ & $\begin{array}{l}\text { Die meisten von ihnen sind keine Flüchtlinge im Sinne der Genfer } \\
\text { Flüchtlingskonvention (GFK), weil Voraussetzung für die Zuerkennung } \\
\text { des Flüchtlingsstatus eine Verfolgung des Einzelnen durch den Staat ist } \\
\text { und eine Kriegs-/Bürgerkriegssituation für sich genommen keine } \\
\text { staatliche Verfolgung darstellt. Für Kriegs- und Bürgerkriegsflüchtlinge } \\
\text { wurde durch eine Änderung des Ausländergesetzes mit Wirkung vom } \\
01.07 .1993 \text { in § 32a AuslG die Möglichkeit einer vorübergehenden } \\
\text { Aufnahme ohne Einzelfallprüfung geschaffen. Der für sie vorgesehene } \\
\text { Status ist an die Bedingung gebunden, dass ein Asylantrag nicht gestellt } \\
\text { oder zurückgenommen wurde; auch besteht kein Anspruch auf } \\
\text { Aufenthalt an einem bestimmten Ort oder in einem bestimmten } \\
\text { Bundesland. }\end{array}$ \\
\hline Duldung/Geduldete Flüchtlinge & $\begin{array}{l}\text { Die Duldung ist definiert als „Aussetzung der Abschiebung“. } \\
\text { Geduldete sind Personen, die ausreisepflichtig sind, aber aus } \\
\text { bestimmten Gründen (z. B. Krankheit, Einreiseverweigerung durch } \\
\text { den Herkunftsstaat) tatsächlich nicht ausreisen oder nicht abgeschoben } \\
\text { werden können. Die Duldung ( } \S 55,56 \text { AuslG) stellt keinen } \\
\text { rechtmäßigen Aufenthaltstitel dar. }\end{array}$ \\
\hline
\end{tabular}

Quelle: Zusammengestellt aus Birsl, Ursula 2003: Deutschland. In: Gieler, Wolfgang (Hrsg.) 2003: Handbuch der Ausländer- und Zuwanderungspolitik von Afghanistan bis Zypern. Münster, S. 141-142. und Bundesministerium des Innern (Hrsg.) 2006: Zuwanderungsrecht und Zuwanderungspolitik. Berlin, S. 88-89.; vgl. hierzu Mintzel, Alf 1997: Multikulturelle Gesellschaften in Europa und Nordamerika: Konzepte, Streitfragen, Analysen, Befunde. Passau,

S. $467-470$. 


\section{Migranten}

\subsection{Dimension der geografischen und demografischen Entwicklungen in der EU}

Die Migration in und nach Europa bzw in der Europäischen Union (vgl. Abbildung 5) ist bislang nicht nur durch Kontinuitäten, sondern auch durch Spannungen gekennzeichnet. ${ }^{163}$

\section{Abbildung 5 : Die 27 Mitgliedstaaten der Europäischen Union ${ }^{164}$ \\ Mitgliedsstaaten der Europäischen Union}

Mit Stimmen im Rat der EU, Europaabgeordneten und Einwohnern

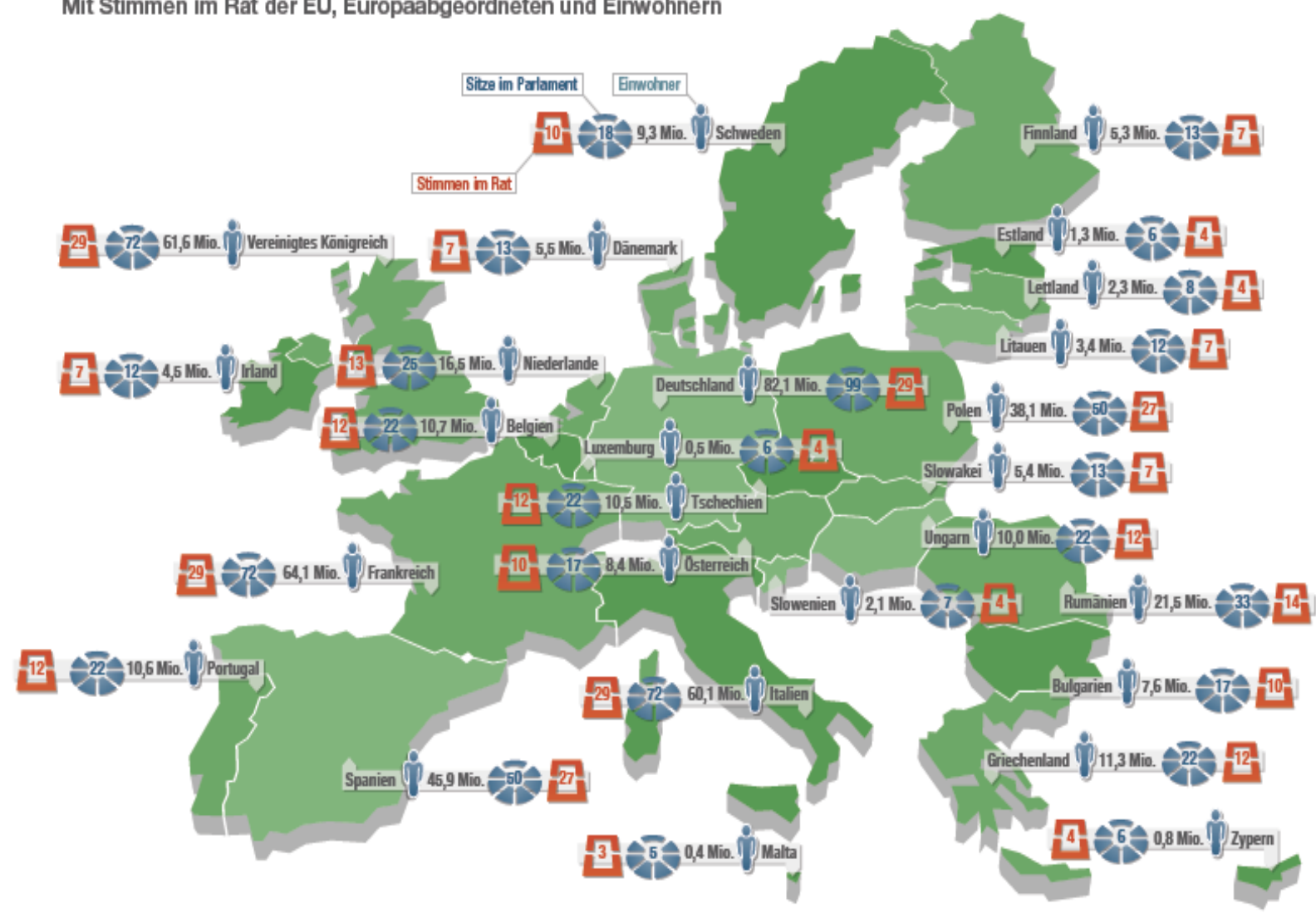

163 Die geografischen Entwicklungen in der EU wurden vor allem in den folgenden Werken berücksichtigt: Fassmann, Heinz / Münz, Rainer (Hrsg.) 1996: Migration in Europa: Historische Entwicklung, aktuelle Trends und politische Reaktionen. Frankfurt a.M, S. 28-30; Münz, Rainer 1997: Phasen und Formen der europäischen Migration. In: Angenendt, Steffen 1997: Migration und Flucht: Aufgabe und Strategien für Deutschland, Europa und die internationale Gemeinschaft. S. 34-47; Birsl, Ursula 2005: Migration und Migrationspolitik im Prozess der europäischen Integration?. S. 81-85.

164 Quelle: Bundeszentrale für politische Bildung (Hrsg.) 2010: Mitgliedstaaten der Europäischen Union. Online verfügbar unter: http://www.bpb.de/themen/R7H216.html 
Die Migrationsbewegungen in Europa begannen in Richtung Ost und West hauptsächlich erst nach dem Zweiten Weltkrieg 1945 und dem Naitonalsozialismus. So entstand die Migration zuerst aus nach Unabhängigkeit strebenden Kolonien in Richtung der ehemaligen Kolonialmächte wie Frankreich, Großbritannien, Belgien und den Niederlanden. Hierbei kannte Deutschland keine Kolonialmacht bzw. Kolonialmigration, dafür aber eine starke Einwanderung von ethnischen Deutschen aus Ost- und Südosteuropa, die heute als „Spätaussiedler“ bezeichnet werden. ${ }^{165}$ Seit Mitte der 1950er Jahre gewann dann die Süd-Nord-Migration in Europa an Bedeutung. Bemerkenswert war in dieser Hinsicht, dass viele europäische Industrieländer in der Anwerbephase Anwerbekampagnen im süd- und südosteuropäischen Ausland starteten, um Arbeitskräfte für die heimischen Arbeitsmärkte zu rekrutieren. Darunter waren nicht nur Länder wie Deutschland, Österrich oder Schweden, sondern auch Großbritannien. Dadurch erhöhte sich insbesondere die Arbeitsmigration sowohl aus Italien, Portugal, Spanien und Griechenland als auch aus der Türkei, der Karibik und Teilen der „Drittstaaten“ (d. h. Nicht-EG/EU-Staaten) nach Westeuropa. Später kehrten infolge des Anwerbestopps von 1973 viele ArbeitsmigrantInnen aus diesen Ländern wieder in ihre Heimatländer zurück, nachdem die Einreise- und Einwanderungsbestimmungen zunehmend restriktiveren Maßstäben unterlagen. Diese Re-Migration war im Wesentlichen nicht freiwillig, sondern erzwungen. So gab es bereits eine beschränkende migrationspolitische Maßnahme der damaligen Europäischen Gemeinschaft (EG) durch das sogenannte „Wiedereinreiseverbot“ für Migrierende aus Drittstaaten, das vor allem ArbeitsmigrantInnen aus der Türkei und dem ehemaligen Jugoslawien betraf. Die Rückwanderung bzw. die Re-Migration in die südlichen Länder war demgemäß vergleichsweise größer als die in die Türkei oder das ehemalige Jugoslawien. Ein Grund dafür stellte das fehlende Wiedereinreiseverbot dar, da Italien von Beginn an Mitglied der EG war und im Zuge der Süderweiterung wurden Griechenland 1981 sowie Spanien und Portugal 1986 nachfolgend ebenso Vollmitglieder. ${ }^{166}$ Aus der damaligen Migrationspolitik des Anwerbestopps und Wiedereinreiseverbots resultierte jedoch das paradoxe Faktum, dass die Anwerbeländer nun zu Einwanderungsländern wurden. So entwickelten sich die europäischen Mittelmeerländer wie Italien, Spanien und Griechenland seitdem kontinuierlich von Auswanderungsländern (Wanderungssaldo 1950 - 1969: -6 Millionen Migranten) zu Einwanderungsländern (1970 - 1993: +2,9 Millionen Migranten). ${ }^{167}$

\footnotetext{
165 Vogel, Wolfram 2010: Die Migration im Hintergrund: Strukturen der Integrationspolitik in Deutschland. In: Bassner, Frank (Hrsg.) 2010: Migration und Integration in Europa. S. 43.

166 Birsl, Ursula 2005: Migration und Migrationspolitik im Prozess der europäischen Integration?. S. 82.

167 Fassmann, Heinz / Münz, Rainer (Hrsg.) 1996: Migration in Europa: a.a.O., S. 29.
} 
Bei einem Überblick über die Einwanderung in Europa bzw. in Westeuropa nach dem Zweiten Weltkrieg war auch die Auswanderung bis in die 1980er Jahre hinein durch ein prägendes Merkmal gekennzeichnet: Zunächst war bis Mitte der 1960er Jahre die Zahl emigrierender Europäer höher als die Zahl der neuen ImmigrantInnen aus den Drittstaaten wie Türkei, Asien, Afrika, der Karibik und Südamerika. Bei der Emigration der Europäer überwogen als Ziele hierbei die USA, Kanada, Israel und andere Länder außerhalb Europas (Wanderungssaldo 1950 - 1959: -2,7 Millionen Einwohner). ${ }^{168}$ Hinzu kam die Emigration innerhalb Europas. Insbesondere die südlichen Länder bezeichneten die größten „Arbeitskräfteexporteure“ auf dem Gebiet der heutigen EU. So verlor etwa Italien während der Anwerbephase zwischen 1960 und 1974 über 1 Mio. Menschen seiner Gesamtbevölkerung und Portugal rund 1,5 Mio. Menschen. ${ }^{169}$

Die Ein- und Auswanderung nach und in Europa wird mittlerweile durch die offenen Grenzen begünstigt: Obwohl erst mit dem Schengener Durchführungsübereinkommen (SDÜ, auch Schengen II, Inkrafttreten 1995) ${ }^{170}$, Regelungen der Reise- und Niederlassungsfreiheit für EU-BürgerInnen der fünf Unterzeichnerstaaten (Deutschland, Frankreich, Belgien, Luxemburg, Niederlande) gezielt geschaffen wurden, galt bereits in den 1970er und 1980er Jahren eine relative Freizügigkeit innerhalb der EG und im Verhältnis zu künftigen Mitgliedstaaten. Einerseits war daher die Migration zwischen den späteren EG-Mitgliedstaaten Südeuropas und den EG-Staaten eher durch eine Pendelmigration im transnationalen Raum und Fluktuation gekennzeichnet als durch dauerhafte Umsiedlung oder Einwanderung. Andererseits war als negative Auswirkung zu beobachten, dass die Öffnung der Grenzen zu einer wachsenden Zahl irregulärer MigrantInnen führte. Unterdessen wurde im Assoziierungsvertrag von 1963 zwischen der EG und der Türkei 1980 auch für türkische Staatsangehörige eine Wiedereinreiseoption aufgenommen, da die Rückwanderungszahlen von TürkInnen hinter den Erwartungen der ehemaligen Anwerbestaaten zurückblieben und zudem durch den Familiennachzug kompensiert wurden. Aufgrund dieser bemerkenswerten Zahl türkischer Migranten in Westeuropa wurden zu Beginn der 1980er Jahre Maßnahmen über sogenannte „Rückkehrhilfen“ ehemaliger Anwerbestaaten wie Frankreich, die Niederlande oder Deutschland eingeführt, die jedoch nicht erfolgreich waren. ${ }^{171}$

\footnotetext{
168 Fassmann, Heinz / Münz, Rainer (Hrsg.) 1996: Migration in Europa: a.a.O., S. 29.

169 Birsl, Ursula 2005: Migration und Migrationspolitik im Prozess der europäischen Integration?. S. 82.

170 Klos, Christian 1999: Eine Reise von Rom nach Amsterdam: Die Entwicklungen des europäischen Einwanderungsrechts. In: Wolter, Achim (Hrsg.) 1999: Migration in Europa: a.a.O., S. 24.

171 Birsl, Ursula 2005: Migration und Migrationspolitik im Prozess der europäischen Integration?. S. 83.
} 
Die Zeit bis zur ersten Hälfte der 1980er Jahre zeichnete sich insgesamt durch ein eher stagnierendes Migrationsgeschehen in den Einwanderungsländern Europas aus. Dies änderte sich allerdings Ende der 1980er Jahre, wobei der sogenannte „Kalte Krieg“ zwischen Ost und West dem Ende entgegenging, was zu einer stark anwachsenden Auswanderungsbewegung innerhalb der osteuropäischen Länder in Richtung Westeuropa, vor allem nach Deutschland, führte. Außerordentlich dramatisch war hierbei die Massenwanderung von DDR-Bürgern. Die zahlreichen DDR-Bürger gelangten 1989 auf unterschiedlichen Wegen in die alte Bundesrepublik Deutschland und beschleunigten damit letztlich den Zusammenbruch der DDR sowie den Zerfall der Berliner Mauer durch die deutsche Wiedervereinigung. Während dieser Ost-WestKonfrontation wurden mehrere Flüchtlingswellen durch innenpolitische Krisen ausgelöst. Die größte Flüchtlingsbewegung in Europa seit dem Ende des Zweiten Weltkrieges entstand somit nach der Auflösung Jugoslawiens und den Kriegen in Kroatien und in Bosnien-Herzegowina: ${ }^{172}$ Von insgesamt fünf Millionen Flüchtlingen dieses Kriegs- und Bürgerkriegsgebietes gelangten eine Millionen Menschen nach Westeuropa; 700.000 von ihnen wurden entweder als politische Flüchtlinge anerkannt oder zumindest übergangsweise aufgenommen. Diese Zahlen haben sich seit 1996 verringert, wobei Deutschland, Österreich, Schweden und Dänemark den größten Rückgang zu verzeichnen hatten. Insbesondere Deutschland war 1996 das erste Land, das konkrete politische Maßnahmen zur Abschiebung geduldeter bosnischer Flüchtlinge in ihre zerstörten Heimatregionen ergriff.

Das Ende der 1980er und der Anfang der 1990er Jahre waren somit im politischen Diskurs in vielen europäischen Ländern durch steigende Zahlen an Asylsuchenden gekennzeichnet. Seitdem verschärften die EU-Mitgliedstaaten nach und nach ihr Asylrecht und begannen auch etappenweise mit der Einführung einer gemeinsamen europäischen Asylpolitik. Des Weiteren wurde illegale Einwanderung auch als ein Problem debattiert, wobei dies vor allem seit den 1990er Jahren in Griechenland und Italien durch die Flucht aus Montenegro und Albanien sowie durch Einwanderung aus Syrien, Irak und Iran $\mathrm{zu}$ einem wichtigen Thema geworden ist. ${ }^{173}$ Seit dem 21. Jahrhundert gehen immer noch ca. drei Viertel der Asylanträge an Europa bzw. die $\mathrm{EU}^{174}$, die in Industrieländern weltweit gestellt werden, aber die Aufnahmebereitschaft der einzelnen EU-27-Mitgliedstaaten ist sehr unterschiedlich (vgl. Abbildung 6).

172 Münz, Rainer 1997: Phasen und Formen der europäischen Migration. In: a.a.O., S. 42.

${ }_{173}$ Birsl, Ursula 2005: Migration und Migrationspolitik im Prozess der europäischen Integration?. S. 84.

174 Von Weizsäcker, Jakob 2010: Die enge Pforte: Prioritäten für die europäische Migrationspolitik. In: Baasner, Frank (Hrsg.) 2010: Migration und Integration in Europa. Baden-Baden, S. 236. 


\section{Abbildung 6 : Entscheidungen über Asylanträge in der EU-27, $2008^{175}$}

\section{Entscheidungen über Asylanträge, 2008}

\begin{tabular}{|c|c|c|c|c|c|c|c|c|}
\hline & \multirow{2}{*}{\multicolumn{3}{|c|}{ Entscheidungen ${ }^{\star}$}} & \multicolumn{5}{|c|}{${\text { Positive Entscheidungen }{ }^{\star \star *}}$} \\
\hline & & & & \multirow[b]{2}{*}{ Insgesamt } & \multicolumn{2}{|c|}{ Erste Instanz } & \multicolumn{2}{|c|}{$\begin{array}{c}\text { Endgültige } \\
\text { Berufungsentscheide }\end{array}$} \\
\hline & Insgesamt & $\begin{array}{l}\text { Erste } \\
\text { Instanz }\end{array}$ & $\begin{array}{l}\text { Endgültige } \\
\text { Berufungs- } \\
\text { entscheide }\end{array}$ & & $\#$ & $\begin{array}{c}\text { Anerkennungs- } \\
\text { rate (in \%) }\end{array}$ & $\#$ & $\begin{array}{l}\text { Anerkennungs- } \\
\text { rate (in \%) }\end{array}$ \\
\hline EU27 $7^{\star \star *}$ & 281120 & 209230 & 71890 & 76320 & 59305 & 28,3 & 17015 & 23,7 \\
\hline$B E$ & 18860 & 13620 & 5240 & 3905 & 3505 & 25,7 & 395 & 7,6 \\
\hline$B G$ & 700 & 670 & 25 & 305 & 295 & 43,8 & 10 & 33,3 \\
\hline$C Z$ & 2880 & 1400 & 1480 & 260 & 215 & 15,5 & 45 & 3,1 \\
\hline DK & 1725 & 1250 & 480 & 890 & 730 & 58,3 & 165 & 34,3 \\
\hline $\mathrm{DE}$ & 30405 & 19330 & 11070 & 10650 & 7870 & 40,7 & 2775 & 25,1 \\
\hline $\mathrm{EE}$ & 15 & 10 & 0 & 5 & 5 & 33,3 & 0 & 0,0 \\
\hline $\mathrm{IE}$ & 7250 & 4790 & 2460 & 1760 & 1465 & 30,6 & 295 & 11,9 \\
\hline $\mathrm{EL}$ & 30915 & 29580 & 1340 & 415 & 55 & 0,2 & 360 & 26,8 \\
\hline ES & 6250 & 5130 & 1120 & 290 & 275 & 5,4 & 10 & 1,1 \\
\hline FR & 56115 & 31765 & 24350 & 11470 & 5150 & 16,2 & 6320 & 25,9 \\
\hline IT & 20260 & 20225 & 30 & 9740 & 9740 & 48,2 & 0 & 0,0 \\
\hline $\mathrm{CY}$ & : & : & 2845 & : & : & : & 35 & 1,3 \\
\hline LV & 25 & 10 & 15 & 5 & 5 & 25,0 & 0 & 0,0 \\
\hline LT & 140 & 105 & 35 & 65 & 65 & 64,1 & 0 & 2,8 \\
\hline LU & 965 & 485 & 480 & 240 & 185 & 38,4 & 55 & 11,5 \\
\hline $\mathrm{HU}$ & 965 & 910 & 55 & 400 & 395 & 43,7 & 0 & 1,8 \\
\hline MT & 2915 & 2685 & 230 & 1410 & 1410 & 52,4 & 0 & 0,4 \\
\hline $\mathrm{NL}$ & 11725 & 10925 & 800 & 6090 & 5675 & 52,0 & 415 & 51,6 \\
\hline AT & 13705 & 5905 & 7795 & 5675 & 3640 & 61,6 & 2035 & 26,1 \\
\hline PL & 4425 & 4245 & 185 & 2800 & 2770 & 65,3 & 30 & 15,8 \\
\hline PT & 105 & 105 & 0 & 70 & 70 & 64,2 & 0 & 0,0 \\
\hline RO & 715 & 675 & 45 & 150 & 110 & 16,0 & 45 & : \\
\hline $\mathbf{S I}$ & 260 & 160 & 100 & 5 & 5 & 2,5 & 0 & 0,0 \\
\hline SK & 445 & 370 & 70 & 100 & 90 & 24,0 & 10 & 12,5 \\
\hline $\mathrm{FI}$ & 1770 & 1675 & 95 & 740 & 655 & 39,1 & 80 & 87,2 \\
\hline SE & 31220 & 29545 & 1680 & 8670 & 7845 & 26,6 & 825 & 49,0 \\
\hline UK & 33525 & 23665 & 9865 & 10190 & 7080 & 29.9 & 3115 & 31.6 \\
\hline IS & 65 & 55 & 10 & 10 & 10 & 17,0 & 0 & 10,0 \\
\hline NO & 10325 & 9015 & 1310 & 3710 & 3050 & 33,9 & 655 & : \\
\hline $\mathrm{CH}$ & 13805 & 7550 & 6255 & 5725 & 4830 & 64,0 & 895 & 14,3 \\
\hline
\end{tabular}

Die Angaben werden auf die Endziffern 5 oder 0 auf- bzw. abgerundet.

0 bedeutet weniger als 3 .

: Daten nicht verfügbar.

- Die Gesamtzahl der Entscheidungen bezieht sich auf die Zahl der administrativen Entscheidungen, nicht auf die Zahl der Einzelpersonen.

* Die Anerkennungsrate ist der Anteil der positiven Entscheidungen (in erster Instanz oder Berufungsentscheide) an den positiven

Entscheidungen im jeweiligen Stadium. Dieser Berechnung wurde anstelle der in der Tabelle enthaltenen gerundeten Zahlen die genaue

Zahl der Entscheidungen zugrunde gelegt.

*:* EU27: Summe oder Durchschnitt der verfügbaren Daten.

EU27: Belgien (BE), Bulgarien (BG), Tschechische Republik (CZ), Dänemark (DK), Deutschland (DE), Estland (EE), Irland (IE), Griechenland (EL), Spanien (ES), Frankreich (FR), Italien (IT), Zypern (CY), Lettland (LV), Litauen (LT), Luxemburg (LU), Ungarn (HU), Malta (MT),

Niederlande (NL), Ósterreich (AT), Polen (PL), Portugal (PT), Rumānien (RO), Slowenien (SI), Slowakei (SK), Finnland (FI), Schweden (SE)

und Vereinigtes Königreich (UK).

Island (IS), Norwegen (NO) und die Schweiz (CH).

175 Quelle: Eurostat Pressestelle (Hrsg.) 2009: Asylentscheidungen in der EU27, 2008: Die EU-

Mitgliedstaaten erkannten 76.300 Asylbewerber als schutzberechtigt an. In: Eurostat

Pressemitteilungen. Nr. 175/2009 - 8. Dezember 2009.; http://ec.europa.eu/eurostat 
Einem Bericht von Eurostat zufolge (Statistisches Amt der Europäischen Union) verzeichnete im Jahr 2008 Frankreich (11.500) die höchste Zahl von Personen, denen ein Schutzstatus zugesprochen wurde, gefolgt von Deutschland (10.700), Großbritannien (10.200), Italien (9.700), Schweden (8.700), den Niederlanden (6.100) und Österreich (5.700). Die größte Gruppe von Asylanträgen im Jahr 2008, denen in der EU-27 der Schutzstatus zuerkannt wurde, waren Staatsangehörige des Irak (16.600 Personen bzw. 22\% aller Personen, die als schutzberechtigt anerkannt wurden), Somalia (9.500: 12\%), Russland (7.400: 10\%), Afghanistan (5.000: 7\%) und Eritrea (4.600: 6\%). (Vgl. Abbildung 7). ${ }^{176}$

Abbildung 7 : Größte Gruppen von Asylanträgen, denen in der EU der Schutzstatus zuerkannt wurde Größte Gruppen, denen der Schutzstatus zuerkannt wurde, 2008

\begin{tabular}{|c|c|c|c|c|c|c|c|c|c|}
\hline & \multicolumn{3}{|c|}{ Größte Gruppe } & \multicolumn{3}{|c|}{ Zweitgrößte Gruppe } & \multicolumn{3}{|c|}{ Drittgrößte Gruppe } \\
\hline & Staatsangehörigkeit & \# & $\%^{*}$ & Staatsangehörigkeit & $\#$ & $\%^{*}$ & Staatsangehörigkeit & $\#$ & $\%^{*}$ \\
\hline EU27 $7^{* *}$ & Irak & 16640 & 21,8 & Somalia & 9520 & 12,5 & Russland & 7440 & 9,7 \\
\hline $\mathrm{BE}$ & Irak & 625 & 16,1 & Russland & 595 & 15,3 & Serbien & 390 & 10,0 \\
\hline BG & Irak & 230 & 76,6 & Afghanistan & 25 & 8,3 & Iran & 10 & 3,0 \\
\hline $\mathrm{CZ}$ & Weißrussland & 50 & 19,5 & Irak & 45 & 16,4 & Russland & 35 & 14,1 \\
\hline DK & Irak & 260 & 29,0 & Russland & 110 & 12,2 & Iran & 100 & 11,1 \\
\hline DE & Irak & 6380 & 59,9 & Iran & 655 & 6,1 & Afghanistan & 475 & 4,5 \\
\hline EE & $:$ & : & : & $:$ & : & : & $:$ & : & : \\
\hline IE & Nigeria & 410 & 23,3 & Irak & 160 & 9,1 & Dem. Rep. Kongo & 115 & 6,5 \\
\hline EL & Irak & 355 & 85,7 & Afghanistan & 20 & 5,3 & Zentralafrikan. Rep. & 10 & 1,9 \\
\hline ES & Irak & 60 & 21,5 & Kolumbien & 30 & 9,7 & Staatenlos & 25 & 8,0 \\
\hline FR & Sri Lanka & 1715 & 14,9 & Russland & 1235 & 10,8 & Mali & 990 & 8,6 \\
\hline IT & Somalia & 3545 & 36,4 & Eritrea & 1625 & 16,7 & Afghanistan & 1050 & 10,8 \\
\hline$C Y^{\star * *}$ & Iran & 10 & 25,0 & Georgien & 10 & 22,2 & Serbien & 5 & 19,4 \\
\hline LV & : & : & : & : & $:$ & : & - & - & - \\
\hline LT & Russland & 50 & 77,6 & Äthiopien & 5 & 4,5 & Kuba & 5 & 4,5 \\
\hline LU & Serbien & 90 & 36,4 & Montenegro & 30 & 12,8 & Angola & 20 & 7,4 \\
\hline $\mathrm{HU}$ & Somalia & 105 & 26,4 & Afghanistan & 60 & 15,6 & Irak & 55 & 13,8 \\
\hline MT & Somalia & 1120 & 79,3 & Eritrea & 260 & 18,5 & Sudan & 15 & 1,0 \\
\hline NL & Irak & 2305 & 37,9 & Somalia & 1515 & 24,9 & Afghanistan & 200 & 3,3 \\
\hline AT & Russland & 2020 & 35,6 & Afghanistan & 875 & 15,4 & Serbien & 435 & 7,6 \\
\hline $\mathrm{PL}$ & Russland & 2695 & 96,3 & Irak & 30 & 1,1 & Weißrussland & 20 & 0,7 \\
\hline PT & Somalia & 20 & 27,9 & Kolumbien & 10 & 17,6 & Sri Lanka & 5 & 10,3 \\
\hline RO & Irak & 105 & 68,2 & Somalia & 10 & 5,3 & Serbien & 5 & 4,6 \\
\hline $\mathbf{S I}$ & : & : & : & $:$ & : & : & $:$ & $:$ & : \\
\hline SK & Afghanistan & 35 & 34,7 & Irak & 35 & 33,7 & Kuba & 10 & 9,2 \\
\hline $\mathrm{FI}$ & Irak & 235 & 31,8 & Somalia & 150 & 20,3 & Afghanistan & 70 & 9,8 \\
\hline SE & Irak & 3975 & 45,9 & Somalia & 1540 & 17,8 & Eritrea & 655 & 7,6 \\
\hline UK & Simbabwe & 1635 & 16,0 & Eritrea & 1455 & 14,3 & Afghanistan & 1260 & 12,3 \\
\hline IS & Russland & 5 & 40,0 & Sri Lanka & 5 & 40,0 & : & : & \\
\hline NO & Eritrea & 715 & 19,3 & Irak & 610 & 16,5 & Afghanistan & 495 & 13,4 \\
\hline $\mathrm{CH}$ & Eritrea & 1355 & 23,7 & Sri Lanka & 525 & 9,1 & Türkei & 440 & 7,7 \\
\hline
\end{tabular}

Die Angaben werden auf die Endziffern 5 oder 0 auf- bzw. abgerundet. 0 bedeutet weniger als 3 .

$$
\text { Entfällt }
$$

Für die Länder, auf deren Staatsangehörige während des Bezugszeitraums höchstens zwei positive Entscheidungen entfielen, werden keine Angaben gemacht.

* Anteil (in \%) der Personen mit der betreffenden Staatsangehörigkeit an allen Personen, denen in diesem Land der Schutzstatus zugesprochen wurde.

Dewogener Durchschnitt der verfügbaren Daten. **: Keine Daten zur ersten Instanz verfügbar.

176 Quelle: Eurostat Pressestelle (Hrsg.) 2009: Eurostat Pressemitteilungen. Nr. 175/2009 - a.a.O. 
Es lassen sich folglich in Europa über die Zeit insgesamt klare Veränderungen beobachten, wobei die Einwanderung sowie Flucht und Asyl in etlichen Fällen deutlich zunahm. Beispiele hierfür waren das Verschwinden „-der 28 Jahre lang existierenden Berliner Mauer, des 40 Jahre bestehenden Eiserner Vorhangs zwischen Österreich und Ungarn sowie der während 50 Jahren weitgehend unterbrochene Personenverkehr zwischen Skandinavien und dem Baltikum." "177 So war und ist die Migration nach und in Europa keine Einbahnstraße, sondern führt zugleich zu der Festung Europa.

Vor diesem Hintergrund stehen bei der Migrationspolitik der EU, die 2007 auf 27 Mitgliedstaaten anwuchs, vor allem potenzielle Wanderungen von sog. Drittstaatsangehörigen (d. h. von Nicht-Unionsbürgern) im Zentrum der Aufmerksamkeit. ${ }^{178}$ In diesem Zusammenhang führt die EU heute den Begriff „managing migration“ an, in dem nicht nur den wirtschaftlichen, sondern auch den demografischen Aspekten Rechnung getragen wird. ${ }^{179}$ Der demografische Wandel der EU zeigt seit Jahrzehnten in erster Linie die zunehmende Bevölkerungsalterung, was zeitgleich bedeutet, dass eine sinkende Zahl von Erwerbstätigen zu erkennen ist. Ein starkes Indiz dafür sind die zwei nachfolgenden Hauptkomponenten: konstant niedrige Geburtenraten und eine steigende Lebenserwartung. ${ }^{180}$ An dieser Stelle ist darauf aufmerksam zu machen, dass die von der Bevölkerungsgröße der EU ausgehende strategische Demografiepolitik Lösungen vorgeben sollte, die insbesondere in der gemeinsamen Migrationspolitik gefunden werden können.

Im Folgenden werden zunächst die demografischen Rahmendaten geschildert, um die Herausforderung des demografischen Wandels und mögliche Lösungsansätze herauszuarbeiten.

Die Zahl der Gesamtbevölkerung in den EU-27-Mitgliedstaaten wurde im Jahr 2010 auf etwa 500 Millionen beziffert: ${ }^{181}$ Darunter war Deutschland als der bevölkerungsreichste Mitgliedstaat, wo fast 82 Millionen bzw. 16,5\% der Einwohner der EU-27 lebten. Zusammen mit Frankreich, dem Vereinigten Königreich und Italien, die eine ähnlich große Bevölkerung aufwiesen, zählte es zu den vier EU-Mitgliedstaaten, die 2008 fast

\footnotetext{
177 Fassmann, Heinz / Münz, Rainer (Hrsg.) 1996: Migration in Europa: a.a.O., S. 30.

178 Klos, Christian 1999: Eine Reise von Rom nach Amsterdam: a.a.O., S. 19.

179 Von Loeffelholz, Hans Dietrich 2011: Demografischer Wandel und Migration als Megatrends. In: Aus Politik und Zeitgeschichte (APuZ) 2011/61. Jg., B 10-11/2011. Bonn, S. 34-40, hier S. 35.

180 Vgl. Schwentker, Björn / Vaupel, James W. 2011: Eine neue Kultur des Wandels. In: Aus Politik und Zeitgeschichte (APuZ) 2011/61. Jg., B 10-11/2011. Bonn, S. 3-10, hier S. 3.

181 Eurostat (Hrsg.) 2010: Europa in Zahlen: Eurostat Jahrbuch 2010. Luxemburg, S. 161-162.
} 
54\% der Einwohner der EU-27 erfassten. Auch hinter den Prognosen für eine relativ unveränderte Bevölkerungszahl in der EU-27 in den Jahren 2008 bis 2060 finden sich beträchtliche Unterschiede zwischen den einzelnen Mitgliedstaaten: In den meisten Staaten der alten EU-15 werden die Bevölkerungszahlen weiter steigen, wohingegen die Zahl der Einwohner in den meisten EU-12-Mitgliedstaaten von Mittel- und Osteuropa, die der EU seit 2004 beigetreten sind ${ }^{182}$, zurückgehen wird (vgl. Abbildung 8).

Abbildung 8 : Gesamtbevölkerung und Bevölkerungsvorausschätzungen in der EU ${ }^{183}$

\begin{tabular}{|c|c|c|c|c|c|c|c|c|c|c|c|c|}
\hline & 1960 & 1970 & 1980 & 1990 & 2000 & 2008 & 2010 & 2020 & 2030 & 2040 & 2050 & 2060 \\
\hline EU-27 ${ }^{(2)}$ & 402,6 & 435,5 & 457,1 & 470,4 & 482,8 & 497,4 & 499,4 & 513,8 & 519,9 & 520,1 & 515,3 & 505,7 \\
\hline Euroraum $(E R)\left({ }^{2}\right)$ & 257,1 & 278,7 & 292,5 & 300,9 & 312,7 & 326,9 & 328,3 & 339,5 & 344,4 & 345,5 & 342,2 & 335,1 \\
\hline Belgien & 9,1 & 9,7 & 9,9 & 9,9 & 10,2 & 10,7 & 10,8 & 11,3 & 11,7 & 12,0 & 12,2 & 12,3 \\
\hline Bulgarien & 7,8 & 8,5 & 8,8 & 8,8 & 8,2 & 7,6 & 7,6 & 7,2 & 6,8 & 6,3 & 5,9 & 5,5 \\
\hline Tschech. Rep. & 9,6 & 9,9 & 10,3 & 10,4 & 10,3 & 10,4 & 10,4 & 10,5 & 10,4 & 10,2 & 9,9 & 9,5 \\
\hline Dänemark & 4,6 & 4,9 & 5,1 & 5,1 & 5,3 & 5,5 & 5,5 & 5,7 & 5,8 & 5,9 & 5,9 & 5,9 \\
\hline Deutschland & 72,5 & 78,3 & 78,2 & 79,1 & 82,2 & 82,2 & 82,1 & 81,5 & 80,2 & 77,8 & 74,5 & 70,8 \\
\hline Estland & 1,2 & 1,4 & 1,5 & 1,6 & 1,4 & 1,3 & 1,3 & 1,3 & 1,3 & 1,2 & 1,2 & 1,1 \\
\hline Irland & 2,8 & 2,9 & 3,4 & 3,5 & 3,8 & 4,4 & 4,6 & 5,4 & 5,9 & 6,2 & 6,5 & 6,8 \\
\hline Griechenland & 8,3 & 8,8 & 9,6 & 10,1 & 10,9 & 11,2 & 11,3 & 11,6 & 11,6 & 11,6 & 11,4 & 11,7 \\
\hline Spanien & 30,3 & 33,6 & 37,2 & 38,8 & 40,0 & 45,3 & 46,7 & 51,1 & 52,7 & 53,3 & 53,2 & 51,9 \\
\hline Frankreich $\left({ }^{2}\right)$ & 45,5 & 50,5 & 53,7 & 56,6 & 60,5 & 63,8 & 62,6 & 65,6 & 68,0 & 69,9 & 71,0 & 71,8 \\
\hline Italien & 50,0 & 53,7 & 56,4 & 56,7 & 56,9 & 59,6 & 60,0 & 61,4 & 61,9 & 62,0 & 61,2 & 59,4 \\
\hline Zypern & 0,6 & 0,6 & 0,5 & 0,6 & 0,7 & 0,8 & 0,8 & 1,0 & 1,1 & 1,2 & 1,3 & 1,3 \\
\hline Lettland & 2,1 & 2,4 & 2,5 & 2,7 & 2,4 & 2,3 & 2,2 & 2,2 & 2,0 & 1,9 & 1,8 & 1,7 \\
\hline Litauen & 2,8 & 3,1 & 3,4 & 3,7 & 3,5 & 3,4 & 3,3 & 3,2 & 3,1 & 2,9 & 2,7 & 2,5 \\
\hline Luxemburg & 0,3 & 0,3 & 0,4 & 0,4 & 0,4 & 0,5 & 0,5 & 0,6 & 0,6 & 0,7 & 0,7 & 0,7 \\
\hline Ungarn & 10,0 & 10,3 & 10,7 & 10,4 & 10,2 & 10,0 & 10,0 & 9,9 & 9,7 & 9,4 & 9,1 & 8,7 \\
\hline Malta & 0,3 & 0,3 & 0,3 & 0,4 & 0,4 & 0,4 & 0,4 & 0,4 & 0,4 & 0,4 & 0,4 & 0,4 \\
\hline Niederlande & 11,4 & 13,0 & 14,1 & 14,9 & 15,9 & 16,4 & 16,5 & 16,9 & 17,2 & 17,2 & 16,9 & 16,6 \\
\hline Österreich & 7,0 & 7,5 & 7,5 & 7,6 & 8,0 & 8,3 & 8,4 & 8,7 & 9,0 & 9,1 & 9,1 & 9,0 \\
\hline Polen & 29,5 & 32,7 & 35,4 & 38,0 & 38,7 & 38,1 & 38,1 & 38,0 & 37,0 & 35,2 & 33,3 & 31,1 \\
\hline Portugal & 8,8 & 8,7 & 9,7 & 10,0 & 10,2 & 10,6 & 10,7 & 11,1 & 11,3 & 11,5 & 11,4 & 11,3 \\
\hline Rumänien & 18,3 & 20,1 & 22,1 & 23,2 & 22,5 & 21,5 & 21,3 & 20,8 & 20,0 & 19,2 & 18,1 & 16,9 \\
\hline Slowenien & 1,6 & 1,7 & 1,9 & 2,0 & 2,0 & 2,0 & 2,0 & 2,1 & 2,0 & 2,0 & 1,9 & 1,8 \\
\hline Slowakei & 4,0 & 4,5 & 5,0 & 5,3 & 5,4 & 5,4 & 5,4 & 5,4 & 5,3 & 5,1 & 4,9 & 4,5 \\
\hline Finnland & 4,4 & 4,6 & 4,8 & 5,0 & 5,2 & 5,3 & 5,3 & 5,5 & 5,6 & 5,5 & 5,4 & 5,4 \\
\hline Schweden & 7,5 & 8,0 & 8,3 & 8,5 & 8,9 & 9,2 & 9,3 & 9,9 & 10,3 & 10,5 & 10,7 & 10,9 \\
\hline Ver. Königreich & 52,2 & 55,5 & 56,3 & 57,2 & 58,8 & 61,2 & 62,0 & 65,7 & 69,2 & 72,0 & 74,5 & 76,7 \\
\hline Kroatien & 4,1 & 4,4 & 4,6 & 4,8 & 4,5 & 4,4 & : & : & : & : & : & : \\
\hline EJR Mazedonien & 1,4 & 1,6 & 1,9 & 1,9 & 2,0 & 2,0 & : & : & $:$ & : & $:$ & : \\
\hline Türkei & 27,1 & 34,9 & 44,0 & 55,5 & 66,9 & 70,6 & : & : & $:$ & : & : & : \\
\hline Island & 0,2 & 0,2 & 0,2 & 0,3 & 0,3 & 0,3 & $:$ & $:$ & $:$ & : & $:$ & : \\
\hline Liechtenstein $\left({ }^{3}\right)$ & 16,8 & 20,9 & 25,8 & 28,4 & 32,4 & 35,4 & : & : & : & : & : & : \\
\hline Norwegen & 3,6 & 3,9 & 4,1 & 4,2 & 4,5 & 4,7 & 4,8 & 5,2 & 5,5 & 5,7 & 5,9 & 6,0 \\
\hline Schweiz & 5,3 & 6,2 & 6,3 & 6,7 & 7,2 & 7,6 & 7,7 & 8,2 & 8,6 & 8,9 & 9,1 & 9,2 \\
\hline
\end{tabular}

(') Ab 2010 beruhen die Daten auf Vorausschätzungen (Konvergenzszenario EUROPOP2008).

(2) Für den Zeitraum 1960 bis 1990 und ab 2010 französisches Mutterland ohne die vier Überseedepartements (Französisch Guyana,

Guadeloupe, Martinique und Réunion).

(3) In Tsd. statt in Mio.

Quelle: Eurostat (demo_pjan und proj_08c2150p)

182 EU-27 bedeutet die alten EU-15-Mitgliedstaaten (Belgien, Dänemark, Deutschland, Griechenland, Spanien, Frankreich, Irland, Italien, Luxemburg, Niederlande, Österreich, Portugal, Finnland, Schweden, Großbritannien) und die EU-12-Mitgiedstaaten von Mittel- und Ost Europa seit 2004 (Bulgarien, Tschechische Republik, Estland, Zypern, Lettland, Litauen, Ungarn, Malta, Polen, Rumänien, Slowenien, Slowakei).

183 Quelle: Eurostat (Hrsg.) 2010: Europa in Zahlen: Eurostat Jahrbuch 2010. Luxemburg, S. 163. 
Absolut gesehen wird dabei die Einwohnerzahl Deutschlands zwischen 2008 und 2060 voraussichtlich um 11,5 Millionen sinken. Ein bedeutender Bevölkerungsrückgang wird auch für Polen (-7,0 Millionen), Rumänien (-4,6 Millionen) und Bulgarien (-2,2 Millionen) angekündigt. ${ }^{184}$ Neben diesen Unterschieden zwischen den Mitgliedstaaten ist den Prognosen auch zu entnehmen, dass sich die Altersstruktur der Bevölkerung der EU-27 beträchtlich verändern wird. Niedrige Geburtenraten und die steigende Lebenserwartung werden voraussichtlich dazu führen, dass die Bevölkerung in der EU immer älter wird; die Gesamtfruchtbarkeitsziffer für die EU-27 sank von fast 2,6 Kindern pro Frau in der ersten Hälfte der 1960er Jahre auf etwa 1,5 Kinder im vergangenen Jahrzehnt. ${ }^{185}$ Durch die geburtenstarken Jahrgänge von 1950 bis 1970 ist die Zahl der älteren Menschen in der EU-27 deutlich angestiegen, was sich an den Bevölkerungspyramiden für die EU-27 erkennen lässt. Aus dieser Verschiebung der Alterspyramide lässt sich folglich schließen, dass im Jahr 2060 die Altersgruppe der mindestens 65-Jährigen 30\% der Bevölkerung der EU-27 betragen wird, während ihr Anteil 2008 noch 17\% verzeichnete (vgl. Abbildung 9). ${ }^{186}$

Abbildung 9 : Verschiebung der Alterspyramide, EU-27 (in \% der Gesamtbevölkerung)
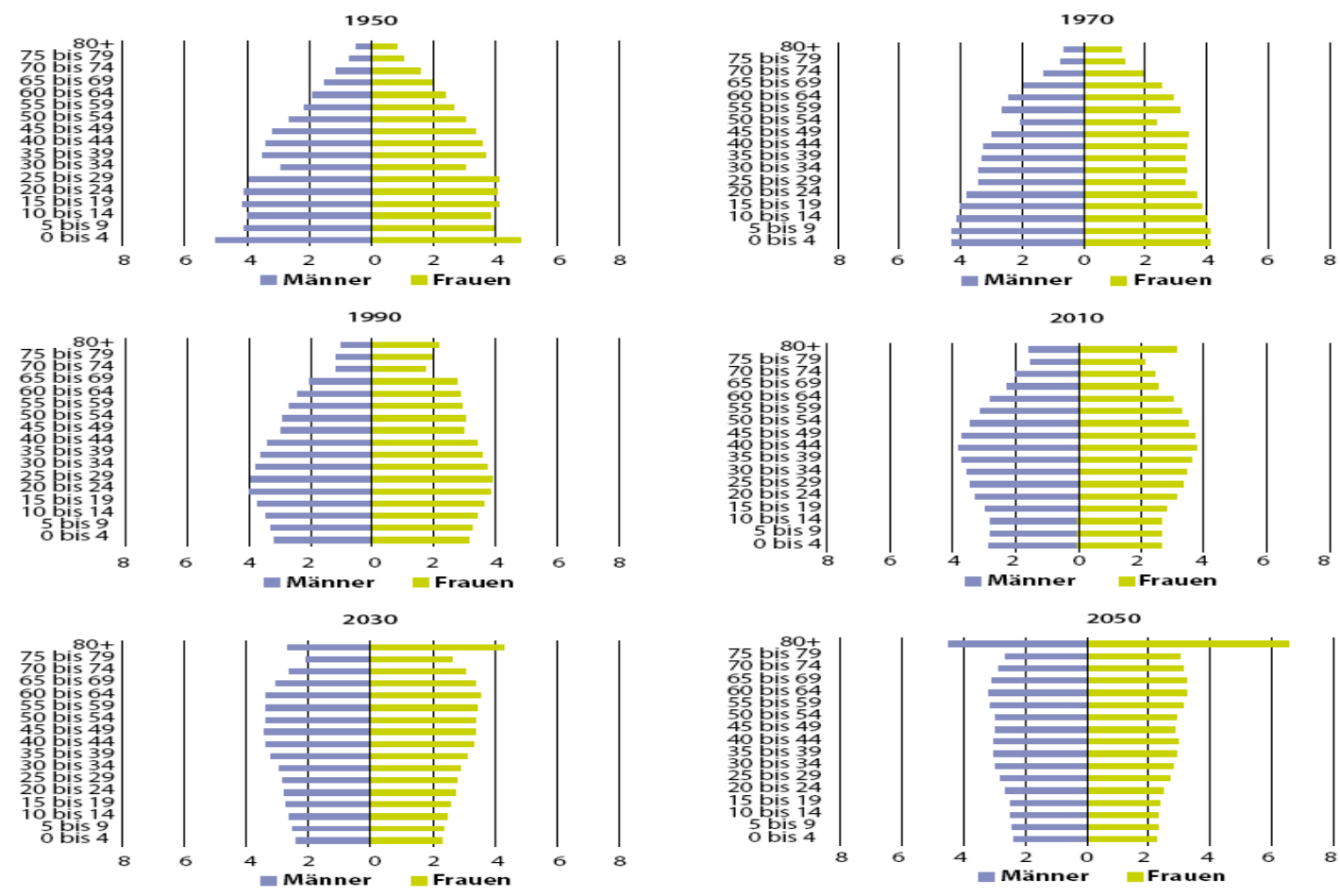

(1) Zwischen 1950 und 1970 wegen begrenzter Datenverfügbarkeit auf die Mitgliedstaaten, für die Daten vorliegen, beschränkt; ab 2010 beruhen die Daten auf Vorausschätzungen (Konvergenzszenario EUROPOP2008).

Quelle: Eurostat (demo_pjan und proj_08c2150p)

184 Eurostat (Hrsg.) 2010: Europa in Zahlen: Eurostat Jahrbuch 2010. Luxemburg, S. 162.

185 Eurostat (Hrsg.) 2010: Europa in Zahlen: Eurostat Jahrbuch 2010. Luxemburg, S. 177., S. 181.

186 Quelle: Eurostat (Hrsg.) 2010: Europa in Zahlen: Eurostat Jahrbuch 2010. Luxemburg, S. 162. u. 167. 
Aus diesem Blickwinkel kann der Wert von Bevölkerungswachstum sowie Bevölkerungsrückgang durch Migration begriffen werden: Im Jahr 2010 wohnten 32,5 Millionen ausländische Staatsangehörige in den EU-27-Mitgliedstaaten. Darunter waren 20,2 Millionen Drittstaatenangehörige bzw. 4\% der EU-Gesamtbevölkerung und 12,3 Millionen Staatsangehörige bzw. 2,5\% eines anderen EU-27-Mitgliedstaats. 6,5\% der Gesamtbevölkerung der EU-27 waren somit Ausländer. Bemerkenswert ist hierbei, dass die Ausländer in der EU-27 im Durchschnitt deutlich jünger waren als die nationale Bevölkerung (Durchschnittsalter 34,4 Jahre verglichen mit 41,5 Jahren in der EU). ${ }^{187}$ Die meisten (mehr als 75\%) ausländischen Staatsangehörigen in der EU-27 wurden im Jahr 2010 in den folgenden fünf Mitgliedstaaten verzeichnet: Deutschland $(7,1$ Millionen Personen bzw. 9\% der Gesamtbevölkerung), Spanien (5,7 Millionen bzw. 12\%), Vereinigtes Königreich (4,4 Millionen bzw. 7\%), Italien (4,2 Millionen bzw. 7\%) und Frankreich (3,8 Millionen bzw. 6\%). (Siehe Abbildung 10). ${ }^{188}$

Abbildung 10 : Ausländische Staatsangehörige in den EU-27-Mitgliedstaaten, 2010

\begin{tabular}{|c|c|c|c|c|c|c|c|}
\hline & \multirow{2}{*}{$\begin{array}{l}\text { Gesamt- } \\
\text { bevolkerung } \\
\text { ooos }\end{array}$} & \multicolumn{2}{|c|}{\begin{tabular}{|c|} 
Ausländische \\
Staatsangehörige insgesamt
\end{tabular}} & \multicolumn{2}{|c|}{\begin{tabular}{|c|} 
Staatsangehörige eines \\
anderen EU27-Mitgliedstaats
\end{tabular}} & \multicolumn{2}{|c|}{$\begin{array}{c}\text { Staatsangehörige eines } \\
\text { Drittstaates }\end{array}$} \\
\hline & & ooos & $\begin{array}{c}\% \text { der } \\
\text { Gesamt- } \\
\text { bevölkerung }\end{array}$ & ooos & \begin{tabular}{c|}
$\%$ der \\
Gesamt- \\
bevölkerung
\end{tabular} & $000 s$ & $\begin{array}{c}\% \text { der } \\
\text { Gesamt- } \\
\text { bevölkerung }\end{array}$ \\
\hline EU27* & 501098,0 & 32493,2 & 6,5 & 12336,0 & 2,5 & 20157,2 & 4,0 \\
\hline Belgien ${ }^{* * *}$ & 10839,9 & 1052,8 & 9,7 & 715,1 & 6,6 & 337,7 & 3,1 \\
\hline Bulgarien & 7563,7 & : & : & : & : & : & : \\
\hline Tschech. Rep. & 10506,8 & 424,4 & 4,0 & 137,0 & 1,3 & 287,4 & 2,7 \\
\hline Dänemark & 5534,7 & 329,8 & 6,0 & 115,5 & 2,1 & 214,3 & 3,9 \\
\hline Deutschland & 81802,3 & 7130,9 & 8,7 & 2546,3 & 3,1 & 4584,7 & 5,6 \\
\hline Estland $^{4}$ & 1340,1 & 212,7 & 15,9 & 11,0 & 0,8 & 201,7 & 15,1 \\
\hline Irland & 4467,9 & 384,4 & 8,6 & 309,4 & 6,9 & 75,0 & 1,7 \\
\hline Griechenland & 11305,1 & 954,8 & 8,4 & 163,1 & 1,4 & 791,7 & 7,0 \\
\hline Spanien & 45989,0 & 5663.5 & 12,3 & 2327,8 & 5,1 & 3335,7 & 7.3 \\
\hline Frankreich & 64716,3 & 3769,0 & 5,8 & 1317,6 & 2,0 & 2451,4 & 3,8 \\
\hline Italien & 60340.3 & 4235.1 & 7.0 & 1241.3 & 2.1 & 2993.7 & 5.0 \\
\hline Zypern & 803.1 & 127.3 & 15.9 & 83.5 & 10.4 & 43.8 & 5.5 \\
\hline Lettland ${ }^{4}$ & 2248.4 & 392.2 & 17.4 & 9.7 & 0.4 & 382.4 & 17.0 \\
\hline Litauen & 3329.0 & 37.0 & 1,1 & 2.4 & 0,1 & 34.6 & 1.0 \\
\hline Luxemburg & 502,1 & 215.7 & 43,0 & 186.2 & 37,1 & 29.5 & 5.9 \\
\hline Ungarn & 10014,3 & 200,0 & 2.0 & 118.9 & 1.2 & 81,1 & 0.8 \\
\hline Malta & 413,0 & 16,7 & 4,0 & 5,4 & 1,3 & 11,3 & 2,7 \\
\hline Niederlande & 16575,0 & 652,2 & 3,9 & 310,9 & 1,9 & 341,3 & 2,1 \\
\hline Österreich & 8367,7 & 876,4 & 10,5 & 328,3 & 3,9 & 548,0 & 6,5 \\
\hline Polen & 38167,3 & 45,5 & 0,1 & 14,8 & $a, a$ & 30,7 & 0,1 \\
\hline Portugal & 10637,7 & 457,3 & 4,3 & 94,2 & 0,9 & 363,1 & 3,4 \\
\hline Rumanien & 21462,2 & : & : & : & : & : & : \\
\hline slowenien & 2047,0 & 82,2 & 4,0 & 4,6 & $a, 2$ & 77,6 & 3,8 \\
\hline Slowakei & 5424,9 & 62,9 & 1,2 & 38,7 & 0,7 & 24,2 & 0,4 \\
\hline Finnland & 5351,4 & 154,6 & 2,9 & 56,1 & 1,0 & 98,5 & 1,8 \\
\hline Schweden & 9340,7 & 590,5 & 6,3 & 265,8 & 2,8 & 324,7 & 3,5 \\
\hline Ver. Königreich ${ }^{\star \star}$ & 62008,0 & 4367,6 & 7,0 & 1922,5 & 3,1 & 2445,1 & 3,9 \\
\hline Island & 317,6 & 21,7 & 6,8 & 17,2 & 5,4 & 4,5 & 1,4 \\
\hline Liechtenstein & 35,9 & : & : & : & : & : & : \\
\hline Norwegen & 4854,5 & 331,6 & 6,8 & 185,6 & 3,8 & 146,0 & 3,0 \\
\hline Schweiz & 7785,8 & 1714,0 & 22,0 & 1073,7 & 13,8 & 640,3 & 8,2 \\
\hline
\end{tabular}

Daten nicht verfügbar
Eurostat Schätzung
Vorläufig

187 Eurostat-Pressestelle (Hrsg.) 2011: Ausländische Staatsangehörige machten 6,5\% der EU27 Bevölkerung im Jahr 2010 aus. In: Eurostat-Pressemitteilung, 105/2011-14.Juli. 2011. Online verfügbar unter: http://ec.europa.eu/eurostat

188 Quelle: Eurostat-Pressestelle (Hrsg.) 2011: Ausländische Staatsangehörige machten 6,5\% der EU27 Bevölkerung im Jahr 2010 aus. In: a.a.O., 105/2011-14.Juli 2011 (http://ec.europa.eu/eurostat). 
In den meisten EU-Mitgliedstaaten wuchs die Bevölkerung im Zeitraum von 2000 bis 2008 weiter, was insbesondere auf den erhöhten Wanderungssaldo in Spanien und Italien zurückzuführen war; 2008 verzeichneten Spanien mit 414.000 und Italien mit 438.000 Personen die höchsten Zuwächse beim Wanderungssaldo; lediglich fünf Mitgliedstaaten hatten 2008 im Gegensatz dazu einen negativen Wanderungssaldo: Deutschland (-53.600), Polen (-14.900), Litauen (-7.700), Lettland (-2.500) und Bulgarien (-900). ${ }^{189}$

Überdies ließ sich im Jahr 2009 die grenzüberschreitende Zu- und Einwanderung in die EU-27-Mitgliedstaaten auch auf die zehnthäufigste ausländische Staatsangehörigengruppe zurückführen. Die wesentlichen Einflussgrößen bezüglich der Migrantenbevölkerungsentwicklung, statistisch erfasst nach den Herkunkftsländern, ergaben folgende Reihenfolge: Von den Drittstaatenangehörigen kamen die größten Gruppen aus der Türkei (ca. 2,4 Millionen bzw. 7,5\% aller Drittstaatenangehörigen), Marokko (ca. 1,7 Millionen bzw. 5,8\%) und Albanien (ca. 1,0 Millionen bzw. 3,2\%) sowie China (ca. 0,6 Millionen bzw. 2,1\%). Die größten Migrantengruppen von EU-27Mitgliedstaaten kamen aus Rumänien (ca. 1,9 Millionen bzw. 6,2\% aller ausländischen Staatsangehörigen eines anderen EU-Mitgliedstaats), Polen (ca. 1,5 Millionen bzw. 4,6\%) und Italien (ca. 1,3 Millionen bzw. 4,0\%) im Jahr 2009 (vgl. Abbildung 11).

Abbildung 11 : Zehnthäufigste ausländische Staatsangehörigengruppe in der EU, $2009^{190}$

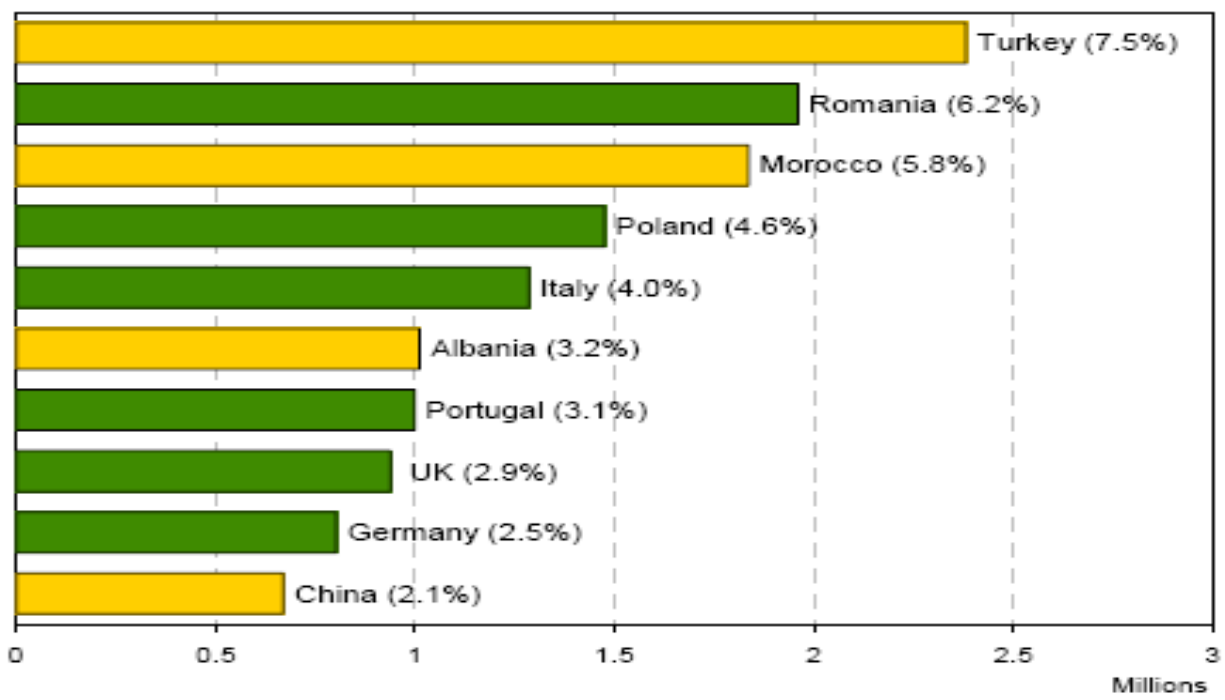

189 Eurostat (Hrsg.) 2010: Europa in Zahlen: Eurostat Jahrbuch 2010. Luxemburg, S. 171, 173 -174.

190 Quelle: Vasileva, Katya 2010: Foreigners living in the EU are diverse and largely younger than the nationals of the EU Member States. In: Eurostat (Hrsg.) 2010: Statistics in focus, 45/2010. Catalogue number: KS-SF-10-045-EN-N. Luxembourg, S. 3. Online verfügbar unter: http://epp.eurostat.ec.europa.eu/portal/page/portal/population/publications/migrationasylum 
Die Bedeutung der Migration als Erklärung für das Bevölkerungswachstum innerhalb der EU-27 hat somit in den letzten Jahren zugenommen. Das mit Blick auf die europäische Bevölkerungsentwicklung und die weltweiten Migrations- und Fluchtbewegungen dennoch relativ geringe Migrationsvolumen hängt auch eng mit der restriktiven Migrationspolitik in der EU zusammen. Die Restriktionen setzen daher nicht beim Umfang von Einwanderung ein, sondern finden ihre besondere Ausprägung in der politischen Zuordnung bzw. dem jeweiligen Migrationssystem. Beispiele hierfür sind etwa Aufenthaltsgenehmigung und garantierte Rechte von Zuwanderern sowie Zugang zu den Arbeitsmärkten und Ansprüche auf soziale Sicherungssysteme. ${ }^{191}$ Parallel zu der Gewinnung qualifizierter Zuwanderungen, um sich auf den globalen Wettbewerb um junge MigrantInnen in Europa bzw. der EU einzulassen, dient die „managed migration“ im Kontext dieser restriktiven EU-Migrationspolitik vor allem auch zur Anwerbung hoch und gut qualifizierter Arbeitskräfte aus dem Ausland; so werden heute beispielsweise mit der sogenannten „Blue Card EU“ die gemeinsamen Mindeststandards für die Aufnahme von drittstaatsangehörigen Fachkräften in den EUMitgliedstaaten festgelegt (hierauf wird in Kapitel IV. 2.2 näher eingegangen). ${ }^{192}$

Die meisten Mitgliedstaaten haben somit der Entwicklung einer gemeinsamen Migrationspolitik zugestimmt, um die Migrationsbewegungen mit einem koordinierten Konzept, das der wirtschaftlichen und demografischen Situation in der EU Rechnung trägt, besser steuern zu können. In der Zukunft muss man darüber hinaus überdenken, dass Zuwanderung an sich keine Lösung für das Problem der europäischen Bevölkerungsalterung darstellt. Es könnte allerdings in den nächsten Jahrzehnten durchaus ein anhaltender Zuzug von MigrantInnen erforderlich sein, damit der Bedarf des EU-Arbeitsmarktes in Bezug auf das EU-Bevölkerungswachstum gedeckt und entwickelt werden kann.

191 Birsl, Ursula 2005: Migration und Migrationspolitik im Prozess der europäischen Integration?. S. 92 f.

192 Richtlinie 2009/50/EG des Rates vom 25. Mai 2009 über die Bedingungen für die Einreise und den Aufenthalt von Drittstaatsangehörigen zur Ausübung einer hochqualifizierten Beschäftigung. In: Amtsblatt der Europäischen Union, L 155 vom 18. 06. 2009, S. 17-29. Auch im Internet: http://www.aufenthaltstitel.de/rl_2009_50_eg.html 


\subsection{Dimension der geografischen und demografischen Entwicklungen in Deutschland}

Die Bundesrepublik Deutschland ist innerhalb der Europäischen Union das Land mit der längsten EU-Außengrenze. Die Gesamtlänge der Bundesgrenze beträgt $5.075 \mathrm{~km}$, davon $3.757 \mathrm{~km}$ Landgrenze und $1.318 \mathrm{~km}$ Seegrenze. ${ }^{193}$ Infolge der zentralen geografischen Lage Deutschlands in Europa trägt die Bundesrepublik jedoch die Hauptlast der kontinentalen Ost-West-Migration und hat sich überdies in den vergangenen Jahrzehnten zu einem Einwanderungsland entwickelt (vgl. Abbildung 12).

\section{Abbildung 12 : Die zentrale geografische Lage Deutschlands in Europa ${ }^{194}$}

Bundesrepublik Deutschland

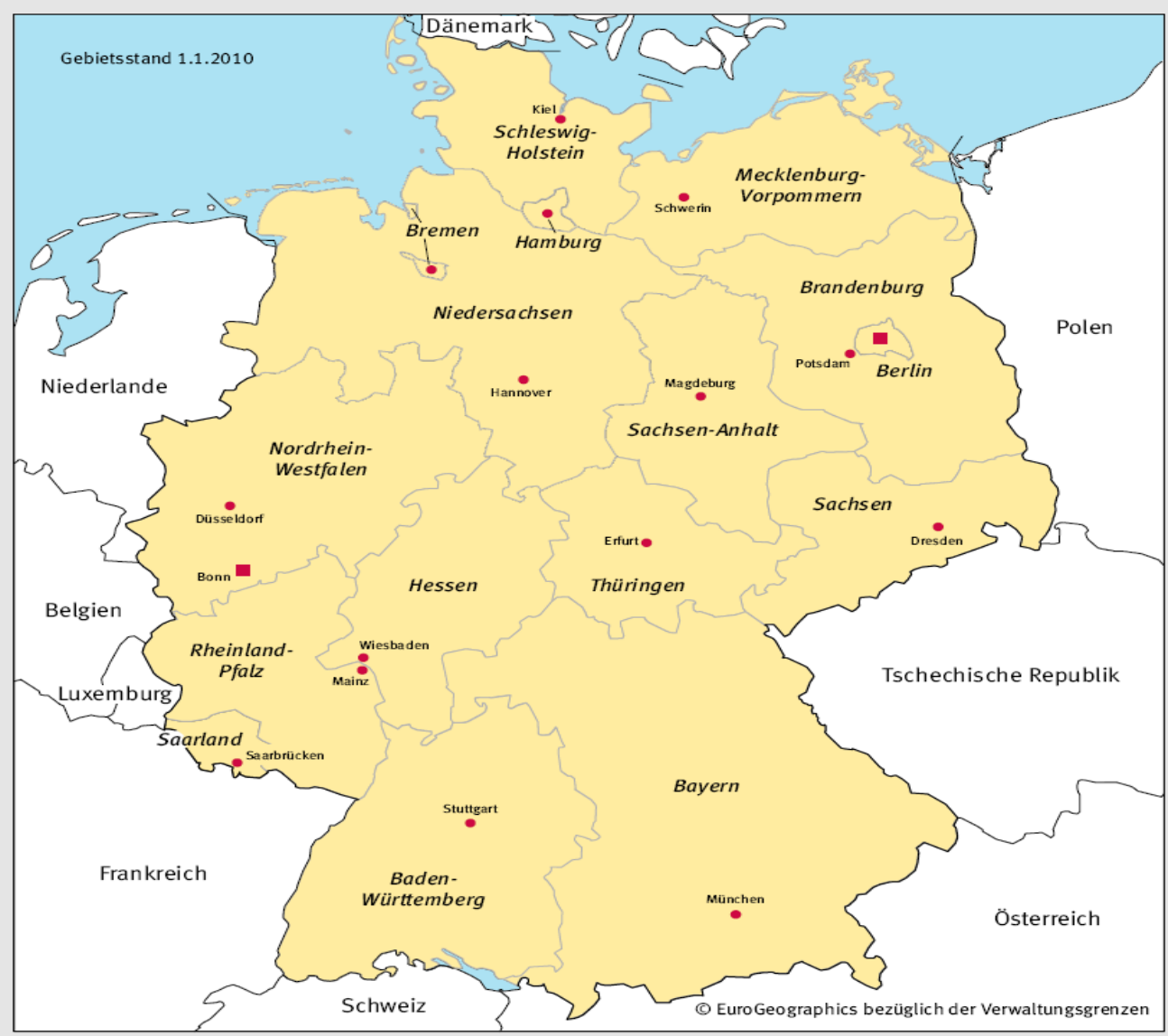

$2010-01-0362$

Statistisches Bundesamt, Statistisches lahrbuch 2010

193 Statistisches Bundesamt (Hrsg.) 2010: Statistisches Jahrbuch 2010: Für die Bundesrepublik Deutschland mit „Internationalen Übersichten“. Wiesbaden, S. 21 (www.destatis.de).

194 Quelle: Statistisches Bundesamt (Hrsg.) 2010: Statistisches Jahrbuch 2010: a.a.O., Wiesbaden, S. 19. 
Die grenzüberschreitenden Zuwanderungen und die damit zusammenhängenden Bevölkerungsveränderungen sind demzufolge wichtige Elemente des sozialen Wandels in Deutschland. Über Migration im sozialen Wandel zu reden legt daher nahe, dass es sich hier um einen Prozess handelt, der mit einer kontinuierlichen Bevölkerungszunahme für das Aufnahmeland verknüpft ist. ${ }^{195}$ Das heißt, die Bevölkerungsentwicklung ergibt sich somit durch die natürliche Entwicklung (Geburten, Sterbefälle) und durch räumliche Wanderungen ( $\mathrm{Zu}$ - und Fortzüge). Entscheidend für die Bevölkerungsentwicklung sind daraus folgend drei Komponenten als Einflussfaktoren, - Geburtenhäufigkeit versus Sterblichkeit und steigende Lebenserwartung sowie Immigration - anzugeben. ${ }^{196}$ In Deutschland ist bereits seit ca. 30 Jahren eine kontinuierlich niedrige Geburtenhäufigkeit $\mathrm{zu}$ beobachten, $\mathrm{d}$. h. es werden weniger Kinder geboren, als dies zur langfristigen Erhaltung der Bevölkerung erforderlich wäre. ${ }^{197}$ Vor allem mit dem Ende des „Babybooms“ in den 1960er Jahren kam es zu einem massiven Rückgang der Geburtenzahlen auf 1,4 geborene Kinder pro Frau. Zur langfristigen Sicherung der Bevölkerung wäre aber eine Geburtenrate von 2,1 geborenen Kinder pro Frau unerlässlich. ${ }^{198}$ Parallel $\mathrm{zu}$ der stagnierenden Geburtenhäufigkeit nimmt die Lebenserwartung der Bevölkerung beständig zu. Die Lebenserwartung von Frauen ist etwa seit 1960 von 72 auf 81 Jahre, die der Männer von 67 auf 75 Jahre angestiegen. Die Zunahme der Lebenserwartung ist zurückzuführen auf den Rückgang der Säuglings- und Kindersterblichkeit, verbesserte Lebensumstände und medizinischen Fortschritt sowie einen starken Rückgang der Alterssterblichkeit. ${ }^{199}$ Daraus folgernd wird die Gesamtbevölkerung für Deutschland bis in das Jahr 2050 von heute rund 82 Millionen auf 68 - 75 Millionen abnehmen, wobei sie bezüglich des Wanderungssaldos von durchschnittlich 140.000 Personen pro Jahr (sogar 200.000 ab 2010) erfasst wird (vgl. Abbildung 13). ${ }^{200}$ Unabhängig von der absoluten Bevölkerungszahl wird sich hierbei das Verhältnis von jüngeren zu älteren Menschen

${ }^{195}$ Vgl. Schulte, Axel / Treichler, Andreas 2010: Integration und Antidiskriminierung: Eine interdisziplinäre Einführung. München, S. 7.

196 Vgl. Statistisches Bundesamt (Hrsg.) 2010: Statistisches Jahrbuch 2010: a.a.O., S. 27.; vgl. auch Bundesamt für Bauwesen und Raumordnung (BBR) 2000: Raumordnungsbericht 2000. Bonn, S. 12.

197 Statistisches Bundesamt (Hrsg) 2003: Bevölkerung Deutschlands bis 2050 - 10. koordinierte Bevölkerungsvorausberechnung. Wiesbaden, S. $10 \mathrm{ff}$.

198 Birg, Herwig 2003: Dynamik der demographischen Alterung, Bevölkerungsschrumpfung und Zuwanderung in Deutschland. In: Aus Politik und Zeitgeschichte (APuZ) 2003/53. Jg., B20/2003. S. 7.

199 Deutscher Bundestag 2002: Schlussbericht der Enquéte-Kommission „Demographischer Wandel Herausforderungen unserer älter werdenden Gesellschaft an den Einzelnen und die Politik“. S. 36.

200 Birg, Herwig 2004: Bevölkerungsentwicklung: Zur aktuellen Lage der Weltbevölkerung: Sonderfall Deutschland. In: Informationen zur politischen Bildung, Nr. 282/2004. Bonn, S. 20 (www.bpb.de/publikationen/70Z856.html).; vgl. auch Kröhnert, Steffen 2011: Zur demografischen Lage der Nation. In: Bundeszentrale für politischen Bildung (Hrsg.) 2011: Demografischer Wandel in Deutschland. Online verfügbar unter: http://www.bpb.de/themen/WM0Z6D.html 
stark verändern. Die Zahl der Menschen im heute üblichen Erwerbsalter zwischen 20 und 60 Jahren wird bis 2050 um mehr als ein Fünftel sinken, die der unter 20-Jährigen sogar um 30 Prozent. Parallel dazu ist von einem Anstieg des Anteils der über 60Jährigen an der Gesamtbevölkerung von heute 26 auf künftig 39 Prozent auszugehen (vgl. Abbildung 14).

Abbildung 13 : Altersaufbau der Bevölkerung Deutschlands ${ }^{201}$

\begin{tabular}{|l|c|c|c|c|c|}
\hline \multirow{2}{*}{} & \multirow{2}{*}{\begin{tabular}{c} 
Insgesamt am \\
\multirow{2}{*}{}
\end{tabular}} & Jahresende & & \multicolumn{4}{|c|}{ Davon im Alter von ... bis ... Jahren } \\
\cline { 3 - 6 } & & unter 20 & $20-59$ & \multicolumn{2}{|c|}{60 und älter } \\
\cline { 3 - 6 } & Millionen & & & \multicolumn{4}{|c|}{ In \% } \\
\hline 1950 & 69,3 & 30,4 & 55,0 & 14,6 & 1,0 \\
\hline 1970 & 78,1 & 30,0 & 50,1 & 19,9 & 2,0 \\
\hline 1990 & 79,8 & 21,7 & 57,9 & 20,4 & 3,8 \\
\hline 2001 & 82,4 & 20,9 & 55,0 & 24,1 & 3,9 \\
\hline 2010 & 82,1 & 18,7 & 55,7 & 25,6 & 5,0 \\
\hline 2030 & 81,2 & 17,1 & 48,5 & 34,4 & 7,3 \\
\hline 2050 & 75,1 & 16,1 & 47,2 & 36,7 & 12,1 \\
\hline
\end{tabular}

Abbildung 14 : Bevölkerungsentwicklung und Altersstruktur in Deutschland ${ }^{202}$

- Bevölkerungsentwicklung und Altersstruktur

Bevölkerung in abs. Zahlen, Anteile der Altersgruppen in Prozent, 1960 bis 2060 , stand: Ende 2010
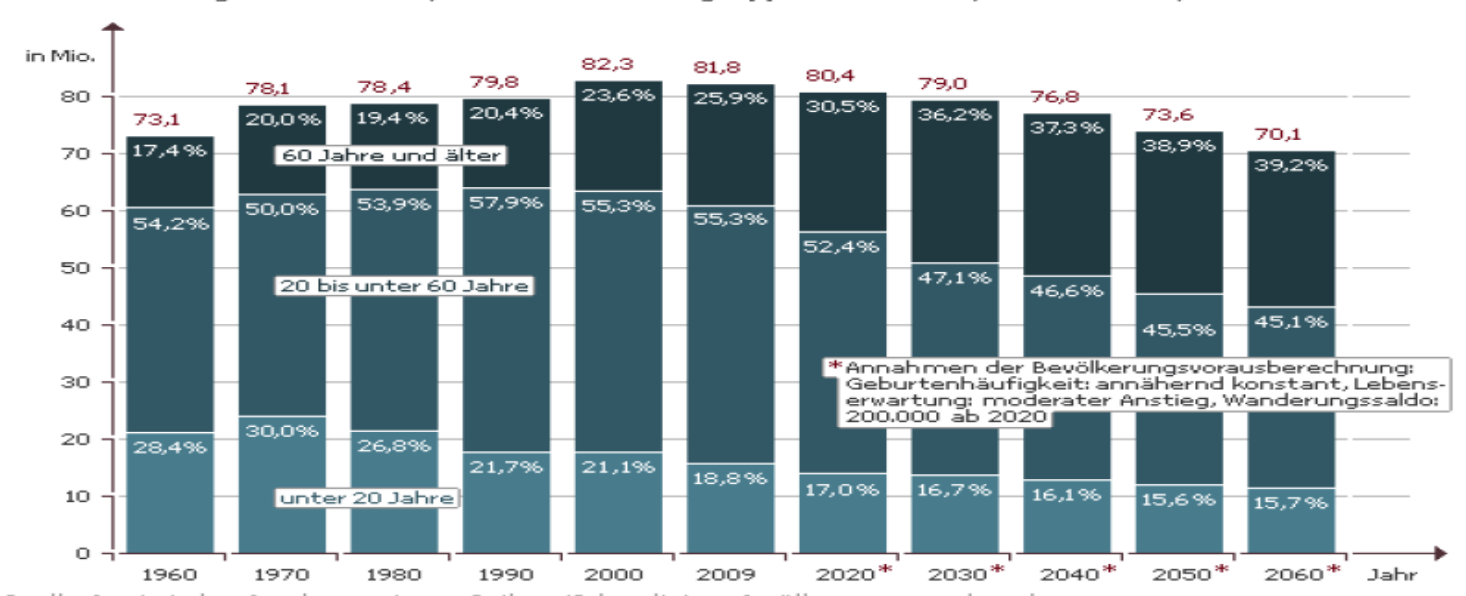

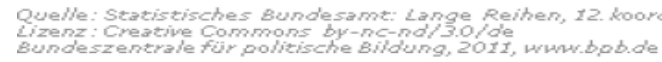

$(\infty)$ EY-NO-ND

201 Quelle: Statistisches Bundesamt (Hrsg.) 2003: Bevölkerung Deutschlands bis 2050 - a.a.O., S. 31.; vgl. Statistisches Bundesamt (Hrsg.) 2010: Statistisches Jahrbuch 2010: a.a.O., Wiesbaden, S. 42.

202 Quelle: Kröhnert, Steffen 2011: Zur demografischen Lage der Nation. In: Bundeszentrale für politischen Bildung (Hrsg.) 2011: Demografischer Wandel in Deutschland. Online verfügbar unter: http://www.bpb.de/popup/popup_bild.html?guid=BKH7J9\&x=590\&y=460 
Bezogen auf die heutigen demografischen Bedingungen prognostizierte ein Fachgutachter bereits im Jahr 2001, dass sich spätestens im Jahr 2020 ein rapider Anstieg der Rentenversicherungsbeiträge auf 24 bis $32 \%$ des Einkommens ankündige. ${ }^{203}$ Ein Wirtschaftsjournalist bemerkte zuvor, dass aus der demografisch bedingten „Rentenfalle“ nur zwei Wege führen: „Entweder die Beiträge steigen drastisch, oder die Renten müssen radikal gekürzt werden.“ ${ }^{204}$ Ein weiterer Kommentar: , [...] mit dem Rückzug der Babyboomer vom Arbeitsmarkt kippt auch die für das deutsche Rentensystem entscheidende Variable: der Altenquotient. [...]. “205 Der Bevölkerungsrückgang ist dementsprechend eine Folge des niedrigen Geburtenniveaus sowie der damit verbundenen abnehmenden Zahl der nachwachsenden jüngeren Altersgruppen. Gleichzeitig verändert sich die Alters- bzw. Bevölkerungsstruktur als Folge der oben dargestellten Einflussfaktoren. Die Zahl der Älteren wächst, sodass der Bevölkerungsrückgang unvermeidlich an eine Alterung der Gesellschaft ${ }^{206}$ gekoppelt $^{2}$ ist (vgl. Abbildung 15).

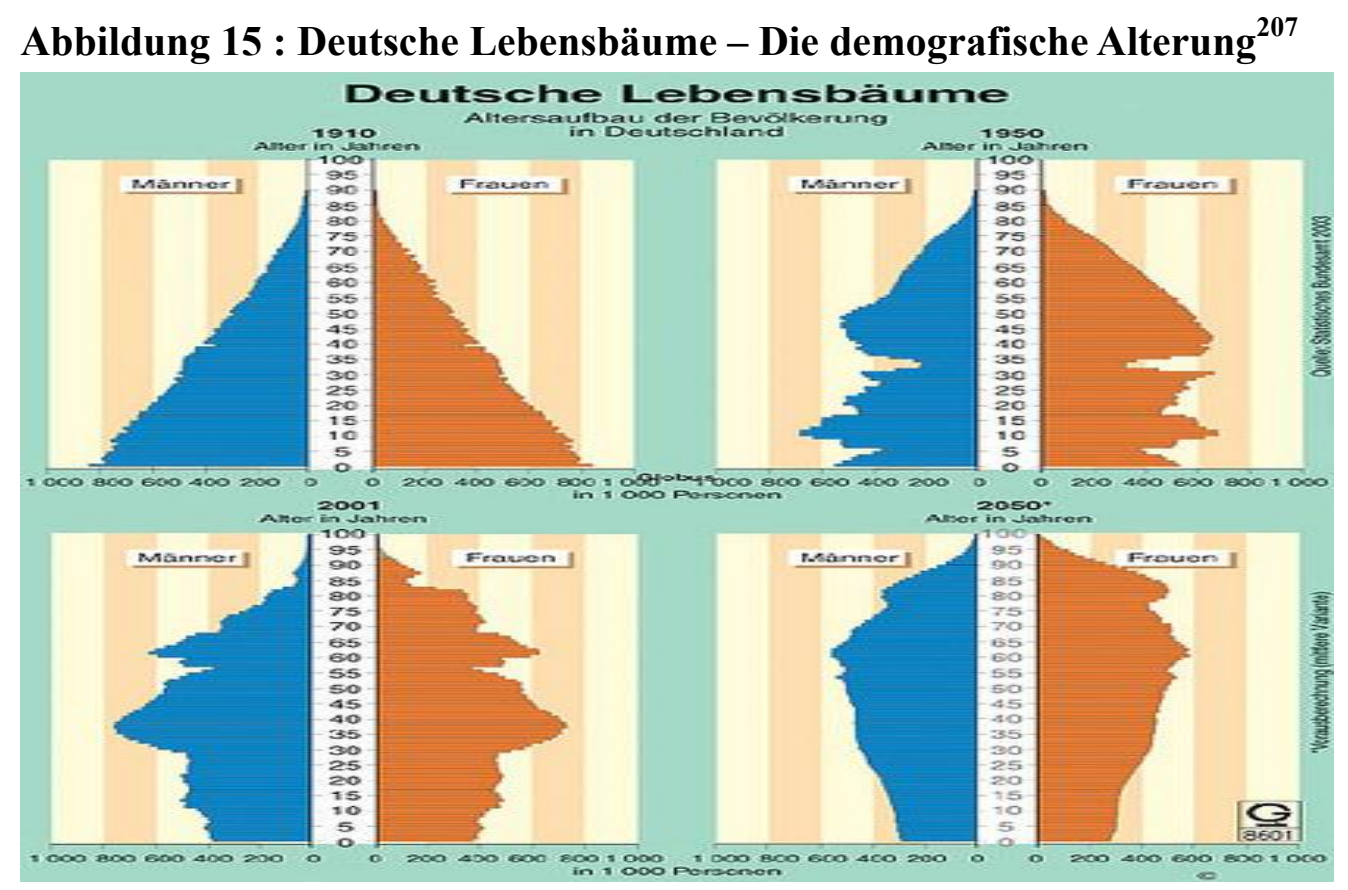

203 Henkel, Hans-Olaf 2001: Perspektiven der Zuwanderungspolitik. In: Klemmer, Paul 2001: Migration in Europa, Beihefte der Konjunkturpolitik, H. 52. Berlin, S. 10.

204 Vgl. Wallace, Paul 1999: Altersbeben. Wie wir die demographische Erschütterung in Wirtschaft und Gesellschaft meistern werden. Frankfurt a. M./New York, S. 187.

205 Brendler, Michael 2003: Wenn die Babyboomer in Ruhestand gehen: Während auf Deutschland riesige Probleme bei der Bevölkerungsentwicklung zukommen, stehen die USA dank Zwanderung gut da. In: Süddeutsche Zeitung vom 20.10.2003. S. 2. Hinweis: Babyboom-Jahrgänge von 1958 bis 1973.

206 Vgl. Lehr, Ursula 2003: Die Jugend von gestern - und die Senioren von morgen. In: Aus Politik und Zeitgeschichte (APuZ) 2003/53. Jg., B 20/2003. Bonn, S. 3-5, hier S. 3.

207 Quelle: Birg, Herwig 2004: Bevölkerungsentwicklung (www.bpb.de/publikationen/70Z856.html). 
Es werden immer mehr Menschen 60 Jahre und älter sein, während die Anzahl und der Anteil Jüngerer in der Bevölkerung weiter abnehmen wird. Es kommt hinsichtlich dieser Altersstruktur somit zu einer Verschiebung von der „Bevölkerungspyramide“ im Jahr 1910 und 1950 - hin zu einem „Tannenbaum“ im Jahr 2001 - und im Jahr 2050 sogar zu einem „Bevölkerungspilz““ ${ }^{208}$ Es kommen also weniger junge Menschen nach, als an der oberen Schicht die mittlere Altersgruppe in die ältere übergeht: Bei einer nahezu gleichen Bevölkerungszahl von 69 Millionen im Jahr 1950 und 70 Millionen im Jahr 2050 wird sich der Altersaufbau des 21. Jahrhunderts umkehren. Waren 1950 noch etwa doppelt so viele Menschen unter 20 Jahren als über 59 Jahre alt, so wird es 2050 mehr als doppelt so viele ältere als jüngere Menschen geben. Diese Bevölkerungsabnahme und Bevölkerungsalterung könnte, wie bezüglich der oben erwähnten Rentenfalle, somit automatisch $\mathrm{zu}$ negativen Auswirkungen auf die öffentlichen und privaten Sozialversicherungs-, Bildungs- und Gesundheitssysteme führen. ${ }^{209}$ In diesem Zusammenhang empfahlen bereits die Unabhängige Kommission für Zuwanderung und der Bundesausschuss der CDU eine durchgreifende Neuordnung hinsichtlich der Familienpolitik ${ }^{210}$ Anfang des 21. Jahrhunderts; eine Erhöhung des Renteneintrittsalters wird hierbei als zentral erachtet.

Alles in allem lässt sich festhalten, dass aufgrund des demografischen Rückgangs und der Alterung in der Bundesrepublik und auch in der EU bereits die „Immigration“ (jüngerer Menschen) als wichtiger Faktor einer Stabilisierung der Bevölkerungsgröße vorgesehen ist: „Since the mid 1960's, the EU has experienced a continuous fall in its natural population increase; that means that the excess of births over deaths has continually decreased. Meanwhile, towards the end of the 1960's, net immigration became an increasingly important factor affecting population growth. Except for a period during the first half of the 1980's, when natural population growth temporarily gained in significance, the net migration rates have clearly been of greater importance since then than the rate of natural population growth." ${ }^{211}$ Das Statistische Bundesamt errechnete darüber hinaus eine Relation zwischen Beschäftigten und

${ }^{208}$ Birg, Herwig 2003: Dynamik der demographischen Alterung, a.a.O. In: APuZ, B20/2003. S. 11.; vgl. Birg, Herwig 2004: Bevölkerungsentwicklung. In: Informationen zur politischen Bildung, a.a.O, S. 21.

${ }^{209}$ Birg, Herwig 2003: Dynamik der demographischen Alterung a.a.O. In: APuZ, B20/2003. S. 11-12.

210 Zum Beispiel sollte die Vereinbarkeit von Kindern und Beruf durch Ganztagsbetreuungseinrichtungen ermöglicht werden. Außerdem sollten private Dienstleistungsangebote für Familien gefördert sowie ein finanzieller Ausgleich und steuerliche Berücksichtigung von Erziehungszeiten garantiert werden. In: Bericht der Unabhängigen Kommission Zuwanderung 2001: Zuwanderung gestalten - Integration fördern, 04.07.2001. Berlin, S. 36.; Beschluss des Bundesausschusses der CDU Deutschlands 2001: Zuwanderung steuern und begrenzen. Integration fördern, 07.06.2001. Berlin, S. 7.

211 Angenendt, Steffen (Ed.) 1999: Asylum and Migration Policies in the European Union. Berlin, S. 29. 
Ruheständlern in Deutschland „ohne Zuwanderung“ im Jahr 2050 von zwei zu eins. ${ }^{212}$ Nach vielen Expertenprognosen wird somit die Bevölkerungszahl in Deutschland sinken. ${ }^{213}$ Bereits seit längerem, insbesondere seit dem Jahr 2004, begann die Gesamtbevölkerungszahl in Deutschland drastisch abzunehmen, wobei seit 2004 parallel wenige MigrantInnen auf Dauer gewonnen worden sind (siehe Abbildung 16).

Abbildung 16 : Gesamtbevölkerung der Bundesrepublik Deutschland von 2000 bis $2009^{214}$

\begin{tabular}{|c|c|c|c|}
\hline \multirow{2}{*}{ Jahr } & Gesamtbevölkerung & $\begin{array}{c}\text { Ausländische } \\
\text { Bevölkerung }\end{array}$ & $\begin{array}{c}\text { Ausländeranteil in } \\
\text { v. H. }\end{array}$ \\
\cline { 2 - 4 } & in 1000 & in 1000 & 8,9 \\
\hline 2000 & 82.188 & 7.297 & 8,9 \\
\hline 2001 & 82.339 & 7.319 & 8,9 \\
\hline 2002 & 82.482 & 7.336 & 8,9 \\
\hline 2003 & 82.532 & 7.335 & 8,1 \\
\hline 2004 & 82.501 & 6.717 & 8,2 \\
\hline 2005 & 82.438 & 6.756 & 8,2 \\
\hline 2006 & 82.351 & 6.751 & 8,2 \\
\hline 2007 & 82.218 & 6.745 & 8,2 \\
\hline 2008 & 82.002 & 6.728 & 8,2 \\
\hline 2009 & 81.802 & 6.695 & \\
\hline
\end{tabular}

Dies bedeutet: Ohne Berücksichtigung politischer, wirtschaftlicher und gesellschaftlicher Anpassungsreaktionen wird Deutschland in der Zukunft, spätestens im Jahr 2060, nicht mehr das Land mit der größten Bevölkerung in der heutigen EU-27 sein. Die Megatendenzen des Bevölkerungsrückgangs und der Bevölkerungsalterung

212 Statistisches Bundesamt (Hrsg.) 2003: Bevölkerung Deutschlands bis 2050 - 10. koordinierte Bevölkerungsvorausberechnung. Wiesbaden, S. 33.

213 Vgl. Von Loeffelholz, Hans Dietrich 2011: Demografischer Wandel und Migration ... a.a.O., S. 3440.; Birg, Herwig 2003: Dynamik der demographischen Alterung, a.a.O. In: APuZ, B20/2003. S. 11.; vgl. Birg, Herwig 2004: Bevölkerungsentwicklung. In: Informationen zur politischen Bildung, Nr. 282/2004.; Münz, Rainer / Ulrich, Ralf 2000: Migration und zukünftige Bevölkerungsentwicklung in Deutschland. In: Bade, Klaus / Münz, Rainer 2000: Migrationsreport 2000. S. 39 ff. u. S. 56.; vgl. Angenendt, Steffen (Ed.) 1999: Asylum and Migration Policies in the European Union. Berlin, S. 177.

214 Zusammengestellt aus Statistisches Bundesamt (Hrsg.): Statistisches Jahrbuch 2002: Für die Bundesrepublik Deutschland. Wiesbaden, S. 44 u. S. 65.; Statistisches Jahrbuch 2003: S. 44 u. S. 65.; Statistisches Jahrbuch 2004: S. 26 u. S. 47.; Statistisches Jahrbuch 2005: S. 34 u. S. 48.; Statistisches Jahrbuch 2006: S. 34 u. S. 48.; Statistisches Jahrbuch 2007: S. 34 u. S. 48.; Statistisches Jahrbuch 2008: S. 34. u. S. 47.; Statistisches Jahrbuch 2009: S. 34. u. 51.; Statistisches Jahrbuch 2010: Für die Bundesrepublik Deutschland mit „Internationalen Übersichten“. Wiesbaden, S. 34. u. S. 52. 
verlaufen ebenso wie in anderen EU-Mitgliedstaaten, „wie etwa in Polen, der Slowakei, Ungarn und Rumänien, aber anders jedoch als in Frankreich, Großbritannien und in ganz Skandinavien, wo die jeweiligen Bevölkerungen zunehmen werden.“215

Der demografische Wandel in Deutschland sowie in anderen EU-Mitgliedstaaten hat somit nicht nur die Sozialversicherungssysteme, sondern auch die Haushaltspolitik oder die Kinder- und Familienpolitik ins Visier der Öffentlichkeit und Politik gerückt. Das Thema Zuwanderung wird demgemäß neu diskutiert: Deutschland und Europa bzw. die EU-Länder versuchen zunehmend, die Migration in das eigene Land jeweils nach dem ökonomischen Bedarf, insbesondere nach dem zukünftigen Bedarf der demografisch tendenziell schrumpfenden Arbeitsmärkte zu beeinflussen; das beginnt bereits mit der Gewinnung von ausländischen Studierenden und Auszubildenden sowie Rückkehrenden aus dem Ausland und reicht bis zur Verringerung von Abwanderungen. ${ }^{216}$ So ließ sich beispielsweise auch mit der „Blue Card EU“ ab Mitte 2011 eine weitere Strategie erkennen, mit der über die Adressierung hoch qualifizierter Arbeitskräfte aus Drittstaaten (also Nicht-EU-Staaten) ein Zuzug erreicht werden soll.

Es hat sich somit zumindest in breiten Teilen der Politik die Erkenntnis durchgesetzt, dass Deutschland und auch Europa bzw. die EU aufgrund des Bevölkerungsrückgangs auf Zuwanderer angewiesen ist. Eine Studie kam bereits $\mathrm{zu}$ dem Schluss, dass Einwanderer einen positiven Nettobeitrag zu den Staatsfinanzen leisten. ${ }^{217}$ Eine andere Studie kam diesbezüglich $\mathrm{zu}$ einem gegenteiligen Ergebnis, wie etwa Integrationsproblemen, die als finanzielle Belastung für die öffentlichen Haushalte berüchsichtigt werden: „It became apparent that immigration was a burden for the national budget during the first phase of immigration, because it had to cover extra housing, education and social services." 218 Die Diskussion um Zuwanderung konzentriert sich somit zum einen auf die Frage, wie sich Zuwanderung innergesellschaftlich auswirkt und welche Kosten durch Zuwanderung entstehen bzw. welcher Nutzen aus ihr gezogen werden kann. Zum anderen wurde gefragt, welche Art von Zuwanderung wirtschaftlich erforderlich ist. Weitgehende Einigkeit im Kontext des demografischen Wandels besteht darüber, dass eine gesteuerte Zuwanderung unerlässlich ist, um die Zukunftsfähigkeit Deutschlands zu erhalten.

\footnotetext{
215 Von Loeffelholz, Hans Dietrich 2011: Demografischer Wandel...a.a.O. In: APuZ, B 10-11/2011. S. 36.

216 Von Loeffelholz, Hans Dietrich 2011: Demografischer Wandel...a.a.O. In: APuZ, B 10-11/2011. S. 38.

217 Vgl. Birg, Herwig 2003: Dynamik der demographischen Alterung, a.a.O. In: APuZ, B20/2003. S. 12.; vgl. Loeffelholz, Hans-Dietrich / Köpp, Günter 1998: Ökonomische Auswrikungen der Zuwanderung nach Deutschland. Essen, S. 83.

218 Angenendt, Steffen (Ed.) 1999: Asylum and Migration Policies in the European Union. Berlin, S. 27.
} 
In diesem Zusammenhang wird schließlich der Ausländeranteil in Deutschland noch genauer betrachtet. Die Zahl der Ausländer in Deutschland, d. h. Menschen, die in der Bundesrepublik Deutschland leben und nicht die deutsche Staatsangehörigkeit im Sinne des Artikels 116 Absatz 1 des GG besitzen, hat seit der Nachkriegszeit 1945 stetig zugenommen: ${ }^{219}$ Die Ausländerzahl hat sich vor allem zwischen 1970 und 1997 mehr als verdoppelt, was einem Bevölkerungsanteil von etwa neun Prozent entsprach. Im Zuge der Gastarbeiteranwerbung lebten bereits 1974 rund 4,1 Millionen Ausländer in Deutschland. Nach dem Anwerbestopp (1973) sank ihre Anzahl zunächst geringfügig, stieg danach jedoch aufgrund von Familienzusammenführungen bis 1982 auf knapp 4,7 Millionen an. Ab 1988 wuchs die Anzahl der Ausländer stark an: Von rund 4,6 Millionen auf über 7,3 Millionen zu Beginn des Jahres 1998. Hierzu wurden im Zusammenhang mit den politischen Umbrüchen in Osteuropa und dem Fall des Eisernen Vorhangs die erheblich angestiegenen Flüchtlings- und Asylbewerberzahlen berücksichtigt. $^{220}$ Seit der Wiedervereinigung 1989 hat sich die Ausländerzahl in Deutschland von 5,0 Millionen auf 7,2 Millionen Personen zum 31.08.2009 laut Bevölkerungsfortschreibung erhöht und in den letzten fünf Jahren blieben die Zahlen weitgehend konstant (siehe Abbildung 17). ${ }^{221}$

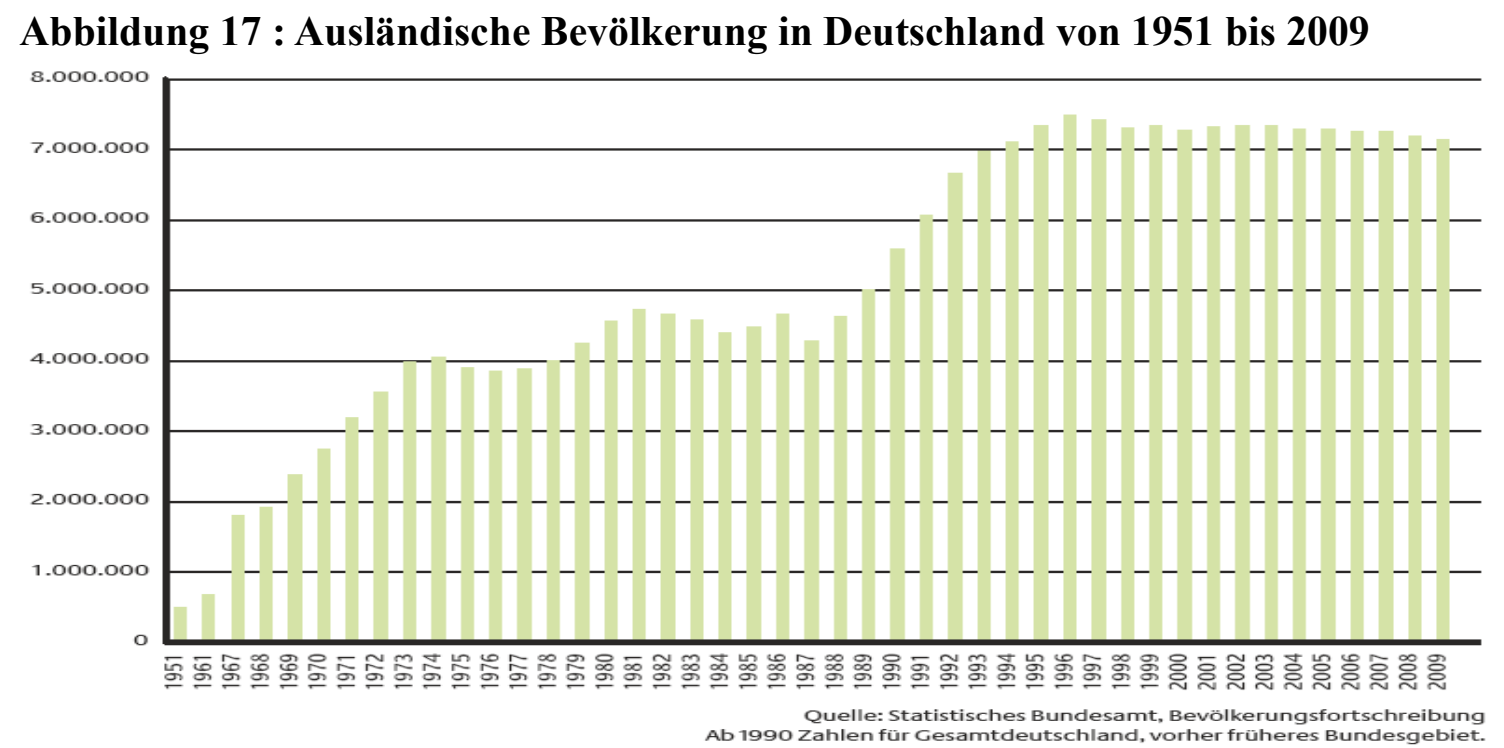

219 Vgl. Münz, Rainer / Seifert, Wolfgang / Ulrich, Ralf (Hrsg.) 1997: Zuwanderung nach Deutschland: Strukturen, Wirkungen, Perspektiven. Frankfurt a. M./New York; Sassen, Saskia 1996: Migranten, Siedler, Flüchtlinge. Von der Massenauswanderung zur Festung Europa. Frankfurt a. M.

220 Zum Vergleich: 1992 lebten mehr als 10 Millionen Drittstaatsangehörige legal in den damaligen 12 EU-Mitgliedstaaten, davon der größte Anteil mit rund 4,15 Millionen in Deutschland und mit rund 2,3 Millionen in Frankreich. Vgl. Schieffer, Martin 1998: Die Zusammenarbeit der EU-Mitgliedstaaten in den Bereichen Asyl und Einwanderung. Baden-Baden, S. 63.

221 Quelle: Bundesamt für Migration und Flüchtlinge 2009: Ausländerzahlen 2009. S.5-7. Hinweis: Diese Zahlen weichen von den Daten aus dem Ausländerzentralregister (AZR) ab.; www.bamf.de 
Ende 2009 betrug die Gesamtebevölkerung in Deutschland 82 Millionen und der Ausländeranteil fiel damit auf 8,2 Prozent (auf 6,7 Millionen). Zusätzlich zu diesen Menschen mit einem ausländischen Pass leben in Deutschland Personen mit Migrationshintergrund. ${ }^{222}$ Davon waren im Jahr 2008 8,3 Millionen Deutsche, darunter etwa 2,8 Millionen Spätaussiedler, und 7,3 Millionen Ausländer. Der Anteil der Personen mit Migrationshintergrund an der Gesamtbevölkerung betrug 19,0\%. Zusammengefasst lebten im Jahr 2008 etwa 15,6 Millionen Menschen mit Migrationshintergrund in Deutschland, was etwa einem Fünftel der Gesamtbevölkerung von 82 Millionen entspricht. ${ }^{223}$ In demografischer Hinsicht unterscheiden sich auch diese Migranten von der übrigen Bevölkerung durch das um zehn Jahre jüngere Durchschnittsalter (ca. 34,3 Jahre gegenüber 44,9 Jahre bei Deutschen ohne Migrationshintergrund) und durch ihre höhere Geburtenrate (Deutsche 1,4 Kinder pro Frau, Ausländer inzwischen nur noch 1,6). ${ }^{224}$ Die wichtigsten Herkunftsländer der Migranten mit Migrationshintergrund im Jahr 2008 waren die Türkei (19,4\% bzw. rund 3 Millionen Migranten), Polen (6,8\%), die Russische Föderation (6,6\%), Italien (5,5\%), Serbien (3,7\%), Kroatien (3,2\%) und Griechenland (3,1\%). ${ }^{225}$ Dieser Bevölkerungsanteil mit Migrationshintergrund wird künftig wachsen: „Deutschland wird also nicht nur älter und zahlenmäßig kleiner, sondern immer „,bunter“, auch wenn in Zukunft die tatsächliche Migration auf Dauer vergleichsweise niedrig bleibt.“226

Der Anteil der ausländischen Gesamtbevölkerung an der deutschen Gesamtbevölkerung ist mittlerweile von 8,9\% (im Jahr 2000) auf 8,2\% (im Jahr 2009) gesunken, ${ }^{227}$ wovon am 31. Dezember 2009 etwa 35,3\% (2,4 Millionen Personen) aus den anderen EU-26Mitgliedstaaten der Europäischen Union stammten. ${ }^{228}$ Damit kommt jeder dritte

\footnotetext{
${ }^{222}$ Personen mit „Migrationshintergrund“ sind nach der amtlichen Definition alle ,die nach 1949 auf das heutige Gebiet der Bundesrepublik Deutschland zugezogen sind, sowie alle in Deutschland geborenen Ausländer/-innen und alle in Deutschland als Deutsche Geborene mit zumindest einem zugezogenen oder als Ausländer in Deutschland geborenen Elternteil.“ In: Statistisches Bundesamt (Hrsg.) 2010: Statistisches Jahrbuch 2010: a.a.O., Wiesbaden, S. 31.

223 Statistisches Bundesamt (Hrsg.) 2010: Statistisches Jahrbuch 2010: a.a.O., Wiesbaden, S. 48-50.; vgl. auch Statistisches Bundesamt (Hrsg.) 2009: Statistisches Jahrbuch 2009: Für die Bundesrepublik Deutschland. Wiesbaden, S. 48-50.

224 Birg, Herwig 2009: Integration und Migration im Spiegel harter Daten, FAZ vom 9. April. 2009. S. 37.; vgl. Schulte, Axel / Treichler, Andreas 2010: Integration und Antidiskriminierung: Eine interdisziplinäre Einführung. München, S. 38.

${ }^{225}$ Birg, Herwig 2009: Integration und Migration im Spiegel harter Daten, FAZ vom 9. April. 2009. S. 37.

226 Von Loeffelholz, Hans Dietrich 2011: Demografischer Wandel und Migration als Megatrends. In: Aus Politik und Zeitgeschichte (APuZ) 2011/61. Jg., B 10-11/2011. Bonn, S. 34-40, hier S. 37.

227 Vgl. Statistisches Bundesamt (Hrsg.): Statistisches Jahrbuch 2002: Für die Bundesrepublik Deutschland. Wiesbaden, S. 44 u. S. 65.; Statistisches Jahrbuch 2010: Für die Bundesrepublik Deutschland mit „Internationalen Übersichten“. Wiesbaden, S. 34. u. S. 52.

228 Statistisches Bundesamt (Hrsg.) 2010: Statistisches Jahrbuch 2010: a.a.O., S. 52.
} 
Migrant in der Bundesrepublik Deutschland aus einem EU-Mitgliedsland. Die höchsten Anteile an den ehemaligen 14 EU-Ausländern hatten hierbei Italiener (7,7\%), Griechen $(4,2 \%)$, Österreicher $(2,6 \%)$, Niederländer $(2,0 \%)$, Portugiesen $(1,7 \%)$, Franzosen $(1,6 \%)$, Spanier $(1,6 \%)$ und Briten (1,4\%). Wie bereits erwähnt, lebten laut Angaben des Statistischen Bundesamtes Ende Dezember 2009 in der Bundesrepublik Deutschland insgesamt 6.694.776 Millionen ausländische Personen; das bezeichnet eine Abweichung von der Zahl der Bevölkerungsfortschreibung zum 31.08.2009 (etwa 7,2 Millionen). Die größten Gruppen der ausländischen Bevölkerung bildeten Ende 2009 die Türken mit 1,65 Millionen (24,8\%), Italiener mit 0,51 Millionen (7,7\%), Polen mit 0,39 Millionen (6,0\%), Griechen mit 0,27 Millionen (4,2\%), Kroaten mit 0,22 Millionen $(3,3 \%)$ und Serben mit 0,16 Millionen $(2,5 \%){ }^{229}$ (Vgl. Abbildung 18, 19).

Abbildung 18 : Ausländer in Deutschland nach Staatsangehörigkeit, 2009

\begin{tabular}{|c|c|c|c|c|c|}
\hline \multicolumn{6}{|c|}{31.12 .2009} \\
\hline Land der Staatsangehörigkeit & Anzahl & $\%$ & Land der Staatsangehörigkeit & Anzahl & $\%$ \\
\hline Europa & 5.322 .333 & 79,5 & \multirow{4}{*}{$\begin{array}{l}\text { Drittstaaten } \\
\text { außerhalb Europas }\end{array}$} & \multirow[t]{4}{*}{1.310 .027} & \multirow[t]{4}{*}{19,6} \\
\hline EU-26-Mitgliedstaaten & 2.362 .642 & 35,3 & & & \\
\hline EU-Staaten 14-alt & 1.618 .083 & 24,2 & & & \\
\hline EU-Staaten 10-neu (ab 01.05.2004) & 577.725 & 8,6 & & & \\
\hline \multirow[t]{2}{*}{ EU-Staaten 2-neu (ab 01.01.2007) } & 166.834 & 2,5 & Asien & 815.104 & 12,2 \\
\hline & & & Afrika & 268.410 & 4,0 \\
\hline Drittstaaten in Europa & 2.959 .691 & 44,2 & Amerika & 215,116 & 3,2 \\
\hline $\begin{array}{l}\text { EU-Kandidatenländer } \\
\text { (Kroatien, Mazedonien, Türkei) }\end{array}$ & 1.942 .193 & 29,0 & Australien und Ozeanien & 11.397 & 0,2 \\
\hline $\begin{array}{l}\text { EWR-Staaten }^{230} \\
\text { (Island, Liechtenstein, Norwegen, Schweiz) }\end{array}$ & 44.218 & 0,7 & & & \\
\hline Sonstiges Europa & 973.280 & 14,5 & & & \\
\hline \multicolumn{4}{|l|}{ Staatenlos, ungeklärt, ohne Angabe } & 62.416 & 0,9 \\
\hline \multicolumn{3}{|c|}{ Ausländische Bevölkerung in Deutschland (im Jahr 2009) } & Summe & 6.694 .776 & 100,0 \\
\hline
\end{tabular}

229 Statistisches Bundesamt (Hrsg.) 2010: Statistisches Jahrbuch 2010: a.a.O., S. 52.

230 Staaten des Europäischen Wirtschaftsraums. 


\section{Abbildung 19: Ausländer in Deutschland nach den häufigsten Staatsangehörigkeiten}

\begin{tabular}{|c|c|c|c|c|c|c|c|c|}
\hline \multirow{4}{*}{$\begin{array}{l}\text { Land der } \\
\text { Staatsangehörigkeit } \\
\text { (Grundlage: Statistisches Bundesamt 2010: } \\
\text { Statistisches Jahrbuch 2010. S. 52). } \\
\text { 1. Türkei }\end{array}$} & \multicolumn{6}{|c|}{31.12 .2009} & \multicolumn{2}{|c|}{ Durchschnitts- } \\
\hline & \multicolumn{2}{|c|}{ Insgesamt } & \multicolumn{2}{|c|}{ Männlich } & \multicolumn{2}{|c|}{ Weiblich } & \multirow{2}{*}{\begin{tabular}{|l|} 
Alter \\
$\mathrm{J}$
\end{tabular}} & \multirow{2}{*}{$\begin{array}{l}\text { Aufent- } \\
\text { haltsdauer } \\
\text { hre }\end{array}$} \\
\hline & Anzahl & $\%$ & Anzahl & $\%$ & Anzahl & $\%$ & & \\
\hline & 1.658 .083 & 24,8 & 870.472 & 25,5 & 787.611 & 24,0 & 37,3 & 23,2 \\
\hline 2. Italien & 517.474 & 7,7 & 304.716 & 8,9 & 212.758 & 6,5 & 41,6 & 27,3 \\
\hline 3. Polen & 398.513 & 6,0 & 190.478 & 5,6 & 208.035 & 6,3 & 37,3 & 9,7 \\
\hline 4. Griechenland & 278.063 & 4,2 & 150.930 & 4,4 & 127.133 & 3,9 & 42,7 & 26,6 \\
\hline 5. Kroatien & 221.222 & 3,3 & 107.464 & 3,1 & 113.758 & 3,5 & 45,2 & 27,7 \\
\hline 6. Russische Föderation & 189.326 & 2,8 & 73.247 & 2,1 & 116.079 & 3,5 & 37,6 & 8,1 \\
\hline 7. Österreich & 174.548 & 2,6 & 91.952 & 2,7 & 82.596 & 2,5 & 48,7 & 27,4 \\
\hline 8. Serbien & 164.942 & 2,5 & 84.241 & 2,5 & 80.701 & 2,5 & 35,6 & 19,0 \\
\hline 9. Bosnien und Herzegowina & 154.565 & 2,3 & 79.403 & 2,3 & 75.162 & 2,3 & 39,8 & 20,6 \\
\hline 10. Niederlande & 134.850 & 2,0 & 74.223 & 2,2 & 60.627 & 1,8 & 46,3 & 23,2 \\
\hline 11. Ukraine & 125.617 & 1,9 & 48.215 & 1,4 & 77.402 & 2,4 & 41,2 & 8,5 \\
\hline 12. Portugal & 113.260 & 1,7 & 61.743 & 1,8 & 51.517 & 1,6 & 40,0 & 21,8 \\
\hline 13. Frankreich & 107.257 & 1,6 & 50.213 & 1,5 & 57.044 & 1,7 & 41,1 & 18,3 \\
\hline 14. Rumänien & 104.980 & 1,6 & 47.814 & 1,4 & 57.166 & 1,7 & 34,3 & 7,1 \\
\hline 15. Spanien & 104.002 & 1,6 & 51.743 & 1,5 & 52.259 & 1,6 & 44,1 & 27,4 \\
\hline 16. USA & 98.352 & 1,5 & 55.898 & 1,6 & 42.454 & 1,3 & 43,7 & 16,8 \\
\hline 17. Großbritannien & 95.852 & 1,4 & 58.360 & 1,7 & 37.492 & 1,1 & 45,2 & 19,9 \\
\hline 18. Vietnam & 84.437 & 1,3 & 40.556 & 1,2 & 43.881 & 1,3 & 33,1 & 13,5 \\
\hline 19. Kosovo & 84.043 & 1,3 & 42.515 & 1,2 & 41.528 & 1,3 & 27,7 & 12,2 \\
\hline 20. China (ohne Taiwan) & 79.870 & 1,2 & 39.720 & 1,2 & 40.150 & 1,2 & 31,0 & 6,5 \\
\hline 21. Irak & 79.413 & 1,2 & 49.001 & 1,4 & 30.412 & 0,9 & 27,2 & 6,9 \\
\hline 22. Marokko & 64.842 & 1,0 & 36.261 & 1,1 & 28.581 & 0,9 & 36,7 & 15,9 \\
\hline 23. Mazedonien & 62.888 & 0,9 & 33.225 & 1,0 & 29.663 & 0,9 & 36,8 & 19,7 \\
\hline 24. Bulgarien & 61.854 & 0,9 & 28.962 & 0,8 & 32.892 & 1,0 & 33,3 & 6,5 \\
\hline 25. Ungarn & 61.417 & 0,9 & 36.081 & 1,1 & 25,336 & 0,8 & 39,3 & 11,4 \\
\hline 26. Thailand & 55.324 & 0,8 & 7.569 & 0,2 & 47.755 & 1,5 & 37,6 & 11,3 \\
\hline 27. Kasachstan & 52.583 & 0,8 & 24.093 & 0,7 & 28.490 & 0,9 & 37,2 & 8,1 \\
\hline 28. Iran, Islamische Republik & 52.132 & 0,8 & 29.184 & 0,9 & 22.948 & 0,7 & 40,0 & 14,0 \\
\hline
\end{tabular}


Hierbei weist die Geschlechts-, Altersstruktur und Aufenthaltsdauer einige Besonderheiten auf. Es ist heute noch ein Männerüberschuss festzustellen. Von den 6,69 Millionen der ausländischen Gesamtbevölkerung waren im Jahr 2009 3,41 Millionen bzw. 51,0\% der Migranten männlichen und 3,28 Millionen bzw. 49,0\% weiblichen Geschlechts. Das Durchschnittsalter der Migranten betrug 38,4 Jahre und die durchschnittliche Aufenthaltsdauer lag bei 18,6 Jahren. ${ }^{231}$ Die ausländische Gesamtbevölkerung ist somit im Vergleich zur deutschen wesentlich jünger (siehe Abbildung 20). Bemerkenswert ist diesbezüglich, dass die Zahl der Ausländer in der jüngsten Altersgruppe (unter 5 Jahren) seit einigen Jahren sinkt, weil neugeborene Kinder ausländischer Eltern durch das Territorialprinzip („Ius soli“) des Staatsangehörigkeitsrechts im Jahr 2000 in zunehmenden Maße bereits bei der Geburt die deutsche Staatsangehörigkeit erhalten. ${ }^{232}$

\section{Abbildung 20 : Alterspyramide 2008 - Deutsche und Ausländer ${ }^{233}$}

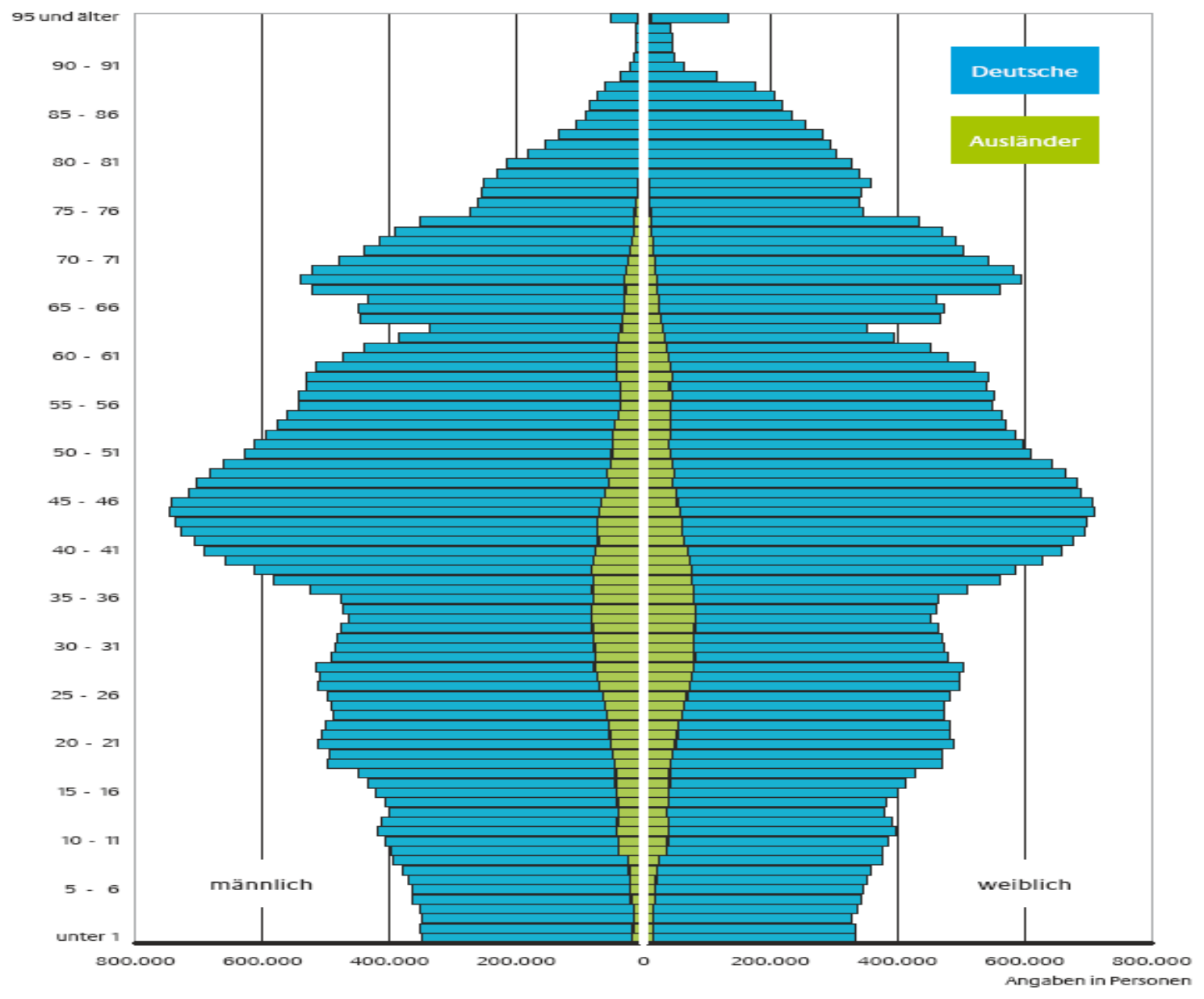

231 Vgl. Statistisches Bundesamt (Hrsg.) 2010: Statistisches Jahrbuch 2010: a.a.O., S. 52.

${ }^{232}$ Bundesamt für Migration und Flüchtlinge (BAMF) 2009: Ausländerzahlen 2009. S. 9.; www.bamf.de

233 Quelle: Bundesamt für Migration und Flüchtlinge 2009: Ausländerzahlen 2009. S. 10.; www.bamf.de 
Die räumliche Verteilung der ausländischen Bevölkerung nach Bundesländern und Regionen ist sehr unterschiedlich. So lebten Ende 2008 allein in den vier Flächenländern gut 70\% aller MigrantInnen: Die höchsten Ausländeranteile hatten im Jahr 2008 neben den Stadtstaaten Hamburg (13,8\%), Berlin (14\%) und Bremen (12,5\%) die vier Bundesländer Baden-Württemberg (11,8\%), Hessen (11,1\%), NordrheinWestfalen (10,5\%) und Bayern (9,4\%). In den neuen Bundesländern waren die Migrantenanteile sehr gering. Mit Ausnahme von Brandenburg (2,6\%) und Sachsen (2,7\%) lagen sie unter 2,5\%. Insgesamt lebten 2008 in den neuen Bundesländern nur rund 309.000 Ausländer. Die restlichen rund 6,9 Millionen Ausländer im Jahr 2008 konzentrierten sich auf die alten Bundesländer (siehe Abbildung 21).

Abbildung 21 : Ausländische Bevölkerung nach Bundesländern, 2008

\begin{tabular}{|c|c|c|c|c|}
\hline \multirow[t]{3}{*}{ 16-Bundesländer } & Fläche & Gesamtbevölkerung & Ausländis & völkerung \\
\hline & \multirow[t]{2}{*}{$\mathrm{km}^{2}$} & \multicolumn{2}{|c|}{ Insgesamt } & dav. \\
\hline & & \multicolumn{2}{|c|}{ in 1000} & Anteil: \% \\
\hline \multicolumn{5}{|c|}{ Ergebnisse der Bevölkerungsfortschreibung zum 31.12.2008 } \\
\hline Deutschland & 357.112 & 82.002 & 7.184 & 8,8 \\
\hline Baden-Württemberg & 35.751 & 10.750 & 1.266 & 11,8 \\
\hline Bayern & 70.552 & 12.520 & 1.175 & 9,4 \\
\hline Berlin & 892 & 3.432 & 480 & 14 \\
\hline Brandenburg & 29.481 & 2.522 & 65 & 2,6 \\
\hline Bremen & 404 & 662 & 83 & 12,5 \\
\hline Hamburg & 755 & 1.772 & 245 & 13,8 \\
\hline Hessen & 21.115 & 6.065 & 674 & 11,1 \\
\hline Mecklenburg-Vorpommern & 23.186 & 1.664 & 39 & 2,3 \\
\hline Niedersachsen & 47.627 & 7.947 & 524 & 6,6 \\
\hline Nordrhein-Westfalen & 34.088 & 17.933 & 1.887 & 10,5 \\
\hline Rheinland-Pfalz & 19.854 & 4.028 & 308 & 7,6 \\
\hline Saarland & 2.569 & 1.030 & 86 & 8,3 \\
\hline Sachsen & 18.419 & 4.193 & 115 & 2,7 \\
\hline Sachsen-Anhalt & 20.448 & 2.382 & 43 & 1,8 \\
\hline Schleswig-Holstein & 15.799 & 2.834 & 147 & 5,2 \\
\hline Thüringen & 16.172 & 2.268 & 47 & 2,1 \\
\hline $\begin{array}{l}\text { Quelle: Statistisches Bund } \\
\text { Deutschland mit „Internatio }\end{array}$ & $\begin{array}{l}\text { sg.) } 201 \\
\text { rsichten“" }\end{array}$ & $\begin{array}{l}\text { istisches Jahrbuch } \\
\text { aden, S. 29.; www. }\end{array}$ & $\begin{array}{l}\text { 0: Für di } \\
\text { atis.de. }\end{array}$ & esrepublik \\
\hline
\end{tabular}


Noch höher war der Ausländeranteil in einigen größeren Städten, zum Beispiel Offenbach, Frankfurt am Main, München oder Stuttgart. Die fünf häufigsten Staatsangehörigkeitsgruppen nach Bundesländern Ende 2009 stellten hier in Stadtteilen und Vierteln bereits die multiethnische Mehrheit dar (vgl. Abbildung 22). Migration ist somit von seiner sozialräumlichen Dimension vor allem ein westdeutsches- und darüber hinaus primär ein städtisches Phänomen. ${ }^{234}$

Abbildung 22 :Die fünf häufigsten Staatsangehörigkeitsgruppen nach Bundesländern ${ }^{235}$

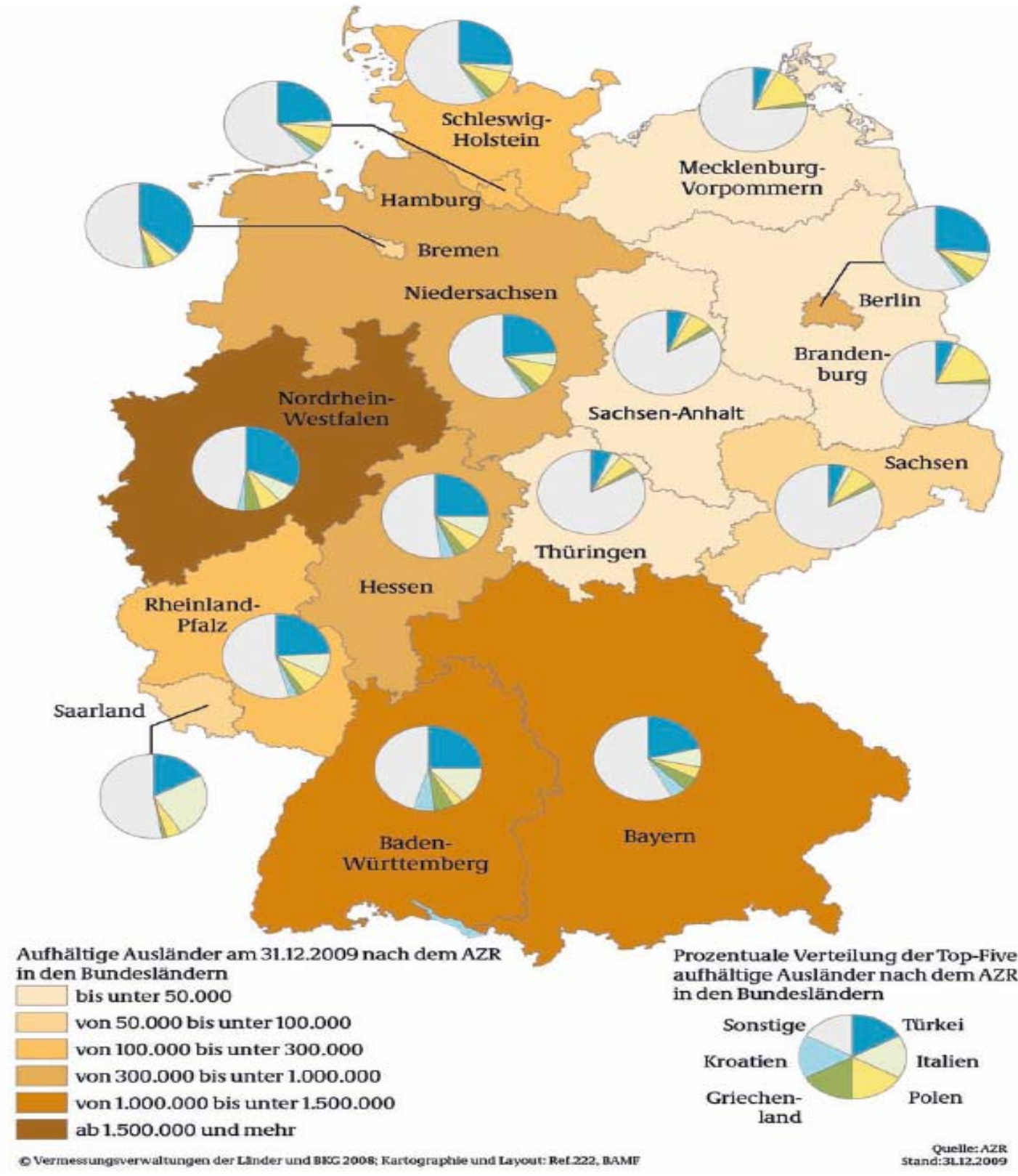

${ }^{234}$ Vgl. Schulte, Axel / Treichler, Andreas 2010: Integration und Antidiskriminierung: a.a.O., S. 39-40.

${ }^{235}$ Quelle: Bundesamt für Migration und Flüchtlinge 2009: Ausländerzahlen 2009. S. 13.; www.bamf.de 


\section{Migrationspolitik : Historische Dimension der deutschen Migrationspolitik}

Die Migrationspolitik hat wie überall auf der Welt auch in Deutschland ${ }^{236}$ eine lange Geschichte. Es wurde mittlerweile im Zuge der deutschen Migrationspolitik viel über die Frage gestritten, ob die Bundesrepublik Deutschland ein Einwanderungsland ist oder nicht. ${ }^{237}$ Daraufhin fokussierte bzw. fokussiert die deutsche Migrationspolitik vor allem auf einen besonders rationalen institutionellen Rahmen für die Migration und erfuhr bzw. erfährt „Wandlungsprozesse“ in der Vergangenheit und Gegenwart, die jedoch bisher zu den weniger erforschten Themen gehören. Die folgende historische Dimension bezüglich der Migrationspolitik Deutschlands zeigt infolgedessen eine Perspektive, die nicht die Kontinuitäten, sondern die Wandlungsprozesse akzentuiert.

Im Kontext dieser Wandlungsprozesse ist nun die Frage gestellt, welche Migrationspolitik in der Migrationsgeschichte Deutschlands als „Politikwandel“ oder „Paradigmenwechsel“‘238 bezeichnet werden kann. Hier soll zuerst der Begriff des „policy paradigm“ im Sinne von Peter Hall geklärt werden, der die Rolle von Ideen im politischen Prozess beleuchtet. Der Begriff des „policy paradigm“ bezeichnet „a framework of ideas and standards that specifies not only the goals of policy and the kind of instruments that can be used to attain them, but also the very nature of the problems they are meant to be addressing. "239 Als „Paradigmenwechsel“ beschreibt Hall nun den Wandel eines solchen Interpretationsrahmens, z. B. durch das Wirken der Wirtschaft und durch angemessene Interventionen. Häufig stehe im Zusammenhang mit einem solchen Paradigmenwechsel ein umfassendes, radikales Umsteuern in der Politik; dies nennt Hall Politikwandel dritter Ordnung. Des Weiteren bezeichnet Hall die kontinuierlichen kleineren Anpassungen als Politikwandel erster und Veränderungen der Interventionsinstrumente bei gleich bleibenden Prioritäten als Politikwandel zweiter Ordnung. ${ }^{240}$

${ }^{236}$ Unter der Bezeichnung Deutschland wird in dieser Arbeit die Bundesrepublik Deutschland sowie nach der Wiedervereinigung von 1989/1990 - Gesamtdeutschland verstanden.

237 Vgl. Tomei, Verónica 2001: Das Einwanderungsland Deutschland und die Europäisierung. In: Currle, Edda / Wunderlich, Tanja (Hrsg.) 2001: Deutschland - ein Einwanderungsland? Rückblick, Bilanz und neue Fragen. Stuttgart, S. 141.

238 Schönwälder, Karen 2006: Politikwandel in der (bundes-) deutschen Migrationspolitik. In: Davy, Ulrike / Weber, Albrecht (Hrsg.) 2006: Paradigmenwechsel in Einwanderungsfragen?: Überlegungen zum neuen Zuwanderungsgesetz. Baden-Baden, S. 8-22, hier S. 9.

239 Hall, Peter 1993: Policy Paradigms, Social Learning, and the State: The Case of Economic Policymaking in Britain. In: Comparative Politics, 25. Jg. S. 279.

${ }^{240}$ Schönwälder, Karen 2006: Politikwandel in der (bundes-) deutschen Migrationspolitik. In: Davy, Ulrike / Weber, Albrecht (Hrsg.) 2006: Paradigmenwechsel in Einwanderungsfragen?: a.a.O., S. 9. 
Über diesen Kontext des ,policy paradigm“ hinaus wird in der folgenden Untersuchung gleichzeitig der Frage nachgegangen, welche Voraussetzungen in der deutschen Geschichte im Politikfeld Migration zu einem Politikwandel oder Paradigmenwechsel führten und führen. Dabei wird auch die Frage gestellt, welche Einflüsse von Ideen und von bestimmten Akteuren im politischen Prozess wirken.

Im Folgenden wird somit die historische Dimension von 1945 bis in die Gegenwart der deutschen Migrationspolitik in sieben Phasen dargestellt. Hierbei wurde durchgängig das Werk von Ulrich Herbert ${ }^{241}$ und anderen Autoren, vor allem die Analyse der Wandlungsprozesse von Karen Schönwälder ${ }^{242}$ berücksichtigt, sowie durch aktuelle Quellen aus dem Internet ergänzt. Die im Folgenden skizzierten sieben Phasen $^{243}$ lassen sich nun nach verschiedenen zeitlichen Kriterien unterscheiden.

${ }^{241}$ Herbert, Ulrich 2001: Geschichte der Ausländerpolitik in Deutschland: Saisonarbeiter, Zwangsarbeiter, Gastarbeiter, Flüchtlinge. München.

${ }^{242}$ Schönwälder, Karen 2006: Politikwandel in der (bundes-) deutschen Migrationspolitik. a.a.O., S. 8-22.

243 Über die Phaseneinteilung vgl. Mintzel, Alf 1997: Multikulturelle Gesellschaften in Europa und Nordamerika: Konzepte, Streitfragen, Analysen, Befunde. Passau, S. 470-474.; Motte, Jan / Ohliger, Rainer / Von Oswald, Anne (Hrsg.) 1999: 50 Jahre Bundesrepublik-50 Jahre Einwanderung: Nachkriegsgeschichte als Migrationsgeschichte. Frankfurt a. M.; vgl. Birsl, Ursula 2003: Deutschland. In: Gieler, Wolfgang (Hrsg.) 2003: Handbuch der Ausländer- und Zuwanderungspolitik: Von Afghanistan bis Zypern. Hamburg, S. 129-147.; vgl. Nuscheler, Franz 2004: Internationale Migration: Flucht und Asyl. Wiesbaden, S. 137-173.; vgl. Reißlandt, Carolin 2005: Von der „Gastarbeiter“Anwerbung zum Zuwanderungsgesetz: Migrationsgeschehen und Zuwanderungspolitik in der Bundesrepublik. Abzurufen unter: http://www.bpb.de/themen/6XDUPY.html (Stand: 15.03.2005).; vgl. Flam, Helena (Hrsg.) 2007: Migranten in Deutschland. Statistiken - Fakten - Diskurse. Konstanz, S. 293-296.; vgl. Schulte, Axel / Treichler, Andreas 2010: Integration und Antidiskriminierung: Eine interdisziplinäre Einführung. München, S. 17-29.; vgl. Meier-Braun, Karl-Heinz 2007: Der lange Weg ins Einwanderungsland Deutschland. In: Frech, Siegfried / Meier-Braun, Karl-Heinz (Hrsg.) 2007: Die offene Gesellschaft: Zuwanderung und Integration. Baden-Württemberg, S. 21-39. 


\subsection{Phase 1 : Nachkriegsdeutschland und die dreifache Zuwanderung 1945-1954}

Der Wandel Deutschlands zu einem Einwanderungsland begann direkt nach der Niederlage des Nationalsozialismus und dem Ende des Zweiten Weltkriegs 1945 mit einer Massenwanderung. ${ }^{244}$ Betrachtet man die deutsche Migrationspolitik im Verlauf dieser Anfangsphase, so wird deutlich, dass Deutschland insbesondere die folgenden drei Migrantengruppen in seinen politischen Paradigmen einsetzen wollte.

\section{1. „Displaced Persons (DPs)“ :}

Direkt bei Kriegsende befanden sich in Deutschland zunächst schätzungsweise 4,5 Millionen „Displaced Persons (DPs)“ bzw. „Heimatlose Ausländer“, wobei sich in ganz Europa 10,5 bis 11,7 Mio. DPs aufhielten. ${ }^{245}$ Diese DPs entstammten rund 20 Nationalitäten mit über 35 verschiedenen Sprachen und waren zumeist Zwangsarbeiter/innen. ${ }^{246}$ In dieser Situation wurde auch im Hinblick auf die Teilung Deutschlands in zunächst vier alliierte Besatzungszonen nach dem Zweiten Weltkrieg, woraus im Jahr 1949 in der Gründung zweier deutscher Staaten - der Bundesrepublik Deutschland (BRD) und der Deutschen Demokratischen Republik (DDR) - resultierte, eine dringende Maßnahme gefordert. ${ }^{247}$ Erst auf internationaler Ebene eröffneten daraufhin die Auswanderungsprogramme der im Juni 1947 gegründeten ,International Refugee Organization' (IRO) einer großen Zahl von DPs eine neue Perspektive. Bis 1951 arrangierten die „Resettlement-Programme“ der IRO europaweit ca. 712.000 DPs die Auswanderung. Es begann somit eine Phase von Abwanderung, vor allem in Richtung USA, Australien und Kanada sowie Frankreich und Großbritannien. ${ }^{248}$ Diese Maßnahme sollte den DPs ermöglichen, neue Heimatländer $\mathrm{zu}$ finden. Alternativ beabsichtigten die Alliierten, die DPs so rasch wie möglich in ihre Heimatländer zurückzubringen. Bemerkenswert ist dabei, dass in der BRD bereits im Jahr 1949 das Grundrecht auf Asyl aus humanitären Verpflichtungen (Art. 16a GG) bestand. ${ }^{249}$

\footnotetext{
244 Birsl, Ursula 2003: Deutschland. In: Gieler, Wolfgang (Hrsg.) 2003: Handbuch der Ausländer- und Zuwanderungspolitik: Von Afghanistan bis Zypern. Hamburg, S. 130.; Schulte, Axel / Treichler, Andreas 2010: Integration und Antidiskriminierung: a.a.O., S. 18.; Mahnig, Hans 2001: „Ist Deutschland wirklich anders?“ Die deutsche Integrationspolitik im europäischen Vergleich. In: Currle, Edda / Wunderlich, Tanja (Hrsg.) 2001: Deutschland - ein Einwanderungsland? Rückblick, Bilanz und neue Fragen. Stuttgart, S. 159-195, hier S. 175.

245 Birsl, Ursula 2005: Migration und Migrationspolitik im Prozess der europäischen Integration?. S. 201.

246 Bade, Klaus J. / Emmer, Pieter C. / Lucassen, Leo / Oltmer, Jochen (Hrsg.) 2008: Enzyklopädie: Migration in Europa: Vom 17. Jahrhundert bis zur Gegenwart. Paderborn, S. 157.

247 Currle, Edda 2004: Migration in Europa - Daten und Hintergründe. Stuttgart, S. 18.

248 Oltmer, Jochen 2010: Migration im 19. und 20. Jahrhundert. München, S. 45.

249 Flam, Helena (Hrsg.) 2007: Migranten in Deutschland: Statistiken-Fakten-Diskurse. Konstanz, S. 293.
} 
Als die Westalliierten 1950 die Verantwortung für diese DPs an die Bundesregierung übergaben, blieben noch rund 150.000 dieser DPs in Westdeutschland (BRD) zurück. ${ }^{250}$ Es waren zumeist kranke, alte oder als nicht arbeitsfähig geltende und $\mathrm{zu}$ stark geschwächte Menschen, die nicht mehr migrieren wollten und konnten. ${ }^{251}$ Es wurde das „Gesetz über die Rechtsstellung heimatloser Ausländer“ vom 25. April 1951 in der BRD geschaffen, durch das die BRD den DPs einen im Vergleich zum internationalen Flüchtlingsrecht speziellen, großzügigen Rechtsstatus einräumte. Es gab allerdings in weiten Bereichen keine vollständige Gleichstellung mit der rechtlichen Position der Bundesbürger, vor allem mit den deutschen Flüchtlingen und Vertriebenen. ${ }^{252}$ Vielmehr war das Verhältnis der deutschen Bevölkerung zu den DPs im Integrationsprozess von Abwehrreaktionen bis hin zu offener Feindseligkeit, aber auch Neid geprägt, z. B. durch die Bezeichnung als „Untermenschen.“253 Die DPs bildeten jedoch nur eine unter den großen Migrantengruppen im Deutschland der unmittelbaren Nachkriegszeit.

\section{2. „Vertriebene“ :}

Zeitgleich fand auch eine große Wanderungsbewegung in Ost-West-Richtungen statt, die durch Flucht und Vertreibung gekennzeichnet und vor allem eine Folge des Nationalsozialismus war. ${ }^{254}$ Bereits aufgrund der „Germanisierungspolitik“ im Nationalsozialismus bzw. im Zuge der sogenannten „NS-Volkstumspolitik“ wurden sogenannte „Reichsdeutsche“ und „Volksdeutsche“ in den osteuropäischen Ländern umgesiedelt. Diese Gruppen versuchten sich nun gegen Ende des Weltkrieges vor der sowjetischen Armee in Richtung Westen neu anzusiedeln, wurden aber nach den Beschlüssen der Alliierten wiederum vertrieben bzw. deportiert. ${ }^{255}$ Hiervon betroffen waren auch Migrantengruppen, ,die im Verlauf der Ostsiedlungsbewegung Jahrhunderte zuvor in Regionen Polens, Rumäniens, der früheren Tschechoslowakei, Ungarns oder in Gebiete an der Wolga gewandert waren.“256 In Bezug auf die neuen staatlichen Grenzziehungen bzw. Reorganisationen durch die Politik der Alliiertenmächte wurden große Teile dieser Ostsiedlungsbewegung wieder rückgängig gemacht. Ein Beispiel dafür war die Zwangsumsiedlung der Nachfahren deutscher Zuwanderer, die in der Sowjetunion (z. B. in Kasachstan) verblieben waren. ${ }^{257}$ Diese Vertriebenen lassen sich

\footnotetext{
250 Bade, Klaus J. / Emmer, Pieter C. / Lucassen, Leo / Oltmer, Jochen 2008: Enzyklopädie:a.a.O., S. 157.

251 Birsl, Ursula 2003: Deutschland. In: Gieler, Wolfgang (Hrsg.) 2003: a.a.O., S. 131.

252 Bade, Klaus J. / Emmer, Pieter C. / Lucassen, Leo / Oltmer, Jochen 2008: Enzyklopädie:a.a.O., S. 157.

253 Bade, Klaus J. / Emmer, Pieter C. / Lucassen, Leo / Oltmer, Jochen 2008: Enzyklopädie:a.a.O., S. 158.

254 Birsl, Ursula 2005: Migration und Migrationspolitik im Prozess der europäischen Integration?. S. 201.

255 Birsl, Ursula 2005: Migration und Migrationspolitik im Prozess der europäischen Integration?. S. 201f.

256 Birsl, Ursula 2003: Deutschland. In: Gieler, Wolfgang (Hrsg.) 2003: a.a.O., S. 132.

257 Birsl, Ursula 2003: Deutschland. In: Gieler, Wolfgang (Hrsg.) 2003: a.a.O., S. 132.
} 
mit einigen markanten Zahlen noch genauer beschreiben: „Von rund 18 Millionen Reichsdeutschen in den Ostprovinzen des Reiches und Volksdeutschen in den deutschen Siedlungsgebieten in Ost-, Ostmittel- und Südosteuropa waren in der Endphase des Krieges rund 14 Millionen in Richtung Westen geflüchtet oder nach dem Kriegsende vertrieben bzw. deportiert worden. ${ }^{، 258}$ Eine weitere Statistik gibt Hinweise darauf: Bis Ende 1950, also zwischen 1945 und 1950 wanderten rund 8,1 Millionen (oder 60\%) Vertriebene deutscher Staatsangehörigkeit in den westlichen Teil Deutschlands, der späteren Bundesrepublik Deutschland (BRD) ein, sowie circa 3.6 Millionen (37\%) in die sowjetische Besatzungszone (SBZ), die spätere Deutsche Demokratische Republik (DDR). ${ }^{259}$ Seitdem wurden diese Wanderungsbewegungen als sogenannte, ethnische Migration' oder, deutsche Minderheiten' begriffen, die sich später mit dem Bau der Berliner Mauer im 1961 durch die Binnenwanderung von Ost- nach Westdeutschland noch verstärkt hat. Im Vergleich zu allen anderen westlichen Einwanderungsländern ist diese Migrationsform bis heute das Spezifikum im Migrationssystem von Deutschland. $^{260}$

Auch anders als die ausländischen Zwangsarbeiter bzw. DPs waren die Vertriebenen eine sozial heterogene Migrantengruppe und nicht der Unterprivilegierung ausgesetzt. Es handelte sich bei den Vertriebenen um Personen deutscher Nationalität sowie Sprache, daher entstanden hier weder ausländerrechtliche noch sprachliche Probleme. ${ }^{261}$ Durch das Wahlrecht wurden die Vertriebenen von den deutschen Parteien auch politisch als ein ernstzunehmender Faktor berücksichtigt. ${ }^{262}$ Es ist jedoch naheliegend, dass der Integrationsprozess der Vertriebenen nicht linear und reibungslos erfolgen konnte. Vor allem gab es hierbei eine ungleichmäßige räumliche Verteilung der Vertriebenen, also erhebliche regionale Belastungsunterschiede im Nachkriegsdeutschland, was auch die Probleme bei der Eingliederung der Vertriebenen sehr ungleich verteilte. ${ }^{263}$

${ }^{258}$ Bade, Klaus J. / Emmer, Pieter C. / Lucassen, Leo / Oltmer, Jochen 2008: Enzyklopädie:a.a.O., S. 158. 259 Rudolph, Hedwig 1996: Die Dynamik der Einwanderung im Nichteinwanderungsland Deutschland. In: Fassmann, Heinz / Münz, Rainer (Hrsg.) 1996: Migration in Europa: a.a.O., S. 163.; vgl. Oberpenning, Hannelore 1999: Das ,Modell Espelkamp': Zur Geschichte der sozialen und kulturellen Eingliederung von Flüchtlingen, Vertriebenen und Aussiedlern. In: Motte, Jan et. al. 1999:a.a.O., S. 31.

${ }^{260}$ Birsl, Ursula 2005: Migration und Migrationspolitik ... a.a.O., S. 202.

${ }^{261}$ Herbert, Ulrich 2001: Geschichte der Ausländerpolitik in Deutschland: a.a.O., S. 197.

${ }^{262}$ Herbert, Ulrich 2001: Geschichte der Ausländerpolitik in Deutschland: a.a.O., S. 200.

${ }^{263}$ Der Anteil der Vertriebenen an der Wohnbevölkerung lag in Schleswig-Holstein im Jahre 1950 bei $33,0 \%$, in Niedersachsen bei $27,2 \%$, in Bayern bei $21,1 \%$. In Rheinland-Pfalz wohnten hingegen nur $5,1 \%$, in Hamburg 7,2 \% und in Baden-Württemberg 13,4 \% der Vertriebenen. In: Bethlehem, Siegfried 1982: Heimatvertreibung, DDR-Flucht, Gastarbeiterzuwanderung: Wanderungsströme und Wanderungs-politik in der Bundesrepublik Deutschland. Stuttgart, S. 30.; Herbert 2001: S. 195. 


\section{3. „Republikflüchtlinge“ oder „Übersiedler“ :}

Mit der Gründung zweier Deutscher Staaten 1949 begann eine große Wanderungsbewegung aus der DDR in die BRD. Diese Migrierenden, legal oder illegal, wurden in Westdeutschland offiziell als „Übersiedler“ und in Ostdeutschland als „Republikflüchtlinge“ bezeichnet. ${ }^{264}$ Bis zum Bau der Berliner Mauer, bzw. zwischen 1950 und 1961 überschritten 3,6 Mio. Menschen die innerdeutschen Grenzen von Ost nach West, im Vergleich 0,5 Mio. von West nach Ost. ${ }^{265}$ Hierbei wanderte auch eine unbekannte Zahl von Vertriebenen aus der DDR in die BRD weiter. Diese Wanderungsbewegung der Übersiedler wie auch die der Vertriebenen bzw. Aussiedler aus Osteuropa wurde mit dem Bau der Berliner Mauer beschleunigt. ${ }^{266}$ Es waren später bis zum Fall der Mauer 1989 rund 15 Mio. Menschen in die Bundesrepublik gelangt, was ungefähr einem Viertel der bundesdeutschen Bevölkerung entsprach. Diese Zuwanderungsform wird auch als ,ethnische Migration“ bezeichnet. $^{267}$

Noch während diese ethnische Migration in den Nachkriegsjahren erheblich war, versuchte die Bundesrepublik Deutschland ein arbeitsmarktorientiertes Paradigma einzuführen; also das Wirtschaftswachstum im Nachkriegsdeutschland durch die Arbeitskräfte der ethnischen Migration zu fördern. Bereits seit der Währungsreform 1948 begann der wirtschaftliche Aufschwung in den drei Westzonen der späteren BRD. Hierbei waren zwei Voraussetzungen wesentlich: Zunächst standen wirtschaftliche Aufbauhilfen im Zuge des Marshall-Planes durch die USA zur Verfügung. So waren einerseits das entsprechende Kapital und andererseits ausreichend viele Arbeitskräfte vorhanden. ${ }^{268}$ Vor diesem Hintergrund machte das Wort vom ,deutschen Wirtschaftswunder' die Runde. ${ }^{269}$ In Bezug auf den Arbeitsmarkt wurde deutlich, dass durch die ethnische Migration die in Westdeutschland entstandenen Arbeitskräftelücken ausgefüllt wurden. ${ }^{270}$ So gab es beispielsweise nach der Währungsreform 1948 einen Bedarf an Fachkräften, der in großen Teilen durch die Zuwanderung von Vertriebenen und Flüchtlingen abgedeckt wurde und unter denen sich höher Qualifizierte befanden. ${ }^{271}$ Zugleich erfuhren die deutschen Westzonen der späteren BRD wegen Armut und Erwerbslosigkeit bis Anfang der 1980er Jahre eine erhebliche Abwanderung im Umfang

\footnotetext{
264 Birsl, Ursula 2005: Migration und Migrationspolitik ... a.a.O., S. 202.

265 Rudolph, Hedwig 1996: Die Dynamik der Einwanderung im Nichteinwanderungsland Deutschland. In: Fassmann, Heinz / Münz, Rainer (Hrsg.) 1996: Migration in Europa: a.a.O., S. 163.

266 Birsl, Ursula 2005: Migration und Migrationspolitik ... a.a.O., S. 202.

267 Birsl, Ursula 2003: Deutschland. In: Gieler, Wolfgang (Hrsg.) 2003: a.a.O., S. 132.

268 Herbert, Ulrich 2001: Geschichte der Ausländerpolitik in Deutschland: a.a.O., S. 193.

269 Schulte, Axel / Treichler, Andreas 2010: Integration und Antidiskriminierung: a.a.O., S. 19.

270 Herbert, Ulrich 2001: Geschichte der Ausländerpolitik in Deutschland: a.a.O., S. 193.

271 Birsl, Ursula 2005: Migration und Migrationspolitik ... a.a.O., S. 203.
} 
rund 3 bis 4 Mio. ${ }^{272}$ Bemerkenswert war hierbei die Anfang der 1950er Jahre zunehmende Auswanderung qualifizierter Personen mit Berufsabschluss nach Übersee. ${ }^{273}$ Es zeigt sich somit, dass in der Nachkriegszeit Deutschlands vor allem in der ersten Hälfte der 1950er Jahren ohne diese Migration der Vertriebenen und Flüchtlinge bzw. Übersiedler volkswirtschaftlich ein erhebliches Defizit an Arbeitskräften entstanden wäre. ${ }^{274}$

Für die Ausländerbeschäftigung in Bezug auf das deutsche Wirtschaftswunder blieb jedoch die vom NS-Regime erlassene Verordnung weithin bruchlos bestehen. So wurde Anfang 1951 die „Ausländerpolizeiverordnung“ (APVO) des Naziregimes von 1938 durch das Bundesinnenministerium wieder in Kraft gesetzt. ${ }^{275}$ Denn die Bundesregierung wollte das alte Regelungsinstrumentarium für eine Wiederaufnahme der Ausländerbeschäftigung zur Verfügung stellen, wofür eine Rechtsgrundlage notwendig war. An dieser Stelle, also für die Wiederbelebung der APVO bezüglich des Ausländergesetzes, waren mehrere Motive maßgeblich. Als ein Beispiel dafür ist „der Wunsch nach Wiederherstellung eines gewohnten und weitgehend unhinterfragten Kontroll- und Überwachungsinstrumentariums gegenüber Fremden“6276 zu nennen. Die APVO galt bis zum Inkrafttreten des Ausländergesetzes am 1. Oktober 1965 und wurde ohne Beteiligung des Bundestages durch die Exekutive in Kraft gesetzt. Auf dem Feld der Migrationspolitik bzw. Ausländerpolitik in der Nachkriegszeit Deutschlands leitete somit innerhalb des politisch-administrativen Systems die Exekutive bis Mitte der 1960er Jahre den Entscheidungsprozess. Die wesentlichen politischen Entscheidungen wurden daher ohne Beteiligung des Bundestages durchgeführt. ${ }^{277}$

Insgesamt zeigt sich im Verlauf der ersten Phase der deutschen Migrationspolitik (19451954), dass vor allem die Umsetzung von Menschenrechtsnormen nach 1945 betrachtet wurde (z. B. die Entstehung des Grundrechts auf Asyl sowie das Gesetz über die Rechtsstellung heimatloser Ausländer). Es ergaben sich jedoch keine wirksamen Standards und keine umfassende oder systematische Migrationspolitik im Nachkriegsdeutschland bezüglich des deutschen Wirtschaftswunder.

\footnotetext{
272 Birsl, Ursula 2005: Migration und Migrationspolitik ... a.a.O., S. 203.

273 Schulte, Axel / Treichler, Andreas 2010: Integration und Antidiskriminierung: a.a.O., S. 20.

274 Herbert, Ulrich 2001: Geschichte der Ausländerpolitik in Deutschland: a.a.O., S. 195.

275 Luft, Stefan 2009: Staat und Migration: Zur Stuerbarkeit von Zuwanderung und Integration. S. 36.

276 Schönwälder, Karen 1999: „Ist nur Liberalisierung Fortschritt?“: Zur Entstehung des ersten Ausländergesetzes der Bundesrepublik. In: Motte, Jan et. al. 1999: S. 128.

277 Luft, Stefan 2009: Staat und Migration: Zur Stuerbarkeit von Zuwanderung und Integration. S. 36.
} 


\subsection{Phase 2 : Anwerbepolitik zu Gastarbeiter und Anwerbestopp 1955-1973}

Die zweite Phase der bundesdeutschen Migrationspolitik, die als die sogenannte europaweite „Anwerbeperiode“ oder „Gastarbeiterperiode“"278 bezeichnet wird, kann auf die Zeit zwischen 1955 bis 1973 terminiert werden. Sie war von Arbeitsmigration, also gezielten Anwerbevereinbarungen bzw. von staatlicher Organisation flankierter Anwerbung ausländischer Arbeitskräfte in süd- und südosteuropäischen Ländern geprägt. ${ }^{279}$ Als Hintergrund dieser Anwerbepolitik kann die enorme Expansion des bundesdeutschen Arbeitsmarkts im Zeichen des „Wirtschaftswunders“ und darauf „ein steigender Bedarf vorrangig an billigen Arbeitskräften im un- und angelernten Arbeitsmarktsegment der Industrie“ gesehen werden. ${ }^{280}$ Hierbei bildete zuvor das abnehmende Interesse der einheimischen Arbeitskräfte an bestimmten Beschäftigungsbereichen den Hintergrund, in denen ,schwere und schmutzige Arbeit, Akkordlohn, Schichtsystem sowie serielle Produktionsformen mit niedrigen Qualifikationsanforderungen (Fließband) besonders häufig waren“'281 und die darum für einheimische Arbeiter immer unattraktiver wurden.

Die Bundesrepublik versuchte daraufhin, ein neues migrationspolitisches Paradigma, also das sogenannte „Gastarbeitersystem nach dem Rotationsprinzip“ einzurichten: „'Gäste auf Zeit', die in ihre Herkunftsländer zurückkehren und durch neue ,Gastarbeiter' ersetzt werden.“282 Dieses Rotationskonzept gab es z. B. in den USA und anderen Einwanderungsländern nicht. ${ }^{283}$ Die Ausländerbeschäftigung sollte demnach eine vorübergehende Erscheinung sein und die Gastarbeiter sollten eine wichtige ökonomische „Ersatz- und Pufferfunktion“ in der Industrie übernehmen. ${ }^{284} \mathrm{Im}$

\footnotetext{
278 Mintzel datiert diese Periode auf 1960 bis 1973. In: Mintzel, Alf 1997: a.a.O., S. 472.; vgl. Rudolph, Hedwig 1996: Die Dynamik der Einwanderung im Nichteinwanderungsland Deutschland. In: Fassmann, Heinz / Münz, Rainer (Hrsg.) 1996: Migration in Europa: a.a.O., S. 168-173.; Meyer, Thomas 2002: Sozialstruktur und Migration - Die soziale Lage der Arbeitsmigranten in Deutschland. In: Treichler, Andreas (Hrsg.) 2002: Wohlfahrtsstaat, Einwanderung und ethnische Minderheiten: Probleme, Entwicklungen, Perspektiven. Wiesbaden, S. 70.; Treichler, Andreas 2002: Einwanderung und Europäisierung. Postnationale Arbeitsmärkte ohne wohlfahrtspolitische Verfassung?. In: Treichler, Andreas (Hrsg.) 2002: a.a.O., S. 116-117.; vgl. Birsl, Ursula 2003: Deutschland. a.a.O., S. 132-133.

279 Birsl, Ursula 2003: Deutschland. In: Gieler, Wolfgang (Hrsg.) 2003: a.a.O., S. 132.

280 Oltmer, Jochen 2010: Migration im 19. und 20. Jahrhundert. München, S. 52.; Birsl, Ursula 2005: Migration und Migrationspolitik ... a.a.O, S. 203.

281 Herbert, Ulrich 2001: Geschichte der Ausländerpolitik in Deutschland: a.a.O., S. 213.

282 Mintzel, Alf 1997: Multikulturelle Gesellschaften in Europa und Nordamerika: a.a.O., S. 472.

283 Treibel, Annette 2003: Migration in modernen Gesellschaften: Soziale Folgen von Einwanderung, Gastarbeit und Flucht. München, S. 55.

284 Oltmer, Jochen 2010: Migration im 19. und 20. Jahrhundert. München, S. 53.
} 
Dezember 1955 wurde darüber hinaus ein erstes Anwerbeabkommen zwischen der Bundesrepublik Deutschland und Italien geschlossen. ${ }^{285}$ In der Folge begann Mitte der 1950er Jahre in der Bundesrepublik die Geschichte der Arbeitsmigration. ${ }^{286}$ Dieser Wandel in der Anfangsphase der Gastarbeiterära griff jedoch noch nicht umfangreich in die deutschen Migrationssysteme bzw. migrationspolitischen Prozesse ein. Denn es gab zunächst noch die starke Zuwanderung aus der DDR, mit der der wachsende Bedarf des bundesdeutschen Arbeitsmarkts gedeckt wurde. ${ }^{287}$ Dieser Zustrom von Flüchtlingen bzw. Übersiedlern aus der DDR endete erst nach dem Bau der Berliner Mauer 1961 abrupt, sodass sich die Situation änderte.

Bereits Mitte der 1950er Jahre profitierte die westdeutsche Wirtschaft von der stetigen Zuwanderung aus der DDR bzw. aus Ostdeutschland, es stellte sich jedoch ein steigender Arbeitskräftebedarf ein. Auf bestimmten westdeutschen Arbeitsmärkten, vor allem Landwirtschaft und Baugewerbe ${ }^{288}$, wurden trotz der noch hohen Arbeitslosigkeit (ca. 7-10\% im Jahr 1955) 289 $^{28 u}$ ausländische Arbeitnehmer benötigt. Bemerkenswert ist hier, dass die bundesdeutsche Anwerbepolitik somit nicht wegen eines generellen Arbeitskräftedefizits erfolgte, sondern aufgrund der spezifischen Mangelsituation in einigen Sektoren der bundesdeutschen Wirtschaft. ${ }^{290}$ Auch zu Beginn der 1960er Jahre wurde in der Bundesrepublik die Vollbeschäftigung auf dem Arbeitsmarkt erreicht. So war 1960 zum ersten Mal seit 1945 die Anzahl der offenen Stellen höher als die Zahl der Arbeitslosen. ${ }^{291}$ Da zudem mit der Mauer 1961 der Zustrom von Übersiedlern und Flüchtlingen aus der DDR ausblieb, wurden weitgehend Anwerbeabkommen zur Rekrutierung ausländischer Arbeitskräfte für den bundesdeutschen Arbeitsmarkt verstärkt, sodass seitdem die Gastarbeiter den entstehenden Arbeitskräftemangel kompensierten. ${ }^{292}$ Erst mit den 1960er Jahren begann dann die eigentliche Gastarbeiterperiode. Die Bundesregierung schloss weitere Anwerbeabkommen mit Spanien und Griechenland (1960), der Türkei (1961), Marokko (1963), Portugal (1964),

${ }^{285}$ Schulte, Axel / Treichler, Andreas 2010: Integration und Antidiskriminierung: a.a.O., S. 20.

${ }^{286}$ Meyer, Thomas 2002: Sozialstruktur und Migration - Die soziale Lage der Arbeitsmigranten in Deutschland. In: Treichler, Andreas (Hrsg.) 2002: Wohlfahrtsstaat, Einwanderung und ethnische Minderheiten: Probleme, Entwicklungen, Perspektiven. Wiesbaden, S. 71.

${ }^{287}$ Bade, Klaus J. / Emmer, Pieter C. / Lucassen, Leo / Oltmer, Jochen (Hrsg.) 2008: Enzyklopädie: Migration in Europa: Vom 17. Jahrhundert bis zur Gegenwart. Paderborn, S. 159.

${ }^{288}$ Mintzel, Alf 1997: Multikulturelle Gesellschaften in Europa und Nordamerika: a.a.O., S. 470.

289 Santel, Bernhard 1995: Migration in und nach Europa: Erfahrungen. Strukturen. Politik. S. 57.

${ }^{290}$ Santel, Bernhard 1995: Migration in und nach Europa: Erfahrungen. Strukturen. Politik. S. 57.

${ }^{291}$ Münz, Rainer / Seifert, Wolfgang / Ulrich, Ralf 1997: a.a.O., S. 36.

292 Treichler, Andreas 2002: Einwanderung und Europäisierung. Postnationale Arbeitsmärkte ohne wohlfahrtspolitische Verfassung?. In: Treichler, Andreas (Hrsg.) 2002: a.a.O., S. 116.; Herbert, Ulrich 2001: Geschichte der Ausländerpolitik in Deutschland: a.a.O., S. 208. 
Tunesien (1965), Jugoslawien (1968) und zuletzt 1970 mit Südkorea (siehe Abbildung 23). ${ }^{293}$ Die Rekrutierungen aus Marokko und Tunesien blieben allerdings für den bundesdeutschen Arbeitsmarkt relativ wirkungslos. ${ }^{294}$ Die höchsten Ausländerquoten in dieser Gastarbeiterperiode waren z. B. 1963 im Baugewerbe, im Bergbau sowie in der Eisen- und Metallindustrie zu verzeichnen. ${ }^{295}$

\section{Abbildung 23 : Anwerbeabkommen der BRD}

\begin{tabular}{|l|l|}
\hline 1955 & Italien \\
\hline 1960 & Spanien, Griechenland \\
\hline 1961 & Türkei \\
\hline 1963 & Marokko \\
\hline 1964 & Portugal \\
\hline 1965 & Tunesien \\
\hline 1968 & Jugoslawien \\
\hline 1970 & Südkorea \\
\hline
\end{tabular}

Mit den Anwerbeabkommen trat in zunehmendem Maße ein demographischer Wandel auf: Es gab 1955 in der Bundesrepublik nur rund $79.000(0,4 \%)$ ausländische Arbeitskräfte, während es 1961 nach dem Bau der Berliner Mauer etwa 549.000 (2,5\%) waren. Die Zahl der Arbeitsmigranten stieg in der Folgezeit rasch an und erreichte 1973 mit 2,6 Millionen (11,9\%) ihren bisherigen Höhepunkt. ${ }^{296}$ Die erhebliche Gastarbeiterzuwanderung aus europäischen und außereuropäischen Staaten führte in der Summe zum Anstieg der Ausländerquote von 1,2 \% (1961) auf 6,4\% (1973). ${ }^{297}$ Insgesamt gab es zwischen 1955 und 197314 Millionen Ausländer in der Bundesrepublik, wovon im gleichen Zeitraum 11 Mio. zurückkehrten. ${ }^{298}$ In diesem Zeitraum bildeten Arbeitsmigranten aus der Türkei (605.000), aus Jugoslawien (535.000) und aus Italien (450.000) die größten Migrantengruppen. ${ }^{299}$

293 Mintzel, Alf 1997: Multikulturelle Gesellschaften in Europa und Nordamerika: a.a.O., S. 471.; Schmalz-Jacobsen, C. / Hinte, H. / Tsapanos, G., 1993: Einwanderung - und dann? München, S. 28.; Herbert, Ulrich 2001: S. 208; Treibel, Annette 2003: Migration in modernen Gesellschaften: S. 56.

294 Treichler, Andreas 2002: Einwanderung und Europäisierung. Postnationale Arbeitsmärkte ohne wohlfahrtspolitische Verfassung?. In: Treichler, Andreas (Hrsg.) 2002: a.a.O., S. 116.

295 Herbert, Ulrich 2001: Geschichte der Ausländerpolitik in Deutschland: a.a.O., S. 213.

296 Herbert, Ulrich 2001: Geschichte der Ausländerpolitik in Deutschland: a.a.O., S. 198-199.; vgl. auch Schulte, Axel / Treichler, Andreas 2010: Integration und Antidiskriminierung: a.a.O., S. 21.

297 Herbert, Ulrich 2001: Geschichte der Ausländerpolitik in Deutschland:a.a.O., S. 198-199 (Tabelle 19.).

298 Meyer, Thomas 2002: Sozialstruktur und Migration - a.a.O., S. 71.

299 Münz, Rainer / Seifert, Wolfgang / Ulrich, Ralf 1997: a.a.O., S. 37. 
Der starke Zuwachs der Gastarbeiterbeschäftigung in der bundesdeutschen Hochkonjunktur bzw. Vollbeschäftigung wurde (u. a.) zum einen durch die Grenzschließung der DDR im Jahre 1961 verursacht, die hiernach rasch zu einer Verschärfung der bundesdeutschen Arbeitsmarktlage führte. ${ }^{300}$ Zum anderen war eine sinkende Zahl der deutschen Erwerbspersonen seit 1962 zu beobachten. ${ }^{301}$ Die bundesdeutschen Gastarbeiter in der Zeit der Hochkonjunktur und Vollbeschäftigung wurden insofern als eine wichtige Arbeitskraftreserve betrachtet, wobei diese Menschen nur als temporäre Arbeitskräfte und nicht als Einwanderer kamen. Daher entstanden in dieser Zeit keine größeren sozialen Probleme. ${ }^{302}$ Allerdings wurde eine Zunahme der Aufstiegschancen für deutsche Arbeitnehmer durch die „Unterschichtung“ der Gastarbeiter ermöglicht. ${ }^{303}$

Ähnlich den Gastarbeitern in der BRD behandelte später auch die DDR in geringem Umfang die Ausländerbeschäftigung auf der Grundlage von Regierungsabkommen. In der DDR wurden ab den 1960er Jahren zur Verringerung des Arbeitskräftemangels Vertragsarbeiter, „die ausländischen Werktätigen“, aus staatssozialistischen Ländern Mitteleuropas, später auch aus Vietnam, Mosambik und Kuba rekrutiert. ${ }^{304}$ Zugleich stellten sich hier doch Einwanderungsprobleme ein, aber nur im Falle der seltenen Eheschließungen zwischen DDR-Bürger/-innen und ausländischen Werktätigen. ${ }^{305}$ Familienzuwanderung war in dem strengen Rotationssystem der DDR nicht vorgesehen, in dem die ausländischen Arbeitsmigranten nach Beendigung ihrer Arbeitsverträge in ihre Heimatländer unbedingt zurückkehren mussten. ${ }^{306}$

Es ging somit der BRD und auch der DDR bei der Gastarbeiterbeschäftigung in bestimmten Bereichen eher um arbeitsmarktpolitische Fragen. In Anbetracht dieses großen Vorteils der Ausländer für die deutsche Volkswirtschaft wurde in der BRD ,das Ausländergesetz vom April 1965“ eingeführt, das vor allem ein Aufenthalts- und Arbeitserlaubnisrecht für Ausländer aus Nicht-EWG-Staaten ermöglichte. ${ }^{307}$ Demgegenüber sollten die Gastarbeiter aus EWG-Staaten, z. B. Italiener und Spanier den deutschen Arbeitnehmern arbeitsrechtlich gleichgestellt werden. Eine ständige

\footnotetext{
300 Mintzel, Alf 1997: Multikulturelle Gesellschaften in Europa und Nordamerika: a.a.O., S. 471.

301 Herbert, Ulrich 2001: Geschichte der Ausländerpolitik in Deutschland: a.a.O., S. 208.

302 Mintzel, Alf 1997: Multikulturelle Gesellschaften in Europa und Nordamerika: a.a.O., S. 471.

303 Herbert, Ulrich 2001: Geschichte der Ausländerpolitik in Deutschland: a.a.O., S. 225.

304 Bade, Klaus J. / Emmer, Pieter C. / Lucassen, Leo / Oltmer, Jochen 2008: Enzyklopädie: Migration in Europa: a.a.O., S. 161.; vgl. Münz, Rainer / Seifert, Wolfgang / Ulrich, Ralf 1997: a.a.O., S. 38.

305 Bade, Klaus J. / Emmer, Pieter C. / Lucassen, Leo / Oltmer, Jochen 2008: Enzyklopädie:a.a.O., S. 162.

306 Currle, Edda 2004: Migration in Europa - Daten und Hintergründe. Stuttgart, S. 19.

307 Herbert, Ulrich 2001: Geschichte der Ausländerpolitik in Deutschland: a.a.O., S. 211.
} 
Niederlassung der Gastarbeiter in der BRD war allerdings in dieser Phase nicht beabsichtigt, sondern nur ein vorübergehender Aufenthalt. Die Mehrheit der Gastarbeiter bekam zunächst nach dem Rotationskonzept nur für ein Jahr das Aufenthaltsrecht, wobei ihr Leben wesentlich von der Arbeit bzw. dem jeweiligen Arbeitgeber in Deutschland geprägt war. ${ }^{308}$ Das Ausländergesetz von 1965 verankerte auch das Asylrecht. ${ }^{309}$ Vorrangig aber war das Gesetz ein möglichst effektives Instrument, mit dem die BRD tatsächlich eine Kontrolle der Bevölkerung und eine Liberalisierung der Nachkriegszeit erzielen wollte. ${ }^{310}$ Hinzu schuf die BRD weitere politische Paradigmen. „Die Einigung Europas und die wirtschaftliche Liberalisierung“ stand im Zentrum, was auch zur Europäisierug der Prioritäten führte: „mit der Zustimmung zu den europäischen Freizügigkeitsregelungen ordnete die Bundesregierung staatliche Kontrollinteressen der europäischen Integration unter.“311

Während diese unterschiedlichen politischen Paradigmen koexistierten, stieß die Hochkonjunktur auf Grenzen. Als im Jahr 1966/67 die erste Wirtschaftsrezession einsetzte, wurde kurzfristig der Gastarbeiterboom (1970-1973) durch die steigende Zahl der Arbeitslosen abgebremst. ${ }^{312}$ Die Wirtschaft erholte sich jedoch rasch und setzte ihren Wachstumspfad fort. Eine markante Zäsur in dieser Entwicklung stellte jedoch die zweite Wirtschaftsrezession dar, die aufgrund der sogenannten ,Ölpreiskrise' stattfand. Wieder stiegen die Arbeitslosenzahlen und zugleich wurden viele Gastarbeiter erwerbslos. So stellten sie im Jahr 1973 mit 273.000 1,2\% der offiziell registrierten Erwerbslosen. Dementsprechend verkündete am 23. November 1973 die Bundesregierung einen europaweiten ,Anwerbestopp' für Gastarbeiter. ${ }^{313}$ Infolge der Ölkrise und steigender Arbeitslosigkeit endete mit diesem Anwerbestopp die zweite Phase der sogenannten Gastarbeiterperiode bzw. Anwerbepolitik. ${ }^{314}$

Der Anwerbestopp von 1973 hatte zwei wesentliche Konsequenzen: ${ }^{315}$ 1. Das ,gate of

308 Herbert, Ulrich 2001: Geschichte der Ausländerpolitik in Deutschland: a.a.O., S. 211-212.

309 Nuscheler, Franz 2004: Internationale Migration: Flucht und Asyl. Wiesbaden, S. 144.

310 Schönwälder, Karen 2006: Politikwandel in der (bundes-) deutschen Migrationspolitik. In: Davy, Ulrike / Weber, Albrecht (Hrsg.) 2006: Paradigmenwechsel in Einwanderungsfragen?: a.a.O., S. 11.

311 Schönwälder, Karen 2006: Politikwandel in der (bundes-) deutschen Migrationspolitik. a.a.O., S. 12.

312 Mintzel, Alf 1997: Multikulturelle Gesellschaften in Europa und Nordamerika: a.a.O., S. 471.

313 Schulte, Axel / Treichler, Andreas 2010: Integration und Antidiskriminierung: a.a.O., S. 22 .; vgl. Treichler, Andreas 2002: Einwanderung und Europäisierung. Postnationale Arbeitsmärkte ohne wohlfahrtspolitische Verfassung?. In: Treichler, Andreas (Hrsg.) 2002: a.a.O., S. 117.

314 Mintzel, Alf 1997: Multikulturelle Gesellschaften in Europa und Nordamerika: a.a.O., S. 472.

315 Birsl, Ursula 2003: Deutschland. In: Gieler, Wolfgang (Hrsg.) 2003: a.a.O., S. 133.; vgl. Mintzel, Alf 1997: Multikulturelle Gesellschaften in Europa und Nordamerika: a.a.O., S. 472.; vgl. auch Currle, Edda 2004: Migration in Europa - Daten und Hintergründe. Stuttgart, S. 19. 
entry" für Gastarbeiter wurde geschlossen. 2. Die Bundesrepublik Deutschland hat sich nach dem Anwerbestopp definitiv zu einem Einwanderungsland gewandelt. Hintergrund war, dass Gastarbeiter aus Nicht-EG-Staaten bzw. Drittstaaten einem „Wiedereinreiseverbot ${ }^{\star 316}$ unterlagen, wenn sie die Bundesrepublik verlassen hatten. Das Wiedereinreiseverbot traf vor allem Gastarbeiter aus der Türkei und dem ehemaligen Jugoslawien, während es für die Gastarbeiter aus EG-Staaten (Italien, Griechenland, Spanien und Portugal), die inzwischen Mitglieder der damaligen Europäischen Gemeinschaft (EG) waren und zugleich die grenzüberschreitenden Freizügigkeitsrechte der ,Marktbürger, ${ }^{317}$ besaßen, nicht oder nur zeitweilig galt. Somit wurde auch zum ersten Mal deutlich, dass das unterstellte ,Rotationsprinzip' des Gastarbeitersystems tatsächlich nicht funktionieren konnte: Im Durchschnitt war die Aufenthaltsdauer der Gastarbeiter angestiegen und die Gastarbeiter begannen, ihre Familienangehörige nachzuholen. ${ }^{318}$ In der Folge dominierte der verstärkte Familiennachzug aus den sogenannten Nicht-EG-Staaten und daraufhin die dauerhafte Einwanderung in die Bundesrepublik. Diesem Phänomen wurde ab 1980 mit einem „Rückkehrhilfegesetz“ entgegengesteuert, was mit einer „Wiedereinreiseoption“ für die Türkei ergänzt wurde. ${ }^{319}$

Insgesamt zeigt sich, dass die Anwerbepolitik bzw. das deutsche Gastarbeitersystem nach dem Rotationskonzept ,auf Annahmen stetigen wirtschaftlichen Wachstums mit entsprechendem Arbeitskräftebedarf einerseits und einem nationalstaatlich regulier- und kontrollierbaren Arbeitsmarkt andererseits" basierte. ${ }^{320}$ Daraus ist feststellbar, dass die Anwerbepolitik bzw. Gastarbeiterpolitik in der zweiten Phase (1955-1973) einerseits zu einem umfassenden Wandel des ,policy paradigm“, also der „Ideen und Prinzipien“321 des migrationspolitischen Handelns, führte, andererseits aber zu keinem langfristigen Politikwechsel bezüglich der Einwanderungsprozesse, was vor allem durch den Anwerbestopp 1973 deutlich wurde.

316 Vgl. hierzu Birsl, Ursula 2005: Migration und Migrationspolitik ... a.a.O., S. 81-82. u. 204 f.

317 Santel, Bernhard 1995: Migration in und nach Europa: Erfahrungen, Strukturen, Politik. S. 63.; vgl. auch Münz, Rainer / Seifert, Wolfgang / Ulrich, Ralf 1997: Zuwanderung nach Deutschland: Strukturen, Wirkungen, Perspektiven. Frankfurt a.M., S. 41.

318 Mintzel, Alf 1997: Multikulturelle Gesellschaften in Europa und Nordamerika: S. 472.

319 Birsl, Ursula 2005: Migration und Migrationspolitik ... a.a.O., S. 204-205.

320 Treichler, Andreas 2002: Einwanderung und Europäisierung. Postnationale Arbeitsmärkte ohne wohlfahrtspolitische Verfassung?. In: Treichler, Andreas (Hrsg.) 2002: a.a.O., S. 117.; vgl. auch Faist, Thomas 1998: Immigration, Integration und Wohlfahrtsstaaten. Die Bundesrepublik Deutschland in vergleichender Perspektive. In: Bommes, Michael / Halfmann, Jost (Hrsg.) 1998: Migration in nationalen Wohlfahrtsstaaten: Theoretische und vergleichende Untersuchungen. S. 147-170.

321 Schönwälder, Karen 2006: Politikwandel in der (bundes-) deutschen Migrationspolitik. In: Davy, Ulrike / Weber, Albrecht (Hrsg.) 2006: Paradigmenwechsel in Einwanderungsfragen?: a.a.O., S. 12 f. 


\subsection{Phase 3 : Konsolidierung und Eingliederungspolitik 1974-1980}

Die dritte Phase der bundesdeutschen Migrationspolitik (1974-1980) war von den Folgen des Anwerbestopps 1973 geprägt und kann als Phase einer „Konsolidierung der Ausländerbeschäftigung“ und auch einer ersten „Eingliederungspolitik für die ausländischen Familien“ bezeichnet werden. ${ }^{322}$ Die politischen Entscheidungen dieser Konsolidierungs- und Eingliederungsphase lösten einen Prozess der Niederlassung ausländischer Arbeitskräfte und ihrer Familien in der Bundesrepublik aus. Die migrationspolitische Leitlinie der Bundesrepublik seit 1974 hieß insofern: „Eingliederung ja - Einwanderung nein.“ ${ }^{323}$ Darüber hinaus verfolgte die Migrationspolitik der Bundesregierung in dieser Phase eine deutliche Doppelstrategie: Diese umfasste zum einen die Begrenzung des Zuzuges von weiteren Ausländern und zum anderen verstärkte Anpassungsmaßnahmen der bereits hier lebenden Ausländer. ${ }^{324}$

In Verbindung mit der Stichtagsregelung von 1974 setzte die Bundesregierung u. a. zwei migrationspolitische Maßnahmen durch, die sich jedoch durchaus widersprüchlich gestalteten. ${ }^{325}$ So wurden einerseits mit der Änderung des Kindergeldgesetzes vom 1. Januar 1975 höhere Kindergeldsätze auch für Ausländerkinder gestattet. Das galt allerdings nur für diejenigen, die nach dem „Territorialitätsprinzip“ in der Bundesrepublik lebten. ${ }^{326}$ Dies führte indes zum starken Anstieg der in die BRD nachgeholten Ausländerkinder. Darüber hinaus sah die Arbeitserlaubnisverordnung vor, dass ausländische Arbeitskräfte, die nach 1974 in die BRD eingereist waren und ihren Arbeitsplatz verloren hatten, hier keine Arbeitsgenehmigung mehr erhielten. ${ }^{327}$ Diese Regelung wurde 1980/1981 durch eine Wartezeitregelung ersetzt: Es galten nunmehr für Familienangehörige Wartezeiten (Kinder zwei, Ehegatten vier Jahre) vor Erteilung einer Arbeitserlaubnis. ${ }^{328}$ Die Arbeitsmigration wurde also in zunehmendem Maße erschwert. Als eine weitere politische Maßnahme führte andererseits die Regierung 1975 eine

${ }^{322}$ Meier-Braun, Karl-Heinz 2007: Der lange Weg ins Einwanderungsland Deutschland. In: Frech, Siegfried / Meier-Braun, Karl-Heinz (Hrsg.) 2007: Die offene Gesellschaft: Zuwanderung und Integration. Baden-Württemberg, S. 21-39, hier S. 23.; Münscher, Alice 1979: Ausländische Familien in der Bundesrepublik Deutschland: Familiennachzug und generatives Verhalten. München, S. 36.

${ }^{323}$ Herbert, Ulrich 2001: Geschichte der Ausländerpolitik in Deutschland: a.a.O., S. 238.

${ }^{324}$ Herbert, Ulrich 2001: Geschichte der Ausländerpolitik in Deutschland: a.a.O., S. 244.; Treibel, Annette 2003: Migration in modernen Gesellschaften: a.a.O., S. 59.; Currle, Edda 2004: S. 20.

${ }^{325}$ Treibel, Annette 2003: Migration in modernen Gesellschaften: a.a.O., S. $59 \mathrm{f}$.

326 Luft, Stefan 2009: Staat und Migration: Zur Stuerbarkeit von Zuwanderung und Integration. S. 59.; Herbert, Ulrich 2001: Geschichte der Ausländerpolitik in Deutschland: a.a.O., S. 244.

327 Luft, Stefan 2009: Staat und Migration: Zur Stuerbarkeit von Zuwanderung und Integration. S. 60.

${ }^{328}$ Herbert, Ulrich 2001: Geschichte der Ausländerpolitik in Deutschland: a.a.O., S. 244. 
„Zuzugssperre (Sperrgebietserlass)“ für Ausländer ein, um den Problemen der regionalen Konzentration der Ausländer entgegenzusteuern bzw. „überlastete Siedlungsgebiete vor der Ghettobildung“ zu bewahren. ${ }^{329}$ Diese Steuerungsmaßnahme wurde jedoch aufgrund der EG-Vereinbarungen von 1977 wieder aufgehoben. ${ }^{330}$

Um die an diesen beiden Beispielen erkennbare negative Entwicklung bzw. Konzeptionslosigkeit der Migrationspolitik zu bewältigen, veranlasste die damalige SPD/FDP-Koalitionsbundesregierung unter Bundeskanzler Helmut Schmidt 1978 als eine der wichtigsten institutionellen Neuerungen die Einführung des Amtes eines Ausländerbeauftragten. Zum ersten Ausländerbeauftragten der Bundesregierung wurde der ehemalige Ministerpräsident von Nordrhein-Westfalen Heinz Kühn (SPD) ernannt. $^{331}$ Kühn legte im September 1979 sein Memorandum über „Stand und Weiterentwicklung der Integration der ausländischen Arbeitnehmer und ihrer Familien in der Bundesrepublik Deutschland“ ${ }^{332}$ vor. Die zentrale Forderung des „KühnMemorandums“ war eine konsequente Integrationspolitik und damit eine Abkehr von der arbeitsmarktpolitischen Priorität: „Anerkennung der faktischen Einwanderung bei gleichzeitigem Ausschluß neuer Zuwanderung; verstärkte Bemühungen um Integration der ausländischen Kinder und Jugendlichen, vor allem im schulischen Bereich; keine ,segregierenden' Maßnahmen - wie etwa getrennter Unterricht nach Nationalitäten; Ausbau des vollen Rechtsanspruchs der ausländischen Jugendlichen auf Zugang zu Arbeits- und Ausbildungsplätzen; Optionsrecht der in der Bundesrepublik geborenen und aufgewachsenen Jugendlichen auf Einbürgerung; Gewährung des kommunalen Wahlrechts für Ausländer nach längerem Aufenthalt.، ‘333

So verlangte Kühn bereits 1979 in seinem Memorandum ,endlich die faktisch bestehende Einwanderungssituation von Gastarbeitern der nun schon zweiten Generation auch politisch zu akzeptieren.“'334 Das Kühn-Memorandum bewirkte zwar

${ }^{329}$ Mahnig, Hans 2001: „Ist Deutschland wirklich anders?“: Die deutsche Integrationspolitik im europäischen Vergleich. In: Currle, Edda / Wunderlich, Tanja (Hrsg.) 2001: Deutschland - ein Einwanderungsland? Rückblick, Bilanz und neue Fragen. Stuttgart, S. 176.

${ }^{330}$ Herbert, Ulrich 2001: Geschichte der Ausländerpolitik in Deutschland: a.a.O., S. 244.

331 Mahnig, Hans 2001: „Ist Deutschland wirklich anders?“: a.a.O., S. 176.; vgl. auch Geiß, Bernd 2001: Die Ausländerbeauftragten der Bundesregierung in der ausländerpolitischen Diskussion. In: Currle, Edda / Wunderlich, Tanja (Hrsg.) 2001: S. 128.; Herbert, Ulrich 2001: S. 245.

332 Treibel, Annette 2003: Migration in modernen Gesellschaften: a.a.O., S. 61.; Herbert, Ulrich 2001: S. 245.; Mahnig, Hans 2001: „Ist Deutschland wirklich anders?“: a.a.O., S. 177.

333 Herbert, Ulrich 2001: Geschichte der Ausländerpolitik in Deutschland: a.a.O., S. 245 f.

334 Butterwegge, Carolin 2009: Fit für die Globalisierung? Deutschland auf dem Weg zur Modernisierung seiner Migrations- und Integrationspolitik. In: Butterwegge, Christoph / Hentges, Gudrun (Hrsg.) 2009: Zuwanderung im Zeichen der Globalisierung: a.a.O., S. 139. 
eine Wende in der politischen Debatte um eine Neuorientierung der Migrationspolitik und stieß auch eine relativ breite Debatte zum Thema Integration an, wurde aber im Beschluss der Bundesregierung von 1980 zur „Weiterentwicklung der Ausländerpolitik“ nicht berücksichtigt. ${ }^{335}$ Vor allem das kommunale Wahlrecht für Ausländer und die Einbürgerungserleichterungen für ausländische Jugendliche wurden abgelehnt. ${ }^{336}$ Die SPD/FDP-Koalitionsbundesregierung hielt stattdessen an einer durch Integrationskonzepte, also durch Konzepte zur „sozialen Integration auf Zeit“, ergänzten Migrationspolitik bzw. Arbeitsmarktpolitik fest. ${ }^{337}$

Inzwischen stieg der Anteil der ausländischen Bevölkerung an: 1979 war die Zahl der gesamten in der BRD lebenden Ausländer auf 4,1 Mio. angewachsen, während die ausländischen Beschäftigten jedoch auf 1,9 Mio. zurückgegangen waren. ${ }^{338}$ Ende der siebziger Jahre hatte sich somit eine große Anzahl ausländischer Personen in der BRD niedergelassen. Damit wurde Integration im migrationspolitischen Diskurs zu einer primären Zielsetzung. Staatliche Institutionen verstanden unter Integration vor allem „die Förderung der Eingliederung der ausländischen Familien durch politischadministrative Maßnahmen, z. B. die Maßnahmen zur beruflichen und sozialen Eingliederung (MBSE).“339 Mit diesem Verständnis führte die Bundesregierung seit 1977 erstmals „Sprachkurse“ für arbeitslose ausländische Jugendliche zur Förderung der beruflichen Integration ein. Diese Sprachkurse wurden 1980 zu Integrationsprogrammen weiterentwickelt, den sog. MBSE. ${ }^{340}$

Betrachtet man nun zum Schluss die Migrationspolitik in der dritten Phase (1974-1980), zeigt sich, dass sich in der Phase ein partieller Politikwandel vollzog. In diesem wurden zwar wichtige migrationspolitische Entscheidungen bezüglich der Institutionalisierung (z. B. Bundesausländerbeauftragte und Sprachkurse für Ausländer) getroffen. Allerdings fand kein Politikwechsel zur Anerkennung der faktischen Einwanderungssituation statt, wie sich insbesondere durch das Scheitern des Kühn-Memorandums zeigte.

\footnotetext{
335 Mahnig, Hans 2001: „Ist Deutschland wirklich anders?“: a.a.O., S. 177.

336 Meier-Braun, Karl-Heinz 2007: Der lange Weg ins Einwanderungsland Deutschland. In: Frech, Siegfried / Meier-Braun, Karl-Heinz (Hrsg.) 2007: Die offene Gesellschaft: a.a.O., S. 24.

337 Deutscher Bundestag 2000: Drucksachen: BT-Drs. 14/4357: Unterrichtung durch die Bundesregierung: Sechster Familienbericht: Familien ausländischer Herkunft in Deutschland: Leistungen-Belastungen-Herausforderungen und Stellungnahme der Bundesregierung. S. 40. Online verfügbar unter: www.bundestag.de; vgl. auch Bade, Klaus. J. 1990: Ausländer, Aussiedler, Asyl in der Bundesrepublik Deutschland. Niedersächsische Landeszentrale für politische Bildung, S. 15.

338 Treibel, Annette 2003: Migration in modernen Gesellschaften: a.a.O., S. 60.

339 Treibel, Annette 2003: Migration in modernen Gesellschaften: S. 60 f.; Mahnig, Hans 2001: S. 176.

340 Mahnig, Hans 2001: „Ist Deutschland wirklich anders?“: a.a.O., S. 177.
} 


\subsection{Phase 4 : Begrenzungspolitik als Wende der Migrationspolitik 1981-1990}

Die vierte Phase der deutschen Migrationspolitik (1981-1990) lässt sich unter das Motto „Wende in der Ausländerpolitik“ stellen und war durch einen Politikwandel von dem kurzen Wettlauf um Integrationskonzepte 1979 hin zum Wettlauf um Begrenzungs- und Abwehrmaßnahmen seit 1981 bestimmt. $^{341}$

Unter diesem Motto entwickelte die damalige SPD/FDP-Bundesregierung im Dezember 1981 Empfehlungen an die Bundesländer für eine „Begrenzungspolitik“ und verschärfte 1981/1982 ihre Politik zur Zuzugsbegrenzung prägend. ${ }^{342}$ Als „Sofort-Regelung“ der Begrenzungsmaßnahmen ging es vor allem um die Verringerung des Familiennachzugs, konkret um die Senkung des Nachzugsalters für Kinder von 18 auf 16 Jahre und um die Beschränkung des Ehegattennachzugs. ${ }^{343}$ Die sozial-liberale Bundesregierung unter Bundeskanzler Helmut Schmidt kündigte sich bereits dementsprechend an: „Es besteht Einigkeit, dass die BRD keine Einwanderungslandschaft ist und auch nicht werden soll. Das Kabinett ist sich einig, dass für alle Ausländer außerhalb der EG ein weiterer Zuzug unter Ausschöpfung aller rechtlichen Möglichkeiten verhindert werden soll. [...].“344

Noch im Juli 1982 verabschiedete das Kabinett Schmidt Begrenzungsmaßnahmen zur Rückkehrförderung $^{345}$, in denen mehrere Bundesländer im Bundesrat schon im März 1982 den Entwurf eines Ausländerkonsolidierungsgesetzes („Konsolidierung des Zuzugs und Förderung der Rückkehrbereitschaft von Ausländern“) vorlegten. ${ }^{346}$ Diese Rückkehrmaßnahmen wurden nach dem Regierungswechsel in der CDU/CSU/FDPKoalition unter Bundeskanzler Helmut Kohl weiter diskutiert, da eine zunehmende Ausländerfeindlichkeit existierte. Insofern nahm die Migrationspolitik in Beginn der Regierungszeit des Kabinetts Kohl einen prominenten Platz ein. In der Regierungserklärung am 13. Oktober 1982 verkündete Bundeskanzler Helmut Kohl,

\footnotetext{
341 Meier-Braun, Karl-Heinz 2007: Der lange Weg ins Einwanderungsland Deutschland. In: Frech, Siegfried / Meier-Braun, Karl-Heinz (Hrsg.) 2007: Die offene Gesellschaft: Zuwanderung und Integration. Baden-Württemberg, S. 21-39, hier S. 24.; vgl. Deutscher Bundestag 2000: Drucksachen: BT-Drs. 14/4357: a.a.O., S. 40 (www.bundestag.de).

342 Deutscher Bundestag 2000: Drucksachen: BT-Drs. 14/4357: a.a.O., S. 40 (www.bundestag.de).; Mintzel, Alf 1997: Multikulturelle Gesellschaften in Europa und Nordamerika: a.a.O., S. 473.

343 Meier-Braun, Karl-Heinz 2007: Der lange Weg ins Einwanderungsland Deutschland. In: Frech, Siegfried / Meier-Braun, Karl-Heinz (Hrsg.) 2007: Die offene Gesellschaft: a.a.O., S. 25.

344 Zitiert in Mintzel, Alf 1997: Multikulturelle Gesellschaften in Europa und Nordamerika: a.a.O., S. 473.

345 Deutscher Bundestag 2000: Drucksachen: BT-Drs. 14/4357: a.a.O., S. 40 (www.bundestag.de).

346 Treibel, Annette 2003: Migration in modernen Gesellschaften: a.a.O., S. 63.
} 
dass die Ausländerpolitik bzw. Migrationspolitik als gleichwertiger Gestaltungsbereich neben Wirtschafts-, Sozial-, Außen- und Sicherheitspolitik seines „Dringlichkeitsprogramms“, vor allem einen Ausgangspunkt enthielte: „Deutschland ist kein Einwanderungsland““ ${ }^{347}$ Daher war und blieb die Migrationspolitik der Regierung Kohl in den 1980er Jahren an drei Zielen orientiert: „1. Die ,Integration' der hier lebenden Ausländer. 2. Die Förderung der Rückkehrbereitschaft. 3. Die Verhinderung eines weiteren Zuzugs. “348

Erst nach der Bundestagswahl vom März 1983 beschloss dann schließlich im Juni 1983 die neue Bundesregierung Kohl einen „Gesetzentwurf zur befristeten Förderung der Rückkehrbereitschaft von Ausländern“, der durch eine zeitliche begrenzte finanzielle Sonderregelung als Rückkehranreiz insbesondere an türkische ArbeitnehmerInnen adressiert war, und berief sich auf jenes vom ehemaligen sozial-liberalen Kabinett Schmidt bereits verabschiedete Maßnahmenbündel. ${ }^{349}$ Mittlerweile wurde das nur für ein halbes Jahr in Kraft gesetzte „Rückkehrförderungsgesetz“ oder „Rückkehrhilfegesetz“ zwar als Erfolg in der Rückkehrförderung dargestellt, aber mit einer kritischen Bewertung wieder außer Kraft gesetzt. Vor allem das Rückkehrförderungsgesetz sah zuvor eine „Spar- und Sanierungsmaßnahme für die Rentenversicherung auf Kosten der ausländischen Arbeitnehmer“ vor, sowie zugleich beim Arbeitslosen- und Kurzarbeitergeld und beim Kindergeld. ${ }^{350}$ Im Rückblick galt die Rückkehrförderung - die sog. „Rückkehrhilfe“ - sogar eher als eine „symbolische Maßnahme“ bzw. „Symbolpolitik“ für die Beruhigung einer durch die Konzeptions- und Perspektivlosigkeit in der Migrationspolitik ausgelösten Missstimmung. ${ }^{351}$ Tatsächlich war die ursprüngliche Zielsetzung der Bundesregierung, die Ausländerzahl insbesondere der Türken durch diese Rückkehrmaßnahme erheblich zu senken, nicht erfolgreich. ${ }^{352}$

Demgegenüber entwickelte die Bundesregierung neue Strategien, den direkten Zugang zum staatlichen Territorium der Bundesrepublik Deutschland zu steuern. ${ }^{353}$ Bereits seit

\footnotetext{
347 Herbert, Ulrich 2001: Geschichte der Ausländerpolitik in Deutschland: a.a.O., S. 249-250.

348 Herbert, Ulrich 2001: Geschichte der Ausländerpolitik in Deutschland: a.a.O., S. 250.

349 Deutscher Bundestag 2000: Drucksachen: BT-Drs. 14/4357: S. 40.; Herbert, Ulrich 2001: S. 253 f.; Treibel, Annette 2003: Migration in modernen Gesellschaften: a.a.O., S. 63.

350 Meier-Braun, Karl-Heinz 2007: Der lange Weg ins Einwanderungsland Deutschland. In: Frech, Siegfried / Meier-Braun, Karl-Heinz (Hrsg.) 2007: Die offene Gesellschaft: a.a.O., S. 27.; Deutscher Bundestag 2000: Drucksachen: BT-Drs. 14/4357: S. 40.

351 Meier-Braun, Karl-Heinz 2007: Der lange Weg ins Einwanderungsland Deutschland. a.a.O., S. 27.; Deutscher Bundestag 2000: Drucksachen: BT-Drs. 14/4357: S. 40.; Herbert, Ulrich 2001: S. 256.

352 Herbert, Ulrich 2001: Geschichte der Ausländerpolitik in Deutschland: a.a.O., S. 256.

353 Birsl, Ursula 2003: Deutschland. In: Gieler, Wolfgang (Hrsg.) 2003: Handbuch der Ausländer- und Zuwanderungspolitik von Afghanistan bis Zypern. Münster, S. 139.
} 
den frühen 1980er Jahren begann sich die Migrationspolitik in der Bundesrepublik zunehmend dadurch zu wandeln, dass in Folge der Vertiefung und Erweiterung der Europäischen Gemeinschaft (EG) zur Europäischen Union (EU) ein Teil der ehemaligen Anwerbeausländer schrittweise zu europäischen Bürgern wurde. Demgemäß wurden die Ausländer nun in zwei Kategorien unterschieden, in „EU-Ausländer und Nicht-EUAusländer.“ ${ }^{354}$ Parallel dazu garantierten die EU-Verträge den EU-Ausländern wirtschaftliche und soziale Gleichstellung. Außerdem wurde ihnen durch den EUGerichtshof Rechtsschutz (z. B. Freizügigkeitsrecht) geboten. Somit wurde die Stellung der EU-Bürger durch die Stabilität und Legitimität der EU in Deutschland verbessert. ${ }^{355}$

Darüber hinaus gestattete die Bundesregierung insbesondere in Anbetracht der vertraglich garantierten Freizügigkeit „Sichtvermerke“, also „Visa für Migranten bestimmter Länder“. ${ }^{356}$ Diese Sichtvermerke zeichnen sich vornehmlich dadurch aus, dass sie in der Regel in den deutschen Konsulaten im Herkunftsland beantragt werden müssen, wodurch ganze Bereiche der deutschen Einreisekontrollen ins Ausland verlagert worden sind. Mittlerweile stehen die meisten Länder außerhalb der OECD in einer Visumspflicht. Gleichzeitig entwickelte die Bundesregierung bilaterale „Rückübernahmeübereinkommen“, vor allem mit den osteuropäischen Staaten im Zuge des Zerfalls des kommunistischen Ostblocks und des Wegfalls des sog. „Eisernen Vorhangs“" zwischen Ost- und Westeuropa: ${ }^{357}$ Einreisewillige aus den Nachbarländern sind somit durch dieses Übereinkommen nicht berechtigt, ohne ein gültiges Visum in die Bundesrepublik einzureisen. Die Migrationspolitik der Sichtvermerke und bilateralen Übereinkommen wurde auch von anderen westeuropäischen Staaten angewendet bzw. untereinander koordiniert. So fanden diese migrationspolitischen Maßnahmen letztlich im Rahmen der sogenannten „Schengener Abkommen“ von 1985 statt, die autonom außerhalb der EG auf deutsch-französische Initiative mit den Benelux Staaten getroffen wurden. Ziel war es hierbei, einen Abbau der Binnengrenzen zwischen den fünf Schengen-Staaten zu erwirken und kritische Fragen in der EG über die Reiseund Niederlassungsfreiheit vor allem im Hinblick auf den Europäischen Binnenmarkt zu klären. ${ }^{358}$

${ }^{354}$ Mintzel, Alf 1997: Multikulturelle Gesellschaften in Europa und Nordamerika: a.a.O., S. 473.

355 Thränhardt, Dietrich 1995: Ausländer und Asyl. In: Andersen, Uwe / Woyke, Wichard (Hrsg.) 1995: Handwörterbuch des politischen Systems der Bundesrepublik Deutschland. Opladen, S. 14.

356 Birsl, Ursula 2003: Deutschland. In: Gieler, Wolfgang (Hrsg.) 2003: a.a.O., S. 139.

357 Birsl, Ursula 2003: Deutschland. In: Gieler, Wolfgang (Hrsg.) 2003: a.a.O., S. 139.

358 Tomei, Verònica 1996: Migrationspolitische und europapolitische Perspektiven des Schengener Abkommens. In: Heckmann, Friedrich / Tomei, Verònica (Hrsg.) 1996: Freizügigkeit in Europa: Migrations- und europapolitische Aspekte des Schengen-Vertrages. Bonn, S. 95-96.; Birsl, Ursula 2003: Deutschland. In: Gieler, Wolfgang (Hrsg.) 2003: a.a.O., S. 139. 
Die neue, aber schon restriktive Migrationspolitik der Regierung Kohl wurde in der Folge seit Ende der achtziger Jahre durch steigende Asylbewerberzahlen noch bestärkt: Mit dem Fall der Berliner Mauer im November 1989 und der deutschen Vereinigung im Oktober 1990 sowie der Grenzöffnung der ehemaligen Ostblockstaaten nach dem Ende des Kalten Kriegs änderte sich die Zuwanderung nach Deutschland gänzlich. Als neue Einwanderungsgruppen kamen vor allem Migrierende mit sogenannter „deutscher Volkszugehörigkeit“ nach Art. 116 Grundgesetz, also sog. „Spätaussieder“ bzw. deutschstämmige Aussiedler aus Osteuropa und Juden aus Russland als sog. „Kontingentflüchtlinge“ hinzu, sowie später „Bürgerkriegsflüchtlinge“ aus dem ehemaligen Jugoslawien. ${ }^{359}$ Vergleichbar stark erhöhten sich in dem Zeitraum auch die Zuzugszahlen von Flüchtlingen aus afrikanischen und insbesondere asiatischen Ländern, wie Afghanistan, dem Iran, dem Irak, Pakistan, oder Sri Lanka, welche kamen, um in der Bundesrepublik Asyl zu suchen. ${ }^{360}$ Somit ist erkennbar, dass Ende der 1980er Jahre die Migrationssituation in Deutschland ebenfalls zu einem Anstieg der Zahlen von Asylbewerbern führten, indem besonders die Zahl der neu ankommenden deutschstämmigen Aussiedler, also Spätaussiedler, sprunghaft stieg; zwischen 1986 und 1990 hatte sich die Zahl der neu eingereisten Aussiedler in Deutschland von über 40.000 auf knapp 400.000 verzehnfacht und war damit höher als die Asylbewerberzahl (siehe Abbildung 24).

\section{Abbildung 24 : Asylbewerber und Aussiedler in der BRD, 1986 bis $1990^{361}$}

\begin{tabular}{|l|c|c|c|c|c|}
\hline Jahr & 1986 & 1987 & 1988 & 1989 & 1990 \\
\hline Asylbewerber & 99.650 & 57.379 & 103.076 & 121.318 & 193.063 \\
\hline Aussiedler (Spätaussiedler) & 42.788 & 78.523 & 202.673 & 377.055 & 397.073 \\
\hline
\end{tabular}

Seit Ende der 1980er Jahre hatte darum in Deutschland die Zuwanderung vor allem Form und Weg verändert. Dementsprechend verlagerte sich das politische Interesse von den Arbeitsmigranten, also den sogenannten ehemaligen „Gastarbeitern“ sowie ihrem Familiennachzug, nun vorrangig auf Fluchtmigranten und Aussiedler. ${ }^{362}$ Diese führten zunehmend zu einer Debatte um Restriktionen im Bereich Flucht und Asyl.

359 Butterwegge, Carolin 2009: Fit für die Globalisierung? Deutschland auf dem Weg zur Modernisierung seiner Migrations- und Integrationspolitik. S. 140.; Birsl, Ursula 2003: Deutschland. a.a.O., S. 135.

360 Birsl, Ursula 2003: Deutschland. In: Gieler, Wolfgang (Hrsg.) 2003: a.a.O., S. 136.

361 Zusammengestellt auf der Grundlage von Ulrich Herbert 2001: Geschichte der Ausländerpolitik in Deutschland: a.a.O., S. 274 (Tabelle 26.) und S. 276 (Tabelle 27.).

362 Kühne, Peter / Rüßler, Harald 2000: Die Lebensverhältnisse der Flüchtlinge in Deutschland. Frankfurt a. M., S. 22.; Herbert, Ulrich 2001: Geschichte der Ausländerpolitik in Deutschland: a.a.O., S. 263. 
Vor diesem Hintergrund stellte die Bundesregierung im Frühjahr 1990 das „neue“ Ausländergesetz (Inkrafttreten am 1. 1. 1991) unter dem damaligen Bundesinnenminister Wolfgang Schäuble vor. ${ }^{363}$ Die Bestimmungen des „neuen“ Ausländerrechts über Aufenthaltsverfestigung und Familiennachzug, über Rechtsansprüche der zweiten Generation und Einbürgerungen boten insofern Inländern mit ausländischem Pass erstmals eine Art legalen Einwandererstatus. ${ }^{364}$ Darüber hinaus erleichterte das Ausländergesetz einerseits die Einbürgerungen von hier in Deutschland aufgewachsenen Jugendlichen und von bereits länger hier lebenden ZuwanderInnen. Zugleich wurde der Schutz von Ehepartnern und Kindern ,ppolitisch Verfolgter“ auf ein sogenanntes „kleines Asyl“365 ausgedehnt und eine so genannte „Altfallregelung“ für geduldete AsylbewerberInnen eingeführt. ${ }^{366}$ Andererseits verschärfte das Gesetz jedoch Ausweisungsbefugnisse (z. B. bei Straftaten) und erweiterte die Ermessensspielräume der Ausländerbehörden im Aufenthaltsrecht. ${ }^{367}$ Die Rechtsreform 1990, also das „neue“ Ausländergesetz“, brachte gegenüber dem ersten Ausländergesetz von 1965 zwar Fortschritte (z. B. das Aufenthaltsrecht für lange in Deutschland lebende Ausländer und die „Anwerbestoppausnahme-Verordnung“ befristeter Arbeitskräfte), wurde aber sehr kompliziert und schuf neue Widersprüche. ${ }^{368}$ Außerdem versuchte die Regierung den Zustrom von Aussiedlern durch das „Aussiedleraufnahmegesetz“ von 1990 weiter einzuschränken. ${ }^{369}$

Insgesamt lässt sich in der „Begrenzungspolitik“ (1981-1990) der 1980er Jahre, der „migrationspolitischen Wende“, vor allem unter der Regierung Kohl, lediglich ein Kontroll- und Abwehrparadigma erkennen (wie durch das Rückkehrförderungsgesetz, die Visumeinführung und das Rückübernahmeübereinkommen sowie das „neue“ Ausländergesetz 1990), wobei dies letztlich nicht zu einem umfassenden Politikwandel, sondern nur zu einem partiellen Wandel führte. ${ }^{370}$

363 Butterwegge, Carolin 2009: Fit für die Globalisierung? a.a.O., S. 140.

364 Deutscher Bundestag 2000: Drucksachen: BT-Drs. 14/4357: a.a.O., S. 41 (www.bundestag.de).

365 „Politische Verfolgte erhalten rechtlichen und sozialen Schutz entweder durch die Anerkennung als Asylberechtigte, in Deutschland nach Art 16a Abs. 1GG, oder in Form des Genfer Konventionsstatus nach § 51 Abs. 1 des Ausländergesetzes von 1990 (AuslG), auch „kleines Asyl“ genannt.“ In: Nuscheler, Franz 2004: Internationale Migration: Flucht und Asyl. Wiesbaden, S. 190.

366 Nuscheler, Franz 2004: Internationale Migration: Flucht und Asyl. Wiesbaden, S. 138 f.

367 Butterwegge, Carolin 2009: Fit für die Globalisierung? a.a.O., S. 140.

368 Reißlandt, Carolin 2005: Von der „Gastarbeiter“-Anwerbung zum Zuwanderungsgesetz: Migrationsgeschehen und Zuwanderungspolitik in der Bundesrepublik. S. 6. Abzurufen unter: http://www.bpb.de/themen/6XDUPY.html (Stand: 15.03.2005).; vgl. Treibel, Annette 2001: Von der Anwerbestoppausnahme-Verordnung zur Green Card: Reflexion und Kritik der Migrationspolitik. In: In: Currle, Edda / Wunderlich, Tanja (Hrsg.) 2001: Deutschland - a.a.O., S. 115.

369 Nuscheler, Franz 2004: Internationale Migration: Flucht und Asyl. Wiesbaden, S. 144.

370 Schönwälder, Karen 2006: Politikwandel in der (bundes-) deutschen Migrationspolitik. a.a.O., S. 15 f. 


\subsection{Phase 5 : Fokussierung auf die Asylpolitik 1991-1997}

Die fünfte Phase der deutschen Migrationspolitik begann mit dem Inkrafttreten des neuen Ausländergesetzes am 1. Januar 1991 und dauerte bis zum Jahr 1997, während der Regierungszeit unter Bundeskanzler Helmut Kohl. Die offiziellen Leitlinien dieser Phase lauteten unter Fortsetzung der Migrationspolitik der 1970er und 1980er Jahre: ${ }^{371}$ 1. Deutschland als Nicht-Einwanderungsland. 2. Inländer-Primat auf dem Arbeitsmarkt. 3. Die Integration lang ansässiger Migranten bei gleichzeitiger Begrenzung des Zuzugs von Drittstaatsangehörigen. Diese Phase war auch zunehmend von der hochkomplexen neuen Einwanderungssituation seit der deutschen Vereinigung und der militärischen Konflikte auf dem europäischen Kontinent seit dem Zweiten Weltkrieg geprägt sowie von dem starken Anstieg der Zahl von Flüchtlingen und Asylsuchenden. ${ }^{372}$

Bereits seit Ende der 1980er Jahre konzentrierte sich die Zuwanderung von Flüchtlingen nach Westeuropa in starkem Maße auf die Bundesrepublik. Während in Deutschland zwischen 1990 und 1998 knapp 1,8 Millionen Flüchtlinge politisches Asyl beantragten, waren es in den westeuropäischen Nachbarländern eindeutig weniger: In Großbritannien gab es 405.589 Flüchtlinge, in den Niederlanden 282.896, in Frankreich 267.332, in der Schweiz 236.654 und in Schweden 233.823. ${ }^{373}$ Diese Situation wurde vor allem durch die Bürgerkriege in Kroatien sowie Bosnien und Herzegowina Anfang der 1990er und auch später im Kosovo Ende der 1990er Jahre verursacht. Darauf folgend wurden viele Flüchtlinge von den westeuropäischen Ländern, vor allem von Deutschland, unterstützt. ${ }^{374}$ In Deutschland erhielten seither insbesondere die sog. „Bürgerkriegsflüchtlinge aus Ex-Jugoslawien“ einen neuen Flüchtlingsstatus; im Jahr 1992 kamen beispielsweise 300.000 Bürgerkriegsflüchtlinge aus diesen Gebieten. ${ }^{375}$ Mit diesem Flüchtlingsstatus schuf die Flüchtlingspolitik der Bundesregierung ,die Legitimationsgrundlage für den ersten Friedenseinsatz der Bundeswehr in der Geschichte der Bundesrepublik im Rahmen der UN-Friedenstruppen in Bosnien und die erste Beteiligung an einer NATO-Militärintervention im Kosovo.“376

\footnotetext{
371 Treibel, Annette 2001: Von der Anwerbestoppausnahme-Verordnung zur Green Card: Reflexion und Kritik der Migrationspolitik. In: Currle, Edda / Wunderlich, Tanja (Hrsg.) 2001: Deutschland - ein Einwanderungsland? Rückblick, Bilanz und neue Fragen. Stuttgart, S. 116.; Currle, Edda 2004: Migration in Europa - Daten und Hintergründe. Stuttgart, S. 20.

372 Birsl, Ursula 2003: Deutschland. In: Gieler, Wolfgang (Hrsg.) 2003: a.a.O., S. 135.

373 Herbert, Ulrich 2001: Geschichte der Ausländerpolitik in Deutschland: a.a.O., S. 289.

374 Birsl, Ursula 2003: Deutschland. In: Gieler, Wolfgang (Hrsg.) 2003: a.a.O., S. 135.

375 Herbert, Ulrich 2001: Geschichte der Ausländerpolitik in Deutschland: a.a.O., S. 289.

376 Birsl, Ursula 2003: Deutschland. In: Gieler, Wolfgang (Hrsg.) 2003: a.a.O., S. 135.
} 
Diese Politik war eine Konsequenz der riesigen Zahl an Flüchtlingen und Asylbewerbern in Deutschland: Im Vergleich mit den frühen 1980er Jahren hatte sich die Migrationsstruktur Deutschlands in den 1990er Jahren deutlich verändert, in denen der überwiegende Teil aus Flüchtlingen bestand, die sich wiederum aus verschiedenen Gruppen mit mannigfachem Rechtsstatus zusammensetzten. ${ }^{377}$ (Siehe Abbildung 25).

\section{Abbildung 25 : Flüchtlingsgruppen in Deutschland zwischen 1992 und $1998^{378}$}

\begin{tabular}{|l|c|c|c|c|c|c|c|}
\hline Flüchtlingsgruppen & $\mathbf{1 9 9 2}$ & $\mathbf{1 9 9 3}$ & $\mathbf{1 9 9 4}$ & $\mathbf{1 9 9 5} \mathbf{1 9 9 6}$ & $\mathbf{1 9 9 7}$ & $\mathbf{1 9 9 8}$ \\
\hline Asylberechtigte & 100.000 & 108.500 & 136.800 & 158.600 & 170.000 & 177.500 & 182.500 \\
\hline $\begin{array}{l}\text { Familienangehörige } \\
\text { von Asylberechtigten }\end{array}$ & 130.000 & 130.000 & 130.000 & 130.000 & 130.000 & 130.000 & 130.000 \\
\hline Asylbewerber & 610.000 & 530.000 & 390.000 & 345.000 & 330.000 & 320.000 & 285.000 \\
\hline De-facto-Flüchtlinge & 640.000 & 755.000 & 650.000 & 550.000 & 500.000 & 360.000 & 370.000 \\
\hline Kontingentflüchtlinge & 38.000 & 53.000 & 67.000 & 88.000 & 103.000 & 95.000 & 112.311 \\
\hline $\begin{array}{l}\text { Bürgerkriegsflüchtlinge } \\
\text { aus Ex-Jugoslawien }\end{array}$ & 300.000 & 350.000 & 350.000 & 320.000 & 330.000 & 254.000 & 100.000 \\
\hline Heimatlose Ausländer & 28.000 & 22.000 & 20.600 & 18.800 & 17.000 & 16.000 & 15.000 \\
\hline $\begin{array}{l}\text { Gesamtzahl der sich in } \\
\text { Deutschland legal auf- } \\
\text { haltenden Flüchtlinge }\end{array}$ & Ca. & Ca. & Ca. & Ca. & Ca. & Ca. & Ca. \\
\hline
\end{tabular}

Etwa zwischen 1987 und 1993 wuchs die Zahl der sich in Deutschland legal aufhaltenden Flüchtlinge von etwa 700.000 auf ca. 1,9 Millionen an. ${ }^{379}$ Davon bildeten die sogenannten „De-facto-Flüchtlinge“ die größte Gruppe, deren „Antrag auf politisches Asyl abgelehnt worden war oder die keinen Asylantrag gestellt hatten, von denen aber vermutet wurde, dass sie im Heimatland politische oder religiöse Verfolgung zu erdulden hätten und die deshalb nicht abgeschoben wurden“6380, die aber nicht zu dauerhaft Asylberechtigten werden sollten. Hinzu kamen jüdische Emigranten aus der ehemaligen Sowjetunion und sogenannte „Kontingentsflüchtlinge“, die im Rahmen humanitärer Hilfsaktionen in Deutschland aufgenommen wurden, z. B. so genannte

\footnotetext{
377 Herbert, Ulrich 2001: Geschichte der Ausländerpolitik in Deutschland: a.a.O., S. 287.

378 Quelle: Herbert, Ulrich 2001: Geschichte der Ausländerpolitik in Deutschland: Saisonarbeiter, Zwangsarbeiter, Gastarbeiter, Flüchtlinge. München, S. 289 (Tab. 30).

379 Herbert, Ulrich 2001: Geschichte der Ausländerpolitik in Deutschland: a.a.O., S. 288.

${ }^{380}$ Herbert, Ulrich 2001: Geschichte der Ausländerpolitik in Deutschland: a.a.O., S. 288.
} 
„Boat-people“ aus Vietnam. ${ }^{381}$ Neben diesen Ereignissen nahm die Zahl der europäischen Asylsuchenden, insbesondere jener aus der Türkei in der ersten Hälfte der 1990er Jahre zu. Dies wurde durch die politische und ethnische Situation der Kurden im Südosten der Türkei verursacht, wobei diese jedoch in aller Regel kein Recht auf Asyl zuerkannt bekamen. ${ }^{382}$ Insbesondere die Abschiebung von Kurden wurde darauf zum Gegenstand politischer Debatten über das Asylrecht. ${ }^{383}$ Aus diesen Widersprüchen bzw. aus dieser Asylrechtsprechung bezüglich der Maßstäbe des eng definierten Begriffes von politischer Verfolgung entstanden neue Formen des zivilen Protestes, insbesondere in Bezug auf die Gewährung des sog. „Kirchenasyls“ für solche Asylbewerber, deren Antrag auf Asyl abgelehnt worden war. ${ }^{384}$ Diese Initiative wies auf die Kluft zwischen gesetzlicher Definition und der Wirklichkeit politische Verfolgung hin. Es waren somit die ethnischen und politischen Konflikte in Europa, die die Zahl der Flüchtlinge und Asylbewerber rapid anwachsen ließen. Im Verlaufe der 1990er Jahre aber reduzierte sich die Flüchtlings- und Asylbewerberzahl wieder infolge des Rückgangs der neu gestellten Anträge auf Asyl nach der Novellierung des Asylrechts im Jahre 1993 sowie wegen der Heimkehr zahlreicher Bürgerkriegsflüchtlinge aus Ex-Jugoslawien. ${ }^{385}$

Die Bundesregierung erarbeitete indes zunehmend restriktive Gesetzvorlagen. Zunächst versuchte die Regierung durch das „Kriegsfolgenbereinigungsgesetz (KfbG)“ von 1992, den Zustrom von Flüchtlingen und Aussiedlern einzuschränken. Weiterhin wurde der so genannte „Asylkompromiss“ von 1992 zwischen der CDU/CSU/FDPRegierungskoalition und der SPD-Opposition ausgehandelt. Er schränkte das Grundrecht auf politisches Asyl durch die „Drittstaatenregelung“, also durch die Deklaration sicherer Drittstaaten und Herkunftsländer, ${ }^{386}$ sowie durch das „Flughafenverfahren“ im Asylverfahrensgesetz (§ 18a) stark ein. ${ }^{387}$

381 Bundesministerium des Innern (Hrsg.) 2006: Zuwanderungsrecht und Zuwanderungspolitik. S. 89.

382 Birsl, Ursula 2003: Deutschland. In: Gieler, Wolfgang (Hrsg.) 2003: a.a.O., S. 136.

383 Der Spiegel 1995: „Nur wer schweigt, ist sicher“, Interview mit Justizministerin Sabine LeutheusserSchnarrenberger (FDP) über die Abschiebung von Kurden. In: Der Spielgel vom 13.3.1995 (Nr. 11/1995). S. 25.; vgl. auch „Koalition streitet über Abschiebestop für Kurden“, FAZ, 16.12.1994.; vgl. Herbert, Ulrich 2001: Geschichte der Ausländerpolitik in Deutschland: a.a.O., S. 320 f.

384 Vgl. Schultz-Süchting, Nikolaus 2000: Kirchenasyl: zeitgeschichtliche und rechtliche Aspekte. Berlin (Humboldt-Univ. Diss.); vgl. Herbert, Ulrich 2001: a.a.O., S. 321.

385 Herbert, Ulrich 2001: Geschichte der Ausländerpolitik in Deutschland: a.a.O., S. 288.

${ }^{386}$ Die „Drittstaatenregelung“ meint hierbei, „dass Flüchtlinge, die aus vermeintlich sicheren Herkunftsländern kommen oder über vermeintlich sichere Transitländer versuchen, in die Bundesrepublik einzureisen, in diese zurückgeschoben werden und nicht in ein Asylverfahren kommen können." Birsl, Ursula 2003: Deutschland. In: Gieler, Wolfgang (Hrsg.) 2003: a.a.O., S. 140.; vgl. Nuscheler, Franz 2004: Internationale Migration: Flucht und Asyl. Wiesbaden, S. 149.

387 „Politisches Asyl konnte seither nur noch erlangen, wer mit dem Flugzeug nach Deutschland kam.“ In: Herbert, Ulrich 2001: Geschichte der Ausländerpolitik in Deutschland: a.a.O., S. 319. 
Der Asylkompromiss verschärfte somit die Rechtssituation des politischen Asyls durch den neu eingeführten Artikel 16a GG und trat am 1. Juli 1993 in Kraft. ${ }^{388}$ Die Auswirkungen des neuen Asylrechts, also der Änderung des Grundrechtes auf Asyl im Jahr 1993 waren trotz harter Kritik weitreichend. Vor allem sank die Asylbewerberzahl drastisch. ${ }^{389}$ Insofern waren es die Bestimmungen über die begrenzte Zulassung von ausländischen Arbeitsnehmern im Rahmen dieses „Asylkompromisses“ von 1992/93, die, nach dem Anwerbestopp von 1973, neue Formen der Arbeitsmigration ermöglichten. Das heißt, dass Arbeitsmigranten (z. B. „Werkvertragsarbeitnehmer“, „Gastarbeitnehmer“, „Saisonarbeitnehmer") unter besonderen Voraussetzungen (z. B. erwachsene Einzelpersonen, in der Regel mit abgeschlossener Berufsausbildung, nicht aber deren Familienangehörige) einen allerdings eingeschränkten legalen Aufenthaltsstatus besaßen und über einen äußerst engen Zugang zum Arbeitsmarkt verfügten. ${ }^{390}$ Die Bundesregierung verabschiedete außerdem das neue „Asylverfahrensgesetz“ von 1993 und das „Asylbewerberleistungsgesetz (AsylbLG)“ von 1993, mit dem nicht anerkannte Flüchtlinge vom Schutz des sog. Bundessozialhilfegesetzes (BSHG) ausgeschlossen und in ein neues Sozialleistungssystem mit abgesenktem Existenzminimum eingeordnet wurden. ${ }^{391}$ Diese im Jahr 1993 verfassten Gesetze gelten bis heute als Grundlage des Asylrechts in Deutschland $^{392}$, nachdem sie mit erneuten Nachbesserungen, später u. a. durch das Zuwanderungsgesetz (ZuWG) 2005 und auch die Novellierung des Zuwanderungsgesetzes 2007 (das sogenannte „EU-Richtlinienumsetzungsgesetz“), erweitert wurden. In dichter Folge wurde auch die „Bleiberechtsregelung“ vom Juni 1993 für die ehemaligen DDR-Vertragsarbeiter (z. B. die Gruppe der vietnamesischen Arbeitskräfte) eingeführt, die aber in Wirklichkeit kein dauerhaftes, sondern weiterhin nur ein begrenztes Aufenthaltsrecht bedeutete. ${ }^{393}$

\footnotetext{
388 Butterwegge, Carolin 2009: Fit für die Globalisierung? Deutschland auf dem Weg zur Modernisierung seiner Migrations- und Integrationspolitik. In: Butterwegge, Christoph / Hentges, Gudrun (Hrsg.) 2009: Zuwanderung im Zeichen der Globalisierung: Migrations-, Integrations- und Minderheitenpolitik. Wiesbaden, S. $140 \mathrm{f}$.

389 Herbert, Ulrich 2001: Geschichte der Ausländerpolitik in Deutschland: a.a.O., S. 289, 320.

${ }^{390}$ Deutscher Bundestag 2000: Drucksachen: BT-Drs. 14/4357: a.a.O., S. 45 (www.bundestag.de).; vgl. Birsl, Ursula 2003: Deutschland. In: Gieler, Wolfgang (Hrsg.) 2003: a.a.O., S. 142.

391 Butterwegge, Carolin 2009: Fit für die Globalisierung? a.a.O., S. 141.; vgl. Herbert, Ulrich 2001: Geschichte der Ausländerpolitik in Deutschland: a.a.O., S. 319.; vgl. Nuscheler, Franz 2004: Internationale Migration: Flucht und Asyl. Wiesbaden, S. 147.

392 Reißlandt, Carolin 2005: Von der „Gastarbeiter“-Anwerbung zum Zuwanderungsgesetz: Migrationsgeschehen und Zuwanderungspolitik in der Bundesrepublik. S. 7. Abzurufen unter: http://www.bpb.de/themen/6XDUPY.html (Stand: 15.03.2005).

${ }^{393}$ Deutscher Bundestag 2000: Drucksachen: BT-Drs. 14/4357: a.a.O., S. 44 (www.bundestag.de).
} 
In der zweiten Hälfte der 1990er Jahre beschloss die Bundesregierung mehrere migrationspolitische Rechtssetzungen ${ }^{394}$ wie z. B. das Rückführungsabkommen für VietnamesInnen (aus der früheren DDR) von 1995, das Gesetz über die Festlegung eines vorläufigen Wohnortes für Spätaussiedler von 1996, Novellierungen des Ausländergesetzes von 1997, durch das sowohl die Einbürgerung als auch der Familiennachzug zunehmend erleichtert wurde, und die Verordnung zur Visums- und Aufenthaltsgenehmigungspflicht für Minderjährige aus Nicht-EU-Staaten, das so genannte Kindervisum von 1997. ${ }^{395}$ Trotz dieser migrationspolitischen Gesetze und Verordnungen blieben die zentralen Probleme der Migrationspolitik, insbesondere der Integration, unter der damaligen CDU/CSU/FDP-Koalition weiterhin ungelöst. Es gab im Wohlfahrtsstaat Bundesrepublik Deutschland lediglich ein „Marktorientiertes“ Modell der Integration, welches EU-Bürger bevorzugte und NichtEU-Bürger benachteiligte, unter ihnen insbesondere türkische Arbeitsmigranten. Der Kontrapunkt dieser arbeitsmarktorientierten Integration war in erster Linie durch ein „einwanderungsfeindliches und auch einseitig am Vererbungsprinzip (Ius sanguinis) orientiertes Staatsangehörigkeitsrecht" gekennzeichnet. ${ }^{396}$

Abschließend ist zu sagen, dass die deutsche Migrationspolitik in der fünften Phase (1991-1997) vornehmlich im asylpolitischen Bereich restriktiv betrachtet wurde. Bemerkenswert ist dabei, dass es in dieser Phase, verglichen mit den 1980er Jahren, viele migrationspolitisch restriktive Gesetze (z. B. das „Kriegsfolgenbereinigungsgesetz (KfbG)“ von 1992 und die Grundgesetzänderung auf Asyl im „Asylkompromiss“ von 1993) gab, aber weiterhin „keine konsistente, integrierte Migrationspolitik.“ 397 Insgesamt ist somit für die Zeit der CDU/CSU/FDP-Regierungskoalition in den 1990er Jahren durchaus ein begrenzter Politikwandel ohne Paradigmenwechsel festzustellen.

\footnotetext{
394 Vgl. Treibel, Annette 2003: Migration in modernen Gesellschaften: Soziale Folgen von Einwanderung, Gastarbeit und Flucht. München, S. 57.

395 Treibel, Annette 2001: Von der Anwerbestoppausnahme-Verordnung zur Green Card: Reflexion und Kritik der Migrationspolitik. In: Currle, Edda / Wunderlich, Tanja (Hrsg.) 2001: Deutschland - ein Einwanderungsland? Rückblick, Bilanz und neue Fragen. Stuttgart, S. 114.

396 Deutscher Bundestag 2000: Drucksachen: BT-Drs. 14/4357: a.a.O., S. 45 (www.bundestag.de).

397 Treibel, Annette 2001: Von der Anwerbestoppausnahme-Verordnung zur Green Card: S. 117.
} 


\subsection{Phase 6 : Staatsangehörigkeitsreform und Zuwanderungsgesetz 1998-2004}

Die sechste Phase der deutschen Migrationspolitik dauerte von 1998 bis $2004 .{ }^{398}$ In dieser Phase fanden die migrationspolitischen Meilensteine der rot-grünen Regierungszeit statt, sowie, seit Ende der 1990er Jahre, ein relativer Gleichklang mit der EU-Migrationspolitik und dem Amsterdamer Vertrag von 1999, in den ein Paradigmenwechsel zur faktischen Anerkennung Deutschlands als Einwanderungsland festgeschrieben wurde. 399 Der Paradigmenwechsel der rot-grünen Koalitionsvereinbarung ist vor allem an drei zentralen Reformprojekten zu erkennen: ${ }^{400}$ 1. Staatsbürgerrechtsänderung mit der eingeschränkten Möglichkeit einer doppelten Staatsangehörigkeit 2. Einführung der sogenannten „Green Card“ zur Anwerbung von hoch-qualifizierten Fachkräften für den IT-Bereich 3. Erstes Zuwanderungsgesetz seit 2001 in der Migrationsgeschichte Deutschlands.

Diese zentrale Reformvorhaben der rot-grünen Migrationspolitik hatten jedoch unterschiedliche Konsequenzen; die Gesetzgebungsverfahren führten mehrfach zu heftigen Konflikten und Debatten in der Politik. Zuerst ist in Bezug auf die Reform des Staatsangehörigkeitsrechts die Ablösung des aus dem Jahr 1913 stammenden Reichsund Staatsangehörigkeitsgesetzes (RuStAG) zu nennen. ${ }^{401}$ Diese bedeutete ,eine Abkehr vom Abstammungsprinzip (,Ius sanguinis'-,Recht des Blutes').“ Kern der Reform war nun die Einbürgerung durch das Geburtsortsprinzip (,Ius soli“-,,Recht des Bodens, Landes“). ${ }^{402}$ Dies hat dazu geführt, dass in Deutschland geborene Ausländerkinder seither unter bestimmten Voraussetzungen automatisch die deutsche Staatsbürgerschaft erhalten, wenn ein Elternteil sich seit acht Jahren rechtmäßig in Deutschland dauerhaft aufhält. So gab es inzwischen ca. 300.000 Ausländerkinder (bis zum Ende des Jahres 2007) mit Doppelpass. ${ }^{403}$ Diese Ausländerkinder mit zwei Pässen müssen sich aber bis zu ihrem 18 bzw. 23. Lebensjahr zwischen der Staatsangehörigkeit

\footnotetext{
398 Meier-Braun, Karl-Heinz 2007: Der lange Weg ins Einwanderungsland Deutschland. In: Frech, Siegfried / Meier-Braun, Karl-Heinz (Hrsg.) 2007: Die offene Gesellschaft: Zuwanderung und Integration. Baden-Württemberg, S. 21-39, hier S. $28 \mathrm{f}$.

399 Birsl, Ursula 2003: Deutschland. In: Gieler, Wolfgang (Hrsg.) 2003: Handbuch der Ausländer- und Zuwanderungspolitik von Afghanistan bis Zypern. Münster, S. 136, 142.; vgl. auch Butterwegge, Carolin 2009: Fit für die Globalisierung? a.a.O., S. 142.

400 Birsl, Ursula 2003: Deutschland. In: Gieler, Wolfgang (Hrsg.) 2003: a.a.O., S. 136. u. S. 142-143.

401 Nuscheler, Franz 2004: Internationale Migration: Flucht und Asyl. Wiesbaden, S. 155.

402 Meier-Braun, Karl-Heinz 2007: Der lange Weg ins Einwanderungsland Deutschland. a.a.O., S. 29.

403 Vogel, Wolfram 2010: Die Migration im Hintergrund: Strukturen der Integrationspolitik in Deutschland. In: Baasner, Frank (Hg.) 2010: Migration und Integration in Europa. Baden-Baden, S 45.
} 
ihrer Eltern oder der deutschen entscheiden. Wenn dies unterbleibt verlieren die ausländischen Jugendlichen die deutsche Staatsangehörigkeit wieder. Diese Regelung bzw. das Prinzip der „Vermeidung von Mehrstaatigkeit“ galt seit dem 1. Januar 2000 und bestand in der von der FDP vorgeschlagenen „Optionspflicht“. ${ }^{404}$ Allerdings erschwerte dieses Angebot vielen Ausländerkindern die Entscheidung gegen ihre bisherige Staatsangehörigkeit. Parallel wurden die Voraussetzungen für die Einbürgerung Erwachsener nach dem Ausländergesetz erheblich verändert: Seit dem 1. Januar 2000 wurde die notwendige Mindestaufenthaltsdauer bei Anspruchseinbürgerungen von 15 auf 8 Jahre gesenkt, wozu auch das Bestehen eines Sprachtests gehört. ${ }^{405}$ Die Einbürgerung wurde danach beträchtlich erleichtert und die Einbürgerungszahlen wuchsen seit Inkrafttreten der Staatsangehörigkeitsreform 2000 kontinuierlich an. ${ }^{406}$ Mit der Schaffung eines ,,modernen Staatsangehörigkeitsrechts “407 im Jahr 2000 wurde insgesamt ein historisch bedeutsamer Kurswechsel in der Migrationspolitik vorgenommen. ${ }^{408}$

Mit der deutschen „Green-Card“ nach dem amerikanischen Vorbild wurde parallel der Anwerbestopp von 1973 weiter gelockert und damit längerfristige Arbeitsimmigration mit sozialer Absicherung für Höherqualifizierte in der IT-Branche wieder zugelassen. ${ }^{409}$ Die Green-Card-Regelung trat durch zwei Verordnungen, der „Verordnung über Aufenthaltserlaubnisse für hochqualifizierte ausländische Fachkräfte der Informationsund Kommunikationstechnologie“ und der „Verordnung über die Arbeitsgenehmigung für hochqualifizierte ausländische Fachkräfte der Informations- und Kommunikationstechnologie“ (kurz: ITArGV oder „Green-Card-Verordnung“) am 1. August 2000 in Kraft, die aufgrund eines akuten Fachkräftemangels in den Bereichen Computer- und Informationstechnologie erlassen wurde. ${ }^{410}$ Die Einführung der „Green Card“ als Anwerbeanreiz verlief zunächst schleppend. Denn es fanden sich zum einen nicht so viele BewerberInnen auf die Green Card, zum anderen befand sich der IT-

404 Butterwegge, Carolin 2009: Fit für die Globalisierung? Deutschland auf dem Weg zur Modernisierung seiner Migrations- und Integrationspolitik. In: Butterwegge, Christoph/Hentges, Gudrun (Hg.): S. 143.

405 Butterwegge, Carolin 2009: Fit für die Globalisierung? a.a.O., S. 143.

406 Vgl. Butterwegge, Carolin 2009: Fit für die Globalisierung? a.a.O., S. 144.

407 Herbert, Ulrich 2001: Geschichte der Ausländerpolitik in Deutschland: a.a.O., S. 332.

408 Meier-Braun, Karl-Heinz 2007: Der lange Weg ins Einwanderungsland Deutschland. a.a.O., S. 29.

409 Birsl, Ursula 2003: Deutschland. In: Gieler, Wolfgang (Hrsg.) 2003: Handbuch der Ausländer- und Zuwanderungspolitik von Afghanistan bis Zypern. Münster, S. 136, 143.

410 Angenendt, Steffen 2002: Einwanderungspolitik und Einwanderungsgesetzgebung in Deutschland 2000-2001. In: Migrationsreport 2002: Fakten-Analysen-Perspektiven. Frankfurt a. Main, S. 35.; Reißlandt, Carolin / Schneider, Jan 2007: Regelungen der Arbeitsmigration bis 2004. Abzurufen unter http://www.bpb.de/themen/U189VO.html (Stand: 16. 05. 2007). 
Bereich, insbesondere die sogenannten „Start-up-Unternehmen“, in einer Krise. ${ }^{411}$ Die Bundesanstalt für Arbeit vergab diese Green Card bis Ende Oktober 2001 lediglich an 10.000 ausländische, zu 88 Prozent männliche IT-Fachkräfte, wovon 14 Prozent ausländische Absolventen einer deutschen Fachhoch- oder Hochschule waren. ${ }^{412}$ Zwischen August 2000 und Ende 2004 erhielten insgesamt 17.931 IT-Experten Arbeitserlaubnisse für eine erstmalige Beschäftigung nach der Green-Card-Verordnung, wobei die Zahlen zuletzt stark abgenommen hatten. ${ }^{413}$ Die Green-Card-Spezialisten wiesen eine heterogene Herkunftsstruktur auf: Sie kamen meist aus Indien (21 Prozent), Russland, Weißrussland, der Ukraine und den Baltischen Staaten (14 Prozent) sowie aus Rumänien (8 Prozent), der Tschechischen und der Slowakischen Republik (7 Prozent) und dem ehemaligen Jugoslawien (6 Prozent). ${ }^{414}$ Die Green-Card ermöglichte somit hoch-qualifizierten IT-Fachkräften aus Nicht-EU-Staaten (Drittstaaten) einen erleichterten Zugang zum Arbeitsmarkt in Deutschland. ${ }^{415}$ Allerdings war diese GreenCard-Regelung zeitlich begrenzt, also eine vorübergehende Sonderarbeitserlaubnis für zunächst fünf Jahre, wobei Familienangehörige erst nach einer Wartezeit von zwei Jahren einer bezahlten Tätigkeit nachgehen durften. ${ }^{416}$ Damit war die deutsche GreenCard im Wesentlichen restriktiver gefasst als die US-amerikanische Green Card und stand in der bisherigen Tradition der deutschen Migrationspolitik. Sie schuf also keine neue Rechtsgrundlage für die Arbeitskräfteimmigration, sondern korrigierte nur bereits bestehende Regelungen. ${ }^{417}$ Es wurde vielfach kritisiert, dass die Green-CardRegelungen nicht weit genug gingen und angesichts eines sich verstärkenden internationalen Wettbewerbs man mit der zeitlichen Begrenzung und der Wartezeit für den Familiennachzug nicht die ,besten Köpfe“ nach Deutschland holen könne. ${ }^{418}$ Zeitgleich folgte der Green Card eine „Blue-Card“, der sich mehrere Bundesländer (z. B. Bayern, Hessen, Thüringen und Niedersachsen) für eine eigene zusätzliche Regelung für hochqualifizierte Arbeitskräfte anschlossen. ${ }^{419}$

411 Birsl, Ursula 2003: Deutschland. In: Gieler, Wolfgang (Hrsg.) 2003: Handbuch der Ausländer- und Zuwanderungspolitik von Afghanistan bis Zypern. Münster, S. $136 \mathrm{f}$.

412 Birsl, Ursula 2003: Deutschland. In: Gieler, Wolfgang (Hrsg.) 2003: a.a.O., S. 137.

413 Reißlandt, Carolin / Schneider, Jan 2007: Regelungen der Arbeitsmigration bis 2004. Abzurufen unter http://www.bpb.de/themen/U189VO.html (Stand: 16. 05. 2007).

414 Birsl, Ursula 2003: Deutschland. In: Gieler, Wolfgang (Hrsg.) 2003: a.a.O., S. 137.

415 Reißlandt, Carolin 2005: Von der „Gastarbeiter“-Anwerbung zum Zuwanderungsgesetz: Migrationsgeschehen und Zuwanderungspolitik in der Bundesrepublik. S. 9. Abzurufen unter: http://www.bpb.de/themen/6XDUPY.html (Stand: 15.03.2005).

416 Angenendt, Steffen 2002: Einwanderungspolitik und Einwanderungsgesetzgebung in Deutschland 2000-2001. In: Migrationsreport 2002: Fakten-Analysen-Perspektiven. Frankfurt a. Main, S. 35.; vgl. Butterwegge, Carolin 2009: Fit für die Globalisierung? a.a.O., S. 144.; Herbert, Ulrich 2001: S. 333.

417 Angenendt, Steffen 2002: Einwanderungspolitik und Einwanderungsgesetzgebung ... a.a.O., S. 35.

418 Angenendt, Steffen 2002: Einwanderungspolitik und Einwanderungsgesetzgebung ... a.a.O., S. 35-36.

419 Angenendt, Steffen 2002: Einwanderungspolitik und Einwanderungsgesetzgebung ... a.a.O., S. 36. 
Eine neue Dynamik in den Reformprojekten ergab im Sommer 2000 die Einberufung der Unabhängigen Kommission „Zuwanderung“ (UKZU) unter Vorsitz der früheren Bundestagspräsidentin Prof. Dr. Rita Süssmuth (CDU) durch Bundesinnenminister Otto Schily (SPD), die am 4. Juli 2001 ihr Gesamtkonzept zur künftigen Gestaltung der Zuwanderung nach Deutschland vorlegte. ${ }^{420}$ In der Auseinandersetzung um die künftige Zuwanderung nach Deutschland stand zunächst die Streitfrage: Welche und wie viele Zuwanderer dürfen nach Deutschland kommen angesichts einer alternden und schrumpfenden Bevölkerung und trotz hoher Arbeitslosigkeit. ${ }^{421}$ Die 21-köpfige so genannte „Süssmuth-Zuwanderungskommission““422 forderte mit dieser zentralen Frage einen grundlegenden Wandel in der Migrationspolitik: Eine gesteuerte Zuwanderung, die sich aus wirtschaftlichen und demographischen Gründen insbesondere an den Folgen des Geburtenrückgangs und aus dem Bedarf an Qualifizierten orientierte. Zu diesem Zweck empfahl die Kommission vor allem ein Zuwanderungsmodell für ausländische Arbeitskräfte durch ein „Punktesystem“, über das eine Auswahl der BewerberInnen nach verschiedenen Kriterien wie z. B. Ausbildung, Alter und Sprachkenntnisse erfolgen sollte. ${ }^{423}$ Dieses „Punktesystem“ zur Steuerung der Einwanderung nach kanadischem Vorbild wurde allerdings zurückgewiesen.

Als drittes wichtigstes Reformprojekt der rot-grünen Bundesregierung folgte das erste Zuwanderungsgesetz in der Migrationsgeschichte der Bundesrepublik, das seit 2001 in der politischen Debatte war und die zentralen Einwanderungs- und Asylregelungen zusammenfasste. Das Zuwanderungsgesetz sah grundsätzlich drei ,gates of entry“ vor: (1) Asyl, (2) Familiennachzug, (3) eine arbeitsmarktorientierte Einwanderung, also Arbeitsimmigration mit mehr rechtlicher Absicherung. ${ }^{424}$ Dieses umfasste auch die Regelungen für SpätaussiedlerInnen und die Anforderungen an Integration. ${ }^{425}$

${ }^{420} \mathrm{Zu}$ den Reformvorschlägen der Süssmuth-Zuwanderungskommission siehe Angenendt, Steffen 2002: Einwanderungspolitik und Einwanderungsgesetzgebung ... a.a.O., S. 38-42.

${ }^{421}$ Nuscheler, Franz 2004: Internationale Migration: Flucht und Asyl. Wiesbaden, S. 161.; vgl. auch Angenendt, Steffen 2002: Einwanderungspolitik und Einwanderungsgesetzgebung ... a.a.O., S. 49.

${ }^{422} \mathrm{Zu}$ den Mitgliedern der Süssmuth-Zuwanderungskommission siehe Fuhrer, Armin 2000: Schily provoziert rot-grünen Asyl-Streit. In: Die Welt vom 13.07.2000. S. 2.

${ }^{423}$ Reißlandt, Carolin 2005: Von der „Gastarbeiter“-Anwerbung zum Zuwanderungsgesetz: a.a.O., S. 9. Im Internet: http://www.bpb.de/themen/6XDUPY.html (Stand: 15.03.2005).; vgl. Geis, Matthias 2000: Offensiver Rückzug: Wie sich die CDU die Leitkultur als Leitbild verordnet. In: Die Zeit vom 09.11.2000. S. 4.; vgl. auch Heilwagen, Oliver 2000: Zuwanderungskommission: Süßmuth pfeift Fücks zurück. In: Die Welt vom 18.10.2000. S. 4.: „Derzeit findet Einwanderung nach Deutschland ungeregelt und unkoordiniert statt. Dies müssen wir mit einem Einwanderungsgesetz ändern, das im Rahmen fester Quoten die Einwanderung regelt und begrenzt", sagte die stellvertretende Regierungssprecherin Marlene Mühe-Martin.

${ }^{424}$ Birsl, Ursula 2003: Deutschland. In: Gieler, Wolfgang (Hrsg.) 2003: a.a.O., S. 130, 143.

${ }^{425}$ Birsl, Ursula 2003: Deutschland. In: Gieler, Wolfgang (Hrsg.) 2003: a.a.O., S. 130. 
Das „Zuwanderungsgesetz“ (ZuWG), vollständig „Gesetz zur Steuerung und Begrenzung der Zuwanderung und zur Regelung des Aufenthalts und der Integration von Unionsbürgern und Ausländern“, wurde von damaligen Bundesinnenminister Otto Schily Anfang August 2001 vorgelegt und ist nach vierjährigen Debatten am 1. Januar 2005 in Kraft getreten. ${ }^{426}$ In den Gesetzentwurf von Schily fanden auch einige Vorschläge der Süssmuth-Zuwanderungskommission Eingang, aber einige zentrale Ergebnisse wiederum nicht, wie das Punktesystem und die Anhebung des Kindernachzugsalters auf 18 Jahre. $^{427}$ Die Kerninhalte des Zuwanderungsgeesetzes 2005 waren vor allem in den Artikeln 1 und 2 vorgesehen: Erwerb der deutschen Staatsbürgerschaft, Beibehaltung des Kindernachzugsalters bis zum 16. bzw. 18 . Lebensjahr, Vereinfachung der Rechtslage bei den Aufenthaltstiteln von fünf auf zwei Rechtstitel, also eine befristete Aufentshalts- und unbefristete Niederlassungserlaubnis. ${ }^{428}$ Eine weitere Neuheit gab es im humanitären Bereich und beim Flüchtlingsschutz: Regelungen zur Aufnahme nichtstaatlicher und geschlechtsspezifischer Verfolgung als Asylschutzgründe ( $§$ 60, Abs. 1) sowie Abschaffung der „Kettenduldung“ (diese Regelung blieb allerdings in der Praxis ohne Verwirklichung und ging einher mit einer Verschlechterung des Aufenthalstsstatus von geduldeten Flüchtlingen). ${ }^{429}$ Auch infolge der Terroranschläge des 11. September 2001 in New York, Washington und des 11. März 2004 in Madrid wurden Abwehr- und Sicherheitsmaßnahmen zur Bekämpfung von Terrorismus und Kriminalität (sogenannte Sicherheitspakete I und II) an dem Gesetz vorgenommen. ${ }^{430}$ Außerdem behielt das Zuwanderungsgesetz den Anwerbestopp von 1973 im Bereich der Arbeitsmigration weitgehend bei. Ausnahmen vom „Anwerbestopp“ gab es lediglich bei Hochqualifizierten sowie bei Selbständigen, die 1 Mio. Euro investieren oder mindestens zehn Arbeitsplätze schaffen. ${ }^{431}$ Das Kernstück des Zuwanderungsgesetzes liegt im Bereich der Integration: Insbesondere die erstmalige gesetzliche Verankerung eines umfassenden Konzepts zur sprachlichen Integration von MigrantInnen (Sprachund Orientierungskurse) ist bemerkenswert. Die Kosten der Integrationskurse wurde vom Bund getragen und als neues Kompetenzzentrum für Integrationsförderung das Bundesamt für Migration und Flüchtlinge (BAMF) geschaffen, das aus dem Bundesamt

\footnotetext{
426 Butterwegge, Carolin 2009: Fit für die Globalisierung? a.a.O., S. 148.

427 Angenendt, Steffen 2002: Einwanderungspolitik und Einwanderungsgesetzgebung ... a.a.O., S. 42.

428 Meier-Braun, Karl-Heinz 2007: Der lange Weg ins Einwanderungsland Deutschland. a.a.O., S. 31-33.

429 Newsletter ,Migration und Bevölkerung' 2004: Deutschland: Einigung auf ein Zuwanderungsgesetz. Im Internet: http://www.migration-info.de/mub_artikel.php?Id=040501 (Ausgabe 05/04).

430 Schneider, Jan 2007: Rückblick: Zuwanderungsgesetz 2005. S. 6. Im Internet: http://www.bpb.de/themen/TLG91N.html (Stand: 15.05.2007).

431 Newsletter, Migration und Bevölkerung' 2004: Ausgabe 05/04.
} 
für die Anerkennung ausländischer Flüchtlinge (BAFI) in Nürnberg hervorging. ${ }^{432}$

Insgesamt zeigt die sechste Phase der deutschen Migrationspolitik (1998-2004), wie aufgezeigt, dass es mit der 1998 neu gewählten Koalitionsregierung von SPD und Bündnis 90/Die Grünen einen Paradigmenwechsel zur faktischen Anerkennung Deutschlands als Einwanderungsland gegeben hat. Die Reformprojekte der damaligen rot-grünen Bundesregierung in der sechsten Phase (die sog. Staatsangehörigkeitsreform von 2000 durch das Ius soli und Green-Card-Initiative sowie die Einberufung der Süssmuth-Zuwanderungskommission (UKZU) und der Gesetzentwurf für das erste Zuwanderungsgesetz (ZuWG)) brachten Deutschland einen Politikwandel von einer eher reaktiven zu einer aktiven Gestaltung von Einwanderungsprozessen. Das war ein wichtiger Fortschritt auf dem Weg zu einem formellen moderenen Einwanderungsland Deutschland. Allerdings blieb es hier bei einem Politikwandel „zweiter Ordnung“ im Sinne Peter Halls, in dessen Rahmen zwar neue Interventionsinstrumente zur Verfügung gestellt wurden, es aber keine umfassende Veränderung politischer Prioritäten und Interventionsziele gab: Es steht immer noch die Abwehr von Einwanderungsprozessen an erster Stelle (z. B. die Beibehaltung des Anwerbestopps von 1973). ${ }^{433}$ Darüber hinaus kann die sechste Phase der deutschen Migrationspolitik schließlich trotz des Paradigmenwechsels jedoch nicht als umfassender, sondern nur als begrenzter Politikwandel bezeichnet werden. Denn die von der rot-grünen Bundesregierung reformierte Migrationspolitik hat sich nie als eine auf verschiedenen Ebenen gut vorbereitete pragmatische Politik erwiesen, sondern ist noch unter Einbeziehung breiterer gesellschaftlicher Debatten geblieben. Auch der Paradigmenwechsel zur faktischen Anerkennung von Einwanderungsprozessen durch die Reformprojekte der rot-grünen Migrationspolitik muss zeigen, ob künftig wirklich von einem Paradigmenwechsel in der Migrationsgeschichte Deutschlands gesprochen werden kann.

\footnotetext{
432 Butterwegge, Carolin 2009: S. 149; Newsletter ,Migration und Bevölkerung’ 2004: Ausgabe 05/04.

433 Vgl. Schönwälder, Karen 2006: Politikwandel in der (bundes-) deutschen Migrationspolitik. In: Davy, Ulrike / Weber, Albrecht (Hrsg.) 2006: Paradigmenwechsel in Einwanderungsfragen?: a.a.O., S. 1718.; vgl. auch Butterwegge, Carolin 2009: Fit für die Globalisierung? a.a.O., S. 156.
} 


\subsection{Phase 7 : Neue Zuwanderungs- und Integrationspolitik 2005-2012}

Mit dem Inkrafttreten des Zuwanderunggesetzes (ZuWG) am 1. Januar 2005 begann die siebte Phase der deutschen Migrationspolitik, die bis in die Gegenwart (2012) andauert. Mit dem Zuwanderungsgesetz 2005 wurde in der Bundesrepublik erstmalig legislativ und institutionell eine grundlegende Neuregelung des gesamten Ausländer- und Asylrechts vorgenommen. ${ }^{434}$ Allerdings wurde mit dem Zuwanderunggesetz die deutsche Migrationspolitik nicht rundum erneuert, weil bereits die rot-grüne Regierung im Gesetzgebungsverfahren die Grundstruktur des ZuWG aus dem bis dahin gültigen Ausländergesetz von 1991 übernahm. Die Gesetzgebung knüpfte somit erneut an die historisch gewachsene Tradition der restriktiveren, alten Migrationspolitik an. ${ }^{435}$ Gleichwohl führte das Gesetz an verschiedenen Stellen zu deutlichen Änderungen und Vereinfachungen gegenüber der alten Rechtslage. ${ }^{436}$ Das Zuwanderungsgesetz 2005 ist inzwischen evaluiert (,Zuwanderungsänderungsgesetz“ von 2007) und verschiedentlich kontrovers kommentiert worden. ${ }^{437}$

Vor und nach dem Inkrafttreten des Zuwanderungsgesetzes 2005 gab es auch eine hitzige Debatte vor allem um das integrationspolitisch bedeutsame Antidiskriminierungsgesetz (oder das Allgemeine Gleichbehandlungsgesetz - AGG), zu dem die Bundesregierung seit dem Jahr 2000 mittlerweile durch vier EUGleichbehandlungsrichtlinien verpflichtet war. ${ }^{438}$ Bereits Anfang Dezember 2001 stellte die damalige rot-grüne Bundesregierung einen Gesetzentwurf für ein Antidiskriminierungsgesetz vor. ${ }^{439}$ Der Entwurf des Antidiskriminierungsgesetzes ging insbesondere im Zivilrecht über die EU-Richtlinien hinaus, die ein Benachteiligungsverbot wegen Rasse, ethnischer Herkunft und Geschlecht vorschreiben. Auch im Arbeitsrecht sollte ein umfassender Schutz vor „Diskriminierung aufgrund von Rasse, ethnischer Herkunft, Geschlecht, sexueller Orientierung, Alter, Behinderung,

${ }^{434}$ Bundesministerium des Innern (Hrsg.) 2006: Zuwanderungsrecht und Zuwanderungspolitik. S. 28.; Butterwegge, Carolin 2009: Fit für die Globalisierung? Deutschland auf dem Weg zur Modernisierung seiner Migrations- und Integrationspolitik. In: Butterwegge, Christoph / Hentges, Gudrun (Hrsg.) 2009: Zuwanderung im Zeichen der Globalisierung: Migrations-, Integrations- und Minderheitenpolitik. Wiesbaden, S. 148.

${ }^{435}$ Butterwegge, Carolin 2009: Fit für die Globalisierung? a.a.O., S. 156.; Schneider, Jan 2007: Rückblick: Zuwanderungsgesetz 2005. S. 6. Im Internet: http://www.bpb.de/themen/TLG91N.html (Stand: 15.05.2007).

436 Schneider, Jan 2007: Rückblick: Zuwanderungsgesetz 2005. S. 6.

${ }^{437}$ Schneider, Jan 2007: Rückblick: Zuwanderungsgesetz 2005. S. 6.

${ }^{438}$ Butterwegge, Carolin 2009: Fit für die Globalisierung? a.a.O., S. 150.

${ }^{439}$ Butterwegge, Carolin 2009: Fit für die Globalisierung? a.a.O., S. 150 f. 
Weltanschauung und Religion“ verankert werden. ${ }^{440}$ Der erste Entwurf stieß allerdings auf erhebliche Kritik, vor allem bei Wirtschaftsverbänden und Oppositionsparteien. Daraufhin legten die Regierungsparteien SPD und Bündnisgrüne am 6. Mai 2004 den zweiten „Entwurf eines Gesetzes zum Schutz vor Diskriminierung (Antidiskriminierungsgesetz - ADG) dem Bundestag vor. ${ }^{441}$ Nach langen und kontroversen Politikprozessen trat das Antidiskriminierungsgesetz am 18. August 2006 in Kraft. ${ }^{442}$ Derweil kündigte die EU-Kommission im August 2004 gegen Deutschland und vier andere EU-Mitgliedsländer ein Strafverfahren vor dem Europäischen Gerichtshof $(\mathrm{EuGH}) \mathrm{an}^{443}$, da die Umsetzung der EU-Antidiskriminierungsrichtlinien bis zum 19. Juli 2003 bzw. bis zum 31. Dezember 2003 im nationalen Recht erfolgen sollte. ${ }^{444}$ Das in Kraft getretene ADG steht im Bereich des Arbeitsrechts in zentralen Punkten, z. B. bei den Regelungen zum Kündigungsschutz nicht eindeutig hinter den Vorgaben der EU-Richtlinien. ${ }^{445}$ Allerdings wird das ADG insgesamt als ein gelungenes Instrumentarium bezüglich eines möglichst wirksamen und umfassenden Diskriminierungsschutzes bewertet. ${ }^{446}$

Noch während der siebenjährigen Regierungsperiode von SPD und Bündnis 90/Die Grünen markierten die Arbeitsmarktreformen zusammen mit der Sozialhilfereform unter dem an „Zuckerbrot und Peitsche“ erinnernden Motto „Fördern und Fordern“ “447 eine historische Zäsur in Bezug auf die Entwicklung des Wohlfahrtsstaates Deutschlands, dessen Auswirkungen für verschiedene Betroffenengruppen (z. B. Langzeitarbeitslose, Niedriglohnempfänger/-innen sowie Alleinerziehende) ${ }^{448}$ immer noch in den politischen Debatten heftig umstritten sind.

${ }^{440}$ Newsletter ,Migration und Bevölkerung' 2006: Deutschland: Antidiskriminierungsgesetz. Im Internet: http://www.migration-info.de/mub_artikel.php?Id=060302 (Ausgabe 03/06).; Butterwegge, Carolin 2009: Fit für die Globalisierung? a.a.O., S. 151.

${ }^{441}$ Keskin, Hakki 2005: Deutschland als neue Heimat: Eine Bilanz der Integrationspolitik. S. 163.

${ }^{442}$ Reißlandt, Carolin 2007: Arbeitsmarktinitiativen. S. 6. Im Internet: http://www.bpb.de/themen/4007ZM.html (Stand: 16.05.2007).

${ }^{443}$ Butterwegge, Carolin 2009: Fit für die Globalisierung? a.a.O., S. 151.

${ }^{444}$ Keskin, Hakki 2005: Deutschland als neue Heimat: Eine Bilanz der Integrationspolitik. S. 152.; vgl. auch Kürsat-Ahlers, Elcin 2002: Die Vorreiterrolle der Europäischen Union bei der Etablierung einer Antidiskriminierungsgesetzgebung in der Bundesrepublik Deutschland - Lernen von anderen Ländern. In: Treichler, Andreas (Hrsg.) 2002: Wohlfahrtsstaat, Einwanderung und ethnische Minderheiten. Wiesbaden, S. 257-277, hier S. 261.

${ }^{445}$ Reißlandt, Carolin 2007: Arbeitsmarktinitiativen. S. 6. Im Internet: http://www.bpb.de/themen/4007ZM.html (Stand: 16.05.2007).

${ }^{446}$ Vgl. Keskin, Hakki 2005: Deutschland als neue Heimat: Eine Bilanz der Integrationspolitik. S. 164.

${ }^{447}$ Butterwegge, Christoph 2005: Krise und Zukunft des Sozialstaates. Wiesbaden, S. 189.

${ }^{448}$ Butterwegge, Carolin 2009: Fit für die Globalisierung? Deutschland auf dem Weg zur Modernisierung seiner Migrations- und Integrationspolitik. In: Butterwegge, Christoph / Hentges, Gudrun (Hrsg.) 2009: Zuwanderung im Zeichen der Globalisierung: Migrations-, Integrations- und Minderheitenpolitik. Wiesbaden, S. 152. 
Mit den vier sogenannten Hartz-Gesetzen ,für moderne Dienstleistungen am Arbeitsmarkt “449 versuchte die rot-grüne Bundesregierung die Arbeitsmarktreformen umzusetzen. Damit zielte die Regierung zunächst darauf, die Arbeitslosigkeit zu reduzieren und auch parallel die wohlfahrtsstaatlichen Systeme zu entlasten. ${ }^{450}$ Neben diesen Zielsetzungen der Bundesregierung lassen sich die Migrantengruppen in besonderem Maße berücksichtigen, da sie häufiger als Deutsche arbeitslos und einkommensarm sind. ${ }^{451}$ Die Hartz-Gesetze, die an den Vorschlägen der sogenannten Hartz-Kommission ${ }^{452}$ unter Leitung des ehemaligen VW-Manager Peter Hartz angelehnt waren, erweitern die Möglichkeit flexibler Beschäftigungsformen. ${ }^{453}$ Unter die Beschäftigungsförderung und die Flexibilisierung fallen die mit Hartz II im Jahr 2003 eingeführten „Mini-Jobs (Monatsverdienst: bis 400 Euro)“ ohne Sozialversicherungsbeiträge und „Midi-Jobs (Monatsverdienst: 400,01 bis 800 Euro)“ ${ }^{\star 44}$, sowie der Existenzgründungszuschuss (drei Jahre lang ein finanzieller Zuschuss vom Staat) für eine „Ich-AG“ und Leiharbeit (Harz I von 2003) im Rahmen der Personalservice-Agenturen (PSA). ${ }^{455}$ Hinzu kommt angesichts der Beschleunigung der Arbeitsvermittlungsprozesse die Umstrukturierung der „Bundesagentur für Arbeit“" (Hartz III von 2004). ${ }^{456}$

Als letztes Gesetz ist insbesondere Hartz IV anzuführen, das am 1. Januar 2005 mit dem Zuwanderungsgesetz in Kraft trat: „Die Abschaffung der Arbeitslosenhilfe bzw. deren Abschmelzung zum Arbeitslosengeld II (ALG II), die weitere Verschärfung der Zumutbarkeitsregeln und die Möglichkeit des Zwangs zu einer Aufnahme äußerst gering bezahlter Tätigkeiten („Ein-Euro-Jobs“).“ 457 In Verbindung mit dem Zuwanderungsgesetz (ZuWG) 2005 stellte sich hierbei auch die folgende Frage: Wie wirkt sich Hartz IV gemeinsam mit dem ZuWG integrationspolitisch bezüglich der

\footnotetext{
449 Butterwegge, Christoph 2005: Krise und Zukunft des Sozialstaates. Wiesbaden, S. 184.

450 Giesecke, Johannes / Groß, Martin 2005: Arbeitsmarktreformen und Ungleichheit. In: Aus Politik und Zeitgeschichte (APuZ), 55. Jahrgang, 16/2005. Bonn, S. 25-31, hier S. 27.

451 Butterwegge, Carolin 2009: Fit für die Globalisierung? a.a.O., S. 152.

452 Die Hartz-Kommission wurde im Februar 2002 von der Bundesregierung eingesetzt. Offiziell firmiert sie unter dem Namen: „Kommission zum Abbau der Arbeitslosigkeit und zur Umstrukturierung der Bundesanstalt für Arbeit“. In: Seifert, Hartmut 2005: Was bringen die Hartz-Gesetze?. In: Aus Politik und Zeitgeschichte (APuZ), 55. Jahrgang, 16/2005. Bonn, S. 17, Fußnote 1.

453 Giesecke, Johannes / Groß, Martin 2005: Arbeitsmarktreformen und Ungleichheit. a.a.O., S. 27.

454 Butterwegge, Christoph 2005: Krise und Zukunft des Sozialstaates. Wiesbaden, S. 187.; vgl. Seifert, Hartmut 2005: Was bringen die Hartz-Gesetze? a.a.O., S. 22-23.

455 Seifert, Hartmut 2005: Was bringen die Hartz-Gesetze?. In: APuZ 2005, 16/2005. S. 21.; Giesecke, Johannes / Groß, Martin 2005: Arbeitsmarktreformen und Ungleichheit. In: APuZ, 16/2005. S. 27.

456 Giesecke, Johannes / Groß, Martin 2005: Arbeitsmarktreformen und Ungleichheit. a.a.O., S. 27 ; vgl. Butterwegge, Christoph 2005: Krise und Zukunft des Sozialstaates. Wiesbaden, S. 188.

457 Giesecke, Johannes / Groß, Martin 2005: Arbeitsmarktreformen und Ungleichheit. a.a.O., S. 27.
} 
Einkommenslagen und Armutsrisiken von Migrantengruppen aus? ${ }^{458}$ In der Praxis führte Hartz IV (wie etwa mit der ,neuen“ Sozialhilfe nach dem Sozialgesetzbuch SGB XII und II) im Zusammenhang mit dem ZuWG zu erheblichen Unsicherheiten bei den Migrantengruppen. ${ }^{459}$ Beispielsweise gestaltete sich die Lage für Flüchtlingsgruppen noch problematischer, „die mit 225 Euro für einen Haushaltsvorstand erheblich niedrigere Leistungen des Asylbewerberleistungsgesetzes“ erhielten. ${ }^{460}$ Die Verschärfung der Zumutbarkeitsregeln für ALG-II-Bezieher/-innen, insbesondere für niedrig qualifizierte Drittstaatsangehörige, dürften problematisch sein und vor allem im Niedriglohnsektor zur erheblichen Verschlechterung ihrer sozialen Lage führen. D. h., dass Arbeitsplätze, die für Einheimische vorher wenig attraktiv waren und durch Migrantengruppen ersetzt wurden, nun von Deutschen und auch bevorrechtigten EUBürger/-innen überlassen werden. ${ }^{461}$ Darüber hinaus wurden bei diesen ALG-IIbeziehenden Drittstaatsangehörigen automatisch die Möglichkeiten der Aufenthaltsverfestigung verringert. Da „die Höchstbezugsdauer des Arbeitslosengeldes von 36 auf 12 Monate (bzw. 18 Monate für Ältere) “462 herabgesetzt wurde, verkürzte man gleichermaßen den Antragszeitraum zur Verlängerung der Aufenthaltsgenemigung. Außerdem führte Hartz IV aufgrund der Eingliederungshilfe durch das deutlich niedrigere Arbeitslosengeld II zur Verschlechterung der Einkommenslage für einen Teil der arbeitslosen Spätaussiedler. ${ }^{463}$

Letztendlich werden die Hartz-Reformen als Umbau des deutschen Arbeitsmarktes zu einem Richtungswechsel sozial weniger abgesicherter Beschäftigungsformen festgeschrieben. Sie führten jedoch bislang zu keinen positiven Wirkungen bezüglich der Zielsetzung zu mehr Beschäftigung auf dem Arbeitsmarkt: So gab es im Juli 2007 rund 3,7 Millionen Arbeitslose, über 5 Millionen waren kurz nach Einführung der Hartz-Gesetze arbeitslos. ${ }^{464}$ Zudem führten diese Hartz-Reformen zu einer sozialen Spaltung $^{465}$ und vor allem mit Blick auf die Migrantengruppen zur Mehrung von Verarmungs- und Exklusionsrisiken. Die Hartz-Gesetze sind zwar als wichtige Instrumente der Arbeitsmarktreformen für das System sozialer Ungleichheit gekennzeichnet, aber zugleich auch „Symbol für die Reformfähigkeit des deutschen

\footnotetext{
458 Butterwegge, Carolin 2009: Fit für die Globalisierung? a.a.O., S. 152.

459 Butterwegge, Carolin 2009: Fit für die Globalisierung? a.a.O., S. 153.

460 Butterwegge, Carolin 2009: Fit für die Globalisierung? a.a.O., S. 153.

461 Butterwegge, Carolin 2009: Fit für die Globalisierung? a.a.O., S. 154.

462 Butterwegge, Carolin 2009: Fit für die Globalisierung? a.a.O., S. 155.

463 Butterwegge, Carolin 2009: Fit für die Globalisierung? a.a.O., S. 155.

464 Bundeszentrale für politische Bildung (Hrsg) 2007: Hintergrund aktuell: Fünf Jahre Hartz-Reformen. In: http://www.bpb.de/themen/70CALY,0,0,F\%FCnf-Jahre_HartzReformen.html (Stand: 16.08.2007).

465 Butterwegge, Christoph 2005: Krise und Zukunft des Sozialstaates. Wiesbaden, S. 188.
} 
Arbeitsmarkt- und Sozialsystems schlechthin." 466 Heute steht immer noch eine grundlegende Überholung der Hartz-Reformen an.

Die siebte Phase der deutschen Migrationspolitik begann im Wesentlichen nach dem Regierungswechsel im November 2005, in der 16. Legislaturperiode (2005 bis 2009). Die CDU/CSU/SPD-Bundesregierung von 2005 unter Bundeskanzlerin Angela Merkel (CDU) erklärte das Thema „Integration“ zu einer Schwerpunktaufgabe innerhalb der Migrationspolitik, mit der zuerst der Posten der ersten Staatsministerin für Integration und Migration im Bundeskanzleramt geschaffen und Prof. Dr. Maria Böhmer (CDU) als Bundesintegrationsbeauftragte ernannt wurde. ${ }^{467}$ Den ersten Akzent bezüglich ihrer neuen Integrationspolitik setzte die Bundesregierung somit am 14. Juli 2006 mit einem ersten sogenannten „Integrationsgipfel“ im Berliner Kanzleramt und am 27. September 2006 mit einer ersten „Deutsche Islamkonferenz (DIK)“ unter dem Motto ,Muslime in Deutschland - Deutsche Muslime'. ${ }^{468}$ Das Ziel des Integrationsgipfels war ein neuartiger Dialog mit Migranten und Migrantinnen und die Entwicklung eines „Nationalen Integrationsplans“. Auch mit der DIK erzielte die Regierung einen mehrjährigen Dialog mit Muslimen über eine verbesserte religions- und gesellschaftspolitische Integration in Deutschland. ${ }^{469}$ Mit diesen ersten Initiativen verstärkte und verstärkt die Bundesregierung die Integrationspolitik unter dem Motto „Fördern und Fordern“ weiter: So beschlossen die für Integration zuständigen Minister und Senatoren der Bundesländer am 10. April 2008 in Kiel ein „Integrationsmonitoring“, das auf der Grundlage des Nationalen Integrationsplans etabliert wurde, um die Integrationsmaßnahmen sowie Integrationsprozesse nach Einbürgerung der Zuwanderer in den amtlichen Statistiken zu beobachten und deren Wirksamkeit zu bemessen. ${ }^{470}$ Wichtig ist es hier, länderübergreifend und flächendeckend einheitlich zu begreifen, wie sich etwa Herkunftsländer, Alter, Erwerbstätigkeit, Sprachkenntnisse und Bildungsstand bei verschiedenen Migrantengruppen darstellen und verändern. Langfristiges Ziel ist es, dieses Monitoringsystem auch europaweit zu harmonisieren. ${ }^{471}$

\footnotetext{
466 Seifert, Hartmut 2005: Was bringen die Hartz-Gesetze?. In: APuZ, 55. Jahrgang, 16/2005. Bonn, S. 17.

467 Meier-Braun, Karl-Heinz 2007: Der lange Weg ins Einwanderungsland Deutschland. a.a.O., S. 36 f.

468 Bommes, Michael / Krüger-Potratz, Marianne (Hrsg.) 2008: Migrationsreport 2008: Fakten-AnalysenPerspektiven. Frankfurt a. M., S. 239-240 u. S 246; vgl. Meier-Braun, Karl-Heinz 2007: Der lange Weg ins Einwanderungsland Deutschland. a.a.O., S. 37.

469 Bommes, Michael / Krüger-Potratz, Marianne (Hrsg.) 2008: Migrationsreport 2008: a.a.O., S. 240, 246.; vgl. Reißlandt, Carolin 2007: Neue Zuwanderungs- und Integrationspolitik seit 2005. Im Internet: http://www.bpb.de/themen/0MOQFQ.html (Stand: 20.07.2007).

470 Newsletter ,Migration und Bevölkerung' 2008: Deutschland: Integrationsmonitoring beschlossen. Im Internet: http://www.migration-info.de/mub_artikel.php?Id=080401 (Ausgabe 04/08).

471 Newsletter ,Migration und Bevölkerung' 2008: Deutschland: Integrationsmonitoring beschlossen. Im Internet: http://www.migration-info.de/mub_artikel.php?Id=080401 (Ausgabe 04/08).
} 
Das Kieler Treffen für Integration 2008 führte - nach dem ersten Bericht im Herbst 2008 - Mitte Januar 2012 den zweiten Integrationsindikatorenbericht. ${ }^{472}$ Dieser zweite Integrationsindikatorenbericht 2012 umfasst anhand zentraler Kennzahlen des Integrationsmonitoring vertiefte Auswertungen der strategisch bedeutsamen Bereiche wie Sprache, (Aus-)Bildung, Arbeitsmarkt. Während insbesondere im Bereich Arbeitsmarktintegration Fortschritte festzustellen sind, stagniert die Entwicklung auf dem Ausbildungsmarkt und der Schulbildung weiterhin: ${ }^{473}$ Im Bereich Schulbildung ist der Anteil der 18- bis 25-Jährigen ohne Schulabschluss unter Personen mit Migrationshintergrund 2010 (4,4\%, 2005: 5,1\%) zurückgegangen, jedoch war dieser Anteil mehr als doppelt so hoch als bei der Gesamtbevölkerung (2010: 2,3\%, 2005: 2,5\%). Im Bereich Ausbildung ging der Anteil der 25- bis 35-Jährigen ohne Berufsabschluss unter Personen mit Migrationshintergrund 2010 (31,6\%, 2005: 37,1\%) zurück, allerdings war er weiterhin mehr als doppelt so hoch als bei der Gesamtbevölkerung (2010: 14,9\%, 2005: 17,6\%). Im Bereich Arbeitsmarktintegration sank die Arbeitslosenquote bei der ausländischen Bevölkerung mit 15,8\% (2005: $25,1 \%$ ), war aber ebenfalls doppelt so hoch als bei der Gesamtbevölkerung (2010: 7,7\%, 2005: 11,7\%). Der zweite Integrationsindikatorenbericht wurde jedoch von Politikern der Opposition kritisiert: ${ }^{474}$ So beklagte die integrationspolitische Sprecherin der Linkspartei Sevim Dagdelen die schlechten Beteiligungsquoten von Migranten in den Bereichen Arbeitsmarkt und (Aus-)Bildung und forderte die Einführung einer gesetzlichen Ausbildungsplatzvergabe sowie die Abschaffung des mehrgliedrigen Schulsystems. Darüber hinaus stellte die Integrationsbeauftragte der SPDBundestagsfraktion Aydan Özoguz die Frage, ob die soziale Herkunft und nicht der Migrationshintergrund der wesentliche Faktor für den Schulerfolg sei. Auch der integrationspolitische Sprecher von Bündnis 90/Die Grünen im Bundestag Memet Kilic forderte ein partizipatives und modernes Bildungssystem nach skandinavischem Vorbild.

Den zweiten Integrationsindikatorenbericht 2012 führte Ende Januar der „Nationale Aktionsplan Integration“ (NAP-I) fort. Mit dem Aktionsplan zielte die Regierung auf die Erhöhung der gleichen Teilhabechancen von Migranten. Der NAP-I wurde in elf sogenannten Dialogforen festgeschrieben: „Frühkindliche Förderung; Bildung, Ausund Weiterbildung; Arbeitsmarkt und Erwerbsleben; Migranten im öffentlichen Dienst;

\footnotetext{
472 Newsletter ,Migration und Bevölkerung' 2012: Deutschland: Bericht zu Integrationsmonitoring. Im Internet: http://www.migration-info.de/mub_artikel.php?Id=120103 (Ausgabe 01/12).

473 Newsletter ,Migration und Bevölkerung' 2012: Deutschland: Bericht zu Integrationsmonitoring. Im Internet: http://www.migration-info.de/mub_artikel.php?Id=120103 (Ausgabe 01/12).

474 Newsletter ,Migration und Bevölkerung' 2012: Deutschland: Bericht zu Integrationsmonitoring. Im Internet: http://www.migration-info.de/mub_artikel.php?Id=120103 (Ausgabe 01/12).
} 
Gesundheit und Pflege; Integration vor Ort; Sprache- und Integrationskurse; Sport; Bürgerschaftliches Engagement; Medien und Kultur.“475 Vor allem wurden im NAP-I erstmals die Bereiche „Migration im öffentlichen Dienst“" sowie „Gesundheit und Pflege“ bezüglich der Kampagne der Bundesregierung „Meine Stadt. Mein Land. Meine Aufgabe.“" ${ }^{476}$ berücksichtigt. Darüber hinaus löst der Aktionsplan den auf dem 2. Integrationsgipfel 2007 verabschiedeten Nationalen Integrationsplan (NIP) ab. Außerdem sieht der NAP-I die Unterstützung des Bildungszugangs für Migrantenkinder und -jugendliche ohne Aufenthaltsstatus vor. Zudem legt der Aktionsplan fest, die Arbeitsmarktintegration hinsichtlich einer arbeitsmarktorientierten Migrationspolitik voranzutreiben: „Ausländische Berufsabschlüsse sollen schneller anerkannt, Migranten besser qualifiziert und bei der Existenzgründung stärker unterstützt werden.“477 Im Hinblick auf den NAP-I kritisierte vor allem Memet Kilic, Sprecher für Integrationspolitik der Bundestagsfraktion von Bündnis 90/Die Grünen, die vielen Vorhaben im NAP-I als „Symbolpolitik“ der Regierung. Überdies forderte er, die hohen Einbürgerungshürden aufzuheben und das kommunale Wahlrecht auf Nicht-EU-Bürger auszuweiten. Auch einige Politiker der Opposition verlangten jeweils Reformen beim Staatsbürgerschafts- und Asylrecht, darunter die Abschaffung der Optionspflicht für ausländische Kinder und die Akzeptanz der doppelten Staatsbürgerschaft. ${ }^{478}$ Im NAP-I werden somit wichtige Integrationshürden nicht berücksichtigt.

Im Bereich Religion bestehen in Deutschland ebenfalls beträchtliche Integrationshürden. Beispielsweise steht heute noch das erweiterte Kopftuchverbot. So dürfte eine muslimische Lehrerin das Kopftuch im Schuldienst weder durch eine Mütze noch durch eine andere Kopfbedeckung ersetzen. Sie dürfte vielmehr gar keine Kopfbedeckung tragen. Als ein Grund dafür präsentierte das Landesarbeitsgericht Düsseldorf in einer Berufungsentscheidung Anfang April 2008, dass dieses Kopftuch eine vom Schulgesetz untersagte religöse Bekundung sei. ${ }^{479}$ Ähnliche Fälle gibt es auch in anderen Bundesländern. Im Gegensatz dazu findet sich bezüglich des Arbeitsmarktes eine

\footnotetext{
475 Newsletter ,Migration und Bevölkerung' 2012: Deutschland: Integrationspolitik soll verbindlicher werden. http://www.migration-info.de/mub_artikel.php?Id=120201 (Ausgabe 02/12).

476 Newsletter ,Migration und Bevölkerung' 2012: Deutschland: Integrationspolitik soll verbindlicher werden. http://www.migration-info.de/mub_artikel.php?Id=120201 (Ausgabe 02/12).

477 Newsletter ,Migration und Bevölkerung' 2012: Deutschland: Integrationspolitik soll verbindlicher werden. http://www.migration-info.de/mub_artikel.php?Id=120201 (Ausgabe 02/12).

478 Newsletter ,Migration und Bevölkerung' 2012: Deutschland: Integrationspolitik soll verbindlicher werden. http://www.migration-info.de/mub_artikel.php?Id=120201 (Ausgabe 02/12); vgl. Newsletter ,Migration und Bevölkerung' 2011: Kurzmeldungen-Deutschland: Abschaffung der Optionspflicht gescheitert. Im Internet: http://www.migration-info.de/mub_artikel.php?Id=110905 (Ausgabe 09/11).

479 Newsletter ,Migration und Bevölkerung' 2008: Deutschland: NRW: Erweitertes Kopftuchverbot. Im Internet: http://www.migration-info.de/mub_artikel.php?Id=080403 (Ausgabe 04/08).
} 
positive Bilanz. Seit dem 1. Mai 2011 ist der Zugang zum deutschen Arbeitsmarkt für Staatsbürger der acht mittel- und osteuropäischen EU-Mitgliedstaaten, die der EU 2004 beigetreten sind, nicht mehr beschränkt. ${ }^{480}$ Auch im Bereich Bleiberecht sieht man eine positive Integrationsbilanz vor. Anfang Dezember 2011 hat sich die Innenministerkonferenz (IMK) geeinigt, dass eine Verlängerung von Aufenthaltserlaubnissen nach der Bleiberechtsregelung (für rund 14.000 Ausländer) unnötig ist. Als Grund dafür gaben die Innenminister von Bund und Ländern an, dass das Bleiberecht individuell von den Ländern verlängert werden könne. ${ }^{481}$ Über einen Gesetzentwurf muss sich der Bundesrat nun noch einigen. Flüchtlingsinitiativen und Pro Asyl fordern seit langem eine neue Gesetzgebung für ein dauerhaftes Bleiberecht für Geduldete und sie lehnen somit eine sich immer wieder verlängernde Duldung ${ }^{482}$ für lange in Deutschland lebende Menschen ab.

Als zweiten Schwerpunkt der neuen Migrationspolitik in der 16. Legislaturperiode lässt sich die „Novellierung des Zuwanderungsgesetzes 2007“ nennen. ${ }^{483}$ Aufgrund der grundsätzlichen Umsetzung der „Elf-EU-Richtlinien“ (siehe Anhang: Übersicht 4) zum Aufenthalts- und Asylrecht, darunter Regelungen zur Familienzusammenführung, zum Daueraufenthalt und zur Aufnahme von Asylbewerbern, wurde eine Erneuerung des Zuwanderungsgesetzes (ZuWG) 2005 notwendig. ${ }^{484}$ Bereits kurz nach dem Inkrafttreten war offenkundig, dass das $\mathrm{ZuWG}$ bald reformiert werden musste, um einige EU-Richtlinien in deutsches Recht umzusetzen. Die umstrittene Reform des Zuwanderungsgesetzes trat am 28. August 2007 in Kraft. ${ }^{485}$ Kernpunkte der Zuwanderungsgesetz-Novelle 2007 waren das Bleiberecht, die Integration, Einbürgerung und der Ehegattennachzug. ${ }^{486}$ Besonders die Restriktionen beim

\footnotetext{
${ }^{480}$ Newsletter ,Migration und Bevölkerung' 2011: Deutschland: Arbeitsmarkt offen. Im Internet: http://www.migration-info.de/mub_artikel.php?Id=110504 (Ausgabe 05/11).

481 Newsletter ,Migration und Bevölkerung' 2012: Deutschland: Beschluss der Innenminister zum Bleiberecht. http://www.migration-info.de/mub_artikel.php?Id=120105 (Ausgabe 01/12).

${ }^{482}$ In Deutschland lebten in den Vergangenen Jahren zwischen 180.000 und 200.000 Menschen mit einer „Duldung“. Eine Duldung ist eine „,vorübergehende Aussetzung der Abschiebung“ von ausreisepflichtigen Ausländern. Sie stellt keinen Aufenthaltstitel dar und begründet daher keinen rechtmäßigen Aufenthalt. Geduldete Personen müssen jederzeit mit ihrer Ausweisung rechnen. Zitiert in: Newsletter ,Migration und Bevölkerung' 2012: Deutschland: Beschluss der Innenminister zum Bleiberecht. http://www.migration-info.de/mub_artikel.php?Id=120105 (Ausgabe 01/12).

${ }^{483}$ Reißlandt, Carolin 2007: Neue Zuwanderungs- und Integrationspolitik seit 2005. S. 2. Im Internet: http://www.bpb.de/themen/0MOQFQ.html (Stand: 20.07.2007).

${ }^{484}$ Vgl. Maaßen, Hans-Georg 2006: Zum Stand der Umsetzung von elf aufenthalts- und asylrechtlichen Richtlinien der Europäischen Union. In: Zeitschrift für Ausländerrecht und Ausländerpolitik (ZAR) 5-6/2006, 26. Jahrgang. S. 161-167 hier, S. 162.

485 Schneider, Jan 2007: Die Novellierung des Zuwanderungsgesetzes 2007. S. 1. Online verfügbar unter: http://www.bpb.de/themen/OGZA5T.html (Stand: 15.05.2007).

${ }^{486}$ Schneider, Jan 2007: Die Novellierung des Zuwanderungsgesetzes 2007. a.a.O., S. 1.
} 
Ehegattennachzug wurden kontrovers diskutiert. Künftig dürfen Ehegatten aus NichtEU-Staaten erst nach Deutschland ziehen, wenn sie mindestens 18 Jahre alt sind und bereits vor der Einreise einfache Deutschkenntnisse nachweisen können. ${ }^{487}$ Diese Regelung betrifft jedoch nicht Angehörige von Staaten, deren Bürger ohne Visum nach Deutschland einreisen können. Ehepartner aus Ländern wie Australien, Japan, Südkorea oder den USA müssten deshalb keine Sprachkenntnisse nachweisen, wohingegen Ehepartner aus afrikanischen Staaten, Thailand und der Türkei eben diesen Nachweis erbringen müssten. ${ }^{488}$ Die Restriktionen beim Ehegattennachzug sollten nach Ansicht der Bundesregierung ,arrangierte Ehen“ oder Zwangsehen vermeiden und die Integration von Zuwanderern erleichtern. Die Regelungen stoßen jedoch bei den Migrantenverbänden, darunter z. B. die Türkisch-Islamische Union (DITIB) und die Föderation der Arbeitsimmigranten aus der Türkei in Deutschland (AGIF), sowie bei den zahlreichen Politikern auf heftigen Widerstand, vor allem in Bezug auf die unterschiedlichen Anforderungen je nach Herkunftsland. ${ }^{489}$ Somit gelten diese Maßnahmen als grundrechtswidrig und auch integrationsfeindlich.

Im Hinblick auf die weiteren Reformmaßnahmen, zu denen Erleichterungen bei der Ausweisung sowie höhere Anforderungen bei der Einbürgerung und Integration, die Einführung einer gesetzlichen Altfallregelung für langjährig Geduldete zählen, entstand ebenfalls eine intensive Debatte. ${ }^{490}$ Insbesondere die Zuwanderungsregelungen für qualifizierte Fachkräfte und Selbstständige führten zu einer erheblichen Kontroverse. Die Neuregelungen sahen zwar Zuzugserleichterungen für Selbstständige vor; für diese senkte man die Grenzen bei Firmengründungen insofern, als dass nicht mehr eine Mio. Euro investiert und zehn Arbeitsplätze geschaffen werden müssen, sondern lediglich die Hälfte, also mindestens fünf Arbeitsplätze und 500.000 Euro, um ein Aufenthaltsrecht zu erhalten. Dagegen wird die jährliche Mindestverdienstgrenze für ausländische Fachkräfte nicht gesenkt und bleibt bei 85.000 Euro pro Jahr. Dadurch erhielten im Zeitraum Mai 2005 bis Mai 2007 nur 1.650 hoch qualifizierte ausländische Arbeitnehmer eine dauerhafte Aufenthaltserlaubnis. ${ }^{491}$ Außerdem enthielt das Gesetz

\footnotetext{
487 Schneider, Jan 2007: Die Novellierung des Zuwanderungsgesetzes 2007. S. 3. Online verfügbar unter: http://www.bpb.de/themen/OGZA5T.html (Stand: 15.05.2007).

488 Newsletter ,Migration und Bevölkerung' 2007: Deutschland: Novellierung des Zuwanderungsrechts. http://www.migration-info.de/mub_artikel.php?Id=070601 (Ausgabe 06/07).

489 Schneider, Jan 2007: Die Novellierung des Zuwanderungsgesetzes 2007. S. 3-4. Online verfügbar unter: http://www.bpb.de/themen/OGZA5T.html (Stand: 15.05.2007).

490 Schneider, Jan 2007: Die Novellierung des Zuwanderungsgesetzes 2007. S. 4. Online verfügbar unter: http://www.bpb.de/themen/OGZA5T.html (Stand: 15.05.2007).

491 Newsletter ,Migration und Bevölkerung' 2007: Deutschland: Novellierung des Zuwanderungsrechts. http://www.migration-info.de/mub_artikel.php?Id=070601 (Ausgabe 06/07).
} 
eine Altfallregelung für Geduldete, die eine Aufenthaltserlaubnis allerdings nur ,auf Probe“ und darüber hinaus einen gleichrangigen Zugang zum Arbeitsmarkt lediglich dann bekommen können, wenn sie sich mindestens acht (leben minderjährige Kinder im Haushalt sind es sechs) Jahre in Deutschland aufhalten, straffrei sind und über ausreichend Wohnraum verfügen sowie grundlegende Deutschkenntnisse besitzen. ${ }^{492}$ Insgesamt wurden somit die bereits im Zuwanderungsgesetz 2005 angelegten Grundzüge des Ausländer- und Aufenthaltsrechts im neuen Zuwanderungsgesetz 2007 neu justiert, weiterentwickelt und zum Teil verschärft. Jedoch stoßen einige Maßnahmen auf heftige Kritik.

Als dritten Schwerpunkt der neuen Migrationspolitik in der siebten Phase ist der „Koalitionsvertrag“ anzuführen. Bereits nach dem Regierungswechsel im Oktober des Jahres 2009 betrachtete die CDU/CSU/FDP-Regierungskoalition die Integration von Menschen mit Migrationshintergrund als „Schlüsselaufgabe für Deutschland“. ${ }^{493}$ Dementsprechend beschlossen am 26. Oktober 2009 Bundeskanzlerin Angela Merkel (CDU), Außenminister und Vizekanzler Guido Westerwelle (FDP) sowie der bayerische Ministerpräsident Horst Seehofer (CSU) in Berlin den Koalitionsvertrag für die Bundesregierung in der 17. Legislaturperiode. Im Mittelpunkt des Koalitionsvertrags stand insbesondere die Förderung der Integration. ${ }^{494}$ Im Bereich der Sprachförderung plante die neue Bundesregierung daraufhin die Einführung bundesweit vergleichbarer „Sprachstandstests“, die für alle Kinder im Alter von vier Jahren verbindlich sein sollen. ${ }^{495}$ Damit zielte die Große Koalition auf ausreichende Deutschkenntnisse bei der Einschulung der ausländischen Kinder. In diesem Kontext der Sprachförderung beschloss die Bundesregierung bereits in der 16 . Legislaturperiode den bundeseinheitlichen „Einbürgerungstest“ als Voraussetzung für die Einbürgerung, der am 1. September 2008 in Kraft trat. Alle Einbürgerungswilligen ohne deutschen Schulabschluss können seither erst nach bestandenem Einbürgerungstest die deutsche Staatsbürgerschaft erwerben. ${ }^{496}$ Auch im Januar 2009 führte die Bundesregierung für

492 Schneider, Jan 2007: Die Novellierung des Zuwanderungsgesetzes 2007. S. 2. Online verfügbar unter: http://www.bpb.de/themen/OGZA5T.html (Stand: 15.05.2007),; vgl. auch Butterwegge, Carolin 2009: Fit für die Globalisierung? a.a.O., S. 162.

493 Newsletter ,Migration und Bevölkerung' 2009: Deutschland: Zuwanderungs- und Integrationspolitik im Koalitionsvertrag. http://www.migration-info.de/mub_artikel.php?Id=090901 (Ausgabe 09/09).

494 Newsletter ,Migration und Bevölkerung' 2009: Deutschland: Zuwanderungs- und Integrationspolitik im Koalitionsvertrag. http://www.migration-info.de/mub_artikel.php?Id=090901 (Ausgabe 09/09).

495 Newsletter ,Migration und Bevölkerung' 2009: Deutschland: Zuwanderungs- und Integrationspolitik im Koalitionsvertrag. http://www.migration-info.de/mub_artikel.php?Id=090901 (Ausgabe 09/09).

496 Newsletter ,Migration und Bevölkerung' 2008: Deutschland: Bundeseinheitlicher Einbürgerungstest. Im Internet: http://www.migration-info.de/mub_artikel.php?Id=080601(Ausgabe 06/08: August 2008). 
die Integrationskurse (Sprach- und Orientierungskurs) einen bundeseinheitlichen „Abschlusstest“ ein. Demzufolge erhalten Ausländer ohne bestandene Abschlussprüfung des Integrationskurses weder eine Niederlassungserlaubnis noch ein unbefristetes Aufenthaltsrecht. ${ }^{497}$ Diese Sprachförderung als Maßnahme der Integration ist aus mehreren Gründen innerhalb der Opposition und bei Migrantenverbänden heftig umstritten. So kritisierte z. B. Volker Beck, Erster Parlamentarischer Geschäftsführer von Bündnis 90/Die Grünen, dass die Einbürgerung erschwert werde, anstatt sie zu erleichtern. Auch Migrantenverbände monieren zum einen einzelne Fragen als ideologisch missverständlich gefärbt und zum anderen die fehlerhaften Antwortvorgaben. ${ }^{498}$ Des Weiteren sah der Koalitionsvertrag die Schaffung einer zentralen „Visa-Warndatei“ vor. Damit werden nicht nur Daten von Personen festgehalten, die gegen Visa-Regelungen verstoßen haben, sondern auch von denjenigen Personen, die häufiger Einladungen oder Verpflichtungserklärungen besiegelt haben. ${ }^{499}$ Außerdem legte der Koalitionsvertrag eine ,systematisch an den Bedürfnissen des deutschen Arbeitsmarktes“" auszurichtende Steuerung der Zuwanderung qualifizierter Arbeitskräfte fest, ebenso eine Vereinfachung des Zugangs zum Arbeitsmarkt. ${ }^{500}$ Als Reaktionen übten Opposition und Migrantenverbände weiterhin Kritik am Koalitionsvertrag. Beispielsweise beanstandete der migrationspolitische Sprecher der Bundestagsfraktion von Bündnis 90/Die Grünen Josef Winkler, dass im Koalitionsvertrag eine Positionierung der Bundesrepublik zur europäischen Flüchtlingspolitik fehle. Auch Kenan Kolat, Vorsitzender der Türkischen Gemeinde in Deutschland (TGD), monierte, dass erstmals in einem Koalitionsvertrag nicht mehr von „Ausländern“, sondern von „Menschen mit Migrationshintergrund“ die Rede sei. ${ }^{501}$ Außerdem plante die Große Koalition im Jahr 2009 „Integrationsverträge“, deren Ziel es sein sollte, den Zuwanderern lange vor einer Einbürgerung die Bindung an Werte der Bundesrepublik zu vermitteln. ${ }^{502}$ Allerdings wurden die Integrationsverträge bislang noch nicht eingeführt.

\footnotetext{
497 Newsletter ,Migration und Bevölkerung' 2009: Deutschland: Einbürgerungstest wird fast immer bestanden. Im Internet: http://www.migration-info.de/mub_artikel.php?Id=090101 (Ausgabe 01/09).

498 Newsletter ,Migration und Bevölkerung' 2008: Deutschland: Bundeseinheitlicher Einbürgerungstest. Im Internet: http://www.migration-info.de/mub_artikel.php?Id=080601(Ausgabe 06/08).

499 Newsletter ,Migration und Bevölkerung' 2009: Deutschland: Zuwanderungs- und Integrationspolitik im Koalitionsvertrag. http://www.migration-info.de/mub_artikel.php?Id=090901 (Ausgabe 09/09).

500 Newsletter ,Migration und Bevölkerung' 2009: Deutschland: Zuwanderungs- und Integrationspolitik im Koalitionsvertrag. http://www.migration-info.de/mub_artikel.php?Id=090901 (Ausgabe 09/09).

501 Newsletter ,Migration und Bevölkerung' 2009: Deutschland: Zuwanderungs- und Integrationspolitik im Koalitionsvertrag. http://www.migration-info.de/mub_artikel.php?Id=090901 (Ausgabe 09/09).

502 Newsletter ,Migration und Bevölkerung' 2009: Deutschland: Diskussion um Integrationsvertrag. Im Internet: http://www.migration-info.de/mub_artikel.php?Id=091003 (Ausgabe 10/09).
} 
Als vierten Schwerpunkt der neuen Migrationspolitik in der siebten Phase ist die absehbare Einführung der „EU Blue Card“ für Hochqualfizierte zu berücksichtigen. Anfang November 2011 hatte sich die Regierungskoalition von CDU/CSU/FDP darauf geeinigt, mit der europäischen Blue Card die Einwanderung Hochqualifizierter in Deutschland zu erleichtern und damit auch eine entsprechende EU-Richtlinie zur „EU Blue Card“ (2009/50/EG) ${ }^{503}$ umzusetzen. ${ }^{504}$ Die Europäische Union führte bereits im Mai 2009 die Blue Card ein, um Hochqualifizierten aus Nicht-EU-Staaten die Erwerbstätigkeit in der EU zu ermöglichen. Die Koalitionsregierung legte nun darüber hinaus fest, das umstrittene Mindesteinkommen als Voraussetzung für deren Zuwanderung von derzeit 66.000 Euro auf 48.000 Euro pro Jahr zu senken und auch eine unbefristete Niederlassungserlaubnis für Hochqualifizierte $\mathrm{zu}$ erteilen. ${ }^{505}$ Allerdings kritisierte die Opposition die Pläne der Regierung als zu wirtschaftsorientiert und ungenügend. Dagegen bewertete der Präsident des Deutschen Industrie- und Handelskammertags (DIHK) Hans Heinrich Driftmann die erleichterte Zuwanderung für Hochqualifizierte als positiv, wobei insbesondere die deutliche Absenkung der Einkommensgrenze als ,gutes Signal für die Unternehmen“ bezüglich der Anstrengungen zur Gewinnung von mehr Fachkräften im Inland mit gezielter Zuwanderung zum Arbeitsmarkt zu verstehen sei. ${ }^{506}$ Am 10. Februar 2012 gab der Bundesrat den Gesetzentwurf zur Umsetzung der „EU Blue Card“, der sogenannten „Hochqualifizierten-Richtlinie“, an den Bundestag zurück und forderte, entsprechende Zusatzbestimmungen zu beschließen. ${ }^{507}$ Infolgedessen ist zumindest fraglich, inwiefern die Pläne der Koalitionsregierung zu einem angemessenen Gesetzentwurf ausgearbeitet und im Bundestag diskutiert werden.

Insgesamt wurde hinsichtlich der deutschen Migrationspolitik in der siebten Phase (2005-2012) vornehmlich das erweiterte Engagement in der aktiven Integrationspolitik betrachtet: Die Aufwertung des Politikfeldes Integration im Rahmen des Koalitionsvertrags sowie die Bereitschaft zum Dialog mit Migrantengruppen und auch

503 Richtlinie 2009/50/EG des Rates vom 25. Mai 2009 über die Bedingungen für die Einreise und den Aufenthalt von Drittstaatsangehörigen zur Ausübung einer hochqualifizierten Beschäftigung. In: Amtsblatt der Europäischen Union, L 155 vom 18. 06. 2009, S. 17-29. Auch im Internet: http://www.aufenthaltstitel.de/rl_2009_50_eg.html

504 Newsletter ,Migration und Bevölkerung’ 2011: Deutschland: Einführung der „EU Blue Card“ für Hochqualifizierte. http://www.migration-info.de/mub_artikel.php? Id=110902 (Ausgabe 09/11).

505 Newsletter ,Migration und Bevölkerung' 2011: Deutschland: Einführung der „EU Blue Card“ für Hochqualifizierte. http://www.migration-info.de/mub_artikel.php?Id=110902 (Ausgabe 09/11).

506 Newsletter ,Migration und Bevölkerung' 2011: Deutschland: Einführung der „EU Blue Card“ für Hochqualifizierte. http://www.migration-info.de/mub_artikel.php? Id=110902 (Ausgabe 09/11).

507 Newsletter ,Migration und Bevölkerung' 2012: Kurzmeldungen-Deutschland: Bundesrat begrüßt Blue Card. Im Internet: http://www.migration-info.de/mub_artikel.php?Id=120205 (Ausgabe 02/12). 
Migrantenverbänden im Rahmen der Integrationsgipfel, der Islamkonferenzen (DIK) und der „Nationale Aktionsplan Integration“ (NAP-I) stellen diesbezüglich markante Anfänge dar. Außerdem bildet die absehbare Einführung der „EU Blue Card“ für Hochqualfizierte einen wichtigen Anlass für die Zuwanderungserleichterung der Drittstaatsangehörigen bezüglich der gesteuerten Zuwanderung an den Bedürfnissen des deutschen Arbeitsmarktes. Allerdings kann man bisher kaum beurteilen, ob die neue Migrationspolitik substanzielle Fortschritte gebracht hat oder nur noch als Symbolpolitik betrieben wird, anstatt einen Grundstein zur Gleichberechtigung legen. Zugleich lässt sich die siebte Phase der deutschen Migrationspolitik noch stärker als eine systematische Restriktions- bzw. Abschottungspolitik darstellen, wie die Novellierung des Zuwanderungsgesetzes 2007 (das sogenannte „EURichtlinienumsetzungsgesetz") zeigte. In diesem Zusammenhang hatte sich die deutsche Migrationspolitik bereits im Zuwanderungsgesetz (ZuWG) 2005 darüber verständigt, dass Migration und Integration nach wie vor unter dem Primat deutscher nationaler Interessen und innerer Sicherheit stehen. Seither ist die Frage noch offen, ob Deutschland mit seinem neuen Staatsangehörigkeitsrecht bzw. seiner Optionspflicht für Volljährige mit Doppelpass und dem zweiten restriktiven Zuwanderungsgesetz nun ein faktisches Einwanderungsland ist. Ob die Bemühungen der Großen Koalition seit 2005 von CDU/CSU/SPD und seit 2009 von CDU/CSU/FDP unter Bundeskanzlerin Angela Merkel auf die Migrationsprobleme in einer mehr und mehr durch Migration geprägten, globalisierten Welt oder gar durch die kritisierten Gesetzesbestimmungen in die richtige Richtung weisen, steht jedoch auf einem anderen Stern.

Schließlich ist seit 2005 bei der neuen Zuwanderungs- und Integrationspolitik in der siebten Phase der Migrationsgeschichte Deutschlands durchaus ein partieller Politikwandel mit dem Prioritätenwechsel hin zur aktiven Integration der Einwanderer und auch ein partieller Paradigmen- und Politikwechsel hin zu einer Förderung von Arbeitsmigration und gesteuerte Zuwanderung festzustellen, wie die absehbare Einführung der „EU Blue Card“ im Bereich der Hochqualifizierten darlegte. 


\subsection{Fazit}

Die historische Dimension deutscher Migrationspolitik in den sieben Phasen entwickelte eine Perspektive, die Wandlungsprozesse betont. Über den Begriff des „policy paradigm“ (Peter Hall 1993) hinaus wurde in der Untersuchung gleichzeitig der Frage nachgegangen, welche Migrationspolitik in der Migrationsgeschichte Deutschlands als Politikwandel oder Paradigmenwechsel bezeichnet werden kann und welche Voraussetzungen es dabei gibt, sowie welche Einflussfaktoren im politischen Prozess wirken. Als Ergebnis der Wandlungsprozesse hat sich gezeigt, dass sich die deutsche Migrationspolitik seit 1945 umfangreichen Umorientierungen mit oder ohne Paradigmen- und Politikwechsel unterzog. Darauf können mit Schönwälder (2006) konkret drei bzw. vier „umfassende Umorientierungen“ deutscher Migrationspolitik erkannt werden: ${ }^{508}$ 1. Die Durchsetzung der menschenrechtlichen Normen nach 1945. 2. Der durch den Anwerbestopp im Jahr 1973 eingeleitete Politikwechsel zur Steuerbarkeit von Migrationsprozessen bezüglich der sog. „Gastarbeiter“. 3. Der Paradigmenwechsel zur (unvollständigen) Anerkennung der dynamischen Migrationsprozesse seit den 1990er Jahren nach der deutschen Wiedervereinigung. 4. Der Prioritätenwechsel hin zur aktiven Integration der MigrantInnen seit dem 21. Jahrhundert.

Zielsetzung der deutschen Migrationspolitik war und ist insbesondere seit den 1990er Jahren mit dem Motto „Förderung und Fordern“ die gesteuerte Zuwanderung und Integration schon in Deutschland ansässiger Migranten und Migrantinnen, aber auch zeitweise die Rückkehrförderung. Darauf folgend wurde parallel in der Öffentlichkeit bereits die Frage gestellt, ob man von Deutschland als einem Einwanderungsland sprechen könne. Die Tendenz zur Einwanderungssteuerung in Deutschland wurde tatsächlich mit dem Anwerbestopp von 1973 betrachtet. Diesbezüglich lassen sich nun im Hinblick auf die sieben Phasen deutscher Migrationspolitik in der Migrationsgeschichte folgende Wandlungsprozesse festhalten: 1. Nach dem Ende des Zweiten Weltkriegs begann mit einer Massenwanderung die erste Phase (1945-1954) der Migrationsgeschichte Deutschlands, in der insbesondere nach 1945 die Umsetzung von Menschenrechtsnormen betrachtet wurde, jedoch keine wirksamen Standards und keine umfassende oder systematische Migrationspolitik und auch kein umfassender Politikwandel existierte, obwohl es in dieser Zeit das „,deutsche Wirtschaftswunder“ gab.

508 Vgl. hierzu die Analyse der Wandlungsprozesse von Schönwälder, Karen 2006: Politikwandel in der (bundes-) deutschen Migrationspolitik. In: Davy, Ulrike / Weber, Albrecht (Hrsg.) 2006: a.a.O., S. 10. 
2. In der zweiten Phase (1955-1973) führte die Anwerbepolitik bzw. Gastarbeiterpolitik einerseits zu einem umfassenden Wandel des ,policy paradigm“, zum anderen aber zu keinem langfristigen Politikwechsel bezüglich der Einwanderungsprozesse, wie dies vor allem durch den Anwerbestopp 1973 verdeutlicht wurde. Aus dem Anwerbestopp von 1973, der eine rund zwanzig Jahre anhaltende sogenannte „Gastarbeiter“-Phase ankündigte, resultierten jedoch Verschiebungen der politischen Prioritäten deutscher Migrationspolitik. 3. Darauf folgend vollzog sich in der dritten Phase (1974-1980) ein lediglich partieller Politikwandel, indem sich wichtige Paradigmen oder hegemoniale Deutungsmuster in Bezug auf die Institutionalisierung veränderten, letztlich jedoch nicht in einem umfassenden Politikwandel umgesetzt wurden, wie sich insbesondere durch das Scheitern des Kühn-Memorandums zeigte. 4. In der vierten Phase (19811990) wurde lediglich ein Kontroll- und Abwehrparadigma (wie z. B. das Rückkehrförderungsgesetz, die Visumeinführung und das „,neue“ Ausländergesetz 1990 belegte) in den Mittelpunkt gerückt, wobei dies allerdings letztlich nicht zu einem umfassenden Politikwandel, sondern nur zu einem partiellen Wandel führte. 5. Die fünfte Phase (1991-1997) der deutschen Migrationspolitik zeigte, dass sie den Fokus insbesondere auf die restriktive Asylpolitik richtete und darüber hinaus viele restriktive Gesetze (z. B. das „Kriegsfolgenbereinigungsgesetz (KfbG)“ von 1992 und den sogenannte „Asylkompromiss“ von 1993 sowie Novellierungen des Ausländergesetzes von 1997) verfolgte, es fand jedoch keine konsistente, angepasste Migrationspolitik statt. Diese in den 1990er Jahren gebildeten Gesetze gelten bis heute als Grundlage des Asylrechts in Deutschland, nachdem sie mit erneuten Nachbesserungen, später u. a. durch das Zuwanderungsgesetz (ZuWG) 2005 und auch die Novellierung des Zuwanderungsgesetzes 2007 (das sogenannte „EU-Richtlinienumsetzungsgesetz“), erweitert wurden. Vor diesem Hintergrund wurde jedoch die fünfte Phase deutscher Migrationspolitik durchaus als ein begrenzter Politikwandel ohne Paradigmenwechsel berücksichtigt. 6. In der sechsten Phase der deutschen Migrationspolitik (1998-2004) erfolgte ein Paradigmenwechsel zur faktischen Anerkennung des Einwanderungslands Deutschland, wie dies vor allem das neue Staatsangehörigkeitsgesetz von 2000, also das Ius soli (Geburtsortsprinzip) und der Gesetzentwurf für das Zuwanderungsgesetz (ZuWG) 2005 zeigte. Indes blieb es hier bei einem Politikwandel ,Zweiter Ordnung“ im Sinne Peter Halls, in dessen Rahmen zwar neue Interventionsinstrumente gestellt wurden. Es gab aber keine umfassende Veränderung politischer Prioritäten und Interventionsziele, in der die Abwehr von Einwanderungsprozessen an erster Stelle steht (z. B. die Beibehaltung des Anwerbestopps von 1973 im Entwurf für das ZuWG 2005). 
Darum vollzog sich in der sechsten Phase deutscher Migrationspolitik trotz des Paradigmenwechsels jedoch kein umfassender, sondern nur ein begrenzter Politikwandel. 7. Schließlich lässt sich die siebte Phase (2005-2012) deutscher Migrationspolitik vornehmlich als das erweiterte Engagement in der aktiven Integrationspolitik bezeichnen, wie z. B. der „Nationale Aktionsplan Integration“ (NAPI) zeigte. Es kam und kommt in dieser siebten Phase zwar im Hinblick auf einen partiellen Paradigmen- und Politikwechsel zu einer Förderung von Arbeitsmigration und zur gesteuerten Zuwanderung, wie z. B. die absehbare Einführung der „EU Blue Card“ im Bereich der Hochqualifizierten verdeutlichte, nicht aber $\mathrm{zu}$ einem umfassenden Politikwandel, sondern zu einem partiellen Politikwandel mit dem Prioritätenwechsel hin zur aktiven Integration der Migrantengruppen.

Aus diesem Überblick über die Wandlungsprozesse der deutschen Migrationspolitik werden im Folgenden die zentralen Einflussfaktoren ${ }^{509}$ festgehalten: 1. Die Staatsgestaltung als ethnisch homogene Gesellschaft Deutschlands durch das bis ins Jahr 2000 bestehende Abstammungsprinzip (,Ius sanguinis“). ${ }^{510}$ 2. Das lange dominierende Selbstverständnis „Deutschlands als Nicht-Einwanderungsland.“511 3. Seit dem Anwerbestopp von 1973 die Konjunkturen. 4. Das deutsche „semisouveräne“ Föderalismussystem zwischen Bund, Länder und Kommunen. ${ }^{512}$ Als Voraussetzungen der Politikwandel innerhalb der Wandlungsprozesse werden insbesondere die Interessenkonstellationen der Akteure, die Handlungskapazitäten der Institutionen und die jeweils möglichen Problemlösungsstrategien sowie Konjunkturen der öffentlichen Problemwahrnehmung gesehen. Auch angesichts des Paradigmen- und Politikwechsels hin zur faktischen Anerkennung der Einwanderungsprozesse ist jedoch ein deutlicher Verlust reformorientierter sowie humanitärer Paradigmen festzustellen, während arbeitsmarktorientierte Paradigmen zunehmend an Bedeutung gewinnen. Alles in allem wird erkennbar, dass sich Politikwandel in der Gegeschichte der deutschen Migrationspolitik nicht nur aus dem Politikfeld Migration selbst heraus, sondern stets auch im weiteren Zusammenhang politischer Prioritäten und gesellschaftlicher sowie ökonomischer Einflüsse erklären, worauf künftig auch unter der Perspektive „Deutschland: weniger, älter und bunter“6513 hingewiesen werden soll.

\footnotetext{
509 Vgl. Müller, Doreen 2010: Flucht und Asyl in europäischen Migrationsregimen. Göttingen, S. 209; vgl. Schönwälder, Karen 2006: Politikwandel in der (bundes-) deutschen Migrationspolitik: S. 8-20.

510 Vgl. Brubaker, Rogers 1992: Citizenship and Nationhood in France and Germany. Cambridge MA.

511 Vgl. Lavenex, Sandra 2002: The Europeanisation of Refugee Policies: a.a.O., S. 39.

512 Vgl. Katzenstein, Peter J. 1987: Policy and Politics in West Germany. The Growth of a Semisovereign State. Philadelphia.

513 Meier-Braun, Karl-Heinz 2007: Der lange Weg ins Einwanderungsland Deutschland. In: a.a.O., S. 37.
} 


\section{Migrationspolitik der Europäischen Union}

Ausgehend von der historischen Übersicht des vorherigen Kapitels zur deutschen Migrationspolitik folgt nun eine Untersuchung der Migrationspolitik der Europäischen Union (EU). Zwei Ausgangsfragen stehen im vorliegenden Kapitel im Mittelpunkt des Interesses: (1) Weshalb und wann wurde die Migrationspolitik von der nationalstaatlichen Ebene auf die EU-Ebene gehoben? (2) In welchem Maße kann die Migrationspolitik in der EU im europäischen Mehrebenensystem (multi-level system) als „europäisiert“ betrachtet werden? Beide Fragen führen zu der Ausgangsthese, dass die Migrationspolitik der EU weitgehend auf die Mitgliedstaaten übergreift, und eine besonders enge Einbindung der nationalen Ebene im Rahmen der ,institutionellen Balance“ bewirkt: „Sinn der institutionellen Balance ist somit, den Interessenausgleich zwischen den Beteiligten so zu lenken, dass eine allseits befriedigende Politikentscheidung produziert und gleichzeitig die langfristige Zusammenarbeit stabilisiert wird. Maßstab für das institutionelle Arrangement der Verträge und deren zwischenzeitliche Entwicklung ist somit zunächst einmal diese doppelte Zielvorgabe." 514 Unter Verwendung des theoretischen Rahmens des NeoInstitutionalismus (NI) können hierzu klare Anzeichen für einen Europäisierungsprozess ersehen werden: „Der Neo-Institutionalismus (NI) ist vor allem ein makrosoziologischer Ansatz, der den Einfluss der gesellschaftlichen Umwelt auf Organisationen untersucht und der umgekehrt auch der Frage nachgeht, welchen Einfluss Organisationen auf die gesellschaftliche Umwelt haben. Die gesellschaftliche Umwelt wird dabei als aus Institutionen bestehend verstanden." ${ }^{\text {"515 }}$ Für die vertragliche Entwicklung auf EU-Ebene lassen sich diesbezüglich theorieimmanente Gründe ausmachen (darauf wird in III.2 näher eingegangen).

Die Migrationsbewegungen in Europa bzw. in der EU erfolgten dabei im Wesentlichen in vier Stufen: Flucht und Vertreibung nach dem Zweiten Weltkrieg, die Anwerbung dringend benötigter Arbeitskräfte in einigen westeuropäischen Volkswirtschaften, die Entkolonialisierung Afrikas, Süd- und Südostasiens, und schließlich durch den Nachzug von Familienangehörigen der Arbeitsmigranten. ${ }^{516}$ Hierfür waren drei

\footnotetext{
514 Kohler-Koch, Beate / Conzelmann, Thomas / Knodt, Michéle 2004: Europäische Integration Europäisches Regieren. Wiesbaden, S. 110.

515 DiMaggio, Paul J. / Powell,Walter W. 1983: The Iron Cage Revisited: Institutional Isomorphism and Collective Rationality in Organization Fields. In: American Sociological Review 48. S. 147-160.

516 Vgl. Bendel, Petra 2008: Migration und Integration in Europa: Geschichte der europäischen
} 
Entwicklungsprozesse von ausschlaggebender Wirkung: ${ }^{517}$

1. Zunehmende Schwierigkeiten der einzelnen Mitgliedstaaten der Europäischen Union, die Migration auf rein nationaler Ebene zu steuern, da der Zuwanderungsdruck auf die meisten Mitgliedsländer zunimmt. Bedingt durch die hohe Anzahl von Asylbewerbern ab Mitte der 1980er Jahre (von 1983 bis 1992 verzehnfachte sich die Zahl der in Europa gestellten Asylanträge auf rund $700.000^{518}$ ), bemühte sich in erster Linie die Bundesrepublik Deutschland Anfang der 1990er Jahre um eine Regelung der Asylpolitik auf Gemeinschaftsebene. Mit der Reform des Asylrechts im Rahmen des sogenannten Asylkompromisses als ,institutionelle Garantie " wurde von der Bundesregierung im Jahr 1993 die Basis für eine tatsächliche Lastenteilung der Asylbewerber zwischen den Mitgliedstaaten geschaffen. Wenngleich inzwischen in den meisten EU-Staaten die Anzahl der Asylsuchenden deutlich zurückgegangen ist, erhöhte sich allerdings der Nachzug von Familienangehörigen der bereits Zugewanderten und der Zuzug von Arbeitsmigranten. Auch die Problematik der illegalen Einwanderung kann allein durch nationalstaatliche Regelungen nicht gelöst werden.

2. Die Aufhebung der Binnengrenzen innerhalb der EU und die vertraglich vereinbarte sogenannte Freizügigkeit für EU-Bürger ermöglichte es, zwischen den Mitgliedstaaten frei zu reisen. Aufgrund der fehlenden Grenzkontrollen können sich allerdings auch Angehörige von Drittstaaten (d. h. von Nicht-EU-Staaten) und illegale Einwanderer unkontrolliert von einzelnen Staaten innerhalb der EU und damit von einem Land in das nächste bewegen.

3. Die zunehmende Überalterung der Bevölkerung innerhalb der Europäischen Union, zumal laut Eurostat im Jahr 2060 voraussichtlich ein Drittel der heute 500 Millionen BürgerInnen der Europäischen Union über 65 Jahre alt sein wird ${ }^{519}$, wodurch für viele europäische Staaten ein Mangel an Erwerbstätigen abzusehen ist.

Migrationspolitik; http://www.bpb.de/themen/K9YHTK.html (Stand: 29.01.2008).

517 Vgl. Bendel, Petra / Haase, Marianne 2008: Migration und Integration in der EU: Warum überhaupt Europa? Online verfügbar unter http://www.bpb.de/themen/MOPDNW.html (Stand: 29.01.2008).

518 Salt, John 2005: Current trends in international migration in Europe. Evolution actuelle des migrations internationales en Europe. Strasbourg: Council of Europe Publ. (Migration collection), S. 11.

519 Vgl. Eurostat (Hrsg.) 2010: Europa in Zahlen: Eurostat Jahrbuch 2010. Luxemburg, S. 162. 
Dazu ist zu bemerken, dass die Asyl- und Einwanderungspolitik von vielen Mitgliedstaaten in den 1990er Jahren und bis heute als ein unverzichtbarer Bestandteil nationalstaatlicher Zuständigkeit angesehen wird. ${ }^{520}$ Eine zunehmende europäische Zusammenarbeit sollte in der Folge das Spektrum der nationalen Möglichkeiten bei der Lösung dieser Probleme durch Synergieeffekte erweitern. Deshalb hatten die europäischen Nationalstaaten infolge des Austauschs ihrer Erfahrungen und Strategien ein zunehmend stärkeres Interesse, effizientere Wege $\mathrm{zu}$ finden, sich dem durch die verstärkte Zuwanderung nach Westeuropa entstandenen Bedarf an Problemlösungen stellen zu können. ${ }^{521}$ So hat es bereits seit Längerem Bestrebungen gegeben, innerhalb von Europa in konzentrierter Form auf Wanderungsbewegungen zu reagieren. Den Interessen der Europäischen Union als Ganzes Rechnung tragend, ist daneben in Zukunft die Bereitschaft aller Mitgliedstaaten vonnöten, gemeinsame Kompromisse in diesem Politikbereich $\mathrm{zu}$ finden und untereinander Solidarität $\mathrm{zu}$ beweisen. Einwanderung und Asyl sind, wie sich schon hier zeigt, gesamteuropäische Probleme, die bereits heute aber noch viel stärker in Zukunft einzelstaatlich schwer lösbar sind. Eben deshalb ist es unabdingbar, verstärkt gemeinschaftliche Regeln zu erarbeiten und diese $\mathrm{zu}$ realisieren bis schließlich eine Harmonisierung der Einwanderungs- und Asylbestimmungen zwischen der EU und den nationalen Staaten erreicht ist.

Im Folgenden wird zunächst die Einordnung der Untersuchung in die allgemeine Diskussion zur „Europäisierung“ der Politik dargelegt. Im zweiten Abschnitt wird die Europäisierung durch die vertragliche Institutionalisierung auf EU-Ebene analysiert, die ein institutionentheoretisches Modell (Neo-Institutionalismus: NI) der EUPolitikentwicklung im Bereich der Migration ergibt. Dabei werden auch zwei Aspekte als Leitmotive nationalstaatlichen Handelns untersucht, sprich die nationalstaatlichen Interessen vor den Schwerpunkten innerer Sicherheit und Souveränität. Um die Ausgangsthese $\mathrm{zu}$ verdeutlichen, wird nicht die in der Forschung übliche Perspektive von oben nach unten in Form einer Wirkungsanalyse europäischer Politik gewählt, sondern der Blickwinkel verändert. Der für den nachfolgenden Abschnitt gewählte Begriff der „Europäisierung“ ist deshalb vieldeutig.

\footnotetext{
${ }^{520}$ Vgl. Santel, Bernhard 1995: Migration in und nach Europa. Erfahrungen, Strukturen, Politik. S. 177 ff.

${ }^{521}$ Vgl. Tomei, Verónica 2001: Europäisierung nationaler Migrationspolitik: Eine Studie zur Veränderung von Regieren in Europa. Stuttgart, S. 45.
} 


\section{Europäisierung}

"In particular, the idea of Europeanization, relative to that of European integration, appears to add two significant dimensions. First, Europeanization evokes parallel and interconnected processes of change at both the national and the supranational levels. [...]. Second, the concept of Europeanization also tends to be associated with a much stronger focus on the interrelationship of institutions and identities. „522

Die Europäisierungsforschung thematisiert die wechselseitige Beeinflussung nationaler und europäischer Politik, die sich in zwei Richtungen vollziehen kann: Die eine Richtung verläuft durch den Einfluss europäischer Institutionen auf die Nationalstaaten, ,von oben nach unten' (sog. Top down-Perspektive), während die andere zweite Richtung infolge der europäischen Politikformulierung durch die Nationalstaaten, ,von unten nach oben', beeinflusst wird (sog. Bottom-up-Perspektive). ${ }^{523}$

Der Begriff der Europäisierung bezieht sich bis heute auf zwei unterschiedliche Dimensionen des europäischen Integrationsprozesses, die freilich sehr eng zusammenhängen. ${ }^{524}$ „Europäisierung“ bedeutet, dass die Übertragung staatlicher Kompetenzen auf die Europäische Union politische Entscheidungen verstärkt auf supranationaler Ebene treffen lässt. Von dieser, traditionell als Vergemeinschaftung politischer Aufgaben bezeichneten Dimension, hebt sich eine neuere Begriffsverwendung ab, die den Kompetenztransfer nach ,Brüssel' nicht mehr als primären Gegenstand betrachtet, sondern vielmehr zum Ausgangspunkt erhebt und darauf abzielt, dass die „Europäisierung“ die Aufgabenübertragungen von der Europäischen Union auf die nationalstaatlichen Institutionen und Entscheidungsstrukturen herbeiführt. ${ }^{525}$ Dies impliziert Fragen, die sich darauf konzentrieren, ob und inwieweit „Anpassungsprozesse“ an die europäische Integration als begreifbare Veränderungen im nationalen Institutionsgefüge identifiziert werden können. ${ }^{526}$

${ }^{522}$ Harmsen, Robert / Wilson, Thomas M. (Ed.) 2000: Europeanization: Institution, Identities and Citizenship. Amsterdam, S. 19-20.

${ }^{523}$ Blum, Sonja / Schubert, Klaus 2009: Politikfeldanalyse. Wiesbaden, S. 19.; König, Thomas / Rieger, Elmar / Schmitt, Hermann (Hrsg.) 1996: Das europäische Mehrebenensystem. Frankfurt a. M., S. 21.

${ }^{524}$ Vgl. Pehle, Heinrich / Sturm, Roland 2005: Die Europäisierung des politischen Systems. In: Gabriel, Oscar W./Holtmann, Everhard (Hrsg.) 2005: Handbuch Politisches System der Bundesrepublik Deutschland. München, S. 885.

${ }_{525}$ Pehle, Heinrich / Sturm, Roland 2005: Die Europäisierung des politischen Systems. In: a.a.O., S. 885.

${ }^{526}$ Pehle, Heinrich / Sturm, Roland 2005: Die Europäisierung des politischen Systems. In: a.a.O., 885. 
Die neuere Europäisierungsforschung ist dabei eng mit der Implementationsforschung und deren Interesse an Mustern und Problemen bei der Umsetzung von politischen Entscheidungen verbunden. Es ist dabei nicht zwangsläufig, dass sich Europäisierung ausschließlich als Folge der nationalen Umsetzung europäischer Policies vollzieht, denn der europäische Integrationsprozess vermag mittels einer Reihe anderer Mechanismen nationale Strukturen, Prozesse und Politikinhalte zu beeinflussen (zu denken ist an die Veränderung politischer Ideen, nationaler Identitäten oder an die Handlungsoptionen nationaler Akteure). ${ }^{527}$ Europäisierung meint hier die Auswirkung europäischer Strukturen und Politiken auf die jeweils nationale Politik ${ }^{528}$, im Gegensatz zur Vergemeinschaftung im Sinne der Entwicklung von Politiken und Strukturen auf europäischer Ebene.

Europäisierung umfasst alle drei Dimensionen des Politikbegriffs ${ }^{529}$ (policy, politics und polity). Um die Wirkungsweise europäischer Policies auf der nationalen Ebene (auf nationale Institutionen (Polity), politische Prozesse (Politics) und Politikinhalte (Policy)) erfassen zu können, haben Knill und Lehmkuhl ${ }^{530}$ einen einfachen analytischen Rahmen vorgestellt, in dem sie drei Mechanismen der Europäisierung durch sogenannte Top-down-Prozesse unterscheiden, nämlich die positive Integration, die negative Integration und die umrahmende (framing) Integration (siehe Abbildung 26).

527 Knill, Christoph 2005: Die EU und die Mitgliedstaaten. In: Holzinger, Katharina / Knill, Christoph / Peters, Dirk / Rittberger, Berthold / Schimmelfennig, Frank / Wagner, Wolfgang 2005: Die europäische Union: Theorien und Analysekonzepte. Paderborn, S. 155.

528 Lavenex, Sandra 2001: The Europeanisation of Refugee Policies. Between human rights and Internal security. Aldershot, S. 16; vgl. Kreienbrink, Axel 2004: Einwanderungsland Spanien: a.a.O., S. 19 f. und Fußnote 26 auf S. 20. Vgl. ebenso Tanja A. Börzel / Thomas Risse 2000: When Europe Hits Home: Europeanization and Domestic Change. In: European Integration Online Papers (EIoP), Vol. 4 (2000) $\mathrm{N}^{0} 15$, S. 3. Abrufbar unter: http://www.eiop.or.at/eiop/texte/2000-015.htm (Stand: 29.11.2000). Diesem Konzept folgt auch Verónica Tomei 2001: Europäisierung nationaler Migrationspolitik. Eine Studie zur Veränderung von Regieren in Europa, (Forum Migration 6). Stuttgart. Zur weiteren Bedeutungsvielfalt des Konzepts „Europäisierung“ siehe Johan P. Olsen 2002: The Many Faces of Europeanization. In: JCMS, 40 (5), S. 921-952 (ARENA Working Paper, WP 01/2), Oslo $<$ [http://www.arena.uio.no/publications/wp01_2.htm] (Stand: 23.08.2002) >).

529 Böhret, Carl / Jann, Werner / Kronenwett, Eva 1988: Innenpolitik und politische Theorie. Opladen, S. 7.; vgl. Schubert, Klaus / Bandelow, Nils C. (Hrsg.) 2009: Lehrbuch der Politikfeldanalyse 2.0. S. 5.

530 Knill, Christoph / Lehmkuhl, Dirk 1999: How Europe Matters. Different Mechanisms of Europeanization. In: European Integration Online Papers (EIoP) Vol. 3 (1999) $\mathrm{N}^{0}$ 7, bes. S. 1-4. Abrufbar unter: http:/www.eiop.or.at/eiop/texte/1999-007.htm (Stand: 15.06.1999); Knill, Christoph / Lehmkuhl, Dirk 2002: The National Impact of European Union Regulatory Policy: Three Europeanization Mechanisms. In: European Journal of Political Research 41, S. 255-280. 
Abbildung 26: Drei Mechanismen der Europäisierung ${ }^{531}$ (durch sog. Top- down-Prozesse)

\begin{tabular}{|c|c|c|}
\hline Form & Mechanismus & Wirkungsweise / Logik \\
\hline Positive Integration & $\begin{array}{l}\text { Europäisierung durch Vorgabe } \\
\text { institutioneller Modelle }\end{array}$ & $\begin{array}{c}\text { Rechtlicher Zwang (compliance), } \\
\text { z. B. Arbeitnehmerfreizügigkeit } \\
\text { und Familiennachzug }\end{array}$ \\
\hline Negative Integration & $\begin{array}{l}\text { Europäisierung durch } \\
\text { Veränderung } \\
\text { nationaler } \\
\text { Gelegenheitsstrukturen }\end{array}$ & $\begin{array}{l}\text { Umverteilung von Macht und } \\
\text { Ressourcen, } \\
\text { z. B. Arbeitnehmerfreizügigkeit } \\
\text { und Familiennachzug }\end{array}$ \\
\hline $\begin{array}{l}\text { Framing Integration } \\
\qquad \text { (weichere } \\
\text { Politikangebote) }\end{array}$ & $\begin{array}{l}\text { Europäisierung durch } \\
\text { Veränderung } \\
\text { nationaler Ideen und } \\
\text { Annahmen }\end{array}$ & $\begin{array}{l}\text { Kognitiv (Perzeption und } \\
\text { Konzeption politischer } \\
\text { Probleme), } \\
\text { z. B. Flüchtlingspolitik und } \\
\text { Staatsbürgerschaft }\end{array}$ \\
\hline
\end{tabular}

Im Rahmen der positiven Integration diktiert die europäische Ebene, also die Europäische Kommission oder der Europäische Rat, mittels Verordnungen feste europäische Vorgaben und schreibt ein Modell vor, das der Mitgliedstaat in eben dieser Form ohne Spielräume und Variationsmöglichkeiten umzusetzen hat. ${ }^{532}$ Auf diesem Wege vermag europäische Politik ein konkretes institutionelles Modell im Hinblick auf die Anpassung und Ausgestaltung nationaler Staatlichkeit vorzuschreiben. Dieser Mechanismus der Europäisierung, der Weg über direkte institutionelle Wirkungen europäischer Vorgaben ist vor allem in Fällen der positiven Integration vorzufinden ${ }^{533}$, wie etwa in den Bereichen Umweltschutz, Arbeitsschutz, Verbraucherschutz oder Sozialpolitik. ${ }^{534}$ Auch in der Wirtschaftsmigration kann Arbeitnehmerfreizügigkeit und Familiennachzug verzeichnet werden. Den Fällen ist gemeinsam, dass die Effekte der Europäisierung sich primär auf rechtlicher Verpflichtung, also auf rechtlichem Zwang bzw. Regelbefolgung (compliance) gründen. ${ }^{535}$

531 Zusammengestellt aus Knill, Christoph 2005: Die EU und die Mitgliedstaaten. A.a.O., S. 158. und Knill, Christoph / Lehmkuhl, Dirk 2002: The National Impact of European Union Regulatory Policy: Three Europeanization Mechanisms. In: European Journal of Political Research 41, S. 255-280 sowie Schmidt, Susanne K. / Blauberger, Michael / van den Nouland, Wendelmoet 2008: Jenseits von Implementierung und Compliance - Die Europäisierung der Mitgliedstaaten. In: Tömmel, Ingeborg (Hrsg.) 2008: Die Europäische Union: Governance und Policy-Making. PVS-Sonderheft 40/2007. Wiesbaden, S. 277.

532 Kreienbrink, Axel 2004: Einwanderungsland Spanien: a.a.O., S. 20.

533 Schmidt, Susanne K. / Blauberger, Michael / van den Nouland, Wendelmoet 2008: Jenseits von Implementierung und Compliance - Die Europäisierung der Mitgliedstaaten. In: a.a.O., S. 277.

534 Knill, Christoph 2005: Die EU und die Mitgliedstaaten. A.a.O., S. 159.

535 Knill, Christoph 2005: Die EU und die Mitgliedstaaten. A.a.O., S. 158. 
Bei der negativen Integration liegt ein erheblich größerer Spielraum des Staates vor, da es der europäischen Ebene lediglich obliegt, in der Regel durch Richtlinien einen festen Zielrahmen zu fixieren, innerhalb dessen die nationalen Gelegenheiten (Opportunity Structures) auszugestalten sind, sprich die Umverteilung von Macht und Ressourcen zwischen nationalen Akteuren. ${ }^{536}$ Es ist daher möglich, dass die europäische Politik ausschließlich die strategischen Handlungsmöglichkeiten nationaler Akteure gezielt und systematisch beschränkt. Insbesondere der Bereich der Marktliberalisierung (negative Integration) ist ein hervorstechendes Beispiel für diesen Mechanismus der Europäisierung. ${ }^{537}$ Die EU induziert somit Verschiebungen im Hinblick auf das Machtund Einflusspotenzial, was wiederum dazu führt, dass nationale Regulierungsmuster demgemäß angepasst werden. ${ }^{538}$

Die schwächste Form schließlich stellt die ,framing ' Integration dar, bei der zwar auch ein Rahmen existiert, dieser ist jedoch unverbindlich, zumal auf der Ebene der Gemeinschaft feste Zielvorgaben entweder nicht getroffen werden oder aber diese nicht durchgesetzt werden können. ${ }^{539}$ Man hat es folglich mit einem dritten Mechanismus der Europäisierung zu tun, der weder durch institutionelle Modellvorgaben (die Stärke des Anpassungsdrucks) definiert ist noch auf die Veränderung nationaler Opportunitätsstrukturen abzielt; stattdessen geht es der europäischen Politik in solchen Fällen vornehmlich darum, auf die auf nationaler Ebene dominanten Ideen und Annahmen einzuwirken, die für die Perzeption und Lösung bestimmter politischer Probleme relevant sind, sodass die Effekte der Europäisierung kognitionsbasiert sind. ${ }^{540}$ Kognitive Effekte europäischer Politiken auf nationale Politiken, Entscheidungsprozesse und Identitätsaspekte wurden im Bereich der Flüchtlingspolitik ${ }^{541}$ und der Staatsbürgerschaft ${ }^{542}$ nachgewiesen. Veränderungen werden hier bei der ,framing ' Integration so erklärt, dass der unverbindliche Rahmen von Vorstellungen und Erwartungen der involvierten Akteure dahingehend beeinflusst

536 Vgl. Kreienbrink, Axel 2004: Einwanderungsland Spanien: Migrationspolitik zwischen Europäisierung und nationalen Interessen. Frankfurt a. M., S. 20.

537 Knill, Christoph 2005: Die EU und die Mitgliedstaaten. A.a.O., S. 161.

538 Knill, Christoph 2005: Die EU und die Mitgliedstaaten. A.a.O., S. 158

539 Kreienbrink, Axel 2004: Einwanderungsland Spanien: a.a.O., S. 20.

540 Knill, Christoph 2005: Die EU und die Mitgliedstaaten. A.a.O., S. 158-159. u. S. 164; vgl. auch Ingram, Helen / Schneider, Anne 1990: Improving Implementation Through Framing Smarter Statutes. Journal of Public Policy 10, S. 67-88.

541 Lavenex, Sandra 2001: The Europeanisation of Refugee Policies: Between human rights and internal security. Aldershot.

542 Checkel, Jeffrey T. 2001: The Europeanization of Citizenship? In: James A. Caporaso, Maria Green Cowles und Thomas Risse (Hrsg.) 2001: Transforming Europe. Europeanization and Domestic Change. Ithaca, NY: Cornell University Press, S. 180-197. 
wird, dass sie aus eigenem Antrieb zu Reformen bereit sind oder aber der Hinweis auf das europäische Vorbild Reformen zum Durchbruch verhilft. ${ }^{543}$

Durch diese rein analytische Unterscheidung der drei Mechanismen der Europäisierung haben Knill und Lehmkuhl deutlich gemacht, dass auf der Basis dieses analytischen Instrumentariums die national und sektoral variierenden Auswirkungen europäischer Integration erklärt werden können. ${ }^{544}$ In diesem Zusammenhang steht auch die Definition von Caporaso, Green Cowles und Risse, die sich stark auf die Formierung politischer Institutionen auf der EU-Ebene fokussiert. Europäisierung als „the emergence and development at the European level of distinct structures of governance, that is of political, legal and social institutions associated with political problem solving that formalize interactions among the actors, and of policy networks specializing in the creation of authoritative European rules." 545 Europäisierung ist hier also ein eindimensionaler Prozess „[...] by which domestic policy areas are becoming increasingly subject to European policy-making." "546 So ist es naheliegend, dass Europäisierung eine Top-down-Perspektive einnimmt und "Auswirkungen“" sowie „Effekte“ Schlüsselbegriffe sind. ${ }^{547}$

Manche Autoren, wie etwa Knill, Lehmkuhl, Caporaso u. a. ${ }^{548}$ fassen ihre Definition des Phänomens der Europäisierung enger, nämlich als die Herausbildung und Entwicklung eines eigenständigen politischen Systems auf europäischer Ebene, d. h. als

543 Kreienbrink, Axel 2004: Einwanderungsland Spanien: Migrationspolitik zwischen Europäisierung und nationalen Interessen. Frankfurt a. M., S. 21 und Fußnote 29 auf S. 21 (Knill, Christoph / Lehmkuhl, Dirk 1999: How Europe Matters. Different Mechanisms of Europeanization. In: European Integration Online Papers (EIoP) Vol. 3 (1999) $\mathrm{N}^{0}$ 7, bes. S. 1-4. Abrufbar unter: http://www.eiop.or.at/eiop/texte/1999-007.htm (Stand: 15.06.1999). Die Bedingungen für den Wandel auf der nationalen Ebene ähnlich bei Tanja A. Börzel / Thomas Risse 2000: When Europe Hits Home: Europeanization and Domestic Change. In: European Integration Online Papers (EIoP), Vol. 4 (2000) $\mathrm{N}^{0}$ 15, S. 4-10. Abrufbar unter: http://www.eiop.or.at/eiop/texte/2000-015.htm (Stand: 29.11.2000). Sie bezeichnen allerdings die institutionelle Unangepasstheit (misfit) an die Vorgabe als notwendige Bedingung für einen Wandel. Die anderen beiden Bedingungen benennen sie allerdings etwas anders: als Umverteilung von Ressourcen beziehungsweise als Sozialisierungs- und Lernprozess, die sie als hinreichende Bedingungen ansehen).

544 Knill, Christoph 2005: Die EU und die Mitgliedstaaten. A.a.O., S. 166.

${ }^{545}$ Caporaso, James / Cowles, Maria Green / Risse, Thomas 2001: Europeanization and Domestic Change: Introduction. In: Cowles, Maria Green / Caporaso, James / Risse, Thomas (Hrsg.) 2001: Transforming Europe. Europeanization and Domestic Change. Ithaca: Cornell University Press, S. 3.

546 Börzel, Tanja A. 1999: Institutional Adaptation to Europeanization in Germany and Spain. In: Journal of Common Market Studies (JCMS), 37 (4), 1999, S. 573-596. hier S. 574.

${ }^{547}$ Kohler-Koch, Beate 2000: Europäisierung: Plädoyer für eine Horizonterweiterung. In: Knodt, Michéle / Kohler-Koch, Beate (Hrsg.) 2000: Deutschland zwischen Europäisierung und Selbstbehauptung. Frankfurt a. M., S. 11-31., hier S. 20.

548 Vgl. Knill, Christoph / Lehmkuhl, Dirk 2002: The National Impact of European Union Regulatory Policy: Three Europeanization Mechanisms. European Journal of Political Research 41: 255-280. 
sog. Top-down-Prozesse. Andererseits wird durch die Definitionen von Ladrech, Radaelli und Kohler-Koch anhand einer neuen politischen Ordnung exemplarisch verdeutlicht, dass ein anderes Verständnis von „Europäisierung“ ebenfalls möglich ist, ${ }^{549}$ also auf nationaler Ebene, sprich als sog. Bottom-up-Prozesse. Ladrech versteht unter Europäisierung einen Anpassungsprozess von Organisationen an eine veränderte Umwelt, woraus folgt, dass die Europäische Gemeinschaft zu einem „Teil der Organisationslogik nationaler Politik und Entscheidungsprozesse“ 550 wird: „Europeanization is an incremental process re-orienting the direction and shape of politics to the degree that EC political and economic dynamics become part of the organizational logic of national politics and policy-making. “551 Eine weiterführende Definition von Radaelli betrachtet Europäisierung als einen Prozess der Konstruktion, Diffusion und Institutionalisierung von Regeln, Normen, Paradigmen, Prozeduren, „which are first defined and consolidated in the making of EU decisions and then incorporated in the logic of domestic discourse, identities, political structures and public policy." ${ }^{552}$ Hier wird die erweiterte Definition von Kohler-Koch, wonach Europäisierung als „die Erweiterung des Wahrnehmungshorizontes und des politischen Handlungsraumes um die europäische Dimension“6553 aufgefasst wird, verdeutlicht.

Eine Definition von Karl Kaiser und Steffen Angenendt bezüglich des Terminus der Europäisierung lautet zusammengefasst wie folgt: Einerseits kann Europäisierung als „ein Prozess [verstanden], bei dem staatliche Kompetenzen und politische Entscheidungen auf die EU übertragen werden“ und andererseits als „ein Prozess [...], in dem das europäische polititsche System zur Bezugseinheit für gemeinsames Handeln wird“ ${ }^{654}$, verstanden werden. Diese Definition von Karl Kaiser und Steffen Angenendt

${ }^{549}$ Vgl. Große Hüttmann, Martin / Knodt, Michéle 2000: Die Europäisierung des deutschen Föderalismus. In: Aus Politik und Zeitgeschichte (APuZ), B 52-53/2000. Bonn, S. 32.

${ }^{550}$ Ladrech, Robert 1994: Europeanization of Domestic Politics and Institutions: The Case of France. In: Journal of Common Market Studies (JCMS), 32 (1), 1994, S. 69-88. hier S. 69.

${ }^{551}$ Ladrech, Robert 1994: Europeanization of Domestic Politics and Institutions: The Case of France. In: Journal of Common Market Studies (JCMS), 32 (1), 1994, S. 69-88. hier S. 69.

552 Radaelli, Claudio M. 2000: Whither Europeanization? Concept Stretching and Substantive Change. In: European Integration Online Papers (EIoP) Vol. 4 (2000) $\mathrm{N}^{0}$ 8, S. 4. Abrufbar unter: http://www.eiop.or.at/eiop/texte/2000-008.htm (Stand: 17.07.2000); vgl. dazu Kohler-Koch, Beate 2000: Europäisierung: Plädoyer für eine Horizonterweiterung. In: a.a.O., S. 21 und Fußnote 17 auf S. 28 f.; vgl. Radaelli, Claudio M. 2003: The Europeanization of Public Policy. In: Featherstone, Kevin / Radaelli, Claudio M. (Hrsg.) 2003: The Politics of Europeanization. Oxford, S. 27-56.; vgl. Radaelli, Claudio M. / Exadaktylos, Theofanis 2009: Research Design in European Studies: The Case of Europeanization. In: Jounal of Common Market Studies (JCMS) 2009, Volume 47. Number 3: June 2009, S. 507-530.

${ }_{553}$ Kohler-Koch, Beate 2000: Europäisierung: Plädoyer für eine Horizonterweiterung. In: a.a.O., S. 22.

554 Kaiser, Karl / Angenendt, Steffen 2002: Asyl- und Migrationspolitik der Europäischen Union: Strukturen, Prozesse und Inhalte im Spannungsfeld nationalstaatlicher, intergouvernementaler, 
ist somit eindeutig auf die Europäisierung als Bottom-up-Prozess bezogen. Bei der Europäisierung als politische Horizonterweiterung im Mehrebenensystem steht die gestaltende Rolle politischer Akteure im Mittelpunkt. ${ }^{555}$ Daher stellt sich die zentrale Frage in der aktuellen Europäisierungsdebatte nach einem Souveränitätsverlust durch EU-Vorgaben oder der Steuerungsfähigkeit durch nationale Kompetenzenübertragung.

Die bisherigen Überlegungen zur Europäisierung sind real dadurch miteinander verbunden, dass unterschiedliche Europäsierungsprozesse nicht in Reinkultur, sondern in Mischformen auftreten, wie z. B. sog. Top-down-Prozesse versus sog. Bottom-upProzesse. Im Folgenden sollen diese zweiseitigen selten thematisierten Zusammenhänge mit der einleitenden Frage aufgezeigt werden, welche Prozesse im europäischen Mehrebenensystem im Rahmen der EU zueinander in Konkurrenz stehen und welche alternativen Bezugspunkte des migrationspolitischen Handelns konstituiert werden.

supranationaler und internationaler Regulierung. Eine Studie zur Dynamik des Regierens in einem postnationalen Mehrebenensystem, Forschungsprojekte der DGAP (die Deutsche Gesellschaft für Auswärtige Politik: Director, German Council on Foreign Relations: http://www.aicgs.org). Berlin, S. 15; vgl. auch Baumann, Mechthild 2006: Der deutsche Fingerabdruck: a.a.O., S. 37.

555 Kohler-Koch, Beate 2000: Europäisierung: Plädoyer für eine Horizonterweiterung. In: Knodt, Michéle/Kohler-Koch, Beate (Hrsg.) 2000: Deutschland zwischen Europäisierung und Selbstbehauptung. Frankfurt a. M., S. 23. 


\section{Europäisierung durch die vertragliche Institutionalisierung auf EU-Ebene}

Es folgt zuerst die Europäisierung des Politikfeldes Migration unter den europäischen Verträgen $^{556}$, die die Grundlage für die migrationsrelevante Zusammenarbeit seit den neunziger Jahren bilden. In den vergangenen Jahren hat sich institutionell das Gefüge um die Migrationspolitik zwischen den EU-Organen entscheidend verändert. Seit den 1990er Jahren bezeichnete somit die Institutionalisierung der Regierensformen ein wichtiger Impuls in Untersuchungen über die Europäische Union. Infolge der Aufnahme der „offenen Methode der Koordinierung“ (OMK) werden diese Regierensformen bereits im Vertrag von Maastricht gleichgesetzt. ${ }^{557}$ Der Schwerpunkt der europäischen Zusammenarbeit der Migrationspolitik ist besonders in ihren Institutionen zu finden. ${ }^{558}$

Unter diesem Aspekt ist es eine Zielsetzung dieser Arbeit, einen funktionierenden Ansatz der Theorie zur Analyse von Europäisierungsprozessen zu erarbeiten, der sich nicht auf das Modell eines „Anpassungsdrucks“ konzentriert. Als Basis diente hierbei die in der neo-institutionalistischen (NI) Diskussion der Politikwissenschaften vertretene These einer Strukturierung des Akteurshandelns durch den institutionellen Zusammenhang, in dem sich dieses Handeln vollzieht. ${ }^{559}$ Das Außergewöhnliche des europäischen Mehrebenensystems ist in den unterschiedlichen politischen Paradigmen der EU-Mitgliedstaaten in Bezug auf den historischen Institutionalismus zu finden, die innerhalb einzelner Politikfelder miteinander konfrontiert werden, ohne dass sich eines dieser Paradigmen konsequent behaupten könnte. Da eine Monopolisierung legitimer Gewalt bzw. die soziale Legitimität hinsichtlich des soziologischen Institutionalismus nicht vertreten ist, können sich eine konkurrierende politische Bezugsebene sowie im Zuge derer prägende paradigmatische Orientierungen nicht etablieren. Hier werden

${ }_{556}$ Bezüglich der EU-Verträge vgl. auch im Internet: http://europa.eu.int/eur-lex/de/index.html.

557 Vgl. Ette, Andreas / Kreienbrink, Axel 2008: Kooperation statt Harmonisierung: Konsequenzen europäischer Governance für die Europäisierung der deutschen Rückkehr- und Abschiebungspolitik. In: Hunger, Uwe / Aybek, Can M. / Ette, Andreas / Michalowski, Ines (Hrsg.) 2008: Migrations- und Integrationsprozesse in Europa: Vergemeinschaftung oder nationalstaatliche Lösungswege?. Wiesbaden, S. 51.

558 Institutionen sind definiert als "cognitive, normative and regulative structures and activities that provide stability and meaning to social behavior.” In: Scott, W. Richard 1995: Institutions and Organizations. Thousand Oaks, S. 33.

559 Vgl. Harmsen, Robert 2000: Europeanization and Governance: A New Institutionalist Perspective. In: Harmsen, Robert / Wilson, Thomas M. (Ed.) 2000: Yearbook of European Studies 14. Europeanization: Institution, Identities and Citizenship. Amsterdam-Atlanta. S. 58; vgl. auch Senge, Konstanze / Hellmann, Kai-Uwe (Hrsg.) 2006: Einführung in den Neo-Institutionalismus: Mit einem Beitrag von W. Richard Scott. Wiesbaden. 
durchsetzungskräftige EU-organisatorische Ressourcen wirksam, wie das sogenannte „institutionelle Dreiecksgefüge“: das Europäische Parlament (EP), die Europäische Kommission (KOM) und der Rat der Europäischen Union (Ministerrat). Außerdem streben sowohl der Europäische Gerichtshof (EuGH) als auch der Europäische Rat nach einer wirksamen Umsetzung des Akteurshandelns. Mit Blick darauf entstand die Vorstellung einer Auseinandersetzung zwischen supranationaler und nationaler Migrationspolitik in Form von „Institutionenkämpfen“. Organisationen und Akteure sollten hierbei als Vertreter der jeweiligen unterschiedlichen Leitideen und paradigmatischen Orientierungen für die verbindliche Umsetzung dieser Institutionalisierungen fungieren. Institutionelle Aspekte sind als zentraler prägender Einfluss in der Migrationspolitik der EU anzusehen.

Wie zuvor dargestellt wurde, ergab sich demnach die Notwendigkeit einer Europäisierung der Migrationspolitik. In der Anfangszeit der Europäischen Gemeinschaft war eine gemeinsame europäische Migrationspolitik weder beabsichtigt noch langfristig geplant._Kern der europäischen Einigung war ursprünglich nur die Idee einer Wirtschaftsgemeinschaft - eines gemeinsamen Marktes - und keineswegs die gemeinsame Gestaltung der Immigration aus Drittstaaten. Seit den Römischen Verträgen von 1957, die heute allgemein als historische Grundlage der heutigen Zusammenarbeit in der Zuwanderungspolitik angesehen werden ${ }^{560}$, lassen sich drei unterschiedlich lange Phasen erkennen: ${ }^{561}$ 1. Phase (1957 - 1990): Koordination der Mitgliedstaaten zur Realisierung der innereuropäischen Grenzöffnung. 2. Phase (1990 1999): zwischenstaatliche Zusammenarbeit. 3. Phase (1999 - 2010): die Tendenz zur Vergemeinschaftung. Ausgehend von diesen Phasen stellen sich hier die folgenden Fragen: Was ist derzeit der rechtliche Handlungsrahmen der EU und kann dieser als ausreichend angesehen werden? Welche Veränderungen ergeben sich durch die Neuordnung des Unionsvertrags und welche Faktoren haben dabei eine wesentliche Rolle gespielt? Mit welchen Blockaden sieht sich die weitere Harmonisierung im europäischen Mehrebenensystem konfrontiert und welche Fortschritte des substanziellen Einwanderungsrechts sind auf europäischer Ebene $\mathrm{zu}$ erhoffen? Inwiefern wird in den Verträgen das Spannungsverhältnis zwischen den nationalen

\footnotetext{
560 Vgl. Han, Petrus 2005: Soziologie der Migration: Erklärungsmodelle. Fakten. Politische Konsequenzen. Perspektiven. Stuttgart, S. 200.

561 Vgl. Bendel, Petra 2008: Migration und Integration in Europa: Geschichte der europäischen Migrationspolitik. Online verfügbar unter http://www.bpb.de/themen/K9YHTK.html (Stand: 29.01.2008); vgl. Märker, Alfredo 2005: Europäische Zuwanderungspolitik und globale Gerechtigkeit: Über die normative Dimension der Vergemeinschaftung zuwanderungspolitischer Maßnahmen in der Europäischen Union. Baden-Baden, S. 42.
} 
Souveränitätsansprüchen und dem Kooperationszwang aufgelöst? ${ }^{562}$ Inwiefern wird die europäische Migrationspolitik von der Koordination zur Vergemeinschaftung entwickelt? Welche inhaltlichen Konsequenzen wird dabei die umfassende Europäisierung mit sich bringen? Ist die fortschreitende Europäisierung der Migrationspolitik annehmbar? Welche Perspektiven bietet die bisherige vertragliche Entwicklung für die künftige Zuwanderungspolitik der Europäischen Union? Es stellt sich hier ferner die Frage, welche Rolle den europäischen Institutionen zukommt. Hierbei wird die Berücksichtigung nationaler Interessen durch das europäische Mehrebenensystem und der Europäisierungstrend betrachtet, der sich anhand der „Entwicklung der Rolle der Gemeinschaftsinstitutionen“563 beobachten lässt.

Wenn die Kernaussage der Theorie des Neo-Institutionalismus (NI) in Betracht gezogen wird, wie sie von March und Olsen entwickelt wurde, ${ }^{564}$ dann ist die Annahme naheliegend, dass (a) durch das institutionelle Arrangement der Verträge des europäischen Mehrebenensystems eine Anpassung der nationalen politischen Systeme erzielt wird, und dass (b) die durch die Geschichte erwachsenen institutionellen Strukturen der EU-Mitgliedstaaten eine große Differenz in Bezug auf die Veränderung im Politikbereich Migration und deren Geschwindigkeit bewirken. Ausgehend von dieser Annahme lautet eine zentrale These dieses Abschnitts: Der Prozess der Europäisierung der EU-Migrationspolitik liegt hauptsächlich in einer parallelen Institutionalisierung der gemeinschaftlichen Interessen.

Zur Verdeutlichung dieser These wird zunächst die vertragliche Institutionalisierung der Migrationspolitik auf der EU-Ebene im historischen Ablauf untersucht (Abschnitt 2.1 2.10). Im Anschluss daran wird die Frage erörtert, welchen Beitrag die hier entstandenen Verträge zur Diskussion der Europäisierungsprozesse leisten können (Abschnitt 2.11).

\footnotetext{
${ }^{562}$ Vgl. Tomei, Verónica 2001: Europäisierung nationaler Migrationspolitik: Eine Studie zur Veränderung von Regieren in Europa. Stuttgart, S. 52.

563 Tomei, Verónica 2001: Europäisierung nationaler Migrationspolitik: a.a.O., S. 52.

564 Vgl. March, James G. / Olsen, Johan P. 1989: Rediscovering Institutions: The Organizational Basis of Politics. New York.; vgl. Immergut, Ellen 1998: The Theoretical Core of the New Institutionalism. In: Politics and Society 26 (1), S. 5-34; vgl. auch Kohler-Koch, Beate / Conzelmann, Thomas / Knodt, Michéle 2004: Europäische Integration - Europäisches Regieren. Wiesbaden, S. 177.
} 


\subsection{Die Schengener Abkommen}

Die zwei völkerrechtlichen Verträge, sprich das Schengener Abkommen in Verbindung mit dem Schengener Durchführungsübereinkommen sind als die größten Erfolge in puncto fortschrittlicher Zusammenarbeit der Bereiche Inneres und Justiz zu bezeichnen. Durch das sogenannte „Schengener Übereinkommen“, das als völkerrechtlicher Vertrag außerhalb des EG-Rechts geschlossen wurde, ist auch Staaten außerhalb der EG der Beitritt ermöglicht worden. ${ }^{565}$ Der Bedarf einer zum Binnenmarkt flankierenden Zusammenarbeit in migrationspolitisch wichtigen Bereichen sowie die Relevanz von Fragen der nationalstaatlichen Souveränität sind im Schengen-Vertrag zum Ausdruck gekommen. Dies zeigte zum einen die Wahl des institutionellen Rahmens der rein intergouvernementalen Zusammenarbeit sehr deutlich und zum anderen die Gemeinschaftsinstitutionen Kommission, Parlament und Gerichtshof, die in dieser Hinsicht allerdings außen vor blieben. Die EU-Mitgliedstaaten, und hier in erster Linie die Ministerien des Äußeren und des Inneren bezeichneten diesbezüglich die entscheidenden Akteure, wobei der Exekutivausschuss, der einstimmig beschloss, als das Entscheidungsgremium galt. ${ }^{566}$ Schengen stellte vor allem für die einzelnen Mitgliedstaaten die optimale Verbindung zwischen einer verstärkten Wirtschaftsintegration und parallel dazu der Weiterführung einer restriktiven Zuwanderungspolitik dar. Jedoch kann Schengen nicht bloß als Mittel der Durchsetzung nationaler Interessen gesehen werden: „It put in place structures that indicated deeper integrative intent among a core group of member states. In this sense, Schengen was a testing ground [...] for the future developments within the formal Treaty structure. Schengen also demonstrated the willingness of member states to pursue more 'flexible' forms of co-operation and integration with smaller groups of pioneer states pushing for closer integration. ${ }^{, 567}$

Das erste Schengener Abkommen, kurz „SchÜk (auch Schengen I)“, wurde am 14.06.1985 auf deutsch-französische Initiative in dem kleinen Ort Schengen (Luxemburg) zwischen Deutschland, Frankreich und der Benelux-Wirtschaftsunion (Belgien, Luxemburg und den Niederlanden) abgeschlossen. ${ }^{568}$ Das Schengener

\footnotetext{
565 Vgl. Nuscheler, Franz 2004: Internationale Migration: Flucht und Asyl. Wiesbaden, S. 178.

566 Vgl. Tomei, Verónica 2001: Europäisierung nationaler Migrationspolitik: a.a.O., S. 52 f.

567 Geddes, Andrew 2003: The Politics of Migration and immigration in Europe. London:Sage, S. 132.

568 Vgl. Tomei, Verónica 1997: Europäische Migrationspolitik: zwischen Kooperationszwang und Souveränitätsansprüchen. Bonn, S. 17; vgl. auch Eigmüller, Monika 2007: Grenzsicherungspolitik:
} 
Abkommen schreibt eine vertraglich festgeschriebene internationale Zusammenarbeit auf ministerieller Ebene vor, während gleichzeitig die Unterzeichnerstaaten ihre nationale Souveränität bewahren. Schwerpunkt des Abkommens ist der Abbau der Personenkontrollen an den jeweiligen Binnengrenzen zur Verwirklichung der Personenfreizügigkeit ${ }^{569}$ zwischen diesen fünf Gründerstaaten. Es wurden sowohl Schritte zur Vereinbarung einer gemeinsamen Asyl- und Visapolitik ${ }^{570}$ als auch eine vermehrte polizeiliche Zusammenarbeit beschlossen. In dem Bestreben, besonders die Kriminalität erfolgreich zu bekämpfen, wurde in dem Abkommen eine verstärkte Zusammenarbeit der Zoll- und Polizeibehörden der Vertragsstaaten angestrebt (Art. 9 SchÜk), wobei Entscheidungen über konkrete Regelungen hierzu nicht getroffen wurden. ${ }^{571}$ So trug Schengen - inzwischen als gleichbedeutend geltend mit europäischer Grenzpolitik - seine Prägung von Anfang an durch die Gegensätze von Freiheit und Sicherheit. In dieser ersten Phase auf dem Weg zu einer gemeinsamen europäischen Asyl- und Migrationspolitik boten sich hinsichtlich des Verlaufs der Verhandlungen mit deutscher und französischer Einflussnahme neue Möglichkeiten. Vor allem die Bundesrepublik Deutschland unter der Führung der Regierung von Helmut Kohl prägte und lenkte die Grenzpolitik durch die Verfolgung ihrer eigenen Interessen entscheidend. ${ }^{572}$ Der Beschluss des Bundestages vom 12. Dezember 1985 bildete indes die Grundlage der Verhandlungen der Bundesrepublik Deutschland mit den anderen Vertragsstaaten. ${ }^{573}$ Das erste Schengener Abkommen besteht aus zwei Teilen: a) Den kurzfristig durchzuführenden Maßnahmen (Titel I, Art. 1-16 SchÜk), die eine Erleichterung der Grenzkontrollen, speziell durch die Einrichtung gemeinsamer Grenzkontrollstellen und einfacher Sichtkontrollen im Personenverkehr vorsahen, und b) den längerfristig durchzuführenden Maßnahmen (Titel II, Art. 17-27 SchÜk), die den völligen Abbau der Grenzkontrollen ermöglichen sollten und zeitgleich kompensierende

Funktion und Wirkung der europäischen Außengrenze. Wiesbaden, S. 59.

569 Zuvor hatten Deutschland und Frankreich mit Unterzeichnung des sogenannten „Saarbrückener Abkommens“ am 13. Juli 1984 eine erste bilaterale Übereinkunft bezüglich der Aufhebung der Personenkontrollen an der gemeinsamen Binnengrenze getroffen. In: BGBl (Bundesgesetzblatt). 1994 II: Abkommen zwischen der Regierung der Bundesrepublik Deutschland und der Regierung der Französischen Republik über den schrittweisen Abbau der Kontrollen an der deutsch-französischen Grenze vom 13. Juli 1984. S. 768 ff.

570 Vgl. Kohler-Koch, Beate / Conzelmann, Thomas / Knodt, Michéle 2004: a.a.O., S. 137.

571 Vgl. Würz, Karl 1997: Das Schengener Durchführungsübereinkommen: Einführung. Erläuterungen. Vorschriften. Stuttgart u.a., S. 29.

572 Vgl. Baumann, Mechthild 2008: Der Einfluss des Bundeskanzleramts und des Bundesministeriums des Innern auf die Entwicklung einer europäischen Grenzpolitik. In: Hunger, Uwe / Aybek, Can M. / Ette, Andreas / Michalowski, Ines (Hrsg.) 2008: Migrations- und Integrationsprozesse in Europa: Vergemeinschaftung oder nationalstaatliche Lösungswege?. Wiesbaden, S. 17-33, hier S. 28.

573 Vgl. Deutscher Bundestag: Drucksachen: BT-Drs. 10/4555 vom 12. 12. 1985, 11/3594 vom 7. 5. 1990. 
Maßnahmen für den Wegfall der Grenzkontrollen umfassten. ${ }^{574}$ Geplant war hierfür, die Abschaffung der Grenzkontrollen bis zum 01.01.1990 zu realisieren. Jedoch konnte das Übereinkommen infolge datenschutzrechtlicher und sichrheitstechnischer Probleme bei dem Aufbau eines gemeinsamen Informationssystems nicht rechtzeitig umgesetzt werden. Durch ein Informationssystem (SIS) sollten Daten und Informationen einerseits über Kriminalität andererseits über Einwanderinnen und Einwanderer aus Drittstaaten ${ }^{575}$ erfasst werden. ${ }^{576}$

Die Umsetzung erfolgt dann durch das vom 19.6.1990 abgeschlossenes zweite Übereinkommen, sprich „das Schengener Durchführungsübereinkommen“, das die offizielle Abkürzung „SDÜ“ oder „Schengen II“ trägt, in dem ein neuer Zeitplan bestimmt und die Vorgaben von Schengen I konkretisiert wurden. ${ }^{577}$ SDÜ (Schengen II) trat am 26.03.1995 in Kraft und brachte der Gemeinschaft den klischeehaften Beinamen „Festung Europa“6578 ein. Beabsichtigtes Ziel war eine Harmonisierung von Grenzkontrollen- und Visavorschriften, eine Annäherung des Asylrechts und eine neue Zuständigkeitsverteilung zur Prüfung von Asylgesuchen nach dem Prinzip des „one state only“: Die Zuständigkeit für ein in der Gemeinschaft gestelltes Asylbegehren sollte nur noch einen Staat betreffen. ${ }^{579}$ Das SDÜ (Schengen II) umfasst insgesamt 142 Artikel, eine Schlussakte und ein Protokoll und ist in acht Titel folgenden Inhalts gegliedert: ${ }^{580}$ Der Titel II Art. 2 Abs. 1 SDÜ bezieht sich auf die Abschaffung der Kontrollen an den Binnengrenzen und am Personenverkehr. Anschließend (Art. 3 - 8

574 Vgl. Epiney, Astrid 1995: Das zweite Schengener Abkommen: Entstehung, Konzept und Einbettung in die Europäische Union. In: Achermann, Alberto / Bieber, Roland / Epiney, Astrid / Wehner, Ruth (Hrsg.) 1995: Schengen und die Folgen: Der Abbau der Grenzkontrollen in Europa. Bern u.a., S. 24 f.; Foerster, Viktor 1996: Rechtliche Grundlagen des Schengener Abkommen. In: Heckmann, Friedrich / Tomei, Verònica (Hrsg.) 1996: Freizügigkeit in Europa: Migrations- und europapolitische Aspekte des Schengen-Vertrages. Bonn, S. 25-28.

575 Ein Drittstaat wurde zunächst als ein Staat definiert, der nicht Vertragspartei ist. Ein Drittausländer wurde dabei einsweilen als eine Person bezeichnet, die nicht Staatsangehöriger eines der Mitgliedstaaten der Europäischen Gemeinschaften ist bzw. als Nicht-EU-Bürger. In: Würz, Karl 1997: Das Schengener Durchführungsübereinkommen: a.a.O., S. 164.

576 Vgl. Birsl, Ursula 2005: Migration und Migrationspolitik im Prozess der europäischen Integration?. Opladen, S. 112.

577 Vgl. Klos, Christian 1999: Eine Reise von Rom nach Amsterdam: Die Entwicklung des europäischen Einwanderungsrechts. In: Wolter, Achim (Hrsg.) 1999: Migration in Europa: Neue Dimensionen, neue Fragen, neue Antworten. Baden-Baden, S. 24.

578 Bendel, Petra 2004: Migrationspolitik der Europäischen Union: Kompetenzen, Inhalte, Prognosen. In: Werz, Nikolaus / Nuthmann, Reinhard (Hrsg.) 2004: Abwanderung und Migration in Mecklenburg und Vorpommern. Wiesbaden, S. 257.

579 Vgl. Schmid, Christian / Bartels, Romy 2001: Handbuch zum Dubliner Übereinkommen. Baden-Baden.

580 Vgl. Epiney, Astrid 1995: Das zweite Schengener Abkommen: a.a.O., S. 26-29; Würz, Karl 1997: Das Schengener Durchführungsübereinkommen: Einführung. Erläuterungen. Vorschriften. S. 163-223. 
SDÜ) folgen detaillierte Vorschriften über die Art der Durchführung der Kontrollen an den Außengrenzen. In Verbindung hiermit steht ebenfalls die in Planung befindliche Harmonisierung der Sichtvermerke (Art. 9 ff. SDÜ), die Reiseverkehrsregelung für Drittausländer (Art. 19 ff. SDÜ) und die Verpflichtung der einzelnen Länder zum Erlass innerstaatlicher Gesetze angesichts der Rückschaffung von Personen, denen die Einreise untersagt ist, an eine Außengrenze (Art. 26 SDÜ). Die Basis dafür bildet eine vom Exekutivausschuss (Entscheidungen auf Ministerebene) formulierte verbindliche Auflistung von für zurzeit 127 visapflichtige Drittstaaten, ${ }^{581}$ die Gefahren im Hinblick auf die innere Sicherheit und das Risiko illegaler Einwanderung für die Schengenstaaten bergen. Eine visapflichtige Person aus einem Drittstaat ist mittels eines einheitlichen Sichtvermerks, der von dem Schengenland als Hauptreiseziel ausgestellt wird, drei Monate lang berechtigt, im ganzen Raum von Schengen frei zu reisen (Art. 5 Abs. 1 und Art. 9-17 SDÜ). Die Ausstellung von Sichtvermerken für einen längerfristigen Aufenthalt, also für einen Aufenthalt von mehr als drei Monaten, ist gemäß Art. 18 SDÜ den einzelnen Schengenländern nach ihren jeweiligen innerstaatlichen Rechtsvorschriften vorbehalten. Die Art. 28 bis 38 SDÜ regeln die Zuständigkeiten für das Asylbegehren, sodass nur eine Schengener Vertragspartei für das Asylbegehren eines Drittausländers zuständig ist (Art. 29 Abs. 3 SDÜ), und deren Entscheidung, die sie nach nationalem Recht zu treffen hat, für alle anderen gültig ist. Dabei bleibt der materielle Prüfungsmaßstab das einheimische Recht (Art. 32 SDÜ), d. h., die nationalen Asylrechte bleiben bestehen. Die dementsprechenden Regelungen beruhen mit dem New Yorker Protokoll vom 31. Januar 1967 (Art. 28 SDÜ) auf der Genfer Flüchtlingskonvention vom 28. Juli 1951 und bieten folglich in sämtlichen SchengenStaaten die gleichen Rechtsgrundsätze für Asylbewerber, wobei diese nunmehr kein Interesse haben, nach Abschluss eines Verfahrens weitere Verfahren in anderen Schengen-Staaten $\mathrm{zu}$ eröffnen. ${ }^{582}$ Das umfassende Schengener Informationssystem (SIS), ein computergesteuertes Informations- und Verhandlungssystem auf supranationaler Ebene, ist von zentraler Wichtigkeit im Rahmen der sogenannten Schengener Ausgleichsmaßnahmen (Titel IV Art. 92 ff. SDÜ). Art. 93 SDÜ zeigt, dass es sich beim SIS nicht nur um reine Ausgleichsmaßnahmen handelt, sondern auch um die öffentliche Sicherheit und Ordnung einschließlich der Staatssicherheit. Mit dem

\footnotetext{
581 Vgl. Hildebrandt, Achim 1996: Das Visumregime im Schengener Vertragswerk. In: Heckmann, Friedrich / Tomei, Verònica (Hrsg.) 1996: Freizügigkeit in Europa: a.a.O., S. 47.

582 Das Dubliner Übereinkommen hat die Schengener Bestimmungen des SDÜ über die Zuständigkeit für die Behandlung von Asylanträgen außer Kraft gesetzt. Vgl. BGBl. 1995 II: Gesetz zum Protokoll vom 26.04.1994 bezüglich der Konsequenzen des Inkrafttretens des Dubliner Abkommens für einige Bestimmungen des Durchführungsübereinkommens zum Schengener Übereinkommen vom 11.09.1995 (sog. Bonner Protokoll). S. 738; vgl. auch Würz, Karl 1997: a.a.O., S. 50.
} 
Schengen-Vertrag haben sich die Mitgliedstaaten verpflichtet, zum einen im Rahmen ihrer innerstaatlichen Bestimmungen Bußgeldvorschriften für den illegalen Transport von Personen $\mathrm{zu}$ verhängen, die nicht im Besitz gültiger Papiere sind, sowie zum anderem Sanktionen gegen sogenannte Schlepper zu erwirken, um der unrechtmäßigen Einreise Einhalt zu gebieten (Art. 26 - 27 SDÜ).

SDÜ (Schengen II) hat allerdings eine völlige Einstellung der Binnengrenzkontrollen zwischen den Signaturstaaten nicht gänzlich obsolet werden lassen. Die liberale niederländische Drogenpolitik beispielsweise wird von Frankreich als ernst zu nehmende Gefahr für eine verstärkte Ausbreitung des Drogenhandels im eigenen Land gesehen, weswegen in Abstimmung mit dem Schengener Exekutivausschuss an manchen Grenzübergangsstellen vermehrte Kontrollen durchgeführt werden. Die Zuständigkeitsregelungen des Umgangs mit Asylanträgen sind von besonderer praktischer Bedeutung, wobei diese weder eine Harmonisierung des materiellen noch des prozessualen Asylrechts und ebenso wenig eine ausgeglichenere Aufteilung der Asylsuchenden auf die Unterzeichnerstaaten zur Folge haben. ${ }^{583}$ Beschlüsse bezüglich der Gewährung von Asyl werden nach wie vor nach den Bestimmungen des jeweiligen nationalstaatlichen Rechts gefasst. Das Schengener Abkommen erzielte überdies als zwischenstaatlicher Vertrag außerhalb des EU-Rechts eine Binnen- und Außenwirkung: Es wurde etwa in Deutschland der Druck auf Art. 16 GG verschärft, sodass sich die damaligen EFTA (European Free Trade Association)-Staaten genötigt sahen, dem Abkommen beizutreten, um einer etwaigen Umleitung von Migrationsströmen zu entgehen. ${ }^{584}$ Darüber hinaus hat Schengen im Bereich der Abschiebung für die gesamte Europäische Union eine Vorreiterfunktion eingenommen. Die Abschiebungsverantwortung für das gesamte Hoheitsgebiet liegt laut Vertrag bei den Außengrenzstaaten, wobei die Kosten im Falle eines entstehenden Ungleichgewichts verteilt werden. Des Weiteren hat Schengen gleichfalls im Bereich der Visapolitik auf den zukünftigen Umgang der EU mit Visabegehren verweisende Maßstäbe gesetzt. ${ }^{585}$

Mit Italien hatte sich die Schengen-Gruppierung bereits 1990 neben den fünf GründerVetragsstaaten um einen Mitgliedsstaat erweitert. Spanien und Portugal folgten 1991, Griechenland 1992 und Österreich 1995 sowie die skandinavischen Staaten Dänemark,

${ }^{583}$ Vgl. Deutscher Bundestag: Drucksachen: BT-Drs. 12/2453 vom 12. 12. 1995, S. 91, S. 93; 12/6485 (Anlage 2) vom 7. 5. 1995.; vgl. Würz, Karl 1997: a.a.O., S. 49.

584 Vgl. Nuscheler, Franz 2004: Internationale Migration: Flucht und Asyl. Wiesbaden, S. 178.

${ }^{585}$ Vgl. Tomei, Verònica 1996: Migrationspolitische und europapolitische Perspektiven des Schengener Abkommens. In: Heckmann, Friedrich / Tomei, Verònica (Hrsg.) 1996: Freizügigkeit in Europa: Migrations- und europapolitische Aspekte des Schengen-Vertrages. Bonn, S. 95-96. 
Schweden und Finnland als EU-Länder 1996. ${ }^{586}$ Auch Island und Norwegen sind als Nicht-EU-Staaten seit 1996 dem Schengen-Raum zugehörig, ${ }^{587}$ wodurch sich die Anzahl der Schengen-Vertragsstaaten mit Ausnahme von Großbritannien, Irland und mit Einschränkungen Dänemark auf 15 erhöhte. Großbritannien und Irland haben insbesondere unter Beibehaltung ihrer Grenzkontrollen (die sog. „opt in“ Klausel) ${ }^{588}$ den Schengen-Besitzstand nur zum Teil übernommen. Der Schengen-Raum wurde bis Ende 2008 um 22 EU-Staaten und drei weitere Staaten erweitert. Auch die Schweiz hat den Schengen-Besitzstand übernommen, weswegen seit dem 12.12.2008 an den Schweizer Grenzen keine systematischen Personenkontrollen mehr erfolgen. ${ }^{589}$ Neben einer vermehrten Reise- und Niederlassungsfreiheit der Staatsangehörigen der Unterzeichnerländer durch das SDÜ bieten die neuen Regelungen auch Personen aus Drittstaaten eine bis zu drei Monaten andauernde ungehinderte Reisefreiheit in einem der Schengen-Länder, sofern sie sich im Besitz gültiger Aufenthaltspapiere befinden. Jedoch bleibt diesbezüglich zu erwähnen, dass eingedenk der Schengener Abkommen trotz eines schrittweisen Abbaus der Kontrollen an den Außengrenzen der einzelnen Länder eine totale Freiheit von Binnengrenzkontrollen innerhalb des vorgesehenen Raumes nicht oder nur teilweise erreicht werden konnte.

Grundsätzlich muss dazu angemerkt werden, dass die Schengener Abkommen als nicht ratifizierungsbedürftige Verwaltungsabkommen in Form von Regierungsabkommen galten. Sie bezeichneten damit völkerrechtliche Verträge, da die zwei Abkommen ohne Konsultation und Unterrichtung der Gemeinschaftsorgane geschlossen wurden. Diesem Aspekt ist Wichtigkeit beizumessen, weil der Schengen-Acquis, mit dem die Inhalte von Schengen I und II tituliert werden, mit Inkrafttreten des Amsterdamer Vertrags in das Europäische Gemeinschaftsrecht integriert worden ist. Damit hat Schengen eine prägende Funktion für die künftige Kooperation der einzelnen Vertragsstaaten in puncto

586 In erster Linie machten Finnland und Schweden ihren Beitritt zum SDÜ von der Beibehaltung des freien Personenverkehrs innerhalb der Nordischen Paßunion abhängig. Bereits 1957 war die Nordische Paßunion in Kraft getreten, die einen freien Personenverkehr zwischen den skandinavischen Ländern (Dänemark, Finnland, Schweden, Island, Norwegen) gewährleistete. Die Nordische Paßunion sollte durch das Schengener Übereinkommen nicht gefährdet werden. Vgl. Hailbronner, Kay / Thiery, Claus 1997: Schengen II und Dublin - Der zuständige Asylstaat in Europa. In: Zeitschrift für Ausländerrecht und Ausländerpolitik (ZAR). Bd. 17. 1997. Baden-Baden, S. 55.

587 Die skandinavischen Nicht-EU-Mitglieder Island sowie Norwegen hatten im Dezember 1996 das Übereinkommen unterzeichnet und wurden hierdurch als assoziierte Mitglieder aufgenommen. Erst im März 2001 wurden die Nicht-EU-Mitgliedstaaten Norwegen und Island zu SchengenVollmitgliedstaaten.

588 Art. 3 und 5 Schengen-Protokoll. Vgl. Kohler-Koch, Beate / Conzelmann, Thomas / Knodt, Michéle 2004: Europäische Integration -Europäisches Regieren. Wiesbaden, S. 138.

589 Vgl. Weidenfeld, Werner / Wessels, Wolfgang (Hrsg.) 2009: Europa A bis Z: Taschenbuch der europäischen Integration. Berlin, S. 445. 
Einwanderungspolitik gehabt, und überdies als Maßstäbe setzender Vertrag eine bedeutende Rolle für die gesamte Europäische Union eingenommen. Diese intergouvernementale Zusammenarbeit wird dabei in den Dienst des jeweiligen nationalstaatlichen Interesses gestellt, das trotz aller durch die einmal begonnene Zusammmenarbeit entstandene Dynamik die weiteren Arbeiten hemmt. Das Einstimmigkeitserfordernis führt beispielsweise in diesem für Kompromisslösungen sehr sensiblen Bereich zu Minimalergebnissen. Darüber hinaus können die Schengener Abkommen mit einem sogenannten ,spill-over“ Effekt der funktionalen Integration erklärt werden, d. h., Integration zieht in einem Bereich zwangsläufig die Integration in funktional damit zusammenhängenden Bereichen nach sich. ${ }^{590}$ So bezwecken die Abkommen zunächst nur den Abbau der Binnengrenzen, sie weisen aber gleichzeitig auch auf die dafür notwendigen flankierenden Maßnahmen. Deshalb kann Schengen als erstes greifbares Modell für ein „Europa der zwei Geschwindigkeiten“ erachtet werden, das verschiedene neuartige Wege der Integrations- und Zusammenarbeit beschreitet, und auf lange Sicht die Hoffnung trägt, dass die anderen Mitgliedstaaten seinem Beispiel folgen. ${ }^{591}$ Die durch den Amsterdamer Vertrag bekräftigte Musterrolle der Schengener Zusammenarbeit für die gesamte EU wird eine Integration in das Europarecht erfahren, wobei das Risiko angesichts der intergouvernementalen Ausprägung der europäischen Migrationspolitik bestehen bleibt, dass den Interessen von Einzelstaaten entgegenstehende Fortschritte ausbleiben oder zumindest erschwert werden.

${ }^{590}$ Vgl. Haas, Ernst Bernard 1958: The Uniting of Europe: political, social, and economic forces 19501957. London; vgl auch Cram, Laura 1996: Integration theory and the study of the European policy process. In: Richardson, Jeremy J. (ed.) 1996: European Union: power and policy-making. London, S. 40-58, hier S. 46-47.

591 Vgl. Tomei, Verònica 1996: Migrationspolitische und europapolitische Perspektiven des Schengener Abkommens. In: Heckmann, Friedrich / Tomei, Verònica (Hrsg.) 1996: Freizügigkeit in Europa: Migrations- und europapolitische Aspekte des Schengen-Vertrages. Bonn, S. 92-93 u. S. 98. 


\subsection{Das Dubliner Abkommen}

Das am 15.06.1990 in Dublin unterzeichnete Dubliner „Übereinkommen über die Bestimmung des zuständigen Staates für die Prüfung eines in einem Mitgliedstaat der Europäischen Gemeinschaften gestellten Asylantrags، ${ }^{\text {‘592 }}$ ist das EG-weite Gegenstück zu den asylrechtlichen Regeln des SDÜ (Schengen II). ${ }^{593}$ Angesichts des Zusammenbruchs der ehemaligen Ostblockstaaten hatte sich Anfang der 90er Jahre in allen EG-Staaten die Anzahl der Asylbewerber und Flüchtlinge beträchtlich erhöht. Daher beinhaltet das Abkommen vor allem Regelungen zur Bestimmung des zuständigen Asyllandes. Ebenso wie die Schengener Abkommen wurde das Dubliner Übereinkommen (im Folgenden DÜ bzw. Dublin I) als rechtlich bindendes Instrumentarium auf der Grundlage eines zwischenstaatlichen Dialogs durch die nationalen Ministerialbürokratien außerhalb der EU-Institutionen beschlossen. Es wurde folglich als völkerrechtlicher Vertrag und als erster rechtskräftiger Schritt im Hinblick auf eine gemeinsame Asylpolitik ${ }^{594}$ von allen damaligen EG-Mitgliedstaaten (mit Ausnahme von Dänemark, das dem Abkommen später beitrat) unterzeichnet. Es trat schließlich nach einem langwierigen Ratifizierungsprozess am 01.09.1997 als Ergänzung zum Schengener Abkommen in Kraft. ${ }^{595}$

Nach der Präambel verfolgte das DÜ das Ziel der „Harmonisierung der Asylpolitiken“. ${ }^{596}$ Sinn des Dubliner Übereinkommens war in erster Linie die Realisierung eines ,Systems geteilter Verantwortung“6977, im Gegensatz zu individuellen Anrechten, wobei der Schwerpunkt wie im SDÜ auf dem One-State-Only bzw. OneChance-Only-Prinzip ${ }^{598}$ liegt. Dadurch sollten illegale Weiterwanderungen und

592 Dubliner Asylrechtsübereinkommen vom 15.06.1990, BGB1. 1994 II. S. 792.; vgl. Würz, Karl 1997: Das Schengener Durchführungsübereinkommen: Einführung. Erläuterungen. Vorschriften. S. 49 f.; vgl. Artikel 63 Absatz 1 EGV. In: Geiger, Rudolf 2004: EUV/EGV: Vertrag über die Europäische Union und Vertrag zur Gründung der Europäischen Gemeinschaft. München, S. 370.

593 Vgl. Klos, Christian 1999: Eine Reise von Rom nach Amsterdam: Die Entwicklung des europäischen Einwanderungsrechts. In: Wolter, Achim (Hrsg.) 1999: Migration in Europa: Neue Dimensionen, neue Fragen, neue Antworten. Baden-Baden, S. 24.

594 Vgl. Schmid, Christian / Frank, Michaela 2001: Europäisches Asylrecht. Wien. S. 17.

595 Vgl. Herdegen, Matthias 2006: Europarecht. München, S. 55.

596 Huber, Bertold 1998: Das Dubliner Übereinkommen. In: Neue Zeitschrift für Verwaltungsrecht (NVwZ). Bd. 17. 1998, Heft 2. München, S. 150.

597 Hailbronner, Kay 2000: Immigration and Asylum Law and Policy of the European Union. Hague u. a., S. 383.

598 Vgl. Hailbronner, Kay 1995: Die europäische Asylrechtsharmonisierung nach dem Vertrag von Maastricht. In: Zeitschrift für Ausländerrecht und Ausländerpolitik (ZAR). Bd. 15. 1995. BadenBaden, S. 3; vgl. Hailbronner, Kay / Thiery, Claus 1997: Schengen II und Dublin - Der zuständige 
mehrfache Asylanträge in verschiedenen Mitgliedstaaten verhindert werden (sog. „Asylum-Shopping“). ${ }^{599}$ Ein Asylbewerber soll demnach nur noch die Möglichkeit erhalten, jeweils in einem EG-Staat einen Antrag stellen zu dürfen. Daher ist jeweils nur ein Mitgliedstaat für die Prüfung eines Asylantrages zuständig. Des Weiteren ist die Zuständigkeit für Asylanträge mit der Pflicht verbunden, einen illegal weitergereisten Asylbewerber zurückzunehmen. So garantierte das DÜ grundsätzlich Asylbewerbern ein ordentliches Asylverfahren und verhinderte dadurch ein „Weiterschieben“ von Staat zu Staat (sog. Refugees in Orbit). ${ }^{600}$ Jedoch ist das Dubliner Übereinkommen in Bezug auf die Zuständigkeitskriterien stark kritisiert worden, da die Verantwortung der Bearbeitung eines Asylbegehrens oft dem Staat obliegt, dessen Grenze der Antragsteller zuerst passiert hat. Infolgedessen betrifft die hauptsächliche Last vor allem Mitgliedstaaten, die südlich oder östlich gelegene Außengrenzen haben. Damit wird das Ziel einer gerechten Lastenverteilung innerhalb der EU verfehlt. ${ }^{601}$ Die Asylverfahren waren von dem Abkommen nicht betroffen, sie sollen auch künftig nach dem geltenden Recht der einzelnen Nationalstaaten geführt werden, sodass die Verfahren gemäß Art. 3 Abs. 3 im Rahmen des nationalen materiellen Asylrechts und damit nach den verschiedenen gesetzlichen Normen durchgeführt werden. ${ }^{602}$ Den zentralen Inhalt des Abkommens bezeichnete also in keiner Weise die Form, wie Asylverfahren in der EU einheitlich gestaltet werden könnten, sondern es wurden in erster Linie Fragen der Aufteilung der Zuständigkeiten beantwortet. Die im DÜ enthaltenen Zuständigkeitsregeln lösen abgesehen davon allerdings weder das Problem des Refugees in Orbit („Phänomen der umherirrenden Asylbewerber“) noch das Phänomen des Asylum-Shoppings (,,multiple-Antragsstellung“). ${ }^{603}$ Das Abkommen verfolgte demnach nicht die Zielsetzung einer Harmonisierung des materiellen Asylrechts, sondern lediglich eine Regulierung der Anerkennungsfrage der Erstzuständigkeit bei Asylentscheidungen. ${ }^{604}$

Asylstaat in Europa. In: Zeitschrift für Ausländerrecht und Ausländerpolitik (ZAR). Bd. 17. 1997. Baden-Baden, S. 55.

599 Vgl. Weber, Albrecht 1993: Einwanderungs- und Asylpolitik nach Maastricht. In: Zeitschrift für Ausländerrecht und Ausländerpolitik (ZAR). Bd. 13. 1993. Baden-Baden, S. 13; vgl. Klos, Christian 1999: Eine Reise von Rom nach Amsterdam: a.a.O., S. 25; vgl. Santel, Bernhard 1995: Migration in und nach Europa: Erfahrungen. Strukturen. Politik. Opladen, S. 181.

${ }^{600}$ Vgl. Braun, Wilfried 1996: Asylpolitik in der Europäischen Union. In: Müller-Graff, Peter-Christian (Hrsg.) 1996: Europäische Zusammenarbeit in den Bereichen Justiz und Inneres: Der dritte Pfeiler der Europäischen Union. Baden-Baden, S. 78.

${ }^{601}$ Vgl. Gallagher, Stephen 2002: Towards a Common European Asylum System: Fortress Europe redesigns the ramparts. In: International Journal. Bd. 57. Summer 2002. Toronto, S. 385.

${ }^{602}$ Vgl. Klos, Christian 1999: Eine Reise von Rom nach Amsterdam: a.a.O., S. 25.

${ }^{603}$ Vgl. Han, Petrus 2005: Soziologie der Migration - Erklärungsmodelle, Fakten, Politische Konsequenzen, Perspektiven. Stuttgart, S. 203-204.

${ }^{604}$ Vgl. Nuscheler, Franz 2004: Internationale Migration: Flucht und Asyl. Wiesbaden, S. 178. 
Der Kernpunkt der vermehrten Kritik am Dubliner Übereinkommen bzog sich auf seine mangelnde Effizienz. Dies kann sich in einer Verfügung des Berufungsgerichts im Vereinigten Königreich vom 23. Juli 1999 finden. Diese Verfügung besagt, „dass Frankreich und Deutschland in manchen Fällen nicht als sichere Staaten angesehen werden können, so dass die britischen Behörden unter Anwendung des Dubliner Übereinkommens Asylbewerber nicht zurück in diese Staaten schicken dürfen. Dies betrifft Fälle, in denen Asylbewerber vor der Verfolgung nichtstaatlicher Organe geflohen waren - Frankreich und Deutschland (und andere Mitgliedstaaten, unter verschiedenen Bedingungen) erkennen im Gegensatz zum Vereinigten Königreich einen solchen Verfolgungsgrund für die Bewilligung des Flüchtlingsstatus nicht an, sondern halten sich strikt an die Bestimmungen der GFK“. ${ }^{605}$ Des Weiteren werden laut Dubliner Übereinkommen lediglich Anträge von Asylbewerbern anerkannt, die um Schutz als politische Flüchtlinge im Sinne der Genfer Flüchtlingskonvention (GFK) fragen, während Menschen, die um einen temporären oder humanitären Status unter der Europäischen Menschenrechtskonvention (EMRK) ersuchen, nicht berücksichtigt werden. ${ }^{606}$

Als eine weitere generelle Beanstandung dieses Abkommens vonseiten verschiedener Menschenrechtsorganisationen, wie beispielsweise UNHCR (United Nations High Commissioner for Refugees) und zahlreiche NGOs (Non Governmental Organizations) sowie PRO ASYL oder Amnesty International, wurde angeführt, dass das im Dubliner Abkommen formulierte Verantwortlichkeitskonzept von keinerlei Garantie begleitet wurde, das zumindest ein Mitgliedstaat das Asylbegehren auch substanziell prüft. Den um Asyl suchenden Flüchtlingen wurde hiermit in diesem Übereinkommen kein individuelles Recht auf materielle Prüfung des Antrages eingeräumt. Auf der Grundlage anderer Konzepte, wie z. B. durch die Regelung zu sogenannten sicheren Drittstaaten (safe third countries), ${ }^{607}$ wie sie in den Londoner Entschließungen (siehe nächsten Absatz) von 1992 existieren, kann der durch das Abkommen ermittelte zuständige Staat

605 Europäisches Parlament (Hrsg.) 2000: Arbeitsvorlage: Asyl in den EU-Mitgliedstaaten.

Generaldirektion Wissenschaft. PE 285.899. Januar 2000. S. 31; vgl. auch Bendiek, Annegret 2004: Der Konflikt im ehemaligen Jugoslawien und die Europäische Integration: eine Analyse ausgewählter Politikfelder. Wiesbaden, S. 207-208.

606 Vgl. Marinho, Clotilde / Heinonen, Matti 1998: Dublin after Schengen: Allocating Responsibility for Examining Asylum Applications in Practice. In: Institut Européene d'Administration Publique: EIPASCOPE, No. 1998/3. S. 7.

607 Vgl. Lavenex, Sandra / Ucarer, Emek M. 2003: Introduction: The Emergent EU Migration Regime and Its External Impact. In: Lavenex, Sandra / Ucarer, Emek M. (eds.) 2003: Migration and the Externalities of European Integration. Lanham, S. 7. 
die individuelle Prüfung der Flüchtlingseigenschaft ablehnen. ${ }^{608}$ Deshalb folgen aus dem schwerfälligen Einsatz des Dubliner Übereinkommens nicht nur Effizienzprobleme, sondern auch uneinheitliche Asylverfahrensstandards in der EU und unweigerlich die Nichtbeachtung von völkerrechtlichen Mindeststandards im Flüchtlingsschutz. Das essenzielle Funktionsdefizit des Dubliner Abkommens hat hierin seine Grundlage. ${ }^{609}$

Am 18. Februar 2003 nahm der Rat der Europäischen Union die Verordnung (EG) Nr. 343/2003 (im Folgenden als „Dublin II-Verordnung“ bezeichnet) des Rates zur Festlegung der Kriterien und Verfahren zur Bestimmung des Mitgliedstaates an, der für die Prüfung eines von einem Drittstaatsangehörigen in einem Mitgliedstaat gestellten Asylantrag zuständig ist. ${ }^{610}$ Die Dublin II-Verordnung greift die in Art. 63 Abs. 1a EGV geforderte Maßnahme auf, die mit Inkrafttreten der Verordnung am 17.03.2003 das Dubliner Übereinkommen (DÜ) ersetzte. Die Verordnung gilt für 24 Staaten, für Norwegen, Island und nunmehr auch für Dänemark und die Schweiz. ${ }^{611}$ Ebenso wie Dublin I vom 01.09.1997 schränkt Dublin II das System der Zuständigkeitsprüfung zwischen den Mitgliedsstaaten ein, indem es jedem Mitgliedstaat freistellt, unter Wahrung der Genfer Flüchtlingskonvention einen Asylbewerber in einen Drittstaat zurück- oder auszuweisen. So kann das eher schwerfällige und komplizierte Dublin-ISystem vermieden werden. Im Falle von Rückübernahmeabkommen zwischen einem Mitgliedstaat und einem Drittstaat stellt dies für die Mitgliedstaaten oft den überschaubarsten Weg zum Abschluss eines Verfahrens dar. ${ }^{612}$ Divergierende zu Dublin I gelten erneuerte Zuständigkeitskriterien (Dublin II) zugunsten unbegleiteter Minderjähriger sowie zur verbesserten Wahrung der Einheit von Familiengemeinschaften. ${ }^{613}$ Damit legt die Kommission in der Verordnung (EG) Nr.

${ }^{608}$ Vgl. Seifer, Kerstin 2009: Governance als Einfluss-System: Der politische Einfluss von NGOs in asymmetrisch strukturierten Interaktionsarrangements. Illustriert am Beispiel der Harmonisierung der Asylpolitik der Europäischen Union. Wiesbaden, S. 169.

${ }^{609}$ Siehe dazu Bendiek, Annegret 2004: Der Konflikt im ehemaligen Jugoslawien und die Europäische Integration: eine Analyse ausgewählter Politikfelder. Wiesbaden, S. 208.

${ }^{610} \mathrm{Vgl}$. ABL (Amtsblatt der Europäischen Union). L50/1, 25. Februar 2003. Hierzu auch im Internet: http://europa.eu/legislation_summaries/justice_freedom_security/free_movement_of_persons_asylum immigration/133153_de.htm (Stand am 24.06.2009).

611 Vgl. Jahn, Daniela / Maurer, Andreas / Oetzmann, Verena / Riesch, Andrea 2006: Asyl- und Migrationspolitik der EU: Ein Kräftespiel zwischen Freiheit, Recht und Sicherheit. In: Diskussionspapier der FG 1, 2006 / 09, Juli 2006 SWP Berlin. Berlin, S. 44. Online verfügbar unter http://www.swp-berlin.org

612 Vgl. Piotrowicz, Ryszard 2003: Dublin II und zukünftige Perspektiven eines gemeinsamen europäischen Asylsystems. In: Zeitschrift für Ausländerrecht und Ausländerpolitik (ZAR). Bd. 23. 2003. Baden-Baden, S. 386.

${ }^{613}$ Siehe dazu Bundesamt für Migration und Flüchtlinge (BAMF) 2007: Dublin II Verordnung: Der Umfang des Bundesamtes für Migration und Flüchtlinge mit dem Dublinverfahren. Fachtagung am Montag, 17. Dezember 2007 in Mainz. S. 5. Im Internet: http://www.diakonie-hessen- 
1560/2003 vom 02.09.2003 präzise Regeln für die Anwendung der Dublin-IIVerordnung fest, insbesondere im Zusammenhang mit der Durchführung von Überstellungen und der Anwendung der ,humanitären Klausel (Art. 15 Dublin II)،“614 Auch die EURODAC-Datenbank ist seit dem 15. Januar 2003 technisch funktionsfähig. ${ }^{615}$ Ziel von EURODAC (Europäisches Daktyloskopie System bzw. europäisches automatisiertes Fingerabdruckerkennungssystem) ist eine erleichterte Verwendung des Dubliner-Asylübereinkommens, welches zum einen die Bestimmung des für die Prüfung eines Asylantrags zuständigen Mitgliedstaats ermöglicht und zum anderen die Erschaffung präventiver Maßnahmen für den Missbrauch des Asylrechts mit der Einrichtung eines Systems für die Abgleichung von Fingerabdrücken von Asylbewerbern und illegalen Einwanderern möglich macht. ${ }^{616}$ Als unterstützendes Instrument zur Feststellung des zuständigen EU-Staates zur Durchführung eines Asylverfahrens wird die Anwendung von EURODAC mehrheitlich von Europäischer Kommission, Ministerrat und Europäischen Parlament als unerlässlich für das Gelingen des DÜ gesehen.

Zusammenfassend lässt sich das Folgende festhalten: Die Dublin II-Verordnung muss heute als ein Kernelement im Rahmen der rechtlichen Instrumente im Bereich Asyl auf europäischer Ebene gesehen werden und als eine der schärfsten Abwehrmechanismen gegen Flüchtlinge. Neben Dublin I wurde der protektionistische Charakter der Dublin II-Verordnung auch daran erkennbar, dass als Asylanträge nur solche anerkannt werden sollten, die unter Berufung auf the Geneva Convention gestellt wurden, ${ }^{617}$ während der gesamte Bereich der Vertriebenen und die Flüchtlingsaufnahme aus humanitären Gründen außer Acht gelassen wurden.

nassau.de/DWHN/rathilfe/Seiten/Migration/Dublin2/BAMF1Praesentation.pdf (Stand: 07.10.2009).

614 „Jeder Mitgliedstaat kann aus humanitären Gründen, die sich insbesondere aus dem familiären oder kulturellen Kontext ergeben, Familienmitglieder und andere abhängige Familienangehörige zusammenführen“ (Art. 15. Abs. 1. Dublin II). Vgl. UNHCR 2006: The Dublin II Regulation - A UNHCR Discussion Paper: Auszugsweise Übersetzung der UNHCR-Studie vom April 2006. S. 2-4.

Im Internet: http:/www.unhcr.de/fileadmin/unhcr_data/pdfs/rechtsinformationen/2_EU/2_EUAsyl/B.01_Dubliner_Uebereinkommen/B.1.07.UNHCR-DublinII.pdf (Stand : 05.10.2009).

615 Vgl. Jahn, Daniela / Maurer, Andreas / Oetzmann, Verena / Riesch, Andrea 2006: a.a.O., S. 45.

616 Vgl. EG/2000/2725: Verordnung des Rates vom 11. Dezember 2000 über die Einrichtung von „EURODAC“ für den Vergleich von Fingerabdrücken zum Zwecke der effektiven Anwendung des Dubliner Übereinkommens. Im Internet:

http://europa.eu.int/smartapi/cgi/sga_doc?smartapi!prod!CELEXnumdoc\&1g=DE\&numdoc=32000R 2725\&model=guichett (Stand: 13.02.2006); vgl. auch Boswell, Christina 2007: Migration Control in Europe After 9/11: Explaining the Absence of Securitization. In: Journal of Common Market Studies (JCMS) 2007: Septemebr, Volume 45. Number 3, S. 589-610, hier S. 601.

617 Lavenex, Sandra 2001: The Europeanisation of Refugee Policies: Between human rights and internal security. Aldershot u.a., S. 96-97. 


\subsection{Londoner Entschließungen}

Der vom Europäischen Rat im Dezember 1991 auf seiner Sitzung in Maastricht gebilligte Bericht der für Einwanderungsfragen zuständigen Minister (,Maastrichter Bericht") beinhaltet ein konkretes Arbeitsprogramm für eine Harmonisierung der nationalen Asylpolitik. ${ }^{618}$ Im Rahmen dieses Arbeitsprogramms haben die für die Fragen der Asylpolitik zuständigen Minister der Mitgliedstaaten auf ihrer Konferenz am 30. November und 1. Dezember 1992 in London drei grundlegende Entschließungen bzw. Schlussfolgerungen verabschiedet: ${ }^{619}$ London I regelt die „Entschließungen zur Behandlung von offensichtlich unbegründeten Asylanträgen" und bestimmt die Einführung eines Schnellverfahrens für diese Fälle. London II legt die „Entschließung zu einem einheitlichen Konzept in Bezug auf Aufnahmedrittländer“ bzw. zum Prinzip des „sicheren Drittstaates“ fest. Asylbewerber, die als sicher eingestufte Länder durchquert haben, können laut einer Regelung der sicheren Drittstaaten in diese Länder zurückgeschickt werden. London III firmiert „Schlussfolgerungen über sichere Herkunftsländer“. Es handelt sich hierbei um eine Liste von Ländern, in denen im Allgemeinen keine Verfolgungsgefahr besteht.

Obwohl alle drei Londoner Entschließungen keinen Vertragsstatus hatten bzw. nicht bindendes soft law waren, wurden sie von den Mitgliedstaaten in unterschiedlicher Weise umgesetzt. ${ }^{620}$ Allerdings bezeichneten diese Entschließungen vor allem Steuerungsinstrumente, die auf die Einschränkung der Zugangsmöglichkeiten zum Asylverfahren abzielten. Besonders gemäß Artikel 33 der GFK von 1951 wird dadurch das Prinzip des sogenannten Non-refoulement („Nichtabschiebungsprinzip“) verletzt. ${ }^{621}$ Diese Politik hat deshalb schwerwiegende Konsequenzen: Durch das Vorpreschen einiger Länder wie Deutschland wurde ein „Domino-Effekt“ und ein Gegeneinander der Nationalstaaten in ihrer restriktiven Politik ausgelöst, was eine westeuropaweite Verallgemeinerung bewirkte. Daraus resultierte letztlich ein politischer Zirkelschluss, der bis heute nicht aufgelöst ist. ${ }^{622}$

\footnotetext{
${ }^{618}$ Vgl. Braun, Wilfried 1996: Asylpolitik in der Europäischen Union. In: Müller-Graff, a.a.O., S. 79.

${ }^{619}$ Braun, Wilfried 1996: Asylpolitik in der Europäischen Union. In: Müller-Graff, a.a.O., S. 80-81.

${ }^{620}$ Die Bundesrepublik Deutschland hat die drei genannten Entschließungen mit der Neuregelung des Asylrechts zum 1. Juli 1993 umgesetzt und die Prinzipien des „sicheren Drittstaates“ und des „sicheren Herkunftstaates“ eingeführt. Vgl. Bundesministerium des Innern (Hrsg.) 1998: Ausländer und Ausländerpolitik in der Bundesrepublik Deutschland. Bonn, S. 148.

${ }^{621}$ Vgl. Menzel, Jörg / Pierlings, Tobias / Hoffmann, Jeannine (Hrsg.) 2005: Völkerrechtsprechung. Tübingen, S. 465-466.

${ }^{622}$ Birsl, Ursula 2005: Migration und Migrationspolitik im Prozess der europäischen Integration?. S. 323.
} 


\subsection{Der Maastrichter Vertrag}

Der Maastrichter Vertrag umfasst u. a. den Vertrag zur Gründung der Europäischen Union (EUV). Am 07. Februar 1992 unterzeichnet trat er nach der Ratifizierung durch die nationalstaatlichen Parlamente der 12 EG-Länder am 01. November 1993 in Kraft. $^{623}$ Der Vertrag stellt eine Bilanz interner und externer Einflüsse dar. Die Auflösung des Kommunismus und die absehbare Wiedervereinigung Deutschlands waren auf der außenpolitischen Ebene verantwortlich dafür, dass man sich für eine Verstärkung der internationalen Position der Gemeinschaft entschied, während auf der internen Ebene die Mitgliedstaaten, die durch das Projekt eines gemeinsamen Binnenmarktes ohne Grenzen, das mit der Einheitlichen Europäischen Akte 1986 (EEA) auf den Weg gebracht wurde, und die mit anderen Reformen erreichten Fortschritte sichern und darauf aufbauen wollten. ${ }^{624}$

Mit dem Vertrag von Maastricht wurde die Struktur der Europäische Union nach dem Abbild eines Tempels geschaffen, ${ }^{625}$ dessen Dach von drei Säulen getragen wird (siehe Abbildung 27). Die erste Säule wird von den Regelbereichen gebildet, die in den Bereich der Gemeinschaftskompetenz, also in die Kompetenz der Europäischen Gemeinschaft fallen, was eine verbindliche Verlagerung nationalstaatlicher Kompetenzen auf die europäische Ebene bedeutet. Dieser Bereich ist damit zugleich supranational. ${ }^{626}$ Es sind die drei Gemeinschaften EG (Europäische Gemeinschaft), EGKS (Europäische Gemeinschaft für Kohle und Stahl) und EURATOM (Europäische Atomgemeinschaft) zusammengefasst. Hier werden supranationale Entscheidungsmechanismen gültig: mit dem Initiativmonopol der Europäischen Kommission, verschiedenen Formen der Beteiligung des Europäischen Parlaments, die bis zur Mitentscheidung gehen können, mit Verordnungen und Richtlinien als allgemeinen Rechtsinstrumente und Rechtsprechungskompetenz des Europäischen Gerichtshofes. $^{627}$ Dabei ist die Visapolitik von einwanderungsrechtlichem Interesse,

${ }^{623}$ Zum Vertrag von Maastricht siehe Amtsblatt der Europäischen Union (ABL.): ABL. 1992. EG Nr. C 191. S. 1 ff.; ABL. 1993. EG Nr. L 293. S. 61.; BGBl (Bundesgesetzblatt). 1992 II. S. 1253.; BGB1. 1993 II. S. 1947. Vgl. Im Internet: http://eur-lex.europa.eu/de/treaties/dat/11992M/htm/11992M.html

${ }^{624}$ Vgl. http://eur-lex.europa.eu/de/treaties/dat/11992M/htm/11992M.html (Stand: 10.07.2007).

625 Müller-Graff, Peter-Christian 1994: The legal Bases of the third Pillar and its Position in the Framework of the Union Treaty. In: Common Market Law Review (CMLR) 31. S. 493, S. 495.

626 Vgl. dazu Birsl, Ursula 2005: Migration und Migrationspolitik im Prozess der europäischen Integration?. Opladen, S. 114.

627 Tomei, Verónica 1997: Europäische Migrationspolitik: zwischen Kooperationszwang und Souveränitätsansprüchen. Bonn, S. 25. 
sprich die Vorschrift über Visumzwang und einheitliche Visagestaltung des Art. 100c $\mathrm{EGV}^{628}$ Bis dahin war sie die einzige echte gemeinschaftsrechtliche Kompetenz die Einwanderung von Drittstaatsangehörigen betreffend. ${ }^{629}$ Die Entscheidungsmechanismen sind damit Gegenstand der Gemeinschaftspolitik. Hier hat nämlich nicht nur eine institutionelle Einbindung in den Unionsrahmen, sondern gleich eine Vergemeinschaftung von Teilen der Kooperation stattgefunden. Art 100c EGV gesteht der Gemeinschaft derzeit zwei verschiedene Zuständigkeiten zu: Nach Art. 100c Abs. 1, in VO 2317/95 $5^{630}$ und Abs. 3 Satz 1 EGV vom Rat der EG zunächst einstimmig beschlossen, ab dem 1. Januar 1996 mit qualifizierter Mehrheit auf Vorschlag der Kommission und nach Anhörung des Parlaments, werden zum einen diejenigen dritten Länder bestimmt, deren Staatsangehörige beim Überschreiten der Außengrenzen der Mitgliedstaaten im Besitz eines Visums sein müssen, mithin wird eine gemeinsame sog. Negativliste aufgestellt. Außerdem hat der Maastricht-Vertrag hier auch den automatischen Übergang vom Einstimmigkeitsprinzip zum Verfahren der qualifizierten Mehrheit ab dem 1. Januar 1996 festgeschrieben. ${ }^{631}$ Zum anderen hat der Rat nach Art. 100c Abs. 3 Satz 2 EGV die Kompetenz, im gleichen Verfahren, bis zum 1. Januar 1996 jedoch von vornherein nur mit qualifizierter Mehrheit, Maßnahmen zur einheitlichen Visagestaltung zu treffen, ${ }^{632}$ was aber schon allein bereits eine Verallgemeinerung der restriktiven Politik, wie sie zum Beispiel Deutschland ausübte, beinhaltet. ${ }^{633}$ Die Instrumente gemeinsamer Visapolitik sowie der gemeinsamen Listen visapflichtiger Staaten sind jedoch nicht erst in den Verhandlungen zum Maastrichter Vertrag entwickelt worden, vielmehr diente hier das Schengener Durchführungsabkommen von 1990 als Vorlage, da hier bereits ähnliche Regelungen formuliert waren (Art. 9 und Art 17, Schengener Durchführungsabkommen von 1990). ${ }^{634}$ Die zweite Säule beschäftigt sich mit der „Gemeinsamen Außen- und Sicherheitspolitik (GASP, Titel V EUV)“, die migrationspolitisch allerdings nur eingeschränkt von Belang ist. Die dritte Säule

628 Vgl. Rinsche, Günter / Friedrich, Ingo (Hrsg.) 1997: Europa als Auftrag: ,Der dritte Pfeiler des Maastrichter Vertrags - zwischenstaatliche Zusammenarbeit oder gemeinschaftliches Handeln'. Köln.

629 Vgl. Klos, Christian 1999: Eine Reise von Rom nach Amsterdam: Die Entwicklung des europäischen Einwanderungsrechts. In: Wolter, Achim (Hrsg.) 1999: Migration in Europa: Neue Dimensionen, neue Fragen, neue Antworten. Baden-Baden, S. 25.; vgl. Oppermann, Thomas 1999: Europarecht. München, S. $204 \mathrm{ff}$.

630 Vgl. ABL (Amtsblatt der Europäischen Union). EG Nr. L 234, 1 vom 3.10.1995.

631 Vgl. Tomei, Verónica 2001: Europäisierung nationaler Migrationspolitik: a.a.O., S. 57.

632 König, Christian / Pechstein, Matthias 1995: Die Europäische Union - Der Vertrag von Maastricht. Tübingen. S. 114.; Pechstein, Matthias / König, Christian 1998: Die Europäische Union. Die Verträge von Maastricht und Amsterdam. Tübingen. S. 180.

633 Vgl. Birsl, Ursula 2005: Migration und Migrationspolitik im Prozess der europäischen Integration?. Opladen, S. 115.

${ }^{634}$ Vgl. Achermann, Alberto / Bieber, Roland / Epiney, Astrid / Wehner, Ruth (Hrsg.) 1995: Schengen und die Folgen: Der Abbau der Grenzkontrollen in Europa. Bern u.a. 
bezeichnet die „Zusammenarbeit in den Bereichen Justiz und Inneres“ (ZBJI, Titel VI EUV). Diese beiden Säulen sind intergouvernemental. Die Kooperation ist also rein zwischenstaatlich und nicht gemeinschaftlich geprägt. Dadurch sind die Entscheidungsverfahren im Rat nach dem Einstimmigkeitsprinzip organisiert und die Umsetzung von völkervertraglichen Regeln unter den nationalen Zustimmungserfordernissen belassen. ${ }^{635}$

\section{Abbildung 27 : \\ Drei-Säulen-Tempel - die Europäische Union nach dem Maastrichter Vertrag ${ }^{636}$}

\section{Europäische Union (EU) : Einheitlicher institutioneller Rahmen}

\begin{tabular}{c}
\hline "Erste Säule“" \\
Regelbereiche, die in die \\
volle \\
Gemeinschaftskompetenz \\
überführt sind. \\
Im Bereich \\
Migrationspolitik: \\
Vorschrift über \\
Visumszwang und \\
einheitliche \\
Visumgestaltung.
\end{tabular}

\begin{tabular}{c}
\hline ,Zweite Säule“6 \\
Außen- und \\
Sicherheitspolitik \\
(GASP), \\
auf der Basis \\
intergouvernementaler \\
Zusammenarbeit; \\
Kooperation ist rein \\
zwischenstaatlich und \\
nicht gemeinschaftlich \\
angelegt.
\end{tabular}

\begin{tabular}{c}
,Dritte Säule“' \\
Justiz und Inneres \\
(ZBJI), \\
Basis wie bei der, ,Zweiten \\
Säule“; \\
Bereich \\
Migrationspolitik: Zum \\
gemeinsamen Interesse \\
werden Asylpolitik, \\
Außengrenzen und \\
Einwanderungspolitik \\
erklärt; Sachgebiete u.a. \\
Einreise, Aufenthalt, \\
Familienzusammenführung, \\
Beschäftigung und \\
undokumentierte \\
Migration. \\
\hline
\end{tabular}

635 Vgl. O`Keeffe, David 1995: Recasting the Third Pillar. In: Common Market Law Review (CMLR) 32. S. 893. S. 898, S. 901.; vgl. Klos, Christian 1999: Eine Reise von Rom nach Amsterdam: a.a.O., S. 26; vgl. Pechstein, Matthias / König, Christian 1998: Die Europäische Union. Die Verträge von Maastricht und Amsterdam. Tübingen.

636 Zusammengestellt aus Klos, Christian 1999: a.a.O., S. 25 f. und Birsl, Ursula 2005: a.a.O.,S. 115. 
Insbesondere schuf Titel VI des Unionsvertrags unter der dritten Säule (ZBJI) erstmalig eine vertragsrechtliche Grundlage für die migrationspolitische Kooperation der EUStaaten, wobei diese Zusammenarbeit der „ [...] Verwirklichung der Ziele der Union, insbesondere der Feizügigkeit [...]“ (Art. K.1 EUV/Maastricht) dienen sollte. Die Bereiche Asylpolitik (Nr. 1), Außengrenzkontrollen (Nr. 2) und Einwanderungspolitik (Nr. 3) wurden dafür von den Mitgliedstaaten als „Angelegenheiten von gemeinsamen Interesse" angesehen (Art. K.1 EUV). Im Rahmen der Einwanderungspolitik werden in einem nicht abschließenden Katalog bestimmte Sachgebiete, wie Einreise, Aufenthalt, Familienzusammenführung, Beschäftigungszugang und illegale Einwanderung, erforderlichenfalls bei bestimmten Aspekten des Zollwesens und in Verbindung mit dem Aufbau von EUROPOL ${ }^{637}$ (Art. K. 1 EUV/Maastricht) unterstrichen. Darüber hinaus sollen alle drei der oben genannten Bereiche unter Beachtung der Europäischen Menschenrechtskonvention (EMRK), der Genfer Konvention (GFK) über die Rechtstellung der Flüchtlinge sowie unter Berücksichtigung des Schutzes für politisch Verfolgte umgesetzt werden (Titel VI, Art. K. 2 EUV). Parallel dazu stellt die bereits erfolgte intergouvernementale Zusammenarbeit den ,organisatorischen und sachlichen Besitzstand“638 von Titel VI des Unionsvertrags dar.

Eine Konsequenz dieser ersten Verrechtlichung der migrationspolitischen Zusammenarbeit ist die Tatsache, dass sie nicht mehr ausschließlich vom Willen der Mitgliedstaaten zur Kooperation abhängt. In Artikel K 3 EUV ist das Verfahren der Zusammenarbeit bzw. eine Verpflichtung der Staaten zumindest zur Koordination beschrieben: „In den Bereichen des Artikel K. 1 unterrichten und konsultieren die Mitgliedstaaten einander im Rat, um ihr Vorgehen $\mathrm{zu}$ koordinieren. [... $]^{\text {“. }}$. Strukturmerkmal der Zusammenarbeit ist jedoch ihre primär intergouvernementale Form und ihre essentielle Abhängigkeit vom Kooperationswillen jedes einzelnen Mitgliedslandes. ${ }^{639}$ Die handelnden Rechtssubjekte sind daher nicht die Gemeinschaftsorgane, sondern die Unionsstaaten selbst, was jedoch nicht bedeutet, dass es keinerlei Mitwirkung der EU-Institutionen gibt. Als koordinierendes Gremium agiert

${ }^{637}$ Der Vertrag von Maastricht beinhaltete auch erste Schritte zur Konkretisierung der Gründung eines Europäischen Polizeiamtes (EUROPOL), was mit der EUROPOL-Konvention (EPK) von 1995 gegenständlich wurde. Am 01.07.1999 nahm es seine Tätigkeit auf. EUROPOL ist eine unabhängige, völkerrechtliche Organisation mit eigener Rechtspersönlichkeit und somit kein formales Organ der EU (Art. 26 EPK). Vgl. BGBl (Bundesgesetzblatt). 1998 II. S. 2930. Zitierte Fundstelle in: http://bgbl.makrolog.de

${ }^{638}$ Groeben, Hans von der / Thiesing, Jochen / Ehlermann, Claus-Dieter (Hrsg.) 1997: Kommentar zum EU-/EG-Vertrag. Band 5. Baden-Baden, S. 1013.

${ }^{639} \mathrm{Vgl}$. Tomei, Verónica 2001: Europäisierung nationaler Migrationspolitik: a.a.O., S. 55. 
der Rat der Innen- und Justizminister, der nach dem Einstimmigkeitsprinzip ${ }^{640}$ entscheidet, und gemäß Art. K 1 Nr. 1-3 EUV verfügen sowohl die Mitgliedstaaten als auch die Kommission über ein Initiativrecht (Art. K 3 Abs. 2 EUV/Maastricht), wobei die Kommission dieses Initiativrecht allerdings mit den Mitgliedstaaten teilt. Es liegt somit also kein Initiativmonopol vor. Die Kommission wird in vollem Umfang an den Arbeiten in den Bereichen Justiz und Inneres (JI) partizipiert (Art. K.4 Abs. 2 EUV). ${ }^{641}$ Hervorzuheben ist diesbezüglich, dass die Befugnisse der Kommission in der dritten Säule wesentlich beschränkter sind als im Rahmen der Gemeinschaftspolitiken (erste Säule). Das Europäische Parlament (EP) ist hingegen an der Ausarbeitung der Politik in diesen Bereichen nicht beteiligt. Die Rechtspositionen des Europäischen Parlaments sind auf Informations- und Anhörungsmöglichkeiten begrenzt, ihm wird überdies kein wirksames Kontrollrecht zugebilligt (Art. 39 EUV/Maastricht). ${ }^{642}$ Dem EU-Parlament wird allerdings das Recht gewährt, durch die Kommission regelmäßig über die laufende Arbeit unterrichtet $\mathrm{zu}$ werden. ${ }^{643}$ In diesem Kontext wurde wiederholt auf das Demokratiedefizit der Europäischen Union verwiesen, weil dem einzig direkt gewählten repräsentativen Gremium nur eine sehr marginale Position in den Politikgestaltungsprozessen eingeräumt wurde. Der Gesamtbereich der intergouvernementalen Zusammenarbeit ist grundsätzlich von der Zuständigkeit des Europäischen Gerichtshofes $(\mathrm{EuGH})$ ausgenommen und weder die gemeinsamen Standpunkte noch die gemeinsamen Maßnahmen im Rahmen der dritten Säule unterliegen einer Rechtskontrolle durch den EuGH. Primär konnte der EuGH nur als Ausnahme auf Beschluss des Rates zur Auslegung der innerhalb der dritten Säule gefassten Beschlüsse herangezogen werden. Inzwischen hat er ein allgemeiner definiertes Auslegungsrecht, das allerdings der gesonderten Anerkennung durch die Mitgliedstaaten bedarf (Art. 35 EUV/Maastricht). ${ }^{644}$

${ }^{640}$ Das Einstimmigkeitsprinzip wird hierbei als gewichtiges Hindernis angesehen, welches der Erfüllung der Erwartungen und der vom Rat angestrebten Ziele und Handlungspläne entgegengestanden hat: „Aufgrund von politischen Differenzen und nationalen Empfindlichkeiten bewirkt das Einstimmigkeitsprinzip, daß wenige und nur Maßnahmen auf dem kleinsten gemeinsamen Nenner verabschiedet wurden.“ In: Pechstein, Matthias / König, Christian 1998: Die Europäische Union. Die Verträge von Maastricht und Amsterdam. Tübingen. S. 192.

${ }^{641}$ Vgl. Müller-Graff, Peter-Christian 1994: The legal Bases of the third Pillar and its Position in the Framework of the Union Treaty. In: Common Market Law Review (CMLR) 31. S. 498 f.; Klos, Christian 1999: Eine Reise von Rom nach Amsterdam: a.a.O., S. 27.

${ }^{642}$ Die legislative Prozedur des Konsultationsprozesses (Art. 250, Vertrag über die Europäischen Gemeinschaften 1993) besteht aus nur einer Lesung: Der Ablauf umfasst Kommissionsvorschlag, Konsultation des Parlaments, Entscheidung des Rates. Hierbei ist die Meinung des Parlaments nicht bindend. Der Rat dagegen kann den Kommissionsvorschlag nur mit Einstimmigkeit ändern.

${ }^{643}$ Das EU-Parlament verfügte nur über die Instrumente Anfrage und Empfehlung an den Rat (Art. K.6.).

${ }^{644}$ Vgl. Kohler-Koch, Beate / Conzelmann, Thomas / Knodt, Michéle 2004: Europäische Integration Europäisches Regieren. Wiesbaden, S. 134.; vgl. auch Schieffer, Martin 1998: Die Zusammenarbeit 
Für die Integration der migrationspolitischen Zusammenarbeit zwischen den EU-Staaten lässt sich zusammenfassend festhalten, dass der Maastrichter Vertrag lediglich zu einer institutionellen Einbindung der bisherigen Kooperation in die Europäische Union beigetragen hat. ${ }^{645}$ Auch der starke Anstieg des Migrationsdrucks Anfang der 90er Jahre innerhalb Europas hat in entscheidender Weise zur institutionellen Aufwertung der gemeinsamen migrationspolitischen Bemühungen im Maastrichter Vertrag beigesteuert. Gleichwohl ist das Spannungsverhältnis zwischen Kooperationsbedarf und Souveränitätsbeharren in einer möglichst ,,autonomieschonenden“646 Kooperationsform aufgelöst worden. Herausragend ist der Titel VI des Maastrichter Vertrags über die ZBJI in der Charakterisierung ,,verbesserte Intergouvernementalität““ ${ }^{647}$ Die Erstellung eines umfassenden Handlungsrahmens für die Lösung der zutreffend benannten Angelegenheiten von gemeinsamem Interesse ist hier als wesentlicher Fortschritt zu sehen. Dennoch bleibt die Zusammenarbeit bislang hinter den Erwartungen und insbesondere auch hinter den vom Rat aufgestellten Zielen und Handlungsplänen zurück. ${ }^{648}$ Zudem liegt der zentrale inhaltliche Punkt auf der Bekämpfung der Phänomene illegale Einwanderung und der Berufung auf das Asylrecht in Einwanderungsabsichten. ${ }^{649}$ Zur Lösung dieser Problematik enthält der Unionsvertrag dagegen keinerlei inhaltliche Vorgaben. Hierbei sollte nach Meinung der deutschen Bundesregierung eine möglichst weitgehende Harmonisierung des Asylrechts angestrebt und auch aus Kohärenzgründen die gesamte Visapolitik vergemeinschaftet werden. ${ }^{650}$ Mittels institutioneller Integration kann Maastricht damit als die Station bezeichnet werden, an der die rechtlichen Weichen für die weiteren Stationen bis Amsterdam gestellt wurden.

\footnotetext{
der EU-Mitgliedstaaten in den Bereichen Asyl und Einwanderung. Baden-Baden, S. 74.

645 Vgl. Müller-Graff, Peter-Christian 1994: a.a.O., S. 493 u. S. 496.

646 Scharpf, Fritz 1994: Autonomieschonend und gemeinschaftsverträglich. Zur Logik einer europäischen Mehrebenenpolitik. In: Scharpf, Fritz 1994: Optionen des Föderalismus in Deutschland und Europa. Frankfurt a. M., S. 131-155.

647 Tomei, Verónica 1997: Europäische Migrationspolitik: a.a.O., S. 29.

648 Vgl. Pechstein, Matthias / König, Christian 1998: Die Europäische Union. a.a.O., S. 192.

649 Vgl. Tomei, Verónica 1997: Europäische Migrationspolitik: a.a.O., S. 53 f.

650 Schelter, Kurt 1996: Innenpolitische Zusammenarbeit in Europa zwischen Maastricht und Regierungskonferenz 1996. In: Aus Politik und Zeitgeschichte (APuZ) B 1-2, S. 25.
} 


\subsection{Der Amsterdamer Vertrag}

Der Amsterdamer Vertrag, ${ }^{651}$ der am 16. Juli 1997 unterzeichnet und am 01. Mai 1999 in Kraft getreten ist, ${ }^{652}$ nimmt den Bereich „Justiz und Inneres (ZBJI)“ und damit Teile der sogenannten dritten Säule aus dem Maastrichter Vertrag ein; er ordnet die Aufgabenbereiche neu: Es wird demnach im EG-Vertrag ein neuer Titel IV „Visa, Asyl, Einwanderung und andere Politiken betreffend den freien Personenverkehr" (Art. 61-69 EGV/Amsterdam) eingefügt. Im Artikel $61 \mathrm{ff}$. geht es ferner um das Ziel, im Laufe von fünf Jahren nach Inkraftsetzung des Vertrags sowohl eine gemeinsame Migrations- und Asylpolitik anzubahnen als auch die Anrechte Drittstaatsangehöriger sowie die Zuständigkeiten und Mindeststandards für Asylsuchende festzusetzen. ${ }^{653}$ Eines der wesentlichen Hauptmerkmale des gesamten Vertrags bilden hierbei die Regeln zum sukzessiven Aufbau eines „Raums der Freiheit, der Sicherheit und des Rechts“ (ehemaliger Artikel B. Art. 2, 4. Spiegelstrich EGV/Amsterdam), die vornehmlich einwanderungsrechtliche Vorschriften betreffen. ${ }^{654}$ Mit dem Amsterdamer Vertrag wurden somit zweierlei wichtige Neuerungen erreicht: Erstens wurde die gesamte Einwanderungspolitik von der dritten Säule in die erste Säule der Europäischen Union überführt und eine supranationale Gemeinschaftszuständigkeit erwirkt (siehe Abbildung 28). ${ }^{655}$ Indes wurde dieser Gemeinschaftungsschub nur mittels einer partiellen „Aufweichung“ der supranationalen Charakteristika der EG-Säule im Entscheidungsverfahren und ebenso in der gerichtlichen Kontrolle erlangt. ${ }^{656}$ Zweitens wurde der Schengen-Besitzstand in den rechtlichen und institutionellen Rahmen der Europäischen Union aufgenommen. ${ }^{657}$ Das bedeutet Visumsvorschriften beim Überschreiten der Außengrenzen (Art. 62 EGV/Amsterdam), Abbau der Kontrollen

651 Zum Vertrag von Amsterdam siehe Pechstein, Matthias / König, Christian 1998: Die Europäische Union. Die Verträge von Maastricht und Amsterdam. Tübingen.; vgl. auch Läufer, Thomas (Hrsg.) 1998: Vertrag von Amsterdam: Texte des EU-Vertrages und des EG-Vertrages. Bonn.; vgl. im Internet: http://europa.eu.int/en/agenda/igc-home/amst.htm

652 Vgl. ABL (Amtsblatt der Europäischen Union). EG Nr. C 340/1ff vom 10.11.1997.

653 Vgl. Birsl, Ursula 2005: Migration und Migrationspolitik im Prozess der europäischen Integration?. Opladen, S. 117

654 Vgl. Pechstein, Matthias / König, Christian 1998: Die Europäische Union. Die Verträge von Maastricht und Amsterdam. Tübingen. S. 193. u. S. 288 ( Anhang).

655 Vgl. Klos, Christian 1999: Eine Reise von Rom nach Amsterdam: Die Entwicklung des europäischen Einwanderungsrechts. In: Wolter, Achim (Hrsg.) 1999: Migration in Europa: Neue Dimensionen, neue Fragen, neue Antworten. Baden-Baden, S. 29.

656 Vgl. Beutler, Bengt / Bieber, Roland / Pipkorn, Jörn / Streil, Jochen 2001: Die Europäische Union. Rechtsordnung und Politik. Baden-Baden, S. 460.

657 Siehe Protokoll (Nr. 2) EUV zur Einbeziehung des Schengen-Besitzstands im Rahmen der Europäischen Union. Vgl. Pechstein, Matthias / König, Christian 1998: a.a.O., S. 318-319 (Anhang). 
beim Überschreiten der Binnengrenzen, Asylrecht und Einwanderungspolitik, die jede für sich erhebliche innerstaatliche Anpassungen nach sich ziehen könnten. ${ }^{658}$

\section{Abbildung 28 \\ Drei-Säulen-Tempel - die Europäischen Union nach dem Amsterdamer Vertrag ${ }^{659}$}

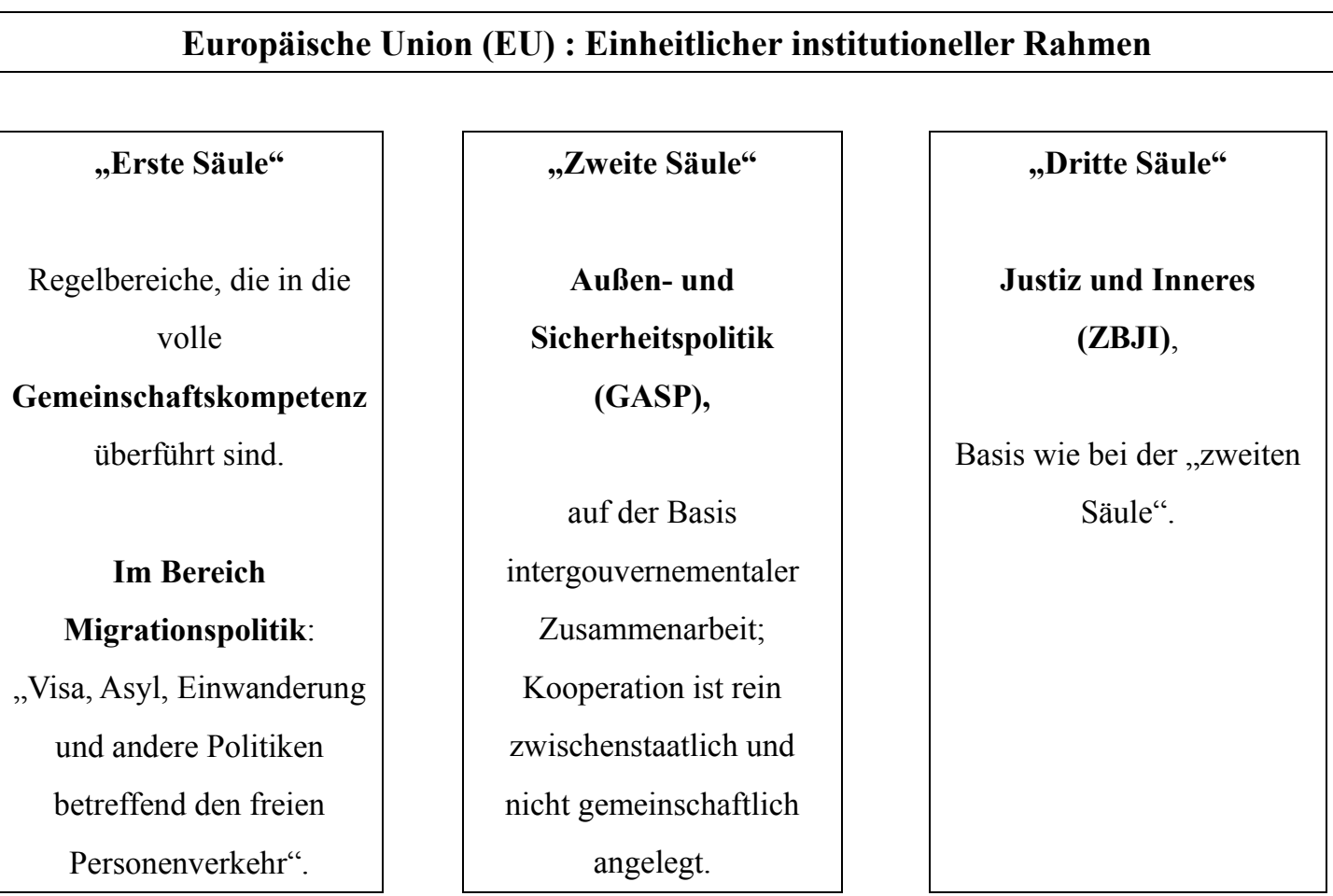

Im Amsterdamer Vertrag sind weitere Regelungen zu Asyl- und Einwanderungsfragen vorgesehen, wie etwa zum Aufbau gemeinschaftsweiter Mindestnormen für die Aufnahme von Asylbewerbern und die Anerkennung von Staatsangehörigen dritter Länder als Flüchtlinge, Maßnahmen zur ausgewogenen Verteilung von Asylbewerbern und Flüchtlingen auf die einzelnen Mitgliedstaaten, Aufbau von einwanderungspolitischen Maßnahmen, wie beispielsweise die Regelung von Einreiseund Aufenthaltsvoraussetzungen oder Maßnahmen bei illegaler Zuwanderung und illegalem Aufenthalt einschließlich der Rückführung solcher Personen (Art. 63 EGV/Amsterdam). ${ }^{660}$

658 Vgl. Wessel, Wolfgang 1997: Der Amsterdamer Vertrag - Durch Stückwerksreformen zu einer effizienteren, erweiterten und föderalen Union? In: Integration, Jg. 20. 3/1997. S. 122.

659 Zusammengestellt auf der Grundlage von Klos, Christian 1999: a.a.O., S. 25 f. u. S. 30; Birsl, Ursula 2005: a.a.O., S. 117.

660 Vgl. Pechstein, Matthias / König, Christian 1998: Die Europäische Union. A.a.O., S. 309; vgl. KohlerKoch, Beate / Conzelmann, Thomas / Knodt, Michéle 2004: Europäische Integration a.a.O., S. 136. 
Um diesen vertragsrechtlichen Gemeinschaftskonsens $\mathrm{zu}$ erreichen, sind Kompromissformeln mit einigen Mitgliedsstaaten erzielt worden: „Möglich wurde die Überführung dieser wichtigen Sachbereiche vom dritten Pfeiler in den ersten Pfeiler aber nur, weil sowohl die dänische als auch insbesondere die neue britische Regierung ihre bisherige Haltung aufgegeben haben. Dieses Entgegenkommen musste allerdings einerseits mit der Aufrechterhaltung des Einstimmigkeitserfordernisses und andererseits mit einer ,stay-out/opt-in-Sonderregelung' für das Vereinigte Königreich, Irland und Dänemark erkauft werden“. ${ }^{661}$ Großbritannien, Irland und Dänemark haben keine Verpflichtung, sich an Maßnahmen, die unter diesen neuen Titel IV fallen, zu beteiligen (stay-out bzw. opt-out), sie haben aber jeweils die Gelegenheit, sich anzuschließen (optin: Protokoll 2-5 EGV/Amsterdam). Dänemarks Beteiligung basiert ausschließlich auf dem Völkerrecht und nicht auf dem EU-Recht (Protokoll 5(5) EGV/Amsterdam). Dies besagt bereits im Schengener Abkommen eindeutig eine „flexible Integration“, d. h. eine ungleichmäßige Beteiligung der Mitgliedstaaten an bestimmten Aspekten der EGoder der EU-Beschlüsse. Die „flexible Integration“ hat durch den Amsterdamer Vertrag zur sogenannten verstärkten Zusammenarbeit zwischen einzelnen Mitgliedstaaten eine vertragsmäßige Konsolidierung gefunden. ${ }^{662}$ Die Vergemeinschaftung des Politikfeldes Migration wird auch dann aufrechterhalten, wenn die in den Protokollen verankerten Ausnahme- und Sonderregelungen für das Vereinigte Königreich, Irland und Dänemark einbezogen werden. ${ }^{663}$ Auch diese Einbindung der zurückhaltenderen Mitgliedstaaten in den institutionalisierten Verhandlungsprozess und ihre flexible opt-out/opt-in Möglichkeit kann ferner auf lange Sicht die Einwände gegen die voranschreitende Europäisierung beheben oder auch angemessene Lösungen für signifikante Anforderungen an Inselstaaten zu Tage bringen. ${ }^{664}$

Im Vergleich $\mathrm{zu}$ den Maastrichter Regelungen wird die Position der Gemeinschaftsinstitutionen in migrationspolitischen Bereichen unter dem neuen Titel IV des Amsterdamer Vertrages noch weiter bekräftigt. Als juristisches Kernstück der Neuregelungen ist dabei die Festlegung des Entscheidungsverfahrens gemäß Artikel 67 des Amsterdamer Vertrag (ehemaliger Artikel 73 O) zu sehen: „Der Rat handelt

${ }^{661}$ Hailbronner, Kay / Thiery, Claus 1998: Amsterdam-Vergemeinschaftung der Sachbereiche freier Personenverkehr, Asyl und Einwanderung sowie Überführung des Schengen-Besitzstands auf EUEbene. In: Europarecht, Heft 5, 33. Jahrgang 1998, September-Oktober 1998. S. 585.

${ }^{662}$ Vgl. Kohler-Koch, Beate / Conzelmann, Thomas / Knodt, Michéle 2004: Europäische Integration Europäisches Regieren. Wiesbaden, S. 137.

${ }^{663}$ Vgl. Wessel, Wolfgang 1997: Der Amsterdamer Vertrag - a.a.O., S. 122.

${ }^{664}$ Vgl. Klos, Christian 1999: Eine Reise von Rom nach Amsterdam: Die Entwicklung des europäischen Einwanderungsrechts. In: Wolter, Achim (Hrsg.) 1999: Migration in Europa: Neue Dimensionen, neue Fragen, neue Antworten. Baden-Baden, S. 33. 
während eines Übergangszeitraums von fünf Jahren nach Inkrafttreten des Vertrags von Amsterdam einstimmig auf Vorschlag der Kommission oder auf Initiative eines Mitgliedstaats und nach Anhörung des Europäischen Parlaments. Nach Ablauf dieser fünf Jahre handelt der Rat auf der Grundlage von Vorschlägen der Kommission; die Kommission prüft jeden Antrag eines Mitgliedstaats, wonach sie dem Rat einen Vorschlag unterbreiten soll.“665 Bis zum 1. Mai 2004 (also in den ersten fünf Jahren nach Inkrafttreten des Amsterdamer Vertrages) sollten Entscheidungen daher nicht durch Mehrheitsentscheidungen, sondern zwingend unter Verwendung des Einstimmigkeitsprinzips getroffen werden. Das heißt, den Rat schränkte diesbezüglich am stärksten ein, dass Beschlüsse im Ministerrat einstimmig gefasst werden mussten. Jedoch wird in absehbarer Zeit das Verfahren der qualifizierten Mehrheitsentscheidungen im Ministerrat nur in Bezug auf die Visapolitik möglich sein (Art. 67 Abs. 3 EGV, ehemaliger Artikel 100c Abs. 3 EGV/Amsterdam). Als eine weitere Besonderheit ist hier anzuführen, dass die Kommission das Initiativrecht für Gesetzesvorschläge für die ersten fünf Jahre mit den Mitgliedstaaten teilt (sogenanntes Ko-Initiativrecht), eine außergewöhnliche Maßnahme für eine Politik der ersten Säule. Zwischen Intergouvernementalität und Supranationalität bezeichnet dies eine Kompromisslösung, die dem Gemeinschaftsvertrag ansonsten grundsätzlich nicht eigen ist. ${ }^{666}$ Die Europäische Kommission erhält nach Ablauf der fünfjährigen Übergangszeit das Initiativmonopol. Die Kommission hat hiermit der wachsenden Bedeutung des innenpolitischen Bereichs und seiner Anknüpfung an eine gemeinsame europäische Politik sowie der Zuweisung neuer Kompetenzen an die EU im Bereich Justiz und Inneres durch den Vertrag von Amsterdam Rechnung getragen. Das Europäische Parlament (EP) wird in den ersten fünf Jahren wie bisher in den innenpolitischen Feldern vom Rat lediglich angehört. Bezüglich des Anhörungsrecht des Parlaments wurde eine Präzisierung vorgenommen und es wurde verfahrensmäßig verbessert. Es erhält nach Beendigung der fünfjährigen Testphase mit Einführung des Mitentscheidungsverfahrens (Art. 67 Abs. 1 EGV/Amsterdam) entscheidend mehr Mitwirkungs- und Entscheidungsbefugnisse. Das EP bezeichnet sich somit selber als einen der großen „Gewinner“667 von Amsterdam. Eine neue Entwicklung stellt die Kontrollbefugnis dar, die dem Europäischen Gerichtshof (EuGH) derweil im Bereich

\footnotetext{
${ }^{665}$ Pechstein, Matthias / König, Christian 1998: Die Europäische Union. a.a.O., S. 310. u. S. 196-197.

${ }^{666}$ Vgl. Moravcsik, Andrew / Nicolaidis, Kalypso 1999: Explaining the Treaty of Amsterdam: Interests, Influence, Institutions. In: Journal of Common Market Studies (JCMS), Vol. 37 (1999). S. 59-85. v. a. S. 79.

${ }^{667}$ Brok, Elmar 1997: Der Amsterdamer Vertrag: Etappen auf dem Weg zur europäischen Einigung. In: Integration 4/1997. S. 211-218.; Brok, Elmar 1997: Die Gewinner von Amsterdam. In: Frankfurter Allgemeine Zeitung vom 27. Juni 1997.
} 
Asyl und Einwanderung zukommt. Jedoch sind auch seine Zuständigkeiten modifiziert und teilweise beschränkt worden. Er kann ausschließlich im Falle von Auslegungsfragen (die sogenannte Auslegungskompetenz) zum EG-Vertrag oder eines darauf gestützten Rechtsakts angerufen werden (Art. 68 Nr. 1 EGV/Amsterdam). Darüber hinaus erhält der EuGH mit dem Amsterdamer Vertrag Vorabentscheidungskompetenzen in den vergemeinschafteten Bereichen (Art. 35, ehemaliger Artikel K.7 EGV/Amsterdam). Das Vorabentscheidungsverfahren kann dabei lediglich von letztinstanzlichen nationalen Gerichten (das sogenannte obligatorische Vorabentscheidungsverfahren für letztinstanzliche Gerichte) angestrengt werden. ${ }^{668}$ Weiterhin bietet der Amsterdamer Vertrag, gemeinschaftsrechtlicher Zuständigkeit zum Trotz, die Möglichkeit nationaler Sonderwege. Nationale Maßnahmen bezüglich der Binnengrenzkontrollen (Art. 62 Nr. 1 EGV/Amsterdam), die mit der öffentlichen Ordnung und einem Schutz der inneren Sicherheit begründet sind (sog. Ordre-public-Klausel von Art. 35 Abs. 5 EGV), sind nicht der Rechtsprechungsbefugnis des Europäischen Gerichtshofs unterstellt (Art. 68 Nr. 1 und Nr. 2 EGV n.F./Amsterdam). ${ }^{669}$ Nach der Amsterdamer Reform kann jedoch auch im Hinblick auf diese Einschränkungen der migrationspolitischen Kooperation in der EU durch den EuGH künftig von einer „Verdichtung der Rechtsgemeinschaft“ 670 gesprochen werden.

Insgesamt lässt sich bezüglich der Kooperationsform der migrationspolitischen Zusammenarbeit der EU-Staaten im Amsterdamer Vertrag eine klare Verringerung der Berücksichtigung nationaler Souveränitätsbedürfnisse feststellen. Durch den neuen Titel IV „Visa, Asyl, Einwanderung und andere Politiken betreffend den freien Personenverkehr“" (Art. 61 ff. EGV/Amsterdam) erfolgt hier eine Vergemeinschaftung von vielen der vorab unionsrechtlichen ZBJI-Bereichen der dritten Säule in Form konkurrierender EG-Rechtssetzungskompetenzen. Der Sprung von der dritten in die erste Säule kommt einem Richtungswechsel in diesem Politikbereich gleich: Im

668 Die Regierungsvertreter wollten anhand dessen die Möglichkeit einer Verlängerung nationaler Asylgerichtsverfahren durch Vorlagen beim EuGH ausschließen. Im Rechtssystem der Europäischen Union hat das Vorabentscheidungsverfahren eine Verzahnungsfunktion und leistet einen entscheidenden Beitrag zur Durchführung und vereinheitlichen Geltung des europäischen Rechts. Vgl. Oppermann, Thomas 1999: Europarecht. München, S. 285 ff.

669 Vgl. Klos, Christian 1999: Eine Reise von Rom nach Amsterdam: Die Entwicklung des europäischen Einwanderungsrechts. In: Wolter, Achim (Hrsg.) 1999: Migration in Europa: Neue Dimensionen, neue Fragen, neue Antworten. Baden-Baden, S. 33.; Pechstein, Matthias / König, Christian 1998: Die Europäische Union. Die Verträge von Maastricht und Amsterdam. Tübingen. S. 308-311.

670 Müller-Graff, Peter-Christian 1997: Justiz und Inneres nach Amsterdam - Die Neuerungen in erster und dritter Säule. In: Integration, Jg. 20 (1997), S. 280. 
Rahmen dessen wird die bislang vorherrschende zwischenstaatliche Zusammenarbeit von einer supranationalen Rechtssetzungskompetenz der EU abgelöst. ${ }^{671}$ Diese Vergemeinschaftung hatte jedoch auch zur Folge, dass die in dem neuen Titel enthaltenen Bestimmungen und das auf ihrer Grundlage beschlossene Sekundärrecht im Vereinigten Königreich, Irland und Dänemark nicht gültig sind, wenn diese Staaten nicht auf ihre in Zusatzprotokollen vereinbarten Sonderstellungen verzichten. Abgesehen davon zeigt der neue Titel IV besonders, wie schwer die Einigung der Unionsstaaten hinsichtlich einer Vergemeinschaftung auf dem Feld der Innen- und Justizpolitik fiel. Es lässt sich beispielsweise bei der Kompetenz- und Machtverteilung zwischen den nationalen und europäischen Akteuren klar erkennen, dass dem Ministerrat eine ausgesprochen dominante Position gewährt wurde. ${ }^{672}$ Die Entwicklung geeigneter Rechtsinstrumente in den genannten Feldern bildete allerdings den Kern der darauf folgenden Aktivitäten der EU-Institutionen sowie der Mitgliedstaaten. Erst die gemeinsame Migrationspolitik diente im Übrigen als Basis dafür, dass mit dem Amsterdamer Vertrag (1997/99) eine Vollharmonisierung ernstlich erwogen wurde. Aus diesen Gründen erscheint es gerechtfertigt, anzunehmen, dass nach dem Ablauf der Übergangszeit tatsächlich Einstimmigkeit erzielt werden kann. Infolge der impliziten eigenen Dynamik der Zusammenarbeit kann es dazu kommen, dass bremsende Maßnahmen zur Beibehaltung der mitgliedstaatlichen Souveränität für die Migrationspolitik praktisch nicht mehr möglich sind. ${ }^{673}$

\footnotetext{
${ }^{671}$ Vgl. Hailbronner, Kay 1998: European Immigration and Asylum Law under the Amsterdam Treaty. In: Common Market Law Review (CMLR) 35. S. 1047-1067.

${ }^{672}$ Vgl. Pechstein, Matthias / König, Christian 1998: Die Europäische Union. Die Verträge von Maastricht und Amsterdam. Tübingen. S. 193.

${ }^{673}$ Vgl. Klos, Christian 1999: Eine Reise von Rom nach Amsterdam: a.a.O., S. 32 f.
} 


\subsection{Das Tampere Programm}

Vom Europäischen Rat von Tampere (Finnland), der im Oktober 1999 tagte, wurden die im Amsterdamer Vertrag gesetzten Ziele über „die Schaffung eines Raums der Freiheit, der Sicherheit und des Rechts in der Europäischen Union““674 weiterentwickelt. In der Konsequenz bedeutet dies, dass somit der politische Rahmen für die Schaffung einer gemeinsamen Asyl- und Migrationspolitik der EU festgelegt wurde, während den sechs folgenden konkreten Handlungsfeldern politische Priorität gewährt wurde: die Ausgestaltung der Partnerschaft mit Herkunfts- und Transitländern, die Errichtung eines gemeinsamen europäischen Asylsystems, eine finanzielle Lastenverteilung im Falle eines Massenzulaufs von Flüchtlingen, das EURODAC-System zur Identifizierung von Asylsuchenden, die gerechte Behandlung von Drittstaatsangehörigen sowie die Steuerung der Migrationsströme, und im besonderen eine gemeinsame Visapolitik der EU für illegale Migration. ${ }^{675}$ Eine Bekräftigung des im Amsterdamer Vertrags formulierten Ziels, ein gemeinsames Asylsystem im Sinne einer materiellen Angleichung des Asylrechts zu entwickeln, bezeichnete den zentralen Beschluss des Gipfels. Ein gemeinsames europäisches Asylsystem sollte dabei Folgendes einschließen: eine klare und praktikable Formel für die Bestimmung des für die Prüfung eines Asylantrags zuständigen Staates, gemeinsame Standards für Asylverfahren und die Aufnahme von Asylbewerbern, die Annäherung der Bestimmungen über die Zuerkennung der Flüchtlingseigenschaft und Vorschriften über die Formen des subsidiären Schutzes. ${ }^{676}$ Dabei wurde betont, dass das Völkerrecht und eine solidarische Grundhaltung den Harmonisierungsprozess leiten sollten. Innerhalb dieser Periode wurden verschiedene Legislativmaßnahmen entwickelt, verhandelt und verabschiedet. Die Tampere-Beschlüsse galten somit als Meilenstein in der europäischen Einwanderungs- und Asylpolitik, allerdings sind sie insgesamt durch folgenden „Dreiklang“ strukturiert: ein eindeutiges Bekenntnis zur Genfer Flüchtlingskonvention, ohne tatsächliche Umsetzung, eine wirkungsvolle Abschottung gegenüber Flucht- und Migrationsbewegungen sowie die Durchführung von koordinierten und rigiden Abschiebeverfahren. ${ }^{677}$

\footnotetext{
674 Europäischer Rat 1999: Schlussfolgerungen des Vorsitzes in Tampere, 15. und 16. Oktober 1999; SN 200/99; http://www.consilium.europa.eu/ueDocs/cms_Data/docs/pressData/de/ec/00200-rl.d9.htm

675 Vgl. Ardittis, Solon/Lewis, Richard/Manchip, Colin 2005: From Rome to The Hague. European Union Policy-Making on Asylum. London: Institute for Public Policy Research. S. 15 f.

676 Vgl. Europäischer Rat 1999: Schlussfolgerungen des Vorsitzes in Tampere, a.a.O.

677 Pro Asyl 2000: Offenes Europa oder Abschottungsgemeinschaft? Die Union auf dem Weg zu einem gemeinsamen Asylrecht. Frankfurt a. M.
} 


\subsection{Der Vertrag von Nizza}

Die Institutionen und Entscheidungsverfahren der Europäischen Union sollten eingedenk der EU-Erweiterung bzw. der EU expansion ${ }^{678}$ („15 plus 12“) durch den am 26. Februar 2001 unterzeichneten Vertrag von Nizza $(\mathrm{VvN})^{679}$ reformiert werden. Das Ziel bestand darin, auch nach der Aufnahme neuer Mitglieder die Funkitonsfähigkeit der EU aufrechtzuerhalten. Unverzichtbar war in diesem Zusammenhang die Überarbeitung der Verträge der Europäischen Union, also die sogenannten Left-overs des Amsterdamer Vertrags, im Hinblick auf vier zentrale Reformthemen, die die Staats- und Regierungschefs der Regierungskonferenz bereits im Dezember 2000 nach harten Kontroversen unterzeichnet hatten: Größe und Zusammensetzung der Kommission, Stimmengewichtung im Rat der EU, Ausweitung der Abstimmung mit qualifizierter Mehrheit sowie verstärkte Zusammenarbeit. ${ }^{680}$ Trotz dieser Institutionenreform war das Ergebnis allerdings ernüchternd: Verkleinerung der Kommission, dem Prinzip folgend „weniger Kommissare als Mitgliedstaaten“, wurde vertagt. Es war zwar im Vertrag von Nizza vorgesehen, dass von 2005 an jeder Staat lediglich einen Kommissar stellen darf (Art. 213 EGV), was zur Folge hätte, dass die großen Mitgliedstaaten ab diesem Zeitpunkt ihren zweiten Kommissar aufgeben müssten. Die Stimmengewichtung im Rat der EU, d. h. die Stimmen für eine qualifizierte Mehrheit würden neu gewichtet, jedoch verkompliziert. Es wäre also gemäß Nizza nur noch dann möglich, Mehrheitsentscheidungen zu erzielen, wenn eine Mehrheit der Stimmen, der Staaten und Bevölkerung erreicht wird (,dreifache Mehrheit“). Doch auch bezüglich dieser dreifachen Absicherung wagte man eine eindeutige Ausdehnung der Mehrheitsentscheidungen im Rat nicht. ${ }^{681}$ In der Debatte um die Ergebnisse von „Nizza“ zeigte sich der Wandel des EP in seiner Rolle als „Systemgestalter“: vom Utopischen und Abstrakten zum Konkreten und Pragmatischen. ${ }^{682}$ Eine der wesentlichsten Reformen fand somit in Bezug auf die Erweiterung des

678 „Am Ende der 90er Jahre zeichnete sich damit ein Beitritt von insgesamt zwölf neuen Staaten - sowie möglicherweise der Türkei - ab. [...] Die Vergrößerung der EU von 15 auf 27 Mitgliedstaaten.” In: Weidenfeld, Werner / Wessels, Wolfgang (Hrsg.) 2007: Europa von A bis Z. S. 37-39, hier S. 37.

679 Zum Vertrag von Nizza siehe Fischer, Klemens H. 2003: Der Vertrag von Nizza. Text und Kommentar. Baden-Baden. Vgl. auch im Internet: http://europa.eu.int/comm/nice_treaty/index_en.htm

${ }^{680}$ Vgl. Maurer, Andreas 2007: Vertrag von Nizza. In: Weidenfeld, Werner / Wessels, Wolfgang (Hrsg.) 2007: Europa von A bis Z. Baden-Baden, S. 369-373.

${ }^{681}$ Weidenfeld, Werner / Wessels, Wolfgang (Hrsg.) 2007: Europa von A bis Z. Baden-Baden, S. 35-36.

${ }^{682}$ Vgl. Große Hüttmann, Martin 2005: Vom abstrakten zum konkreten Systemgestalter: Die Rolle des Europäischen Parlaments in den Regierungskonferenzen bis Nizza. In: Maurer, Andreas / Nickel, Dietmar (Hrsg.) 2005: Das Europäische Parlament: Supranationalität, Repräsentation und Legitimation. Baden-Baden, S. 42-45. 
Mitentscheidungsverfahrens des EP statt. Als Resultat des Vertrages von Nizza verfügt das EP nun auch bei den vergemeinschafteten Politikfeldern des „Raums der Freiheit, der Sicherheit und des Rechts“6833 über ein Mitentscheidungsrecht.

Jedoch war der Vertrag von Nizza auch von heftiger Kritik betroffen. Obgleich er von der großen Mehrheit stark kritisiert wurde - nach Meinung des damaligen EP Abgeordneten Elmar Brok ist der Vertrag von Nizza der „Auftrag“ von Amsterdam, eine Lösung der left overs herbeizuführen, jedoch sei dieses in Nizza nicht erfüllt, sondern vielmehr ,in sein Gegenteil verkehrt“ worden ${ }^{684}$ - waren die daraus gezogenen Schlüsse vollkommen verschieden: Der Vertrag von Nizza ließ viele Fragen unbeantwortet. Dieses wird in der angefügten Erklärung Nr. 23 der Schlussakte der Konferenz von Nizza zur Zukunft der Union ${ }^{685}$ erkenntlich, die den sogenannten „PostNizza-Prozess “686 festlegt. Der hiermit eingeleitete Post-Nizza-Prozess enthielt daher mindestens vier Kernthemen: Die Frage der Kompetenzordnung zwischen der EU und ihren Mitgliedstaaten, die Neuordnung und Vereinfachung der Verträge, der Status der in Nizza verabschiedeten Charta der Grundrechte und die Rolle der nationalen Parlamente in der EU. ${ }^{687}$

In den migrationsrelevanten Bereichen wurde durch den am 1. Februar 2003 in Kraft getretenen Vertrag von Nizza das Entscheidungsverfahren im Asyl- und Flüchtlingsbereich verändert. Mit der Inkraftsetzung der Richtlinie für Mindestnormen zum Asylverfahren im Januar 2006 kam es zu einer Implementierung des Mehrheitsprinzips im Rat und zur Anwendung des Mitentscheidungsverfahrens im Europäischen Parlament (Art. 67 EGV), ${ }^{688}$ nachdem der Rat der Europäischen Union sich bezüglich kollektiver Regeln und wesentlicher Grundsätze geeinigt hatte. Der Vertrag von Nizza wandelte einiges davon ab. Einige Mitgliedstaaten, allen voran Deutschland, aber auch andere, wollten das geltende Einstimmigkeitsprinzip in der legalen Einwanderung nicht aufgeben, da sie besonders den Einlass zu den

${ }^{683}$ Vgl. Maurer, Andreas / Wessels, Wolfgang 2003: Das Europäische Parlament nach Amsterdam und Nizza: Akteur, Arena oder Alibi?. Baden-Baden, S. $14 \mathrm{ff}$.

${ }^{684}$ Vgl. Elmar, Brok 2001: Der Vertrag von Nizza: Wird die EU handlungsfähig?. In: Frankfurter Allgemeine Zeitung vom 13. Januar 2001, S. 11.

685 Vgl. ABL (Amtsblatt der Europäischen Union). EU 2001 Nr. C 80/85.

${ }^{686} \mathrm{Um}$ so vor allem Reminiszenzen zu den Amsterdam-left-overs zu vermeiden.

687 Vgl. Wessels, Wolfgang 2008: Das politische System der Europäischen Union. S. 101; Neisser, Heinrich / Verschraegen, Bea 2001: Die Europäische Union. Anspruch und Wirklichkeit. Wien, S. 23.

688 Vgl. Bundesministerium des Innern (Hrsg.) 2009: Europäische Harmonisierung des Flüchtlings- und Migrationsrechts; http://www.bmi.bund.de/nn_161630 (Stand: 30.11.2009). 
Arbeitsmärkten als eine nationale Angelegenheit auslegten. ${ }^{689}$ Da jedem Mitgliedsland außerdem de facto eine Vetoposition zukam, stellte die Einstimmigkeitsregelung im Rat für diesen speziellen Teilbereich eine schwer zu überwindende Barriere in Bezug auf eine Ausdehnung der Gemeinschaftskompetenzen dar. In der Vergangenheit haben taktische Sperren und Verzögerungen im Gesetzgebungsprozess mehrfach die von der Kommission erarbeiteten Richtlinienvorschläge bis zur Unkenntlichkeit verzerrt, wie zum Beispiel im Falle der vielfach kritisierten Richtlinie (RL) zur Familienzusammenführung (RL 2003/86/EG des Rates). ${ }^{690}$ In der Europäischen Union gab es bis zum September 2003 keine gemeinschaftliche Grundlage für die Familienzusammenführung von Drittstaatsangehörigen. Die im September verabschiedete RL (2003/86/EG) zur Familienzusammenführung begrenzt die Nachzugsberechtigten auf die Kernfamilie, schränkt den Nachzug von Kindern über 12 Jahren ein und bestimmt eine Altersgrenze für Ehepartner. So wurde etwa der Nachzug von Familienangehörigen bestimmter Länder in Deutschland an den Nachweis von Sprachkenntnissen gekoppelt, was empörte Proteste von Migrantenorganisationen, besonders türkischen Hintergrunds, auslöste. ${ }^{691}$ Ferner war ein wesentlich gewichtigerer Punkt in Nizza die Verkündung der „Charta der Grundrechte der Europäischen Union“, vor deren Hintergrund sich die EU zu zentralen Bestandteilen der GFK und zur Freizügigkeit und Aufenthaltsfreiheit bekennt. ${ }^{692}$

Der Vertrag von Nizza muss als eine weitere Stufe zu einer Integration Europas gesehen werden, da erstmalig die institutionelle Annäherung in konkreter Art und Weise vonstatten ging. ${ }^{693}$ Allerdings können die Ergebnisse von Nizza als Vertrag der „Institutionenreform“ nicht als großer Schritt nach vorn gewertet werden. Es wird diesbezüglich verschiedentlich die Ansicht vertreten, auf der Grundlage des Vertrages von Nizza sei die Europäische Union aufgrund ihrer Erweiterung nicht zukunftsfähig. ${ }^{694}$ Hier wird in erster Linie ein Konflikt nationaler Interessen deutlich.

\footnotetext{
689 Vgl. Jahn, Daniela / Maurer, Andreas / Oetzmann, Verena / Riesch, Andrea 2006: a.a.O.

690 Vgl. Bendel, Petra 2009: Die Migrationspolitik der Europäischen Union: Inhalte, Institutionen und Integrationsperspektiven. In: Butterwegge, Christioph / Hentges, Gudrun (Hrsg.) 2009: a.a.O., S. 131; vgl. auch Fischer, Klemens H. 2003: Der Vertrag von Nizza. Text und Kommentar. S. 357-358.

691 Bendel, Petra / Haase, Marianne 2008: Integrationspolitik der Europäischen Union. Online verfügbar unter: http://www.bpb.de/themen/A3OEJX,2,0,Integrationspolitik_der_Europ\%E4ischen_Union.html.

692 Birsl, Ursula 2005: a.a.O., S. 118.

693 Vgl. Neisser, Heinrich / Verschraegen, Bea 2001: Die Europäische Union. a.a.O., S. 22.

${ }^{694}$ Vgl. Streinz, Rudolf 2008: Der europäische Verfassungsprozess: Grundlagen, Werte und Perspektiven nach dem Scheitern des Verfassungsvertrags und nach dem Vertrag von Lissabon. München, S. 20.
} 


\subsection{Das Haager Programm}

Das sogenannte Haager Programm stellten von Staats- und Regierungschefs der Mitgliedstaaten der Europäischen Union auf ihrem Gipfeltreffen am 5. November 2004 weiterentwickelte Leitlinien im Bereich der Politik für Inneres und Justiz dar. ${ }^{695}$ Das Haager Programm ist für eine Dauer von fünf Jahren vorgesehen. Seine Hauptziele sind die Schaffung eines „Gemeinsamen europäischen Asylsystems“ bis zum Jahr 2010, die Steuerung legaler Zuwanderung, eine Lastenverteilung bei der Kontrolle der Außengrenzen der Europäischen Union und darüber hinaus Maßnahmen zur Bekämpfung der organisierten Kriminalität und des internationalen Terrorismus. ${ }^{696}$ Insgesamt kann das Programm in zehn prioritäre Ziele aufgeteilt werden (vgl. Anhang: Übersicht 5). Aufbauend auf dem Acquis der Tampere-Agenda in der Asyl- und Einwanderungspolitik will das Haager Programm mit seinen Leitlinien die im EUVertrag normierten Ziele der Freiheit, Sicherheit und des Rechts stärken. Hierbei steht die Terrorismusbekämpfung als erste und wichtigste gemeinschaftliche Obliegenheit im Vordergrund. Dank dieser erneuerten Sicherheitsansprüche kam es für den Bereich der Migrationspolitik nicht $\mathrm{zu}$ einer umfassenden Vergemeinschaftung. Das zentrale Gewicht lag stattdessen hauptsächlich auf der Kontrolle und Sicherheit von Zuwanderung. Im Vordergrund stand besonders der Kampf gegen illegale Einwanderung, eine effektive Rückehr- und Rückübernahmepolitik, die in erster Linie durch einen verstärkten Außengrenzschutz gesichert sein sollte. ${ }^{697}$ Der in der Kompetenz einzelner Mitgliedstaaten befindliche Schutz der Außengrenzen wurde folglich auf EU-Ebene anhand der Schaffung einer European Agency for the Management of Operational Cooperation at the External Borders of the member states of the EU (FRONTEX) im Jahr 2005 koordiniert. ${ }^{698}$ Die Mitgliedstaaten wurden zudem $\mathrm{zu}$ einer Intensivierung ihrer Bemühungen aufgefordert, biometrische Daten in

695 Vgl. Maurer, Andreas / Parkes, Roderick 2006: Asylum Policy and Democracy in the European Union from Amsterdam towards the Hague Programme. In: Diskussionspapier der FG 1, 2006 / 16. November 2006 SWP Berlin. Berlin, S. 25. Online verfügbar unter http://www.swpberlin.org/en/common/get_document.php?asset_id=2730\&PHPSESSID=7b23d71b9deec5ceb9c8e90c 7ec9807f (Stand: 30.11 .2007 )

${ }^{696}$ Vgl. Jahn, Daniela / Maurer, Andreas / Oetzmann, Verena / Riesch, Andrea 2006: Asyl- und Migrationspolitik der EU: Ein Kräftespiel zwischen Freiheit, Recht und Sicherheit. In: Diskussionspapier der FG 1, 2006 / 09, Juli 2006 SWP Berlin. Berlin, S. 25. Online verfügbar unter: http://www.swp-berlin.org (Stand: 30.11.2007).

697 Vgl. Bendel, Petra 2005a: Immigration Policy in the European Union. Still bringing up the walls for Fortress Europe?. In: Migration Letters 2. 1: S. 20-31.

698 Vgl. Jorry, Héléne 2007: Construction of a European Institutional Model for Managing Operational Cooperation at the EU's External Borders: Is the FRONTEX Agency a decisive step forward? In: CEPS Challenge Liberty \& Security, Research Paper 6: http://www.ceps.be (Stand: 09.10.2008). 
Ausweisdokumenten zu speichern. Der Europäische Rat beauftragte die EUKommission anhand des „Haager Programms“, die Eignung und Durchführbarkeit einer Behandlung von Asylanträgen außerhalb des EU-Territoriums zu prüfen. Eine Mitteilung bezüglich (KOM/2005/388. endgültig) der sogenannten Regionalen Schutzprogramme wurde von der Kommission Anfang September 2005 vorgelegt. Darunter fallen die Rückkehr in die Herkunftsstaaten, die örtliche Eingliederung in den Erstasylstaat oder die Neuansiedlung (resettlement-Programm) in einem Drittland. Besonders in Transitländern und in Herkunftsregionen, wie dem Gebiet der Großen Seen in Ostafrika, sollen diese Schutzprogramme Verwendung finden. Es besteht allerdings seitens der NGOs (Non Governmental Organizations) wie beispielsweise dem UNHCR (United Nations High Commissioner for Refugees) die Befürchtung, „dass die regionalen Schutzprogramme das Recht, in der EU Asyl zu beantragen, untergraben könnten, indem die Zielländer vorzeitig als ,sichere Drittländer' eingestuft werden und diese dann die Rückführung der durchreisenden Asylbewerber beschleunigen, ohne deren Schutzbedürfnisse zu berücksichtigen.“699 Das steht im Widerspruch zu dem Recht auf Asyl, das u. a. in der GFK (Genfer Flüchtlingskonvention) und der EMRK (Europäische Menschenrechtskonvention) verbrieft ist, und kommt einem Refoulement (erzwungener Rückkehr) gleich. Vonseiten Europas wird damit die gleiche Zielrichtung verfolgt - eine Verminderung der Asylzuwanderung, wobei internationale Verpflichtungen zum Schutz von Asylsuchenden formal beibehalten und Asylsuchende in so bezeichnete „sichere“ Staaten versendet werden. Die erfolgsversprechende Zweckdienlichkeit potenzieller Schutzprogramme wird von anderen NGOs hervorgehoben. Weil der größte Anteil der Flüchtlinge Schutz in Nachbarstaaten sucht, könnte eine EU-Hilfe im Rahmen der Schutzprogramme hilfreich sein, die Lage der Flüchtlinge vor Ort zu optimieren, so der European Council on refugees and exiles (ECRE). ${ }^{700}$ Des Weiteren legte die EU-Kommission am 11. Januar 2005 ein EUKonzept für Arbeitsmigration, d. h. ,ein Grünbuch zur Steuerung der Zuwanderung von Arbeitskräften aus Drittstaaten“701 mit der Frage vor, wie viel Vereinheitlichung die EU anstreben sollte. Ferner unterbeleitete die Kommission am 21. Dezember 2005 einen „Strategieplan zur legalen Einwanderung“ (KOM/2005/669 endgültig) für die Jahre

699 UNHCR 2006: Anmerkungen zur Mitteilung der Europäischen Kommission an den Rat und das Europäische Parlament über Regionale Schutzprogramme: http://www.unhcr.at/pdf/1474.pdf (Stand: 28.06.2006).

700 Haase, Marianne / Jugl, Jan C. 2007: Asyl- und Flüchtlingspolitik der EU: Vergemeinschaftung der Asyl- und Migrationspolitik im neuen Jahrtausend; http://www.bpb.de/themen/7H6FAJ,2,0,Asyl_und_F1\%FCchtlingspolitik_der_EU.html\#art2.

701 Europäische Kommission (KOM) 2005: Mitteilung der Kommission vom 21.12.2005: Der Strategische Plan zur legalen Einwanderung, KOM/2005/669 endgültig. Brüssel, S. 8-9.; http://europa.eu.int/eur-lex/lex/LexUriServ/site/de/com/2005/com2005_0669de01.pdf. 
2006 bis 2009 mit dem Schwerpunkt auf der Wirtschaftsmigration. Vier spezifische Richtlinienvorschläge konkretisierten den Strategieplan (vgl. Anhang: Übersicht 6). Von EU-Justizkommissar Frattini erfolgte diesbezüglich die Erklärung, er messe dem Strategieplan als Ergebnis eines echten Bottom-up-Prozesses große Bedeutung bei. ${ }^{702}$ Bei einem Treffen der EU-Innenminister in Brüssel am 1./2 Dezember 2005 wurden die Pläne einer EU-Einwanderungspolitik dagegen vonseiten des Bundesinnenministers Wolfgang Schäuble (CDU) eindeutig negativ beschieden: Legale Immigration wirke sich unmittelbar auf den Arbeitsmarkt aus und müsse daher eine nationale Kompetenz bleiben. ${ }^{703}$ Eine Vergemeinschaftung der legalen Arbeitsmigration wurde somit von den Mitgliedstaaten, allen voran Deutschland, als nationale Angelegenheit abgelehnt. Damit bleibt die Veto-option in diesem Bereich weiterhin erhalten, eine Blockade durch einzelne Staaten durchzuführen. ${ }^{704}$ Das unter der niederländischen Ratspräsidentschaft (zweites Halbjahr 2004) anfänglich entwickelte Programm beinhaltete überdies in institutioneller und verfahrensmäßiger Hinsicht, in den Bereichen Asyl, Einwanderung und Schutz der Außengrenzen vom 1. April 2005 an zur qualifizierten Mehrheitsentscheidung im Rat und zum Verfahren der Mitentscheidung des Europäischen Parlaments überzugehen. ${ }^{705}$

Das Fünfjahresprogramm von Den Haag betonte daazu ferner, die bisher geschaffenen Grundlagen der gemeinsamen Migrations- und Asylpolitik festigen und gegen irreguläre Einwanderungsnetzwerke vorgehen zu wollen, besonders den Kampf gegen den Terrorismus aufzunehmen, und sprach sich des Weiteren gegen den Menschenhandel aus. Dies sollten die zentralen Zielsetzungen der Politik darstellen. Hierbei werden allerdings sowohl die Regionalisierung des Flüchtlingsschutzes als auch der Ausbau einer legalen Einwanderungspolitik zunehmend als EU-Querschnittspolicy betrachtet. Außerdem ist das Politikfeld der Wirtschaftsmigration im Spannungsfeld zwischen Primat des Nationalstaates und Erfordernis der Vergemeinschaftung zu finden. Folglich kann als ein bedeutsamer Aspekt im Haager Programm das Gewicht bezeichnet werden, das der effektiven Umsetzung von EU-Richtlinien in den nationalen Rechtssystemen beigemessen wird. ${ }^{706}$

\footnotetext{
${ }^{702}$ Bommes, Michael / Schiffauer, Werner 2006: Migrationsreport 2006: a.a.O., S. 253.

${ }^{703}$ Bommes, Michael / Schiffauer, Werner 2006: Migrationsreport 2006: a.a.O., S. 253.

704 Vgl. Fellmer, Simon 2008: Europäische Migrationspolitik gegenüber Drittstaatsangehörigen. Ein klubtheoretischer Deutungsansatz zum Vergemeinschaftungswillen der Nationalstaaten. In: Hunger, Uwe/Aybek, Can M./Ette, Andreas/Michalowski, Ines (Hrsg.) 2008: Migrations- und Integrationsprozesse in Europa: Vergemeinschaftung oder nationalstaatliche Lösungswege?. Wiesbaden, S. 104-105.

${ }^{705}$ Vgl. Jahn, Daniela / Maurer, Andreas / Oetzmann, Verena / Riesch, Andrea 2006: a.a.O., S. 25.

706 Vgl. Jahn, Daniela / Maurer, Andreas / Oetzmann, Verena / Riesch, Andrea 2006: a.a.O., S. 26.
} 


\subsection{Der Vertrag von Lissabon}

In der Geschichte der konstitutionellen Systemgestaltung der europäischen Integrationskonstruktion wurde am 13. Dezember 2007 vom Europäischen Rat als konstitutioneller Architekt ein weiterer Meilenstein gelegt. Durch den Vertrag von Lissabon ${ }^{707}$ wird die Europäische Union institutionell reformiert und vom Europäischen Rat als „Reformvertrag“ konzipiert. $^{708}$ Vom Lissabonner Vertrag wird auch der bereits im Vertrag von Nizza angelegte Prozess vollzogen. ${ }^{709}$ Das Ziel des Vertrages ist es, die EU demokratischer, transparenter und effizienter zu machen. Das Ergebnis wurde von einer Mehrheit der EU-Mitgliedstaaten zeitnah ratifiziert. Allerdings wurde die Inkraftsetzung von einem Referendum in Irland und einzelnen weiteren Widerständen gebremst, sodass der Vertrag letztendlich erst Ende 2009, gemäß seinem Artikel 6 am 1. Dezember 2009 rechtsgültig wurde. ${ }^{710}$ Die aktuelle Struktur der vertraglichen Grundlagen des europäischen Konstrukts wird vom Vertrag von Lissabon in einigen Punkten verändert, so wird der Ausdruck „Gemeinschaft“ generell vom Ausdruck „Union“ ersetzt. Vertragliche Grundlage der Union bilden von nun an der „Vertrag über die Europäische Union“ (EUV) sowie der „Vertrag über die Arbeitsweise der Europäischen Union“ (AEUV), der den bestehenden „Vertrag zur Gründung der Europäischen Gemeinschaft" (EGV) ablöst. In erster Linie sind im EUV strukturelle Änderungen zu beobachten. Ferner ist ein hervorstechendes Merkmal, dass in der Lissabonner Version des EUV kein Hinweis mehr auf die ,polizeiliche und justizielle Zusammenarbeit in Strafsachen“711 zu findet ist. Dieser Teil des Regelwerks wurde komplett in den AEUV integriert und löst dort die vorherigen Titel „Visa, Asyl, Einwanderung“, als neuer Titel V „Raum der Freiheit, der Sicherheit und des Rechts“ (RFSR), und im dritten Teil „Die internen Politiken und Maßnahmen der Union“, ab - die bisher bestehende „dritte Säule“ der Union ist aufgelöst. ${ }^{712}$ Damit die

707 Zum Vertrag von Lissabon siehe: http://europa.eu/lisbon_treaty/index_de.htm; http://eur-lex.europa.eu/de/treaties/index.htm

708 Vgl. Streinz, Rudolf 2008: Der europäische Verfassungsprozess: Grundlagen, Werte und Perspektiven nach dem Scheitern des Verfassungsvertrags und nach dem Vertrag von Lissabon. München, S. 5 u. S. 22 (Fn. 11).

709 Vgl. Streinz, Rudolf / Ohler, Christoph / Herrmann, Christoph 2008: Der Vertrag von Lissabon zur Reform der EU: Einführung mit Synopse. München, S. 143.

710 Siehe dazu: http://www.europa.eu/lisbon_treaty/take/index_de.htm (Stand: 26.06.2010).

711 Hofmann, Andreas / Wessels, Wolfgang 2009: Eine dauerhafte Verfassung für Europa? Die Beantwortung konstitutioneller Grundfragen durch den Vertrag von Lissabon. In: Decker, Frank (Hrsg.) 2009: Die Verfassung Europas: Perspektiven des Integrationsprojekts. Wiesbaden, S. 71-72.

712 Hofmann, Andreas / Wessels, Wolfgang 2009: Eine dauerhafte Verfassung für Europa? Die Beantwortung konstitutioneller Grundfragen durch den Vertrag von Lissabon. In: Decker, Frank 
bisherige Rechtsnatur zusammengefasst werden kann, die derzeit geteilt ist - das heißt, in supranationale Handlungsbefugnisse (Art. $61 \mathrm{ff}$. EGV) und vorstrukturierte intergouvernementale Handlungsmöglichkeiten (Art. 29 ff. EUV) - , sieht nun der Reformvertrag grundsätzlich ein supranationales Vorgehen vor. ${ }^{713}$ Die Gemeinsame Außen- und Sicherheitspolitik (GASP) bleibt jedoch als Titel V im EUV bestehen (vgl. Anhang: Übersicht 7).

Der Text des nun im Dezember des Jahres 2009 ratifizierten Vertrages von Lissabon etabliert das „ordentliche Gesetzgebungsverfahren“ nach Art. 294 AEUV (zuvor: Mitentscheidungsverfahren). Desgleichen untersteht dem ordentlichen Gesetzgebungsverfahren von Parlament und Rat das ,gemeinsame europäische Asylsystem“ (Art. 78 AEUV) sowie die ,gemeinsame Einwanderungspolitik“ (Art. 79 AEUV). Neu ist allerdings, dass sowohl die Normen für einen langfristigen Aufenthalt als auch die Rechte von Drittstaatsangehörigen, die sich legal in einem Mitgliedstaat befinden, inklusive der Bedingungen, unter denen ihnen in den anderen Mitgliedstaaten freies Reisen und ein Aufenthaltsrecht erlaubt ist, der Gemeinschaftsregelung unterliegen - mithin Regelungen, die unter anderem die Integrationsfrage anbelangen. Jedoch ist auch hier von Bedeutung, dass die Möglichkeit einer gemeinsamen Anwerbepolitik zur Wirtschaftsmigration auch in Zukunft de facto verschlossen bleibt. So bleibt den Mitgliedstaaten das Recht vorbehalten, „festzulegen, wie viele Drittstaatsangehörige aus Drittländern in ihr Hoheitsgebiet einreisen dürfen, um dort als Arbeitnehmer oder Selbstständige Arbeit zu suchen“ (Art. 79 Abs. 5 AEUV). ${ }^{714}$ Das heißt, dass die arbeitsmarktbezogene Zuwanderung weiterhin durch das Einstimmigkeitsprinzip im Rat geregelt ist und dort auch in Zukunft kaum europäisches und harmonisiertes Handeln zu erhoffen sein wird. Trotzdem sieht der EGV bereits den Grundsatz der Solidarität zwischen den Mitgliedstaaten bei der Aufnahme der mit diesen Politiken verknüpften Lasten ansatzweise vor (Art. 63 Nr. 2 lit. b) EGV), der

(Hrsg.) 2009: Die Verfassung Europas: Perspektiven des Integrationsprojekts. Wiesbaden, S. 71-72.; vgl. Everling, Ulrich 2009: Rechtsschutz in der Europäischen Union nach dem Vertrag von Lissabon. In: Schwarze, Jürgen / Hatje, Armin (Hrsg.) 2009: Europarecht (EuR): Der Reformvertrag von Lissabon. EuR-Beiheft 1/2009. Baden-Baden, S. 79.; vgl. Streinz, Rudolf / Ohler, Christoph / Herrmann, Christoph 2008: Der Vertrag von Lissabon zur Reform der EU: a.a.O, S. $133 \mathrm{f}$.

${ }^{713}$ Vgl. Müller-Graff, Peter-Christian 2009: Der Raum der Freiheit, der Sicherheit und des Rechts in der Lissabonner Reform. In: Schwarze, Jürgen / Hatje, Armin (Hrsg.) 2009: Europarecht: a.a.O., S. 119.

714 Vgl. Thym, Daniel 2008: Europäische Einwanderungspolitik: Grundlagen, Gegenstand und Grenzen. In: Hoffmann, Rainer / Löhr, Tillmann (Hrsg.) 2008: Europäisches Flüchtlings- und Einwanderungsrecht: Eine kritische Zwischenbilanz. Baden-Baden, S. 186.; vgl. Bendel, Petra 2009: Die Migrationspolitik der Europäischen Union: Inhalte, Institutionen und Integrationsperspektiven. In: Butterwegge, Christioph / Hentges, Gudrun (Hrsg.) 2009: Zuwanderung im Zeichen der Globalisierung: Migrations-, Integrations- und Minderheitenpolitik. Wiesbaden, S. 131-132. 
AEUV beinhaltet in Art. 80 dafür eine autonome Formulierung, die dieses präzisiert. ${ }^{715}$ Kompetenzen der EU bezüglich der Förderung der Integration von Migranten stellen eine wesentliche Neuerung dar. Es ist jedoch vertraglich festgehalten, dass das Ziel hierbei nicht eine Harmonisierung nationalstaatlicher Integrationspolitiken ist (Art. 79 Abs. 4 AEUV). Eine gemeinsame Politik auf diesem Feld sollte vielmehr darauf abzielen, dass Integrationsanstrengungen in den Mitgliedstaaten von der EU unterstützt werden und ein Erfahrungsaustausch der Regierungen stattfindet. Außerdem wird innerhalb des Rates ein ständiger Ausschuss gebildet, der bei der „operativen Zusammenarbeit" der Mitgliedstaaten, etwa beim Schutz der Außengrenzen und dem Einsatz der Agentur FRONTEX, eine Hilfe darstellen soll, dieses besser zu koordinieren (Art. 71 AEUV). ${ }^{716}$ Daneben ist es allerdings Großbritannien, Irland und Dänemark durch die Protokolle Nr. 21 und 22 weiterhin freigestellt, sich entweder an der gemeinsamen Migrationspolitik der EU nicht zu beteiligen (opt-out) oder zukünftig daran zu partizipieren (opt-in). ${ }^{717}$

Im Lissaboner Vertrag ist auch eine „Passerelle“-Klausel vorgesehen, die eine Vergemeinschaftung derjenigen Bereiche der Justiz- und Innenpolitik zulässt, die noch in der sogenannten dritten Säule zu finden sind. Ferner sollen die qualifizierten Mehrheitsentscheidungen nach dem sogenannten Prinzip der doppelten Mehrheit (Art. 16 Abs. 4 EUV/vgl. Anhang: Übersicht 8) $)^{718}$ vor allem auf solche Bereiche ausgeweitet werden, die im Zusammenhang mit Asyl, Einwanderung, polizeilicher Zusammenarbeit und justizieller Kooperation in Strafsachen, Außengrenzkontrolle sowie diplomatischem

715 Art. 80: Präzise formuliert als „Grundsatz der Solidarität und der gerechten Verteilung der Verantwortlichkeiten unter den Mitgliedstaaten, einschließlich in finanzieller Hinsicht“. Zitiert nach: Müller-Graff, Peter-Christian 2009: a.a.O., S. 115.; vgl. Streinz, Rudolf / Ohler, Christoph / Herrmann, Christoph 2008: Der Vertrag von Lissabon zur Reform der EU: a.a.O., S. 138.

716 Vgl. Parusel, Bernd 2010: Abschottungs- und Anwerbungsstrategien: EU-Institutionen und Arbeitsmigration. (Dissertation Universität Osnabrück). Wiesbaden, S. 225.

717 De facto haben sich Großbritannien und Irland bislang an allen Elementen der Migrationspolitik in den Bereichen Asyl, Flüchtlinge und illegale Einwanderung beteiligt, während sie in den Bereichen Visumpolitik, Grenzsicherung und legale Migration (darunter auch Arbeitsmigration) außen vor geblieben sind. Vgl. Haack, Stefan 2010: Der Raum der Freiheit, der Sicherheit und des Rechts im Vertrag von Lissabon - Rhetorik oder Integrationsschub?. In: Leiße, Olaf (Hrsg.) 2010: Die Europäische Union nach dem Vertrag von Lissabon. Wiesbaden, S. 220-233, hier S. 232.; vgl. auch Geddes, Andrew 2005: The Politics of Migration and Immigration in Europe. London u.a., S. 137.

718 Aufgrund politischer Widerstände gegen die Neuregelung wird eine qualifizierte Mehrheit im Rat allerdings erst ab 2014 ausreichen, indes müssen zumindest 55 Prozent der Mitgliedstaaten ihre Zustimmung geben, die zugleich mindestens 65 Prozent der Bevölkerung repräsentieren. Vgl. Pöttering, Hans-Gert 2009: Von Rom nach Lissabon. Die europäische Perspektive. In: Decker, Frank (Hrsg.) 2009: Die Verfassung Europas: Perspektiven des Integrationsprojekts. Wiesbaden, S. 27.; vgl. Schwarze, Jürgen 2009: Der Reformvertrag von Lissabon - Wesentliche Elemente des Reformvertrages. In: Schwarze, Jürgen / Hatje, Armin (Hrsg.) 2009: Europarecht (EuR): Der Reformvertrag von Lissabon. EuR-Beiheft 1/2009. Baden-Baden, S. 14. 
und konsularischem Schutz stehen. Durch diese Regelung wird die Entscheidungs- und Handlungsfähigkeit der EU verbessert und Blockaden im Ministerrat (Kriterium der Effizienz) werden umgangen. Gleichzeitig erhöht sich allerdings das Risiko von package deals über Politikfelder hinweg, die gegenständlich nicht verbunden sind. ${ }^{719}$ Die signifikanteste Neuerung des Abstimmungsverfahrens der doppelten Mehrheit im Rat der EU (Staaten und Bevölkerung) wurde vorwiegend auf deutschen Wunsch eingeführt. Diese Einführung der doppelten Mehrheit ist zudem von Vorteil für die bevölkerungsreichsten Mitgliedstaaten (vgl. Anhang: Übersicht 9). Relativ gesehen erfährt in erster Linie Deutschland letztendlich den größten Machtzuwachs im Rat. ${ }^{720}$

Ferner ist besonders die Stärkung des Europäischen Parlaments (EP), das (außer auf dem Feld der Außen- und Sicherheitspolitik) zu einem neben dem Rat der Europäischen Union gleichberechtigten Gesetzgeber wird (sog. Mitentscheidungsrecht), an institutionellen Änderungen zu beobachten. ${ }^{721}$ Damit kommen dem EP entscheidend mehr Gestaltungsmöglichkeiten bei der Gesetzgebung in den Bereichen Asyl- und Einwanderungspolitik, bezüglich des Kampfes gegen grenzüberschreitende Kriminalität sowie der zivil- und strafrechtlichen Zusammenarbeit zu. ${ }^{722}$ Ebenso wird erstmalig den nationalen Parlamenten eine direkte Mitwirkung am EU-Gesetzgebungsprozess gewährt, allerdings nicht in gestaltender, sondern vielmehr in beratender und blockierender Funktion (sogenanntes Informations- und Kontrollrecht). Des Weiteren sind Kontrollrechte der nationalen Parlamente im Hinblick auf die Arbeiten von Eurojust und Europol vorgesehen (Art. 85 und 88 AEUV). ${ }^{723}$ Der Kernbereich der Mitwirkung nationaler Parlamente stellt jedoch die Kontrolle über die Berücksichtigung des Grundsatzes der Subsidiarität (Art. 12 EUV) dar. Insbesondere gegenüber der Kommission wird den nationalen Parlamenten ein vermehrtes Mitspracherecht im Rahmen eines sogenannten Frühwarnsystems ${ }^{724}$ eingeräumt. Im Kontext des Raums der

${ }^{719}$ Vgl. Bendel, Petra 2009: Die Migrationspolitik der Europäischen Union: a.a.O., S. 132-133.

720 Vgl. Emmanouilidis, Janis. A. 2009: Deutschland in der EU. In: Weidenfeld, Werner / Wessels, Wolfgang (Hrsg.) 2009: Europa von A bis Z: Taschenbuch der europäischen Integration. Bonn, S. 112.

${ }^{721}$ Vgl. Schwarze, Jürgen 2009: Der Reformvertrag von Lissabon - a.a.O., S. 12-13.

722 Pöttering, Hans-Gert 2009: Von Rom nach Lissabon. Die europäische Perspektive. In: a.a.O., S. 25.

${ }^{723}$ Vgl. Schoo, Johann 2009: Das neue institutionelle Gefüge der EU. In: Schwarze, Jürgen / Hatje, Armin (Hrsg.) 2009: Europarecht (EuR): EuR-Beiheft 1/2009. A.a.O., S. 55.

${ }^{724}$ Das Frühwarnsystem gibt es in zwei Formen: Zunächst können die nationalen Parlamente nach dem im Protokoll über die Anwendung der Grundsätze der Subsidiarität und der Verhältnismäßigkeit festgelegten Verfahren innerhalb von acht Wochen - im Gegensatz zu noch sechs Wochen nach dem Verfassungsvertrag - mit mindestens einem Drittel der Stimmen gegen beabsichtigte Rechtsakte der EU Einspruch erheben, sofern sie der Ansicht sind, dass diese Rechtsakte die nationalen Zuständigkeiten verletzen (sogenanntes Gelbe-Karte-Verfahren). Im Rahmen dieses Verfahrens hat jedes nationale Parlament zwei Stimmen, die anhand des einzelstaatlichen parlamentarischen Systems verteilt werden. In einem Zweikammersystem hat jede Kammer eine Stimme. Steht dem Vorschlag 
Freiheit, der Sicherheit und des Rechts werden die nationalen Parlamente in verschiedene Aktivitäten einbezogen. Durch eine Einbeziehung der nationalen Parlamente wird somit die Transparenz und Akzeptanz des Entscheidungsprozesses gesteigert. Allerdings stößt die Teilnahme an ihre Grenzen, da sie sich vom Inhalt her auf die Subsidiarität beschränkt und nicht den gesamten Gesetzesentwurf berücksichtigt. Bezüglich der Art und Weise der Mitwirkung ist keine Institutionalisierung der Zusammenarbeit der nationalen Parlamente in Planung. ${ }^{725}$ Indes wird ein duales Legitimationsprinzip in der EU betont: die Union als „Union der Bürgerinnen und Bürger“ und als „Union der Staaten“. ${ }^{726}$ In dieser Hinsicht wird als Novität ein europäisches Bürgerbegehren eingeführt (vgl. Art. 10 Abs. 2 EUV). Der Union der Bürger ist überdies die neu eingeführte Möglichkeit zur „Bürgerinitiative“ (Art. 11 Abs. 4 EUV) hinzuzurechnen. ${ }^{727}$ Der Präsident des Europäischen Rats, der nun für eine Amtszeit von zweieinhalb Jahren gewählt wird, bezeichnet eine der bedeutendsten neuen Errungenschaften (Art. 15 Abs. 5 EUV). ${ }^{728}$ Eine Innovation besonderer Art ist zudem der „Hohe Vertreter der Union für Außen- und Sicherheitspolitik“ (Art. 18 EUV), der gleichzeitig Vizepräsident der Europäischen Kommission (Art. 18 Abs. 3 und 4 EUV) sein und einen eigenen „Europäischen Auswärtigen Dienst (EAD)“ (Art. 27 Abs. 3 EUV) in Anspruch nehmen wird. ${ }^{729}$ Die Zuständigkeit des Gerichtshofs (EuGH) bezieht sich künftig für alle Tätigkeiten der Union, mit Ausnahme der Gemeinsamen Außen- und Sicherheitspolitik. Ansonsten sieht der Reformvertrag keine wesentlichen inhaltlichen Änderungen den Gerichtshof betreffend vor. Eine ab 2014 einsetzende Verkleinerung der Kommission (KOM) soll nebenbei die Handlungsfähigkeit der Institution optimieren. ${ }^{730}$ Die Kommission, die in vielen Politikbereichen als agenda

der Kommission die einfache Mehrheit der Gesamtzahl dieser Stimmen entgegen, und stimmen auch 55\% der Mitglieder im Rat oder eine Mehrheit im Europäischen Parlament gegen den Vorschlag, so wird der Vorschlag nicht angenommen (sogenanntes Rote-Karte-Verfahren). Das angeführte Beteiligungsverfahren kann auch in eine Klage münden (Subsidiaritätsklage). Zitiert in: Schwarze, Jürgen 2009: Der Reformvertrag von Lissabon - a.a.O., S. 19.

725 Schoo, Johann 2009: Das neue institutionelle Gefüge der EU. In: Schwarze, Jürgen / a.a.O., S. 57.

726 Hofmann, Andreas / Wessels, Wolfgang 2009: Eine dauerhafte Verfassung für Europa? Die Beantwortung konstitutioneller Grundfragen durch den Vertrag von Lissabon. In: Decker, Frank (Hrsg.) 2009: Die Verfassung Europas: Perspektiven des Integrationsprojekts. Wiesbaden, S. 79-81.

727 Hofmann, Andreas / Wessels, Wolfgang 2009: Eine dauerhafte Verfassung für Europa? Die Beantwortung konstitutioneller Grundfragen durch den Vertrag von Lissabon. A.a.O., S. 79-81.

728 Bundeszentrale für politische Bildung 2009: Der Lissabonner Vertrag auf einen Blick: a.a.O., S. 2-3. Online verfügbar unter http://www.bpb.de/files/634ZGY.pdf (Stand: 20.02.2010).

729 Hofmann, Andreas / Wessels, Wolfgang 2009: Eine dauerhafte Verfassung für Europa? a.a.O., S. 80 f.

730 Es bleibt bis Oktober 2014 nach Art. 17 Abs. 4 EUV 2007 dabei, dass von jedem Mitgliedstaat jeweils ein Kommissionsmitglied gestellt wird. Nach Art. 17 Abs. 5 EUV 2007 wird ab November 2014 die Zahl der Kommissionsmitglieder allerdings auf zwei Drittel der Anzahl der Mitgliedstaaten begrenzt, so dass zum Vorteil der Arbeitsfähigkeit dieses Gremiums in Zukunft nicht mehr jeder Mitgliedstaat ein Kommissionsmitglied nach Brüssel entsenden kann. Anhand eines Rotationsverfahrens wird garantiert, dass dessen ungeachtet jeder der Mitgliedstaaten regelmäßig zum Zuge kommt. Zitiert in: 
setter fungiert, nimmt mit den Generaldirektionen „Justiz, Freiheit und Sicherheit“ sowie „Beschäftigung, Soziale Angelegenheiten und Chancengleichheit“ teil. In der Migrationspolitik der vergangenen zehn Jahre wurde von ihr die Position der Impulsgeberin bzw. eines „Motors der Integration“ eingenommen. Der Rat der Innenund Justizminister wurde bis vor kurzer Zeit als die letzte Gesetzgebungsinstanz in Migrationsfragen gesehen. Als „Kontrahent“ der Kommission trat der Ministerrat in der Migrations- und Integrationspolitik bislang tendenziell als Bremser und Blockierer auf. Auch im Mehrebenesystem der Europäischen Union haben bisher nicht nur nationale, sondern ebenfalls subnationale Akteure, so wie die deutschen Bundesländer, mittelbare Macht erlangt. In Anbetracht der zu erwartenden Reformen der Verträge ist auch künftig selbstverständlich mit diesen Vetospielern mindestens dort zu rechnen, wo nationale und teilweise auch subnationale Kompetenzen bestehen bleiben, sprich in der Anwerbepolitik und auf all den Gebieten, die konkrete Integrationsmaßnahmen zum Gegenstand haben. ${ }^{731}$

Es lässt sich zusammenfassend festhalten, dass innerhalb der Europäischen Union durch die institutionellen Reformen des Lissabonner Vertrages in Bezug auf die Migrationspolitik supranational eine deutliche Verbesserung ihrer demokratischen Legitimation zu beobachten ist. Dies ist zum einen mit der eindeutigen Anerkennung des EP im Gesetzgebungsverfahren begründet und zum anderen sowohl durch die neue Definition der Mehrheitsentscheidungen im Rat als auch durch die Einbeziehung der nationalen Parlamente in den Entscheidungsprozess der Union belegt. Zugleich stärkt der Vertrag allerdings auch die Stellung der Mitgliedstaaten innerhalb und gegenüber der Union, wobei dieser Tendenz eher noch größere Bedeutung zukommt. ${ }^{732}$ Der Vertrag von Lissabon festigt insbesondere die Struktur durch die Beseitigung der zweifelhaften Tempelkonstruktion und erleichtert dadurch die einheitliche Willensbildung in dem sensiblen Bereich der Migrationspolitik. Jedoch muss auf diesem Politikfeld weiterhin die Bilanz gezogen werden, dass die Mitgliedstaaten sich effektiv um eine Reduktion der illegitimen Einwanderung und Asylbewerberzahlen bemühen, aber bisher keinerlei Verbesserungen bei der legalen Migration erzielt haben. ${ }^{733}$

Schwarze, Jürgen 2009: S. 13.

731 Vgl. Bendel, Petra 2009: Die Migrationspolitik der Europäischen Union: a.a.O., S. 132.

732 Vgl. Everling, Ulrich 2009: Rechtsschutz in der Europäischen Union nach dem Vertrag von Lissabon. In: Schwarze, Jürgen / Hatje, Armin (Hrsg.) 2009: a.a.O., EuR-Beiheft 1/2009. Baden-Baden, S. 85.

733 Vgl. Angenendt, Steffen / Parkes, Roderick 2009: EU-Migrationspolitik nach Lissabon und Stockholm: Neue Kompetenzen, bessere Politik?. In: SWP-Aktuell 71, Dezember 2009. Berlin, S. 1. Online Verfügbar unter: http://www.swp-berlin.org/common/get_document.php?asset_id=6676 


\subsection{Das Stockholmer Programm}

Wie eingangs ausführlich erläutert, ist Migrationspolitik eine kollektive Obliegenheit, die übergreifende Strategien und Maßnahmen erfordert. Bereits im Dezember 2005 hat der Europäische Rat den sogenannten „Gesamtansatz in der Migrationsfrage“ (Global approach to migration) beschlossen, wobei dieser grundsätzlich auf folgenden drei Säulen ruht: ${ }^{734}$ 1. Restriktive Maßnahmen illegaler Migration. 2. Verbesserte Steuerung legaler Migration. 3. Dichtere Verbindung zwischen Migrations- und Entwicklungspolitik. Dieser Gesamtansatz wurde von den Mitgliedsländern mit dem „Europäischen Pakt zu Einwanderung und Asyl“" (siehe Anhang: Übersicht 10), den der Europäische Rat im Oktober 2008 anerkannte, bekräftigt. Die Vorgaben des Europäischen Paktes werden im Rahmen des „Stockholmer Programms،“735 der EU in Form greifbarer Maßnahmen umgesetzt. Das Stockholmer Programm wurde von der Kommission im Auftrag des Europäischen Rates erarbeitet und seitens des Europäischen Rates im Dezember 2009 beschlossen. ${ }^{736}$ Es setzt das „Haager Programm“ (2005 - 2009) fort und erklärt für den Zeitraum von 2010 - 2014 die Prioritäten der EU-Innenpolitik. ${ }^{737}$ Die Schaffung eines „Gemeinsamen Europäischen Asylsystems (GEAS)“ bis zum Jahr 2012 ist dabei ein zentrales Ziel des „Stockholmer Programms“. ${ }^{738}$ Anhand von fünf Festlegungen ist das Stockholmer Programm erkennbar: „1. Legale Migration: Die bestehenden Regelungen über die Anerkennung von Berufsabschlüssen und anderen Qualifikationen werden evaluiert, um die Anwerbung in Drittstaaten zu verbessern. 2. Irreguläre Zuwanderung: Vorgesehen ist ein Ein- und Ausreiseregister; Visa sollen vorsichtiger erteilt werden. 3. Asyl: Die Behandlung der durch FRONTEX an den EU-Außengrenzen aufgegriffenen irregulären Zuwanderer soll verbessert werden; außerdem will man unter den Mitgliedstaaten für eine Lastenteilung bei Flüchtlingen werben. 4. Migration und Entwicklung: Die Kommission wird aufgefordert, Vorschläge zur Senkung der Kosten von

\footnotetext{
734 Bundesamt für Migration und Flüchtlinge (BAMF) 2010: Die deutschen Interessen bei der Europäisierung des Zuwanderungs- und Flüchtlingsrechts (Rede von BMI-Staatssekretär Klaus-Dieter Fritsche bei den 2. Nürnberger Tagen zum Asyl- und Ausländerrecht am 23. September 2010). S. 2; http://www.bamf.de/cln_092/nn_442764/DE/DasBAMF/Home-Teaser/nuernberger-tage-asyl-2010dokumentation.html (Stand: 21.10.2010).

735 Rat der Europäischen Union 2009: Das Stockholmer Programm - Ein offenes und sicheres Europa im Dienste und zum Schutz der Bürger. Brüssel, den 2. Dezember 2009 (04.12), 17024/09, S. 60.

736 Angenendt, Steffen / Parkes, Roderick 2009: a.a.O. In: SWP-Aktuell 71, Dezember 2009. Berlin, S. 3.

737 Bundesamt für Migration und Flüchtlinge (BAMF) 2010: Die deutschen Interessen bei der Europäisierung des Zuwanderungs- und Flüchtlingsrechts: a.a.O., S. 2.

738 Rat der Europäischen Union 2009: Das Stockholmer Programm - Ein offenes und sicheres Europa im Dienste und zum Schutz der Bürger. Brüssel, den 2. Dezember 2009 (04.12), 17024/09, S. 59.
} 
Rücküberweisungen und zur Förderung von zirkulärer Migration vorzulegen. 5. Integration: Künftig soll Integration als Querschnittsthema der EU-Politik behandelt werden.“739

Insbesondere im Flüchtlingsbereich versucht das Stockholmer Programm, national und international wesentliche Herausforderungen zu bewältigen: ${ }^{740}$ Nach UNHCR-Angaben existieten im Jahr 2009 weltweit über 10 Millionen Flüchtlinge, mehr als 800.000 Asylsuchende, approximativ 15 Millionen Binnenflüchtlinge und nahezu 2 Millionen Rückkehrer. Auch in den Industriestaaten sind im Jahr 2009 rund 377.000 Asylanträge gestellt worden. Allein in der EU gab es 2009 etwa 250.000 Menschen, die um Asyl ersuchten. ${ }^{741}$ Für die nahe Zukunft birgt somit das „Stockholmer Programm“ für diesen Asylbereich substanzielle Handlungsaufträge, wozu unter Folgendes zählt: „1. Die Schaffung eines Gemeinsamen Raums des Schutzes. 2. Die Teilung der Verantwortung im Asylbereich und solidarisches Handeln der Mitgliedstaaten untereinander. 3. Die Berücksichtigung der externen Dimension von Asyl.“742 Daher soll die Schaffung eines GEAS auch künftig als ein zentrales politisches Ziel der EU im Blickfeld des Interesses bleiben. Denn es gibt weiterhin große Differenzen bei den nationalen Vorschriften und deren Verwendung. ${ }^{743}$ Diesbezüglich wird das Europäische Unterstützungsbüro für Asylfragen (EASO) als ein wichtiges Instrument für die Entwicklung und Umsetzung des GEAS angesehen. Zugleich soll durch das EASO eine Weiterentwicklung einer kollektiven Schulungsplattform für nationale Asylbeamte erfolgen, die speziell nach dem europäischen Schulungsprogramm im Asylbereich gestaltet ist. ${ }^{744}$

Auch der Europäische Rat unterstreicht die Wichtigkeit einer „externen Dimension“ der EU-Politik auf dem Gebiet der Freiheit, der Sicherheit und des Rechts und betont die Notwendigkeit, diese vermehrt in die allgemeinen Politikbereiche der EU zu

739 Angenendt, Steffen / Parkes, Roderick 2009: a.a.O. In: SWP-Aktuell 71, Dezember 2009. Berlin, S. 4.

740 Bundesamt für Migration und Flüchtlinge (BAMF) 2010: Die deutschen Interessen bei der Europäisierung des Zuwanderungs- und Flüchtlingsrechts: a.a.O., S. 2 f.

741 Die Anzahl der Asylanträge hat sich zum Beispiel in Deutschland in den vergangenen Jahren merklich erhöht. Verglichen mit dem Jahr 2007 mit 19.164 Erstanträgen stellten im Jahr 200927.659 Menschen Antrag auf Asyl, was einen Anstieg von 44,3 Prozent bedeutet. In: Bundesamt für Migration und Flüchtlinge (BAMF) 2010: Die deutschen Interessen bei der Europäisierung des Zuwanderungs- und Flüchtlingsrechts: a.a.O., S. 3.

742 Bundesamt für Migration und Flüchtlinge (BAMF) 2010: Die deutschen Interessen bei der Europäisierung des Zuwanderungs- und Flüchtlingsrechts. a.a.O., S. 3; vgl. auch Rat der Europäischen Union 2009: Das Stockholmer Programm a.a.O., 17024/09, S. 69-72.

743 Rat der Europäischen Union 2009: Das Stockholmer Programm a.a.O., 17024/09, S. 69.

744 Rat der Europäischen Union 2009: Das Stockholmer Programm a.a.O., 17024/09, S. 70. 
integrieren. ${ }^{745}$ Die Hauptpunkte der externen Dimension der EU-Flüchtlingspolitk im Rahmen des Stockholmer Programms sind: „Neuansiedlung (Resettlement) von Flüchtlingen, Regionale Schutzprogramme, Verbesserung der Unterstützung des UNHCR und neue Konzepte für den Zugang zum Asylverfahren. ${ }^{\text {“746 }} \mathrm{Zu}$ all dem gehört zentral die Förderung der Aufnahmezentren in Drittländern. ${ }^{74}$ Diesbezüglich hat die EU-Kommission bereits im Jahr 2002 der EU ein Neuansiedlungsprogramm vorgeschlagen. ${ }^{748}$ Demzufolge sollte untersucht werden, ob die Möglichkeit einer Durchführung von Asylverfahren außerhalb Europas besteht. Auch die Initiative des damaligen britischen Premierministers Blair, die sogenannte Blair-Initiative von 2003, erörterte dieses Ziel, ebenso die Initiative des ehemaligen Bundesinnenministers Schily 2005. ${ }^{749}$ UNHCR befürwortete den Aufbau von Aufnahnmezentren, jedoch auf europäischem Gebiet und beispielsweise nicht in Nordafrika. Allerdings ist zumindest gegenwärtig davon auszugehen, dass das Thema auf Eis gelegt wird. Es stellen sich hier u. a. die Fragen: „Aufgrund welcher Rechtsgrundlagen würde gehandelt, wer wäre verantwortlich für derartige Zentren, wer wäre verantwortlich für abgelehnte Asylbewerber, zumal in den Fällen, in denen Asylbewerber wegen nicht ausreichender Identifizierung nicht in den Herkunftsstaat zurückgeführt werden können?“750 Eine Beantwortung dieser Fragen ist momentan müßig, weil kein Drittstaat augenblicklich bereit wäre, ein „Aufnahmezentrum“ auf seinem Territorium zu erlauben.

Bereits in Anbetracht der „regionalen Schutzprogramme“ hatten Kommission und Mitgliedstaaten überdies empfohlen, die Neuansiedlung von Flüchtlingen in einem anderen Aufnahmeland, insbesondere in Kenia und im Jemen zu ermöglichen. ${ }^{751}$ Darüber hinaus gibt die EU-Kommission nachfolgende Kernaktivitäten für regionale Schutzprogramme bekannt: „1. Verbesserung des Flüchtlingsschutzes. 2. Ausbildung

745 Rat der Europäischen Union 2009: Das Stockholmer Programm a.a.O., 17024/09, S. 73.

746 Bundesamt für Migration und Flüchtlinge (BAMF) 2010: Schutz und Hilfe außerhalb Europas - die externe Dimension der europäischen Flüchtlingspolitik (Rede vom Koordinator der Intergovernmental Consultations on Migration, Asylum and Refugees Herrn Friedrich Löper in Nürnberg). S. 2; http://www.bamf.de/cln_092/nn_442764/DE/DasBAMF/Home-Teaser/nuernberger-tage-asyl-2010 dokumentation.html (Stand: 21.10.2010).

747 Vgl. Bundesamt für Migration und Flüchtlinge (BAMF) 2010: Schutz und Hilfe außerhalb Europas die externe Dimension der europäischen Flüchtlingspolitik. a.a.O., S. 5.

748 Bundesamt für Migration und Flüchtlinge (BAMF) 2010: Schutz und Hilfe außerhalb Europas - die externe Dimension der europäischen Flüchtlingspolitik. a.a.O., S. 6.

749 Bundesamt für Migration und Flüchtlinge (BAMF) 2010: Schutz und Hilfe außerhalb Europas - die externe Dimension der europäischen Flüchtlingspolitik. a.a.O., S. 6.

750 Bundesamt für Migration und Flüchtlinge (BAMF) 2010: Schutz und Hilfe außerhalb Europas - die externe Dimension der europäischen Flüchtlingspolitik. a.a.O., S. 6.

751 Bundesamt für Migration und Flüchtlinge (BAMF) 2010: Schutz und Hilfe außerhalb Europas - die externe Dimension der europäischen Flüchtlingspolitik. a.a.O., S. 4. 
und Training in Fragen des Flüchtlingsschutzes. 3. Maßnahmen zur Registrierung von Flüchtlingen. 4. Projekte zugunsten der lokalen Gemeinschaft, die geeignet sind, die durch die Präsenz von Flüchtlingen verursachten Belastungen zu mildern. 5. Projekte zur Beförderung der Selbstständigkeit von Flüchtlingen in den Asylländern und zur Förderung einer freiwilligen Rückkehr." ${ }^{\text {"752 }}$ Neben diesen regionalen Schutzprogramme sind einige Initiativen bemerkenswert, die außerhalb des institutionellen Rahmens der EU $\mathrm{zu}$ finden sind. In erster Linie ist hierbei „die dänische Initiative zu Herkunftsregionen (regions of origin initiative)“ anzuführen, die stärkere entwicklungspolitische Ansätze aufweist (z. B. durch spezifische Ausbildungsprogramme und Unterstützung der Re-Integration von Flüchtlingen in ihre Herkunftsstaaten). ${ }^{753}$ Außerdem erwähnenswert ist ein Programm mehrerer europäischer Staaten namens „Resettlement-Plus“: „Resettlement“ bezeichnet die Neuansiedlungskomponente, „Plus“ die Entwicklungshilfekomponente. ${ }^{754}$

Des Weiteren sind die EU und die Mitgliedstaaten weiterhin in starkem Umfang Ziel „illegaler Migration““: ${ }^{75}$ Tausende Migranten unternehmen jedes Jahr den Versuch, illegal die nordafrikanische Küste bzw. die Türkei zu erreichen. Von da aus gelangen sie nach Europa, unter überwiegend lebensbedrohlichen Umständen. Sie stammen zumeist aus Sub-Sahara-Afrika oder Südasien. Erste Zielländer dieser illegalen Migranten in Europa sind hauptsächlich Italien, Griechenland, Malta und Spanien. Somit kann der Schutz der EU-Außengrenzen nicht einzig Obliegenheit der betroffenen Anrainerstaaten sein, sondern verlangt eine europaweite Solidarität unter allen EU-Mitgliedstaaten. Als Verbindung zwischen der europäischen und nationalen Grenzschutzdimension steht die Grenzschutzagentur FRONTEX: „Die koordinierten Einsätze an den See- und Landaußengrenzen im östlichen Mittelmeer sowie an der Grenze zur Türkei“ bilden den Schwerpunkt der FRONTEX-Aktivitäten. ${ }^{756}$ Als weitere Priorität des Stockholmer Programms ist die „Intensivierung der Zusammenarbeit mit den Herkunfts- und Transitländern - zur Verbesserung der Grenzkontrollen, zur Bekämpfung von illegaler Migration, Drogen- und Menschenhandel sowie Terrorismus‘ ${ }^{\text {‘757 }}$ zu nennen.

\footnotetext{
752 Bundesamt für Migration und Flüchtlinge (BAMF) 2010: Schutz und Hilfe außerhalb Europas - die externe Dimension der europäischen Flüchtlingspolitik. a.a.O., S. 4-5.

753 Bundesamt für Migration und Flüchtlinge (BAMF) 2010: Schutz und Hilfe außerhalb Europas - die externe Dimension der europäischen Flüchtlingspolitik. a.a.O., S. 5.

754 Bundesamt für Migration und Flüchtlinge (BAMF) 2010: Schutz und Hilfe - a.a.O., S. 5.

755 Bundesamt für Migration und Flüchtlinge (BAMF) 2010: Die deutschen Interessen bei der Europäisierung des Zuwanderungs- und Flüchtlingsrechts. a.a.O., S. 5-6.

756 Bundesamt für Migration und Flüchtlinge (BAMF) 2010: Die deutschen Interessen bei der Europäisierung des Zuwanderungs- und Flüchtlingsrechts. a.a.O., S. 6.

757 Bundesamt für Migration und Flüchtlinge (BAMF) 2010: Die deutschen Interessen a.a.O., S. 6.
} 
Schließlich muss auf die EU-Migrationspolitik im Bereich der legalen Migration oder der Arbeitsmigration eingegangen werden: ${ }^{758}$ Derzeit fokussiert sich die EU zunehmend auf den Bereich der Höherqualifizierten. Die sogenannte Hochqualifizierten-Richtlinie der EU, die jeder Staat bis Mitte 2011 in nationales Recht umsetzen musste, eröffnet weitere Perspektiven für qualifizierte Arbeitsmigranten. Die Erteilung der EU-Blue- Card $^{759}$ für Hochqualifizierte soll anhand dieser Richtlinie innerhalb des geltenden nationalen Systems im Bereich der Arbeitsmigration ergänzt werden. Außerdem ist der Europäische Rat zuversichtlich, ,dass das Inkrafttreten des Visakodex und die schrittweise Inbetriebnahme des VIS bedeutende neue Möglichkeiten für eine Weiterentwicklung der gemeinsamen Visumpolitik schaffen werden.“ 760 Diesbezüglich wird die regionale konsularische Zusammenarbeit insbesondere unter der Einrichtung gemeinsamer „Visumantragszentren“ auf freiwilliger Basis vertieft. Darüber hinaus wird die Kommission vom Europäischen Rat gebeten, eine Untersuchung der Frage vorzulegen, „ob ein gemeinsamer europäischer Mechanismus für die Ausstellung von Kurzaufenthaltsvisa festgelegt werden kann.“761

Insgesamt werden durch das Stockholmer Programm zwar einige zentrale Punkte erfasst, allerdings verbleibt es bei vereinzelten Bemühungen. Außerdem kritisiert ECLN (European Civil Liberties Network), das Bürgerrechts-, Aktivisten- und Menschenrechtsgruppen in Europa zusammenschließt, am „Stockholmer Programm“, dass die EU mit diesem Programm „einen Apparat innerer und äußerer Sicherheit, einschließlich Strafverfolgung, Sicherheitsbehörden, Datenbanken und Informationssysteme, paramilitärischer Organisationen und einer zunehmenden militärischen Leistungsfähigkeit“" geschaffen hat. ${ }^{762}$ Dieser Apparat wird auch „,von einem dünnen Netzwerk von Verantwortlichen, die nicht zur Rechenschaft gezogen werden können, weiter ausgebaut.، ‘763

\footnotetext{
758 Bundesamt für Migration und Flüchtlinge (BAMF) 2010: Die deutschen Interessen bei der Europäisierung des Zuwanderungs- und Flüchtlingsrechts. a.a.O., S. 7.

759 Die EU-Blue Card erhalten Drittstaatsangehörige mit Hochschulabschluss, wenn diese ein Gehalt in Höhe von mindestens dem 1,5-fachen des durchschnittlichen Jahresbruttogehaltes im jeweiligen Mitgliedstaat nachweisen können. Jedoch können die Mitgliedstaaten auch eine noch etwas höhere Grenze vorsehen. Zitiert in: Bundesamt für Migration und Flüchtlinge (BAMF) 2010: Die deutschen Interessen bei der Europäisierung des Zuwanderungs- und Flüchtlingsrechts. a.a.O., S. 8.

760 Rat der Europäischen Union 2009: Das Stockholmer Programm a.a.O., 17024/09, S. 58.

${ }^{761}$ Rat der Europäischen Union 2009: Das Stockholmer Programm a.a.O., 17024/09, S. 58.

${ }^{762}$ Europolice 2009: ECLN Statement zum „Stockholm Programm“ der EU. Online verfügbar unter: http://www.stockholm.noblogs.org/post2009/04/15/ecln-statement-zum-stockholm-programm-der-eu (Stand: 15.04.2009).

${ }^{763}$ Europolice 2009: ECLN Statement zum „Stockholmer Programm“ der EU.
} 


\subsection{Fazit}

Die Europäisierung der Migrationspolitik führt zu einer weitreichenden Verlagerung der Gesetzgebung auf die europäische Ebene. Migrationspolitische Herausforderungen werden dabei nicht mehr nur als nationale, sondern zunehmend als europäische Obliegenheiten gesehen. Ausgehend von den neo-institutionell-theoretischen Annahmen hat die Untersuchung in Kapitel III.2 verfolgt, wie sich auf der europäischen Ebene Schritt für Schritt eine neue Leitidee in den Verträgen entwickelte, die sich infolge des Spannungsverhältnisses zwischen dem doppelten Kooperationsbedarf und den nationalstaatlichen Souveränitätsansprüchen im Politikfeld Migration bewegt hat. Die Reise von Schengen nach Lissabon und Stockholm hat gezeigt, dass seit 1985 die vertraglichen Grundlagen der europäischen Asyl- und Einwanderungspolitik einer entscheidenden Wandlung unterworfen waren. Sie wurden schrittweise in den supranationalen Rechtsrahmen überführt, den zentralen Meilensteinen der völkerrechtlichen Schengener Übereinkommen folgend, sowie der intergouvernementalen Zusammenarbeit nach dem Vertrag von Maastricht und der seither stattgefundenen Vergemeinschaftung, basierend auf dem Vertrag von Amsterdam. Dabei wurde als Ausnahme die Vergemeinschaftung migrationspolitischer Bereiche im Amsterdamer Vertrag, die auch heute noch unter dem Lissaboner Vertrag Gültigkeit besitzt, von den drei noch zögerlichen EU-Staaten Großbritannien, Irland und Dänemark - durch ein juristisch zwar kompliziertes, aber sehr pragmatisch orientiertes Angebot - erkauft (mit dem sogenannten opt-in und opt-out Regelungen).

Im Überblick der Verträge sind hierbei zwei entscheidende Tendenzen zu beobachten, die bezüglich der migrationspolitischen Zusammenarbeit zwischen den EU-Staaten eine eindeutige Unterscheidung von denjenigen in anderen Kooperationsgremien erkennen lassen. Erstens ist das Solidaritätsprinzip als ein essenzieller Dynamisierungsfaktor der Zusammenarbeit erkannt worden. Die zweite Tendenz entsteht auf direkte Weise innerhalb der Entwicklungsdynamik der Zusammenarbeit, der ein inhärenter Reformbedarf $\mathrm{zu}$ eigen ist. Des Weiteren hat diese vertragliche Einbindung der migrationspolitischen Zusammenarbeit im EU-Rahmen folgende Auswirkungen: Die Konzeption eines gemeinsamen Rechtsraums macht gemeinsame Standards mit einer Tendenz zur Verrechtlichung unerlässlich. Die europapolitische Einbindung bedingt die Beteiligung der Gemeinschaftsinstitutionen, woraus folgt, dass nationale Regierungen nicht mehr die ausschließlichen Akteure sind und andere Interessen Einfluss nehmen 
können. Die entscheidensten Resultate sind hierbei, dass es erstens in einem begrenzten Umfang zur Anpassung mitgliedstaatlicher Migrationspolitik gekommen ist und zweitens als entscheidende Resultate einige der eigentümlicheren Auswirkungen der EU-Migrationspolitik zu sehen sind, nämlich die kohäsionspolitisch orientierte Kompetenzkontrolle der Europäischen Union und die „parallele“ Förderung in den Politikfeldern der Mitgliedstaaten.

Inwieweit die zunehmende Europäisierung sich verändernd auf eine generelle Abschließungs- oder gegenläufige Öffnungstendenz auswirkt, ist durch die Vielzahl der Maßnahmen und Tendenzen schwer abzuschätzen. Anhand eines Großteils der Rechtsakte zur migrationspolitischen Zusammenarbeit ist tatsächlich dank der bislang umgesetzten Europäisierung der Migrationspolitik von einer deutlichen Verschärfung der Aufnahmebedingungen zu sprechen. Bei genauer Betrachtung des geltenden Einwanderungsrechts zur Gebietszulassung von Drittstaatsangehörigen wird das Gefüge europäischer und nationaler Regelungen in einem Rechtsverbund gegenseitiger Verknüpfungen offensichtlich; hier kann allenfalls basierend auf dem vorrangigen Ziel zum Schutze des nationalen Arbeitsmarkts durch restriktive Erlaubnisvorbehalte von einer Gemeinsamkeit europäischer Migrationspolitiken gesprochen werden. Vor diesem Hintergrund überrascht es nicht, dass dem Vorhaben der Kommission für eine eingeschränkte Öffnung der europäischen Grenzen für Wirtschaftsmigranten kein Erfolg beschieden war. Damit herrscht in Bezug auf die Wirtschaftsmigration bis heute eine fundamentale Uneinigkeit über die Zweckdienlichkeit und die Ausrichtung europäischer Regeln. Darüber hinaus lässt sich auch seit den 1990er Jahren in allen Staaten bezüglich der Grenzkontrollen, des Umgangs mit der Problematik illegaler Einwanderung sowie des Maßes der Zuwanderungsbegrenzung durch einzelne EU-Staaten eine Tendenz zur Schließung feststellen. Bereits vor dem Inkrafttreten des Amsterdamer Vertrags waren auf dem Gebiet des Asylrechts vermehrte Gemeinsamkeitstendenzen zu beobachten, wie zum Beispiel die Einführung der sogenannten Drittstaatenregelung im Zuge des Dubliner Übereinkommens zeigte. Das gate of entry hinsichtlich des Asylrechts soll damit weitgehend geschlossen werden, ohne eine Verletzung der Genfer Flüchtlingskonvention allzu deutlich ersichtlich werden zu lassen. Deshalb können die Effekte einer Vergemeinschaftung vor allem im Asylbereich am ehesten offenbar werden. Man kann sicherlich von einer zwangsläufig einschränkenden Zuwanderungspolitik in Europa sprechen, abgesehen von der Flüchtlingspolitik sowie der Politik der Familienzusammenführung, und auch von der Aufnahme aus humanitären Gründen. Dies führt zu der Frage, ob die institutionelle Europäisierung der 
Migrationspolitik zu einer Kräftigung der so bezeichneten „Festung Europas" beigetragen hat und weiter beitragen wird. Dies ist allerdings schon deshalb mutmaßlich, weil man diese einer einzelstaatlichen Abschließungspolitik der Nationalstaaten gegenüberstellen müsste. Daher vertieft sich die Kluft um die „Festung Europa“"764 getaufte Europäische Union. Einwanderung wird ausschließlich dann als wünschenswert erachtet, so sie Vorzüge erbringt, wie etwa positive Effekte für den Arbeitsmarkt, womit sie der Wirtschaft von Nutzen sein kann.

Es ist mit Hinblick auf die migrationspolitischen Grundlagen in den einzelnen Mitgliedstaaten nicht erstaunlich, dass die Migrationspolitik der Europäischen Union ähnliche Tendenzen aufweist, zumal das europäische Konzept in der letzten Instanz auch weiterhin vom politischen Willen der Mitgliedstaaten gelenkt wird. Ansätze anderer, schwächeren EU-Institutionen - wie zum Beispiel der Kommission, Grundsätze für eine gemeinsame Migrationspolitik festzulegen, können angesichts dieser Grundlage nur mit wenigen Erfolgsaussichten rechnen. Insbesondere bezüglich der Grundlagen der Entscheidungsstrukturen in der Europäischen Union muss der Beginn einer neuen Epoche europäischer Migrationspolitik angesichts der Europäisierung der letzten Jahre in Zweifel gezogen werden. Gleichwohl werden bislang alle grundlegenden Entscheidungen in der europäischen Zuwanderungspolitik nicht von der Kommission oder dem europäischen Parlament, sondern vom EU-Rat repräsentiert durch die EU-Innenminister - gefasst. Eine Verlagerung der Kompetenzen auf die europäische Ebene ist folglich tatsächlich bloß bedingt zu sehen, sodass auch in Zukunft europäische Migrationspolitik ohne Berücksichtigung nationaler Einzelinteressen kaum möglich sein wird. Für all jene Staaten, die vor einer Potenzierung der Einwandererzahlen durch ungewollte Einwanderung bangen, bedeutet das geltende Einstimmigkeitsprinzip eine indirekte Aufforderung ihrerseits zum Veto. Die Mitgliedstaaten hingegen stehen somit einer weiteren Vergemeinschaftung der Politik zur Steuerung der legalen (Wirtschafts-) Migration und auch der Integrationspolitik weitgehend skeptisch gegenüber. Einerseits hat das Europäische Parlament mehr Kompetenzen im Rahmen der Migrationspolitik erlangt, andererseits sind allerdings eindeutige Tendenzen des Rates zu erkennen, das EP zu umgehen. Damit zeigt sich anstelle größerer Offenheit innerhalb der Migrationspolitik ein Transparenzund zu guter Letzt ein Legitimationsdefizit, durch das eine weitere Vergemeinschaftung immerhin stark in Zweifel gezogen werden muss.

${ }^{764}$ Birsl, Ursula 2005: Migration und Migrationspolitik im Prozess der europäischen Integration?. Opladen, S. 323. 
Im Überblick der hier veranschaulichten Vertragswerke, die als Grundlage für die migrationspolitische Zusammenarbeit der EU-Mitgliedstaaten seit den 1990er Jahren verstanden werden müssen, ist eine deutliche Entwicklung $\mathrm{zu}$ mehr Beteiligungsmöglichkeiten der Gemeinschaftsinstitutionen in diesem Bereich zu beobachten. Es sind somit institutionelle Lösungen gewählt worden, die eine Eigendynamik des Europäisierungsprozesses begünstigen. Desgleichen lässt sich feststellen, dass sich eine Europäisierung der einzelstaatlichen Politiken auf Gemeinschaftsebene schwierig gestaltet und lediglich bei restriktiven Neuerungen Einigungen erzielt werden konnten. Im Einklang mit neo-institutionalistischen Ansätzen lässt sich diesbezüglich argumentieren, dass diese restriktive EU-Migrationspolitik als Folge vorangegangener Lernerfahrungen gesehen werden kann. 


\section{Europäisierung des Politikfeldes Migration im europäischen Integrationsprozess}

Dieser Abschnitt ist der Erläuterung der Kernfrage gewidmet, wie die Einbindung des Politikfeldes Migration in den europäischen Integrationsprozesse zustande gekommen ist und an welchen Entwicklungen dies ersichtlich wird. Darüber hinaus lassen sich weiterhin die Fragen stellen: Was ist eigentlich der Pfad bzw. die Pfadabhängigkeit oder der Pfadwechsel im europäischen Integrationsprozess? Welche Faktoren wirken dabei effektiv? Wie bereits in den vorherigen Ausführungen veranschaulicht, kann man von einem völlig unabhängigen Wirken in den migrationspolitischen Entscheidungen der EU-Staaten nicht mehr sprechen, da sie an vertragliche Kooperationspflichten und politische Zusammenhänge gebunden sind. In folgenden Bereichen soll innerhalb der oben betrachteten vertraglichen Grundlage der Integrationsprozess der migrationspolitischen Zusammenarbeit der EU näher untersucht werden: 1. Asyl- und Flüchtlingspolitik der EU. 2. Europäische Einwanderungs- und Integrationspolitik.

\subsection{Asyl- und Flüchtlingspolitik der EU}

Ziel der Analyse ist eine Klärung der beiden Fragestellungen: 1. Erfolgt de facto eine Europäisierung auf der EU Ebene zur Erweiterung migrationspolitischer Handlungsmöglichkeiten? 2. Welche Entwicklungstendenz ist seit den neunziger Jahren ersichtlich? Die in dieser Hinsicht gewählten Fallbeispiele sind zum einen der Umgang mit dem schwierigen Thema der Bürgerkriegsflüchtlinge (3.1.1) und zum anderen der Umgang mit der Problematik der inneren Sicherheit am Beispiel von EUROPOL (3.1.2). 


\subsubsection{Bürgerkriegsflüchtlinge aus dem ehemaligen Jugoslawien}

Das Jahr 1991, als sich Slowenien und Kroatien unabhängig erklärten, ist als Beginn der gemeinsamen Auflösung der Sozialistischen Bundesrepublik Jugoslawien zu sehen. Infolge dieser Auflösung wurde die größte Flüchtlingskrise Europas seit dem Zweiten Weltkrieg verursacht. ${ }^{765}$ Die Flüchtlingsaufnahme vollzog sich indessen nicht konzentriert, sondern wurde außerordentlich ungleichgewichtig auf die einzelnen Mitgliedstaaten verteilt. Fast 700.000 Asylbewerber wurden 1992 in Europa registriert. Hierbei nahm beispielsweise Deutschland in absoluten Zahlen betrachtet mit mehr als 400.000 (ca. 440.000) Flüchtlingen aus dem ehemaligen Jugoslawien mit Abstand die meisten auf (58\%). ${ }^{766} \mathrm{Im}$ gleichen Jahr begannen somit die in erster Linie betroffenen Länder (Deutschland, Österreich, Schweiz) über einen Lastenausgleich mit anderen europäischen Ländern zu verhandeln. Zwischen 1992 und 1993 fanden diese Gespräche sogar auf EU-Ebene statt, unter der Leitung des deutschen Bundeskanzlers Helmut Kohl, wobei diese jedoch zu keiner Einigung führten. ${ }^{767}$ Überdies bezeichnete der Großteil der Asylbewerber keine Flüchtlinge im Sinne der Genfer Konvention (GFK) von 1951, da diese nicht durch ihren eigenen Staat verfolgt wurden. ${ }^{768}$ Zugleich war der Maastricht-Vertrag noch nicht in Kraft. Bezüglich der migrationspolitischen Problemfelder des 20 Jahrhunderts innerhalb der EU stellt damit die Frage der Vorgehensweise betreffend die Bürgerkriegsflüchtlinge ein akutes Problem dar.

Die hauptsächlich betroffenen Staaten Schweiz (,sicherer Herkunftsstaat“ 1990), Österreich („Erstasyl-Klausel“ 1991) und Deutschland („Asylkompromiss“ 1993)

765, „...] Allein in Kroatien wurden 1991 etwa 20.000 Menschen getötet. Mehr als 200.000 Menschen flohen ins Ausland, etwa 350.000 wurden zu Binnenvertriebenen.“ In: UNHCR 2000/2001: Zur Lage der Flüchtlinge in der Welt. 50 Jahre Humanitärer Einsatz. Bonn, S. 247; vgl. auch Bendiek, Annegret 2004: Der Konflikt im ehemaligen Jugoslawien und die Europäische Integration: Eine Analyse ausgewählter Politikfelder. Wiesbaden, S. 77.

766 Bundesministerium des Innern 1997: Aufzeichnung zur Ausländerpolitik und zum Ausländerrecht in der Bundesrepublik Deutschland. Bonn, S. 118.; vgl. Tomei, Verónica 2001: Europäisierung nationaler Migrationspolitik: a.a.O., S. 82, Fußnote 117; vgl. auch Widgren, Jonas 1999: Rückkehr nach Bosnien-Herzegowina: Lektionen für eine europäische Migrationspolitik. In: Internationale Politik (IP). 54 Jahrgang/April 1999. Band 1. Nr. 4. S. 31-38, hier S. 33.

767 Denn Frankreich und Großbritannien klagten vor allem Österreich und Deutschland an, diese Krise durch die vorzeitige Anerkennung Sloweniens, Kroatiens und Bosniens herbeigeführt zu haben. In: Widgren, Jonas 1999: Rückkehr nach Bosnien-Herzegowina: Lektionen für eine europäische Migrationspolitik. In: Internationale Politik (IP). 54 Jahrgang/April 1999. Band 1. Nr. 4. S. 33.

768 Die ankommenden Bosnier mussten jedoch nach allen europäischen Menschenrechtsstandards als „richtige“ Flüchtlinge angesehen werden. In: Widgren, Jonas 1999: a.a.O., S. 33.

769 Seit der Einführung von Artikel 16a in das Grundgesetz zum 1. Juli 1993 kann sich in der Bundesrepublik Deutschland kein Ausländer auf das Grundrecht auf Asyl berufen, wenn er aus einem 
mussten demzufolge Anfang der 1990er Jahre ihre Verfassungen ändern, um eine striktere Asylpolitik durchführen zu können. ${ }^{770}$ An die „Stunde Europas“ gemahnend, drängte sich die EG, später die EU, als einziger Vermittler beim Jugoslawienkonflikt auf. ${ }^{771}$ Die Politikformulierung der EG/EU war jedoch vor allem im ersten Konfliktjahr durch eine fehlende äußere und inhaltliche Kohärenz gekennzeichnet. Die lang andauernde Konzeptionslosigkeit der europäischen Jugoslawienpolitik resultierten ebenfalls aus unterschiedlich gelagerten Interessen, insbesondere repräsentiert durch die Troika der drei EG-Staaten im Rahmen der Europäischen Politischen Zusammenarbeit (EPZ). So neigten Großbritannien und Frankreich eher zu einer Unterstützung Serbiens und waren bestrebt, den jugoslawischen Vielvölkerstaat zu erhalten, während die Bundesrepublik Deutschland, für ethnische Selbstbestimmung eintretend, die kroatischen Angelegenheiten befürwortete. ${ }^{772}$

Vor diesem Hintergrund lassen sich die nachfolgenden Fragen stellen: In welcher Weise wurden die Mitgliedstaaten auf EU-Ebene zur Lösung dieser Herausforderungen europäisiert bzw. inwieweit erweist sich die EU als Akteur der Migrationspolitik? Bewirken diese Herausforderungen überdies ein Zusammenwachsen der EUMitgliedstaaten? Welche Schritte halfen, Auswege aus ihrer gemeinsamen Krisenbewältigung zu finden? Die Beurteilungskriterien zur Beantwortung dieser Fragen orientieren sich vor allem an den Verhaltensstrategien der politischen Institutionen im Rahmen der EU und auch in den Mitgliedstaaten. In diesem Kontext könnte die gemeinsame Konfliktbearbeitung als ein Meilenstein für die EU auf ihrem Weg zu einer gemeinsamen Migrationspolitik bzw. zu einer Europäisierung betrachtet werden.

Zunächst vereinbarten die Mitgliedstaaten im Europäischen Rat im Dezember 1992, ihre Zusammenarbeit, betreffend dieser besonderen Herausforderung, zu verstärken und

sogenannten ,sicheren Drittstaat“ nach Deutschland eingereist ist. Vgl. Han, Petrus 2005: Soziologie der Migration: a.a.O., S. 194; vgl. auch Seifert, Wolfgang 2000: Geschlossene Grenzen - offene Gesellschaften?: Migrations- und Integrationsprozesse in westlichen Industriennationen. S. 117.

770 Vgl. Deckers, Daniel 2000: Ruf nach fairer Lastenverteilung. Die Harmonisierung der Asyl- und Flüchtlingspolitik in der Europäischen Union. In: FAZ, 1.12.2001, S. 3; vgl. auch Bendiek, Annegret 2004: Der Konflikt im ehemaligen Jugoslawien und die Europäische Integration: a.a.O., S. 78.

771 Vgl. Calic, Marie-Janine 1993: Jugoslawienpolitik am Wendepunkt. In: Aus Politik und Zeitgeschichte (APuZ) 1993, B 37/93, S. 11-20, hier S. 11; vgl. auch Nadoll, Jörg 2000: Die Europäische Union und die Konfliktbearbeitung in Ex-Jugoslawien 1991-1998 - Mühl- oder Meilenstein?. In: Schubert, Klaus / Müller-Brandeck-Bocquet, Gisela (Hrsg.) 2000: Die Europäische Union als Akteur der Weltpolitik. Opladen, S. 81-101, hier S. 83, 87.

772 Vgl. Nadoll, Jörg 2000: Die Europäische Union und die Konfliktbearbeitung in Ex-Jugoslawien 19911998 - Mühl- oder Meilenstein?. a.a.O., S. 84. 
erklärten sich im Rahmen eines koordinierten Vorgehens aller Mitgliedstaaten grundsätzlich auch zur zeitlich begrenzten Aufnahme besonders schutzbedürftiger Personen bereit. ${ }^{773}$ Nachdem der Maastrichter Vertrag in Kraft getreten war, wurde von der EU-Kommission zu diesem Zwecke eine Angleichung der nationalen Regelungen in puncto vorübergehender Schutz angemahnt. ${ }^{774}$ Inhalt ist hierbei erstens die Frage eines einheitlichen Vorgehens bei der vorübergehenden Aufnahme von Flüchtlingen (bzw. der temporäre Schutz: Temporary Protected Status $=$ TPS). Zweitens stellt sich die Frage eines Lastenausgleichssystems unter den Mitgliedsländern. Beide genannten Aspekte sind seit $1994 \mathrm{im}$ Arbeitsprogramm des Rates enthalten. Eine Entschließung und ein Beschluss bezüglich der Fragestellung der Lastenverteilung wurden verabschiedet. ${ }^{775}$ Im Amsterdamer Vertrag ist eine Herangehensweise für gemeinsame Maßnahmen in diesen Fragen vorgesehen, die die gesamten Asyl- und Einwanderungsfragen von der dritten Säule in die erste Säule der Europäischen Union überführt und eine supranationale Gemeinschaftszuständigkeit erzeugt ${ }^{776}$ (vgl. hierzu Kapitel III.2.5 dieser Arbeit). Die Problemstellung des vorübergehenden Schutzes kann demnach klar als ein Thema eingeordnet werden, deren Behandlung auf EU-Ebene erfolgt. Auch auf nationaler Ebene nahmen alle Aufnahmeländer (Dänemark, Deutschland, die Niederlande, Norwegen, Österreich, Schweiz), mit Ausnahme Schwedens ${ }^{777}$, eine Anpassung ihrer nationalen Gesetze an das EU-TPS-Konzept vor, wobei die europäische Einbettung ihrer Umsetzung stark umstritten war. Dadurch sind in diesen Ländern die Bosnier im Prinzip nicht über reguläre Asylverfahren, sondern durch

773 Vgl. Europäischer Rat 1992: Erklärung zu den Grundsätzen für die externen Aspekte der Einwanderungspolitik, Schlussfolgerungen des Vorsitzes Teil A, Anlage 5. In: EG-Nachrichten. Bericht und Informationen - Dokumentationen Nr. 15 vom 21. Dezember 1992, S. 25 ff; vgl. auch Tomei, Verónica 2001: Europäisierung nationaler Migrationspolitik: a.a.O., S. 82.

774 Vgl. Kommission der Europäischen Union 1994: Mitteilung Zuwanderungs- und Asylpolitik, COM (94) 23 endg. Brüssel.

775 Entschließung zur Lastenverteilung hinsichtlich der Aufnahme und des vorübergehenden Aufenthalts von Vertriebenen. Vgl. ABL (Amtsblatt der Europäischen Union) EG Nr. C 262, 1 vom 7.10.1995; Beschluss zum Warnsystem und Dringlichkeitsverfahren bei der Lastenverteilung bezüglich der Aufnahme und des vorübergehenden Aufenthalts von Vertriebenen. Vgl. ABL. EG Nr. L 63, vom 13.3.1996; vgl. Tomei, Verónica 2001: Europäisierung nationaler Migrationspolitik: a.a.O., S. 82.

776 Rat der Europäischen Union (Innen und Justiz) 1999: Aktionsplan des Rates und der Kommission zur bestmöglichen Umsetzung der Bestimmungen des Amsterdamer Vertrags über den Aufbau eines Raums der Freiheit, der Sicherheit und des Rechts, vom 3.12.98, ABl. EG Nr C 19/1 vom 23.1.1999; vgl. auch Tomei, Verónica 2001: Europäisierung nationaler Migrationspolitik: Eine Studie zur Veränderung von Regieren in Europa. Stuttgart, S. 83, Fußnote 118; vgl. auch Läufer, Thomas (Hrsg.) 1998: Vertrag von Amsterdam: Texte des EU-Vertrages und des EG-Vertrages. Bonn, S. 83.

777 Schweden trat so auf, als ob eine Rückkehr nicht möglich wäre, und stellte sogleich permanente Aufenthaltsgenehmigungen aus. Dänemark, die Niederlande und Norwegen hatten allerdings in ihren Gesetzen Klauseln verankert, die es unmöglich machten, den temporären Schutzstatus über einen Zeitraum von zwei bis vier Jahren hinaus auszudehnen. Deutschland, Österreich und die Schweiz jedoch bestanden trotz der Ausweitung des Krieges auf einer Verlängerung des TPS-Systems. In: Widgren, Jonas 1999: Rückkehr nach Bosnien-Herzegowina: a.a.O., S. 33-34. 
Sonderverfahren aufgenommen worden.

Ein weiteres Motiv der migrationspolitischen Zusammenarbeit im EUMehrebenensystem bezeichnete die Rückkehrpolitik, nach der die Rückführung der Flüchtlinge und Vertriebenen im Kontext des Dayton-Friedensabkommen ${ }^{778}$ von 1995 , welches einen gemeinsamen und koordinierten Ansatz bezüglich der Rückkehrmodalitäten darstellte, als notwendig erachtet wurde. ${ }^{779}$ So waren die Rückkehrbemühungen Ende 1995 ein vordringliches Ziel des Dayton-Abkommens. ${ }^{780}$ Der zeitweilige Schutz (TPS) bedeutet demnach, dass eine Rückkehr nach Beendigung des Konflikts verpflichtend ist. Mit dem Friedensvertrag von Dayton wurde demgemäß die Voraussetzung für eine Rückkehr der bis dahin in der EU-Mitgliedstaaten lebenden zahlreichen Bosnien-Flüchtlinge geschaffen, flankiert auch von einem mit der Regierung von Bosnien und Herzegowina abgeschlossenen Rückübernahme- und Transitabkommen zwischen allen betroffenen Ländern. ${ }^{781}$ Aufmerksam zu beachten ist hierbei jedoch, dass die EU nur eine untergeordnete Rolle bei der Ermöglichung eines allgemeinen Rückkehrplans spielte. Dazu trug auch die Struktur des Maastricht-Vertrags bei, da die zuständigen Einwanderungsminister (unter der dritten Säule ZBJI: „Zusammenarbeit in den Bereichen Justiz und Inneres“, Titel VI EUV) nicht mit der Dayton-Umsetzung der zweiten Säule (GASP: „Die Gemeinsame Außen- und Sicherheitspolitik“, Titel V EUV) oder der Unterstützung für Wiederaufbau und humanitäre Hilfe unter der ersten Säule verbunden waren. ${ }^{782}$

Hinter dieser Krisenbewältigung stand auch ein anderes wesentliches politisches Motiv. Dies bezog sich auf die Bereitschaft der EU-Staaten, in Zukunft grundsätzlich Flüchtlinge aus Krisengebieten aufzunehmen, aber nur unter der Bedingung, dass die Flüchtlinge in ihre Heimatländer zurückkehren. ${ }^{783}$ In der Folge der Lösung der

778 Allgemeines Rahmenübereinkommen für den Frieden in Bosnien-Herzegowina paraphiert am 21. November 1995 in Dayton (Ohio) und unterzeichnet am 14. Dezember 1995 in Paris. In: Internationale Politik (IP). 51. Jahrgang/Januar 1996. Band 1. Nr. 1. S. 80-93 (Auszüge).

779 Vgl. Widgren, Jonas 1999: Rückkehr nach Bosnien-Herzegowina: Lektionen für eine europäische Migrationspolitik. In: Internationale Politik (IP). 54. Jahrgang/April 1999. Band 1. Nr. 4. S. 34-35; Tomei, Verónica 2001: Europäisierung nationaler Migrationspolitik: a.a.O., S. 83.

${ }^{780}$ Nach dem Daytoner Abkommen war der UNHCR für die Erstellung eines Rückkehrplans und für die Rückkehr der Flüchtlinge und Vertriebenen zuständig. In: Bendiek, Annegret 2004: a.a.O., S. 81.

781 Vgl. Bendiek, Annegret 2004: a.a.O., S. 81; vgl. Widgren, Jonas 1999: Rückkehr nach BosnienHerzegowina: a.a.O., S. 36.

782 Vgl. Widgren, Jonas 1999: Rückkehr nach Bosnien-Herzegowina: a.a.O., S. 38.

783 Vgl. Nadoll, Jörg 2000: Die Europäische Union und die Konfliktbearbeitung in Ex-Jugoslawien 19911998 - Mühl- oder Meilenstein?. In: Schubert, Klaus / Müller-Brandeck-Bocquet, Gisela (Hrsg.) 2000: Die Europäische Union als Akteur der Weltpolitik. Opladen, S. 81-101, hier S. 89. 
allgemeinen Asylkrise 1993 - 1994, die eine intensive Zusammenarbeit auf dem Gebiet der dritten Säule des Maastricht-Vertrages nach sich zog (die Asylbewerberzahlen in Europa waren demzufolge 1996 auf einen Stand von 250.000 gesunken), wurde für die EU-Staaten ersichtlich, dass neue EU weite Schutzsysteme entwickelt werden mussten, die auf der Erfahrung der Bosnien-Krise, also auf der Anwendung des TPS-Systems aufbauten. ${ }^{784}$ Damit übernahm die EU ab 1996 eine neue Rolle, indem sie zum Vermittler von Stabilität besonders im Sinne des Amsterdamer Vertrages (vgl. Kapitel III.2.5 dieser Arbeit) ernannt wurde.

Mit Blick auf diese Entwicklungen zeigten sich insbesondere Deutschland, Österreich und die Schweiz als einzige Länder mit vielen bosnischen Bürgern unter TPS (insgesamt 320.000, davon 300.000 in Deutschland zum Zeitpunkt der Umsetzung des Daytoner Abkommens 1996) alarmiert. ${ }^{785}$ Hierbei bezeichnet die Frage der Rückkehr nach Bosnien vor allem ein Problem deutscher Flüchtlingspolitik, da Deutschland seiner Rückkehr- bzw. Abschiebungspolitik von je her große Bedeutung zumisst. Deutschland war bereits während der 1990er Jahre darauf bedacht, seinen nationalen Politikansatz auf die europäische Ebene zu übertragen (vgl. hierzu Kapitel IV.1.1 und 1.1.1 dieser Arbeit): „Bis 1992/1993 hatte Deutschland im europäischen Vergleich nominell die meisten Asylbewerberzugänge, womit Auswirkungen auf das außen- sowie innenpolitische Handeln einhergingen. Auf Betreiben von Deutschland hin fand die Flüchtlingsproblematik einen wesentlichen Niederschlag im DaytonFriedensabkommen. [...]. Innenpolitisch wurden die Erstasylland-Klausel und das Prinzip der sicheren Drittstaaten mit dem Asylkompromiss im Jahr 1993 in das bundesdeutsche Grundrecht auf Asyl aufgenommen. Die deutschen Reformen wirkten auch auf andere Staaten, die ihrerseits zu einer restriktiven Anpassung umlenkten, um die Anzahl von Asylsuchenden auf ihre Territorien zu begrenzen [...]." ${ }^{\text {c786 }}$ Auch die Förderung der freiwilligen Ausreise in Bezug auf die Rückkehrpolitik findet in Deutschland bereits seit langem statt. Die wichtigste Zielgruppe bei dieser befürworteten freiwilligen Rückkehr sind insbesondere Flüchtlinge, die kein dauerhaftes Aufenthaltsrecht erlangen können. Grundlage dieser Maßnahmen ist das seit 1979 bestehende REAG-/GARP-Programm (Reintegration and Emigration Programme for Asylum-Seekers in Germany / Government Assisted Repatriation Programme), das im Auftrag des Bundesinnenministeriums (BMI) sowie der zuständigen Ministerien der

\footnotetext{
784 Vgl. Widgren, Jonas 1999: Rückkehr nach Bosnien-Herzegowina: a.a.O., S. 34.

785 Vgl. Widgren, Jonas 1999: Rückkehr nach Bosnien-Herzegowina: a.a.O., S. 34.

786 Bendiek, Annegret 2004: Der Konflikt im ehemaligen Jugoslawien und die Europäische Integration: Eine Analyse ausgewählter Politikfelder. Wiesbaden, S. 89-90.
} 
Bundesländer von der International Organization for Migration (IOM) durchgeführt wird. ${ }^{787}$ Mittels dieses Programms werden die Kosten der freiwilligen Ausreise getragen und eine Reisebeihilfe gewährt. In Bezug auf dieses REAG/GARP-Programm lässt sich in den vergangenen Jahren ein stetiger Rückgang der Förderfälle in Deutschland registrieren, wodurch es als eines der wirksamsten Programme dieser Form in Europa bezeichnet werden kann. ${ }^{788}$ Allen Flüchtlingen wurde damit in Deutschland nur vorübergehender Schutz, jedoch - mit wenigen Ausnahmen - kein dauerhaftes Bleiberecht gewährt ${ }^{789}$, das seinerzeit in vielen relevanten Aufnahmeländern der EU beschlossen wurde. Diese Ausführungen haben auch verdeutlicht, dass die bundesdeutsche Rückkehrstrategie im europäischen Kontext infolgedessen bislang einzigartig war bzw. ist. Die Bundesrepublik Deutschland hatte hierbei allerdings als einziges EU-Aufnahmeland eine allgemeine Rückkehrpflicht eingeführt, mit dem Verweis darauf, dass die hohen Unterstützungskosten von Flüchtlingen besser zur Wiederaufbauhilfe in Bosnien genutzt werden könnten. ${ }^{790}$

Mit dem deutschen Engagement bzw. dem deutschen prioritärem Ziel im Hinblick auf die Rückkehr der Flüchtlinge konzentrierte sich die EU verstärkt auf die politische und die ökonomische Dimension des Friedensprozesses in Bosnien-Herzegowina. Konkret stellte sie beispielsweise finanzielle Mittel zur Reparatur von Wohnungen sowie Straßen und half bei der Etablierung demokratisch strukturierter Institutionen und Verwaltungsbehörden dieser Länder, um ihre Fähigkeit zur Erfüllung ihrer Rückübernahmeverpflichtungen gegenüber der Union und ihren Mitgliedstaaten zu

787 Vgl. Hemingway, Bernd / Beckers, Hans 2003: Förderung der freiwilligen Rückkehr ausländischer Mitbürger. In: Bundesamt für die Anerkennung ausländischer Flüchtlinge 2003. S. 131-159; vgl. Ette, Andreas / Kreienbrink, Axel 2008: Kooperation statt Harmonisierung: Konsequenzen europäischer Governance für die Europäisierung der deutschen Rückkehr- und Abschiebungspolitik. A.a.O., S. 63; vgl. auch Bendiek, Annegret 2004: Der Konflikt im ehemaligen Jugoslawien und die Europäische Integration: Eine Analyse ausgewählter Politikfelder. Wiesbaden, S. 80-81.

788 Von den anfänglich in Deutschland aufgenommenen 345.000 Bosnien-Flüchtlingen lebten im Jahr 2000 noch ca. 33.300 in Deutschland; ca. 50.600 wanderten weiter und 5.156 Menschen wurden abgeschoben. In: Bundesministerium des Innern (BMI) 2001: Ausländerpolitik und Ausländerrecht in Deutschland. Berlin; vgl. auch Bendiek, Annegret 2004: Der Konflikt im ehemaligen Jugoslawien und die Europäische Integration: a.a.O., S. 83; vgl. Schröder, Tim 2006: Die Fördermöglichkeiten bei der Rückkehr von Ausländern mit Finanzinstrumenten der EU. In: Zeitschrift für Ausländerrecht und Ausländerpolitik (ZAR). 26. Jahrgang 2006. S. 8-14, hier S. 8-9; Ette, Andreas / Kreienbrink, Axel 2008: Kooperation statt Harmonisierung: Konsequenzen europäischer Governance für die Europäisierung der deutschen Rückkehr- und Abschiebungspolitik. A.a.O., S. 63.

789 Vgl. Bagshaw, Simon 1997: Benchmarks or Deutschmarks? Determining the Criteria for the Repatriation of Refugees to Bosnia and Herzegovina. EUI Working Papers. No. 23. Florence, S. 33.; vgl. Bendiek, Annegret 2004: a.a.O., S. 80-81.

790 Vgl. Bendiek, Annegret 2004: Der Konflikt im ehemaligen Jugoslawien und die Europäische Integration: Eine Analyse ausgewählter Politikfelder. Wiesbaden, S. 82. 
festigen. ${ }^{791}$ So hatte die Europäische Union anlässlich der Daytoner Friedensabkommen (1995) einen Finanzrahmen in Höhe vom 1000 Mio. ECU (European Currency Unit) für den Wiederaufbau im ehemaligen Jugoslawien im Zeitraum 1996 - 1999 zur Verfügung gestellt. ${ }^{792}$ Auch im Jahr 1998 wurde von den zuständigen Fachministern eine gemeinsame Maßnahme zur Finanzierung von Rückkehrhilfsprojekten vereinbart. ${ }^{793}$ Diese konkrete Unterstützung des politischen und wirtschaftlichen Wiederaufbaus sowie die humanitäre Hilfe sind seit dem Maastrichter Vertrag als gesamthafte Gemeinschaftskompetenz in der ersten Säule verankert. ${ }^{794}$ Die Steuerung der Migration auch durch den Einsatz finanzieller Mittel ${ }^{795}$ stellt somit seit den 1990er Jahren ein wichtiges Thema auf der politischen Agenda der Europäischen Union dar, wie dies von dem Europäischen Rat vor allem im Tampere-Programm (1999) ausgeführt und entwickelt wurde (vgl. Kapitel III.2.6). Außerdem vereinbarten die zuständigen Fachminister im Rat einen regelmäßigen Informations- und Erfahrungsaustausch über staatliche Hilfsprogramme zur Unterstützung der freiwilligen Rückkehr. ${ }^{796}$

Wie bereits erwähnt, trug die EU-Zusammenarbeit zwischen den EU-Staaten und den internationalen Organisationen zur Behebung der Kriegsschäden nur dann bei, wenn die Maßnahmen mit der schnellen Rückkehr der Flüchtlinge und Vertriebenen in Verbindung standen. In diesem Zusammenhang bedeutet aber die Behandlung der

${ }^{791}$ Nadoll, Jörg 2000: Die Europäische Union und die Konfliktbearbeitung in Ex-Jugoslawien 1991-1998 - Mühl- oder Meilenstein?. In: Schubert, Klaus / Müller-Brandeck-Bocquet, Gisela (Hrsg.) 2000: Die Europäische Union als Akteur der Weltpolitik. Opladen, S. 81-101, hier S. 90; vgl. Schröder, Tim 2006: Die Fördermöglichkeiten bei der Rückkehr von Ausländern mit Finanzinstrumenten der EU. In: Zeitschrift für Ausländerrecht und Ausländerpolitik (ZAR). 26. Jahrgang 2006. S. 8-14, hier S. 9.

792 Vgl. Europäische Kommission 1995: Finanzieller Beitrag der Europäischen Union zum Wiederaufbau im ehemaligen Jugoslawien. KOM (1995) 581 endg. 18.12.1995. Brüssel; vgl. Bendiek, Annegret 2004: Der Konflikt im ehemaligen Jugoslawien und die Europäische Integration: Eine Analyse ausgewählter Politikfelder. Wiesbaden, S. 141; vgl. Nadoll, Jörg 2000: Die Europäische Union und die Konfliktbearbeitung in Ex-Jugoslawien 1991-1998 - Mühl- oder Meilenstein? A.a.O., S. 89.

793 Vgl. ABL (Amtsblatt der Europäischen Union). EG Nr. L 138, v. 9.5.1998, S. 6 f.; vgl. Tomei, Verónica 2001: Europäisierung nationaler Migrationspolitik: a.a.O., S. 83.

794 Vgl. Nadoll, Jörg 2000: Die Europäische Union und die Konfliktbearbeitung in Ex-Jugoslawien 19911998 - Mühl- oder Meilenstein? A.a.O., S. 91; vgl. auch Klos, Christian 1999: Eine Reise von Rom nach Amsterdam: Die Entwicklung des europäischen Einwanderungsrechts. In: Wolter, Achim (Hrsg.) 1999: Migration in Europa: Neue Dimensionen, neue Fragen, neue Antworten. Baden-Baden, S. 25 f.

795 Ferner wurde der Europäische Flüchtlingsfonds (EFF) mit einer Ausstattung von insgesamt 216 Millionen Euro mit dem Ziel eingerichtet, die Mitgliedstaaten der Europäischen Union bei der Aufnahme von Asylbewerbern, Flüchtlingen und Vertriebenen zu unterstützen. In: ABL (Amtsblatt der Europäischen Gemeinschaft) L vom 28.12.2004, S. 52: Entscheidung 2004/904/EG des Rates vom 02.12.2004 über die Errichtung des Europäischen Flüchtlingsfonds für den Zeitraum 2005-2010; vgl. auch Schröder, Tim 2006: Die Fördermöglichkeiten bei der Rückkehr von Ausländern mit Finanzinstrumenten der EU. In: Zeitschrift für Ausländerrecht und Ausländerpolitik (ZAR). 26. Jahrgang 2006. S. 8-14, hier S. 11.

796 Beschluss des Rates vom 26. Mai 1997 über den Informationsaustausch betreffend die Hilfen für die freiwillige Rückkehr von Drittstaatsangehörigen, ABL. EG Nr. L 147, v. 05.06.1997, S. 3 f. 
Fragen des vorübergehenden Schutzes auf europäischer Ebene noch kein gemeinsames und einheitliches Vorgehen der einzelnen Mitgliedstaaten auf diesem Gebiet. Dies wurde in den Jahren 1998/99 hinsichtlich des Kosovo-Konflikt ${ }^{797}$ erneut evident, wobei immer mehr Flüchtlinge aus der Bundesrepublik Jugoslawien einen Asylantrag in den EU-Staaten stellten. Die folgenden Fragen waren daher auf EU-Ebene noch nicht einheitlich geregelt; sie wurden beispielsweise auch in der UNHCR (United Nations High Commissioner for Refugees) bezüglich der notwendigen Weiterentwicklung des internationalen Flüchtlingsschutzes abermals behandelt: „Welche Rechte den Flüchtlingen während ihres Aufenthalts zu gewähren sind; auf welchen Zeitraum sich der Begriff „,vorübergehend“ bezieht; was geschehen soll, wenn der fluchtauslösende Konflikt länger dauert; und wie im Falle einer Beendigung des Konflikts die freiwillige Rückkehr der Flüchtlinge durchzusetzen ist.“ 798 Daraufhin traten die Innen- und Justizminister der 15 EU-Mitgliedstaaten auf Vorschlag der deutschen Ratspräsidentschaft zusammen und einigten sich in den gemeinsamen Regelungen Ende Mai 1999 auf Aufnahmekontingente für den vorübergehenden Schutz. ${ }^{799}$ Die Lastenverteilung war dabei zu einem Brennpunkt zwischen den EU-Mitgliedstaaten geworden; diesbezüglich wurde darüber debattiert, welche Bemühungen solidarisch aufgeteilt werden sollten. ${ }^{800}$ Dementsprechend besteht auch die Frage einer Uneinigkeit über die Form der Lastenteilung: ${ }^{801}$ Hat diese etwa nach dem Modell finanzieller Ausgleichszahlungen oder als eine Verteilung der Flüchtlinge unter den Mitgliedstaaten zu geschehen? Vor dem Hintergrund des elfwöchigen Luftkrieges und zunehmender

797 Vgl. Süddeutsche Zeitung vom 27.4.1999: Luftkrieg gegen Jugoslawien verstärkt; vgl. Tomei, Verónica 2001: Europäisierung nationaler Migrationspolitik: a.a.O., S. 83. f.; vgl. auch Bendiek, Annegret 2004: Der Konflikt im ehemaligen Jugoslawien und die Europäische Integration: Eine Analyse ausgewählter Politikfelder. Wiesbaden, S. 91.

798 Tomei, Verónica 2001: Europäisierung nationaler Migrationspolitik: a.a.O., S. 84.

799 Vgl. Süddeutsche Zeitung vom 28.5.1999: EU-Minister für besseren Schutz der Flüchtlinge; vgl. auch Bendiek, Annegret 2004: Der Konflikt im ehemaligen Jugoslawien und die Europäische Integration: Eine Analyse ausgewählter Politikfelder. Wiesbaden, S. 91.

800 So enthält etwa die 1995 beschlossene Entschließung zur Lastenteilung hinsichtlich der Aufnahme und des Aufenthalts von Vertriebenen unter anderem auch die Berücksichtigung ,des Beitrags der einzelnen Mitgliedstaaten zur Verhinderung bzw. Lösung der Krise, insbesondere durch die Leistung militärischer Hilfe im Rahmen von Einsätzen und Missionen im Auftrag des UN-Sicherheitsrats oder der OSZE sowie durch Maßnahmen der einzelnen Mitgliedstaaten zum Schutz der bedrohten Bevölkerung an Ort und Stelle oder zur Leistung humanitärer Hilfe." Entschließung des Rates vom 25. September 1995 zur Lastenverteilung bezüglich der Aufnahme und des vorübergehenden Aufenthalts von Vertriebenen. In: ABL (Amtsblatt der Europäischen Union) EG Nr. C 262, vom 07.10.1995, S. 1 f.: vgl. Tomei, Verónica 2001: Europäisierung nationaler Migrationspolitik: Eine Studie zur Veränderung von Regieren in Europa. Stuttgart, S. 85; vgl. auch Widgren, Jonas 1999: Rückkehr nach Bosnien-Herzegowina: Lektionen für eine europäische Migrationspolitik. In: Internationale Politik (IP). 54. Jahrgang/April 1999. Band 1. Nr. 4. S. 32-34.

801 Vgl. Tomei, Verónica 2001: Europäisierung nationaler Migrationspolitik: Eine Studie zur Veränderung von Regieren in Europa. Stuttgart, S. 85. 
innenpolitischer Kritik gegenüber den NATO-Luftschlägen ergriff der deutsche Außenminister Joschka Fischer unter deutscher EU-Ratspräsidentschaft weitgehend die Initiative für den „Stabilitätspakt für Südosteuropa“ vom 10. Juni 1999. ${ }^{802}$ Somit verfügte die EU zwar auch Ende der neunziger Jahre noch über kein gemeinsames Instrumentarium für die Aufnahme zum vorübergehenden Schutz, allerdings ist durch die zu diesem Thema geführten Debatten im Vergleich zu Bosnien-Herzegowina eine relativ schnelle Einigung über Grundprinzipien für die Kosovo-Problematik erfolgt. ${ }^{803}$

Überdies ist augenfällig, dass die EU sich mit diesen grundlegenden und später vertraglich verankerten Bestimmungen ein window of opportunity eröffnet hat, zu jeder Zeit den Vergemeinschaftungsprozess instrumentell auszugestalten. Demzufolge kann jede externe Bedrohung dazu genutzt werden, den Institutionalisierungsprozess in einem Politikfeld voranzutreiben (vgl. hierzu in Kapitel I.4. A. den Rational-Choice (RC)-Institutionalismus). So wurde als ein Beispiel dieser Dynamik im Jahr 1992 ECHO (European Community Humanitarian Office), das Amt für humanitäre Hilfe der EU, eingerichtet, das seitdem humanitäre Hilfe im Balkangebiet leistet. Von der europäischen Kommission (KOM) wurde daraus Ende Dezember 1994 die ausdrückliche Zuständigkeit von ECHO für die Nahrungsmittelsoforthilfe und die Zuständigkeit der GD VIII (heute Europe Aid) für die programmierte Nahrungsmittelhilfe bestimmt. ${ }^{804}$ Die humanitäre Hilfe unterliegt demgemäß grundsätzlich sowohl den Bestimmungen des Gemeinschaftspfeilers als auch denen der GASP. $^{805}$ Darüber hinaus ist die migrationspolitische Zusammenarbeit im Kontext der Problematik der Bürgerkriegsflüchtlinge aus dem Balkangebiet untrennbar mit den Aktivitäten der EU-Mitgliedsländer bezüglich der Gemeinsamen Außen- und Sicherheitspolitik (GASP) verknüpft. ${ }^{806}$ In Bezug auf diese Institutionalisierung ist zudem bemerkenswert, dass in den 1990er Jahren die Europäische Gemeinschaft und ihre Mitgliedstaaten etwa die Hälfte der gesamten weltweit gewährten Hilfe bzw. die

802 Vgl. Bendiek, Annegret 2004: Der Konflikt im ehemaligen Jugoslawien und die Europäische Integration: Eine Analyse ausgewählter Politikfelder. Wiesbaden, S. 91.

${ }^{803}$ Durch den Bosnien-Krieg hatte man für den Kosovo-Konflikt ,gelernt“, nicht noch einmal das Prinzip der ,freiwilligen Rückkehr“ in die Heimatorte festzuschreiben. Im Unterschied zum Bosnien-Konflikt war es im Kosovo-Konflikt nunmehr legitim, viele Flüchtlinge in strategisch günstigere Orte zurückzuführen. In: Bendiek, Annegret 2004: Der Konflikt im ehemaligen Jugoslawien und die Europäische Integration: a.a.O., S. 91; vgl. Tomei, Verónica 2001: Europäisierung nationaler Migrationspolitik: a.a.O., S. 87.

${ }^{804}$ Vgl. Kuhn, Marco 2000: Humanitäre Hilfe der Europäischen Gemeinschaft. Entwicklung, System und primärrechtlicher Rahmen. Berlin, S. $249 \mathrm{ff}$.

${ }^{805}$ Vgl. Bendiek, Annegret 2004: Der Konflikt im ehemaligen Jugoslawien und a.a.O., S. 97.

806 Vgl. Rat der Europäischen Union (Innen und Justiz) 1998: Presseerklärung Nr. 11282/98 (Presse 302), vom 24.09.1998. 
Hälfte der Programme zur Verfügung stellten, wobei sich vor allem die Aufwendungen der EU-Kommission nahezu verdoppelten. Dies hat auch zu einer Fragmentierung der Kommissionsverwaltung geführt ${ }^{807}$, obwohl mit der Verordnung des Rates über die humanitäre Hilfe der Grad der Autonomie der Kommission in ihren Exekutivbefugnissen stark eingeschränkt wurde: „Beispielsweise müssen Beiträge über zehn Mio. ECU durch den Ausschuss aus Repräsentanten der Mitgliedstaaten genehmigt werden; globale Pläne, die die Fortsetzung humanitäre Hilfe überhaupt erst ermöglichen, werden von den Mitgliedstaaten festgelegt etc. “808 Die Europäische Union ist somit seit 1991 der Hauptgeber der humanitären Hilfe für das ehemalige Jugoslawien. ${ }^{809}$

Eine weitere Dimension in Bezug auf die Inanspruchnahme von Gemeinschaftsinstrumenten durch die Nutzung der europäischen Ebene besteht beispielsweise in der EG-/EU-Beobachtermission, durch die im Rahmen des Abkommens von Brioni die Entsendung einer European Community Monitoring Mission (ECMM) in die BR Jugoslawien im Jahr 1991 beschlossen wurde. ${ }^{810}$ Bemerkenswert ist dabei, dass die EG-Mission durch Beobachter aus den KSZE (Konferenz für Sicherheit und Zusammenarbeit in Europa)-Ländern Kanada, Polen, Schweden und der Tschechoslowakei verstärkt wurde. Anhand des Memorandums vom 1. Oktober 1991 erfolgte anschließend die Ausdehnung der ECMM auf BosnienHerzegowina, mit dem Mandat, friedenserhaltend und konfliktvorbeugend $\mathrm{zu}$ verfahren. ${ }^{811}$ Die ECMM war, wie übrigens die ganze EPZ (Europäische Politische Zusammenarbeit), jedoch stark von der intergouvernementalen Form geprägt und konnte somit nicht als Grundlage für eine zentrale Planung einer strategischen Konfliktregulierung dienen. ${ }^{812}$

807 Bendiek, Annegret 2004: Der Konflikt im ehemaligen Jugoslawien und die Europäische Integration: a.a.O., S. 101 u. 104; vgl. Nuttall, Simon J. 1995: The Commission and foreign policy-making. In: Edwards, Geoffrey / Spence, David (Ed.) 1995: The European Commission. London, S. 287-302; vgl. Rometsch, Dietrich 1999: Die Rolle und Funktionsweise der Europäischen Kommission. Frankfurt.

${ }^{808}$ Bendiek, Annegret 2004: Der Konflikt im ehemaligen Jugoslawien und ... a.a.O., S. 102.

${ }^{809}$ Bendiek, Annegret 2004: Der Konflikt im ehemaligen Jugoslawien und ... a.a.O., S. 105.

${ }^{810}$ Vgl. „Gemeinsame Erklärung der Ministertroika der Europäischen Gemeinschaft und der jugoslawischen Konfliktparteien über einen Friedensplan für Jugoslawien, vereinbart in Brioni (Jugoslawien) am 7. Juli 1991“. In: Europa-Archiv (EA), 46 Jahrgang:1991, Folge 21/1991, S. D 537539; vgl. auch Maurer, Daniel 2002: Europäische Sicherheit: Konfliktmanagement am Beispiel "ExJugoslawien". In: Spillmann, Kurt R. / Wenger, Andreas (Hrsg.) 2002: Zürcher Beiträge: zur Sicherheitspolitik und Konfliktforschung Nr. 59. Forschungsstelle für Sicherheitspolitik und Konfliktanalyse der ETH Zürich, S. 79.

811 Vgl. Giersch, Carsten 1998: Konfliktregulierung in Jugoslawien 1991-1995: Die Rolle von OSZE, EU, UNO und NATO. Baden-Baden, S. 134.

${ }^{812}$ Vgl. Giersch, Carsten 1998: Konfliktregulierung in Jugoslawien 1991-1995: a.a.O., S. 136. 
Insgesamt zeigte die hohe Anzahl von Flüchtlingen aus dem ehemaligen Jugoslawien, die in den Mitgliedstaaten der EU Schutz suchten, dass der Gegenstand ein gesamteuropäisches Problem bezeichnete. Es erforderte daher in erster Linie eine europäische Lösung; zudem förderte das Solidaritätsprinzip die zunehmende Europäisierung des Politikfeldes Migration. Darüber hinaus hat die Europäisierung durch Nutzung der europäischen Ebene im migrationspolitischen Bereich Probleme ergeben. Zugleich war somit zu beobachten, dass die Kooperationsbereitschaft, eine europäische Problembewältigungsstrategie zu entwickeln, in dem Maße zunahm, wie die einzelstaatliche Problemlösungsfähigkeit abnahm. ${ }^{813}$ Auch der JugoslawienKonflikt konfrontierte die EG von Beginn an mit einer Anzahl konkreter Herausforderungen, die durch die Mitgliedstaaten nur gemeistert werden konnten, indem sie ihre außenpolitische Zusammenarbeit dergestalt verbesserten, dass die Wirtschaftsgemeinschaft außerdem ein sicherheitspolitisches Profil als „Friedensmacht“ zu erlangen vermochte. ${ }^{814}$ Daher lässt sich im Ergebnis festhalten, dass diese Flüchtlingspolitik der EU einerseits eine symbolische Politik bedeutet, die in ihren Auswirkungen hauptsächlich nach Innen gerichtet ist, jedoch kann sie andererseits nach Außen als Abwehrmechanismus verstanden werden. ${ }^{815}$ Konkret bedeutet das, dass die Flüchtlingspolitik der EU, wie beispielsweise im Konflikt im ehemaligen Jugoslawien, mehr den Grundsatz der direkten humanitären Hilfe bzw. Intervention vor Ort befolgte, jedoch weniger der Bereitschaft oder der Strategie, den Flüchtlingen in den EU-Staaten Schutz einzuräumen. Die Lasten der Hauptaufnahmeländer, die aus der Aufnahme von Asylsuchenden hervorgehen, sollen in solchen Notsituationen künftig durch Zahlungen aus dem gemeinsamen Flüchtlingsfond ausgeglichen werden. Dies ist die Bilanz einer genaueren Betrachtung der Resultate des Konfliktes im ehemaligen Jugoslawien. Auch gemäß des Rational Choice-(RC)-Insitutionalismus haben die Kriege im ehemaligen Jugoslawien in den 1990er Jahren als externer Faktor, also als externer Schock für die institutionelle Systementwicklung der EU und zur Herausbildung neuer Problemlösungsstrategien auf europäischer Ebene beigetragen. Darüber hinaus erfolgte vor allem aufgrund der Reaktionen deutscher Akteure während der vertraglichen Verhandlungen in den 1990er Jahren eine hohe Interdependenz im Politikfeld Migration. ${ }^{816}$

\footnotetext{
${ }^{813}$ Vgl. Bendiek, Annegret 2004: a.a.O., S. 91 f.

814 Vgl. Giersch, Carsten 1998: Konfliktregulierung in Jugoslawien 1991-1995: a.a.O., S. 111.

815 Vgl. Bendiek, Annegret 2004: a.a.O., S. 247.

816 Vgl. Moravcsik, Andrew / Nicolaidis, Kalypso 1999: Explaining the Treaty of Amsterdam: Interests, Influence, Institutions. In: Journal of Common Market Studies (JCMS). Volume 37. No. 1: March 1999. S. 59-85, hier S. 63; vgl. Woyke, Wichard 2000: Deutsch-französische Beziehungen seit der Wiedervereinigung: Das Tandem faßt wieder Tritt. Opladen.
} 


\subsubsection{Innere Sicherheit durch EUROPOL ${ }^{817}$ in der EU}

Das zentrale Sujet der mitgliedsstaatlichen Kooperation im Politikfeld innere Sicherheit stellte das „Projekt EUROPOL“ im Rahmen der Maastrichter Zusammenarbeit ${ }^{818}$ (Art. K 1 EUV-Maastricht) und über diese hinaus dar, wobei Europol vor allem nach deutschen Vorstellungen als Gemeinschaftseinrichtung konzipiert wurde. Erstens sollte angesichts der politischen Zuständigkeit und zweitens im Hinblick auf das Entscheidungsverfahren das in Polizeiangelegenheiten übliche Motive des Intergouvernementalismus von einer supranationalen polizeilichen Kooperation ersetzt werden. Dieser Abschnitt ist deshalb der Fragestellung gewidmet, welche Beweggründe und Interessen die Erfordernis einer europäischen Polizeibehörde nötig erscheinen ließen und welche Faktoren letztlich den Beschluss einer gradweisen Einrichtung von Europol beeinflussten - eine Entscheidung, die von den Mitgliedstaaten der EU anlässlich der Verhandlungen zur Regierungskonferenz von Maastricht gemeinschaftlich getroffen wurde. Der Grundgedanke einer europäischen Polizeibehörde „Europol“ ist bereits über zwanzig Jahre alt, wobei in erster Linie die Bundesrepublik Deutschland in der Idee der Gründung eines zentralen europäischen Polizeiamtes einen Weg sah, Appelle bezüglich einer harmonischeren internationalen Zusammenarbeit im Kampf gegen die Kriminalität zu subsumieren. Es existierten auch auf diesem Gebiet in den Details sehr unterschiedliche Vorstellungen hinsichtlich denkbarer Funktionen und des institutionellen Aufbaus eines solchen Amtes. ${ }^{819}$ In diesem Sinne konzentrierten sich damit die Bemühungen der Bundesregierung vorrangig darauf, die innere Sicherheit auf EU-Ebene als politisches Subjekt der Europäischen Staaten markant werden zu lassen. Als offensichtlichstes Ergebnis dieser Bemühungen ist die Initiierung der TREVI (Terrorism, Radicalism, Extremism, Violence International)-Kooperation $\mathrm{zu}$ sehen. Bereits in den Anfangsgründen der TREVIKooperation wurde ersichtlich, welche Maßnahmen in jener Phase unter den Mitgliedstaaten der EG in Bezug auf die Zusammenarbeit im Bereich der inneren Sicherheit konsensfähig waren. In erster Linie hatte die im Kontext der EG für das Jahr 1993 geplante Abschaffung der Binnengrenzkontrollen zu einer Auseinandersetzung betreffend eines möglichen „Verlustes an innerer Sicherheit“ in den Mitgliedstaaten

817 Vgl. dazu http://www.europol.europa.eu

818 Vgl. Eigmüller, Monika 2007: Grenzsicherungspolitik: Funktion und Wirkung der europäischen Außengrenze. Wiesbaden, S. 55.

819 Vgl. Fijnaut, Cyrille 1993: The „Communitization“ of Police Cooperation in Western Europe. In: Schermers, Henry G. et al. (Eds.) 1993: Free Movement of Persons in Europe. Legal Problems and Experiences. Dordrecht u. a., S. 81. 
geführt, angesichts dessen ein europäisches Kriminalpolizeiamt als ein ,geradezu zwingendes Korrelat ${ }^{\text {‘820 }}$ Gestalt annehmen konnte. Von den TREVI-Ministern wurde deshalb zur Behandlung der Materie eine Ad-hoc-Arbeitsgruppe „Europol“ erschaffen. ${ }^{821}$ Hauptaufgabe der Ad-hoc-AG war die Ausarbeitung einer rechtlichen Basis für die Einrichtung von Europol. In Den Haag wurde somit am 2./3. Dezember 1991 vonseiten der TREVI-Minister förmlich beschlossen, die Entwicklung von Europol $\mathrm{zu}$ forcieren. Als dessen zentrale Aufgabe sahen sie den Informationsaustausch über den Handel mit Drogen zwischen den Mitgliedsländern vor. $^{822}$ Jedoch war das Vorbild von Europol immer sehr umstritten. Dem anfängliche während des Europäischen Rates von Luxemburg im Juni 1991 - vorgelegten deutschen Entwurf zur Institutionalisierung von Europol auf Gemeinschaftsebene wurde aus diesem Grunde ablehnend begegnet. ${ }^{823}$ Die negative Bescheidung des Entwurfs erfolgte vor allem von den Regierungen Großbritanniens und Dänemarks. ${ }^{824}$ Aber auch alle weiteren Mitgliedstaaten waren gegenüber dem Konzept einer europäischen Polizeibehörde nicht positiv eingestellt. ${ }^{825}$ Im Hinblick auf die divergierenden Interessen und Standpunkte der Mitgliedstaaten in dieser Angelegenheit konnte nicht mehr als eine Maximalforderung vermerkt werden. Derzeit ist Europol weder eine rein intergouvernementale Vernetzung noch eine supranationale Organisation. Die Debatten über die Art und Weise dieser zwischenstaatlichen Kooperation haben hernach zugenommen und sich intensiviert.

Die Schaffung eines europäischen Polizeiamts wurde mittlerweile im Maastrichter Vertrag festgeschrieben. Die Gründung von Europol wurde mittels eines Rechtsakts des Rates am 26. Juli 1995 besiegelt. ${ }^{826}$ Allerdings kam sie erst im Jahr 1999 zum vollen Einsatz. Der bereits vorher ausgehandelte Kompromiss wurde daraufhin auch vom Maastrichter Vertrag amtlich bestätigt. Europol sollte als eine intergouvernementale Institution des dritten Pfeilers der EU gebildet werden. Von den Mitgliedstaaten wurde in Art. K. 1 (9) EUV-Maastricht erläutert, der Sinn von Europol sei „die polizeiliche

${ }^{820}$ Schmidt-Nothen, Rainer 1987: Der lange Marsch durch viele Konferenzen. Es gibt noch viel zu tun Verträge und Abkommen, die dem Kampf gegen das Verbrechen dienen. In: Kriminalistik 41, S. 411.

${ }^{821}$ Vgl. Benyon, John et al. 1993: Police Co-Operation in Europe: An Investigation. Leicester, S. 160.

${ }^{822}$ Knelangen, Wilhelm 2001: Das Politikfeld innere Sicherheit im Integrationsprozess: a.a.O., S. 207.

${ }^{823}$ Vgl. Storbeck, Jürgen 1997: Aufgaben und Perspektiven von Europol. In: Theobald, Volkmar (Hrg.) 1997: Von der Europäischen Union zur Europäischen Sicherheitsunion. Berlin, S. 110.

${ }^{824}$ Vgl. Benyon, John et al. 1993: Police Co-Operation in Europe: An Investigation. Leicester, S. 159.

${ }^{825}$ Vgl. Peek, Jan / Hoefman, Merle 1993: The Dutch Perspective on Internationalization of Police Cooperation in Western Europe. In: Fijnaut, Cyrille (Ed.) 1993: The Internationalization of Police Cooperation in Western Europe. Deventer, Boston, S. 110.

${ }^{826}$ Vgl. Übereinkommen über die Errichtung eines Europäischen Polizeiamts (EPK-Europolkonvention). In: ABL. C 316 vom 27.11.1995. S. 2-32. 
Zusammenarbeit zur Verhütung und Bekämpfung des Terrorismus, des illegalen Drogenhandels und sonstiger schwerwiegender Formen der internationalen Kriminalität, erforderlichenfalls einschließlich bestimmter Aspekte der Zusammenarbeit im Zollwesen, in Verbindung mit dem Aufbau eines unionsweiten Systems zum Austausch von Informationen im Rahmen eines Europäischen Polizeiamts (Europol)“. ${ }^{827}$ Somit ist Europol zur Angelegenheit gemeinsamen Interesses erklärt worden. Der Wirkungskreis von Europol umfasste überdies gleich zu Beginn das Vorgehen gegen illegale Geschäfte mit nuklearen und radioaktiven Materialien, die Schleuserkriminalität, das Verschieben von Kraftwagen und die Geldwäsche. 1996 kamen die Maßnahmen gegen den Menschenhandel und den Missbrauchs von Kindern hinzu; ferner seit 1998 etappenweise weitere relevante Gebiete, beispielsweise die OK (Organisierte Kriminalitiät), und seit 1999 überdies die Bekämpfung des Terrorismus. ${ }^{828}$ Somit kann Europol als Lösung angesichts der Transformation - Inter- oder Transnationalisierung der Kriminalität angesehen werden. Ihre zentrale Gewichtlegung ist in der aktiven Recherche bei Ermittlungen über das Europol-Informationssystem zu finden. ${ }^{829} \mathrm{Mit}$ dieser Zielsetzung wurde das Europol-Computersystem TECS (The Europol Computer System) erarbeitet, dessen Inhalt ein Informationssystem, ein Arbeitsdateiensystem zu Analysezwecken und ein Indexsystem ist. ${ }^{830}$

Heute ist Europol eine mit eigener Rechtspersönlichkeit zentral gesteuerte und völkerrechtlich intergouvernemental vernetzte Organisation, wodurch die Erlasse der EPK (Europol-Konvention) und des Maastrichter Vertrags somit zu Grundlagen der jetzigen Europol geworden sind. In diesem Rahmen beabsichtigen die europäischen Justiz- und Innenminister, die praktische Zusammenarbeit innerhalb der europäischen Asyl- und Flüchtlingspolitik zu optimieren: ${ }^{831}$ Demgemäß soll die vordergründige Betätigung der Beschäftigten von Europol vor allem in der Beobachtung islamistischer Gruppen im Internet und im Kampf gegen grenzüberschreitende Kriminalität bestehen. Feststellungen im Anti-Terrorkampf der einzelnen Nationalstaaten werden künftig von Europol erfasst und an die Mitgliedstaaten weitergeleitet. Dementsprechend soll der

\footnotetext{
${ }^{827}$ König, Christian /Pechstein, Matthias 1995: Die Europäische Union: Der Vertrag von Maastricht. Tübingen, S. 118.

${ }^{828}$ Vgl. Martínez Soria, José 1998: Die polizeiliche Zusammenarbeit in Europa und der Rechtsschutz des Bürgers. In: Verwaltungsarchiv - Zeitschrift für Verwaltungslehre, Verwaltungsrecht und Verwaltungspolitik 89/1998, S. 418.

${ }^{829}$ Vgl. Knelangen, Wilhelm 2001: Das Politikfeld innere Sicherheit im Integrationsprozess: Die Entstehung einer europäischen Politik der inneren Sicherheit. Opladen, S. 250.

${ }^{830}$ Knelangen, Wilhelm 2001: Das Politikfeld innere Sicherheit im Integrationsprozess: a.a.O., S. 239.

${ }^{831}$ Newsletter ,Migration und Bevölkerung' 2006: EU: Einheitliche Asylregelungen, mehr Befugnisse für EUROPOL. Ausgabe 01/06; http://www.migration-info.de/mub_artikel.php?Id=060112
} 
Informationsaustausch vervollkommnet, die nationalen Asylverfahren harmonisiert und Rückführungen von nicht anerkannten Flüchtlingen und Asylbewerbern abgestimmt werden und einen gemeinschaftlichen Vollzug erfahren.

Zusammenfassend lässt sich festhalten, dass im Kontext der europäischen Zusammenarbeit hinsichtlich des Politikfeldes innere Sicherheit das Europol-Projekt damit eine bezeichnende Tendenzverschiebung angesichts der Anstrengungen der Mitgliedstaaten zur grenzüberschreitenden Kriminalitätsbekämpfung aufweist. Die Bildung von Europol (Art. 30 Abs. 2 EUV) drückt folglich eine erste Namensgebung der Institutionalisierung auf diesem Feld, der Symbolisierung der polizeilichen Zusammenarbeit und der Konkretisierung des Politikfeldes innere Sicherheit, aus. ${ }^{832}$ Wenngleich Europol auch mit dem EU-Organisationssystem fest verknüpft ist, bezeichnet sie doch eine internationale Organisation des Völkerrechts, die durchgängig allen Kriterien des Völkerrechts genügt. ${ }^{833}$ Allerdings hat die Analyse der Verhandlungen zu Europol erwiesen, dass die Lernprozesse durch die langjährige europäische Zusammenarbeit keine vereinheitliche Sicht oder konforme Interessen zur Folge hatten. Eher wurden die Präferenzen der mitgliedstaatlichen Regierungen von grundlegenden integrationspolitischen Standpunkten überwogen. Indes ist anzunehmen, dass sich die Einstellungen im institutionalisierten Umfeld der europäischen Zusammenarbeit entwickelt haben und somit Ergebnis eines gemeinsamen Lernprozesses werden könnten.

${ }^{832}$ Vgl. Knelangen, Wilhelm 2001: Das Politikfeld innere Sicherheit im Integrationsprozess: Die Entstehung einer europäischen Politik der inneren Sicherheit. Opladen, S. 250.

833 Vgl. Petri, Thomas Bernhard 2001: Europol - Grenzüberschreitende polizeiliche Tätigkeit in Europa. Frankfurt a. M., S. 25. 


\subsection{Einwanderungs- und Integrationspolitik der EU}

In der jüngsten Geschichte wurde der intergouvernementalen Zusammenarbeit auf diesem Feld vonseiten der EU-Mitgliedstaaten keine eindeutige Position oder die eigentlich erforderliche Bedeutung zugewiesen, wobei der Grund hierfür in der hohen Souveränitätsrelevanz nationaler Zuwanderungspolitik zu finden war. ${ }^{834}$ Deshalb ist es begreiflich, dass auch heutzutage noch die Einwanderung und Integration in die EUMitgliedstaaten nach sehr verschiedenen nationalen Regelungen erfolgt. Dennoch konnten etappenweise einige bedeutende Fortschritte im Hinblick auf eine europäische Migrationspolitik erreicht werden. Ein vollkommen neuartiges Vorgehen für die Europäische Union war vorgesehen, wie die Schlussfolgerungen des Vorsitzes des Europäischen Rates von Tampere (A II und A IV) hierzu zeigen: Die Europäische Union müsse ,eine gerechte Behandlung von Drittstaatsangehörigen sicherstellen, die sich im Hoheitsgebiet ihrer Mitgliedstaaten rechtmäßig aufhalten. Eine energischere Integrationspolitik sollte darauf ausgerichtet sein, ihnen vergleichbare Rechte und Pflichten wie EU-Bürgern zuzuerkennen. $\mathrm{Zu}$ den Zielen sollte auch die Förderung der Nichtdiskriminierung im wirtschaftlichen, sozialen und kulturellen Leben und die Entwicklung von Maßnahmen zur Bekämpfung von Rassismus und Fremdenfeindlichkeit gehören“. ${ }^{835}$ Ein unvollständiger Wandel in Bezug auf eine offenere Einstellung gegenüber Zuwanderungsprozessen und eine aktive Integrationspolitik konnte in einigen Ländern zunächst auf rein nationaler Ebene, in anderen Ländern parallel zum europäischen Prozess beobachtet werden.

Dieser Abschnitt untersucht als Fallbeispiel zuerst die Integrationspolitik von zwei vollkommen verschieden angelegten Richtlinien der Europäischen Union: die Richtlinie 2000/43/EG des Rates vom 27. November 2000 zur Politik gegen Diskriminierung (die sog. Antidiskriminierungsrichtlinie) (3.2.1) und die Richtlinie 2003/86/EG des Rates vom 22. September 2003 betreffend das Recht auf Familienzusammenführung (die sog. Familiennachzugsrichtlinie) (3.2.2). Darüber hinaus wird analysiert, inwiefern die politischen Absichtserklärungen tatsächlich umgesetzt werden konnten.

\footnotetext{
${ }^{834}$ Vgl. Tomei, Verónica 1997: Europäische Migrationspolitik: zwischen Kooperationszwang und Souveränitätsansprüchen. Bonn.

${ }^{835}$ Europäischer Rat 1999: Schlussfolgerungen des Vorsitzes in Tampere, 15. und 16. Oktober 1999; SN 200/99; http://www.consilium.europa.eu/ueDocs/cms_Data/docs/pressData/de/ec/00200-rl.d9.htm; vgl. Bendel, Petra 2006: Migrations- und Integrationspolitik der Europäischen Union: Widersprüchliche Trends und ihre Hintergründe. In: Baringhorst, Sigrid / Hunger, Uwe / Schönwälder, Karen (Hrsg.) 2006: Politische Steuerung von Integrationsprozessen: Intentionen und Wirkungen. Wiesbaden, S. 98.
} 


\subsubsection{Die Antidiskriminierungsrichtlinie}

Der rechtliche Schutz von Migranten verlangt auch Maßnahmen zum Schutz vor Diskriminierungen, die von gesellschaftlichen Akteuren vorgenommen werden. ${ }^{836}$ Dieses Ziel wird von diversen Regelungen verfolgt, deren Erlass auf Ebene der Europäischen Union seit einigen Jahren im Rahmen des „Kampfs um Gleichheit“ erfolgte. 1997 etwa wurde die „Europäische Stelle zur Beobachtung von Rassismus und Fremdenfeindlichkeit ${ }^{\text {‘837 }}$ eingerichtet. Ferner wurden im Amsterdamer Vertrag zusätzlich zu dem Verbot jeder Diskriminierung aus Gründen der Staatsangehörigkeit (Art. 12) Kompetenzen der Gemeinschaft zum Kampf gegen Diskriminierungen eingebunden (Art. 13 EGV). Vor dem Hintergrund dieses Artikels wurden Konzepte bezüglich unterschiedlicher und weitreichender Antidiskriminierungsbzw. Gleichbehandlungsmaßnahmen geschaffen und gesetzlich verankert. Diese müssen von den einzelnen Mitgliedsländern innerhalb gewisser Fristen umgesetzt werden. Dazu gehört die Richtlinie 2000/43/EG, die sog. Antidiskriminierungsrichtlinie.

Der einstimmige Beschluss der Richtlinie 2000/43/EG (kurz „Rassenrichtlinie“ od. „Antirassismus-Richtlinie“) ,zur Anwendung des Gleichbehandlungsgrundsatzes ohne Unterschied der Rasse oder der ethnischen Herkunft“" wurde am 29. Juni 2000 vom Rat der Europäischen Union gefasst. ${ }^{838}$ Hinzu kommt auch die Richtlinie 2000/78/EG ,zur Verwirklichung der Gleichbehandlung in Beschäftigung und Beruf", die am 27. November 2000 in „Weltrekordzeit“ ${ }^{439}$ von nur 18 Monaten durchgesetzt wurde. Eine Frist von drei Jahren sollte die EU-Länder befähigen, die Richtlinie in ihr nationales Recht einzubetten, d. h., dass sämtliche Mitgliedstaaten die Richtlinie innerhalb der festgesetzten Zeitspanne bis Juli bzw. Dezember 2003 umsetzen sollten. Laut dieser Richtlinie müssen die EU-Mitgliedstaaten Regelungen erlassen, die Diskriminierungen vor dem Hintergrund ethnischer Herkunft oder „Rasse“ untersagen und ferner Chancengleichheit auf dem Arbeitsmarkt, in den sozialen Sicherungssystemen, bei Gesundheitsdiensten, im Bildungssystem sowie anderen Dienstleistungen gewährleisten.

\footnotetext{
836 Bielefeldt, Heiner / Follmar-Otto, Petra 2005: Diskriminierungsschutz in der politischen Diskussion. Berlin: Deutsches Institut für Menschenrechte, S. $8 \mathrm{f}$.

837 Winkler, Beate 2001: Bestrebungen zur Bekämpfung von Rassismus und Fremdenfeindlichkeit in der Europäischen Union. In: Arnim, Gabriele von u. a. (Hrsg.) 2001: Jahrbuch Menschenrechte 2002. Frankfurt a. M., S. 262-270.

838 Vgl. ABL (Amtsblatt der Europäischen Union). Nr. L 180/22 vom 19.07.2000.

839 Geddes, Andrew / Guiraudon, Virginie 2004: Britain, France, and EU Anti-Discrimination Policy. The Emergence of an EU Policy Paradigm. In: West European Politics, Vol. 27, Nr. 2 (March), S. 334.
} 
Die EU-Richtlinie zum Verbot der ethnischen Diskriminierung wurde jedoch nur von vereinzelten der ehemals 15 Mitgliedsländer termingerecht in nationales Recht umgesetzt. Anna Diamantopoulou, die EU-Kommissarin für Beschäftigung und Soziales, wies bereits im Jahr 2003 mit Sorge darauf hin, dass die Umsetzung der Richtlinie bis zur Beendigung der Frist nur sehr geringfügige Erfüllung fand. Im Zuge dessen warnte sie, dass gegen nachlässige Länder nötigenfalls vor dem Europäischen Gerichtshof Klage erhoben werde. ${ }^{840}$ Gegen die Mitgliedsländer, von deren Seite die Frist nicht eingehalten wurde und die keine Verlängerung beantragt hatten, wurden im Juni 2004 von der Kommission sog. Vertragsverletzungsverfahren eröffnet: Dazu zählten die Bundesrepublik Deutschland, Österreich, Finnland, Griechenland, Luxemburg und, aufgrund der Richtlinie 2000/78/EG, außerdem Belgien. ${ }^{841}$ Demnach wurde vonseiten der Kommission ein Vertragsverletzungsverfahren gegen die Bundesrepublik Deutschland geführt. Nachdem der rot-grüne Entwurf eines deutschen Antidiskriminierungsgesetzes gescheitert war, legte die Große Koalition im Mai 2006 einen Gesetzentwurf zur Umsetzung der Richtlinie vor, welcher am 18. August 2006 nach langen Diskussionen in Kraft trat. ${ }^{842}$ Vom Allgemeinen Gleichbehandlungsgesetz (AGG) werden folglich mittlerweile europäische Antidiskriminierungsrichtlinien in deutsches Recht umgesetzt. Allerdings muss laut der Europäischen Kommission das AGG überarbeitet werden. Ein Schreiben vom 31. Januar 2008 enthält eine Rüge der Kommission, Teile der Richtlinie gegen Diskriminierungen am Arbeitsplatz seien unklar bzw. richtlinienwidrig umgesetzt worden. Auf diese Weise schließe das AGG den Diskriminierungsschutz bei Entlassungen nicht explizit ein. Dazu und auch anlässlich weiterer Kritikpunkte verlangt die Kommission Nachbesserungen im Gesetz. Die Erfordernis einer Novellierung des AGG wird von der Bundesregierung jedoch nicht gesehen. ${ }^{843}$ Die Antwort der Bundesregierung Anfang Juni 2008 wurde von der Kommission geprüft, die sodann den Europäischen Gerichtshof in Luxemburg mit der

840 Newsletter ,Migration und Bevölkerung’ 2003: EU: Antidiskriminierungs-Richtlinie kaum umgesetzt. Im Internet: http://www.migration-info.de/mub_artikel.php?Id=030706 (Ausgabe 07/03).

841 Vgl. Bendel, Petra / Haase, Marianne 2008: Integrationspolitik der Europäischen Union: Antidiskriminierungs- und Antirassismus-Richtlinien. Online verfügbar unter http://www.bpb.de/themen/A30EJX.html (Stand: 27.01.2008).

842 Seit Jahren ist dies auch eine der zentralen Forderungen der Migrantenorganisationen. In ihrer Presseerklärung anlässlich des Antirassismus-Tages der UNO am 21. März 2000 unterstrich dies die Türkischen Gemeinde in Deutschland. Bevor von der Europäischen Union die Antidiskriminierungsrichtlinie erlassen wurde, waren die Forderungen der Türkischen Gemeinde bereits seit Jahren von konkreten Vorschlägen begleitet. In: Keskin, Hakki 2005: Deutschland als neue Heimat: Eine Bilanz der Integrationspolitik. Wiesbaden, S. 153.

843 Newsletter ,Migration und Bevölkerung' 2008: EU/Deutschland: Antidiskriminierung. Ausgabe 05/08. Im Internet: http://www.migration-info.de/mub_artikel.php?Id=080508; vgl. http://www.bundestag.de (BT-Drs. 16/8461); vgl. http://www.ec.europa.eu/antidiscrimination 
Angelegenheit betraute. ${ }^{844}$ In Großbritannien wurde bereits mit dem Race Relations Act von 1976 eine Antidiskriminierungskommission geschaffen. Diese an die Bestimmungen der EU-Richtlinie anpassenden Rechtsvorschriften traten im Dezember 2003 in Kraft. Überdies existieren in Irland und auch den Niederlanden umfassende Regelungen zur Gleichbehandlung. ${ }^{845}$

Die Antidiskriminierungsrichtlinie hat somit für die Implementation in den Mitgliedsländern institutionelle Folgen und erfordert eine ausgedehnte Neugestaltung der Grundprinzipien immerhin von Anteilen der bestehenden Rechtssysteme, wenngleich vordem nicht einmal eine Kompetenz der Gemeinschaft feststand. Die hieraus entstandene Debatte verdichtete sich nach der Vorlage des Richtlinienentwurfs essenziell bezüglich der folgenden fünf Punkte: ${ }^{846}$ das verschiedenartige Verständnis von Diskriminierung, in erster Linie der indirekten Diskriminierung, und ihr Beleg, hier die materielle Reichweite von Diskriminierungstatbeständen - zuzüglich der Frage, ob diese ausschließlich im Arbeitsrecht oder ebenso im Zivilrecht verankert sein sollten. Sie bezieht sich des Weiteren auf die Umkehr der Beweislast, die beispielsweise im deutschen Recht kaum zu finden ist, die Einrichtung unabhängiger Kontrollbehörden und den Gegenstand der Möglichkeit positiver Diskriminierung. Die Umsetzung der Richtlinien wurde jedoch in einigen Mitgliedsländern aufgeschoben, da deren nationalen Rechtssystemen solche ausführlichen Regelungen zur Sanktionierung von Diskriminierung partiell unbekannt waren. Indessen wurde kein best practice-Muster bereitgestellt. Gleichwohl lassen sich aber ebenfalls die unabhängigen Institutionen der EU, beispielsweise einige NGOs - allen voran die Starting Line Group (SLG), die aus Akademikern gebildet ist, anglo-niederländisch dominiert ist und deren außerordentlich wirksames Lobbying allseits bekannt ist - als policy maker auf die Entwicklung dieser Richtlinie herausstellen. ${ }^{847}$ In diesem Zusammenhang ist die finanzielle Unterstützung vieler NGO-Projekte durch die EU aufmerksam zu betrachten. Eine Reihe von

${ }^{844}$ Newsletter ,Migration und Bevölkerung’ 2008: EU/Deutschland: Antidiskriminierung. Online verfügbar unter http://www.migration-info.de/mub artikel.php?Id=080508 (Ausgabe 05/08); vgl. http://www.bundestag.de (BT-Drs. 16/8461); vgl. http://www.ec.europa.eu/antidiscrimination

${ }^{845}$ Newsletter ,Migration und Bevölkerung' 2003: EU: Antidiskriminierungs-Richtlinie kaum umgesetzt. Online verfügbar unter: http://www.migration-info.de/mub_artikel.php?Id=030706 (Ausgabe 07/03).

${ }^{846}$ Starting Line Group 2001: The Starting Line and the incorporation of the Racial Equality Directive into the national laws of the EU member states and accession States. Brüssel; vgl. Bell, Mark 2002: Anti-Discrimination Law and the European Union. Oxford: Oxford University Press; vgl. Bendel, Petra / Haase, Marianne 2008: Integrationspolitik der Europäischen Union: Antidiskriminierungs- und Antirassismus-Richtlinien. S. 7-8; http://www.bpb.de/themen/A30EJX.html (Stand: 27.01.2008).

${ }^{847}$ Bendel, Petra 2006: Migrations- und Integrationspolitik der Europäischen Union: Widersprüchliche Trends und ihre Hintergründe. In: Baringhorst, Sigrid / Hunger, Uwe / Schönwälder, Karen (Hrsg.) 2006: Politische Steuerung von Integrationsprozessen: Intentionen und Wirkungen. Wiesbaden, S. 104. 
Maßnahmen bezüglich der Bekämpfung der Diskriminierung werden durch die Europäische Union unterstützt, von der finanziellen Projektförderung bis hin zur Durchführung von Untersuchungen und der Förderung von Sensibilisierungs- und Informationskampagnen. Das PROGRESS-Programm ${ }^{848}$ der EU hat beispielsweise wesentlich zur finanziellen Unterstützung vieler NGO-Projekte beigetragen. Mit PROGRESS wird das Ziel verfolgt, den EU-Beitrag zur Unterstützung der Mitgliedstaaten in ihrem Engagement und ihren Anstrengungen um mehr und bessere Arbeitsplätze sowie eine umfassendere Zusammenarbeit in der Gesellschaft auszubauen. Die Europäische Union hat daneben diese wichtigen Aufgaben der NGO ausdrücklich anerkannt und unterstützt die NGO zunehmend bei ihren entsprechenden Aufgaben bezüglich der Bekämpfung der Diskriminierung. Somit ist dies als Beispiel für die relativ große Einflussnahme der NGOs auf die Entstehung der Richtlinie zu sehen. Auch im Jahre 2008 legte die Kommission einen Vorschlag für eine neue Gleichstellungsrichtlinie vor, die den Schutz gegen Diskriminierung außerhalb des Beschäftigungsbereichs mit einbezieht. ${ }^{849}$ Ferner wurde auch von den zuständigen Ministern Frankreichs, Belgiens und Italiens am 21. Februar 2001 ein gemeinsames Positionspaper veröffentlicht, in dem auf eine rasche Annahme der Antidiskriminierungsrichtlinien gedrängt wurde, um ein „multikulturelles Europa“ zu formen. Das Feld zwecks Durchsetzung der Richtlinie war zugleich, zumindest rückblickend gesehen, bereits vor Eröffnung der Ratsverhandlungen gut präpariert: Das Thema der Diskriminierung war in mehreren Mitgliedsländern schon seit Anfang/Mitte der 1990er Jahre als Problematik definiert und auch angegangen worden. Diesbezüglich lag bereits eine Anzahl nationaler Erfahrungen mit Regelungen gegen Diskriminierung vor, die obgleich unterschiedlichen Orientierungen folgend, dennoch dem Erfahrungsaustausch nutzen konnten. An dieser Stelle kann von einem Handeln der Kommission in Form eines politischen Unternehmers gesprochen werden, da die Vorschläge von ihr gebündelt, für die Beteiligten verständlich zusammengefasst und mithilfe oder sogar konkret nach Vorschlägen von zumindest einer äußerst effektiven NGO entwickelt wurden. Am 25. November 1999 wurde der Vorschlag freigegeben und in das Europäische Parlament eingebracht, das ihn im Februar/März 2000 in den

\footnotetext{
848 PROGRESS ist die Bezeichnung des EU-Programmes für Beschäftigung und soziale Solidarität. Seine Gründung erfolgte, um die Konkretisierung der Ziele der Europäischen Union im Hinblick auf Beschäftigung, soziale Angelegenheiten und Chancengleichheit auf finanzieller Basis zu fördern. Das Programm PROGRESS ersetzt das 2006 beendete Aktionsprogramm der Gemeinschaft zur Bekämpfung der Diskriminierung. Detaillierte Informationen über das PROGRESS-Programm und die Projekte sind verfügbar unter: http://ec.europa.eu/social/main.jsp?catId=327\&langId=de

849 Vgl. Europäische Kommission 2009: Die Rolle der NRO und Gewerkschaften bei der Bekämpfung der Diskriminierung. Luxemburg, S. 4-6; http://ec.europa.eu/social/main.jsp?catId=649\&langId=de
} 
Ausschüssen erörterte und im April und Mai 2000 seine Stellungnahmen abgab. ${ }^{850}$

Zusammenfassend lässt sich dazu festhalten, dass die in Brüsseler Rekordzeit von bloß 18 Monaten durchgesetzte Richtlinie gegen Diskriminierung (2000/43/EG) das erste Anzeichen auf einen policy-change der EU-Migrationspolitik beinhaltet. ${ }^{851}$ Überdies bleibt zu sagen, dass die Richtlinie erstens ein neues Politikfeld betrifft, dass ihr Erlass zweitens Einstimmigkeit im Rat verlangte und dass bei ihrer Umsetzung drittens außerdem eine Zusammenarbeit zwischen Ministerien vonnöten war. Zweifelsohne haben im politischen Entscheidungsprozess daneben Interessen, Handlungsaufträge, strategische Verhandlungspositionen bzw. Drohpotenziale der Verhandlungspartner eine entscheidende Bedeutung, die sich sicherlich auf das verzweigte Verhandlungssystem der Europäischen Union auswirkten. Somit sind die entscheidenden Einflussvariablen für die schnelle und problemlose Durchsetzung dieser Richtlinie partiell in äußeren Umständen zu suchen. In erster Linie erwirkten die Pro-Migranten-Organisationen mittels ihrer schon bestehenden Akzeptanz, ihrer juristischen Fähigkeiten und ihres Kontaktes zur Kommission eine ausnehmend große konkrete Einflussnahme auf die Gesetzgebung. Trotz unterschiedlicher Paradigmen der Mitgliedsländer in Form der Integration von Menschen mit Migrationshintergrund konnte auf diesem Feld innerhalb einer sehr kurzen Zeitspanne eine gemeinschaftliche Lösung gefunden werden. Zumindest wurden von der Kommission Vertragsverletzungsverfahren gegen Österreich, Deutschland, Finnland, Griechenland, Luxemburg und Belgien veranlasst. Die Rede ist hier von all jenen Mitgliedsländern, deren Gesetzgebung vor Einführung der europäischen Richtlinie keinerlei Gleichstellungsgesetze, sondern ausschließlich vorwiegend nicht sehr ausgeprägte - Antidiskrimineirungsgesetze oder diesbezüglich keine gesetzlichen Regelungen beinhaltete. Auch eine öffentliche Diskussion auf nationaler Ebene wird offenbar erst bei der Implementation gegenständlich, von welcher der EU-Prozess überwiegend isoliert ist. Des Weiteren sind die Mitgliedstaaten verpflichtet, sowohl einschlägige policies durchzuführen als auch den „Paradigmenwechsel“ großzügig anzulegen. Von einem wirklichen Paradigmenwechsel kann allerdings erst zu einem Zeitpunkt die Rede sein, ,wenn nicht allein ein Wechsel in der Rhetorik, sondern ein Wandel der tatsächlichen policies“ ${ }^{\text {852 }}$ selbst ersichtlich werden kann.

\footnotetext{
${ }^{850}$ Bendel, Petra 2006: Migrations- und Integrationspolitik der Europäischen Union: a.a.O., S. 105-106.

851 Vgl. Bendel, Petra 2006: Migrations- und Integrationspolitik der Europäischen Union: a.a.O., S. 95.

852 Bendel, Petra 2006: Migrations- und Integrationspolitik der Europäischen Union: a.a.O., S. 100.
} 


\subsubsection{Die Familiennachzugsrichtlinie ${ }^{853}$}

Menschenrechtliche Pflichten betreffend den Schutz der Familie und eine aktive Integrationspolitik sollten so gleichermaßen in der Richtlinie 2003/86/EG des Rates vom 22. September 2003 berücksichtigt werden. ${ }^{854}$ Innerhalb der EU existierte bis zum Jahr 2003 keinerlei gemeinschaftsrechtliche Grundlage für die Familienzusammenführung (bzw. den Familiennachzug) von Drittstaatsangehörigen. Daher erfolgt eine Anerkennung des Rechts auf Familienzusammenführung nur in internationalen Rechtsakten, insbesondere der Europäischen Menschenrechtskonvention (EMRK) und der Europäischen Grundrechtscharta (EuGREH). ${ }^{855}$ Die EUMitgliedstaaten als Unterzeichnerstaaten dieser internationalen Rechtsakte handhaben das Recht auf Familienzusammenführung jedoch unterschiedlich, je nach ihrer nationalen Gesetzgebung. Die Vorstellung der Erschaffung einer EU-weiten Regelung hatte ihren Ursprung in dem Vertrag von Amsterdam (Art. 63, Satz 1 Nr. 3 EGV), mit dem auch der Familiennachzug in den Kompetenzbereich der EU verlagert wurde. Eine faire Behandlung von Drittstaatsangehörigen wird auch von den TampereSchlussfolgerungen des Europäischen Rates von 1999 gefordert. Ziel der Richtlinie war die Erlangung „,vergleichbarer Rechte und Pflichten wie die EU-Bürger“ ${ }^{856}$

Die im September 2003 verabschiedete Richtlinie 2003/86/EG betreffend das Recht auf Familienzusammenführung hat ihren Ursprung in einem Entwurf von 1999 und zwei geänderten Vorschlägen der Kommission: Ein erster ambitionierter Vorschlag anlässlich des Rechts auf Familienzusammenführung wurde von der Kommission schon im Dezember 1999 im Anschluss an den Europäischen Rat von Tampere vorgelegt. ${ }^{857}$ Nach erster Lesung durch das Europäische Parlament erfolgten Änderungen vor dem Hintergrund der Vorschläge des Parlaments, die von der Kommisssion in ihrem

\footnotetext{
853 Vgl. Richtlinie 2003/86/EG des Rates vom 22.9.2003 betreffend das Recht auf Familienzusammenführung, Amtsblatt der EU (ABIEU) 2003 L 251 vom 03. Okt. 2003. S. 12.

854 Vgl. Walter, Anne 2003: Familiennachzug - ein Mittel zur Integration? In: Sahlfeld, Konrad u. a. (Hrsg.) 2003: 43. Assistententagung Öffentliches Recht. Luzern, S. 181-196.

855 Vgl. Sieveking, Klaus 2001: Einwanderungs- und Flüchtlingspolitik: neue Perspektiven nach 'Amsterdam'. In: Friedrich-Ebert-Stiftung (Hrsg.) 2001: Europäische Einwanderungs- und Flüchtlingspolitik. Gesprächskreis Arbeit und Soziales 97. Bonn, S. 21-46.

856 Erwägungsgrund 3 RL 2003/86/EG (Familiennachzug); vgl. auch Europäischer Rat 1999: Schlussfolgerungen des Vorsitzes in Tampere vom 15. und 16. Oktober 1999, Rn. 18.

857 Vgl. KOM (1999) 638 endg. vom 1. Dez. 1999 (Erster Vorschlag Familiennachzugs-RL), ABlEG 2000/C 116E/15, S. 66; Boeles, Pieter 2001: Directive on Family Reunification: Are the Dilemmas Resolved? In: European Journal of Migration and Law (EJML) 2001, 4. 3., S. $61 \mathrm{ff}$.
} 
geänderten Vorschlag vom 10. Oktober 2000 weitgehend übernommen wurden. ${ }^{858}$ Allerdings wurde auch dieser Vorschlag im Rat stark kritisiert. Nach dem Scheitern dieses zweiten Kommissionsvorschlages unter belgischer Präsidentschaft Ende September 2001 wurde auch anlässlich der Frist des Amsterdamer Vertrages der Kommission der „Auftrag“ für einen neuen Vorschlag erteilt. Sie legte am 2. Mai 2002 den dritten Vorschlag ${ }^{859}$ als Kompromiss vor. Die Richtlinie war bis zum 3. Oktober 2005 von den Mitgliedstaaten mittels Rechts- und Verwaltungsvorschriften in nationalen Recht umzusetzen. Ausnahmen bildeten Dänemark, das Vereinigte Königreich und Irland. Diese Länder verwiesen auf die nach Titel IV (über Visa, Asyl und Einwanderung) des Vertrags zur Gründung der Europäischen Gemeinschaft möglichen Opt-outs bzw. beanspruchten das Opt-in-Recht nicht, wonach sie nicht gezwungen sind, gewisse gemeinsame Regelungen zu übernehmen. ${ }^{860}$

Ausschlaggebend für eine lang anhaltende Debatte waren auch die rigorosen Haltungen Deutschlands und Österreichs in Bezug auf das beschränkende Höchstalter für den voraussetzungslosen Nachzug von minderjährigen Familienangehörigen. ${ }^{861}$ Daher veränderte sich die Ratsformation insgesamt zugunsten der Konservativen. Debatten anlässlich Reformierungen nationaler Gesetzgebung erfolgten in Deutschland, Finnland, Griechenland, Italien, den Niederlanden, Österreich, Portugal und Spanien pararell zu den Verhandlungen auf EU-Ebene. Insbesondere in dem damaligen deutschen Innenminister Otto Schily ließ sich ein außerordentlich zäher Blockierer eines großen, verhandlungs- und koalitionsstarken Mitgliedstaates ausmachen, der wiederholt auf die zur gleichen Zeit in Deutschland stattfindenden Beratungen über ein nationales Zuwanderungsgesetz hinwies. Schily als ein Befürworter des Kindernachzuges bis zwölf Jahre vertrat hier auch die Interessen der mehrheitlich unionsregierten Bundesländer, die eine Verschärfung der Einschränkungen des Familiennachzuges in Deutschland und der EU forderten. ${ }^{862}$

${ }^{858}$ Vgl. KOM (2000) 624 endg. vom 10. Okt. 2000 (Zweiter Vorschlag der Familiennachzugs-RL), ABIEG C 62E, S. 99; vgl. Cholewinski, Ryszard 2001: Family Reunification and Conditions Placed on Family Members: Dismantling a Fundamental Human Right. In: European Journal of Migration and Law (EJML) 2001, 4. 3., S. $271 \mathrm{ff}$.

${ }^{859}$ Vgl. KOM (2002) 225 endg. vom 2. Mai 2002 (Dritter Vorschlag der Familiennachzugs-RL), ABIEG C 203, S. 136; vgl. auch Weber, Albrecht / Walter, Anne 2003: The Right of Protection of Family for Migrants in Europe: Access and Integration of Family Reunion. In: von Hoffmann, B. (Hrsg.) 2003: Towards a Common European Immigration Policy. Frankfurt a. M., S. 227 ff.

${ }^{860}$ Vgl. Erwägungsgrund 17 und 18 RL 2003/86/EG (Familiennachzug).

${ }^{861}$ Hailbronner, Kay 2002: Migrationspolitik und Rechte der Drittstaatsangehörigen in der Europäischen Union. In: Zeitschrift für Ausländerrecht und Ausländerpolitik (ZAR), 03.2002, S. 86.

${ }^{862}$ Vgl. Süddeutsche Zeitung vom 26.02.2002: Koalition macht der Union Zugeständnisse. Senkung des Nachzugsalters für Kinder auf zwölf Jahre soll Unionsländern die Zustimmung ermöglichen. S. 1; vgl. 
In der Richtlinie 2003/86/EG kann durchaus ein Paradebeispiel für eine EU-Politik des „kleinsten gemeinsamen Nenners“ gesehen werden: ${ }^{863}$ Den Schwerpunkt der Diskussionen stellte der Familienbegriff dar. Der Umfang von nachzugsberechtigten Familienmitgliedern wurde im Laufe der Verhandlungen erheblich vermindert, wobei hier noch Ermessensspielräume und Ausnahmeregelungen im Kontext zu sehen sind. Die Richtlinie beschränkte den Familienbegriff auf die sogenannte Kernfamilie: Als solche gelten Ehepartner und die minderjährigen und unverheirateten Kinder, denen gegenüber der Zuwanderer unterhaltspflichtig ist. Wie oben erwähnt, wurde hierbei vor allem auf Drängen Deutschlands der Nachzug von Kindern über zwölf Jahren eingeschränkt (Art. 4 Abs. 1 UA 3 RL 2003/86/EG). Obschon der ursprüngliche Vorschlag eine einheitliche Altersgrenze von 18 Jahren beinhaltete, ist in der Richtlinie für Mitgliedsländer mit entsprechender Gesetzgebung zum Zeitpunkt der Umsetzung der Richtlinie die Option offengelassen, Kindern mit einem Alter über zwölf Jahren, die unabhängig vom Rest der Familie eintreffen, den Nachzug zu untersagen, wenn ein gesetzliches Integrationskriterium nicht erfüllt wird (Art. 4 Abs. 1 UA 3 RL 2003/86/EG). Eine Ausnahme bezeichnen hier die Kinder von Flüchtlingen. Folglich können Kinder bis zum Alter von 18 Jahren nur zusammen mit ihren Eltern einreisen. Bei einem Nachzug in einem Alter über zwölf Jahren ist ihr Recht von der Erfüllung nationaler Integrationskriterien abhängig. Mit dieser Einschränkungsoption des Rechts auf Familienzusammenführung bei älteren, nachziehenden Kindern soll laut dieser Richtlinie „der Integrationsfähigkeit der Kinder in den ersten Lebensjahren Rechnung getragen und gewährleistet werden, dass sie die erforderliche Allgemeinbildung und Sprachkenntnisse in der Schule erwerben“" (Erwägungsgrund 12 RL 2003/86/EG). Dies trägt den im deutschen Entwurf des Zuwanderungsgesetzes 2002 (ZuwG) vorgesehenen Sprachanforderungen Rechnung. ${ }^{864}$ Des Weiteren ist eine Altersgrenze für Ehepartner vorgesehen, die nun zumindest 21 Jahre alt sein müssen (Art. 4 Abs. 5 RL 2003/86/EG). Diese Altersgrenze darf überdies nur zur Förderung der Integration und Vermeidung von Zwangsehen erlassen werden. Dänemark kann zum Beispiel, da es von dieser Richtlinie nicht betroffen ist, auch weiterhin 24 Jahre als Altersgrenze vorsehen. ${ }^{865}$ Die für alle

Süddeutsche Zeitung vom 06.12.2001: Schily zu Entgegenkommen bereit. S. 8 .

863 Niessen, Jan 2002: Zwischen Harmonisierung und kleinstem gemeinsamen Nenner: Einwanderungspolitik auf europäischer Ebene. In: Bade, Klaus J. / Münz, Rainer (Hrsg.) 2002: Migrationsreport 2002: Fakten, Analysen, Perspektiven. Frankfurt a. M., S. 207, 214.

864 Vgl. Bericht der Unabhängigen Kommission "Zuwanderung”. Zuwanderung gestalten, Integration fördern. Berlin, 4. Juli 2001; http://www.bmi.bund.de

865 Allerdings äußert die Kommission des Europarats für den Kampf gegen Rassimus und Intoleranz (ECRI) bereits $2001 \mathrm{zu}$ Dänemark, "that such criteria [Altersgrenze] in the area of family reunification may impact in a discriminatory fashion on certain minority groups, such as Muslims [...]", Second Report of the European Commission of the European Council against Racism and 
übrigen Familienangehörigen, also nicht-eheliche Partner und deren Kinder, gültigen Ermessensrichtlinien werden nach den nationalen Rechtsvorschriften festgesetzt. Familienangehörige, die nachgezogen sind, haben generell sofortigen Zutritt zum Arbeitsmarkt und zur Bildung, allerdings können diese Anrechte auf die sogenannte Kernfamilie beschränkt und bis zu zwölf Monate vom Arbeitsmarkt abhängig gemacht werden. Ein Aufenthaltstitel für zugezogene Familienmitglieder ist zunächst auf zumindest ein Jahr befristet. Die Konditionen dafür und die Dauer dieses Titels richten sich nach den jeweiligen nationalen Gesetzen der Mitgliedstaaten.

Zusammenfassend lässt sich festhalten, dass das Ziel der „Richtlinie 2003/86/EG“ zur Angleichung der Rechte von Unionsbürgern und Drittstaatsangehörigen bislang nicht erreicht werden konnte. Im Ergebnis sind somit die Familiennachzugsregelungen für Drittstaatsangehörige im Vergleich zu den Unionsbürgern umfangreicher und weniger großzügig. Allerdings sind die Inhalte der Richtlinie auch von Bedeutung: Viele NGOs und diverse Wissenschaftler sprachen von einer Überprüfung der Richtlinie in toto, da diese einen eigentlich restriktiven Charakter offenbare und das „Menschenrecht auf Familienzusammenführung“ untergrabe. ${ }^{866}$ Bemerkenswert ist dabei, dass hiermit ein jahrelanger Streit um die europäische Regelung des Familiennachzuges zeitweilig beendet wurde, dessen öffentliche Debatte auch in Deutschland u. a. im Kindernachzug (über zwölf Jahren) seinen Kernpunkt hatte. Angesichts der nur sehr geringfügig gelungenen Angleichung ist auch das sich hier offenbarende Integrationskonzept für drittstaatsangehörige Einwanderer nicht stichhaltig. Es kann an dieser Stelle nicht nur von Familiennachzug als Instrument zur Integration, sondern auch von Integrationsanforderungen als Instrument zur Nachzugsbegrenzung gesprochen werden. Alles in allem trägt die Richtlinie in bedeutender Form zur Erschaffung einer gemeinsamen, der Steuerung von Migration förderlichen EUEinwanderungspolitik bei. Obschon der dritte Kompromissvorschlag in den letzten erschöpfenden Verhandlungen nochmals in zahlreichen Punkten abgeändert wurde, erfolgte jedoch auf seiner Grundlage im Rat am 27. Februar 2003 eine politische Einigung über die Regelungen zum Familiennachzug auf europäischer Ebene. ${ }^{867}$ Der „Einwanderungspfad“ des Familiennachzuges bezeichnet somit den ersten Rechtsakt zur legalen Einwanderung, der anlässlich der Harmonisierungszuständigkeit nach Artikel 63 EG beschlossen wurde.

Intolerance on Denmark, CRI (2001) 4, adopted on 16 June 2000, made public on 3 April 2001, p.11.

866 Cholewinski, Ryszard 2001: a.a.O., S. 271-290.

867 Ratsdokument im Bereich Migration und Rückkehr (MIGR) 2003: 6912/03 MIGR 16 (Einigung Familiennachzugs-RL). 


\subsection{Fazit}

Anhand des europäischen Integrationsprozesses seit den neunziger Jahren lässt sich ein Funktionswandel und eine verstärkte migrationspolitische Zusammenarbeit beobachten. Die Einbettung der migrationspolitischen Zusammenarbeit in den europäischen Integrationsprozess wird außerdem dadurch offensichtlich, dass zwischen europapolitischen und migrationspolitischen Interessen ein Zusammenhang besteht und diese sich gegenseitig beeinflussen. Hierbei offenbart sich eine allmähliche Fusion der Migrationspolitik mit der europäischen Verhandlungsmasse: Migrationspolitische Interessen könnten künftig als neue Währungen in den politikfeldübergreifenden Verhandlungsprozess eingehen. ${ }^{868}$ Ebenso weist eine Zunahme migrationsrelevanter Fragen in den Außenbeziehungen der EU auf eine Einbindung migrationspolitischer Kooperation in den europäischen Integrationsprozess hin. Durch die verstärkte Einbettung des Politikfeldes Migration in den europäischen Integrationsprozess ist eine Entwicklung in Gang gesetzt worden, die diesen Politikbereich immer weniger als einen Bereich erscheinen lässt, der allein der ausschließlichen Entscheidungsgewalt des Nationalstaates untersteht. Mithin wurde das Politikfeld europäisiert, da es zu einem Aspekt von zunehmender Bedeutung im Rahmen des europäischen Einigungsprojektes geworden ist.

Die vorangestellten Ausführungen haben anhand aller behandelten Fallbeispiele eine vermehrte Anwendung der EU-Ebene auf dem Feld der Migrationspolitik gezeigt. Als eines der integrationspolitischen Grundprinzipien ist hier die Solidarität zu nennen, kraft derer die anhaltende Europäisierung des Politikfeldes Migration gefördert wird. Die Verknüpfung wird anhand der genannten Fallbeispiele veranschaulicht. Auf dem Gebiet Flüchtlinge und Asyl sind die Fragen von Mindeststandards und der Lastenverteilung von größter Bedeutung, wie im Fall der Bürgerkriegsflüchtlinge aus dem ehemaligen Jugoslawien gezeigt werden konnte. Die Initiative EUROPOL kann auf der einen Seite mittels innerer Sicherheit der EU bezüglich illegal eingereister Personen denjenigen Ländern eine Entlastung bedeuten, in denen zwar ein Asylantrag gestellt wird, in den der Asylbewerber aber nicht als erstes eingereist ist. Auf der anderen Seite werden dann allerdings die Außengrenzstaaten vermehrt betroffen sein, die überdies auch für die Außengrenzsicherung zuständig sind. Anhand dessen wird die Erfordernis einer

${ }^{868}$ Vgl. Wallace, Helen 1990: Making Multilateral Negotiations Work. In: Wallace, William (Hrsg.) 1990: The Dynamics of European Integration. London, S. $223 \mathrm{f}$. 
solidarischen Regelung für den Krisenfall erneut ersichtlich. Jedoch ist hier von einem sehr souveränitätsrelevanten Kooperationsbereich die Rede, bei dem eine Beschränkung der nationalen Handlungsautonomie nur etappenweise Zustimmung findet.

Die „Antidiskriminierungsrichtlinie 2000/43/EG““ stellte den zentralen Punkt dar, der den Erfolg hinsichtlich einiger von den NGOs vorangetriebener Policy-Ideen ermöglichte. Besonders die NGO aus der anglo-niederländisch dominierten Starting Line Group (SLG) konnte ebenso wie die EU-Kommission als ,politischer Unternehmer “869 bezeichnet werden, dessen juristischen Kenntnisse im europäischen Policy-Gestaltungsprozess hervorragend einwirkten. Im Gegensatz $\mathrm{zu}$ der Antidiskriminiserungspolitik hatte der Blick der Politik auf das Thema „legale Zuwanderung“ über den Familiennachzug ohnehin nur geringfügig und nur bei manchen der EU-Mitgliedstaaten seine Couleur geändert. Angesichts der „Familiennachzugsrichtlinie 2003/86/EG“ kann jedoch festgestellt werden, dass Regelungen zum Familiennachzug ohnedies stark den internationalen Abkommen unterliegen, womit die staatliche Souveränität bereits Begrenzungen unterworfen ist. ${ }^{870}$ Insbesondere jegliche Versuche, die Wirtschaftsmigration auf gemeinschaftlicher Basis $\mathrm{zu}$ regeln, wurden im Hinblick auf die Arbeitsmarktlage in einigen großen Mitgliedsländern seitens des Rates negativ aufgenommen. Dabei erwies sich die Bundesrepublik Deutschland als ein zentral wichtiger Mitgliedstaat in erster Linie als Blockierer einer Politik, die als Einfallstor für mehr Familiennachzug gesehen wurde.

Die auf anderen Gebieten der Migrations-, aber auch der Sicherheits- und Außenpolitik fortschreitende Integration wird Kompromisse unvermeidbar machen. Des Weiteren wird es immer Gelegenheit geben, Beschlüsse aus unterschiedlichen politischen Feldern miteinander zu verknüpfen und Entscheidungen auf einem Feld mit Zugeständnissen auf anderen $\mathrm{zu}$ erhandeln. Es ist durchaus eine Tendenz hin $\mathrm{zu}$ einer „Festung Europa“ ersichtlich, deren zentrales Augenmerk tatsächlich überwiegend auf Gesichtspunkten wie etwa der Grenzsicherung, Rückführung und Unterbindung illegaler Migration liegt.

\footnotetext{
${ }^{869}$ Bendel, Petra 2006: Migrations- und Integrationspolitik der Europäischen Union: a.a.O., S. 116.

${ }^{870}$ Vgl. Franz, Mariella 2006: Familienzusammenführung in der Einwanderungspolitik der Europäischen Union. Rechtsfragen aus dem Europa- und Völkerrecht. IMIS-Beiträge, Heft 30/2006. Osnabrück: Institut für Migrtionsforschung und interkulturelle Studien. S. 45-68.
} 


\section{Europäisierung durch Einbindung des deutschen Migrationssystems}

Das Ziel der folgenden Ausführungen ist eine Durchleuchtung und Veranschaulichung des Europäisierungsprozesses, des Politikfeldes Migration im Hinblick auf eine zunehmende Einbindung des nationalen Migrationssystems in das europäische Mehrebenensystem. Es wird aus dem Blickwinkel untersucht, wie die deutsche Migrationspolitik, also deutsche ,nationale Interessen, Strukturen und Politiken die Entwicklung von Institutionen und Policies auf supranationaler Ebene beeinflussen.“ Genauso werden mögliche Rückwirkungen „,der europäischen Integration auf politische Prozesse, Institutionen und Politikinhalte ${ }^{\text {‘871 }}$ in Deutschland unter der Europäisierung thematisiert. In diesem Verständnis wird ebenso die zentrale Frage gestellt, inwiefern deutsche nationale Migrationspolitik innerhalb der EU ausgeführt bzw. vertieft und infolgedessen zur Europäisierung entwickelt werden kann. Daran schließt sich weiterhin die Frage an, ob deutsche nationale Migrationspolitik eigene Konzepte hat oder als Anregung hegemonialer Einflussnahme gesehen werden sollte. Ist die Anpassung an Vorgaben der EU ferner nur eine Option für die deutschen Interessen bzw. für die Europastrategien deutscher Akteure? Anschließend wird gefragt, wie sich die Kontextualisierung deutscher Migrationspolitik heute zwischen „keinem Einwanderungsland“ und „einem Einwanderungsland“ darstellt.

Im folgenden Abschnitt wird zunächst das Akteursfeld im Zusammenhang mit den institutionellen Rahmenbedingungen unter der organisatorischen Einbettung der Bundesrepublik Deutschland seit den 1990er Jahren bis heute im Bereich der Migrationspolitik dargestellt.

${ }^{871}$ Knill, Christoph 2005: Die EU und die Mitgliedstaaten. In: Holzinger, Katharina / Knill, Christoph / Peters, Dirk / Rittberger, Berthold / Schimmelfennig, Frank / Wagner, Wolfgang 2005: Die europäische Union: Theorien und Analysekonzepte. Paderborn, S. 153. 


\section{Das Akteursfeld im Kontext der deutschen institutionellen Rahmenbedingungen}

Das Akteursfeld der Migrationspolitik wird in Verbindung mit den folgenden deutschen institutionellen Rahmenbedingungen skizziert. Je nach der institutionellen Konfiguration eines politischen Systems sind als angemessene Regierungstechnik „unterschiedliche Formen hierarchischer Politik oder koordinierende Strategien“ ${ }^{\text {" } 872}$ in Betracht zu ziehen. Das deutsche Regierungssystem lässt sich als „hochgradig fragmentiert“ betrachten, sodass sich die Macht ,auf eine Vielzahl von mitentscheidenden Institutionen verteilt", wozu maßgeblich die „konsensdemokratischen Merkmale des politischen Systems“ und die „fortschreitende europäische Verflechtung“ beitragen. ${ }^{873}$ Die Kunst des heutigen Regierens besteht darin, die Vielzahl verschiedener Handlungsebenen zu verknüpfen und zuzuordnen. Beispielsweise wurden die Verhandlungen zur Migrationspolitik in Deutschland von Angehörigen des Bundeskanzleramts (BK), des Bundesministeriums des Innern (BMI), des Auswärtigen Amtes (AA) und des Bundesamts für Migration und Flüchtlinge (BAMF) geprägt. Ausgehend „,vom institutionellen Gefüge des Regierungssystems“, „stehen nachfolgend die vielfältigen Koordinationsprozesse und Regierungstechniken im Vordergrund der Betrachtung.“ ${ }^{874}$ Wenn „Regieren“ zunehmend mit der Verknüpfung ,verschiedener Handlungsebenen bzw. Arenen“ zu tun hat, verdienen auch „sog. Vorentscheider oder Grenzstellenakteure bzw. Machtmakler, die auf mehreren solcher Spielfelder (z. B. Regierung, Parlament, föderale Gremien, europäische Institutionen) gleichzeitig agieren“" ${ }^{\text {875 }}$, stärkere Aufmerksamkeit. Deshalb gilt es konsequenterweise „den Beziehungsmustern zwischen solchen zentralen Spielern und den formal entscheidungsbefugten Institutionen“" sowie den damit verbundenen „Einfluss- und Kontrollbeziehungen“876 eingehender nachzugehen.

Es stellen sich folgende Fragen: Wer regiert Deutschland im Politikfeld Migration bzw. wer sind die Hauptakteure, die den Entscheidungsprozess und die politische Entscheidungsfindung im Kontext der Europäisierung beeinflussen? Welche Interessen werden von den deutschen Akteuren zur Europäisierung der Migrationspolitik verfolgt?

\footnotetext{
${ }^{872}$ Kropp, Sabine 2005: Regieren: Akteure, Strukturen, Prozesse. In: Gabriel, Oscar W. / Holtmann, Everhard (Hrsg.) 2005: Handbuch Politisches System der Bundesrepublik Deutschland. München, S. 125-158, hier S. 129.

873 Kropp, Sabine 2005: Regieren: Akteure, Strukturen, Prozesse. a.a.O., S. 129.

874 Kropp, Sabine 2005: Regieren: Akteure, Strukturen, Prozesse. a.a.O., S. 131.

875 Kropp, Sabine 2005: Regieren: Akteure, Strukturen, Prozesse. a.a.O., S. 131.

876 Kropp, Sabine 2005: Regieren: Akteure, Strukturen, Prozesse. a.a.O., S. 131.
} 


\section{1 Bundesregierung}

Die Bundesregierung hat viele Jahre mit dem Leitmotiv „Deutschland ist kein Einwanderungsland“ die Grundposition der deutschen Migrationspolitik festgehalten. Für die christlich-liberale Regierung unter Helmut Kohl (CDU) von 1982 bis 1998 war die Migrationspolitik im Rahmen der Europapolitik eher von einer deutlichen Tendenz zu nationalstaatlicher Individualität gekennzeichnet, die später als supranationale Integrität erkannt wurde. ${ }^{877}$ In dieser Zeit vollzog sich die deutsche Wiedervereinigung und zumindest die vertragliche Vollendung der Europäischen Union. Doch erst mit der Wiedervereinigung Deutschlands 1990 erlangte der europäische Integrationsprozess eine neue Dimension. Die veränderte Rolle Deutschlands unter der Regierung Kohl, durch die obsolet gewordene Sicherheitspolitik des westlichen Verteidigungsbündnisses und die strukturellen Veränderungen durch weitere Beitritte zur Gemeinschaft, erforderten von den politisch Verantwortlichen eine neue Handlungsstrategie. Als vorläufiges Ergebnis externer und interner Einflüsse stand die Vollendung der Währungsunion mit der Einführung des Euro zum 1.1.1999. In diesem Zusammenhang wurde das EG-Vertragswerk in der Europäischen Akte 1984, dem Maastrichter Vertrag 1991 und auf dem Amsterdamer Gipfel 1997 als ein klares Produkt einer spezifischen, aber vergangenen internationalen und europäischen Konstellation dargestellt, vor allem angesichts der deutschen Hegemonialmacht unter der Führung der Regierung Kohl. Zugpferde für die Reformen von Maastricht und Amsterdam waren dabei die Vorschläge des französisch-deutschen Führungsduos Mitterand-Kohl bzw. Chirac-Kohl, die vorangegangene Partnerschaften, so etwa zwischen Valéry Giscard d'Estaing und Helmut Schmidt, fortsetzten und quasi-konstitutionelle Meilensteine für das neu konzipierte EU-System bzw. EU-Migrationssystem setzten. ${ }^{878}$ Das 1990 erlassene Ausländergesetz Deutschlands bedeutete auch schon innenpolitisch einen Schritt in die Richtung der Regierung Kohl, die die mit der Gastarbeiteranwerbung eingeleiteten Einwanderungsprozesse zumindest teilweise wieder rückgängig zu machen. ${ }^{879}$

\footnotetext{
877 Walter, Peter 2001: Die Darstellung der Europäischen Integrationspolitik des Bundeskanzlers Helmut Kohl in ausgewählten deutschen Printmedien (Diss., Gießen). Gießen, S. 11.

878 Wessels, Wolfgang 2008: Das politische System der Europäischen Union. Wiesbaden, S. 89.

879 Schönwälder, Karen 2004: Kleine Schritte, verpasste Gelegenheiten, neue Konflikte:

Zuwanderungsgesetz und Migrationspolitik. In: Blätter für deutsche und internationale Politik, Jahrgang 49/2004, Heft 2. Bonn, S. 1205-1214, hier S. 1205.
} 
Die Migrationspolitik Kohls wurde durch die deutsche Vereinigung und den mit ihr verbundenen kurzen Wirtschaftsboom bestimmt. ${ }^{880}$ Seit Anfang der 1990er Jahre ist somit in Deutschland eine Renaissance der Gastarbeiterpolitik und eine erneute Steigerung der Rekrutierung von Arbeitsmigranten auf der Grundlage von Werkverträgen, als Saisonarbeiter oder in besonderen Berufsgruppen ersichtlich. Außerdem wurden den Arbeitsmigranten in der Neufassung des Ausländergesetzes 1990 erstmals Rechtsansprüche auf Einbürgerung garantiert ${ }^{881}$, das allerdings nicht weniger umstritten war als die früheren Maßnahmen: Während dabei der einen Seite die Maßnahmen zur Reduzierung der Anzahl von Ausländern nicht weit genug gingen, kritisierte die andere wiederum, dass die Einwanderungssituation weiterhin verleugnet werde. So stand angesichts von hoher Arbeitslosigkeit das „Credo des NichtEinwanderungslandes“ im Widerspruch zur tatsächlichen Situation. ${ }^{882}$ Auch der Bonner „Asylkompromiss“ von $1993^{883}$ erreichte sehr schnell seinen eigentlichen Zweck: den augenblicklichen Rückgang des Zustroms von Asylsuchenden. Andererseits führte er zu einem asylrechtlichen Sonderweg in den Verfassungen einiger anderer EU-Staaten, wie in Frankreich, Spanien und Italien. Das Asylrecht des „Asylkompromisses“ von 1993 zeigte allerdings, wie schlecht es um die Humanität der deutschen Gesellschaft und Politik stand. ${ }^{884}$ Denn die AsylantragstellerInnen sollten im Zuge dieses „Asylkompromisses“ ohne Prüfung ihres Antrags an der Grenze zu einem so bezeichneten ,,sicheren Drittstaat (EU-Staat oder Listenstaat) ${ }^{، 885}$ abgelehnt oder aus

${ }^{880}$ Hauchler, Ingomar / Messner, Dirk / Nuscheler, Franz (Hrsg.) 1997: Globale Trends 1998. FaktenAnalysen-Prognossen. Frankfurt a. M., S. 108.

${ }^{881}$ Bommes, Michael 2006: Integration durch Sprache als politisches Konzept. In: In: Davy, Ulrike / Weber, Albrecht (Hrsg.) 2006: Paradigmenwechsel in Einwanderungsfragen?: Überlegungen zum neuen Zuwanderungsgesetz. Baden-Baden, S. 61.

882 Angenendt, Steffen 2008: Die Steuerung der Arbeitsmigration in Deutschland: Reformbedarf und Handlungsmöglichkeiten. Bonn, S. 12. Online verfügbar unter: http://www.library.fes.de/pdffiles/wiso/05705.pdf (Stand: 07.08.2010).; vgl. auch Beck, Marieluise 2001: Ihr Inderlein kommet. In: Blätter für deutsche und internationale Politik, Jahrgang 46/2001, Heft 1. Bonn, S. 7-9, hier S.7.

883 Der Hintergrund des „Asylkompromisses“ von 1993 war, dass begründet durch den Fall des Eisernen Vorhangs und der kriegerischen Auseinandersetzungen auf dem Gebiet des ehemaligen Jugoslawiens die Zahl der Flüchtlinge, die in Deutschland Schutz suchten, wesentlich gestiegen war. Anhand der Einführung der Drittstaatenregelung im Rahmen des „Asylkompromisses“ sollte erreicht werden, dass Asylanträge nach Möglichkeit nicht weiterhin in Deutschland geprüft werden müssen, sondern in den Transitstaaten, über die die Einreise der AntragstellerInnen erfolgt war. Vgl. Weinzierl, Ruth 2009: Der Asylkompromiss 1993 auf dem Prüfstand. Deutsches Institut für Menschenrechte, Berlin, Juli 2009. Im Internet: http://www.institut-fuer-menschenrechte.de/fileadmin/user_upload/PDFDateien/Ergebnispapiere_Zusammenfassungen_Hintergrundpapiere/zusammenfassung__tudie_der_as ylkompromiss_1993_auf_dem_pruefstand.pdf

${ }^{884}$ Nuscheler, Franz 2004: Internationale Migration: Flucht und Asyl. Wiesbaden, S. 151-152.

${ }^{885}$ Es gelten Staaten als sicher, in denen die Genfer Flüchtlingskonvention (GFK) und die Europäische Menschenrechtskonvention (EMRK) angewandt werden. Unter diesem Gesichtspunkt gelten alle Nachbarn der Bundesrepublik und die Europäische Union in ihrer Gesamtheit als sicher. Finnland, Norwegen, Österreich, Polen, Schweden, die Schweiz und die Tschechische Republik sind nach 
Deutschland in diesen abgeschoben werden können. Dies bedeutet, dass kein Asylbewerber, der auf dem Landweg über einen sicheren Drittstaat in die Bundesrepublik einreiste, einen Asylanspruch stellen konnte. Damit ging ein Teil des ursprünglichen Menschenrechts verloren. Auch in Bezug auf die Integration von Zuwanderern gab es am Ende der Regierungszeit Kohls wohl kaum eine Entwicklungsvorstellung. ${ }^{886}$

Nach der sechzehnjährigen Regierungszeit von Helmut Kohl (CDU) zwischen 1982 und 1998 stellte sich die Regierung von Gerhard Schröder (SPD) unter der rot-grünen Regierungskoalition (1998 - 2005) der Herausforderung, Deutschland für den internationalen Wettbewerb in einer globalisierten Welt in allen Bereichen zu stärken. Ein Teilbereich war hier der Wettbewerb um die besten Köpfe. Mit der Reform des Staatsangehörigkeitsrechts, also zum ersten Mal vom Abstammungsprinzip (,Ius Sanguinis') hin zum Territorialprinzip (,Ius Soli'), wurde hierfür bereits im Jahr 2000 der Grundstein gelegt. ${ }^{887}$ Zudem ist die Einbürgerungsfrist in gewissen Fällen von fünfzehn auf acht Jahre verknappt worden. Steigende Einbürgerungszahlen waren die Folge; was natürlich mit der Tatsache einhergeht, dass die in Deutschland geborenen Kinder von Migranten die deutsche Staatsbürgerschaft erhalten. ${ }^{888}$ Eine bedeutsame neue Migrationspolitik bestand in der Verabschiedung der sogenannten Green-CardRegelung aus dem Jahr 2000, deren Zweck es war, IT-Fachkräfte aus den Nicht-EUStaaten für einen begrenzten Zeitraum anzuwerben. Durch diesen Beschluss der Regierung Schröder wurde seit Jahrzehnten erstmals intensiv über die Vor- und Nachteile gezielter Anwerbung diskutiert. ${ }^{889}$ Diesbezüglich erfolgte eine

Anlage $1 \mathrm{zu} \S 26 \mathrm{a}$ des Asylverfahrensgesetzes sichere Drittstaaten. Auch unter Zustimmung des Bundestages und Bundesrates werden gesetzlich Länder festgelegt, in denen es keine politische Verfolgung gibt. Jegliche Asylanträge von aus diesen Ländern stammenden Personen werden als „offensichtlich unbegründet“ abgelehnt. Bulgarien, Gambia, Ghana, Polen, Rumänien, Senegal, die Slowakische Republik, die Tschechische Republik und Ungarn werden durch das Asylverfahrensgesetz zu den ,sicheren Herkunftsländern“ erklärt. In: Han, Petrus 2005: Soziologie der Migration: a.a.O., S. 194.; vgl. Seifert, Wolfgang 2000: Geschlossene Grenzen - offene Gesellschaften?: Migrations- und Integrationsprozesse in westlichen Industriennationen. S. 117.

886 Vgl. Santel, Bernhard / Weber, Albrecht 2000: Zwischen Ausländerpolitik und Einwanderungspolitik: Migrations- und Ausländerrecht in Deutschland. In: Bade, Klaus J. / Münz, Rainer (Hrsg.) 2000: Migrationsreport 2000. Frankfurt a. M., S. 123.; vgl. auch Seidel, Eberhard 2001: Grenzverläufe des Zumutbaren: Einsichten und Absichten deutscher Einwanderungspolitik. In: Blätter für deutsche und internationale Politik. 46/2001, Heft 2. S. 857-862, hier S. 860. auch im Internet: www.blaetter.de

887 Bundesministerium des Innern (BMI) 2006: Zuwanderungsrecht und Zuwanderungspolitik. S.3.

888 Eine der Auswirkungen des neuen Rechts bestand darin, dass sich die Zahl der Einbürgerungen in den Jahren 2000 und 2001 gegenüber dem Jahr 1999 um 25 bis 30 Prozent erhöhte. Vgl. Bundesministerium des Innneren 2000: Ausländerpolitik und Ausländerrecht in Deutschland. Berlin, S. 54 ff.; Bundesministerium des Innneren 2006: Zuwanderungsrecht und Zuwanderungspolitik. Berlin, S. 76 f.; Nuscheler, Franz 2004: Internationale Migration: Flucht und Asyl. S. 156-157.

889 Wilp, Markus 2007: Die Arbeitsmarktintegration von Zuwanderern in Deutschland und den 
Arbeitsmarktöffnung für Arbeitsmigranten allerdings nur ganz partiell, nämlich im Bereich der Hochqualifizierten. ${ }^{890}$ Bereits Anfang Juli 2004 wurde ein Entwurf des Zuwanderungsgesetzes (ZuWG) von Bundestag und Bundesrat bestätigt. ${ }^{891}$ Es wurde vorgesehen, „dass qualifizierte Arbeitsnehmer aus den EU-Beitrittsländern bis zum Ablauf der voraussichtlich fünfjährigen Übergangsfrist für die Arbeitnehmerfreizügigkeit grundsätzlich als Arbeitsmigranten zugelassen werden dürfen ( $\$ 39$ Abs. 6 AufenthG).“ ${ }^{\text {892 }}$ Die EU hat zwar seit dem Amsterdamer Vertrag (1999) die Regelungskompetenzen für eine gemeinsame Migrationspolitik inne (Art. $61 \mathrm{ff}$ des EG-Vertrags), die EU hat dennoch bisher keinerlei Rechtsvorschriften bezüglich der Arbeitsmigration geschaffen. ${ }^{893}$ Daraufhin wurde von der deutschen Regierung eine Klausel in den EU-Verfassungsvertrag eingefügt, die den Mitgliedsländern das Recht vorbehält, die Zahl der neu einreisenden Arbeitsmigranten für ihr Hoheitsgebiet selbst zu definieren (Art. III 168 Abs. 5 des Entwurfs des EUVerfassungsvertrages). ${ }^{894}$

Der Ansatz der rot-grünen Regierung, die Migrationspolitik zu modernisieren und mittels unausweichlicher Konzessionen angesichts der Globalisierung anzupassen, stießen allerdings auf ernsthaften Widerstand, zum Beispiel bei dem Zuwanderungsgesetz: ${ }^{895}$ In der kritischen Auseinandersetzung sah man die „Steuerung und Begrenzung“" als zentrale Botschaft des Zuwanderungsgesetzes und nicht die Öffnung eines Einwanderungslandes Deutschlands, wie es eigentlich angestrebt

Niederlanden: Hintergründe, aktuelle Entwicklungen und politische Maßnahmen. Münster, S. 72.

890 Als Hochqualifizierte werden Wissenschaftler sowie Spezialisten betrachtet, die zumindest 84.000 Euro im Jahr verdienen müssen. Vgl. Schönwälder, Karen 2004: Kleine Schritte, verpasste Gelegenheiten, neue Konflikte: Zuwanderungsgesetz und Migrationspolitik. In: Blätter für deutsche und internationale Politik, Jahrgang 49/2004, Heft 2. Bonn, S. 1205-1214, hier S. 1206 (Fußnote 1).; vgl. auch Schönwälder, Karen 2006: Politikwandel in der (bundes-) deutschen Migrationspolitik. In: Davy, Ulrike / Weber, Albrecht (Hrsg.) 2006: Paradigmenwechsel in Einwanderungsfragen?: Überlegungen zum neuen Zuwanderungsgesetz. Baden-Baden, S. 18.

891 Vgl. Frankfurter Allgemeine Zeitung (FAZ) 2004: „Einwanderungsgesetz tritt am 1. Januar 2005 in Kraft." FAZ vom 10. 07. 2004.

892 Weizsäcker, Esther 2005: Vom ,Inlandslegitimierungszwang“ zum „Zuwanderungsgesetz“: Zur rechtlichen Regulierung der Arbeitsmigration in Deutschland. In: Geisen, Thomas (Hrsg.) 2005: Arbeitsmigration: WanderarbeiterInnen auf dem Weltmarkt für Arbeitskraft. Frankfurt a. M., S. 173195, hier S. 192.

893 Weizsäcker, Esther 2005: Vom „Inlandslegitimierungszwang“ zum „Zuwanderungsgesetz“: a.a.O., S. 192.; vgl. Läufer, Thomas 1998: Vertrag von Amsterdam: Texte des EU-Vertrages und des EGVertrages. Bonn, S. $81 \mathrm{f}$.

894 Weizsäcker, Esther 2005: Vom „Inlandslegitimierungszwang“ zum „Zuwanderungsgesetz“: S. 193.

895 Butterwegge, Carolin 2009: Fit für die Globalisierung?: Deutschland auf dem Weg zur Modernisierung seiner Migrations- und Integrationspolitik. In: Butterwegge, Christoph / Hentges, Gudrun (Hrsg.) 2009: Zuwanderung im Zeichen der Globalisierung: Migrations-, Integrations- und Minderheitenpolitik. Wiesbaden, S. 137-170 hier, S. 137. 
wurde. ${ }^{896}$ Diesbezüglich stellt sich die Frage, was demzufolge die Logik dieser politischen Interventionen ist. Sie lässt sich vor allem in dem Glaubenssatz festhalten, „dass die Bundesrepublik kein Einwanderungsland sei und es auch nicht werden dürfe.“897 Dieses migrationspolitische Paradigma führte über Jahrzehnte hinweg die deutsche Migrationspolitik an, wobei es sich noch in der Ära der rot-grünen Bundesregierung fand. Das Zuwanderungsgesetz stand folglich eher in der Kontinuität der vergangenen Migrationspolitik. ${ }^{898}$ Alles in allem führte die rot-grüne Bundesregierung insbesondere mit dem Zuwanderungsgesetz und der Staatsangehörigkeitsrechtsreform einen Paradigmenwechsel zur faktischen Anerkennung der Einwanderungsprozesse durch, dieser blieb allerdings „unvollständig“. ${ }^{899}$ Die Regierung Schröder (SPD) anerkannte somit erstmals generell die Einwanderungssituation.

Die nachfolgende Bundesregierung der Großen Koalition aus CDU, CSU und SPD unter Bundeskanzlerin Angela Merkel (CDU), bestehend seit November 2005, modernisierte im Rahmen des immer engeren Zusammenwachsens der Europäischen Union die Migrationspolitik weiterhin. Zentrales Gewicht kam dabei der Förderung der Integration von MigrantInnen und der systematischen Steuerung weiterer Einwanderung zu (vgl. Kapitel II. 3.7 dieser Arbeit). Insbesondere die erlassenen Gesetze in der 16. Legislaturperiode (2005 bis 2009) stießen zwar auf weitaus weniger öffentliches Interesse als das Zuwanderungsgesetz der rot-grünen Koalition, folgten dessen ungeachtet aber derselben Logik und verstärkten dessen restriktiven Politikinhalt eher zusätzlich, wie beispielhaft anhand des Folgenden dargestellt werden soll: „1. Konterkarierung der Integrationsbemühungen durch das EU-RichtlinienUmsetzungsgesetz. 2. Einbürgerungstests. 3. Das Aktionsprogramm zur Anwerbung Hochqualifizierter und das Arbeitsmigrationssteuerungsgesetz. “900

Betrachtet man die Veränderungen der Migrationspolitik seit den 1990er Jahren unter Helmut Kohl (CDU), über Gerhard Schröder (SPD) bis hin zur jetzigen Regierung unter Angela Merkel (CDU), sind die Veränderungen bemerkenswert: Einerseits ist die Migrationspolitik eindeutig restriktiver geworden, aber andererseits umfasst sie die Integration der MigrantInnen bezüglich der wirtschaftlichen und demografischen

\footnotetext{
896 Schönwälder, Karen 2004: Kleine Schritte, verpasste Gelegenheiten, neue Konflikte: a.a.O., S. 1207.

897 Butterwegge, Carolin 2009: Fit für die Globalisierung?: a.a.O., S. 137.

898 Schönwälder, Karen 2004: Kleine Schritte, verpasste Gelegenheiten, ... a.a.O., S. 1214.

899 Schönwälder, Karen 2006: Politikwandel in der (bundes-) deutschen Migrationspolitik. a.a.O., S. 10.

900 Butterwegge, Carolin 2009: Fit für die Globalisierung?: a.a.O., S. 161-164.
} 
Entwicklung. Die nationalen Interessen Deutschlands führten nebenbei besonders zum Fortschritt auf europäischer Ebene. So war unter der Regierung Kohl (CDU) in den 1990er Jahren vor allem die Beziehung zu Frankreich nicht nur als europäische Kernmacht, sondern auch als Führungsmacht auf dem Weg zu einem engeren Zusammenschluss in Europa gekennzeichnet. ${ }^{901}$ Innenpolitisch betrachtet, betrieb die Regierung Kohl bisweilen kaum Integrationspolitik, aber unter der rot-grünen Regierung (1998 - 2005) wurden neue Wege auf dem Feld der Integrationspolitik beschritten. Die nachfolgende Regierung der Großen Koalition aus CDU/CSU/SPD in der 16. Legislaturperiode (2005 - 2009) und aus CDU/CSU/FDP in der 17. Legislaturperiode (2009 - 2013) unter Kanzlerin Angela Merkel (CDU) verstärkte und verstärkt die Integrationspolitik abermals, so auch die Steuerungspolitik im Bereich Migration, deren Grundstein bereits von ihrer rot-grünen Vorgängerin gelegt wurde.

Insgesamt lässt sich kaum beurteilen, ob die deutsche Migrationspolitik unter der Bundesregierung seit den 1990er Jahren substanzielle Fortschritte gemacht hat. Als Begründung wurde genannt, dass die richtungsweisenden ersten Schritte der deutschen Migrationspolitik bereits Anfang der 1970er Jahre durch den Anwerbestopp von 1973 unternommen wurden. Der Anwerbestopp von 1973, der als „Pfad der Restriktion““902 der deutschen Migrationspolitik bezeichnet werden kann, leitete weiterhin die restriktiven Gesetze der 1990er Jahre ein, die bis heute als Grundlage für migrationspolitische Reformen in Deutschland gelten. ${ }^{903}$ Darüber hinaus wurden die wichtigsten Reformprojekte der Bundesregierung seit den 1990er Jahren als Paradigmenwechsel zur ,unvollständigen“ Anerkennung der Einwanderungsprozesse bezeichnet. $^{904}$

Im Folgenden soll nun in Bezug auf das Thema Europäisierung vertiefend auf die migrationspolitisch wichtigen Akteure innerhalb der Bundesregierung und auch auf die nicht-gouvernementalen Akteure (NGOs) eingegangen werden.

\footnotetext{
901 Vgl. Haftendorn, Helga 1994: Gulliver in der mitte Europas. Internationale Verflechtung und nationale Handlungsmöglichkeiten. In: Kaiser, Karl / Maul, Hanns W. (Hrsg.) 1994: Deutschlands neue Außenpolitik. Band 1: Grundlagen. Oldenbourg, S. 141.

902 Müller, Doreen 2010: Flucht und Asyl in europäischen Migrationsregimen. Göttingen, S. 208.

903 Butterwegge, Carolin 2009: Fit für die Globalisierung? a.a.O., S. 137.

904 Schönwälder, Karen 2006: Politikwandel in der (bundes-) deutschen Migrationspolitik. a.a.O., S. 10.
} 


\section{1. 1 Bundeskanzler und Bundeskanzleramt (BK)}

Die Bundesrepublik Deutschland hat als parlamentarisches Regierungssystem eine doppelköpfige Exekutive, bestehend aus dem Bundespräsidenten als Staatsoberhaupt und dem Bundeskanzler als Regierungschef der Bundesregierung. ${ }^{905}$ Der Bundeskanzler ist somit der vom Parlament gewählte Chef der Bundesregierung (vgl. Anhang: Übersicht 11). Der Bundeskanzler legt die Richtlinien der Politik fest (Richtlinienkompetenz), fixiert die Zahl und Aufgaben seiner Ministerien (Organisationsgewalt) und übernimmt schließlich die gesamte Verantwortung der Regierung. Trotz seiner Verantwortlichkeit gegenüber dem Parlament entscheidet er allein. Der Kanzler nimmt infolgedessen eine „Vorrangstellung“ im politischen System der Bundesrepublik ein, der den Begriff der Kanzlerdemokratie auf den Punkt bringt. ${ }^{906}$

Für die Politik des Bundeskanzlers Helmut Kohl (CDU) sind drei politische Leitlinien charakteristisch: Die Deutsche Einheit, die Friedenssicherung und die europäische Einigung. ${ }^{907}$ Nach der Wiedervereinigung konzentrierte sich Kohl auf die europäische Perspektive. So forcierte er ab 1990 die Verwirklichung der internen Grenzöffnung der EU und eine sich daran anschließende einheitliche europäische Währung. Bundeskanzler Kohl markierte allerdings einen tatsächlichen Meilenstein bezüglich der Migrationspolitik erst in dem „Vertrag von Amsterdam“ (1997/99), den man durchaus an dieser Stelle als treibende Kraft bezeichnen kann; er führte besonders eine gemeinsame Migrationspolitik mit Frankreich ein. Ebenso wie im Maastrichter Vertrag sind auch im Amsterdamer Vertrag vereinigte deutsch-französische Vorschläge wiederzufinden, wie etwa die „Flexibilitätsklausel oder die Übertragung der Asyl- und Visumspolitik in die erste Säule“908 der Europäischen Union. Dies besagt „eine wichtige Impulsfunktion für die europäische Integration" seitens der deutschfranzösischen Kooperation und „eine Fortführung der aktiven Europapolitik“, die unter Mitterand und Kohl betrieben wurde, und ebenso unter Chirac und Kohl festzustellen

905 Schmidt, Manfred G. 2007: Das politische System Deutschlands: Institutionen, Willensbildung und Politikfelder. München, S. 163.

${ }^{906}$ Niclauß, Karlheinz 2004: Kanzlerdemokratie. Regierungsführung von Konrad Adenauer bis Gerhard Schröder. Paderborn.

907 Baumann, Mechthild 2008: Der Einfluss des Bundesknazleramts und des Bundesministeriums des Innern auf die Entwicklung einer europäischen Grenzpolitik. In: Hunger, Uwe / Aybek, Can M. / Ette, Andreas / Michalowski, Ines (Hrsg.) 2008: a.a.O., S. 19.

908 Woyke, Wichard 2000: Deutsch-französische Beziehungen seit der Wiedervereinigung: Das Tandem faßt wieder Tritt. Opladen, S. 70. 
war. ${ }^{909}$ Auch die Grenzkontrollen wurden 1995 tatsächlich abgeschafft, wobei mit der Aufhebung das Bundeskanzleramt auch wirtschaftliche Interessen verfolgte. ${ }^{910} \mathrm{Im}$ Bereich der Grenzpolitik kam somit der Wille zur Europäisierung des Bundeskanzlers zum Tragen: „Unser Ziel ist das Europa ohne Grenzen. Wir treten für weitere Fortschritte bei der Abschaffung der Grenzkontrollen ein und werden hierfür auch unsere Präsidentschaft im Rahmen der Schengener Übereinkommen nutzen. [...]. Vordringlich sind insbesondere: eine gemeinsame europäische Asyl- und Einwanderungspolitik sowie eine europäische Zentrale - und zwar mit Kompetenzen zum Kampf gegen die Drogenmafia und gegen das organisierte internationale Verbrechen und den Terrorismus. Wir werden im Rahmen der Regierungskonferenz zur Politischen Union nachdrücklich - und, wie ich hoffe, erfolgreich - dafür eintreten, diese Kernbereiche in die Gemeinschaftsverträge mit einzubeziehen. [...]. Die Bundesrepublik Deutschland ist kein Einwanderungsland."911 Im Rahmen seiner Interessen traf Kohl „die Entscheidung zur Abschaffung der Grenzkontrollen allein. “912 Außerdem kündigte die Erklärung des Bundeskanzlers Kohl am 30.01.1991 eine grundlegende Neuregelung des Wahlrechts für EG-Bürger an: „Wir wollen kein zentralistisches Europa, sondern ein Europa der Vielfalt. [...]. Neues Element eines solchen Europas der Bürger könnte eine „Europa-Bürgerschaft“ sein, die auf der nationalen Staatsbürgerschaft aufbaut. Ich denke, in dieser Perspektive ist dann auch die Frage des Kommunalwahlrechts für EG-Bürger $\mathrm{zu}$ prüfen. [..].“ ${ }^{913}$ Der Referentenentwurf zu einem Kommunalwahlrechts für EG-Bürger hatte eine leitende Position Deutschlands innerhalb der EU zur Folge. Im Jahr 1994 wurde endgültig das kommunale Wahlrecht für Bürger der Europäischen Union eingeführt, was zu neuerlichen Diskussionen über die Gewährung dieses Rechts für alle Ausländer führte. Eine Veränderung der Rechtslage in Deutschland fand allerdings keineswegs statt. ${ }^{914}$

Auf dem Weg zur Europäisierung waren jedoch auch einige Hindernisse zu verzeichnen,

909 Woyke, Wichard 2000: Deutsch-französische Beziehungen seit der Wiedervereinigung: a.a.O., S. 70.

910 Baumann, Mechthild 2008: Der Einfluss des Bundesknazleramts und des Bundesministeriums des Innern auf die Entwicklung einer europäischen Grenzpolitik. a.a.O., S. 19.

911 Presse- und Informationsamt der Bundesregierung 1991: Deutschlands Einheit vollenden. Die Einheit Europas gestalten. Dem Frieden der Welt dienen: Regierungspolitik 1991-1994 (Regierungserklärung von Bundeskanzler Dr. Helmut Kohl vor dem Deutschen Bundestag am 30. Januar 1991). S. 80-83.

912 Baumann, Mechthild 2008: Der Einfluss des Bundesknazleramts und des Bundesministeriums des Innern auf die Entwicklung einer europäischen Grenzpolitik. a.a.O., S. 21.

913 Presse- und Informationsamt der Bundesregierung 1991: Deutschlands Einheit vollenden. Die Einheit Europas gestalten. Dem Frieden der Welt dienen: Regierungspolitik 1991-1994. a.a.O., S. 80-83.

914 Beauftragte der Bundesregierung für Ausländerfragen 2002: Bericht der Beauftragten der Bundesregierung für Ausländerfragen über die Lage der Ausländer in der Bundesrepublik Deutschland. Berlin und Bonn, S. 169. 
so z. B. das Scheitern der deutschen Anstrengungen um eine gleichmäßigere Lastenteilung (burden-sharing), ${ }^{915}$ die eines der Hauptziele deutscher Asylpolitik auf EU-Ebene während der 1990er Jahre bezeichnete. Hauptgrund der Lastenteilung war folgender: ${ }^{916}$ Angesichts des 1991 begonnenen kriegerischen Konflikts in Bosnien und Herzegowina hatten bis zu dessen Ende durch das Abkommen von Dayton (Dezember 1995) rund 345.000 bosnische Flüchtlinge aus humanitären Gründen vorübergehende Aufnahme in Deutschland gefunden, mehr als in den übrigen EU-Staaten zusammen. ${ }^{917}$ Dieses zeigte sich besonders deutlich in einem Zitat Helmut Kohls von 1997 im Rahmen der Regierungskonferenz von Amsterdam: „In den Bereichen Asyl- und Visapolitik, Einwanderung [...] hat die Konferenz von Amsterdam die Grundlagen für ein gemeinsames effektiveres Handeln gelegt. Dabei konnten und mussten wir zur Wahrung unserer Interessen sicherstellen, dass in Fragen der Einwanderung und des Asyls auch künftig das Prinzip der Einstimmingkeit gilt. [...] Es gibt in Brüssel Behauptungen, dass wir, die Deutschen eine Renationalisierung der EU-Politik betreiben würden. Davon kann überhaupt keine Rede sein. Ich will das Beispiel anführen, das ich auch in Amsterdam genannt habe. Wir hatten im Jahr 1996 in Deutschland 117000 Asylbewerber. Das waren 52 Prozent der Asylbewerber in der gesamten Europäischen Union. Das heißt, die Mehrheit der Asylbewerber, die nach Europa kommt, geht nach Deutschland. [...] Wir sind nicht europamüde, aber wir haben hier wohlverstandene eigene Interessen zu vertreten. “918 Welch wichtige Rolle dem nationalen Interesse im Migrationsbereich zukommt, wird indes dann offensichtlich, wenn selbst Kohl in Anbetracht der spezifischen „migrationspolitischen Betroffenheit Deutschlands die Notwendigkeit der Vetomöglichkeit“ 919 unterstreicht. Kohl verweigerte somit den Übergang vom Konsensprinzip zu Mehrheitsabstimmungen in der Justiz- und Innenpolitik der EU (vgl. hierzu Kapitel III.2.5 und Anhang: Übersicht 12). ${ }^{920}$ Denn im Falle von Einstimmigkeit ist selbstverständlich nach wie vor ein Staat

915 Marshall, Barbara 2000: Closer Integration or Re-Nationalization? Recent Trends in EU Migration and Asylum Policies: The Case of Germany. In: European Integration 22 (2000), 4. S. 425.

916 Bundesministerium des Innern 2008: Migration und Integration: Aufenthaltsrecht, Migrations- und Integrationspolitik in Deutschland. Berlin, S. 17.

917 So kamen im Jahr 1993 mit 322.600 Anträgen weit mehr als die Hälfte der Asylbewerber, die in der EU Schutz suchten, nach Deutschland. Insbesondere suchte auch ein Großteil der Bürgerkriegsflüchtlinge aus Ex-Jugoslawien in Deutschland Zuflucht. In: Bundesamt für die Anerkennung ausländischer Flüchtlinge (BAFI) 2003: Migration und Asyl in Zahlen. Nürnberg, S. 38.

918 Erklärung der deutschen Bundesregierung zum Europäischen Rat in Amsterdam, abgegeben von Bundeskanzler Helmut Kohl am 27. Juni 1997 in Bonn, gekürzt abgedruckt In: Internationale Politik Jg. 52 (1997), Heft 11, S. 81-85, hier S. 83.; vgl. auch Tomei, Verònica 2001: Europäisierung nationaler Migrationspolitik: a.a.O., S. 75-76.

919 Tomei, Verònica 2001: Europäisierung nationaler Migrationspolitik: Eine Studie zur Veränderung von Regieren in Europa (Diss., Bonn). Stuttgart, S. 75.

920 Paulsen, Thomas 1999: Die deutsche Rolle in Europa. In: Weidenfeld, Werner (Hrsg.) 1999: Europa- 
dem anderen an Machtbefugnissen gleichgestellt und als Folge dieser Einstimmigkeit hat jeder Mitgliedstaat ein Veto. ${ }^{921}$ Damit können künftige Entwicklungen im Bereich einer europäischen Migrationspolitik von einem einzigen Mitgliedsland überdies bedeutend gebremst werden. So blockierten beispielsweise vor allem Großbritannien und Dänemark mithilfe des Einstimmigkeitsprinzips jegliche Versuche einer Europäisierung. ${ }^{922}$ Auf das Betreiben Deutschlands hin galt auch im Amsterdamer Vertrag (1999) in der Asylpolitik weiterhin das Einstimmigkeitsprinzip, mit dem Reformforderungen des Europäischen Parlaments abgeblockt werden konnten. ${ }^{923}$ Auch im Amsterdamer Vertrag wurde ebenso bezüglich der Arbeitsmigration die Einstimmigkeitsregelung beschlossen. ${ }^{924}$ Außerdem nahm Bundeskanzler Kohl aufgrund der innenpolitischen Schwächungen im Juni 1997 von seiner grundsätzlich eher supranationalen Einstellung Abstand, indem er anlässlich „,der Vergemeinschaftung der Asyl-, Visums- und Immigrationspolitik für eine Übergangszeit von fünf Jahren nach Inkrafttreten des Amsterdamer Vertrags auf dem Einstimmigkeitsprinzip im Rat" ${ }^{925}$ bestand. Die Führungsrolle Deutschlands in der EU unter der Regierung von Bundeskanzler Kohl zeigt demzufolge, „dass Deutschland trotz der selbstauferlegten Zurückhaltung seine internationale Handlungsfähigkeit ausgebaut hat und auch bereit ist, in Fragen von großem nationalem Interesse die eigene Position gegen den Widerstand anderer Staaten durchzusetzen. ${ }^{\text {“926 }}$

Handbuch. Gütersloh, S. 539-551 hier S. 543.

921 Bei den Abstimmungsregeln der EU zeigten sich im Wesentlichen zwei Veränderungen: Der Übergang von der Einstimmigkeit zur qualifizierten Mehrheit der Stimmen im Ministerrat und der Übergang zur doppelten Mehrheit. Als besonders wichtig geltende Bereiche werden durch das Einstimmigkeitserfordernis geregelt. Bestimmte Entscheidungen von konstitutioneller Bedeutung $-\mathrm{z}$. B. Vertragsänderungen, Beitrittsabkommen und Eigeneinnahmen - erfordern außer der einstimmigen Beschlussfassung im Rat auch eine Ratifizierung durch die Mitgliedstaaten gemäß den jeweiligen verfassungsrechtlichen Vorschriften. Bezüglich der Abstimmungen mit qualifizierter Mehrheit werden die Stimmen der Mitgliedstaaten gewichtet (Art. 205 Abs. 2EGV-A / 148 EGV-M), wobei eine qualifizierte Mehrheit dann erreicht ist, wenn zumindest 62 der insgesamt 87 Stimmen, also etwa 71 Prozent, zugestimmt haben. Folglich ist der Konsensbedarf dadurch auch bei einer solchen Mehrheitsabstimmung wesentlich. Vgl. Wessels, Wolfgang 1999: Das politische System der EU. In: Weidenfeld, Werner (Hrsg.) 1999: Europa-Handbuch. Gütersloh, S. 344.; Holzinger, Katharina 2005: Institutionen und Entscheidungsprozesse der EU. In: Lauth, Hans-Joachim / Zimmerling, Ruth (Hrsg.) 2005: Die Europäische Union: Theorien und Analysekonzepte. Paderborn, S. 107-108, 117.; Wessels, Wolfgang 2008: Das politische System der Europäischen Union. Wiesbaden, S. 201-202. u. S. 441.

922 Geddes, Andrew 2000: Immigration and European Integration. Towards Fortress Europe? Mancester/New York:Manchester University Press. S. 95.

${ }^{923}$ Nuscheler, Franz 2004: Internationale Migration: Flucht und Asyl. Wiesbaden, S. 180.; vgl. auch Glaab, Manuela / Gros, Jürgen / Korte, Karl-Rudolf / Wagner, Peter M. 1998: Wertgrundlagen und Belastungsgrenzen deutscher Europaplitik. In: Weidenfeld, Werner (Hrsg.) 1998: Deutsche Europapolitik: Optionen wirksamer Interessenvertretung. Bonn, S. 174.

924 Angenendt, Steffen 2008: Die Steuerung der Arbeitsmigration in Deutschland: a.a.O., S. 56.

925 Woyke, Wichard 2000: Deutsch-französische Beziehungen seit der Wiedervereinigung: a.a.O., S. 71.

${ }^{26}$ Paulsen, Thomas 1999: Die deutsche Rolle in Europa. In: Weidenfeld, Werner (Hrsg.): a.a.O., 543. 
Die Macht und Verfügungsgewalt des deutschen Bundeskanzlers kann durch die Entfaltung der „Parteimacht innerhalb der Bundesorganisation, auf Landesebene oder auch durch verbessertes Zusammenspiel mit der Bundestagsfraktion“"927 erreicht werden. Gerhard Schröder (SPD) hatte sowohl bei seinem ersten Amtsantritt 1998 als auch seinem zweiten Regierungsabschnitt 2002 optimale Startbedingungen im Bereich der Migrationspolitik: „Mut zum Frieden und Mut zur Veränderung. “928 Mit diesem Leitsatz hat der Medienkanzler Schröder, zusammen mit seiner rot-grünen Bundesregierung viele Reformprojekte durchgeführt, darunter insbesondere die Staatsbürgerschaftsreform, d. h. die „Modernisierung“ des deutschen Staatsangehörigkeitsrechts. ${ }^{929}$ Dies war der erste Schritt im Hinblick auf das Kernstückes seines Reformprojekts: „Unser Nationalbewusstsein basiert eben nicht auf den Traditionen eines wilhelminischen, Abstammungsrechts, sondern auf der Selbstgewissheit unserer Demokratie. [...].“930 Ziel konnte seiner Meinung nach aber nicht die Mehrstaatlichkeit sein: „Ich will keine doppelte Staatsbürgerschaften. Das ist nicht das Ziel des Gesetzes. Aber ich will sie hinnehmen, um das Integrationsziel zu erreichen. ${ }^{\text {(9931 }}$

Weitere Neuerungen der Migrationspolitik unter Bundeskanzler Schröder waren das Zuwanderungsgesetz (ZuWG) von 2005 und die sogenannte Green-Card-Regelung. Insbesondere die Green-Card-Regelung ermöglichte eine Erteilung von (befristeten) Aufenthaltserlaubnissen an IT-Spezialisten in Deutschland. Die Green-Card-Regelung galt hierbei einerseits als ein wichtiger Impuls und als eine wirtschaftliche Notwendigkeit einer Einwanderung qualifizierter Arbeitskräfte. Anderseits zählte sie als ein neues Steuerungsinstrument gegen weitere Zuwanderung. ${ }^{932}$ Das Engagement einiger Politiker lässt jedoch im Hinblick darauf vielmehr genau diese Tendenz erkennen: Angefangen bei Otto Schilys Anstößen nach der Devise „Das Boot ist

${ }^{927}$ Korte, Karl-Rudolf 2007: Der Pragmatiker des Augenblicks: Das Politikmanagement von Bundeskanzler Gerhard Schröder 2002-2005. In: Egle, Christoph / Zohlnhöfer, Reimut (Hrsg.) 2007: Ende des rot-grünen Projektes: Eine Bilanz der Regierung Schröder 2002-2005. Wiesbaden, S. 173.

${ }_{928}$ Presse- und Informationsamt der Bundesregierung 2005: Bundeskanzler Gerhard Schröder: Reden Januar 2003-Dezember 2004. Paderborn, S. 22.

929 Davy, Ulrike / Cinar, Dilek 2001: Deutschland. In: Davy, Ulrike (Hrsg.) 2001: Die Integration von Einwanderern: Rechtliche Regelungen im europäischen Vergleich. Wien, S. 277-423, hier S. 351.

930 Presse- und Informationsamt der Bundesregierung 1998: Die Regierungserklärung von Bundeskanzler Gerhard Schröder. Bonn, S. 34.

931 Bundeskanzler Schröder am 14. Januar 1999 vor der Presse in Berlin. In: Presse- und Informationsamt der Bundesregierung 1999: Vor wichtigen Aufgaben: Das Arbeitsprogramm 1999 der Bundesregierung. Bonn, S. 16.

932 Weizsäcker, Esther 2005: Vom „Inlandslegitimierungszwang“ zum „Zuwanderungsgesetz“: Zur rechtlichen Regulierung der Arbeitsmigration in Deutschland. In: Geisen, Thomas (Hrsg.) 2005: Arbeitsmigration: WanderarbeiterInnen auf dem Weltmarkt für Arbeitskraft. S. 189 f. 
voll“" über die Unterschriftenkampagne Roland Kochs gegen die doppelte Staatsbürgerschaft oder den fatalen Wahlkampfslogan der CDU in Nordrhein-Westfalen „Kinder statt Inder“ bis hin zu den ausdrücklichen Unterscheidungen des bayrischen Innenministers Günther Beckstein zwischen „nützlichen“ und ,ausnutzenden“ Zuwanderern. ${ }^{933}$ Es gab auch Probleme bzw. Fragen bezüglich dieser Instrumente der Green-Card-Initiative: „Wer wird die „sozialen Kosten“ des Umzugs für sich und seine Familie in Kauf nehmen, wenn er/sie keine langfristige und damit unbefristete Perspektive erhält? Wie sollen sprachliche, kulturelle und sonstige Barrieren überwunden werden, wenn die Green Card-Initiativen nach der Philosophie des früheren „Gastarbeitermodells“ - zeitlich eng begrenzter Aufenthalt, Zwang zur Rückkehr, möglichst ohne Familienbegleitung etc. - gestaltet ist?“934 Mit diesem Green-Card-Projekt besetzte Schröder allerdings das Thema Migrationspolitik auf geschickte Weise. ${ }^{935}$ Außerdem erwirkte Schröder kaum eine Verbesserung der politischen Partizipation für Einwanderer, obgleich er weltweite verstärkte Konkurrenz um knappe Fachkräfte („brain drain“ bzw. „Humankapital“) und eine derartige Entwicklung beschleunigen und befördern wollte: Obwohl man in den Koalitionsvereinbarungen zwischen SPD und dem Bündnis 90/Die Grünen die „Förderung der Integration auch der hier lebenden Ausländerinnen und Ausländer, die nicht die Staatsangehörigkeit eines Mitgliedstaates der Europäischen Union besitzen“ anstrebte und deren „Wahlrecht in Kreisen und Gemeinden erhalten“ wollte, bleibt festzuhalten, dass die Einführung des kommunalen Wahlrechts weder in der ersten noch in der zweiten Wahlperiode der rot-grünen Koalition umgesetzt wurde. ${ }^{936}$

Mit dem Ziel einer Verstärkung und Ausweitung der EU unterstützte Schröder in den ersten Jahren des 21. Jahrhunderts auch die Gestaltung des EU-Systems. Nach Beendigung der Amtszeit von Bundeskanzler Helmut Kohl wurde von „Präsident Jacques Chirac und Kanzler Gerhard Schröder ein weiteres französisch-deutsches Duo“6937 dargestellt, das allerdings nur begrenzt Führungskraft entfalten konnte: „Mit der in Nizza beschlossenen Grundrechte-Charta liegt bereits ein wichtiges Element für eine künftige europäische Verfassung vor. [...]. Wir werden daran mitwirken, einen

\footnotetext{
933 Welsch, Johann 2000: Green Cards für die New Economy. Eine erste Bilanz. In: Blätter für deutsche und internationale Politik. Jahrgang 45/2000, Heft 12. Bonn, S. 1473-1482 hier, S. 1480.

934 Welsch, Johann 2000: Green Cards für die New Economy. Eine erste Bilanz. In: a.a.O., S. 1480, 1482.

935 Niclauß, Karlheinz 2004: Kanzlerdemokratie: Regierungsführung von Konrad Adenauer bis Gerhard Schröder. Paderborn, S. 337.

${ }^{936}$ Hanschmann, Felix 2009: Die Ewigkeit dauert lange, besonders gegen Ende“ - eine rechtliche (Neu-) Bewertung des kommunalen Wahlrechts für Drittstaatsangehörige. In: Zeitschrift für Parlamentsfragen (ZParl) 40. Jahrgang, Heft 1/2009. Baden-Baden, S. 74-85, hier S. 75.

937 Wessels, Wolfgang 2008: Das politische System der Europäischen Union. Wiesbaden, S. 97.
} 
umfassenden Verfassungsentwurf $\mathrm{zu}$ präsentieren. Er muss beinhalten: - eine eindeutigere Abgrenzung der Kompetenzen zwischen den Mitgliedstaaten und der Europäischen Union, [...], - Die Reform des Rates, der grundsätzlich mit qualifizierter Mehrheit entscheiden soll, und eine verbesserte Zusammenarbeit der Gemeinschaft in Fragen der inneren und äußeren Sicherheit. Die bevorstehenden historischen Weichenstellungen wie auch die Arbeiten an der europäischen Verfassung werden wir in enger Abstimmung mit Frankreich betreiben. Denn ohne ein gemeinsames deutschfranzösisches Vorgehen werden wir ein Europa der Bürger, dessen Nutzen aus der Vertiefung und Erweiterung allen Europäern zugute kommt, nicht erreichen können. “`938

Im Kontext des Vertrags von Nizza wurde mit seiner neuen Stimmengewichtung die Stellung der europäischen Hauptmächte weiter gestärkt, die Balance zwischen Frankreich und Deutschland zunehmend zementiert und das integrative Gleichgewicht neu festgelegt. Die Tatsache, dass die Mehrheitsentscheidungen nicht auf alle Gebiete Ausdehnung fanden, steht durchaus im Einklang mit den deutschen Interessen. ${ }^{939}$ Mit dem Inkrafttreten des Vertrags von Nizza im Februar 2003 wurde auch das Entscheidungsverfahren in der Asyl- und Flüchtlingspolitik geändert: Es gilt weitgehend das Mehrheitsprinzip im Rat und das Mitentscheidungsverfahren des Europäischen Parlaments (EP). Auf dem Politikfeld der legalen Migration besitzt dagegen weiterhin das Einstimmigkeitsprinzip Gültigkeit. ${ }^{940}$ Die Europäische Währungsunion aus dem Jahr 1999, von der man behaupten kann, dass sie überwiegend nach deutschen Vorstellungen geschaffen wurde, ${ }^{941}$ kann man als Beispiel für eine intergouvernementale „verstärkte Zusammenarbeit“" verstehen, als eine integrative Balance der europäischen Macht gegenüber der amerikanischen „Übermacht““.942 In erster Linie verfolgte Deutschland dabei eine Europäisierung im Hinblick auf die reale ökonomische und währungspolitische Machtverteilung. ${ }^{943}$ Diesbezüglich hatte Bundeskanzler Schröder zudem die EU als „die Antwort der Völker Europas auf Krieg

\footnotetext{
938 Presse- und Informationsamt der Bundesregierung 2002: Gerechtigkeit im Zeitalter der Globalisierung: Regierungserklärung von Bundeskanzler Gerhard Schröder vor dem Deutschen Bundestag. Berlin, S. 21.

939 Link, Werner 2002: Deutschland als europäische Macht. In: Weidenfeld, Werner (Hrsg.) 2002: Europa-Handbuch. Gütersloh, S. 611.

940 Bundesministerium des Innern 2008: Migration und Integration: Aufenthaltsrecht, Migrations- und Integrationspolitik in Deutschland. Berlin, S. 49.

941 Durch die Vergemeinschaftung entfällt zwar die hegemoniale Position der Deutschen Bundesbank bzw. der D-Mark, jedoch folgt diese Vergemeinschaftung in Struktur und Inhalt dem deutschen Modell einer unabhängigen Zentralbank und einer strikten Stabilitätspolitik. In: Link, Werner 2002: Deutschland als europäische Macht. In: Weidenfeld, Werner (Hrsg.) 2002: a.a.O., S. 612.

942 Link, Werner 2002: Deutschland als europäische Macht. In: Weidenfeld, Werner (Hrsg.) a.a.O., S. 611.

943 Link, Werner 2002: Deutschland als europäische Macht. In: Weidenfeld, Werner (Hrsg.) a.a.O., S. 612.
} 
und Zerstörung“ sowie als „Antwort auf die Globalisierung und auf die Herausforderung durch Instabilität und Terrorismus“944 gesehen. Des Weiteren setzte sich Schröder konsequent für eine Politik der Abrüstung, einer internationalen Kontrolle unterliegend, und für eine Politik des Friedens, der Sicherheit und der Menschenrechte ein. Diese theoretische Einstellung bekräftige Schröder im Rahmen seiner Irak-Politik: „An einem etwaigen Militärschlag gegen den Irak werden wir uns nicht beteiligen. “" Schröder wurde damit zum „Friedenskanzler“ der Medien. In seiner Koorperation zu den USA und den europäischen Nachbarn proklamierte er gezielt einen „deutschen Weg““ ${ }^{946}$ Auf diese Weise entsteht zwar kein deutsches Europa, aber doch ein Europa in Deutschland.

Die nachfolgende Bundeskanzlerin Angela Merkel (CDU) schlug in ihrer Regierungserklärung vom 30.11.2005 einen Weg ein, der insbesondere die nationalen Interessen Deutschlands betonte und sie auf europäische Ebene übertrug, wie auch unter Führung Kohl und Schröders geschehen. Merkel setzte die Politik Schröders fort, allerdings erweitert: „Wir können wieder ein starker Partner in Europa und in der Welt werden. Deutsche Außen- und Europapolitik gründet sich auf Werte und sie ist Interessenpolitik. Eine Politik in deutschem Interesse setzt auf Bündnisse und Kooperationen mit unseren Partnern. [...]. Europa hat sich mit den LissabonVerabredungen weit reichende Ziele gesetzt. Wir brauchen einen Erfolg und wir brauchen diesen Erfolg, indem wir Reformen durchführen. Hier bündeln sich im Übrigen unsere innenpolitischen Anstrengungen mit dem, was in Europa stattfindet. “947 Am 13. Dezember 2007 handelten daraus Merkel und die Staats- und Regierungschefs der EU in Lissabon einen neuen Vertrag, d. h. den „Vertrag von Lissabon“ aus (vgl. Kapitel III.2.9). ${ }^{948}$ Dieses war der fünfte Vertrag zur Reform der Verträge zur

${ }^{944}$ Presse- und Informationsamt der Bundesregierung 2002: Gerechtigkeit im Zeitalter der Globalisierung: Regierungserklärung von Bundeskanzler Gerhard Schröder vor dem Deutschen Bundestag. Berlin, S. 20.

945 Presse- und Informationsamt der Bundesregierung 2002: Gerechtigkeit im Zeitalter der Globalisierung: a.a.O., S. 19.; vgl. Niclauß, Karlheinz 2004: Kanzlerdemokratie: a.a.O., S. 339.

${ }^{946}$ Korte, Karl-Rudolf 2007: Der Pragmatiker des Augenblicks: Das Politikmanagement von Bundeskanzler Gerhard Schröder 2002-2005. In: Egle, Christoph / Zohlnhöfer, Reimut (Hrsg.) 2007: Ende des rot-grünen Projektes: Eine Bilanz der Regierung Schröder 2002-2005. Wiesbaden, S. 189.

947 Presse- und Informationsamt der Bundesregierung 2005: Regierungserklärung von Bundeskanzlerin Angela Merkel vor dem Deutschen Bundestag. Berlin, S. 41-42.

948 Durch die Protokolle Nr. 21 und 22 bleiben Großbritannien, Irland und Dänemark auch weiterhin von der Geltung der Regeln über den „Raum der Freiheit, der Sicherheit und des Rechts“ ausgeschlossen, dennoch bleibt für diese Staaten die Möglichkeit bestehen, sich zukünftig hieran zu beteiligen. Die Bundesrepublik ratifizierte den Vertrag von Lissabon am 23.5.2008. In: Leiße, Olaf (Hrsg.) 2010: Die Europäische Union nach dem Vertrag von Lissabon. Wiesbaden, S. 232.; Weidenfeld, Werner (Hrsg.) 2008: Die Europäische Union: Politisches System und Politikbereiche. Bonn, S. 825 (Anhang). 
Europäischen Union. ${ }^{949}$ Merkel (CDU) hatte hier eine gemeinsame Einwanderungsund Asylpolitik zum Ziel, wobei wichtig für Deutschland sei, „dass die Zuwanderung aus Nicht-EU-Staaten auf den Arbeitsmarkt in nationaler Zuständigkeit bleibt. “950 In der Frage nach einer Ausweitung des kommunalen Wahlrechts auf Drittstaatsangehörige gibt es lediglich einen Prüfungsauftrag. Bis heute hat der „Prüfauftrag“ bezüglich der „Frage des kommunalen Wahlrechts für Ausländer, die keine EU-Bürger sind“, noch zu keinen konkreten Gesetzesinitiativen geführt. ${ }^{951}$ Darüber hinaus werden mit dem Beschluss des Bundestages zum Aufenthalts- und Asylrecht insgesamt elf EURichtlinien $^{952}$ (siehe Anhang: Übersicht 4) in deutsches Recht umgesetzt. Das am 28. August 2007 in Kraft getretene Richtlinienumsetzungsgesetz setzte zum Beispiel die Familiennachzugsrichtlinie (RL 2003/86/EG, vgl. Kapitel III.3.2.2.) der Europäischen Union vollständig um. ${ }^{953}$ Ferner stieß der Inhalt des Gesetzespaketes auf Kritik bezüglich der eher integrationsfeindlichen Einstellung, die sich in erster Linie auf die Erhöhung der Altersgrenze bezog. Zeitgleich waren verschiedene Ereignisse in den Mitgliedsländern, bei denen der Familiennachzug im Zentrum der politischen Diskussion stand, von Bedeutung: Eine Erhöhung der Altersgrenze beim Ehegattennachzug wurde in Dänemark bereits beschlossen. In den Niederlanden war ein Vorstoß, den Nachzug an den Nachweis von Sprachkenntnissen zu binden, noch im Gesetzgebungsverfahren. Auf Kritik stieß auch Deutschland. Geplant war dort nämlich, dass der aus einem Nicht-EU-Staat stammende Ehepartner erst zu einem Zeitpunkt nachziehen dürfe, wenn er sich ,zumindest auf einfache Art in deutscher Sprache verständigen kann. “954

Des Weiteren handelte es sich bei diesem EU-Richtlinienumsetzungsgesetz um die sogenannte Asyl-Qualfikationsrichtlinie (RL 2004/83/EG) zur einheitlichen Regelung

949 Presse- und Informationsamt der Bundesregierung 2007: Eine neue Grundlage für Europa: Der Vertrag von Lissabon. Berlin, S. 3.

950 Presse- und Informationsamt der Bundesregierung 2007: Eine neue Grundlage für Europa:a.a.O., S.13.

${ }^{951}$ Hanschmann, Felix 2009: Die Ewigkeit dauert lange, besonders gegen Ende“ - a.a.O., S. 75.; vgl. Bommes, Michael / Krüger-Potratz, Marianne (Hrsg.) 2008: Migrationsreport 2008: a.a.O., S. 262 u. 290.; vgl. Newsletter ,Migration und Bevölkerung' 2012: Deutschland: Integrationspolitik soll verbindlicher werden. http://www.migration-info.de/mub_artikel.php?Id=120201 (Ausgabe 02/12).

952 Die große Zahl einzelner Richtlinien ist Ausdruck eines inkonsistenten ausländerrechtlichen Konzeptes auf Ebene der EU, das zwangsläufig „Umsetzungs- und Anwendungsprobleme“ mit sich bringt. Vgl. Maaßen, Hans-Georg 2006: Zum Stand der Umsetzung von elf aufenthalts- und asylrechtlichen Richtlinien der Europäischen Union. In: Zeitschrift für Ausländerrecht und Ausländerpolitik (ZAR) 5-6/2006, 26. Jahrgang. S. 161-167 hier, S. 162.; vgl. auch im Internet: http://www.abgeordnetenwatch.de/aufenthalts_und_asylrecht-636-120.html (Stand: 14.06.2007).

953 Vgl. Bundesministerium des Innern 2008: Migration und Integration: a.a.O., S. 82.

${ }^{954}$ Newsletter ,Migration und Bevölkerung' 2007: Deutschland: Debatte um Zuwanderungsgesetz im Bundestag. Im Internet: http://www.migration-info.de/mub_artikel.php?Id=070408 (Ausgabe 04/07). 
der Anerkennung von Flüchtlingen, die EU-Asylverfahrensrichtlinie (RL 2005/85/EG), ${ }^{955}$ mit der auch das umstrittene Konzept der sicheren Drittstaaten (Art. 36 $\mathrm{RL}$,super safe third countries“) EU-weit eingeführt wird, sowie um eine Richtlinie zur Festlegung von Mindestnormen bei der Aufnahme von Asylbewerbern (RL 2003/9/EG „Richtlinie Aufnahmebedingungen“). 956 Bezüglich des EURichtlinienumsetzungsgesetzes im Bereich Asyl und Flüchtlinge gab es insbesondere in der Rückkehr- und Abschiebungspolitik bereits eine Übereinstimmung zwischen den Zielen der europäischen Maßnahmen und den Präferenzen der deutschen Regierung. ${ }^{957}$ Deutschland schrieb seiner Rückkehrpolitik traditionell große Bedeutung zu und war vor allem in den 1990er Jahren darauf konzentriert, den eigenen nationalen politischen Ansatz auf EU-Ebene zu übertragen. ${ }^{958}$ Überdies konnte Deutschland die europäischen Maßnahmen als Instrumentarium nutzen, um im Rahmen der Richtlinienumsetzung zusätzliche restriktive Maßnahmen der Migrationskontrolle in deutsches Recht einzuführen. Damit beabsichtigte Bundeskanzlerin Merkel auch eine Verschärfung des Ausländerrechts vor dem Hintergrund der Umsetzung von elf EU-Richtlnien in nationales Recht. ${ }^{959}$ Darüber hinaus war in Deutschland weitgehend eine restriktive Migrationskontrolle vorzufinden, wobei sich diese auch für viele andere Mitgliedsstaaten zeigte, wie z. B. insbesondere für Großbritannien: ${ }^{960}$ In dem Ausdruck

955 Vgl. Hofmann, Rainer / Donath, Philipp B. 2008: Die Asylverfahrensrichtlinie unter besonderer Berücksichtigung völkerrechtlicher Standards. In: Hofmann, Rainer / Löhr, Tillmann (Hrsg.) 2008: Europäisches Flüchtlings- und Einwanderungsrecht: Eine kritische Zwischenbilanz. Baden-Baden, S. $19-45$.

956 Vgl. Newsletter ,Migration und Bevölkerung' 2006: Deutschland: Verschärfung des Ausländerrechts durch Umsetzung von EU-Richtlinien, http://www.migration-info.de/mub_artikel.php?Id=060105 (Ausgabe 01/06).

957 Vgl. Ette, Andreas / Kreienbrink, Axel 2008: Kooperation statt Harmonisierung: Konsequenzen europäischer Governance für die Europäisierung der deutschen Rückkehr- und Abschiebungspolitik. In: Hunger, Uwe / Aybek, Can M. / Ette, Andreas / Michalowski, Ines (Hrsg.) 2008: a.a.O., S. 51-74.

958 Ette, Andreas / Kreienbrink, Axel 2008: Kooperation statt Harmonisierung: a.a.O., S. 59.

959 Newsletter ,Migration und Bevölkerung' 2006: Deutschland: Verschärfung des Ausländerrechts durch Umsetzung von EU-Richtlinien, http://www.migration-info.de/mub_artikel.php?Id=060105 (Ausgabe 01/06).; vgl. Newsletter ,Migration und Bevölkerung' 2006: Deutschland: Verschärfung des Ausländerrechts geplant. Im Internet: http://www.migration-info.de/mub_artikel.php?Id=060901 (Ausgabe 09/06).

960 Um sich eine Handlungsautonomie und nationale Souveränität in Einwanderungsfragen zu bewahren, hat Großbritannien bislang nicht dem Schengener Abkommen und dem damit verbundenen Abbau von Grenzkontrollen für EU-BürgerInnen zugestimmt. Großbritannien beteiligt sich ebenso wie Irland grundsätzlich nicht an der gemeinsame Migrationspolitik. Bereits mit dem Protokoll über die Anwendung bestimmter Aspekte des Artikels 14 des Vertrages zur Gründung der EG waren die beiden Länder trotz der Binnenmarktbestimmungen weiterhin entschlossen, das Recht zu Personenkontrollen an den Grenzen beizubehalten. Dies gilt bis zum heutigen Tag. Vergleichbar mit dem britischen Interesse an der Beibehaltung der Grenzkontrollen ist auch das deutsche Interesse, das eine der Konstanten der politischen Interessenstruktur der 1990er Jahre bezeichnete. Hinsichtlich des deutschen Interesses lag der Schwerpunkt auf einer Aufteilung der im europäischen Vergleich überdurchschnittlichen Belastungen. Deshalb sprach sich die Bundesregierung Anfang der 1990er 
„No integration without immigration control, no immigration control without integration“ ist eine bis heute greifende „Janusköpfigkeit“ 961 der britischen Integrationspolitik zu erkennen.

Alles in allem kann die Umsetzung der elf EU-Richtlinien als wichtiges Vorgehen Angela Merkels, aber nicht als die große neue Tragkraft in der Migrationspolitik Deutschlands gewertet werden. Die folgende Regierungserklärung der Bundeskanzlerin vor dem Deutschen Bundestag im Jahr 2005 zeigt zudem viel Mut zur Veränderung im Bereich der Migrationspolitik: „Wir haben uns vorgenommen, die EU-Richtlinien im Grundsatz nur noch eins zu eins umzusetzen. Ich halte das für ausgesprochen wichtig. Ich weiss, dass das Gegenstand vieler politischer Debatten und Entscheidungen war. [...]. Meine Regierung ist Anwalt aller Deutschen wie aller in Deutschland lebenden MitbürgerInnen. Wir werden deswegen mit allem Nachdruck, wo immer es erforderlich ist, gegen jede Form von Extremismus, Rassismus und Antisemitismus kämpfen. [...]. Wir sind ein tolerantes, wir sind ein weltoffenes Land. [...]. Parallelgesellschaften, in denen die grundlegenden Werte des Zusammenlebens in unserem Land nicht geachtet werden, passen nicht in dieses Denken. Deshalb ist Integration eine Schlüsselaufgabe unserer Zeit. Mit der Ansiedelung der Beauftragten für Migration, Flüchtlinge und Integration im Kanzleramt habe ich sehr bewusst ein Signal gesetzt, dass dies eine gesamtpolitische Aufgabe ist, der wir große Beachtung schenken wollen. [...]. Wir werden deshalb gerade in den Schulen das Erlernen der deutschen Sprache fördern. “962

Vor diesem Hintergrund initiierte die Bundeskanzlerin Merkel als ersten Schwerpunkt unter der Leitung des Kanzleramtes am 14. Juli 2006 einen „Integrationsgipfel“, um den Dialog mit MigrantInnen und Migrantenverbänden zu Integrationsfragen zu suchen (vgl. Kapitel II.3.7). Folglich wurde gemeinsam mit gesellschaftlichen Akteuren und Migrantenorganisationen ein „Nationaler Integrationsplan“ entwickelt, der auf dem zweiten Integrationsgipfel am 12. Juli 2007 präsentiert wurde ${ }^{963}$ und dessen Priorität folgende Themen bildeten: Integrationskurse verbessern; frühkindliche

Jahre für eine Gemeinschaftszuständigkeit in der Asylpolitik aus. Vgl. Tomei, Verònica 2001: Europäisierung nationaler Migrationspolitik: a.a.O., S. 45-46 und S. 61.; vgl. Baringhorst, Sigrid 2009: Nationaler Zusammenhalt versus kulturelle Vielfalt: Die britische Einwanderungs- und Integrationspolitik zwischen globalem Wettbewerb und nationaler Identität. In: Butterwegge, Christoph / Hentges, Gudrun (Hrsg.) 2009: a.a.O., S. 177.

961 Baringhorst, Sigrid 2009: Nationaler Zusammenhalt versus kulturelle Vielfalt: a.a.O., S. 179.

962 Presse- und Informationsamt der Bundesregierung 2005: Regierungserklärung von Bundeskanzlerin Angela Merkel vor dem Deutschen Bundestag. Berlin, S. 23-26.

963 Newsletter ,Migration und Bevölkerung’ 2007: Deutschland: Nationaler Integrationsplan Verabschiedet, http://www.migration-info.de/mub_artikel.php?Id=070602(Ausgabe 06/07). 
Sprachförderung; gute Bildung, Ausbildung sichern, Arbeitsmarktchancen erhöhen; Lebenssituation von Frauen und Mädchen verbessern, Gleichberechtigung verwirklichen; Integration vor Ort unterstützen; Integration durch bürgerschaftliches Engagement und gleichberechtigte Teilhabe stärken. ${ }^{964}$ Im Großen und Ganzen enthält der Nationale Integrationsplan über 400 Maßnahmen und Selbstverpflichtungen aller staatlichen und nichtstaatlichen Akteure zur Integration. Die Bundeskanzlerin legte die Richtlinienkompetenz fest und betitelte den Integrationsplan selbst als Meilenstein und zum ersten Mal tragfähiges Fundament der deutschen Integrationspolitik. ${ }^{965}$ Allerdings wurde im Vorfeld des dritten Gipfeltreffens am 6. November 2008 seitens mehrerer Migrantenverbänden eine Erklärung abgegeben, in der sie einem Nationalen Integrationsplan als solchem zwar positiv gegenüber standen, allerdings übten sie auch scharfe Kritik bezüglich konkreter Rückschritte - beispielsweise „bei der Bildungschancengleichheit von Migrantenkindern oder der restriktiven Migrationsgesetzgebung der Bundesregierung“, etwa im Rahmen der „Einbürgerung und des Ehegattennachzugs“ - und bezeichneten diese Faktoren sowie Maßnahmen als integrationsfeindlich. ${ }^{966}$ Auch auf dem von Angela Merkel einberufenen Bildungsgipfel am 22. Oktober 2008 stand zwar eine Deprivation der Kinder und Jugendlichen mit Migrationshintergrund in Berufsausbildung und Schule bei der Diskussion im Vordergrund, jedoch wurden Strukturreformen so gut wie gar nicht thematisiert, die unerlässlich wären, um die ,institutionelle Diskriminierung““967 in diesem Bereich abzuschaffen oder zumindest einen Wandel zu bewirken. ${ }^{968}$ Dennoch richtete die Ratpräsidentschaft unter der Führung Merkels im ersten Halbjahr 2007 auf deutsche Initiative hin erstmals ein Erfahrungs- und Informationsaustausch auf EU-Ebene im Bereich des interkulturellen Dialogs ein. ${ }^{969}$ So konzentrierte sich Bundeskanzlerin Merkel zunächst vermehrt auf die Integrationspolitik auf nationaler- und europäischer

964 Presse- und Informationsamt der Bundesregierung 2007: Der Nationale Integraionsplan: Neue WegeNeue Chancen. Berlin, S. 8-11.; Bundesministerium des Innern (BMI) 2008: Migration und Integration: Aufenthaltsrecht, Migrations- und Integrationspolitik in Deutschland. Berlin, S. 110-111.

965 Vgl. Bommes, Michael / Krüger-Potratz, Marianne (Hrsg.) 2008: Migrationsreport 2008. S. 279.

966 Butterwegge, Carolin 2009: Fit für die Globalisierung? a.a.O., S. 160.

967 Vgl. Gomolla, Mechtild / Radtke, Frank-Olaf 2007: Institutionelle Diskriminierung. Die Herstellung ethnischer Differenz in der Schule. Wiesbaden.

968 Butterwegge, Carolin 2009: Fit für die Globalisierung? a.a.O., S. 165.

969 Von der Europäischen Kommission wurden ferner mittels einer Vielzahl von Programmen nationale Integrationsmaßnahmen der Mitgliedstaaten gefördert. Anhand der Einrichtung eines europäischen Fonds für die Integration von Drittstaatsangehörigen für den Zeitraum 2007 bis 2013 im Rahmen des allgemeinen Programms „Solidarität und Steuerung der Migrationsströme“ sollen die Mitgliedstaaten in ihren Bemühungen Unterstützung finden, Drittstaatsangehörige diverser kultureller, religiöser und sprachlicher Herkunft in ihre jeweiligen nationalen Gesellschaften integrieren zu können. Hauptsächliches Ziel des mit 825 Millionen Euro ausgestatteten Integrationsfonds sind Maßnahmen, die sich auf die Integration von Neuzuwanderern beziehen. In: Bundesministerium des Innern (BMI) 2008: Migration und Integration: a.a.O., S. 67-68. 
Ebene. Wirkliche Erfolge sind aber noch nicht zu verzeichnen.

Die bisher amtierenden Kanzler, angefangen bei Helmut Kohl (CDU, 1982 - 1998) über Gerhard Schröder (SPD, 1998 - 2005) bis hin zu Angela Merkel (CDU, 2005 - bis heute), gestalten ihre Migrationspolitik ausgehend von der Kanzlerdemokratie. Durchsetzung des Kanzlerprinzips, des ersten Merkmals der Kanzlerdemokratie, gelang dem Europapolitiker Kohl besonders, indem er deutsche nationale Interessen auf EUEbene im Rahmen der Europäisierung durchführte, wie z. B. beim Maastrichter Vertrag und Amsterdamer Vertrag. Gerhard Schröder kann bei der Durchsetzung des Kanzlerprinzips auf eine respektable Bilanz verweisen. Im Rahmen seines Selbst- und Fremdbildes als Medien- und Reformkanzler hatte Schröder viele Reformprojekte in Angriff genommen, allerdings waren die politischen Entscheidungen in seiner Regierung oft sprunghaft und widersprüchlich, es seien hier nur die Reform des Staatsbürgerschaftsgesetzes als Optionsmodell von 2000 und das Zuwanderungsgesetz genannt. Dennoch ist sein Mut zur „Modernisierungsreformpolitik“ durch die Kanzlerdemokratie bemerkenswert. In der Politik von Bundeskanzlerin Angela Merkel ist heute weiterhin eine verstärkte Integrationspolitik zu bemerken. Merkel ermöglichte auch insbesondere mit dem am 28. August 2007 in Kraft getretenen Richtlinienumsetzungsgesetz die Durchsetzung von elf EU-Richtlinien in nationales Recht. Dies kann einerseits als eine Europäisierung aus der „Top down“-Logik gesehen werden, andererseits aber auch als eine Europäisierung aus der „Bottom up“-Logik, demzufolge stehen die europäischen Maßnahmen zugleich im Einklang mit nationalen Interessen. Schließlich bezeichnet in der Kanzlerschaft von Angela Merkel jedoch die außenpolitische Weichenstellung bezüglich der Europäisierung im Bereich Migration ein etwas niedrigeres Niveau als bei den Vorgängern Kohl und Schröder.

Insgesamt wird es künftig fragwürdiger, ob die Kanzlerschaft Deutschlands hinsichtlich der deutschen migrationspolitischen Interessen durch die Kanzlerdemokratie auf EUEbene immer noch wirksam bleiben kann. Nach der Ära von Bundeskanzler Helmut Kohl hat sich Deutschland tatsächlich bereits von seiner traditionellen Führungsrolle entfernt. Infolgedessen wurde Deutschland in vielen EU-Mitgliedstaaten „,zunehmend weniger als Anwalt eines übergeordneten europäischen Gesamtinteresses, von dem sich auch kleinere Mitgliedstaaten vertreten fühlen“, gesehen. ${ }^{970}$

970 Emmanouilidis, Janis. A. 2009: Deutschland in der EU. In: Weidenfeld, Werner / Wessels, Wolfgang (Hrsg.) 2009: Europa von A bis Z: Taschenbuch der europäischen Integration. Bonn, S. 114. 


\section{1. 2 Bundesministerium des Innern (BMI)}

Als Teilakteur der Bundesregierung sieht das Bundesministerium des Innern (BMI) seine migrationspolitischen Interessen vorwiegend in der Bewahrung innerer Sicherheit. Im Kompetenzbereich des BMI stehen auch ,sämtliche Migrationsfragen, beginnend mit der Einreiseerlaubnis über die Integration bis hin zur Abschiebung. “971 Das BMI stellt bislang insbesondere angesichts seiner Sicherheitsinteressen die Zuwanderungsbeschränkung dar. Bereits in der Ära Kohl warnte das BMI explizit vor der Abschaffung der Grenzkontrollen und dem damit verbundenen Sicherheits- bzw. Grenzkontrollverlust. Der ehemalige Innenminister Rudolf Seiters verdeutlichte im Jahr 1993 aus diesem Grund die restriktive Haltung Deutschlands zur Einwanderung: „Begriffe wie ,Einwanderungspolitik' und ,Einwanderungsland' können insoweit irreführend sein, als kein EG-Mitgliedstaat derzeit eine Politik führt, die auf eine Einwanderung abzielt. Im Gegenteil, es geht um die Kontrolle der Einwanderung. “972 Mit der Schaffung einer europäischen Grenzpolizei, mit der Einrichtung der europäischen Grenzschutzagentur FRONTEX u. ä. hat das BMI darüber hinaus noch Initiativen zur Harmonisierung der Migrationspolitik auf EU-Ebene gestartet. Die Einführung eines EU-Visuminformationssystems (VIS) im Jahr 2004 geht auf den Minister Otto Schily zurück, der seit dem 11. September 2001 besonders auf eine Verschärfung der Sicherheitspolitik drängte. ${ }^{973}$ Ziel des VIS ist wie beim EURODAC ${ }^{974}$ „die Verhinderung von Visummehrfachanträgen bei mehreren Mitgliedstaaten (das sogenannte ,Visa-Shopping'), die Verifikation persönlicher Daten, Harmonisierung von Verfahrensabläufen, Bekämpfung von illegaler Migration und Menschenhandel sowie des Terrorismus. “975 Damit hat das BMI für Deutschland insbesondere in Vorhaben der Sicherheitserwägungen hohe politische Priorität im Hinblick auf die Europäisierung.

971 Baumann, Mechthild 2006: Der deutsche Fingerabdruck: Die Rolle der deutschen Bundesregierung bei der Europäisierung der Grenzpolitik. Baden-Baden, S. 47.

972 Baumann, Mechthild 2008: Der Einfluss des Bundeskanzleramts und des Bundesministeriums des Innern auf die Entwicklung einer europäischen Grenzpolitik. In: Hunger, Uwe / Aybek, Can M. / Ette, Andreas / Michalowski, Ines (Hrsg.) 2008: Migrations- und Integrationsproesse in Euroa: Vergemeinschaftung oder nationalstaatliche Lösungswege?. Wiesbaden, S. 23.

973 Vgl. Boswell, Christina 2007: Migration Control in Europe After 9/11: Explaining the Absence of Securitization. In: Journal of Common Market Studies (JCMS) 2007. Volume 45. Number 3: September 2007. S. 589-610, hier S. 596.

974 EURODAC ist ein elektronisches automatisiertes Informationssystem, in welches die Fingerabdrücke von drei Personenkategorien eingegeben werden: Die von Asylbewerbern, Personen, die bei einer illegalen Einreise aufgegriffen wurden sowie Personen, die sich illegal auf dem Hoheitsgebiet eines Mitgliedstaates aufhalten. In: Baumann, Mechthild 2006: Der deutsche Fingerabdruck. S. 141.

975 Bundesministerium des Innern 2008: Migration und Integration: Aufenthaltsrecht, Migrations- und Integrationspolitik in Deutschland. Berlin, S. 63. 


\section{1. 3 Bundesamt für Migration und Flüchtlinge (BAMF)}

Mit dem Inkrafttreten des Zuwanderungsgesetzes (ZuWG) 2005 sind dem Bundesamt für Migration und Flüchtlinge (BAMF) neben der Durchführung von Asylverfahren auch Aufgaben $^{976}$ in den Bereichen der Integrationsförderung, der Migrationsforschung, des Flüchtlingsschutzes und der freiwilligen Rückkehrförderung zugeteilt worden. ${ }^{977}$ Es entscheidet zuerst über Asylanträge und Abschiebeschutz von Flüchtlingen; Mitarbeiter des BAMF verfügen über Asylanträge nach persönlicher Anhörung des Antragstellers und gewissenhafter Prüfung der Asylgründe. Dabei stellen sie fest, ob ein Asylanspruch nach dem Grundgesetz vorliegt, ob der Antragsteller als Flüchtling nach der Genfer Konvention (GFK) zu schützen ist oder ob zielstaatsbezogene Abschiebungsverbote nach dem Aufenthaltsgesetz existieren. ${ }^{978}$ Weiterhin hat das BAMF schwerpunktmäßig die sprachliche, gesellschaftliche sowie soziale Integration von Einwanderern in Deutschland $\mathrm{zu}$ fördern und $\mathrm{zu}$ koordinieren. Außerdem unterstützt das BAMF als zentrale Steuerungsstelle in Migrationsfragen, wenn z. B. jüdische Migranten aus der ehemaligen Sowjetunion verteilt werden, und es vermittelt ferner heimkehrwilligen Migranten Informationen zur freiwilligen Rückkehr. Zudem ist es in der verstärkten Kooperation mit den EU-Mitgliedstaaten auf den Gebieten Asyl und Migration involviert. Schließlich kümmert sich das BAMF als Kontaktstelle um einen zeitlich begrenzten Schutz, sofern es zu einem Massenzustrom von Vertriebenen kommen sollte. ${ }^{979}$

Außerdem wurde angesichts der Umsetzung der EU-Forschungsrichtlinie die Arbeitsmigration von Forschern durch das BAMF ab dem 1. Dezember 2007 vereinfacht. $\mathrm{Zu}$ diesem Arbeitszweck müssen sich die Forschungseinrichtungen beim BAMF zertifizieren lassen und können dann künftig selbst Arbeits- und Aufenthaltserlaubnisse für Arbeitskräfte aus dem Ausland ausstellen. Besonders positiv ist hierbei ein Ehegattenazug der Forscher. ${ }^{980}$ Auch das BAMF hatte ein Konzept für bundeseinheitliche „Einbürgerungsstandards“ (später sog. Einbürgerungstest) entwickelt, das vom Bundesinnenministerium Anfang Juli 2008 vorgestellt wurde und das am 1.

\footnotetext{
$976 \S 75$ AufenthG definiert die Aufgaben des BAMF in Übereinstimmung mit dem verfassungsrechtlichen Bestimmtheitserfordernis des Art. 87 Abs. 3 S. 1 GG.

$977 \mathrm{http} / / /$ www.bamf.de/cln_092/nn_442496/DE/DasBAMF/dasbamf-node.html?_nnn=true

$978 \mathrm{http} / / /$ www.bamf.de/cln_092/nn_442016/DE/DasBAMF/Aufgaben/aufgaben-node.html?_nnn=true

$979 \mathrm{http} / /$ www.bamf.de/cln_092/nn_442016/DE/DasBAMF/Aufgaben/aufgaben-node.html?_nnn=true

980 Bommes, Michael / Krüger-Potratz, Marianne (Hrsg.) 2008: Migrationsreport 2008: Fakten-AnalysenPerspektiven. Frankfurt a. M., S. 292.
} 
September 2008 endgültig in Kraft trat. ${ }^{981}$ Die Prüfungsinhalte der „Einbürgerungstests“ ${ }^{\text {“ }}$ wurden hierbei vom BAMF festgelegt. ${ }^{982}$ Leider fiel es bei Opposition, Migrantenverbänden und anderen Interessengruppen durch, da es als unnötig und diskriminierend galt. ${ }^{983}$

Insgesamt gilt das Bundesamt für Migration und Flüchtlinge (BAMF) heutzutage zunehmend als wichtiger Akteur und spielt eine bedeutende Rolle: ${ }^{984}$ Denn das BAMF wurde bereits auf der Basis des Zuwanderungsgesetzes zur nationalen Koordinierungsstelle für die Integrationspolitik ausgebaut, welche zunehmend den Platz der herkömmlichen Instanz für die Anerkennung der Flüchtlinge einnimmt. Hauptsächlich bei der Entwicklung und Durchführung der Integrationskurse ist das BAMF in Besitz weitgehender Befugnisse, während die Einbürgerungskurse von den Bundesländern in eigener Verantwortung angeboten werden. ${ }^{985}$ Des Weiteren wird vom BAMF immer mehr eine Schlüsselposition bei der Entwicklung neuer Konzepte zur Integrationsförderung eingenommen, der Koordination von diversen Maßnahmen der Fachverwaltungen sowie deren öffentlichkeitswirksamer Darbietung einschließlich eines Integrationsportals im Internet. ${ }^{986}$ Bei der Berücksichtigung dieser Angelegenheiten verfügt das BAMF jedoch über keinerlei Weisungsrechte gegenüber den beteiligten Länderbehörden, Gemeinden und übrigen Akteuren.

981 Butterwegge, Carolin 2009: Fit für die Globalisierung?: Deutschland auf dem Weg zur Modernisierung seiner Migrations- und Integrationspolitik. In: Butterwegge, Christoph/a.a.O., S. 163; vgl. dazu Bommes, Michael / Krüger-Potratz, Marianne (Hrsg.) 2008: Migrationsreport 2008. S. 250.

982 Newsletter ,Migration und Bevölkerung' 2006: Deutschland: Neue Einbürgerungsrichtlinien. Im Internet: http://www.migration-info.de/mub_artikel.php?Id=060503 (Ausgabe 05/06).

983 Newsletter ,Migration und Bevölkerung' 2008: Deutschland: Bundeseinheitlicher Einbürgerungstest. Im Internet: http://www.migration-info.de/mub_artikel.php?Id=080601(Ausgabe 06/08).

984 Thym, Daniel 2010: Migrationsverwaltungsrecht. (Berlin, Humboldt-Univ., Habil. Schr.). Tübingen, S. 282-283.

985 Weitere Bundesbehörden sind außerdem ergänzend mit dem Vollzug einzelner Bestimmungen des Migrationsrechts befasst und tragen im Rahmen ihrer Befugnisse auch zur Integrationsförderung bei. Bezüglich der Arbeitsmarktzulassung wird die Bundesagentur für Arbeit gemäß $\S 39$ ff. AufenthG tätig, Visa stellt nach $\S 71$ Abs. 2 AufenthG das Auswärtige Amt aus, die Bundespolizei ist nach dem BPolG für die Unterbindung illegaler Einwanderung zuständig und die Zollverwaltung führt Kontrollen gegen Schwarzarbeit durch, so z. B. bei der Arbeitnehmerentsendung nach $\S 2$ AEntG.

986 Siehe http://www.integration-in-deutschland.de. 


\section{1. 4 Auswärtiges Amt (AA)}

Das Auswärtige Amt (AA), das für die Pflege der Beziehungen zu anderen Staaten sowie zu den zwischen- und überstaatlichen Organisationen zuständig ist, ist nach Art. 32 Grundgesetz eine Sache des Bundes. ${ }^{987}$ Als das Ausländerrecht 1991 novelliert wurde, erhoben sowohl das Auswärtige Amt (AA) als auch das Bundesministerium des Innern (BMI) insbesondere Anspruch auf die Zuständigkeit für die Visaerteilungsregelung. ${ }^{988}$ So hatte sich das AA immer mit dem BMI abzustimmen, „wenn Entscheidungen, von größerer politischer Tragweite' getroffen wurden, wie z. B. Visaanträge von Staatsangehörigen Libyens, Irans oder Syriens. “989 Im Bereich der Visapolitik, die sog. Visa-Affäre, resultierten deshalb beständig Spannungen zwischen dem BMI, ${ }^{990}$ dem AA und teilweise auch dem Wirtschaftsministerium. Eine weitere Überschneidung liegt im Politikfeld Asyl vor, ,,deren konkrete Ausgestaltung zwar dem BMI obliegt, die jedoch die Außenpolitik eines Landes ist. “991 Ebenfalls kommt der Zusammenarbeit in der EU und in den internationalen Organisationen, wie z. B. den Vereinten Nationen, der NATO (Nordatlantikpakt: North Atlantic Treaty Organisation) oder der OSZE (Organisation für Sicherheit und Zusammenarbeit in Europa) eine große Bedeutung zu.

Das AA, das tatsächliche „Prestigeministerium“, wird daher oft „,vom führenden Regierungsmitglied des kleineren Koalitionspartners übernommen. “992 So waren z. B. Hans-Dietrich Genscher (FDP) von 1974 bis 1992 und Joschka Fischer (Bündnis 90/Die Grünen) von 1998 bis 2005 Bundesminister des Auswärtigen und Vizekanzler. ${ }^{993}$ Die Politik des Auswärtigen Amtes (AA) übt vor allem erhebliche europapolitische Koordinierungsfunktionen innerhalb der Bundesregierung aus. Bereits in der Rede vor dem Deutschen Bundestag vom 11.11.2004 unterstrich Bundesaußenminister Joschka Fischer zum Thema der Europäisierung im Politikfeld Migration vier, für ihn als wichtig einzustufende Kernthemen: „erstens die Lissabon-Strategie, die auf die zentralen

\footnotetext{
987 http://www.auswaertiges-amt.de/diplo/de/AAmt/AuswDienst/Aufgaben.html (Stand: 25.05.2008).

988 Baumann, Mechthild 2006: Der deutsche Fingerabdruck: a.a.O., S. 47.

989 Baumann, Mechthild 2006: Der deutsche Fingerabdruck: a.a.O., S. 47.; vgl. Andreae, Lisette / Kaiser, Karl 1998: Die ,Außenpolitik’ der Fachministerien. In: Eberwein, Wolf-Dieter / Kaiser, Karl 1998: Deutschlands neue Außenpolitik. Bd. 4: Institutionen und Ressourcen. München, S. 41.

990 Vgl. Egle, Christoph 2007: In der Regierung erstarrt? Die Entwicklung von Bündnis 90/Die Grünen von 2002 bis 2005. In: Egle, Christoph / Zohlnhöfer, Reimut (Hrsg.) 2007: a.a.O., S. 114-115.

991 Baumann, Mechthild 2006: Der deutsche Fingerabdruck: a.a.O., S. 47.

992 Sontheimer, Kurt / Bleek, Wilhelm 2003: Grundzüge des politischen Systems Deutschlands. S. 317.

993 Sontheimer, Kurt / Bleek, Wilhelm 2003: Grundzüge des politischen Systems Deutschlands. S. 317.
} 
Bereiche Wachstum und Beschäftigung angepasst und ausgerichtet wurde, zweitens die Verabschiedung des Haager Programms, in dem die gemeinsame europäische Asyl- und Migrationspolitik weiterentwickelt wurde, drittens die europäische Öffentlichkeitsarbeit, die angesichts des anstehenden Prozesses der Ratifizierung der Verfassung verstärkt werden muss, und viertens eine ganze Bandbreite wichtiger außenpolitischer Themen. [...]. Damit wird klar, welche Bedeutung diese neue Dimension in der erweiterten Europäischen Union hat." "994 Weiterhin begriff Fischer „das Haager Programm“, das mit der Bekämpfung des internationalen Terrorismus in einer gemeinsamen europäischen Asyl- und Migrationspolitik verbunden wird, als einen Erfolg in der Kooperation der EU mit den deutschen Interessen: „Dieses neue, auf fünf Jahre ausgerichtete Programm für den Bereich Justiz und Inneres knüpft an die im Oktober 1999 in Tampere vereinbarte Schaffung eines Raumes der Freiheit, der Sicherheit und des Rechts in Europa an. Dies hat zum bisher größten Integrationsschub seit der Schaffung des Binnenmarktes geführt. Dieser Erfolg soll jetzt weitergeführt werden. “995 Auch der ehemalige Bundesaußenminister Steinmeier (SPD) formulierte seine politische Einstellung bezüglich der Migrationspolitik vor dem Europäischen Parlament am 21./22. Juni 2007 wie folgt: "Die Suche nach gemeinsamen Ansätzen mit den nordafrikanischen Transitstaaten war richtig, aber eine europäische Migrationspolitik darf sich nicht auf die Stärkung von Frontex und die Ertüchtigung der Küstenwache in den Partnerländern beschränken.“ 996 Außerdem gilt das AA als „,das federführende Ressort für internationale Menschenrechtspolitik“, wobei es hier bis heute wenig oder gar nichts über einen migrationspolitischen „Aktionsplan für Menschenrechte“ gibt. $^{997}$

Das Auswärtige Amt (AA) markiert die nationalen Interessen auf europäischer Ebene im Zuge der Europäisierung, und auch wenn Unterschiede im Detail in der Ausrichtung des Auswärtigen Amtes existieren, so bleibt doch ein roter Faden unverkennbar, der die restriktive Migrationspolitik Deutschlands betrifft.

\footnotetext{
994 Erklärung von Bundesaußenminister Fischer zu den Ergebnissen der Tagung des Europäischen Rates vor dem Deutschen Bundestag. Berlin, 11.11.2004 (Auszug). Abrufbar im Internet: http://www.auswaertiges-amt.de/diplo/de/Inforservice/Presse/Reden/Archiv/2004 (Stand: 05.05.2009).

995 Erklärung von Bundesaußenminister Fischer zu den Ergebnissen der Tagung des Europäischen Rates vor dem Deutschen Bundestag. Berlin, 11.11.2004 (Auszug). a.a.O.

996 Erklärung von Bundesaußenminister Steinmeier vor dem Europäischen Parlament zum Europäischen Rat am 21./22.6.2007 und zur Vertragsreform. Im Internet: http://www.auswaertigesamt.de/diplo/de/Inforservice/Presse/Reden/2007/070607-MiniEP-ZsfsgEU-Praes.html

997 Vgl. Heinz, Wolfgang S. 2007: Menschenrechtspolitik. In: Schmidt, Siegmar / Hellmann, Gunther / Wolf, Reinhard (Hrsg.) 2007: Handbuch zur deutschen Außenpolitik. Wiesbaden, S. 692-693.
} 


\section{2 Bundestag (BT)}

Aus dem parlamentarischen Regierungssystem Deutschlands geht „die Volksvertretung hervor, auf Bundesebene der Deutshe Bundestag, das einzige direkt vom Staatsvolk gewählte Bundesorgan.“ "998 Funktionen des BT sind, „neben der Bestellung und Abberufung der Regierung, die Gesetzgebung einschließlich der Haushaltsbestimmung, die Kontrolle von Regierung und Verwaltung, die Repräsentation und Artikulation der Interessen und politischen Positionen sowie die Publizität und Transparenz der politischen Willensbildung." ${ }^{999}$ Diesbezüglich konnte der Deutsche Bundestag (BT) insbesondere auf die Vertragsverhandlungen im Rahmen der Amsterdamer Regierungskonferenz 1996/1997 allerdings kaum Einfluss ausüben. ${ }^{1000}$ Dieses ist zum einen darin begründet, dass der BT im Gegensatz zu den Bundesländern keine eigenen Interessen artikulieren konnte, die sich von denen der Bundesregierung unterschieden. Außerdem wurde der Bundestag von der Bundesregierung nicht in die Willensbildungsprozesse integriert, sondern nur als ,Unterrichtungsadressat' behandelt. ${ }^{1001}$ Der Vertreter der Bundesregierung stellte fest, „dass zwar der Bundesrat bei den Ressortgesprächen [zur Festlegung der deutschen Verhandlungspositionen] beteiligt sei, dass aber an eine Ausdehnung auf den Deutschen Bundestag nicht gedacht sei. Die Bundesregierung wolle die Abgeordneten zwar informieren, sie aber nicht an der Entscheidungsfindung teilhaben lassen.“"1002 Dennoch stimmte bei den meisten Themen der Amsterdamer Regierungskonferenz 1996/1997 die BT-Position mit den vertretenen Positionen der Bundesregierung überein. So forderte der BT ebenso wie die Bundesregierung eine Teilvergemeinschaftung der dritten Säule bezüglich der EUJustiz- und Innenpolitik. ${ }^{1003}$ Herausgehoben wurden insbesondere die Bereiche Asyl, Visa und Zoll, wobei alle Fraktionen des BT darin übereinstimmten, dass eine Harmonisierung in diesen Bereichen erstrebenswert sei, gepaart mit einer Kontrolle durch das EP, die nationalen Parlamente und den Europäischen Gerichtshof (EuGH). ${ }^{1004}$

\footnotetext{
998 Sontheimer, Kurt / Bleek, Wilhelm 2003: Grundzüge des politischen Systems Deutschlands. S. 276.

999 Ismayr, Wolfgang 2007: Bundestag. In: Schmidt, Siegmar / Hellmann, Gunther / Wolf, Reinhard (Hrsg.) 2007: Handbuch zur deutschen Außenpolitik. Wiesbaden, S. 175-191, hier S. 176.

1000 Grünhage, Jan 2007: Entscheidungsprozesse in der Europapolitik Deutschlands: Von Konrad Adenauer bis Gerhard Schröder (Diss., Bonn). Baden-Baden, S. 311.

1001 Vgl. Ismayr, Wolfgang 2007: Bundestag. In: Schmidt, Siegmar/a.a.O., S. 175-191, hier S. 187.

1002 Kövel, Svea 2000: Die Mitwirkung des Deutschen Bundestages in Angelegenheiten der Europäischen Union - Unter besonderer Berücksichtigung der Mitwirkung am und der Veränderung durch den Vertrag von Amsterdam. München, S. 169.

1003 Deutscher Bundestag 1996: Drucksachen: BT-Drs. 13/3247 vom 6. 12. 1995, 13/4534 vom 7. 5. 1996.

1004 Deutscher Bundestag 1996: Drucksachen: BT-Drs. 13/3247 vom 6. 12. 1995, 13/4534 vom 7. 5.1996.
} 
Die positive Bemessung des Amsterdamer Vertrages offenbarte sich zudem in der schnellen Annahme des Ratifikationsgesetzes durch den BT mit einer Zweidrittelmehrheit. ${ }^{1005}$ Auch in jünster Zeit musste der Reformvertrag von Lissabon (2007) in allen EU-Mitgliedstaaten ratifiziert werden; in Deutschland war dafür die Zustimmung von zwei Dritteln der Bundestagesmitglieder und zwei Dritteln der Stimmen des Bundesrates vonnöten. ${ }^{1006}$ Bereits im Maastrichter Vertrag (1992/93) war die BT-Teilnahme gegenüber der Bundesregierung im europapolitischen Willensbildungsprozess gestärkt und ein neuer Ausganspunkt gebildet worden. Mit dieser gestärkten Mitwirkung des BT (Artikel 23 GG und Artikel 45 GG) wurden deutliche Schwächen seines europapolitischen Engagement behoben. ${ }^{1007}$ Allerdings kommt noch bis heute dem BT eine eher indirekte Rolle im europäischen Rechtssetzungsprozess zu. Zukünftig soll der BT deshalb maßgeblich an der so genannten „Subsidiaritätskontrolle“ im Bereich der Migrationspolitik mitwirken. ${ }^{1008}$

Die Zahl der bisher dem BT zugeleiteten EG/EU-Vorlagen hat in den vergangenen Jahren stark zugenommen. ${ }^{1009}$ Hingegen wird im Rahmen der formellen Wirkungsmöglichkeiten des BT bezüglich der Migrationspolitik weiterhin deutlich, dass der BT seit Beginn des europäischen Integrationsprozesses diesem ein nur eingeschränktes Interesse entgegenbringt. Ein Fortkommen in der europapolitischen Mitwirkung hat der BT nur dann befürwortet, wenn er sich auf die Bundesländer bezog. Seit der deutschen Vereinigung wurde dem BT bislang, insbesondere durch das Lissabon-Urteil des Bundesverfassungsgerichts von 2009, die europarechtliche Kompetenz weiter zuteil, über jeden Einsatz bewaffneter Streitkräfte zu entscheiden. Die Entscheidung des Bundesverfassungsgerichts vom 30.06.2009 zum Lissaboner Vertrag stellte dabei vor allem die weitgehenden Informations- und Beteiligungsrechte des BT im Rahmen der Mitwirkung der Bundesrepublik an Rechtsetzungsakten der EU dar. ${ }^{1010} \mathrm{Ob}$ der Einfluss des Bundestages auf die migrationspolitischen Vorhaben der Regierung umso erfolgversprechender ist, je früher er einsetzt, ist allerdings ungewiss.

${ }^{1005}$ Läufer, Thomas / Bila, Jacqueline (Hrsg.) 1998: Vertrag von Amsterdam - Die parlamentarische Debatte 1997/98. Bonn, S. 9.

$1006 \mathrm{http} / / /$ www.bundestag.de/aktuell/archiv/2008/20217626_kw17_lissabon/index.html (12.11.2008).

${ }^{1007}$ Ismayr, Wolfgang 2007: Bundestag. In: Schmidt, Siegmar / Hellmann, Gunther /...a.a.O., S. 187.

1008 http://www.bundestag.de/aktuell/archiv/2007/eu_reformvertrag/index.html (20.12.2007).

1009 Ismayr, Wolfgang 2007: Bundestag. In: Schmidt, Siegmar / Hellmann, Gunther / a.a.O., S. 187.

1010 Bundestag 2010: Die Rolle des Bundestages nach Lissabon. Online verfügbar unter: http://www.bundestag.de/dokumente/textarchiv/2010/30212544_kw24_europa_union/index.html (Stand: 25.06.2010); vgl. Kluth, Winfried 2009: Vertrauen ist gut, Kontrolle ist besser: Zur Bedeutung der Entscheidung des Bundesverfassungsgerichts zum Vertrag von Lissabon für das Ausländer- und Staatsangehörigkeitsrecht. In: Zeitschrift für Ausländerrecht und Ausländerpolitik (ZAR), 29. Jahrgang, 10/2009. Baden-Baden, S. 329. 


\section{3 Bundesländer im Föderalismus}

Seit 1990 sind die Bundesländer in der EU vertreten. Die Beteiligung der Länder in der EU-Angelegenheit regelt Artikel 23 Absatz 2 GG: „In Angelegenheiten der Europäischen Union wirken der Bundestag und durch den Bundesrat die Länder mit." 1011 Bei Verhandlungen der Gesetzgebungskompetenz befindet sich diese Kompetenz bis heute weiterhin beim Bund (insbesondere beim BMI), während den Bundesländern durch den Bundesrat ein Zustimmungsrecht zusteht, die Länderparlamente als Legislativorgane jedoch überwiegend irrelevant geworden sind. ${ }^{1012}$ Die Bundesländer sind allerdings legislativ lediglich für ,die Regelung kultureller Angelegenheiten“ (insbesondere Bildungswesen) und für „,das Polizei- und das Kommunalrecht“"1013 zuständig. Seit Beginn der 1990er Jahren verlangten die Bundesländer, dass man ihre „Einflussmöglichkeiten auf europäische Rechtssetzungsaktivitäten an ihre Mitwirkungsrechte an der nationalen Gesetzgebung“ angleiche. ${ }^{1014}$ Diesbezüglich zeigte sich seit den 1990er Jahren, „dass über 50 Prozent aller in Deutschland angewandten Gesetze eher europäischen statt nationalen Ursprungs sind, und dass viele von ihnen Zuständigkeiten der Länder berühren." ${ }^{1015}$ So strebten die Länder in Bezug auf die Verhandlungen des Maastrichter Vertrags 1992/93 größere direkte Mitsprachemöglichkeiten in der EG/EU an: Durch den neuen „Europa-Artikel“ (23 GG) werden seitdem die innerstaatlichen Mitwirkungsrechte der Bundesländer über den Bundesrat hinaus erweitert. Weiterhin verfügen die Länder bis heute infolge der direkten Mitwirkungsmöglichkeiten im Ministerrat über unmittelbare Zugänge zu den EU-Entscheidungsverfahren. Artikel 203 (ehemals Artikel 146) des EG-Vertrags gestattet es somit, Länderminister im Ministerrat $\mathrm{zu}$ entsenden. ${ }^{1016}$ Jedoch ist die deutsche Zustimmung bezüglich der europäischen Vertragsrechtsänderungen weiterhin von einer Zweidrittelmehrheit im Bundesrat abhängig (Art 23 Abs. 1 GG). Dies bedeutet auch, dass die außenpolitische Alleinherrschaft der Bundesregierung von einer zwischen Bund und Ländern geteilten

1011 Sodan, Helge 2009: Grundgesetz: Beck'scher Kompakt-Kommentar. München, S. 243.

1012 Sontheimer, Kurt / Bleek, Wilhelm 2003: Grundzüge des politischen Systems Deutschlands. S. 355.

1013 Sontheimer, Kurt / Bleek, Wilhelm 2003: Grundzüge des politischen Systems Deutschlands. S. 357.

1014 Fischer, Thomas 2007: Bundesländer und Bundesrat. In: Schmidt, Siegmar / Hellmann, Gunther / Wolf, Reinhard (Hrsg.) 2007: Handbuch zur deutschen Außenpolitik. Wiesbaden, S. 194 f.

1015 Bulmer, Simon / Jeffery, Charlie / Paterson, William E. 1998: Deutschlands europäische Diplomatie: die Entwicklung des regionalen Milieus. In: Weidenfeld, Werner (Hrsg.) 1998: Deutsche Europapolitik. Optionen wirksamer Interessenvertrettung. Bonn, S. 11-102 hier, S. 35.

1016 Amt für amtliche Veröffentlichungen der Europäischen Gemeinschaften 2006: Europäische Union: Konsolidierte Verträge. Luxemburg, S. 136. 
Zuständigkeit abgelöst wurde, die in etwa der innenpolitischen Kompetenzverteilung gleichkommt, die man generell als „kooperativen Föderalismus“ bezeichnet. ${ }^{1017}$ Angesichts der EU-Angelegenheiten im Bereich der Außen- und Innenpolitik ist demnach den Bundesländern tatsächlich die „Erweiterung des kooperativen Föderalismus auf die Europapolitik ${ }^{\text {‘1018 }}$ angeraten. Im Jahr 1995 waren die Länder um eine Teilvergemeinschaftung der Asyl- und Flüchtlingspolitik sowie der Gemeinsamen Außen- und Sicherheitspolitik (GASP) und eine Stärkung der Rolle der Europäischen Kommission (EP) in der zweiten und dritten Säule bestrebt. ${ }^{1019}$ Die Länder forderten allerdings ein, dass besonders das Aufenthaltsrechts- und Arbeitsrechts für Ausländer künftig der zwischenstaatlichen Zusammenarbeit unterliegen sollte. ${ }^{1020}$ Denn die Binnenmarktsöffnung mit der Freizügigkeit erforderte „Regelungen auch in den Fragen der Immigration. Einwanderungspolitische Regelungen eines Mitgliedstaates beeinflussen die Einwanderung in die anderen Mitgliedstaaten zwangsläufig.“" ${ }^{1021}$ Der Ländereinfluss zeigte sich auch in den Amsterdamer Verhandlungen (1997) bezüglich der Frage der Reform der EU-Justiz- und Innenpolitik. Für die Bundesländer war das Aufrechterhalten der Einstimmigkeit vor allem im Politikfeld Asyl von großer Bedeutung. Sie wiesen daraufhin, dass Deutschland in den vergangenen Jahren im Vergleich mit anderen EU-Staaten überproportional viele Flüchtlinge aus Drittstaaten aufgenommen hatte. So wurde z. B. den Bürgerkriegsflüchtlingen aus dem ehemaligen Jugoslawien, deren Integration für die Bundesländer eine hohe finanzielle Belastung gewährt. ${ }^{1022}$ (Vgl. Kapitel III.3.1.1). Diesbezüglich setzte Bundeskanzler Kohl den Anspruch der Bundesländer gegen die Abschaffung des Einstimmigkeitsprinzips auch im Bereich Migration insbesondere im Arbeitsmarkt mit Erfolg durch. ${ }^{1023}$

Insgesamt zeigt sich für die Bundesländer im deutschen Föderalismus, dass sie gewiss einen Teil ihrer migrationspolitischen Forderungen durchsetzen können und deshalb eine beträchtliche Aufwertung ihrer Stellung im Europäisierungsprozess kennen. ${ }^{1024}$

\footnotetext{
1017 Bulmer, Simon / Jeffery, Charlie / Paterson, William E. 1998: a.a.O., S. 36.

1018 Bulmer, Simon / Jeffery, Charlie / Paterson, William E. 1998: a.a.O., S. 36.

1019 Bundesrat 1995: Drucksachen: BR-Drs. 169/95 (Beschluss) vom 31. 03. 1995.

1020 Bundesrat 1995: Drucksachen: BR-Drs. $667 / 95$ (Beschluss) vom 15. 12. 1995.

1021 Stein, Otti 1992: Asylpoltik, Unionsbürgerschaft und Innere Sicherheit. In: Borkenhagen, Franz H. U. / Bruns-Klöss, Christian / Memminger, Gerhard / Stein, Otti (Hrsg.) 1992: Die deutschen Länder in Europa: Politische Union und Wirtschafts- und Währungsunion. Baden-Baden, S. 75-88., hier S. 82.

1022 Barth, Christian / Mentler, Michael 1998: Länderpositionen für die Innen- und Rechtspolitik der Europäischen Union. In: Borkenhagen, Franz H. U. (Hrsg.) 1998: Europapolitik der deutschen Länder: Bilanz und Perspektiven nach dem Gipfel von Amsterdam. Opladen, S. 87 ff.

1023 Erler, Petra 1998: Die institutionelle Reform und die Interessen der Länder. In: Borkenhagen H. U. (Hrsg.) 1998: Europapolitik der deutschen Länder: a.a.O., S. 208.

1024 Vgl. Klaus, Henning 1996: Die deutschen Bundesländer und die Europäische Union: Die Mitwirkung
} 


\section{4 Bundesrat (BR)}

Der Art. 23 GG Abs. 4 zeigt, dass „der Bundesrat an der Willensbildung des Bundes zu beteiligen ist, soweit er an einer entsprechenden innerstaatlichen Maßnahme mitzuwirken hätte oder soweit die Länder innerstaatlich zuständig wären.“ 1025 Diesbezüglich ist die Bundesregierung verpflichtet, ,alle vom Kabinett verabschiedeten Gesetzentwürfe zunächst dem Bundesrat zuzuleiten“" (sog. 1. und 2. Durchgang). ${ }^{1026}$ Der Bundesrat (BR) als Ratifikationsorgan hatte bereits ,im ersten Durchgang in seiner Sitzung am 14. Februar 2003“1027 das Zuwanderungsgesetz (ZuWG) verweigert. Es war vor allem an der Ablehnung der Unionsparteien im BR gescheitert. Dabei gab es folgende Streitpunkte: Im Gesetzentwurf des Zuwanderungsgesetzes (ZuWG) wurde von der Union insbesondere auf dem Feld der Flüchtlingspolitik die Anerkennung von nicht-staatlicher und geschlechtsspezifischer Verfolgung als Asylgrund abgelehnt. Außerdem verlangte die Union bezüglich der Arbeitsmigration eine Einschränkung von $\S 20$, der die Arbeitsmigration über ein Auswahlverfahren reguliert. Die Union beabsichtigte daraus eine Beibehaltung des Anwerbestopps von 1973. ${ }^{1028}$ Der Bundesrat billigte 2007 ,die Änderungen des seit 2005 geltenden Zuwanderungsgesetzes“"1029 wieder. Direkt im Anschluss an seine Verkündigung im Bundesgesetzblatt sollte ,das umstrittene Gesetz zur Umsetzung aufenthalts- und asylrechtlicher Richtlinien der Europäischen Union in Kraft treten.“1030

Des Weiteren bezog der Bundesrat (BR) im Jahr 2007 umfangreich Stellung ,zu einem europäischen Richtlinienvorschlag, der sich mit der Zuwanderung hochqualifizierter Arbeitnehmer aus Drittstaaten beschäftigt.“"1031 In diesem Zusammenhang wurde vor allem eine spezielle „Aufenthalts- und Arbeitserlaubnis - die so genannte EU Blue Card - eingeführt. In seiner Stellungnahme erkennt der Bundesrat die Bestrebungen der EUKommission an, durch das EU Blue Card Verfahren die europäischen Arbeitsmärkte für Hochqualifizierte attraktiver zu machen. Gleichzeitig fordert der Bundesrat jedoch die

der Länder am EU-Integrationsprozess seit dem Vertrag von Maastricht. Vierow, S. 92.

${ }^{1025}$ Birgelen, Georg 1998: Europapolitische Meinungsbildung in Deutschland. In: Weidenfeld, Werner (Hrsg.) 1998: Deutsche Europapolitik: Optionen wirksamer Interessenvertretung. Bonn, S. 105.

1026 Sontheimer, Kurt / Bleek, Wilhelm 2003: Grundzüge des politischen Systems Deutschlands. S. 361.

${ }_{1027}$ Bundesrat 2003: Pressemitteilungen: Nr. 102/2003: Bundesrat lehnt Zuwanderungsgesetz ab.

${ }^{1028}$ Newsletter ,Migration und Bevölkerung' 2003: Deutschland: Zukunft des Zuwanderungsgesetzes weiter ungewiss; http://www.migration-info.de/mub_artikel.php?Id=031002 (Ausgabe 10/03).

1029 Bommes, Michael / Krüger-Potratz, Marianne (Hrsg.) 2008: Migrationsreport 2008: a.a.O., S. 280.

1030 Bommes, Michael / Krüger-Potratz, Marianne (Hrsg.) 2008: Migrationsreport 2008: a.a.O., S. 280.

1031 Bundesrat 2007: Pressemitteilungen: Nr. 197/2007: Stellungnahme zur EU Blue Card. 
Einhaltung des Subsidiaritätsprinzips und betont erneut die Kompetenz der Mitgliedstaaten zur Regelung des Zugangs zu den nationalen Arbeitsmärkten. “1032 Der BR lehnte ferner die einzelnen Regelungen insbesondere „die geplante Anknüpfung an das Mindesteinkommen als falsches Signal ab, da dies dem hohen Anspruch an die Beschäftigung hochqualifizierter Arbeitnehmer nicht gerecht wird.“1033 Im Jahr 2009 befürwortete der BR den Vertrag von Lissabon und unterstrich „die wesentlichen Fortschritte des Vertrags, von denen insbesondere auch die Regionen und Kommunen betroffen seien.“ Darüber hinaus forderte der BR „die Stärkung der nationalen Parlamente durch das Subsidiaritäts-Frühwarnsystem sowie das Klagerecht der nationalen Parlamente und des Ausschusses der Regionen zum EuGH bei Verstößen gegen das Subsidiaritätsprinzip.“ 1034 Diesbezüglich sind nochmals die europapolitischen Mitwirkungsbefugnisse des Bundesrates zu berücksichtigen, die erfordern, dass „die deutsche Zustimmung zu Änderungen des europäischen Vertragsrechts von einer Zwei-Drittel-Mehrheit im Bundesrat abhängig (Art. 23 Abs. 1

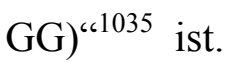

Insgesamt lässt sich der Bundesrat (BR) als wichtiger Akteur festhalten, dessen Funktionslogik sowohl parteipolitisch als auch länderspezifisch und schließlich länderübergreifend föderal gespeist und motiviert wird. ${ }^{1036}$

\footnotetext{
1032 Bundesrat 2007: Pressemitteilungen: Nr. 197/2007: Stellungnahme zur EU Blue Card.

1033 Bundesrat 2007: Pressemitteilungen: Nr. 197/2007: Stellungnahme zur EU Blue Card.

1034 Bundesrat 2008: Pressemitteilungen: Nr. 20/2008: Bundesrat würdigt Vertrag von Lissabon.

1035 Fischer, Thomas 2007: Bundesländer und Bundesrat. In: Schmidt, Siegmar / Hellmann, Gunther / Wolf, Reinhard (Hrsg.) 2007: Handbuch zur deutschen Außenpolitik. Wiesbaden, S. 197.

1036 Sontheimer, Kurt / Bleek, Wilhelm / Gawrich, Andrea 2007: Grundzüge des politischen Systems Deutschlands. München, S. 352.
} 


\section{5 Bundesverfassungsgericht (BVerfG)}

Als politischer Akteur ist das Bundesverfassungsgericht (BVerfG) mit Sitz in Karlsruhe das oberste Gericht Deutschlands, es verkörpert damit ,die Spitze der rechtsprechenden Gewalt" und ist demnach der sogenannte Hüter der Verfassung. ${ }^{1037}$ Hauptaufgabe des BVerfG ist es, „die Einhaltung der Regeln und Wertentscheidungen des Grundgesetzes gegenüber allen Verfassungsorganen wie auch allen Staatsbürgern zu sichern und die verbindliche Interpretation bzw. weitere Entwicklung der Verfassung zu gewährleisten. “1038 In dieser Form ist es offenkundig, dass das BVerfG die Politik in der Bundesrepublik nachhaltig geprägt hat und Beschlüsse $\mathrm{zu}$ den wichtigen innenpolitischen und außenpolitischen Angelegenheiten fasste: Hierzu zählten beispielsweise ,die Überprüfung der Verfassungsverträglichkeit des Weges zur deutschen Einheit“" und die Beschlussfassung zum „Vertrag zur Europäischen Union (,Maastrichter Vertrag') von 1992.“1039

Zudem führte das BVerfG den Begriff des „Kooperationsverhältnisses zum Europäischen Gerichtshof (EuGH)“ ein, d. h., das BVerfG übt seine Gerichtsbarkeit über die Anwendbarkeit von sekundärem Gemeinschaftsrecht zur Gewährleistung des deutschen Grundrechtsschutzes aus. In welcher Art und Weise das BVerfG dieses Verhältnis beachtet, ist unklar. ${ }^{1040}$ Man kann allerdings davon ausgehen, dass das „Kooperationsverhältnis“ die prozessrechtliche Seite des vom BVerfG reklamierten Kontrollanspruchs beschreibt. ${ }^{1041}$ Diesbezüglich stellt sich die Frage, welche Rolle das BVerfG bei der Durchsetzung und Anwendung von europäischem Recht spielt und umgekehrt. BVerfG und EuGH sind bereits im „,Vorabentscheidungsverfahren (Artikel 234 EGV)“ miteinander verknüpft. Bei diesem Verfahren legt das BVerfG dem EuGH vor allem die „Frage der Auslegung und Gültigkeit des Gemeinschaftsrechts“1042 vor.

Als Hüter der Verfassung schließt das BVerfG daneben eine Perspektive im Bereich

1037 Schmidt, Manfred G. 2007: Das politische System Deutschlands: Institutionen, Willensbildung und Politikfelder. München, S. 225.

${ }^{1038}$ Sontheimer, Kurt / Bleek, Wilhelm 2003: Grundzüge des politischen Systems Deutschlands. S. 343.

1039 Schmidt, Manfred G. 2007: Das politische System Deutschlands: a.a.o., S. 230.

1040 Büdenbender, Martin 2004: Das Verhältnis des Europäischen Gerichtshofs zum Bundesverfassungsgericht (Diss. Uni Bonn). Bonn, S. 151.

1041 Schneider, Jens-Peter 1994: Effektiver Rechtsschutz Privater gegen EG-Richtlinien nach dem Maastricht-Urteil des Bundesverfassungsgerichts, AöR 119 (1994), S. 294-320.

1042 Hitzel-Cassagnes, Tanja 2000: Der Europäische Gerichtshof: Ein europäisches „Verfassungsgericht“? In: Aus Politik und Zeitgeschichte (APuZ), B 52-53/2000. Bonn, S. 23. 
Ausländerwahlrecht ein. Das BVerfG hat 1990 in seiner Entscheidung zum kommunalen Wahlrecht zwei Wege eröffnet: ${ }^{1043}$ 1. Änderung des Grundgesetzes (GG) in Artikel 28, der die kommunale Selbstverwaltung gewährleistet, sodass zumindest den EU-BürgerInnen das kommunale Wahlrecht gewährt wird. Dieses beschlossen Bundestag (BT) und Bundesrat (BR) 1992 mit der Zweidrittelmehrheit und führten es im Maastrichter Vertrag von 1993 ein. 2. Einbürgerungserleichterung durch die Novellierung des Staatsangehörigkeitsrechts im einfachen Gesetzgebungsverfahren. Dieses erfolgte mit der Verabschiedung des Staatsangehörigkeitsgesetzes (StAG) im Jahr 1999 nach heftigen migrationspolitischen Debatten. Auch das BverfG stärkte in einem Beschluss am 10. Mai 2007 den Schutz von langjährig in Deutschland lebenden Ausländern vor Ausweisung. ${ }^{1044}$ Des Weiteren verfolgte das BVerfG durch den Vertrag von Lissabon 2009 die Absicht, Fortschritte im Bereich der illegalen Einwanderung zu erzielen. Das BVerfG hat sich erstmals vollständig mit der Frage einer Strafrechtsannexkompetenz innerhalb der EU-Sanktionsrichtlinie (RL 2009/52/EG) im Rahmen des sog. Lissabon-Urteils beschäftigt und die Bestandsanforderungen einer solchen Kompetenz an den Maßstäben des Grundgesetzes ausgeführt. ${ }^{1045}$

Mit der zunehmenden Europäisierung der Rechtsordnung im Politikfeld Migration ist das Bundesverfassungsgericht (BVerfG) im Verhältnis zum EuGH somit „Teil einer Gesamtarchitektur von Verfassungsgerichten“"1046 in und für die EU geworden. Der entsprechende Wandel vollzog sich bereits mit dem Inkrafttreten des Lissabonner Vertrags (Dezember 2009). Mit seinem Lissabon-Urteil vom 30. Juni 2009 ermöglichte das BVerfG die weitere Stärkung der Mitwirkungsrechte von Bundestag (BT) und Bundesrat (BR), ${ }^{1047}$ damit Deutschland hohen Einfluss auf der EU-Ebene erzielen kann.

\footnotetext{
1043 Storz, Henning / Wilmes, Bernhard 2007: Wahlrecht und Einwanderung. Im Internet: http://www.bpb.de/themen/R8AQSN,0,0,Wahlrecht_und_Einwanderung.html (15.05.2007).

$1044 \mathrm{http} / /$ www.bundesverfassungsgericht.de/entscheidungen/rk20070510 2bvr030407.html (05.03.2008).

1045 Hörich, Carsten 2010: Die Sanktionsrichtlinie-Zündstoff zwischen EuGH und BVerfG? In: Zeitschrift für Ausländerrecht und Ausländerpolitik (ZAR), 30. Jahrgang, 2/2010. Baden-Baden, S. 51.

1046 Wahl, Rainer 2001: Das Bundesverfassungsgericht im europäischen und internationalen Umfeld. In : Aus Politik und Zeitgeschichte (APuZ) B 37-38/2001. Bonn, S. 45-54, hier S. 52.

1047 Das Bundesverfassungsgericht (Hrsg.) 2010: Entscheidungen des Bundesverfassungsgerichts. Nr. 9. Urtiel des Zweiten Senats vom 30. Juni 2009. Vertrag von Lissabon. Tübingen, S. 267-268.
} 


\section{6 Kommunen}

Die Kommunen, bestehend aus Gemeinden und Kreisen, sind ,in den Flächenstaaten die dritte politisch-administrative Ebene der Bundesrepublik“, obwohl sie „staatsrechtlich den Ländern zugeordnet sind.““1048 In den Länderverfassungen gibt es entsprechende Selbstverwaltungsgarantien, „die traditionell für das Kommunalrecht zuständig sind.“1049 Die letztendliche Entscheidungskompetenz liegt jedoch ,im dualen System beim Rat.“1050 Die Kommunen partizipieren dabei zwar nicht direkt an den Verhandlungen im Bundestag (BT) und Bundesrat (BR), sie sind dennoch durch das Gesetz an der staatlichen Umsetzung und Ausübung beteiligt.

Betrachtet man die doppelte Politikverflechtung von Bund und Ländern sowie EU kann man den Kommunen durchaus eine Schlüsselrolle für Integration nicht absprechen. Es stellt sich hier die Frage, inwieweit diese Tatsache dazu veranlassen sollte, Integrationspolitik zu einem Zentrum der kommunalen Politik zu machen. Viele Kommunen haben dies vor allem in dem Motto „Integration findet vor Ort statt erhoben. Dabei sind Arbeitsmarkt und Bildung die zentralen Felder, in denen sich die wesentliche Integration von Zuwanderern entscheidet. In beiden Bereichen haben jedoch die Kommunen keine spezifischen Kompetenzen, denn für die Bildungspolitik sind die Länder zuständig, und die Arbeitsmarktpolitik wird auf Bundesebene geregelt. Durch „die Änderungen des II. Sozialgesetzbuchs im Rahmen der sogenannten HartzReform und der Einführung von Integrationskursen für Neuzuwanderer“" 1052 im Rahmen des Zuwanderungsgesetzes (ZuWG) 2005 gewannen die Kommunen seit 2005 neue Aufgaben hinzu, die zuvor nicht direkt in ihre Zuständigkeit fielen. So wird in den „Arbeitsgemeinschaften der Bundesagentur für Arbeit und Kommunen (ARGEn)“ z. B. durch „Job-Center“" lokale Integrationspolitik in den Bereichen Arbeitsmarktvermittlung und Sprachförderung zusammengeführt. ${ }^{1053}$ In der Kompetenz der Landesregierungen liegt ebenfalls die Bildungspolitik. Hierbei bezeichnet die Bildungssituation bzw. „die ethnische Segregation von Schülern“ eines der wichtigsten Themen der

\footnotetext{
1048 Ismayr, Wolfgang 2006: Das politische System Deutschlands. In: Ismayr, Wolfgang (Hrsg.) 2006: Die politischen Systeme Westeuropas. Wiesbaden, S. 445-486, hier S. 477.

1049 Ismayr, Wolfgang 2006: Das politische System Deutschlands. In: a.a.O., S. 477.

1050 Ismayr, Wolfgang 2006: Das politische System Deutschlands. In: a.a.O., S. 478.

1051 Bommes, Michael 2008: „Integration findet vor Ort statt“ - über die Neugestaltung kommunaler Integrationspolitik. In: Bommes, Michael / Krüger-Potratz, Marianne (Hrsg.) 2008: a.a.O., S. 165.

1052 Häußermann, Hartmut / Kapphan, Andreas 2008: Integrationspolitik der Städte - ein Paradigmenwechsel. In: Bommes, Michael / Krüger-Potratz, Marianne (Hrsg.) 2008: a.a.O., S. 32.

1053 Häußermann, Hartmut / Kapphan, Andreas 2008: Integrationspolitik der Städte - a.a.O., S. 32.
} 
Kommunalpolitik. ${ }^{1054}$ Als Reaktion auf die ethnische Segregation entstehen in den letzten Jahren vor allem ,,in den Kindergärten und Kindertagesstätten“ allerorts „Angebote der Sprachförderung für Kinder.“"1055 Außerdem gelten im Bereich der politischen Partizipation bis heute das Kommunalwahlrecht in Deutschland nur für EUBürgerInnen. Diesbezüglich verfestigten die EU-Mitgliedstaaten im Reformvertrag von Lissabon 2007/09 die Einführung einer Unionsbürgerschaft: „Jede Bürgerin und jeder Bürger der Union hat nicht nur die Staatsangehörigkeit des eigenen Landes, sondern auch die Unionsbürgerschaft. [...]. Dazu gehört das Wahlrecht zu den Kommunal- und Europawahlen unabhängig vom Wohnort.“ ${ }^{1056}$ Jedoch sind die eingebürgerte MigrantInnen, also deutsche Staatsangehörige aus Nicht-EU-Staaten, teilweise wahlberechtigt und wählbar.

Die hier genannten wichtigen Themen der Kommunalpolitik werden allerdings bisher nur in einigen Städten unstrukturiert angegangen und/oder weisen deutliche Lücken auf. Dabei wirkt sich auch die finanzielle Krise der Kommunen deutlich auf wesentliche Bereiche der kommunalen Daseinvorsorge aus. Inwieweit sich insofern Versuche des Aufbaus einer kommunalen Migrationspolitik vor allem im Bereich der Integration realisieren lassen, bleibt noch abzuwarten.

1054 Häußermann, Hartmut / Kapphan, Andreas 2008: Integrationspolitik der Städte - a.a.O., S. 32.

1055 Häußermann, Hartmut / Kapphan, Andreas 2008: Integrationspolitik der Städte - a.a.O., S. 34.

1056 Presse- und Informationsamt der Bundesregierung 2007: Eine neue Grundlage für Europa: Der Vertrag von Lissabon. Berlin, S. 5. 


\section{7 Nichtregierungsorganisationen (NGOs)}

Die nationalen- und transnationalen Nichtregierungsorganisationen (NGOs) sowie die freien Wohlfahrtsverbände spielen zunehmend eine wichtige Rolle im Bereich der Migrationspolitik, die vorwiegend „mit Hilfe öffentlicher Zuschüsse“ ${ }^{\text {1057 betrieben }}$ werden. Auch die Positionen der NGOs erstrecken sich freilich von „Gesetzentwürfen“ bis hin zu „einem späten Entwicklungsstadium.“1058 Die NGOs engagieren sich insbesondere maßgeblich für die Entwicklung einer gemeinsamen integrationspolitischen und auch menschenrechtlichen Agenda. Diesbezüglich lässt sich festhalten, dass vor allem ,in der Vorbereitung zum Vertrag von Amsterdam ein verstärktes Engagement" der NGOs zu konstatieren war. ${ }^{1059}$ Eine Vielzahl von NGOs vereinten dabei ihre Vorschläge im „Starting Point Programm“, welches z. B. im Bereich der Integrationspolitik verlangte, „die Unionsbürgerschaft und die damit verbundenen Rechte auf diejenigen Drittstaatsangehörigen $\mathrm{zu}$ übertragen, die mindestens seit fünf Jahren“ legal sesshaft sind. Somit erhöhten die NGOs „den normativen Druck auf die Nationalstaaten.“ 1060

Auch im Bereich der Asyl- und Flüchtlingspolitik üben heutzutage einige NGOs in Deutschland z. B. mit der Kampagne „Jetzt erst Recht(e) für Flüchtlingskinder!، ‘061 scharfe Kritik am Umsetzungswillen der Politik. Dr. Sabine Skutta, Sprecherin der National Coalition für die Umsetzung der UN-Kinderrechtskonvention in Deutschland, kritisierte: „Die eklatante Unterschreitung des Existenzminimums bei Flüchtlingskindern durch das Asylbewerberleistungsgesetz verletzt das Grundgesetz und geltendes Völkerrecht،““1062 Beispielsweise erhält „ein 6-jähriges Kind im Hartz-IVBezug 251 Euro monatlich, ein gleichaltriges Flüchtlingskind muss mit 132 Euro mit fast der Hälfte auskommen. Das sind 4,40 Euro pro Tag für Nahrung, Kleidung,

\footnotetext{
1057 Ismayr, Wolfgang 2006: Das politische System Deutschlands. In: Ismayr, Wolfgang ... a.a.O., S. 471.

1058 Ismayr, Wolfgang 2006: Das politische System Deutschlands. In: Ismayr, Wolfgang ... a.a.O., S. 471.

1059 Rosenow, Kerstin 2008: Die Entstehung einer integrationspolitischen Agenda auf der Ebene der Europäischen Union. In: Hunger, Uwe / Aybek, Can M. / Ette, Andreas / Michalowski, Ines (Hrsg.) 2008: Migrations- und Integrationsprozesse in Europa: Vergemeinschaftung oder nationalstaatliche Lösungswege?. Wiesbaden, S. 123-142, hier S. 133.

1060 Rosenow, Kerstin 2008: Die Entstehung einer integrationspolitischen Agenda auf der Ebene der Europäischen Union. In: Hunger, Uwe u. a. a.a.O., S. 133.

1061 Pro Asyl 2012: Presseerklärung: Bilanz: Ein Jahr Kampagne ,Jetzt erst Recht(e) für Flüchtlingskinder!“; http://www.proasyl.de/de/presse/detail/news (Stand: 04.06.2012).

1062 Pro Asyl 2012: Presseerklärung: Bilanz: Ein Jahr Kampagne ,Jetzt erst Recht(e) für Flüchtlingskinder!“; http://www.proasyl.de/de/presse/detail/news (Stand: 04.06.2012).
} 
Hygiene, Bildung etc.“1063 Die vertretenen NGOs dieser Kampagne fordern daraufhin folgende zentrale Punkte: „Das Kindeswohl muss als vorrangig zu berücksichtigendes Prinzip im Asyl- und Aufenthaltsrecht verankert werden. Die Verfahrensmündigkeit muss auf 18 Jahre heraufgesetzt werden. Die Mangelversorgung nach dem Asylbewerberleistungsgesetz muss beendet werden. Abschiebungen von Minderjährigen in andere EU-Staaten müssen unterbleiben (Dublin-Verfahren). Abschiebungshaft für Minderjährige muss verboten werden. “1064

Des Weiteren verlangt PRO ASYL ein „Ende des deutschen Rückübernahmeabkommens mit Syrien. “' ${ }^{1065}$ Diesbezüglich berichtete die Organisation schon „vor Abschluss des Abkommens über das Ausmaß der Menschenrechtsverletzungen in Syrien. Auch in den Berichten des Auswärtigen Amtes finden sich regelmäßig ausreichende Hinweise z. B. auf mit Folter einhergehende willkürliche Inhaftierungen.“1066

Insgesamt versuchen die NGOs als Interessengruppen somit in allen Bereichen der politischen Entscheidungsprozesse und auf allen Ebenen des Föderalismussystems Einfluss zu nehmen. Ihr Interesse an einer Europäisierung der Migrationspolitik wird jedoch von finanzieller Stabilität und von der Stärkung ihrer Legitimität ${ }^{1067}$ abhängen.

\footnotetext{
1063 Pro Asyl 2012: Presseerklärung: Bilanz: Ein Jahr Kampagne ... a.a.O.

1064 Pro Asyl 2012: Presseerklärung: Bilanz: Ein Jahr Kampagne „Jetzt erst Recht(e) für Flüchtlingskinder!“; http://www.proasyl.de/de/presse/detail/news (Stand: 04.06.2012)

1065 Pro Asyl 2012: Presseerklärung: PRO ASYL fordert Ende des deutschen Rückübernahmeabkommens mit Syrien; http://www.proasyl.de/de/presse/detail/news (Stand: 04.06.2012).

1066 Pro Asyl 2012: Presseerklärung: PRO ASYL fordert Ende des deutschen Rückübernahmeabkommens mit Syrien; http://www.proasyl.de/de/presse/detail/news (Stand: 04.06.2012).

1067 Rosenow, Kerstin 2008: Die Entstehung einer integrationspolitischen Agenda ...a.a.O., S. 133.
} 


\section{8 Parteien}

Politische Parteien sind, so Max Weber, „freiwillig geschaffene und auf freie, notwendig stets erneute, Werbung ausgehende Organisationen“"1068, die interessengeleitet handeln. Legt man Webers Parteienbegriff zugrunde, ergeben sich die wichtigsten Funktionen politischer Parteien im politischen System der Bundesrepublik Deutschland genauer. Klaus von Beyme nennt bereits in seiner vergleichenden Untersuchung der Parteien in westlichen Demokratien vier Funktionen, die von den Parteien wahrgenommen werden sollen: ${ }^{1069}$ 1. die „Zielfindungsfunktion“ durch Programme oder ideologische Festlegung, 2. die „Artikulation und Aggregation“ gesellschaftlicher Interessen (Aggregationsfunktion), 3. die „Mobilisierung und Sozialisierung“ der Bürger (Mobilisierungs- und Integrationsfunktion) und 4. die Rekrutierung der politischen Elite und der Regierungsmitglieder (Elitenrekrutierungs- und Regierungsbildungsfunktion).

Die Vormachtstellung der Parteien innerhalb der Interessenvermittlung zwischen Bürgern und Staat in der Bundesrepublik wurde bisher von fünf Gruppierungen genutzt: $^{1070}$ Den Unionsparteien CDU/CSU, der SPD und den kleineren Parteien FDP, Bündnis 90/Die Grünen und Die Linke. Die wichtigsten heute in den Parlamenten vertretenen Parteien können anhand von zwei Koordinaten auf der Achse der StaatMarkt-Arbeitsteilung von links bis rechts und auf der Liberalismus-KonservatismusAchse vom liberal-libertären bis zum konservativen Pol eingeordnet werden. ${ }^{1071}$

Mit Blick auf die Funktionen von politischen Parteien stellen sich folgende zentrale Fragen: Welche Rolle spielen die politischen Parteien im Bereich Migration? Welche Konzepte vertreten sie? Welche Folgen sind damit für die Gemeinschaft von Deutschen und Migranten verbunden und welche Bedeutung kommt der Europäisierung zu?

\footnotetext{
1068 Weber, Max 1988 (Erstausgabe: 1918): Parlament und Regierung im neugeordneten Deutschland. Zur politischen Kritik des Beamtentums und Parteiwesens. In: Weber, Max: Gesammelte Politische Schriften, hg. v. Johannes Winkelmann. Tübingen, S. 306-443, hier S. 324.

1069 Beyme, Klaus von 1984: Parteien in westlichen Demokratien. München, S. 25. Zitiert nach Niclauß, Karlheinz 1995: Das Parteiensystem der Bundesrepublik Deutschland: eine Einführung. S. 11.; vgl. Poguntke, Thomas 2005: Politische Parteien. In: Gabriel, Oscar W. / Holtmann, Everhard (Hrsg.) 2005: Handbuch Politisches System der Bundesrepublik Deutschland. (S. 623-652), S. 628.

1070 Schmidt, Manfred G. 2007: Das politische System Deutschlands: a.a.O., S. 85 f.

1071 Schmidt, Manfred G. 2007: Das politische System Deutschlands: a.a.O., S. 86.
} 


\section{8. 1 CDU und CSU}

Angesichts des durchschnittlichen Stimmenanteils bei Bundestagswahlen stellt die Union aus CDU (Christlich-Demokratische Union) und ihrer bayerischen Schwesterorganisation der CSU (Christlich-Soziale Union) die größte Parteienformation der Bundesrepublik dar. ${ }^{1072}$ Bis heute haben sich die Unionsparteien CDU und CSU im Themenfeld Schritt für Schritt von konservativen Positionen abgewandt. Bereits mit dem Motto ihres Wahlprogramms 2005, „Zuwanderung begrenzen, Integration stärken“, hielten die Unionsparteien fest, dass sie zwar neue Einwanderung ablehnten, allerdings die Integration der bereits wohnhaften MigrantInnen befürworteten. ${ }^{1073}$ In dieser Hinsicht zielten die Unionsparteien vor allem auf die Einwanderungsreglementierung des Arbeitsmarktes für Hochqualifizierte und Mangelberufe sowie auf die Forderung nach verpflichtender Teilnahme an Integrationskursen für Neueinwanderer. ${ }^{1074}$ Hierbei erfüllte die Einwanderungserleichterung von Hochqualifizierten aus Nicht-EU-Staaten als eine neue Einwanderungspolitik ihr Ziel. Des Weiteren erklärten der innenpolitische Sprecher der CDU und CSU-Bundestagsfraktion, Hans-Peter Uhl (MdB) und der zuständige Berichterstatter, Reinhard Grindel (MdB) im Rahmen der Diskussion über die „Einführung eines Punktesystems für ausländische Arbeitskräfte“ im Jahr 2008 das Folgende: „Die Einführung eines Punktesystems würde zu einer ungesteuerten Zuwanderung ausländischer Arbeitskräfte auf den deutschen Arbeitsmarkt führen. Wir wollen daran festhalten, dass Ausländer nur dann ein Aufenthaltsrecht erhalten, wenn sie einen konkreten Arbeitsplatz nachweisen können. [...]. Mit der Beibehaltung der Vorrangprüfung wird verhindert, dass willige und billige ausländische Arbeitskräfte in eine unfaire Konkurrenz zu heimischen Arbeitslosen treten [...].“ ${ }^{1075}$

Insgesamt verbirgt sich hinter der Migrationspolitik der CDU und CSU insbesondere, die Arbeitsmigration stärker $\mathrm{zu}$ liberalisieren und zugleich systematisch zu restriktivieren.

\footnotetext{
1072 Schmidt, Manfred G. 2007: Das politische System Deutschlands: Institutionen, Willensbildung und Politikfelder. München, S. 86.

1073 Bundesministerium des Inneren 2006: Zuwanderungsrecht und Zuwanderungspolitik. Berlin, S. 10.

1074 Newsletter ,Migration und Bevölkerung' 2005: Deutschland: Wahlprogramm im Vergleich. Im Internet: http://www.migration-info.de/mub_artikel.php?Id=050702 (Ausgabe 07/05).

1075 Uhl, Hans-Peter / Grindel, Reinhard 2008: Zuwanderung: Punktesystem führt zu ungesteuerter Zuwanderung. Abrufbar unter http://www.cdu.de/archiv/2370_24547.htm (Stand: 14.10.2008).
} 


\section{8. 2 SPD}

Die Sozialdemokratische Partei Deutschlands (SPD) wird hauptsächlich durch Begriffe einer demokratischen, sozialreformerischen Mitte-links-Partei geprägt. ${ }^{1076}$ Die SPD legte bislang ein ausdrückliches Bekenntnis dazu ab, dass Deutschland ein Einwanderungsland sei. Im Rahmen des Grundsatzprogrammes 2007 verlangte die SPD darüber hinaus Integration, faire Chancen, aber auch klare Regeln sowie keine Diskriminierung der MigrantInnen: „Wir streben die Einbürgerung der zu uns kommenden Menschen an. Sie ist nicht das Ende der Integration, aber sie ermöglicht die volle politische Teilhabe. Dabei schließen wir Mehrstaatlichkeit nicht aus. Denen, die noch nicht die deutsche Staatsbürgerschaft haben, aber schon längere Zeit hier leben, wollen wir das kommunale Wahlrecht geben, auch wenn sie nicht aus EU-Staaten kommen. Wir stehen zum Grundrecht auf Asyl für politische Verfolgte.“1077 Ebenfalls im Jahr 2009 verlegte die SPD das Papier „Eckpunkte für eine kohärente Migrationspolitik in Deutschland und in Europa“, in dem sie sich für eine moderne Einwanderungspolitik aussprach (z. B. Einführung eines Punktesystems, das Kommunalwahlrecht). ${ }^{1078}$ Des Weiteren erklärten sich die Grundzüge einer solchen kohärenten Migrationspolitik der SPD wie folgt: „Auf die ,Vorrangprüfung', nach der deutsche Bewerber oder EU-Bürger Vorrang beim Zugang $\mathrm{zu}$ einem Beschäftigungsverhältnis genießen, will die SPD beim Punktesystem verzichten. Erweitert werden soll es aber durch ein sogenanntes ,Engpassverfahren“ für Fachkräfte je nach Bedarf. [...]. Bei Erweiterungsrunden der EU plant die SPD die Übergangsfristen für die Arbeitnehmerfreizügigkeit zu verkürzen. Zudem fordert sie die rechtliche Gleichstellung von Flüchtlingen und Personen, die Flüchtlinge auf Basis der Europäischen Menschenrechtskonvention (EMRK) sind, aber nicht die Voraussetzungen der Genfer Flüchtlingskonvention (GFK) erfüllen.“1079

Insgesamt unterstützt die SPD eine moderne Migrationspolitik, die zugleich auf eine Europäisierung der deutschen Migrationspolitik zielt.

\footnotetext{
${ }^{1076}$ Lösche, Peter 2003: SPD - Sozialdemokratische Partei Deutschlands. In: Andersen, Uwe / Woyke, Wichard (Hrsg.) 2003: Handwörterbuch des politischen Systems der Bundesrepublik Deutschland. Opladen, S. 572-577.

1077 Beschluss der Programmkommission (SPD) 2007: Soziale Demokratie im 21. Jahrhundert: Grundsatzprogramm der Sozialdemokratischen Partei Deutschlands. Empfehlungen zum „Bremer Entwurf" für ein neues Grundsatzprogramm der SPD. 22. September 2007, Punkt 42 f., S. 19-20.

1078 SPD-Bundestagsfraktion: Pressemitteilung vom 04.03.2009. Nr. 177/2009; www.spdfraktion.de

1079 Newsletter ,Migration und Bevölkerung' 2009: Deutschland: SPD will „moderne Migrationspolitik“. http://www.migration-info.de/mub_artikel.php?Id=090402 (Ausgabe $04 / 2009$ ).
} 


\section{8. 3 Bündnis 90/Die Grünen}

Die Partei Bündnis 90/Die Grünen steht für links-liberale Positionen und ist aufgrund der starken Verankerung in sozialen Bewegungen auch im Policy-Netz mit der Interessenkoalition einflussreich. ${ }^{1080}$ Die Grünen beschrieben ihre Kernanliegen insbesondere im Wahlprogramm von 2005: Zum Beispiel forderte die Grüne für die illegalen MigrantInnen das Anrecht auf „Gesundheitsversorgung, Schulbesuch und Lohn für ihre Arbeit“" und engagierte sich für ,ein Angebot zur Legalisierung“ nach dem Vorbild der USA. ${ }^{1081}$ Überdies betonten die Grünen im Europawahlprogramm 2009 folgende Position: „Nicht-EU-Staatsbürger, die ihren ständigen Wohnsitz in der EU haben, sollen entsprechend der für EU-Bürger geltenden Fristen ein Kommunalwahlrecht erhalten und nach maximal fünf Jahren das Recht erhalten, die Staatsangehörigkeit des jeweiligen EU-Staates annehmen zu können. [...]. Wir wollen, dass die Bundesregierung die Beschränkung der Arbeitnehmerfreizügigkeit sofort beendet. [...]. Wir wollen die konsequente Durchsetzung des Grundrechts auf Asyl auf europäischer Ebene. [...]. Die Dublin-II-Verordnung ist ein Instrument der von BÜNDNIS 90/DIE GRÜNEN als inhuman erachteten Drittstaatenregelung. Wir wollen eine Reform der EU-Rückführungsrichtlinie und insbesondere Bestimmungen zur Abschiebehaft für Minderjährige und der Wiedereinreisesperre zurücknehmen. [...]. Wir wollen keine Militärisierung der Außengrenzen oder eine Flüchtlingsabwehrpolitik, wie sie bisher durch die ,Europäische Agentur für die operative Zusammenarbeit an den Außengrenzen (FRONTEX) vorangetrieben wird. [...]. GRÜNE stehen für eine längerfristig angelegte Einwanderungspolitik - nicht nur für Höchstqualifizierte, die eine Bereicherung der EU in kultureller, demographischer und auch ökonomischer Hinsicht darstellt. [...]. Darüber hinaus fordern GRÜNE nationale Modelle zur sogenannten Punktemigration, die auf europäischer Ebene koordiniert werden. “1082

Zusammenfassend zeigen Bündnis 90/Die Grünen im Unterschied zu den anderen Parteien eine große Bereitschaft, ihre Positionen auf EU-Ebene durchzusetzen und sehen die Durchsetzung ihrer Interessen als Garantie für eine multikulturelle Entfaltung und Integration der Migranten.

\footnotetext{
1080 Sontheimer, Kurt u. a. 2007: a.a.O., S. 235-240; Schmidt, Manfred G. 2007: a.a.O., S. 94-95.

1081 Newsletter ,Migration und Bevölkerung' 2005: Deutschland: Wahlprogramm im Vergleich http://www.migration-info.de/mub_artikel.php?Id=050702 (Ausgabe 07/2005).

1082 BÜNDNIS 90/DIE GRÜNEN (Hrsg.) 2009: Europawahlprogramm 2009: Für ein besseres Europa. Berlin, S. 79 u. S. 116-120. Im Internet: http://www.gruene.de (Stand: 07.06.2009).
} 


\section{8. 4 FDP}

Die FDP (Die Freie Demokratische Partei) gilt vorwiegend als traditionelle Partei des Liberalismus, wobei seit vielen Jahren die Forderung nach einer marktliberalen Wirtschaftspolitik im Vordergrund steht. ${ }^{1083}$ Ihre Positionen zur Migrationspolitik verdeutlichte die FDP bereits im Bundestagswahlprogramm 2009 an folgenden Kernpunkten: „Die Liberalen fordern die Einführung eines Punktesystems. Mit ihrem Auswahlverfahren zielen die Liberalen zunächst auf Hochqualifizierte und Fachkräfte verschiedenster Berufe. [...]. Die FDP steht dafür ein, dass die Integration durch die doppelte Staatsbürgerschaft gefördert wird, dieses ist als Gegenposition zu den Unionsparteien zu verstehen. “1084

Außerdem zeigte die FDP in jüngster Zeit vermehrt Interesse an der Einwanderung von Hochqualifizierten und verlangte Maßnahmen, die den niedrigen Zuzugszahlen von ausländischen Fachkräften entgegenwirken: Die Grundbedingungen für Hochqualifizierte sollten gelockert werden, vor allem die Einkommensgrenze sei zu senken und auf die Beibehaltung der Vorrangprüfung für Hochqualifizierte zu verzichten. ${ }^{1085}$ Dieser Vorschlag wurde vom ehemaligen Bundeskanzler Schröder und seiner Regierung bei der Veränderung des Zuwanderungsgesetzes (ZuWG) nicht beachtet, somit beinhaltet die Reform des Zuwanderungsgesetzes von 2007 keine neuen Regelungen im Politikfeld der Arbeitsmigration von Hochqualifizierten. ${ }^{1086}$

Insgesamt setzt die FDP als größte Oppositionspartei ${ }^{1087}$ etwas andere Akzente und weist vor allem bei ihrer medialen Darstellung ein hohes Innovationspotenzial in der Migrationspolitik auf. Ihre klaren Konzepte glänzen dabei durch besonders konkrete und weitreichende Forderungen. Die Einführungsschwierigkeiten bleiben unverkennbar.

1083 Dittberner, Jürgen 2005: Die FDP. Geschichte, Personen, Organisation, Perspektiven. Eine Einführung. Wiesbaden.

1084 FDP 2009: Beschluss: Die Mitte stärken. Deutschlandprogramm der Freien Demokratischen Partei. 60. Ord. Bundesparteitags der FDP in Hannover, 15.-17. Mai 2009. S. 36-37.

1085 FDP-Bundestagsfraktion 2007: Pressemitteilung vom 23. Oktober 2007. Berlin.; hierzu vgl. FDPBundestagsfraktion 2008: Presseinformation vom 27.08.2008. Nr. 1083. http:/www.fdp-fraktion.de

1086 Tietze, Klaudia 2008: Migration von Hochqualifizierten im Kontext der Entwicklung der Einwanderungskonzepte deutscher Parteien. In: a.a.O., S. 47.

1087 Bösch, Frank 2002: Bereit für den Wechsel? Die strategische und inhaltliche Positionierung von CDU/CSU und FDP vor der Bundestagswahl 2002. In: Aus Politik und Zeitgeschichte (APuZ) B21/2002. S. 13-21, hier S. 17. 


\section{8. 5 Die Linke}

Die Linke, die am 16. Juni 2007 offiziell gegründet wurde, ${ }^{1088}$ vertritt einen demokratischen Sozialismus. ${ }^{1089}$ Bereits im Bundestagswahlprogramm 2009 stellte sie wichtige Punkte in ihrer Migrationspolitik vor: „Migrationspolitik nach arbeitsmarktlichen Nützlichkeitskriterien beenden; keine Abschiebung von Menschen aus Kriegsgebieten und wegen politischer Verfolgung; aktives und passives kommunales Wahlrecht gewähren; Einbürgerung erleichtern; doppelte Staatsbürgerschaften ermöglichen; länger hier lebenden Menschen - unabhängig von ihrem ausländerrechtlichen Status - ein gesichertes Bleiberecht gewähren; das Asylrecht im Grundgesetz substantiell wiederherstellen; die Genfer Flüchtlingskonvention und die Europäische Menschenrechtskonvention uneingeschränkt gelten lassen und die UNKinderrechtskonvention vollständig umsetzen; für Hunderttausende „Illegale“ elementare Menschenrechte wie die Behandlung von Erkrankungen sichern; behördliche Meldepflichten aussetzen; Perspektiven eines legalen Aufenthalts schaffen; auf europäischer Ebene eine menschenrechtlich fundierte Asylpolitik durchsetzen; die Grenzschutzagentur FRONTEX abschaffen; die unfreiwillige Verschiebung von Flüchtlingen nach dem ungerechten Zuständigkeitsprinzip (Dublin II-Verordnung) verbieten, faire Asylverfahren sichern, Sammellager abschaffen sowie geschlechtsspezifische und nichtstaatliche Verfolgung als Asylgrund anerkennen.“1090 Auch zu den Fragen des Einbürgerungstests erklärte Ali Al Dailami, migrationspolitischer Sprecher Die Linke im Jahr 2008: „Eine gelungene Integration zeichnet sich nicht durch das Bestehen des Einbürgerungstest, sondern vielmehr durch gleiche soziale, politische und wirtschaftliche Teilhabe von MigrantInnen aus. “1091

Im Ganzen befindet sich Die Linke in Übereinstimmung mit den Einstellungen und Positionen vieler MigrantInnen in Deutschland. Ihre Ziele werden oft in bewusster Abgrenzung zu den Positionen der aktuellen Regierungspolitik formuliert.

${ }^{1088}$ Sontheimer, Kurt / Bleek, Wilhelm / Gawrich, Andrea 2007: Grundzüge des politischen Systems Deutschlands. München, S. 241-243.; vgl. Bleek, Wilhelm 2003: PDS-SED. In: Woyke, Wichard / Andersen, Uwe (Hrsg.) 2003: Handwörterbuch des politischen Systems der Bundesrepublik Deutschland. Opladen, S. 475-480.; vgl. http://www.bpb.de/themen/FX7NMJ,0,DIE_LINKE.html

1089 Vgl. Dürr, Tobias 2002: Die Linke nach dem Sog der Mitte. In: Aus Politik und Zeitgeschichte (APuZ) B21/2002. S. 5-12, hier S. 10.

1090 DIE LINKE 2009: Bundestagswahlprogramm der Partei DIE LINKE: Konsequent sozial. Für Demokratie und Frieden. (Leitantrag des Parteivorstandes an den Bundestags-Wahlparteitag 2009 der Partei DIE LINKE am 20./21. Juni in Berlin. S. 20-34. Abrufbar unter: http://die-linke.de

${ }^{1091}$ Die Linke 2008: Pressemitteilung vom 08. Juli 2008. Im Internet: http://die-linke.de/nc/presse 


\subsection{Fazit}

Die deutsche Migrationspolitik kann vorliegend als eine Form der Interessenpolitik durch die Akteure im deutschen Migrationssystem betrachtet werden. Hierbei sind durchgängig historisch die Bundesregierung und Bundeskanzler(in) als Hauptakteure auf dem Politikfeld Migration zu sehen sowie das Bundesministerium des Innern (BMI) als Teilakteuer der Bundesregierung mit entscheidendem Einfluss auf EU-Ebene. Während des Europäisierungsprozesses werden die deutschen Interessen von den deutschen Akteuren insbesondere im Hinblick auf nationalstaatliche Souveränität, Sicherheit und wirtschaftliche Nützlichkeit bzw. arbeitsmarktbezogene Migrationssteuerung wahrgenommen. Der Bundestag hat daneben durch die europäische Integration relativ wenig Funktionsfähigkeit erfahren, was sich erst mit dem Vertrag von Maastricht geändert hat. Durch den Artikel 23 GG erhält der Bundestag gestärkte Mitwirkungsrechte bezüglich seiner europapolitischen Beteiligung im Bereich Migration, bleibt aber im Wesentlichen von der Bundesregierung abhängig. Die Bundesländer forderten vom Bund vermehrte Mitwirkungsrechte in der Migrationspolitik und wurden mit ihren Belangen dabei erfolgreicher als der Bundestag berücksichtigt. Dem Bundesrat soll mit der Regelung des Artikels 23 Absatz 5 Satz 2 GG die Option eröffnet werden, auf die ihn betreffenden europäischen Regeln mittelbaren Einfluss zu nehmen. Bei einer Grundgesetzänderung handelt es sich hier sogar um eine Zweidrittelmehrheit des Bundestages und Bundesrates. Der Bundesrat konnte besonders im Laufe des Jahres 2005 im Rahmen des Zuwanderungsgesetzes (ZuWG) und des Richtlinienumsetzungsgesetzes 2007 vermehrt politischen Einfluss auf den Entscheidungsprozess gewinnen. Als „Hüter der Verfassung“ hat auch das Bundesverfassungsgericht (BVerfG) die Einführung der Migrationspolitik in der Bundesrepublik gestärkt. Das Kooperationsverhältnis der EU bzw. EuGH hatte das BVerfG besonders in seiner Maastricht-Entscheidung 1992/1993 sowie in seiner Amsterdam-Entscheidung 1997/1999 bekräftigt. Das BVerfG ermöglichte indessen mit seinem neuen Lissabon-Urteil vom 30. Juni 2009 die weitere Stärkung der Mitwirkungsrechte von Bundestag und Bundesrat, damit Deutschland einen vermehrten Einfluss auf der EU-Ebene bzw. eine hohe Souveränitätsrelevanz des Politikfeldes Migration erzielen kann. Weiterhin spielen die Kommunen eine besondere Rolle in der Integrationspolitik. Obwohl die Kommunen keine spezifischen Entscheidungskompetenzen in der Migrationspolitik innehaben, beeinflussen sie dennoch die lokale Integrationspolitik erheblich, wie z. B. in den Bereichen 
Arbeitsmarktvermittlung und Sprachförderung. Außerdem erhöhen die Nichtregierungsorganisationen (NGOs) bzw. die freien Wohlfahrtsverbände als Interessengruppen mit ihren migrationspolitischen Forderungen den Druck auf die Nationalstaaten und auf die Europäischen Union. Hierbei ist die finanzielle Stabilität und stärkere Legitimität von Bedeutung, um die Willensbildung durchzusetzen. Auch in der programmatischen Aufstellung der Parteien hat sich eine stärkere Betonung des Themenfeldes Migration ergeben. Kritisch angemerkt werden muss diesbezüglich der negative Zusammenhang zwischen Programmatik einerseits und politischer Umsetzung andererseits. Zum Beispiel wurde das zur Steuerung der Einwanderung geplante Punktesystem nicht ins Gesetz aufgenommen, die Arbeitskräftewanderung nur als Ausnahmefall definiert und auch der Zuwanderung von Hochqualifizierten, Studenten und Selbstständigen werden noch relativ hohe Hürden auferlegt. Die Migrationspolitik Deutschlands ist somit durch ein eigenes politischen System, eigene Akteure, eigene institutionelle Rahmenbedingungen gekennzeichnet, die sich auf den politischen Entscheidungsprozess erstrecken. Die Taktiken und Strategien der Akteure zur Verfolgung ihrer Interessen prägen die Europäisierung im Bereich Migration nachhaltig.

Aus gegenwärtiger Perspektive hat sich rückblickend jedoch gezeigt, dass sich die europäischen Regelungen bezogen auf die nationale Politikgestaltung Deutschlands, also auf das deutsche Akteursfeld, oft als schwer durchführbar erwiesen. Wie zum Beispiel anhand des EU-Richtlinienumsetzungsgesetzes beim Ehegattennachzug nachgewiesen wurde, haben die Bundesrepublik Deutschland und auch einige Mitgliedstaaten mehrfach ihren Willen betont, die Norm in eigenes Recht zu integrieren und ihre Einhaltung durchzusetzen. Darüber hinaus werden Deutschland und auch einige andere Mitgliedstaaten verschärfte Begrenzungen des Familiennachzugsrechts einführen (vgl. Kapitel IV.1.1.1 und III.3.2.2). Es ist allerdings derzeit fraglich, ob Deutschland und auch die jeweiligen anderen Mitgliedstaaten das Familiennachzugsrecht weiterhin beliebig modifizieren können. Des Weiteren scheint jedoch die Erkenntnis paradox, dass das Ergebnis der Europäisierung aus deutscher Sicht dennoch zufriedenstellend war, da mithilfe der Migrationspolitik zahlreiche deutsche Forderungen bzw. Konzepte auf EU-Ebene durchgesetzt werden konnten. Alles in allem war und ist beispielsweise die Vertretung deutscher Interessen in der Debatte aufgrund des Abstimmungsverfahrens im Rat der EU für Deutschland vorteilhaft (vgl. dazu Kapitel III.2.9). Seit den 1990er Jahren ist Deutschland infolgedessen einer der aktivsten Staaten bei der Konzipierung der europäischen Asyl- 
und Migrationspolitik. ${ }^{1092}$ Durch diese Pionierrolle bzw. hegemoniale Einflussnahme, mittels derer Deutschland insbesondere zusammen mit Frankreich vor allem in den 1990er Jahren Vorschläge in die Verhandlungen einbrachte und maßgeblich den Vertrag von Maastricht und Amsterdam beeinflusste, hatte und hat die Bundesrepublik die Aussicht, die Fundamente und die weitere Entwicklung europäischer Migrationspolitik entscheidend mitzugestalten und wesentliche Aspekte der eigenen Politik auf EU-Ebene $\mathrm{zu}$ übertragen. Allerdings ist bei der von den deutschen Akteuren vorangetriebenen migrationspolitischen Vergemeinschaftung auf EU-Ebene im 21. Jahrhundert ein niedrigeres Niveau im Vergleich $\mathrm{zu}$ den 1990er Jahren deutlich zu erkennen. Zu beachten ist nun folgendes Ergebnis: In neuerer Zeit trug die Europäisierung öffentlicher Aufgaben im Bereich Migration zu einem Paradigmenwechsel von Freizügigkeit $\mathrm{zu}$ Sicherheit bei, etwa bezüglich der Schaffung eines EUVisuminformationssystems (VIS) seit 2004 und dem Aufbau einer europäischen Grenzpolizei bzw. von FRONTEX. Dieser Wandel fordert weiterhin die Vergemeinschaftung der Migrationspolitik auf europäischer Ebene.

Insgesamt kann nur schwer entschieden werden, ob die deutsche Migrationspolitik seit den 1990er Jahren substanzielle Fortschritte gemacht hat. Als Begründung hierfür wurde betrachtet, dass die richtungsweisenden ersten Schritte der deutschen Migrationspolitik bereits Anfang der 1970er Jahre durch den Anwerbestopp von 1973 unternommen wurden. Der Anwerbestopp von 1973, der als „Pfad der Restriktion““1093 der deutschen Migrationspolitik bezeichnet werden kann, leitete weiterhin die restriktiven Gesetze der 1990er Jahre ein, die bis heute als Grundlage für migrationspolitische Reformen in Deutschland gelten. ${ }^{1094}$ Insbesondere der sogenannte Asylkompromiss von 1993 führte die deutschen nationalstaatlichen Interessen infolge seiner restriktiven Haltung nicht zur gemeinsamen Asylpolitik im Europäisierungsprozess. Es wird jedoch rechtlich anhand institutioneller Verordnungen eine regulierte Normierung auf EU-Ebene dargestellt. Alles in allem wurden daraufhin die wichtigsten Reformprojekte der Bundesregierung seit den 1990er Jahren als „unvollständige“ Paradigmenwechsel gekennzeichnet. ${ }^{1095}$

\footnotetext{
${ }^{1092}$ Vgl. Prümm, Kathrin / Alscher, Stefan 2007: From Model to Average Student: the Europeanization of Migration Policy and Politics in Germany. In: Faist, Thomas / Ette, Andreas (Hrsg.) 2007: The Europeanization of National Policies and Politics of Immigration. Between Autonomy and the European Union. Basingstoke, S. 73-92.

${ }^{1093}$ Müller, Doreen 2010: Flucht und Asyl in europäischen Migrationsregimen. Göttingen, S. 208.

1094 Butterwegge, Carolin 2009: Fit für die Globalisierung? a.a.O., S. 137.

1095 Schönwälder, Karen 2006: Politikwandel in der (bundes-) deutschen Migrationspolitik. a.a.O., S. 10.
} 
Außerdem wurde auf die legale Migration bzw. Arbeitsmigration der Mitgliedstaaten, allen voran auf dem deutschen Akteursfeld, als nationales Privileg hingewiesen (vgl. Kapitel III.2.8). Damit wird die Vetomacht von Deutschland in diesem Bereich fernerhin berücksichtigt, wobei eine Blockade Deutschlands gegen die zunehmende Europäisierung ebenso wirksam ist. Diesbezüglich wird vor allem aufgrund der gestiegenen Hindernisse für die Einbürgerung und den Familiennachzug von Drittstaatsangehörigen die politische Abwehrhaltung bildhaft deutlich, die häufig die geringer qualifizierten und somit aus wirtschaftlichem Eigeninteresse „unerwünschten“ MigrantInnen erfahren. ${ }^{1096}$ Diese konnten ebenso wie Flüchtlinge, Asylsuchende und Illegalisierte bereits durch das Ziel des Zuwanderungsgesetzes (ZuWG) von 2005 berücksichtigt werden.

Als Quintessenz der vorab geschilderten These lässt sich zusammenfassend festhalten, dass die nationalen Akteure in den migrationsrelevanten institutionellen Strukturen innerhalb der supranationalen Zusammenarbeit zunehmende Bedeutung gewinnen. Darüber hinaus wurde der Europäisierungsprozess zuvor im Zusammenhang mit der Übertragung nationalstaatlicher Entscheidungs- und Handlungskompetenzen durch das nationale Akteursfeld bzw. durch die nationalen Institutionen auf EU-Ebene wahrgenommen. In dieser Hinsicht wurde jedoch gezeigt, ,dass es letztlich nicht europäische Institutionen sind, die den Ausschlag für den Erfolg oder das Scheitern der Schaffung einer gemeinsamen Politik geben.“1097 In der Migrationspolitik bleibt also überdies festzuhalten, dass EU-Institutionen zwar eine wichtige Rolle spielen, dass letztlich aber auch andere Perspektiven, zu berücksichtigen sind, zum gegenwärtigen Zeitpunkt etwa die intergouvernementalistische Sichtweise ${ }^{1098}$, nach der die tatsächliche Interessenmacht bei den Mitgliedstaaten bzw. bei den Akteuren der nationalen Institutionen $\mathrm{zu}$ finden ist. Diese ist besonders im Bereich der Arbeitsmigration zu beobachten. Gleichzeitig wurde jedoch auch gezeigt, dass die Anpassung an EUVorgaben teilweise nur eine Option für die deutschen Interessen bzw. für die Europastrategien deutscher Akteure darstellt, wie die im EURichtlinienumsetzungsgesetz von 2007 betroffenen. Hier wird klar erkennbar, dass sich angesichts der Europäisierungsprozesse die deutsche Migrationspolitik den europäischen Vorgaben anpasst, wenn diese zu den deutschen nationalen Interessen stehen könnten.

\footnotetext{
1096 Butterwegge, Carolin 2009: Fit für die Globalisierung? a.a.O., S. 164.

1097 Parusel, Bernd 2010: Abschottungs- und Anwerbungsstrategien: EU-Institutionen und Arbeitsmigration. Wiesbaden, S. 244.

1098 Vgl. Parusel, Bernd 2010: Abschottungs- und Anwerbungsstrategien: a.a.O., S. 245.
} 


\section{Deutsche Interessen im Europäisierungsprozess der Hochqualifizierten}

Bereits seit einigen Jahren wird die Steuerung und Gestaltung der Arbeitsmigration als eine der wichtigsten gesellschaftlichen Herausforderungen Deutschlands angesehen. Insbesondere ein Paradigmenwechsel in der Migrationspolitik, die eine gezielte Arbeitsmarktöffnung für bestimmte Arbeitsmigranten zur mittel- oder langfristigen Einwanderung vorsah, wurde vornehmlich mit dem 2005 in Kraft getretenen Zuwanderungsgesetz (ZuWG) eingeleitet und danach schrittweise fortgeführt. ${ }^{1099}$ Die neuen Zuwanderungsmöglichkeiten für Arbeitskräfte nach Deutschland wurden somit durch das Zuwanderungsgesetz für drei Personengruppen geschaffen: für qualifizierte Zuwanderer ( $§ 18$ Abs. 4 Aufenthaltsgesetz (AufenthG)), Hochqualifizierte ( 19 AufenthG) und Selbstständige ( $\S 21$ AufenthG). Allerdings ist bezüglich einer Bewertung des heutigen Zuwanderungsgesetzes noch kritisch anzumerken, dass die deutsche Migrationspolitik auch nach der Zuwanderungsreform von 2005 (und der Novellierung des Gesetzes von 2007) weiterhin eine längerfristige und strategische Ausrichtung vermissen lässt. ${ }^{1100}$ Die Defizite bestehen insbesondere im Hinblick auf die Steuerung der Arbeitsmigration. Es fehlen des Weiteren Regelungen für die befristete und dauerhafte Zuwanderung qualifizierter sowie hoch qualifizierter Personen. ${ }^{1101}$ Vor diesem Hintergrund muss auch von einem mangelnden Instrumentarium für eine gezielte demografisch orientierte und arbeitsmarktbezogene Zuwanderung gesprochen werden. Die von Parusel/Schneider (2010) ${ }^{1102}$ analysierten Daten zur Erwerbstätigkeit der Ausländer in Deutschland, der Nachfrage nach Arbeitskräften und der $\mathrm{Zu}$ - und Abwanderung ausländischer Arbeitskräften liefern folgende Einsichten. Im Jahr 2009 waren insgesamt ca. 38.365.000 Menschen in Deutschland erwerbstätig, wobei die Gesamtbevölkerung bei 82.002.356 Personen lag. Hierbei fällt ein Anstieg der Zahl der ausländischen Erwerbstätigen aus Nicht-EUStaaten in Deutschland in absoluten Zahlen auf: ${ }^{1103}$ Von etwa 1.901.000 Menschen im Jahr 2004 auf rund 1.937.000 im Jahr 2009. Laut Abbildung 29 waren „im Jahr 2009 rund $23,4 \%$ der in Deutschland erwerbstätigen Drittstaatsangehörigen Hochqualifizierte

\footnotetext{
1099 Parusel, Bernd / Schneider, Jan 2010: Deckung des Arbeitskräftebedarfs durch Zuwanderung: Studie der deutschen Kontaktstelle für das Europäische Migrationsnetzwerk (EMN). BAMF, S. 20.

1100 Angenendt, Steffen 2008: Die Steuerung der Arbeitsmigration in Deutschland: Reformbedarf und Handlungsmöglichkeiten. S. 8; http://www.library.fes.de/pdf-files/wiso/05705.pdf

1101 Angenendt, Steffen 2008: Die Steuerung der Arbeitsmigration in Deutschland: a.a.O., S. 8.

1102 Parusel, Bernd / Schneider, Jan 2010: Deckung des Arbeitskräftebedarfs durch Zuwanderung: S. 55; vgl. http://epp.eurostat.ec.europa.eu

1103 Parusel, Bernd / Schneider, Jan 2010: Deckung des Arbeitskräftebedarfs durch Zuwanderung: S. 55.
} 
(454.000 von 1.937.000 Personen).“1104

\begin{tabular}{|c|c|c|c|c|}
\hline \multicolumn{5}{|c|}{ Abbildung 29: Erwerbstätige nach Staatsangehörigkeit und Qualifikationsniveau, 2009} \\
\hline \multicolumn{5}{|c|}{$\begin{array}{l}\text { (Quelle: Parusel, Bernd / Schneider, Jan 2010: Deckung des Arbeitskräftebedarfs durch Zuwanderung: Studie der deutschen } \\
\qquad \text { Kontaktstelle für das Europäische Migrationsnetzwerk (EMN). BAMF, S. 95). }\end{array}$} \\
\hline & \multirow{2}{*}{$\begin{array}{c}\text { Erwerbstätige } \\
\text { insgesamt }\end{array}$} & \multicolumn{3}{|c|}{ Darunter Hauptkategorien } \\
\hline & & A. Hochqualifizierte & B. Qualifizierte & C. Geringqualifizierte \\
\hline EU-14-Staaten & 1.030 .000 & 410.000 & 488.000 & 120.000 \\
\hline EU-10-Staaten & 313.000 & 85.000 & 158.000 & 63.000 \\
\hline EU-2-Staaten & 75.000 & 26.000 & 33.000 & 13.000 \\
\hline Drittstaaten & 1.937 .000 & 454.000 & 1.054 .000 & 389.000 \\
\hline \multicolumn{5}{|l|}{$\begin{array}{l}\text { Wichtigste Drittstaaten } \\
(2009)\end{array}$} \\
\hline Türkei & 672.000 & 99.000 & 412.000 & 150.000 \\
\hline Kroatien & 155.000 & 38.000 & 93.000 & 24.000 \\
\hline $\begin{array}{l}\text { Bosnien und } \\
\text { Herzegowina }\end{array}$ & 105.000 & 20.000 & 62.000 & 20.000 \\
\hline $\begin{array}{l}\text { Russische } \\
\text { Föderation }\end{array}$ & 104.000 & 33.000 & 45.000 & 23.000 \\
\hline Serbien & 98.000 & 21.000 & 54.000 & 22.000 \\
\hline $\begin{array}{l}\text { Sonst. Süd- und } \\
\text { Südostasien }\end{array}$ & 83.000 & 24.000 & 38.000 & 18.000 \\
\hline Kosovo & 71.000 & 6.000 & 45.000 & 19.000 \\
\hline Ukraine & 57.000 & 19.000 & 25.000 & 12.000 \\
\hline $\begin{array}{l}\text { Sonst. Afrika } \\
\text { (nicht: Marokko, sonst. } \\
\text { Nordafrika) }\end{array}$ & 53.000 & 9.000 & 24.000 & 1 \\
\hline $\begin{array}{l}\text { Vereinigte Staaten von } \\
\text { Amerika }\end{array}$ & 51.000 & 35.000 & / & I \\
\hline Sonstige & 487.000 & 150.000 & 244.000 & 81.000 \\
\hline Insgesamt & 38.365 .000 & 16.324 .000 & 18.334 .000 & 3.211 .000 \\
\hline
\end{tabular}

Die Mehrheit kann mit rund 54,4\% (1.054.000 Personen) der Drittstaatsangehörigen der

${ }^{1104}$ Parusel, Bernd / Schneider, Jan 2010: Deckung des Arbeitskräftebedarfs durch Zuwanderung: S. 55. 
Gruppe der Qualifizierten zugezählt werden, nur 20,0\% (rund 389.000 Drittstaatsangehörige) waren Geringqualifizierte. Rund 1.030.000 der erwerbstätigen Menschen im Jahr 2009 waren „EU-14-Staatsbürger.“1105 Außerdem sind die türkischen Staatsbürger am stärksten innerhalb der Gruppe der Drittstaatsangehörigen vertreten. So stellten im Jahr 2009 etwa 672.000 Erwerbstätige türkische Staatsbürger dar. ${ }^{106}$ Bezüglich aller Qualifikationsniveaus bezeichnete „die zweitgrößte Nationalitätengruppe innerhalb der Drittstaatsangehörigen die der kroatischen Staatsbürger (ca. 155.000 Erwerbstätige), die drittgrößte die der Staatsbürger aus Bosnien und Herzegowina (ca. 105.000). “1107 Der Anteil der EU-10-Staatsbürger ${ }^{108}$ an der Gesamterwerbstätigenzahl lag 2009 bei 0,8\% (ca. 313.000 Personen), wobei hier ein Anstieg erkennbar ist. Im Jahr 2005 belief sich dieser lediglich auf rund 212.000 Menschen (0,6\% der Gesamterwerbstätigenzahl). Die Zahl der EU-2-Staatsbürger (Bulgarien, Rumänien,) bezifferte sich im Jahr 2009 auf rund 75.000 Erwerbstätige (siehe Abbildung 30).

\begin{tabular}{|l|c|c|c|c|c|c|}
\hline \multicolumn{7}{|c|}{ Abbildung 30: Erwerbstätigkeit in Deutschland (2004-2009) } \\
\hline \multicolumn{6}{|c|}{$\begin{array}{l}\text { (Quelle: Parusel, Bernd / Schneider, Jan 2010: Deckung des Arbeitskräftebedarfs durch Zuwanderung: Studie der } \\
\text { deutschen Kontaktstelle für das Europäische Migrationsnetzwerk (EMN). BAMF, S. 56). }\end{array}$} \\
\hline & 2004 & 2005 & 2006 & 2007 & 2008 & 2009 \\
\hline $\begin{array}{l}\text { Erwerbstätige } \\
\text { insgesamt }\end{array}$ & 35.268 .000 & 36.223 .000 & 37.023 .000 & 37.841 .000 & 38.439 .000 & 38.365 .000 \\
\hline Drittstaatsangehörige & 1.901 .000 & 1.759 .000 & 1.799 .000 & 1.869 .000 & 1.923 .000 & 1.937 .000 \\
\hline EU-14-Bürger & 1.000 .000 & 1.028 .000 & 1.026 .000 & 1.047 .000 & 1.058 .000 & 1.030 .000 \\
\hline EU-10-Bürger & & 212.000 & 229.000 & 262.000 & 285.000 & 313.000 \\
\hline EU-2-Bürger & 31.000 & 48.000 & 62.000 & 64.000 & 71.000 & 75.000 \\
\hline
\end{tabular}

Gemäß Abbildung 31 reisten im Jahr 2009 insgesamt 311 erwerbstätige Drittstaatsangehörige nach Deutschland ein. Darunter waren 142 Forscher, die eine Aufenthaltserlaubnis nach $\S 20$ AufenthG erhielten; 169 waren Hochqualifizierte, die eine Niederlassungserlaubnis nach $\S 19$ AufenthG bekamen.

${ }^{1105}$ EU-14: Belgien, Dänemark, Finnland, Frankreich, Griechenland, Irland, Italien, Luxemburg, Niederlande, Österreich, Portugal, Schweden, Spanien, Vereinigtes Königreich. In: Parusel, Bernd / Schneider, Jan 2010: Deckung des Arbeitskräftebedarfs durch Zuwanderung a.a.O. S. 55. Fußnote 41.

1106 Parusel, Bernd / Schneider, Jan 2010: Deckung des Arbeitskräftebedarfs durch Zuwanderung: S. 56.

1107 Parusel, Bernd / Schneider, Jan 2010: Deckung des Arbeitskräftebedarfs durch Zuwanderung: S. 56.

1108 „Staatsangehörige der 2004 in die EU beigetretenen Staaten Estland, Lettland, Litauen, Malta, Polen, Slowakische Republik, Slowenien, Tschechische Republik, Ungarn, Zypern." In: Parusel, Bernd / Schneider, Jan 2010: Deckung des Arbeitskräftebedarfs durch Zuwanderung: a.a.O., S. 55. 


\begin{tabular}{|c|c|c|c|c|}
\hline \multicolumn{5}{|c|}{ Abbildung 31: Zuzug ausländischer Arbeitskräfte nach Aufenthaltstitel, 2009} \\
\hline \multicolumn{5}{|c|}{ Auswertung aus dem Ausländerzentralregister (AZR), Stichtag: 31.03 .2010} \\
\hline \multicolumn{5}{|c|}{$\begin{array}{l}\text { (Quelle: Parusel, Bernd / Schneider, Jan 2010: Deckung des Arbeitskräftebedarfs durch Zuwanderung: Studie der } \\
\text { deutschen Kontaktstelle für das Europäische Migrationsnetzwerk (EMN). BAMF, S. 110). }\end{array}$} \\
\hline \multicolumn{5}{|c|}{ Drittstaatsangehörige } \\
\hline & männl. & weibl. & unbek. & insgesamt \\
\hline Hochqualifizierte (§ 19) & 137 & 31 & 1 & 169 \\
\hline Forscher $(\S 20 \mathrm{I}+\mathrm{V})$ & 101 & 41 & - & 142 \\
\hline Qualifizierte (§ $18 \mathrm{IV})$ & 11.941 & 2.862 & 13 & 14.816 \\
\hline Geringqualifizierte (§ $18 \mathrm{III})$ & 3.650 & 4.745 & 10 & 8.405 \\
\hline Beschäftigte $(\S 18)$ & 1.509 & 323 & - & 1.832 \\
\hline Selbstständige (§ 21) & 701 & 318 & 5 & 1.024 \\
\hline Gesamt & 18.039 & 8.320 & 29 & 26.388 \\
\hline
\end{tabular}

Die Einwanderung von Hochqualifizierten hat hiermit zwar gegenüber 2008 (221 hochqualifizierte Drittstaatsangehörige, davon 64 Forscher) und 2007 (151 Hochqualifizierte) eine zahlenmäßige Zunahme erfahren, sie bewegt sich dessen ungeachtet insgesamt aber noch immer auf einem eher geringen Niveau ( Abbildung 32).

\begin{tabular}{|l|c|c|c|}
\hline \multicolumn{4}{|c|}{ Abbildung 32: Zuzug von Erwerbstätigen aus Drittstaaten (2007 - 2009) } \\
\hline \multicolumn{4}{|c|}{$\begin{array}{c}\text { Quelle: Parusel, Bernd / Schneider, Jan 2010: Deckung des Arbeitskräftebedarfs durch Zuwanderung: Studie der } \\
\text { deutschen Kontaktstelle für das Europäische Migrationsnetzwerk (EMN). BAMF, S. 60). }\end{array}$} \\
\hline & 2007 & 2008 & 2009 \\
\hline Hochqualifizierte (§ 19 AufenthG) & 151 & 157 & 169 \\
\hline Beschäftigte (§ 18 AufenthG) & 28.761 & 29.141 & 25.053 \\
\hline Forscher (§ 20 AufenthG) & - & 64 & 142 \\
\hline Selbstständige (§ 21 AufenthG) & 891 & 1.239 & 1.024 \\
\hline
\end{tabular}

Auch im Jahr 2009 erhielten 25.053 Drittstaatsangehörige erstmals eine Aufenthaltserlaubnis zum Zweck der Beschäftigung, was gegenüber den Jahren 2008 (29.141) und 2007 (28.761) einen Rückgang bedeutet. Auf dem Gebiet der Zuwanderung von Selbstständigen ist ebenfalls ein Rückgang zu verzeichnen. Diese belief sich im Jahr 2009 auf 1.024 Personen (nach 1.239 Personen im Jahr 2008 und 891 im Jahr 2007). Die wichtigsten Gruppen unter den zu Erwerbszwecken einreisenden Drittstaatsangehörigen sind Staatsbürger der USA (3.229 Personen im Jahr 2009), Indiens (3.094), Chinas (2.356), Kroatiens (1.858) sowie Bosnien und Herzegowinas 
$(1.640)^{1109}$ (vgl. dazu Abbildung 33). Die relative hohe Zahl indischer Staatsbürger in dieser Gruppe erklärt, dass viele indische Staatsbürger als IT-Experten nach Deutschland wandern. ${ }^{1110}$

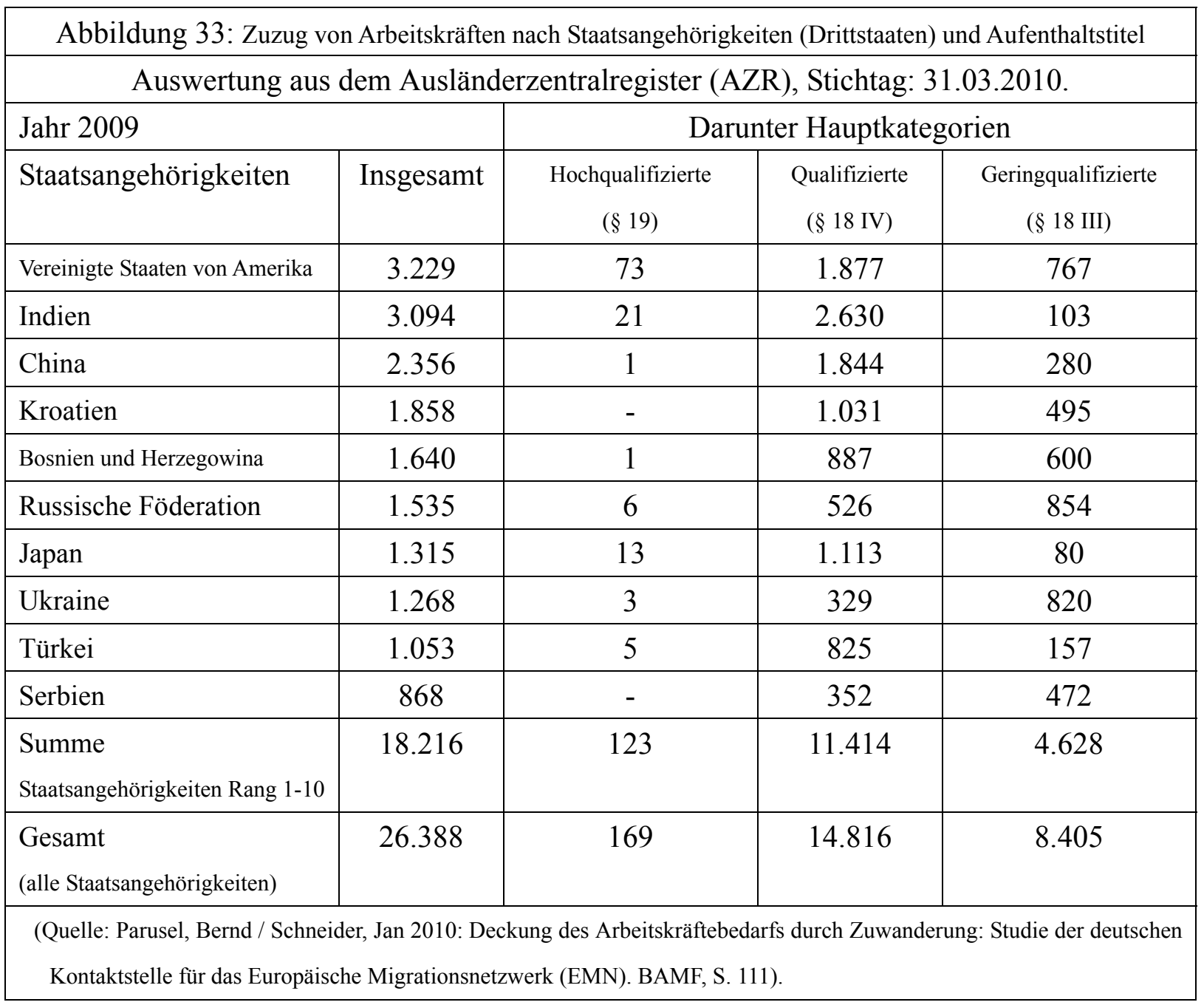

In Anbetracht der Datenanalyse lässt sich festhalten, dass Deutschland in den vergangenen Jahren ungeachtet seiner Hinwendung zu einer arbeitsmarktorientierten Steuerung der Einwanderung relativ wenige Hochqualifizierte erhalten hat. Darüber hinaus ist eine Entwicklung des gegenwärtigen Rechtssystems für die Einwanderung von Erwerbstätigen aus Drittstaaten sowohl auf nationaler als auch auf EU-Ebene zu erwarten. Besonders dürften in Bezug auf ein verbessertes Job-Matchings weitere

${ }^{1109}$ Vgl. auch Heß, Barbara / Sauer, Leonore 2007: Migration von hoch Qualifizierten und hochrangig Beschäftigten aus Drittstaaten nach Deutschland. Working Paper Nr. 9, Nürnberg: Bundesamt für Migration und Flüchtlinge (BAMF), S. 32.

1110 Parusel, Bernd / Schneider, Jan 2010: Deckung des Arbeitskräftebedarfs durch Zuwanderung: S. 61. 
Schritte zur Förderung der Attraktivität Deutschlands eingeleitet werden, beispielsweise auf dem Gebiet der Anerkennung ausländischer Qualifikationen und Abschlüsse. ${ }^{1111}$ Seit Beginn des 21. Jahrhunderts hat in Deutschland eine erneute Debatte über Arbeitsmigration begonnen. Aufgrund der Verringerung der Bevölkerung und demografischen Alterung findet bis heute der mittel- und langfristige Einwanderungsbedarf des Landes zunehmendes migrationspolitisches Interesse. ${ }^{112}$ Trotz des 2005 in Kraft getretenen Zuwanderungsgesetzes (auch nach seiner Novellierung 2007), das als tragfähige und langfristige Grundlage für die deutsche Migrationspolitik betrachtet wird, sind keine neuen Steuerungsinstrumente der Arbeitsmigration eingeführt worden. ${ }^{1113}$ Im Prozess über das Zuwanderungsgesetz ist zwar über entsprechende Vorschläge diskutiert worden, jedoch haben diese ,angesichts der wirtschaftlichen Rezession und der hohen Arbeitslosigkeit keine politische Mehrheit gefunden. “1114 $\mathrm{Zu}$ bedenken ist allerdings, dass die Migration von Hochqualifizierten häufig kein einfaches Unterfangen nach dem Modell „Wir werben. Sie kommen“ ist. Es entstehen komplexe Pfade, die die MigrantInnen in mannigfaltigen, mehr oder weniger adäquaten Segmenten des Arbeitsmarktes beeinflussen. ${ }^{115}$ Auch im Rahmen des Konzeptes „kulturelles Kapital“ spricht Pierre Bourdieu an, dass „Humankapital““ nicht objektiv gegeben ist, sondern dass bezüglich des Wertes des kulturellen Kapitals gesellschaftlich ein Übereinkommen getroffen wird. ${ }^{116}$ Darüber hinaus lässt sich unterdessen die Arbeitsmarktinklusion von Hochqualifizierten als ein zentraler Anhaltspunkt für die folgende Untersuchung berücksichtigen.

Der vorliegende Abschnitt beschäftigt sich mit den Möglichkeiten der künftigen Gestaltung der arbeitsmarktorientierten Migrationspolitik Deutschlands, insbesondere mit der zentralen Frage, mit welchen Verfahren der Bedarf an hoch qualifizierten Einwanderern angeordnet und mit welchen Instrumenten eine Einwanderung gelenkt werden kann. ${ }^{1117}$ Weiterhin legt die Untersuchung die folgenden Fragen dar: Inwieweit benennt die Bundesrepublik Deutschland eigene Interessen hinsichtlich der demografischen Notwendigkeit von Arbeitsmigration aus Drittstaaten? Inwieweit formuliert die Bundesrepublik wirtschaftliche und arbeitsmarktorientierte Interessen?

\footnotetext{
1111 Parusel, Bernd / Schneider, Jan 2010: Deckung des Arbeitskräftebedarfs a.a.O., S. 71-72.

1112 Angenendt, Steffen 2008: Die Steuerung der Arbeitsmigration in Deutschland a.a.O., S. 4.

1113 Angenendt, Steffen 2008: Die Steuerung der Arbeitsmigration in Deutschland a.a.O., S. 4.

1114 Angenendt, Steffen 2008: Die Steuerung der Arbeitsmigration in Deutschland a.a.O., S. 4.

1115 Nohl, Arnd-Michael / Schittenhelm, Karin / Schmidtke, Oliver / Weiß, Anja 2010: Zur Einführung: Migration, kulturelles Kapital und Statuspassagen in den Arbeitsmarkt a.a.O., S. 9-10.

1116 Vgl. Bourdieu, Pierre 1983: Ökonomisches Kapital, kulturelles Kapital, soziales Kapital. In: Kreckel, Reinhard (Hrsg.) 1983: Soziale Ungleichheiten (Soziale Welt, Sonderband 2). Göttingen, S. 183-198.

1117 Vgl. Angenendt, Steffen 2008: Die Steuerung der Arbeitsmigration in Deutschland a.a.O., S. 4.
} 
Welche Gruppen von Arbeitsmigranten sollen nach Deutschland einwandern? Welches Niveau der Vergemeinschaftung auf EU-Ebene wird seitens Deutschlands angestrebt? Diese Frage umfasst die Zuwanderung ,für hoch Qualifizierte (§ 19 AufenthG), Forscher ( $\$ 20$ AufenthG), Selbstständige ( 21 AufenthG) und gering Qualifizierte (vor allem Saisonarbeitskräfte und Werkvertragsarbeitnehmer, nach Beschäftigungsverordnung bzw. Anwerbestoppausnahmeverordnung).“ ${ }^{1118}$ Es ist hierbei in erster Linie die Rede von der Arbeitsmigration aus Nicht-EU-Staaten.

Bezüglich dieser Fragen geht es in den folgenden Abschnitten um zwei Verfahren ${ }^{119}$ als Steuerungsinstrumente; zum einen um das sogenannte Punktesystem, das bereits vonseiten der Unabhängigen Kommission „Zuwanderung“ von 2001 (sogenannte Süssmuth Kommission) vorgelegt wurde und zum anderen um die „Blue Card“ für hoch qualifizierte Arbeitskräfte, die durch die EU-Kommission zur gemeinsamen Regelung der Arbeitsmigration geplant und festgestellt werden kann. Anschließend werden die wesentliche migrationspoltischen Herausforderungen und aktuellen Migrationstendenzen untersucht.

1118 Angenendt, Steffen 2008: Die Steuerung der Arbeitsmigration in Deutschland a.a.O., S. 42.

1119 Vgl. Angenendt, Steffen 2008: Die Steuerung der Arbeitsmigration in Deutschland a.a.O., S. 4. 


\section{1 Punktesystem}

Um eine „Deckung des mittel- und langfristigen Bedarfs an hoch qualifizierten Zuwanderern" zu erreichen, wäre beispielsweise ein Punkteverfahren geeignet, wie es von der Süssmuth-Kommission im Jahr 2001 befürwortet wurde (siehe Anhang: Übersicht 13). ${ }^{1120}$ Eine Bewertung kann anhand der Kriterien (wie etwa Qualifikation, Sprachkenntnisse, Alter, Berufserfahrung, Familienstand) mithilfe dieses Punktesystems ermittelt werden und die Zuwanderung kann von der Erreichung einer bestimmten Punktezahl abhängig gemacht werden. ${ }^{1121}$ Somit kann Bewerber, welche die Punktezahl erfüllen - nach diesem System eine unbeschränkte Arbeitserlaubnis und eine Niederlassungserlaubnis, einschließlich des Rechts auf Familiennachzug - erhalten. Allerdings wurde dieses Steuerungsinstrument für die hoch qualifizierten Zuwanderer in der Folge ersatzlos aus dem Gesetz gestrichen. Besonders die Unionsparteien hatten zur Verhinderung der Einführung eines Punktesystems bei den Verhandlungen um das Zuwanderungsgesetz mit ihrer Mehrheit im Bundesrat beigetragen. ${ }^{1122}$ Auch zum gegenwärtigen Zeitpunkt wird in Deutschland erneut ein möglicher Fachkräftemangel und eine leichtere Einwanderung von gut Ausgebildeten erörtert. Augenblicklich wird auf Anordnung von Bundesarbeitsministerin Ursula von der Leyen eine sogenannte Positivliste von Berufen erstellt, die im Hinblick auf die so bezeichnete Vorrangprüfung temporär entfallen könnte: ${ }^{1123}$ Derzeit ist es jedem Unternehmen gesetzlich vorgeschrieben, welches eine sich um die Anstellung bewerbende Person aus dem nichteuropäischen Ausland beschäftigen möchte, anhand einer Prüfung die Möglichkeit der Einstellung geeigneter Kräfte aus Deutschland und der EU auszuschließen. Umfangreiche zeitaufwendige Maßnahmen begleiten oftmals diese Prüfung. Auch mehrere Politiker legten im Juli und August 2010 Voschläge vor, um die Einwanderung von Fachkräften zu erleichtern: ${ }^{124}$ So empfahl Bildungsministerin Annette Schavan (CDU), „das Bruttojahreseinkommen von zuziehenden Fachkräften, das eine

\footnotetext{
${ }^{1120}$ Unabhängige Kommission Zuwanderung (UKZU) 2001: Zuwanderung gestalten, Integration fördern. Berlin. S. 87 ff. In: http://www.zuwanderung.de/downloads/Zuwanderungsbericht_kurz.pdf.

1121 Angenendt, Steffen 2008: Die Steuerung der Arbeitsmigration in Deutschland: Reformbedarf und Handlungsmöglichkeiten. Bonn, S. 43. In: http://www.library.fes.de/pdf-files/wiso/05705.pdf (WISO Diskurs / Stand: September 2008).

1122 Newsletter ,Migration und Bevölkerung' 2004: Deutschland: Einigung auf ein Zuwanderungsgesetz Online verfügbar unter: http://www.migration-info.de/mub_artikel.php?Id=040501 (Ausgabe 05/04).

1123 Newsletter ,Migration und Bevölkerung' 2010: Deutschland̄: Fortsetzung der Debatte über Fachkräftemangel. In: http://www.migration-info.de/mub_artikel.php?Id=101003 (Ausgabe 10/10).

1124 Newsletter ,Migration und Bevölkerung' 2010: Deutschland: Diskussion um Fachkräftemangel. In: http://www.migration-info.de/mub_artikel.php?Id=100704 (Ausgabe 07/10). S. 4.
} 
Voraussetzung für die Erteilung von langfristigen Arbeitsgenehmigungen ist, von derzeit 66.000 Euro zunächst zu senken.“ Bundeswirtschaftsminister Rainer Brüderle (FDP) kündigte die Vorstellung einer „Fachkräfte-Initiative“ an. Sein erklärtes Ziel ist es, „ein Gesamtkonzept zu entwickeln, mit dem qualifizierte ausländische Arbeitnehmer nach Deutschland kommen“. ${ }^{1125}$ Die Gewerkschaften sprachen sich gegen eine verstärkte Einwanderung von Fachkräften aus. Denn es müsse erst das heimische Potenzial an Arbeitskräften ausgeschöpft werden: Die Gewerkschaft ver.di riet den Arbeitgebern an, einem möglichen Fachkräftemangel durch höhere Ausbildungszahlen entgegenzuwirken. ${ }^{1126}$ Die von Bundeswirtschaftsminister Rainer Brüderle (FDP) Anfang November 2010 erneut geäußerte Forderung beinhaltete die Einführung konkreter Kriterien für die Zuwanderung ausländischer Fachkräfte nach Deutschland durch ein Punktesystem bis spätestens Juli 2011. ${ }^{1127}$ Allerdings ist das von ihm vorgeschlagene Punktesystem in der Union umstritten: Bundesarbeitsministerin Ursula von der Leyen (CDU) sagte diesbezüglich, dass ein Punktesystem, wie es die FDP fordert, allein nicht ausreichend sei. Derzeit werde ein Job-Monitoring-System durch ihr Ministerium, zusammen mit der Bundesagentur für Arbeit, den Gewerkschaften und Wirtschaftsverbänden, aufgebaut. Auch die CSU lehnte die Zuwanderung nach Kontingenten oder durch ein Punktesystem vehement ab. ${ }^{1128}$ Der CSU-Parteichef Horst Seehofer verlangte eine Ausschöpfung bezüglich des heimischen Arbeitsmarktes und der Europäischen Union. Auch er verkündigte eine Arbeitsmöglichkeit, die vorsieht, dass mit dem 1. Mai 2011 Beschäftigte aus acht mittel- und osteuropäischen Ländern ohne Beschränkungen in Deutschland arbeiten können. ${ }^{1129}$ Die Meinung der Oppositionsparteien sind bei der Einwanderung von Fachkräften geteilt. Der SPDVorsitzende Sigmar Gabriel forderte einen Fachkräfte- und Zuwanderungspakt zwischen Bund, Ländern und Arbeitgebern: „Erst wenn mehr Unternehmen sich verpflichten, mehr auszubilden und mehr Stellen für ältere Arbeitnehmer zu schaffen und der Bund den Ländern mehr Geld für Kindertagesstätten und Ganztagsschulen bereit stellt, können wir ernsthaft über eine begrenzte Zuwanderung von Fachkräften sprechen.“1130

1125 Newsletter ,Migration und Bevölkerung' 2010: Deutschland: Diskussion um Fachkräftemangel. In: http://www.migration-info.de/mub_artikel.php?Id=100704 (Ausgabe 07/10). S. 4.

${ }^{1126}$ Newsletter ,Migration und Bevölkerung' 2010: Deutschland: Diskussion um Fachkräftemangel. In: http://www.migration-info.de/mub_artikel.php?Id=100704 (Ausgabe 07/10). S. 5.

1127 Z. B. fehlen nach Angaben des Bundes rund 36.000 Ingenieure und 66.000 Computerspezialisten; http://www.migration-info.de/mub_artikel.php?Id=100903 (Ausgabe 09/10). S. 1.

${ }^{1128}$ Newsletter ,Migration und Bevölkerung' 2010: Deutschland: FDP entfacht neue Debatte um ein Punktesystem. In: http://www.migration-info.de/mub_artikel.php?Id=100903 (Ausgabe 09/10). S. 1.

1129 Newsletter ,Migration und Bevölkerung' 2010: Deutschland: FDP entfacht neue Debatte um ein Punktesystem. In: http://www.migration-info.de/mub_artikel.php?Id=100903 (Ausgabe 09/10). S. 1.

1130 Newsletter ,Migration und Bevölkerung' 2010: Deutschland: FDP entfacht neue Debatte um ein Punktesystem. In: http://www.migration-info.de/mub_artikel.php?Id=100903 (Ausgabe 09/10). S. 1. 
Bündnis 90/Die Grünen kritisierte scharf die Haltung der CSU. Fraktionschef Jürgen Trittin sagte dazu: „Hochqualifizierte werden hier dringend benötigt““. ${ }^{131}$ Die Grünen forderten ein Punktesystem. Hingegen erklärte Ali Al Dailami, Mitglied des Parteivorstandes der Linken: „Die Bundesregierung und Wirtschaftsverbände zeigen mit ihrem Vorstoß zur Steuerung von Zuwanderung durch ein Punktesystem eine menschenverachtende Logik“. ${ }^{1132}$ Bundeskanzlerin Angela Merkel (CDU) brachte allerdings ihre ablehnende Haltung gegenüber Brüderles Vorstoß zum Ausdruck. Ihrer Meinung nach würde ein Punktesystem ,auch nicht alle Probleme lösen“, äußerte sie diesbezüglich in einem Interview. Bundeskanzlerin Merkel ließ bereits die Vorschläge des Wirtschaftsministers zurückweisen und unterstrich, ,,sie sehe keinen Anlass, das erst seit Anfang 2009 geltende Zuwanderungsgesetz zu überarbeiten. Die Bundesregierung sei dabei, die europäische Richtlinie zur so genannten Bluecard umzusetzen, die ,einen zweiten Kanal für Hochqualifizierte' öffnen solle. Die Bluecard soll Fachkräften aus Nicht-EU-Ländern ermöglichen, mehrere Jahre in der EU zu arbeiten und auch innerhalb der EU umzuziehen. “'1133

Der rechtliche Rahmen bezüglich der Regelung des Zuzugs hochqualifizierter Fachkräfte nach Deutschland schließt Gesetzgebungen sowohl auf nationaler als auch auf EU-Ebene ein. Die EU-Migrationspolitik kann dabei eine entscheidende Rahmenbedingung für die nationale Zuwanderungspolitik sein. Besonders im Hinblick auf eine Öffnung für ArbeitsmigrantInnen aus Drittstaaten ist eine Berücksichtigung der Interessen der EU-Mitgliedstaaten unerlässlich. Im Folgenden werden einige EUMitgliedstaaten wie Großbritannien, die Schweiz und Dänemark sowie Frankreich vorgestellt. Die Zuwanderung nach Großbritannien erreichte 2007 einen neuen NettoHöchststand von 237.000 Personen, sank 2009 indessen wieder auf $147.000 .^{1134}$ Das neue Einwanderungssystem bzw. das an australischem Vorbild orientierte fünfstufige Punktesystem in Großbritannien, das seit März 2008 unter der Regierung Gordon Brown (Labor) stufenweise in Kraft getreten ist und mit dessen Hilfe die NettoEinwanderung künftig weiterhin spürbar reduziert werden soll, reguliert die Zuwanderung anhand eines Verfahrens, bei dem die Einwanderer u. a. über ihre

\footnotetext{
1131 Newsletter ,Migration und Bevölkerung' 2010: Deutschland: FDP entfacht neue Debatte um ein Punktesystem. In: http://www.migration-info.de/mub_artikel.php?Id=100903 (Ausgabe 09/10). S. 1.

1132 Newsletter ,Migration und Bevölkerung' 2010: Deutschland: FDP entfacht neue Debatte um ein Punktesystem. In: http://www.migration-info.de/mub_artikel.php?Id=100903 (Ausgabe 09/10). S. 1.

1133 Newsletter ,Migration und Bevölkerung' 2010: Deutschland: Diskussion um Fachkräftemangel. In: http://www.migration-info.de/mub_artikel.php?Id=100704 (Ausgabe 07/10). S. 5.

1134 Newsletter ,Migration und Bevölkerung' 2010: Vereinigtes Königreich: Einwanderungspolitik im Wahlkampf. In: http://www.migration-info.de/mub_artikel.php?Id=100405 (Ausgabe 04/10). S. 3.
} 
berufliche Qualifikation und Sprachkenntnisse Punkte sammeln können. ${ }^{1135}$ Eine Aufenthaltsgenehmigung wird an die Punkthöchsten vergeben. Der größte Anteil der Einwanderer, denen im Jahr 2007 insgesamt ins Vereinigte Königreich mittels des Punktesystems Einlass gewährt wurde, stammen aus Pakistan (16.335), Indien (15.530), gefolgt von Polen (7.300) und Bangladesch (5.330). ${ }^{1136}$ Parallel hierzu gibt es im Vereinigten Königreich in verschiedenen Berufszweigen Arbeitskräftemangel, es besteht Bedarf bezüglich Beschäftigten wie etwa Mathematiklehrern, Ingenieuren, Geologen, qualifiziertem Pflegepersonal sowie Köchen. ${ }^{1137}$ In der jüngsten Vergangenheit wurde das britische Einwanderungssystem oft wegen seiner zu restriktiven Verordnungen und geringen Transparenz gerügt, dies vor allem seitens verschiedener Nichtregierungsorganisationen (NGO) und einer unabhängigen, von der Regierung eingesetzten Asyl-Kommission. $\mathrm{Zu}$ den Hauptkritikpunkten gehörten hierbei die Abschiebepraxis sowie der fehlende Zugang zum Arbeitsmarkt und Gesundheitswesen insbesondere für Asylbewerber. ${ }^{1138}$ Im Jahr 2010 wurde in Großbritannien über eine Einwanderungsquote für Fachkräfte debattiert: „Während die Regierung die Einwanderungszahlen auf das Niveau der 1990er Jahre drücken will, sorgen sich Unternehmensverbände und Universitäten um den Wirtschafts- und Wissenschaftsstandort Großbritannien.“"1139 Die neu gewählte liberal-konservative Regierung Großbritanniens hatte sich Ende Juni 2010 darüber verständigt, dass sie die Einwanderung von Hochqualifizierten und Fachkräften aus Nicht-EU-Staaten über ein Kontingent regeln wolle. Ein festes Jahreskontingent von Arbeitsvisa werde dann ab April 2011 die Einwanderung dieser Personen in den britischen Arbeitsmarkt beschränken. ${ }^{1140}$ Das Vereinigte Königreich hatte im Unterschied zu Deutschland bereits auf den Anspruch verzichtet, die Freizügigkeit für osteuropäische Arbeitnehmer nach der EU-Erweiterung im Jahr 2004 temporär zu begrenzen. Eine deutliche Steigerung der Einwanderungszahlen war in der Folge zu beobachten. Im Rahmen der Wirtschaftskrise und einiger restriktiver Maßnahmen der Labour-Regierung unter Gordon Brown sanken jedoch die Einwanderungszahlen in den letzten Jahren erneut,

1135 Newsletter ,Migration und Bevölkerung' 2008: Vereinigtes Königreich: Einwanderung erreicht Höchststand. In: http://www.migration-info.de/mub_artikel.php?Id=081011 (Ausgabe 10/08).

1136 Newsletter ,Migration und Bevölkerung' 2008: Vereinigtes Königreich: Einwanderung erreicht Höchststand. In: http://www.migration-info.de/mub_artikel.php?Id=081011 (Ausgabe 10/08).

${ }^{1137}$ Newsletter ,Migration und Bevölkerung' 2008: Vereinigtes Königreich: Einwanderung erreicht Höchststand. In: http://www.migration-info.de/mub_artikel.php?Id=081011 (Ausgabe 10/08).

${ }^{1138}$ Newsletter ,Migration und Bevölkerung' 2008: Vereinigtes Königreich: Einwanderung erreicht Höchststand. In: http://www.migration-info.de/mub_artikel.php?Id=081011 (Ausgabe 10/08).

1139 Newsletter ,Migration und Bevölkerung' 2010: Vereinigtes Königreich: Einwanderungsquote in der Kritik. In: http://www.migration-info.de/mub_artikel.php?Id=100806 (Ausgabe 08/10). S. 4.

1140 Newsletter ,Migration und Bevölkerung' 2010: Vereinigtes Königreich: Einwanderungsquote in der Kritik. In: http://www.migration-info.de/mub_artikel.php?Id=100806 (Ausgabe 08/10). S. 4-5. 
stiegen 2009 allerdings wieder leicht an. ${ }^{1141}$ Im Wahlkampf kurz vor den Unterhauswahlen am 6. Mai 2010 hatten die konservativen Tories und die sozialdemokratische Labour-Partei verstärkte Restriktionen propagiert. ${ }^{1142}$ Das vorgesehene Einwanderungskontingent hat ausschließlich für hoch qualifizierte Arbeitskräfte und Facharbeiter Gültigkeit. Saisonarbeitskräfte und Studierende werden von der Regelung nicht berücksichtigt. Auch gering qualifizierte Arbeitskräfte können seit Einführung des Punktesystems nicht mehr nach Großbritannien einwandern. ${ }^{1143}$ In Deutschland ist dagegen $\mathrm{zu}$ erwarten, dass der Bedarf an gering qualifizierten Arbeitskräften, vor allem von Saisonarbeitskräften und Werkvertragsarbeitnehmer (nach Beschäftigungsverordnung bzw. Anwerbestoppausnahmeverordnung) hoch bleiben wird. ${ }^{1144}$ Die Kontingentierungspolitik der britischen Regierung, also die Einwanderungsbeschränkung für Nicht-EU-Bürger, trat am 19. Juli 2010 in Kraft und steht seitdem in der Kritik. ${ }^{1145}$ Unternehmen greifen infolge der Medienberichte seit Inkrafttreten der Quote in verstärktem Maße auf temporäre Arbeitsvisa zurück, um so ihrem Fachkräftebedarf gerecht zu werden. Vehemente Kritik empfing die britische Regierung auch von den Universitäten. ${ }^{1146}$ Jedoch wird die Einbürgerung in Großbritannien somit künftig erschwert.

Der Schweizer Bundesrat hat im Vergleich zu Großbritannien ohne Berücksichtigung des Punktesystems Ende April 2010 die Beschränkung der Kontingente für NichtEU/EFTA-Arbeitskräfte untersagt. Hierdurch bestand im Jahr 2010 die Möglichkeit der Vergabe von insgesamt 3.000 Aufenthalts- und 8.000 Kurzaufenthaltsbewilligungen an „gut qualifizierte“ Arbeitskräfte außerhalb der EU- und EFTA-Staaten. ${ }^{1147}$

Dänemark verfolgt ein strenges Punktesystem: 1148 Bezüglich ihrer

1141 Newsletter ,Migration und Bevölkerung' 2010: Vereinigtes Königreich: Einwanderungsquote in der Kritik. In: http://www.migration-info.de/mub_artikel.php?Id=100806 (Ausgabe 08/10). S. 5.

1142 Newsletter ,Migration und Bevölkerung' 2010: Vereinigtes Königreich: Einwanderungspolitik im Wahlkampf. In: http://www.migration-info.de/mub_artikel.php?Id=100405 (Ausgabe 04/10). S. 3.

1143 Newsletter ,Migration und Bevölkerung' 2010: Vereinigtes Königreich: Einwanderungsquote in der Kritik. In: http://www.migration-info.de/mub_artikel.php?Id=100806 (Ausgabe 08/10). S. 5.

1144 Angenendt, Steffen 2008: Die Steuerung der Arbeitsmigration in Deutschland: Reformbedarf und Handlungsmöglichkeiten. Bonn, S. 42, 58. In: http://www.library.fes.de/pdf-files/wiso/05705.pdf (WISO Diskurs / Stand: September 2008).

1145 Newsletter ,Migration und Bevölkerung' 2010: Vereinigtes Königreich: Einwanderungsquote in der Kritik. In: http://www.migration-info.de/mub_artikel.php?Id=100806 (Ausgabe 08/10). S. 5.

1146 Newsletter ,Migration und Bevölkerung' 2010: Vereinigtes Königreich: Einwanderungsquote in der Kritik. In: http://www.migration-info.de/mub_artikel.php?Id=100806 (Ausgabe 08/10). S. 5.

1147 Newsletter ,Migration und Bevölkerung' 2010: Schweiz: Kontingente für Nicht-EU-Arbeitskräfte. In: http://www.migration-info.de/mub_artikel.php?Id=100510 (Ausgabe 05/10). S. 1.

1148 Newsletter ,Migration und Bevölkerung' 2010: Dänemark: Strenges Punktesystem. 
Haushaltsverhandlungen für 2011 einigte sich die Regierung am 8. November 2010 auf strengere Regeln für Familienzusammenführungen mit dem Ziel, die Einwanderung aus muslimischen Staaten einzuschränken. Bisher lag das Mindestalter beider Ehepartner für eine Familienzusammenführung bei mindestens 24 Jahren. In Zukunft müssen sich zudem beide über ein Punktesystem qualifizieren. Es gibt Pluspunkte z. B. für einen Hochschulabschluss und für Berufserfahrung in Berufen, in denen in Dänemark Arbeitskräftemangel besteht. Ebenso werden für bestimmte Sprachkenntnisse Pluspunkte vergeben, wovon allerdings die Sprachen Arabisch, Urdu oder Türkisch ausgeschlossen sind. Justizsprecher Peter Skaarup, der der rechtspopulistischen Dänischen Volkspartei angehört, äußerte hinsichtlich dieses Systems: Dänemark habe hiermit künftig Europas strengste Regeln.

Frankreich verschärft ebenso wie andere EU-Länder seine Einwanderungspolitik. Bereits Ende März 2009 gaben in einem Schreiben der französiche Staatspräsident Nicolas Sarkozy und Premierminister Francois Fillon ihren Regierungsauftrag dem neuen Minister für Einwanderung und Integration Eric Besson begannt. ${ }^{1149}$ Dabei soll sich besonders in Gemeinschaftsarbeit mit den wichtigsten Herkunftsstaaten (Algerien, China, Mali, Marokko, Türkei, Tunesien, Senegal, Vietnam) bezüglich weiterer Kooperationsabkommen bis 2012 geeinigt werden. ${ }^{1150}$ Des Weiteren beabsichtigten Sarkosy und Fillon, die Arbeitsmigration nach Frankreich zu verringern. ${ }^{1151}$ Besson war in dieser Hinsicht angehalten, die Zusammenarbeit mit der EU bezüglich des Asyl- und Einwanderungspakts zu verbessern. Der gewählte französische Präsident Nicolas Sarkozy (UMP) hatte schon nach dem Wahlsieg im Mai 2007 eine Reform der französischen Einwanderungsgesetze entsprechend seiner Absicht einer ,ausgewählten Zuwanderung“" angekündigt. ${ }^{1152}$ Darüber hinaus hatte im Oktober 2007 die französische Regierung ein neues Einwanderungsgesetz beschlossen, dessen Quintessenz die vorab erwähnte ,ausgewählte Zuwanderung“ ist. ${ }^{1153}$ Mit diesem neuen Gesetz wird insbesondere der Familiennachzug erschwert. Die nachziehenden Familienangehörige

In: http://www.migration-info.de/mub_artikel.php?Id=100907 (Ausgabe 09/10). S. 1-2.

1149 Newsletter ,Migration und Bevölkerung' 2009: Frankreich: Strenge Umsetzung des Einwandrungsgesetzes; www.migration-info.de/mub_artikel.php?Id=090409 (Ausgabe 04/09). S. 1.

${ }^{1150}$ Newsletter ,Migration und Bevölkerung' 2009: Frankreich: Strenge Umsetzung des Einwandrungsgesetzes; www.migration-info.de/mub_artikel.php?Id=090409 (Ausgabe 04/09). S. 2.

1151 Newsletter ,Migration und Bevölkerung' 2009: Frankreich: Strenge Umsetzung des Einwandrungsgesetzes; www.migration-info.de/mub_artikel.php?Id=090409 (Ausgabe 04/09). S. 1.

1152 Newsletter ,Migration und Bevölkerung' 2007: Frankreich: Einwanderungsgesetz erschwert Familiennachzug; http://www.migration-info.de/mub_artikel.php?Id=070801 (Ausgabe 08/07). S. 1.

1153 Newsletter ,Migration und Bevölkerung' 2007: Frankreich: Einwanderungsgesetz erschwert Familiennachzug; http://www.migration-info.de/mub_artikel.php?Id=070801(Ausgabe 08/07). S. 1-2. 
müssen künftig noch vor der Einreise nach Frankreich ihr Wissen über republikanische Werte und ihre Sprachkenntnisse in einem Test beweisen. Der kritisierte Hauptpunkt ist dabei jedoch die geplante Einführung von Gentests, also DNA-Testverfahren zur Überprüfung des Verwandtschaftsverhältnisses. ${ }^{1154}$ Diesbezüglich zeigte sich der Chef der oppositionellen Partei Socialiste (PS) Francois Hollande kritisch. Es sei zwar aufmerksam, über die Idee eines Quotensystems nachzudenken, dabei müsse dies aber in Abstimmung mit den Herkunftsstaaten geschehen. ${ }^{1155}$ Auch Hilfsorganisationen demonstrierten erneut gegen die restriktive Einwanderungspolitik unter der Regierung Sarkosy. ${ }^{156}$ Die Arbeitsmigration nach Frankreich sollen bis heute nur noch diejenigen Einwanderer begrüßen, die für den französischen Arbeitsmarkt von Nutzen sind, wodurch eine Auswahl ausschließlich auf Basis wirtschaftlicher Kriterien erfolgen soll.

Außerdem werden in vielen anderen Ländern Zuwanderungsmöglichkeiten für qualifizierte Arbeitskräfte geschaffen: In Italien mittels eines Quotensystems, in den Niederlanden mittels eines Punktesystem; und sogar Japan hat kürzlich den rigide abgeschotteten Arbeitsmarkt für bestimmte Arbeitsgebiete geöffnet (Ingenieure und Forscher). Irland vergibt eine „Greencard“, und auch Portugal sieht ähnliche Regelungen vor. ${ }^{157}$

Insgesamt geht das bislang gescheiterte und humankapitalorientierte Punktesystem in Deutschland als Steuerungsverfahren davon aus, „dass ein hoch qualifizierter Zuwanderer allein aufgrund seiner Fähigkeiten einen angemessenen Arbeitsplatz in Deutschland finden und sich gesellschaftlich integrieren kann."1158 Von zentraler Bedeutung ist hierbei, dass in Deutschland (und auch einigen anderen EUMitgliedstaaten) eine Tendenz zu verstärkter Zuwanderung von qualifizierten und hoch qualifizierten Fachkräften im Bereich der Arbeitsmigration beobachtet werden kann. In Anbetracht dieser Tendenz sollte künftig die Verwendbarkeit des Punktesystems auf dem Arbeitsmarkt Deutschlands aufgrund seiner wirtschaftlichen und integrationspolitischen Bedeutung weiterhin berücksichtigt werden.

\footnotetext{
${ }^{1154}$ Newsletter ,Migration und Bevölkerung' 2007: Frankreich: Einwanderungsgesetz erschwert Familiennachzug. http://www.migration-info.de/mub_artikel.php?Id=070801 (Ausgabe 08/07). S. 1.

${ }^{1155}$ Newsletter ,Migration und Bevölkerung' 2007: Frankreich: Einwanderungsgesetz erschwert Familiennachzug. http://www.migration-info.de/mub_artikel.php?Id=070801 (Ausgabe 08/07). S. 2.

1156 Newsletter ,Migration und Bevölkerung' 2009: Frankreich: Strenge Umsetzung des Einwandrungsgesetzes; www.migration-info.de/mub_artikel.php?Id=090409 (Ausgabe 04/09). S. 1.

1157 Angenendt, Steffen 2008: Die Steuerung der Arbeitsmigration in Deutschland: Reformbedarf und Handlungsmöglichkeiten. Bonn, S. 42.

1158 Angenendt, Steffen 2008: Die Steuerung der Arbeitsmigration in Deutschland: Reformbedarf und Handlungsmöglichkeiten. Bonn, S. 52.
} 


\section{2 Blue Card}

Die EU entwickelte das Modell einer „Blue Card“ für die Einführung einer Aufenthaltserlaubnis hoch qualifizierter Einwanderer nach dem Vorbild der USamerikanischen Greencard, mit dem Ziel, dem zunehmenden Fachkräftemangel auf dem europäischen Arbeitsmarkt entgegenzuwirken. ${ }^{1159}$ Dies war das erklärte Ziel des ursprünglichen Kommissionsvorschlags von 2007. Anlässlich der Einwanderungskonferenz in Lissabon am 23. Oktober 2007 präsentierte EUJustizkommissar Franco Frattini den Innenministern der Mitgliedstaaten einen Vorschlag: „Europa solle attraktiver für Fachkräfte werden. [...]. Rund 20 Mio. Einwanderer seien nach Studien der EU-Kommission in den kommenden 13 Jahren höchstens notwendig. Migranten aus Asien und Afrika sollen bevorzugt werden, da sie gegenwärtig von legalen Einwanderungsmöglichkeiten am meisten ausgeschlossen werden.“"1160 Daraufhin betonte die EU-Kommission, „dass nur fünf Prozent der Zuwanderer in die EU hochqualifiziert seien, in den USA dagegen 55 Prozent. [...]. Wenn die EU mit den USA um Hochqualifizierte konkurrieren wolle, müsse sie diesen Migranten Zugang zum gesamten EU-Arbeitsmarkt bieten und eine EU-weit gültige, zeitlich unbegrenzte, unbürokratisch erteilte und mit großzügigem Familiennachzug ausgestattete Zuwanderungsmöglichkeit schaffen.“1161

Darüber hinaus wurde einer der im „Strategischen Plan“ skizzierten Vorschläge, die Richtlinie zu Hochqualifizierten in Verbindung mit einer „Blauen Karte EU“, in der Zwischenzeit von Rat und Europäischem Parlament festgesetzt. ${ }^{1162}$ Die Richtlinie enthielt zudem den Vorschlag eines einheitlichen Antragsverfahrens bzw. Genehmigungsverfahrens für die Erteilung einer kombinierten Aufenthalts- und Arbeitserlaubnis („One-Stop-Government“6). ${ }^{1163}$ Allen Arbeitnehmern aus Drittstaaten,

1159 Newsletter ,Migration und Bevölkerung’ 2007: EU-Kommission schlägt „Blue Card“ für Einwanderer vor; http://www.migration-info.de/mub_artikel.php?Id=070802 (Ausgabe 08/07). S. 2.

1160 Newsletter ,Migration und Bevölkerung’ 2007: EU-Kommission schlägt „Blue Card“ für Einwanderer vor; http://www.migration-info.de/mub_artikel.php?Id=070802 (Ausgabe 08/07). S. 2.

1161 Angenendt, Steffen / Parkes, Roderick 2010: Wanderer, kommst du nach Europa?: Strategien zur Anwerbung Hochqualifizierter in der EU. In: Internationale Politik (IP), Juli/August 2010. Nr. 4., 65 Jahrgang. Berlin, S. 75; http://www.internationalepolitik.de

1162 Richtlinie 2009/50/EG des Rates vom 25. Mai 2009 über die Bedingungen für die Einreise und den Aufenthalt von Drittstaatsangehörigen zur Ausübung einer hochqualifizierten Beschäftigung. In: Amtsblatt der Europäischen Union, L 155 vom 18. 06. 2009, S. 17-29. Auch im Internet: http://www.aufenthaltstitel.de/rl_2009_50_eg.html

1163 Vgl. Europäische Kommission ( $\overline{\mathrm{K} O M})$ 2007: Vorschlag für eine Richtlinie des Rates über ein einheitliches Antragsverfahren für eine kombinierte Erlaubnis für Drittstaatsangehörige zum 
die sich rechtmäßig in der EU aufhalten und die nicht bereits unter den Anwendungsbereich der Richtlinie über „langfristig aufenthaltsberechtigte Drittstaatsangehörige“ 1164 fallen, soll somit ein ,gemeinsames Bündel von Rechten" anerkannt werden. In diesem Zusammenhang sind die wichtigsten allgemeinen Bestimmungen zum Aufenthalt sowie Zugang zum Arbeitsmarkt in Deutschland bereits am 1. Januar 2005 im Aufenthaltsgesetz (AufenthG) zusammengefasst worden. ${ }^{165}$ Als wesentliche Neuregelung ist anstelle des doppelten Genehmigungsverfahren hinsichtlich des Aufenthalts (Aufenthaltsgenehmigung) und des Arbeitsmarktzugangs (Arbeitsgenehmigung), welches das Ausländergesetz von 1990 vorsah, lediglich ein Verfahren („One-Stop-Government") für die Erteilung des Aufenthaltstitels bei der Ausländerbehörde erforderlich (§ 4 Abs. 2, $§ 18$ Abs. 2 i.V.m $\S$ 39 AufenthG). ${ }^{1166}$

Die EU-Kommission schlug weiterhin vor, Hochqalifizierten und deren Familienangehörigen einen schnellen und bevorzugten Zugang zum Arbeitsmarkt zu ermöglichen: Das Schnellverfahren sollte innerhalb von 30 Tagen vollzogen und die Gültigkeit der Genehmigung zunächst auf zwei Jahre befristet sein, wobei diese aber verlängert werden konnte. Die wichtigsten Voraussetzungen für die Einwanderung waren ein dreifaches Mindestbruttogehalt und die Qualifikation (dreijährige Berufspraxis und höherer Bildungsabschluss). ${ }^{1167}$ Die EU-Kommission hatte bereits im Jahr 2001 einen Richtlinienentwurf zur Steuerung der wirtschaftlichen Einwanderung vorgelegt, der als ein erstes Grundgerüst für gemeinsame Regeln und Verfahren in Bezug auf die Zuwanderung von Arbeitskräften aus Drittstaaten gedient hat. ${ }^{168}$

Aufenthalt und zur Arbeit im Gebiet eines Mitgliedstaates und über ein gemeinsames Bündel von Rechten für Drittstaatsangehörige, die sich rechtmäßig in einem Mitgliedstaat aufhalten, Dok.-Nr. KOM (2007) 638 endgültig, Brüssel, 23. Oktober 2007. S. 2; vgl. Hoffmann, Holger 2006: „OneStop-Government" - Was bedeuten die neuen Aufenthaltstitel? In: Davy, Ulrike / a.a.O., S. 42-58.

1164 Richtlinie 2003/109/EG des Rates vom 25. November 2003 betreffend die Rechtsstellung der langfristig aufenthaltsberechtigten Drittstaatsangehörigen. In: Amtsblatt der Europäischen Union, L 16, 23. Januar 2004, S. 44-53.

1165 Parusel, Bernd / Schneider, Jan 2010: Deckung des Arbeitskräftebedarfs durch Zuwanderung: Studie der deutschen Kontaktstelle für das Europäische Migrationsnetzwerk (EMN), Working Paper 32 der Forschungsgruppe des BAMF. Nürnberg, S. 27. Im Internet: http://www.bamf.de (Stand: Juni 2010).

1166 Parusel, Bernd / Schneider, Jan 2010: Deckung des Arbeitskräftebedarfs durch Zuwanderung: Studie der deutschen Kontaktstelle für das Europäische Migrationsnetzwerk (EMN), a.a.O., S. 27.

1167 Angenendt, Steffen 2008: Die Steuerung der Arbeitsmigration in Deutschland: Reformbedarf und Handlungsmöglichkeiten. Bonn, S. 57; vgl. Newsletter ,Migration und Bevölkerung' 2007: Novellierung des Zuwanderungsrechts (Ausgabe 06/07); Butterwegge, Carolin 2009: a.a.O., S. 164.

1168 Angenendt, Steffen 2008: Die Steuerung der Arbeitsmigration in Deutschland: Reformbedarf und Handlungsmöglichkeiten. Bonn, S. 56; vgl. Europäische Kommission (KOM) 2001: Vorschlag für eine Richtlinie des Rates über die Bedingungen für die Einreise und den Aufenthalt von Drittstaatsangehörigen zur Ausübung einer unselbstständigen oder selbstständigen Erwerbstätigkeit, Dok.-Nr. KOM (2001) 386 endgültig. Brüssel, 11. Juli 2001. 
Bezüglich der gemeinsamen Regelung der Arbeitsmigration, aber auch im Hinblick auf die Integration von Zugewanderten sind derzeit immer noch gravierende Interessenunterschiede zwischen den EU-Mitgliedstaaten erkennbar, die von der Regulierung der Arbeitsmärkte, von der jeweiligen Wirtschaftsstruktur und von migrationspolitischen Traditionen abhängen. Mit den Verträgen von Amsterdam 1997 bis Lissabon 2009 wurde hinsichtlich der Regelung der Arbeitsmigration - wie auch für andere migrationspolitische Bereiche - betreffend die Zusammenarbeit Einstimmigkeit beschlossen. ${ }^{1169}$ Mit diesem Einstimmigkeitsprinzip wird demgemäß bis heute eine Einigung auf Regelungen zur Förderung der Einwanderung von Hochqualifizierten erschwert.

Deutschland hatte sich vor allem in der Vergangenheit gegen eine EU-weite Regelung ausgesprochen (vgl. Kapitel III.2.8): So äußerte sich Bundeskanzlerin Angela Merkel (CDU) im Jahr 2007 ausweichend gegenüber dem Entwurf der „Blue Card“. Die Bundesregierung betreibe ohnedies gezielte Programme, um Fachkräfte aus dem Ausland anzuwerben, erklärte sie. Auch der Arbeitsminister Franz Müntefering (SPD) unterstrich, dass ,abgesehen von Spitzenkräften Deutsche bei der Stellenbesetzung grundsätzlich Vorrang haben sollten.“ ${ }^{1170}$ Dagegen pries die parlamentarische Geschäftsführerin von Bündnis 90/Die Grünen Thea Dückert die Initiative der EUKommission an. Sie sprach von einer ,zunehmenden Isolation“ Deutschlands mit seiner Abschottungsstrategie in Europa, die sich hier zeige. Der Fraktionsführer der Linken Oskar Lafontaine bezeichnete die „Blue Card“ als einen „Schritt in die richtige Richtung“. In diesem Zusammenhang entwickelte Bayern bereits Anfang Juli 2000 ein „Blue-Card-Programm“, das am 4. Juli 2000 von der bayerischen Landesregierung verabschiedet wurde: ${ }^{171}$ Eine am Arbeitsmarkt orientierte Vergabe der Blue Card sollte dabei verstärkt umgesetzt werden. Diese war mit der Dauer des Beschäftigungsverhältnisses verbunden: „Wer arbeitslos wird, muss wieder ausreisen, wenn er der Sozialkasse zur Last fällt", so der bayerische Innenminister Günther Beckstein (CSU) im Jahr 2000. ${ }^{1172}$ Eine Vergabe der blauen Karten sollte demnach per Verwaltungsanweisung unbürokratisch an Spezialisten erfolgen. Bayern plante einen

\footnotetext{
1169 Vgl. Parusel, Bernd 2010: Abschottungs- und Anwerbungsstrategien: EU-Institutionen und Arbeitsmigration, S. 244-245.

1170 Newsletter ,Migration und Bevölkerung’ 2007: EU-Kommission schlägt „Blue Card“ für Einwanderer vor; http://www.migration-info.de/mub_artikel.php?Id=070802 (Ausgabe 08/07). S. 2.

1171 Newsletter ,Migration und Bevölkerung' 2000: Deutschland: Nach Green Card nun Blue Card. In: http://www.migration-info.de/mub_artikel.php?Id=000604 (Ausgabe 06/00). S. 3.

1172 Newsletter ,Migration und Bevölkerung' 2000: Deutschland: Nach Green Card nun Blue Card. In: http://www.migration-info.de/mub_artikel.php?Id=000604 (Ausgabe 06/00). S. 3.
} 
berufsoffenen, an der Arbeitskräftenachfrage orientierten Einsatz der Blue Card, der nicht nur auf Experten aus dem Bereich der Informationstechnologie begrenzt sein sollte. ${ }^{1173}$ Im Unterschied $\mathrm{zu}$ der Greencard-Initiative der Bundesregierung, der die Länderkammer zustimmen musste, sah Beckstein das bayerische Modell nicht für zustimmungspflichtig an. SPD und Bündnis 90/Die Grünen beurteilten im hessischen Wiesbaden den Vorstoß als „unausgegoren“ und bezeichneten ihn als eine „Hire-andFire-Politik“. ${ }^{1174}$ Denn im Fall eines Arbeitsplatzverlustes sollten Blue-Card-Inhaber lediglich zwei bis drei Monate im Land bleiben dürfen, um eine neue Stelle zu finden. Es bestand jedoch kein Anspruch auf Arbeitslosen- und Sozialhilfe. ${ }^{1175}$

Die nun im Juni 2009 verabschiedete sogenannte „Blue-Card-Richtlinie“ zur einheitlichen Arbeitsgenehmigung für hochqualifizierte Fachkräfte wurde bis 2011 von den EU-Mitgliedstaaten umgesetzt (abgesehen von Dänemark, Irland und Großbritannien). ${ }^{1176}$ Im Falle der Erfüllung folgender Kriterien dürfen hoch qualifizierte Arbeitskräfte aus Drittstaaten für zunächst vier Jahre in der EU beschäftigt sein: „Sie müssen über einen Hochschulabschluss oder eine fünfjährige Berufsausbildung verfügen, einen Arbeitsvertrag oder die Zusage eines Arbeitsplatzes vorweisen, und ihr Bruttoeinkommen muss mindestens 50 Prozent über dem jeweiligen Landesdurchschnitt liegen." 1177 Den einzelnen Mitgliedstaaten kommt dabei die Entscheidung $\mathrm{zu}$, ob eine Blue Card ausgestellt wird. Somit sind in diesem Verfahren keine einheitlichen EU-Vorgaben vorgesehen. Auch die Mitgliedstaaten bestimmen selbst über die Zulassung dieser MigrantInnen zu ihrem Arbeitsmarkt (auch bei einem vorhergehenden Aufenthalt in einem anderen EU-Staat). ${ }^{1178}$ Eine Verlängerung der Blue Card ist möglich und kann nach fünf Jahren in einen dauerhaften Aufenthalt übergehen. Die Blue Card beinhaltet eine sozial- und arbeitsrechtliche Gleichstellung der Inhaber mit den Bürgern des Aufnahmelandes und eine Berechtigung zum Familiennachzug. Die Mitgliedstaaten werden darüber hinaus ab 2013 statistische Daten über die Anzahl der jährlich erteilten Blue Cards erheben. ${ }^{1179}$ Außerdem plant die EU-

\footnotetext{
1173 Newsletter ,Migration und Bevölkerung' 2000: Deutschland: Nach Green Card nun Blue Card. In: http:/www.migration-info.de/mub_artikel.php?Id=000604 (Ausgabe 06/00). S. 3.

1174 Newsletter ,Migration und Bevölkerung' 2000: Deutschland: Nach Green Card nun Blue Card. In: http://www.migration-info.de/mub_artikel.php?Id=000604 (Ausgabe 06/00). S. 4.

1175 Newsletter ,Migration und Bevölkerung' 2000: Deutschland: Nach Green Card nun Blue Card. In: http://www.migration-info.de/mub_artikel.php?Id=000604 (Ausgabe 06/00). S. 4.

1176 Angenendt, Steffen / Parkes, Roderick 2010: Blue Card - (noch) kein Erfolg?: Perspektiven der EUMigrationspolitik für hochqualifizierte Arbeitskräfte. S. 1.

1177 Angenendt, Steffen / Parkes, Roderick 2010: Blue Card - (noch) kein Erfolg? a.a.O., S. 1.

1178 Angenendt, Steffen / Parkes, Roderick 2010: Blue Card - (noch) kein Erfolg? a.a.O., S. 1.

1179 Angenendt, Steffen / Parkes, Roderick 2010: Blue Card - (noch) kein Erfolg? a.a.O., S. 1.
} 
Kommission für 2012 die Veröffentlichung einer Mitteilung über die Bewältigung des Arbeitskräftemangels durch Migration in EU-Mitgliedstaaten. ${ }^{1180}$ In der EU-Blue-CardRichtlinie fehlen jedoch zentrale Punkte, die im Rahmen des vorab genannten ursprünglichen Kommissionsvorschlags aus dem Jahr 2007 erwähnt wurden. ${ }^{1181}$ Die EU-Blue-Card gewährt insbesondere keinen freien Zugang zum gesamten EUArbeitsmarkt, sondern ist an eine konkrete Stelle gebunden. Sollte ein angeworbener Hochqualifizierter seine Stelle verlieren, hat er drei Monate lang Zeit, sich eine neue zu suchen, ansonsten droht der Verlust der Aufenthalts- und Arbeitserlaubnis. Zwei entscheidende Gründe sind rückblickend für das Scheitern des ursprünglichen Entwurfs zu nennen, damit die Entwicklung ergänzender Ansätze bei der EU-Migrationspolitik für Hochqualifizierte erwartet werden kann: ${ }^{1182}$ Der erste liegt darin, dass die Ablehnung der Kommissionsvorschläge seitens der Mitgliedstaaten erfolgte, weil sie einen Verlust an nationaler Souveränität befürchteten. ${ }^{1183}$ Hierbei ist zu beachten, ,dass die Richtlinie nicht das Recht der Mitgliedstaaten berührt, festzulegen, wie viele Drittstaatsangehörige maximal mit einer Blue Card einreisen dürfen. “1184 Ein weiterer Grund ist darin $\mathrm{zu}$ sehen, dass deren Urheber ein wichtiges Anliegen vieler Mitgliedstaaten vernachlässigt haben: Die Intention, inländische Arbeitsmarktpotenziale besser ausschöpfen zu können. ${ }^{1185}$

Zusammenfassend lässt sich festhalten, dass der Blue-Card-Vorschlag auf unterschiedliche Resonanz in den EU-Mitgliedsländern gestoßen ist. In Deutschland ist zum Beispiel angesichts der Notwendigkeit und der Ausgestaltung des EURichtlinienvorschlags ein innenpolitischer Disput entstanden. In erster Linie äußerten die Gegner ihre Befürchtungen, dass die Blue-Card-Regelung einen gravierenden Kontrollverlust in der deutschen Migrationspolitik mit sich bringen würde. Auch die Frage, ob der Richtlinienvorschlag in dieser Prägung eine politische Zukunft hat, konnte nicht vohergesagt werden.

${ }^{1180}$ Vgl. Europäische Kommission (KOM) 2010: Mitteilung der Kommission an das europäische Parlament, den Rat, den europäischen Wirtschafts- und Sozialausschuss und den Ausschuss der Regionen: Ein Raum der Freiheit, der Sicherheit und des Rechts für die Bürger Europas: Aktionsplan zur Umsetzung des Stockholmer Programms. KOM (2010) 171 endgültig. Brüssel, S. 55.

1181 Angenendt, Steffen / Parkes, Roderick 2010: Wanderer, kommst du nach Europa?: Strategien zur Anwerbung Hochqualifizierter in der EU. S. 75.

1182 Angenendt, Steffen / Parkes, Roderick 2010: Wanderer, kommst du nach Europa? a.a.O., S. 74-78.

1183 Angenendt, Steffen / Parkes, Roderick 2010: Wanderer, kommst du nach Europa? a.a.O., S. 75.

$1184 \mathrm{He}$, Barbara 2009: Zuwanderung von Hochqualifizierten aus Drittstaaten nach Deutschland: Ergebnisse einer schriftlichen Befragung. In: Working Paper 28 der Forschungsgruppe des BAMF. Nürnberg, S. 11. Fußnote 1. Online verfügbar unter: http://www.bamf.de (erschienen 2009).

1185 Angenendt, Steffen / Parkes, Roderick 2010: Wanderer, kommst du nach Europa? a.a.O., S. 76. 


\section{3 Fazit}

Die Einwanderungsmöglichkeiten von hoch qualifizierten Arbeitskräften werden bis heute sowohl in der Bundesrepublik als auch in der EU diskutiert und bleiben weiterhin umstritten. ${ }^{1186}$ Bereits in den vergangenen Jahren haben viele EU-Staaten angesichts der wirtschaftlichen und demografischen Herausforderungen nationale Steuerungssysteme zur Gewinnung zusätzlicher Arbeitskräfte aus Drittsstaaten erneuert oder entwickelt. Diesbezüglich eröffnete die Bundesrepublik Deutschland auf nationaler Ebene mit dem Inkrafttreten des Zuwanderungsgesetzes (ZuWG) von 2005 für Hochqualifizierte und auch Selbständige eine Einwanderungsmöglichkeit. Seitdem hat sich die Bundesrepublik ,von einem informellen $\mathrm{zu}$ einem formellen modernen Einwanderungsland“ entwickelt, mit den entsprechenden administrativen und gesetzlichen Instrumentarien. 1187 Als Steuerungsinstrument hat das Zuwanderungsgesetz von 2005 (auch nach seiner Novellierung 2007) jedoch keinen effektiven Beitrag zur Verringerung des Mangels an qualifizierten und hoch qualifizierten Arbeitskräften geleistet. Insbesondere auf dem Gebiet der Zuwanderung von Hochqualifizierten waren nur sehr geringe Fortschritte zu beobachten. ${ }^{1188}$

In den Medien und in der Öffentlichkeit erhielt die Diskussion über den Bedarf an Hochqualifizierten in Deutschland - sowie generell in Europa - ebenfalls fühlbare Aufmerksamkeit. Wie bereits erwähnte, kündigte der ehemalige Bundeskanzler Gerhard Schröder bei seiner Eröffnungsrede auf der CeBIT in Hannover am 23. Februar 2000 die „Greencard“-Initiative (siehe Kapitel IV.1.1 und 1.1.1) für die Einwanderung von IT-SpezialistInnen $a^{1189}$, die zum Inbegriff eines Paradigmenwechsels in der deutschen Migrationspolitik werden sollte: „Menschen aus dem Ausland wurden erstmals nicht nur als billige, aber unqualifizierte Arbeitskräfte angesehen, die ,Integrationsprobleme' hervorbringen, sondern auch als TrägerInnen technischer und sonstiger Intelligenz, als „Humankapital“, wie es die Ökonomie so gerne nennt.“ ${ }^{1190}$ Ungeachtet der inzwischen

1186 Vgl. Angenendt, Steffen / Parkes, Roderick 2010: Wanderer, kommst du nach Europa?: Strategien zur Anwerbung Hochqualifizierter in der EU. In: Internationale Politik (IP), Juli/August 2010. Nr. 4., 65 Jahrgang. Berlin, S. 74. Vgl. auch im Internet: http://www.internationalepolitik.de

1187 Bade, Klaus J. / Oltmer, Jochen 2010: Deutschland. In: Bade, Klaus J. / Emmer, Pieter C. / Lucassen, Leo / Oltmer, Jochen (Hrsg.) 2010: Enzyklopädie: Migration in Europa: Vom 17. Jahrhundert bis zur Gegenwart. Paderborn, S. 169.

1188 Vgl. Angenendt, Steffen 2008: Die Steuerung der Arbeitsmigration in Deutschland: a.a.O., S. 59.

1189 Welsch, Johann 2000: Green Cards für die New Economy. Eine erste Bilanz. In: Blätter für deutsche und internationale Politik (Dezember 2000). S. 1476.

1190 Nohl, Arnd-Michael / Schittenhelm, Karin / Schmidtke, Oliver / Weiß, Anja 2010: Zur Einführung: 
eingetretenen wirtschaftlichen Flaute sah sich auch die von Angela Merkel regierte Große Koalition gezwungen, um den Zuzug von Hochqualifizierten werben zu müssen. Es wurden daher „Gestaltungsmöglichkeiten für begrenzte und im Rahmen des Möglichen gesteuerte Zuwanderung nach einem besonders am kanadischen Vorbild orientierten Punktesystem mit Zulassungskriterien" einbezogen. ${ }^{1191}$ Im Hinblick auf die Gestaltungsmöglichkeiten für die Arbeitsmigration wurde auch die Entwicklung der EU-Migrationspolitik beachtet.

Insbesondere die von der EU-Kommission entwickelten Vorschläge für eine „EU-BlueCard" stellten einen vielversprechenden Fortschritt dar, wobei sie auf den EUArbeitsmarkt gerichtet waren. Ihr zentraler Inhalt ist eine europäische Mobilitätsgarantie. Demgemäß können hoch qualifizierte Einwanderer nach zweijähriger Beschäftigung in einem EU-Staat einer Beschäftigung in einem anderen Mitgliedsland nachgehen, sofern sie den dort erwarteten Anforderungen gerecht werden. Die sogenannte „Blue-CardRichtlinie“" wurde angesichts des Zugangs zum gesamteuropäischen Arbeitsmarkt als ein zugkräftiges Angebot für Hochqualifizierte betrachtet, sich als Fachkräfte in der EU niederzulassen. Allerdings hat die EU-Kommission dabei mit ihren Vorschlägen zur „Förderung der Zuwanderung von Hochqualifizierten“ keine zureichende Antwort für die Integrationsdefizite gegeben. Kommissionsvorschläge fokussierten zuerst auf die „Anwerbung neuer Arbeitskräfte aus Drittstaaten“, die Nutzung inländischer Arbeitskräfte wurde hierbei ausgeschlossen. ${ }^{1192}$ Derweil kritisierten viele Beobachter, die Blue-Card-Regelung als ungenügend, um den großen und weiter wachsenden Bedarf der EU an Hochqualifizierten zu decken. ${ }^{193}$ Auch eine Überarbeitung der Blue-CardRegelung ist indes nicht abzusehen, da die politische Debatte stagniert. Ebenso liegt die Entscheidung für die Ausstellung einer Blue Card in der Verantwortung der einzelnen EU-Mitgliedstaaten. Demzufolge wurde die EU-Blue-Card tatsächlich nicht als einheitliche EU-Vorgabe berücksichtigt.

Migration, kulturelles Kapital und Statuspassagen in den Arbeitsmarkt. In: Nohl, Arnd-Michael / Schittenhelm, Karin / Schmidtke, Oliver / Weiß, Anja (Hrsg.): Kuturelles Kapital in der Migration: Hochqualifizierte Einwanderer und Einwanderinnen auf dem Arbeitsmarkt. Wiesbaden, S. 9.

1191 Vgl. Bade, Klaus J. / Oltmer, Jochen 2010: Deutschland. In: Bade, Klaus J. / Emmer, Pieter C. / Lucassen, Leo / Oltmer, Jochen (Hrsg.) 2010: Enzyklopädie: Migration in Europa: a.a.O., S. 168.

1192 Angenendt, Steffen / Parkes, Roderick 2010: Wanderer, kommst du nach Europa?: Strategien zur Anwerbung Hochqualifizierter in der EU. In: Internationale Politik (IP), Juli/August 2010. Nr. 4., 65 Jahrgang. Berlin, S. 76. Vgl. auch im Internet: http://www.internationalepolitik.de

1193 Vgl. Internationale Politik (IP) 2010: „Für Deutschland wird die Blue Card nicht viel verändern.“ In: Internationale Politik (IP), Juli/August 2010. Nr. 4., 65. Jahrgang. Berlin, S. 80-81.; vgl. auch im Internet: http://www.internationalepolitik.de 
Darüber hinaus zeigt sich, wie vorab erwähnt, dass im Bereich der Arbeitsmigration vor allem Deutschland insgesamt das niedrigste Niveau betreffend die Europäisierung angestrebt hat. ${ }^{1194}$ Des Weiteren wurde eine deutliche Tendenz zum Abbau von Zuwanderungshürden seitens anderer Industrieländer sowie Schwellenländer beobachtet, wobei die EU-Mitgliedstaaten Schwierigkeiten haben, gemeinsame Migrationsstrategien zu entwickeln. Dies betrifft sowohl speziell ausgerichtete „Anwerbeprogramme über neue befristete Zuwanderungsmöglichkeiten oder bilaterale Anwerbeabkommen, wie jüngst zwischen Südkorea und China, Pakistan, Usbekistan sowie Kambodscha oder zwischen Portugal und Brasilien." ${ }^{1195}$ Es sind in dieser Hinsicht zumindest weitere zunehmende Politiktendenzen ersichtlich: ${ }^{196}$ 1. Ersetzung der Arbeitsmarktprüfungen für Hochqualifizierte durch unterschiedliche Kriterienkataloge. Dabei führen einige Länder Systeme ein, welche auf Quoten (z. B. Italien) und Punkten (z. B. die Niederlande und Großbritannien) beruhen. Ebenso werden in einigen Ländern neue temporäre Einwanderungsmöglichkeiten entwickelt, wie etwa in Irland die sogenannte Greencard. Auch werden spezielle Anwerbeprogramme für Arbeitsmarktbereiche, in denen ein besonderer Bedarf besteht, geschaffen. Als Beispiele können hierzu, neben der deutschen „Greencard“ zur Anwerbung von IT-Spezialisten, die in Frankreich gültigen besonderen Regelungen für die Anwerbung von Krankenschwestern genannt werden. 2. Eine weitere Tendenz ist der Versuch, ausländische HochschulabsolventInnen im Land zu halten und ihnen eine Möglichkeit für den Arbeitsmarktzugang zu bieten. Auch an dieser Stelle hat das deutsche Zuwanderungsgesetz eine erkennbare Öffnung bewirkt. 3. Abschließend sollte zudem noch auf die Vereinfachung der Übergangsregelungen für Arbeitskräfte aus den EU-Beitrittsländern verwiesen werden. Hierzu gehört beispielsweise die von der Bundesrepublik durchgeführte Erleichterung des Zuzugs von Elektro- und Maschienenbauingenieuren aus den zwölf neuen EU-Mitgleidsländern.

Mit diesen Tendenzen versuchte man die Einwanderung so $\mathrm{zu}$ lenken, dass die demografischen und wirtschaftlichen Anforderungen des Landes vollzogen werden und gleichzeitig negative Auswirkungen auf den einheimischen Arbeitsmarkt (wie z. B. Lohndumping, eine Verschlechterung von Beschäftigungsstandards oder die

\footnotetext{
${ }^{1194}$ Vgl. Newsletter ,Migration und Bevölkerung' 2000: Deutschland: Nach Green Card nun Blue Card. Online verfügbar unter: http://www.migration-info.de/mub_artikel.php?Id=000604 (Ausgabe 06/00).

1195 Angenendt, Steffen / Parkes, Roderick 2010: Wanderer, kommst du nach Europa?: Strategien zur Anwerbung Hochqualifizierter in der EU. In: Internationale Politik (IP), Juli/August 2010. Nr. 4., 65 Jahrgang. Berlin, S. 75.; http://www.internationalepolitik.de

1196 Vgl. Angenendt, Steffen 2008: Die Steuerung der Arbeitsmigration in Deutschland: Reformbedarf und Handlungsmöglichkeiten. Bonn, S. 42-43.; http://www.library.fes.de/pdf-files/wiso/05705.pdf
} 
Verdrängung von Arbeitskräften) und auf die Herkunftsländer, vor allem durch Braindrain, vermieden werden konnten. Deutschland hat bislang mit den verschiedenen Reformen insbesondere die Einwanderungsmöglichkeiten für hoch qualifizierte und qualifizierte Beschäftigte in bestimmten Bereichen verbessert. Die Untersuchung der bestehenden Einwanderungsmöglichkeiten nach Deutschland weist jedoch mit Angenendt (2008) darauf hin, dass die Steuerungsinstrumente für den Zuzug von qualifizierten und hoch qualifizierten Arbeitskräften bisher noch ungenügend sind und sowohl für die dauerhafte als auch für die befristete Einwanderung einer Verbesserung durch ergänzende Maßnahmen bedürfen. ${ }^{1197}$ Des Weiteren ist anzumerken, dass neben der Gestaltung des Rechtssystems für die Einwanderung auch weitere Aspekte die Attraktivität Deutschlands als Zielland für Fachkräfte und Hochqualifizierte beeinflussen können, wie etwa das Lohnniveau sowie die Sprachbarrieren. ${ }^{1198}$ Ebenso gehören zu den aktuellen und künftigen politischen Herausforderungen für die deutsche Einwanderungspolitik - abgesehen von den Rechtsgrundlagen der Einwanderung - auch begleitende Maßnahmen, beispielsweise Fortschritte in Bezug auf die Anerkennung ausländischer Qualifikationen (z. B. Anerkennung der Bildungs- und Berufsabschlüsse). ${ }^{1199}$

${ }^{1197}$ Vgl. Angenendt, Steffen 2008: Die Steuerung der Arbeitsmigration in Deutschland: Reformbedarf und Handlungsmöglichkeiten. Bonn, S. 43.; http://www.library.fes.de/pdf-files/wiso/05705.pdf

1198 Parusel, Bernd / Schneider, Jan 2010: Deckung des Arbeitskräftebedarfs durch Zuwanderung: Studie der deutschen Kontaktstelle für das Europäische Migrationsnetzwerk (EMN), Working Paper 32 der Forschungsgruppe des BAMF. Nürnberg, S. 71. Im Internet: http://www.bamf.de (Stand: Juni 2010).

1199 Vgl. Parusel, Bernd / Schneider, Jan 2010: Deckung des Arbeitskräftebedarfs durch Zuwanderung: Studie der deutschen Kontaktstelle für das Europäische Migrationsnetzwerk (EMN), Working Paper 32 der Forschungsgruppe des BAMF. Nürnberg, S. 72. 


\section{Schlussfolgerung}

Die vorliegende Untersuchung ist den zentralen Fragen nachgegangen, wie sich die Migrationspolitik in Deutschland seit dem Maastrichter Vertrag der 1990er Jahre entwickelt hat. Welche Entwicklung der europäischen Integration ist dabei gesetzlich verankert und inwieweit ist es in der deutschen nationalen Migrationspolitik zu einer „Europäisierung“ gekommen? Folgende Arbeitshypothesen wurden aufgestellt:

1. Die Migrationspolitik des Nationalstaats Deutschland wird im Kernbereich nationalstaatlicher Souveränität durch die supranationale Institutionalisierung noch nicht penetriert.

2. Wenn Deutschland seine Kompetenzausübung mit den EU-Vorgaben als quasi parallele Institutionalisierung auf nationaler- und europäischer Ebene integrieren kann, dann ist eine Europäisierung deutscher Migrationspolitik wahrscheinlicher.

3. Jedoch ist hierbei der Anpassungsdruck, der von der EU-Ebene ausgeht, also die Top-down-Perspektive keine notwendige Bedingung, um eine Veränderung nationalstaatlicher Politik in Deutschland voranzutreiben.

Das Ziel der vorliegenden Analyse war, die Entwicklung der Migrationspolitik in Deutschland von 1990 bis zur Gegenwart sowie die Auswirkungen des europäischen Integrationsprozesses auf die nationalstaatliche Politik, also hier der deutschen Migrationspolitik zu untersuchen, wobei vor allem die Interessen und Strategien der unterschiedlichen Akteure im Mittelpunkt standen, und somit folglich den Prozess der Europäisierung systematisch herauszuarbeiten. Dabei war Gegenstand der Analyse, die Interessen der EU-Institutionen und der Mitgliedstaaten auf dem Feld der Migrationspolitik und bei der Entwicklung einer gemeinsamen Strategie für Migration aus Drittstaaten in die EU zu ergründen, Veränderungen und Fortschritte dieser Interessen $\mathrm{zu}$ definieren sowie essenzielle Zusammenhänge aufzuzeigen. Vor diesem Hintergrund war es ein weiteres Ziel der Arbeit, einen effektiven theoretischen Ansatz zur Analyse von Europäisierungsprozessen zu entwickeln, der nicht zentral auf dem Modell eines Anpassungsdrucks beruht. Als Ausgangspunkt diente dabei die in der neoinstitutionalistischen Diskussion der Politikwissenschaft vertretene These einer Strukturierung des Akteurshandelns mittels des institutionellen Kontextes, in dem dieses Handeln vonstatten geht. 
Im Folgenden sollen zunächst die Hauptergebnisse der Untersuchung zusammenfassend dargestellt werden (1). Im Anschluss daran wird eine Einordnung dieser Ergebnisse in die drei Ansätze des Neo-Institutionalismus (NI) (2) und letztlich eine Schlussbetrachtung (3) vorgenommen.

\section{Zusammenfassung der Ergebnisse}

Worin also besteht der Europäisierungsprozess der Migrationspolitik in der Bundesrepublik Deutschland? In der Beantwortung der Frage gehe ich in vier Schritten vor. Kapitel V.1.1 rekapituliert den in Kapitel II dieser Arbeit beobachteten Politikwandel in Bezug auf die historische Dimension der deutschen Migrationspolitik. Kapitel V.1.2 befasst sich mit der in Kapitel III erörterten EU-Migrationspolitik, wobei die Europäisierung zunächst durch die vertragliche Institutionalisierung auf EU-Ebene und ferner durch den europäischen Integrationsprozess in Erscheinung getreten ist. Trotz dieser Gemeinsamkeiten in der migrationspolitischen Entwicklung wird die sichtbare politische Dynamik stark durch nationalstaatliche institutionelle Faktoren bzw. durch das Akteursfeld geprägt. Ein Fallbeispiel ist hierbei Deutschland. Dieser prägende Einfluss nationalstaatlicher Institutionenordnung steht im Mittelpunkt des Kapitels V.1.3. Vor dem Hintergrund dieser Erörterungen wird im Anschluss die Bestätigung der in der Einleitung dieser Arbeit formulierten Arbeitshypothesen zusammengefasst und die Frage diskutiert, welchen Beitrag die hier entwickelte deutsche Migrationspolitik zur Diskussion von Europäisierungsprozessen leisten kann (Kapitel V.1.4). 


\subsection{Politikwandel in der historischen Dimension deutscher Migrationspolitik}

In der historischen Dimension deutscher Migrationspolitik (Kapitel II.3) wurden insbesondere die migrationspolitischen Wandlungsprozesse beobachtet. Über den Begriff des ,policy paradigm“ (Peter Hall 1993) hinaus beschäftigte sich die Untersuchung zugleich mit der Frage, welche Migrationspolitik in der Migrationsgeschichte Deutschlands als Politikwandel oder Paradigmenwechsel bezeichnet werden kann und welche Voraussetzungen es dabei gibt sowie welche Einflussfaktoren in den politischen Prozessen wirken.

Als Ergebnis der Wandlungsprozesse wurde mit Karen Schönwälder (2006) ${ }^{1200}$ gezeigt, dass sich die deutsche Migrationspolitik seit 1945 zumindest drei bzw. vier „umfassenden Umorientierungen“ mit oder ohne Paradigmen- und Politikwechsel unterzog: 1. Die Umsetzung von Menschenrechtsnormen nach 1945. 2. Der durch den Anwerbestopp im Jahr 1973 eingeleitete Politikwechsel zur Steuerbarkeit von Migrationsprozessen bezüglich der sogenannten „Gastarbeiter“. 3. Der Paradigmenwechsel zur (unvollständigen) Anerkennung der Einwanderungsprozesse seit den 1990er Jahren nach der deutschen Wiedervereinigung. 4. Der Prioritätenwechsel hin zur aktiven Integration der MigrantInnen seit dem 21. Jahrhundert.

Auch im Hinblick auf den Politikwandel stellt die deutsche Migrationspolitik in den sieben Phasen dar, dass sich seit 1945 kein umfassender, sondern lediglich ein partieller Politikwandel entwickelt hat. Es gab jedoch in der zweiten Phase (1955 - 1973) der sog. Anwerbepolitik bzw. Gastarbeiterpolitik einen umfassenden Wandel des ,policy paradigm“. Allerdings führte dies aufgrund des Anwerbestopps 1973 nicht zum langfristigen Politikwechsel, sondern allein zu den Verschiebungen der politischen Prioritäten. Im Vergleich dazu vollzog sich vor allem in der sechsten Phase deutscher Migrationspolitik (1998 - 2004) trotz des Paradigmenwechsels kein umfassender, sondern nur ein begrenzter Politikwandel. Bemerkenswert ist auch, dass es in der siebten Phase (2005 - 2012) zwar einen partiellen Paradigmen- und Politikwechsel bezüglich einer Förderung von Arbeitsmigration und einer gesteuerten Zuwanderung gab und gibt, allerdings kam und kommt es nicht zu einem umfassenden Politikwandel, sondern nur zu einem partiellen Politikwandel mit einem Prioritätenwechsel hin zur

1200 Schönwälder, Karen 2006: Politikwandel in der (bundes-) deutschen Migrationspolitik. a.a.O., S. 10. 
aktiven Integration der MigrantInnen (wie z. B. die „Nationale Aktionsplan Integration“ (NAP-I) und die absehbare Einführung der „EU Blue Card“ im Bereich der Hochqualifizierten zeigten).

Aus diesem Überblick über den wichtigen Politikwandel der deutschen Migrationspolitik werden im Folgenden die zentralen Einflussfaktoren ${ }^{1201}$ berücksichtigt: 1. Die Staatsgestaltung als ethnisch homogene Gesellschaft Deutschlands durch das bis ins Jahr 2000 bestehende Abstammungsprinzip (Ius sanguinis). ${ }^{1202}$ 2. Das lange dominierende Selbstverständnis „,Deutschlands als NichtEinwanderungsland“. ${ }^{1203}$ 3. Seit dem Anwerbestopp von 1973 die Konjunkturen. 4. Das deutsche „semisouveräne“ Föderalismussystem ${ }^{1204}$ zwischen Bund, Ländern und Kommunen. Als Voraussetzungen der Politikwandel innerhalb der Wandlungsprozesse werden insbesondere die Interessenkonstellationen der Akteure, die Handlungskapazitäten der Institutionen und die jeweils möglichen Problemlösungsstrategien sowie Konjunkturen der öffentlichen Problemwahrnehmung gesehen.

Schließlich lässt sich zusammenfassend festhalten, dass die Wandlungsprozesse in der Geschichte der deutschen Migrationspolitik tatsächlich mit dem Anwerbestopp 1973 begannen, d. h. sie setzen in Deutschland faktisch mit der tendenziellen Einwanderungssteuerung ein. Angesichts des Paradigmen- und Politikwechsels hin zur faktischen Anerkennung der Einwanderungsprozesse ist jedoch ein deutlicher Verlust reformorientierter sowie humanitärer Paradigmen festzustellen, während arbeitsmarktorientierte Paradigmen zunehmend an Bedeutung gewinnen.

${ }^{1201}$ Vgl. hierzu Müller, Doreen 2010: Flucht und Asyl in europäischen Migrationsregimen: Metamorphosen einer umkämpften Kategorie am Beispiel der EU, Deutschlands und Polens. Göttingen, S. 209.; vgl. auch Schönwälder, Karen 2006: Politikwandel in der (bundes-) deutschen Migrationspolitik: S. 8-20.

${ }^{1202}$ Vgl. Brubaker, Rogers 1992: Citizenship and Nationhood in France and Germany. Cambridge MA.

${ }^{1203}$ Vgl. Lavenex, Sandra 2002: The Europeanisation of Refugee Policies: Between human rights and internal security. Aldershot, S. 39.

${ }^{1204}$ Katzenstein, Peter J. 1987: Policy and Politics in West Germany. The Growth of a Semisovereign State. Philadelphia. 


\subsection{Europäisierung : Die Entwicklung einer parallelen Migrationspolitik in der EU}

Bezugnehmend auf die geschichtliche Darstellung der deutschen Migrationspolitik in Kapitel II erfolgte eine Analyse der Migrationspolitik der Europäischen Union (EU) in Kapitel III. Die Untersuchung der EU-Migrationspolitik zeigte dabei noch einmal, dass die Europäisierungsprozesse angesichts der Besonderheit des EU-Mehrebenensystems nicht nur auf einer politischen Handlungsebene, sondern ebenen-übergreifend, d. h. auf supranationaler, nationaler und regionaler Ebene miteinander verbunden werden. ${ }^{1205}$

Als Basis der Analyse in diesem EU-Mehrebenensystem diente, wie oben erwähnt, vor allem die in der neo-institutionalistischen (NI) Diskussion der Politikwissenschaften vertretene „These einer Strukturierung des Akteurshandelns mittels des institutionellen Kontextes“, in dem dieses Handeln stattfindet. Solche Institutionenordnungen sind selbst die Produkte vorangegangener politischer Auseinandersetzungen, die in Bezug auf den historischen Institutionalismus zu finden sind. Aus dieser These des NeoInstitutionalismus (NI) entstand die Vorstellung, dass die Konfrontationen zwischen supranationaler und nationaler Politik in Form von Institutionenkämpfen erfolgen können, in denen Akteure und Organisationen als Vertreter der jeweiligen unterschiedlichen Leitideen und paradigmatischen Orientierungen die konkrete Verwirklichung dieser Institutionalisierungen repräsentieren. Im Hinblick auf diese Ansicht war es Aufgabe der Arbeit in Kapitel III, die drei neo-institutionalistischen Ansätze, also einen akteurszentrierten, einen makrosoziologischen sowie einen historischen Ansatz, zur Analyse von Europäisierungsprozessen zu erarbeiten, die sich nicht in erster Linie auf das Modell eines „Anpassungsdrucks“, sondern auf den Einfluss der gesellschaftlichen Umwelt und in Anbetracht des Vorangegangenen auf die politische Entscheidungsfindung konzentrieren. Die zentrale These in Kapitel III lautete hierbei: „Der Prozess der Europäisierung der EU-Migrationspolitik geht hauptsächlich in einer parallelen Institutionalisierung der gemeinschaftlichen Interessen vonstatten." 1206 Darüber hinaus hat die Untersuchung in Kapitel III zunächst eine Diskussion zur „Europäisierung“ (vgl. Kapitel III.1) der Politik dargelegt und hernach verfolgt, wie sich auf der europäischen Ebene schrittweise eine neue Leitidee in den Verträgen entwickelt, die sich mit den Begriffen des nationalstaatlichen

\footnotetext{
1205 Vgl. Kohler-Koch, Beate / Conzelmann, Thomas / Knodt, Michéle 2004: Europäische Integration Europäisches Regieren. Wiesbaden, S. 171.

1206 Zur Untersuchung einer, ,parallelen“ Politik vgl. Conzelmann, Thomas 2002: Große Räume, kleine Räume: Europäisierte Regionalpolitik in Deutschland und Großbritannien. Baden-Baden.
} 
Souveränitätsbeharrens und des verstärkten Kooperationsbedarfs im Migrationsbereich bezeichnen lässt und schließlich zur Europäisierung durch die vertragliche Institutionalisierung auf EU-Ebene führt (vgl. Kapitel III.2). Des Weiteren wurde innerhalb der vertraglichen Grundlage die Europäisierung im europäischen Integrationsprozess näher untersucht (vgl. Kapitel III.3). Dabei war dieser Abschnitt der Kernfrage gewidmet, wie die Einbindung des Politikfeldes Migration im europäischen Integrationsprozess zustande gekommen ist und an welchen Entwicklungen dies ersichtlich wird. Demzufolge befanden sich die gewählten Fallbeispiele zunächst im Bereich der Asyl- und Flüchtlingspolitik der EU: Der Umgang mit dem Thema der Bürgerkriegsflüchtlinge aus dem ehemaligen Jugoslawien (vgl. Kapitel III.3.1.1) und der Umgang mit der Problematik der inneren Sicherheit am Beispiel von EUROPOL (vgl. Kapitel III.3.1.2). Im Bereich der Einwanderungs- und Integrationspolitik der EU wurden als Fallbeispiele zwei außerordentlich verschieden angelegte Richtlinien der Europäischen Union betrachtet: Die Richtlinie 2000/43/EG des Rates vom 27. November 2000 zur Politik gegen Diskriminierung (die sog. „Antidiskriminierungsrichtlinie“) (vgl. Kapitel III.3.2.1) und die Richtlinie 2003/86/EG des Rates vom 22. September 2003 betreffend das Recht auf Familienzusammenführung (die sog. „Familiennachzugsrichtlinie“) (vgl. Kapitel III.3.2.2). Darüber hinaus wurde analysiert, inwiefern die politischen Absichtserklärungen tatsächlich umgesetzt werden konnten.

Auf den folgenden Seiten sollen nun die entsprechenden Ergebnisse hinsichtlich der Frage erörtert werden, welche Entwicklungen der vertraglichen Institutionalisierung (A) und der Einbindung in den europäischen Integrationsprozess (B) generell über die politischen Dynamiken zur Europäisierug im europäischen Mehrebenensystem im Rahmen der EU nachvollzogen werden können. Vor dem Hintergrund der getroffenen Beobachtungen wird am Ende der Analyse noch einmal die Zusammenfassung (C) der Ergebnisse in Kapitel III vorgenommen. 


\section{A. Ergebnisse in Kapitel III. 2}

Um der Fragestellung einer Entwicklung der europäischen Zusammenarbeit vor allem bei der vertraglichen Verankerung auf europäischer Ebene gerecht zu werden, bedarf es im Folgenden einer differenzierten Beantwortung.

Erstens: In der vertraglichen Institutionalisierung auf der europäischen Ebene werden zuerst die größeren Beteiligungsmöglichkeiten der Gemeinschaftsinstitutionen ${ }^{1207}$ beobachtet. Es sind somit zunehmend institutionelle Lösungen vorgesehen, die eine Eigendynamik des Europäisierungsprozesses fördern. Allerdings werden als handelnde Rechtssubjekte bisher nicht die Gemeinschaftsorgane, sondern die Mitgliedstaaten betrachtet. So werden alle grundlegenden Entscheidungen der EU-Migrationspolitik tatsächlich nicht von der EU-Kommission (KOM) oder dem Europäischen Parlament (EP), sondern vom EU-Rat - repräsentiert durch die EU-Innenminister - getroffen. In dieser Hinsicht wird dem EU-Ministerrat eindeutig eine dominante Position bei der Kompetenz- und Machtverteilung zwischen den nationalen und europäischen Akteuren zugestanden. Eine Verlagerung der Kompetenzen auf EU-Ebene ist demzufolge bloß bedingt $\mathrm{zu}$ sehen, sodass EU-Migrationspolitik künftig ohne Berücksichtigung nationaler Einzelinteressen kaum möglich sein wird. Zweitens: Direkte verfassungspolitische Interventionen in die nationalen Migrationssysteme hat es nicht gegeben. Es ist jedoch anhand der Kompetenzverlagerung auf EU-Ebene eine faktische „Europäisierung öffentlicher Aufgaben“" ${ }^{1208} \mathrm{zu}$ beobachten, welche somit als Indiz für eine gemeinsame europäische Migrationspolitik auf EU-Ebene gewertet werden kann.

Drittens: In der vertraglichen Verankerung auf EU-Ebene lässt sich zugleich eine klare Verringerung der nationalen Souveränitätsbedürfnisse feststellen. Viertens: Die Vergemeinschaftung der Migrationspolitik seit dem Amsterdamer Vertrag 1997/99 zeigt, dass der Sprung von der dritten in die erste Säule sogleich zu einem Richtungswechsel führte. Das heißt, dass die zunehmende Verrechtlichung der migrationspolitischen Zusammenarbeit zu einer restriktiven Migrationspolitik auf EU-Ebene modifiziert wird. Dieser Vergemeinschaftungsschub wurde allerdings mit den grundlegenden Sonderrechten für einige Mitgliedstaaten erhandelt, weshalb künftig unter Umständen

${ }^{1207}$ Vgl. Tomei, Verónica 2001: Europäisierung nationaler Migrationspolitik: Eine Studie zur Veränderung von Regieren in Europa. Stuttgart, S. 67.

${ }^{1208}$ Schmidt, Manfred G. 1999: Die Europäisierung der öffentlichen Ausgaben. In: Ellwein, Thomas / Holtmann, Everhard (Hrsg.) 1999: 50 Jahre Bundesrepublik Deutschland: Rahmenbedingungen, Entwicklungen, Perspektiven. Opladen, S. 385-394.; vgl. Kohler-Koch, Beate / Conzelmann, Thomas / Knodt, Michéle 2004: Europäische Integration -Europäisches Regieren. Wiesbaden, S. 183. 
kaum von der Entstehung eines einheitlichen politischen Raumes die Rede sein kann. So sieht die Vergemeinschaftung seit dem Amsterdamer Vertrag immerhin Ausnahmen vor, d. h. eine „flexible Integration“ mit den sogenannten „opt in“- und „opt out“Regelungen für die drei Mitgliedstaaten Großbritannien, Irland und mit Einschränkungen Dänemark. Fünftens: Das Einstimmigkeitsprinzip in den EUEntscheidungsverfahren ermöglicht eine weitgehende Vetomacht der Mitgliedstaaten.

Sechstens: Die Europäisierung durch die vertragliche Institutionalisierung auf EUEbene hat entscheidende ,policy outcome“ (Auswirkungen), was soviel bedeutet, dass es einerseits $\mathrm{zu}$ einer nur in begrenztem Umfang erkennbaren Anpassung mitgliedstaatlicher Migrationspolitik gekommen ist und andererseits, dass die kohäsionspolitisch orientierte Kompetenzkontrolle der Europäischen Union sowie die „parallele“ Förderung in den Politikfeldern der Mitgliedstaaten steigt. Siebtens: Die vertragliche Institutionalisierung auf EU-Ebene macht schließlich gemeinsame Standards mit einer Tendenz zur Verrechtlichung und Solidarität unabdingbar.

\section{B. Ergebnisse in Kapitel III. 3}

Um der Fragestellung einer Entwicklung der europäischen Zusammenarbeit bei der Einbindung in den europäischen Integrationsprozesse gerecht zu werden, wird im Folgenden eine differenzierte Analyse vorgenommen.

Erstens: In den europäischen Integrationsprozessen, wie die vier Fallbeispiele zeigten, wird die EU-Ebene zunehmend als ,migrationspolitische Problemlösungsebene' betrachtet. ${ }^{1209}$ Hieraus resultiert für die EU-Ebene, dass die Entwicklung der EUMigrationssysteme zum einen als Reaktion auf externen Druck, zum anderen als Aktion im Rahmen von institutionellen, ,incentives und constraints ${ }^{\text {“ } 1210} \mathrm{zu}$ verstehen ist. Besonders bei der Intervention im ehemaligen Jugoslawien und bei der Bildung von EUROPOL (das Europäische Polizeiamt) kann ein solcher Lerneffekt deutlich beobachtet werden (vgl. Kapitel III.3.1.1 und 3.1.2 sowie vgl. FRONTEX-Initiative in

\footnotetext{
${ }^{1209}$ Vgl. Tomei, Verónica 2001: Europäisierung nationaler Migrationspolitik: a.a.O., S. 179.

1210 Tömmel, Ingeborg 2008: Governance und Policy-Making im Mehrebenensystem der EU. In: Tömmel, Ingeborg (Hrsg.) 2008: Die europäische Union: Governance und Policy-Making. Wiesbaden, S. 20, 31.
} 
Kapitel III.2.8). Zweitens: Die EU-Migrationspolitik im Integrationsprozess wird im Grunde von einer primär restriktiven Haltung her betrachtet. Angesichts der zunehmenden Interessen für die Missbrauchsbekämpfung und Kriminalitätsbekämpfung sowie der Erschwerung des Zugangs zum gemeinsamen Territorium liegt der zentrale Schwerpunkt der EU auf den Fragen hinsichtlich eines Mindeststandards und der Lastenverteilung vor allem im Bereich der Flüchtlinge und des Asyls, wie bereits im Fall der Bürgerkriegsflüchtlinge aus dem ehemaligen Jugoslawien dargestellt wurde. Hierin spiegelt sich auch insbesondere der seit $1999 \mathrm{zu}$ beobachtende Einsatz von EUROPOL (Art. 30 Abs. 2 EUV) im Bereich der inneren Sicherheit wider. Mit diesem umfassenden EUROPOL-Einsatz drückt die erste Namensgebung die Institutionalisierung auf diesem Feld, eine Symbolisierung der polizeilichen Zusammenarbeit und Konkretisierung des Politikfeldes innerer Sicherheit, aus. Die Bildung von EUROPOL führt schließlich zu einem eindeutigen Ergebnis, so dass im Kontext der europäischen Zusammenarbeit durch das EUROPOL-Projekt eine bezeichnende Tendenzverschiebung angesichts der Anstrengungen der Mitgliedstaaten zur grenzüberschreitenden Kriminalitätsbekämpfung offensichtlich wird. Drittens: Die zunehmende Bedeutung der Zusammenarbeit mit NGOs (Non Governmental Organisations) auf dem Politikfeld Migration wird betont. Das Fallbeispiel der „Antidiskriminierungsrichtlinie 2000/43/EG“ in der EU-Integrationspolitik bezeichnete den zentralen Punkt, der den Erfolg von einigen NGOs vorangetriebenen Policy-Ideen ermöglichte. In diesem Zusammenhang ist die finanzielle Unterstützung vieler NGOProjekte durch die EU aufmerksam zu betrachten (z. B. das PROGRESS-Programm der EU). Die Untersuchung führt damit zu der Einschätzung, dass die NGOs zwar für die Implementierung der EU-Richtlinie eingetreten sind. Allerdings finden sich die politischen Einflüsse der NGOs nicht direkt in den EU-Entscheidungsprozessen, sondern lediglich in dem EU-Kommissionsentwurf. Diesbezüglich lässt sich beobachten, dass die Positionierung der NGOs vor allem infolge von finanzieller Abhängigkeit und Installierung, von oben' (EU) entstanden ist. Viertens: Im Gegensatz zu der Antidiskriminiserungsrichtlinie im europäischen Integrationsprozess ist auf dem Politikfeld der „legalen Zuwanderung“ hinsichtlich des Familiennachzugs lediglich eine geringfügige Veränderung zu beobachten. Angesichts der „Familiennachzugsrichtlinie 2003/86/EG“، lässt sich anführen, dass aufgrund der Arbeitsmarktlage der wichtigen Mitgliedstaaten und auch insbesondere des Einstimmigkeitsprinzips bei Ratentscheidungen im Bereich dieser legalen Migration die EUFamiliennachzugsregelungen weitestgehend mit Blick auf die Berücksichtigung nationaler Interessen verändert werden können. Hier signalisierte insbesondere 
Deutschland als ein wichtiger Mitgliedstaat bzw. als ein wichtiger Vetospieler eine eindeutige Ablehnung der Vergemeinschaftung bezüglich eines verstärkten Familiennachzugs. Es wurde jedoch deutlich, dass die Familiennachzugsrichtlinie in bedeutender Form zur Erschaffung einer gemeinsamen Steuerung von Migration im Bereich EU-Einwanderungspolitik beiträgt. Daneben zeigt sich auch, dass die EUFamiliennachzugsrichtlinie insofern als der erste Rechtsakt der legalen Einwanderung und somit als Pfad im Bereich Familiennachzug bewertet wurde. Fünftens: Als wichtige Dynamisierungsfaktoren des Integrationsprozesses wurde mit Verónica Tomei (2001) insbesondere das „Solidaritätsprinzip“, der institutionalisierte „Informationsund Erfahrungsaustausch“ sowie „,ein inhärenter Reformbedarf“ betrachtet. ${ }^{1211}$ Hierbei lassen sich als wichtige Träger der Entwicklungsdynamik des Integrationsprozesses die nationalen und europäischen Akteure festhalten. Daraufhin wurden die Integrationsprozesse im Hinblick auf die kontinuierliche Interaktion zwischen nationaler und europäischer Ebene beobachtet. Diesbezüglich konnte die Herausbildung einer migrationspolitischen Zusammenarbeit, im Rahmen der EU vor allem „die Verrechtlichung und die Kontinuität der Kooperation“"1212, berücksichtigt werden. Sechstens: In der Darstellung der vier Fallbeispiele zeichnen sich folgende Trends der EU-Migrationspolitik ab: 1. Solidarität. 2. Verrechtlichung. 3. zunehmende restriktive Maßnahmen. 4. verstärkte Interessenentwicklung zwischen den Abwehrinteressen und den arbeitsmarktpolitischen Nützlichkeitsinteressen.

\section{Zusammenfassung der dargestellten Ergebnisse in Kapitel III}

Zusammenfassend lässt sich anhand der vorherigen Ausführungen der dargestellten Ergebnisse in Kapitel III Folgendes festhalten: Die EU-Migrationspolitik hat sich seit den 1990er Jahren äußerst dynamisch entwickelt, wie vor allem die vertragliche Institutionalisierung auf EU-Ebene gezeigt hat. Allerdings lassen die bisherigen Beobachtungen der europäischen Migrationspolitik ahnen, dass es auch weiterhin Verzögerungen und Degressionen geben wird, insbesondere hinsichtlich der gemeinsamen Regelung der Arbeitsmigration, aber auch in Bezug auf die Integration

1211 Vgl. Tomei, Verónica 2001: Europäisierung nationaler Migrationspolitik: a.a.O., S. 179-180, S. 182.

1212 Vgl. Tomei, Verónica 2001: Europäisierung nationaler Migrationspolitik: a.a.O., S. 182. 
von Zugewanderten. In diesen Bereichen gibt es nach wie vor erhebliche Interessenunterschiede zwischen den Mitgliedstaaten. Gemeinschaftliche Lösungen werden hingegen vor allem dort gefunden werden, wo ähnlicher Handlungsdruck besteht, also besonders bei der „Kontrolle der Außengrenzen.“ Es trifft jedoch gewiß zu, dass so man die Flüchtlingspolitik und die Politik der Familienzusammenführung sowie die Aufnahme aus humanitären Gründen außer Acht lässt, eine europäische Migrationspolitik unvermeidlich restriktiv ist. Desgleichen lässt sich schließlich feststellen, dass sich eine Europäisierung der einzelstaatlichen Migrationspolitik auf EU-Ebene schwierig gestaltet und lediglich bei restriktiven Neuerungen Einigungen erzielt werden konnte. Darüber hinaus findet ein Europäisierungsprozess seit den 1990er Jahren innerhalb des Spannungsverhältnisses zwischen dem verstärkten Kooperationsbedarf und dem nationalstaatlichen Souveränitätsbeharren im Politikfeld Migration statt - sowie ein Kontinuum von Supranationalität und Intergouvernementalität. Europäisierung bedeutet diesbezüglich die Interaktion und das Zusammenspiel oder die institutionalisierte Wechselwirkung zwischen europäischer und nationaler bzw. zwischenstaatlicher Ebene. ${ }^{1213}$

Inwieweit die zunehmende Europäisierung sich dabei verändernd auf eine generelle Abschließungs- oder gegenläufige Öffnungstendenz auswirkt, ist durch die Vielzahl der Maßnahmen und Tendenzen schwer abzuschätzen. Angesichts des verstärkten Kooperationsbedarfs zeigt sich aber die migratonspolitische Zusammenarbeit als die angemessenste Strategie im Rahmen der Europäischen Union. Es werden daraufhin schließlich folgende Trends der EU-Migrationspolitik verfolgt: ${ }^{1214}$ Die zunehmende Verrechtlichung (z. B. die vertragliche Institutionalisierung) auf EU-Ebene, die europäisierte Einbindung in den europäischen Integrationsprozess, die zunehmende Nutzung der EU-Ebene zur Handhabung migrationspolitischer Herausforderungen, die Einbindung des nationalen Migrationssystems (z. B. das deutsche Föderalismussystem) in das europäischen Mehrebenensystem, die zunehmend institutionalisierte intergouvernementale und supranationale Zusammenarbeit, im Rahmen derer die tatsächliche Interessenmacht bei den Mitgliedstaaten zu finden ist.

\footnotetext{
1213 Vgl. Tömmel, Ingeborg 2008: Governance und Policy-Making im Mehrebenensystem der EU. In: Tömmel, Ingeborg (Hrsg.) 2008: a.a.O., S. 25 f.; vgl. Tomei, Verónica 2001: a.a.O., S. 134.

1214 Vgl. hierzu die Arbeiten von Knodt / Kohler-Koch (Hrsg.) 2000, Tomei 2001, Bendiek 2004, Kohler-Koch / Conzelmann / Knodt 2004 und Tömmel (Hrsg.) 2008.
} 


\subsection{Europäisierung: Interessenpolitik von Akteuren des deutschen Migrationssystems}

Als unbestritten muss angesehen werden, dass der zunehmende Einfluss der EU auf nationale Politikgestaltung beträchtlich ist, jedoch sind bislang die Auswirkungen auf das nationale Migrationssystem weniger evident gewesen. Bezüglich der Frage, wie die Europäisierung im migrationspolitischen Prozess ohne tiefgreifende Veränderungen des nationalen Migrationssytems möglich war, besteht somit Erklärungsbedarf. Vor dem Hintergrund dieser Überlegungen widmete sich Kapitel IV den deutschen institutionellen Wandlungsprozessen bzw. der Transformation des Regierens durch die Europäisierung und berücksichtigte hierbei den Neo-Institutionalismus (NI) als Analyseinstrument. Darüber hinaus zielte die Untersuchung in Kapitel IV darauf, das deutsche Migrationssytem bezüglich des Europäisierungsprozess des Politikfeldes Migration im europäischen Mehrebenensystem näher zu betrachten. Es wurde dabei die Thematik vor allem aus dem Blickwinkel untersucht, wie die deutsche Migrationspolitik, also deutsche nationale Interessen, Politiken und Strukturen, die Entwicklung von Policies und Institutionen auf supranationaler EU-Ebene beeinflusst. Genauso wurden mögliche Rückwirkungen der europäischen Integration auf politische Prozesse, Politikinhalte und Institutionen in Deutschland unter der Europäisierung behandelt. In diesem Verständnis wurde die zentrale Frage gestellt, inwiefern deutsche Migrationspolitik im Rahmen der EU ausgeführt bzw. vertieft und infolgedessen zur Europäisierung entwickelt werden kann.

Mit diesen zentralen Fragen über die Art und Weise sowie den Grad der Europäisierung deutscher Migrationspolitik konnte die zentrale These herausgebildet werden, dass die Europäisierung nationaler Migrationspolitik nicht dem Anpassungsdruck „von oben“ (EU), also von der „Top-down“-Perspektive ausgehend, sondern vielmehr durch die parallele Institutionalisierung zwischen nationaler- und europäischer Ebene vorangetrieben werden kann. Darüber hinaus hat die Untersuchung in Kapitel IV zunächst das migrationspolitische Akteursfeld unter den institutionellen Rahmenbedingungen der Bundesrepublik Deutschland seit den 1990er Jahren aufgezeigt (vgl. Kapitel IV.1). Auch vor dem Hintergrund der Entwicklung einer gemeinsamen Migrationspolitik zur Steuerung der Arbeitsmigration aus Drittstaaten wurden ferner die deutschen Interessen im Euopäisierungsprozess der Hochqualifizierten betrachtet. In dieser Hinsicht wurden die Fragen aufgeworfen, wie diese Interessen entstehen können, wovon sie beeinflusst werden und wie sie sich 
deshalb gegebenenfalls verändern, wie die Akteure jeweils aufeinander Bezug nehmen, und inwieweit die Bundesrepublik Deutschland ökonomische und auf den Arbeitsmarkt bezogene Interessen vertritt, sowie auch, welches Niveau der Vergemeinschaftung auf EU-Ebene seitens Deutschlands angestrebt wird (vgl. Kapitel IV.2).

Für die Beantwortung der Fragestellungen des hier untersuchten Europäisierungsprozesses deutscher Migrationspolitik in Kapitel IV sind nun aus den vorangegangenen Ausführungen die Ergebnisse festzuhalten, die sich folgenden Punkten widmen: Bezüglich welcher Entwicklungen deutscher Akteure können unter den institutionellen Bedingungen die Auseinandersetzungen zwischen supranationaler und nationaler Migrationspolitik in Form der „Europäisierung“ ersehen werden (D). Darüber hinaus wird der Frage nachgegangen, ob und wie die Entwicklungen deutscher Interessen im Europäisierungsprozess der Hochqualifizierten einen Beitrag leisten können (E). Im Anschluss daran werden die Ergebnisse in Kapitel IV zusammenfassend dargelegt $(\mathrm{F})$.

\section{Ergebnisse in Kapitel IV. 1}

Um die Fragestellung einer Europäisierung des Politikfeldes Migration näher zu betrachten, soll nun auf nationaler Ebene, hier als Fallbeispiel auf das deutsche Akteursfeld der institutionellen Rahmenbedingungen verwiesen werden und es bedarf daraufhin im Folgenden einer differenzierten Antwort. Erstens: Die deutsche Migrationspolitik beinhaltet tatsächlich einen ausgeprägten, integrationsbefürwortenden Konsens, betrachtet unter den maßgeblichen institutionellen Rahmenbedingungen des deutschen Migrationssystems. Obwohl die Bundesregierung im migrationspolitischen Willensbildungsprozess den dominierenden Akteur darstellt, hat auch der (die) Bundeskanzler(in) in Einzelfällen entscheidenden Einfluss auf die deutsche Migrationspolitik bezüglich des Kanzlerprinzips. Außerdem wurden aufgrund des Ressortprinzips im Wesentlichen die Bundesministerien als Teilakteure der Bundesregierung gesehen. Zweitens: Betrachtet man die deutsche Migrationspolitik im Europäisierungsprozess seit den 1990er Jahren bis heute unter der Regierung Helmut Kohl (CDU), Gerhard Schröder (SPD) und Angela Merkel (CDU), sind die 
Veränderungen bemerkenswert: Einerseits gehen die Veränderungen der deutschen Migrationspolitik eindeutig mit den restriktiven Tendenzen einher, andererseits hängt die Migrationspolitik stark mit der arbeitsmarktorientierten Migrationssteuerung zusammen. Diesbezüglich wird vor allem infolge der gestiegenen Hindernisse für die Einbürgerung und des Familiennachzugs von Drittstaatsangehörigen die politische Abwehrhaltung bildhaft deutlich, die häufig die geringer qualifizierten und somit aus wirtschaftlichem Eigeninteresse ,unerwünschten“ MigrantInnen erfahren. Diese konnten ebenso wie Flüchtlinge, Asylsuchende und Illegalisierte bereits durch das Ziel des Zuwanderungsgesetzes (ZuWG) von 2005 berücksichtigt werden. Drittens: Die nationalen Interessen Deutschlands wurden nebenbei besonders hinsichtlich des Fortschritts auf europäischer Ebene betrachtet. Insbesondere die Regierung Kohl (CDU) in den 1990er Jahren führte mit Frankreich als europäische Kernmacht bzw. als Führungsmacht gemeinsame Vorschläge auf EU-Ebene ein. Innenpolitisch gesehen, bot die Regierung Kohls bisweilen kaum Integrationspolitik. Jedoch wurden unter der rotgrünen Regierung Schröder (1998 - 2005) neue Weichen auf dem Politikfeld der Migration gestellt, die zur sogenannten „Modernisierungsreformpolitik“ führten, wodurch Deutschland somit in der Folge als ein tatsächliches Einwanderungsland anerkannt wurde. Die nachfolgende Regierung der Großen Koalition aus CDU, CSU und SPD (2005 - 2009) sowie aus CDU, CSU und FDP (seit 2009) unter Kanzlerin Angela Merkel (CDU) intensivierte die Integrationspolitik erneut, deren Grundstein schon von ihrer rot-grünen Vorgängerregierung gelegt worden war. Viertens: Insgesamt kann nur schwer entschieden werden, ob die deutsche Migrationspolitik seit den neunziger Jahren substanzielle Fortschritte gemacht hat. Als Begründung hierfür wurde betrachtet, dass die richtungsweisenden ersten Schritte der deutschen Migrationspolitik bereits Anfang der 1970er Jahre durch den Anwerbestopp von 1973 unternommen wurden. Der Anwerbestopp von 1973, der als „Pfad der Restriktion“ (Müller 2010, S. 208) der deutschen Migrationspolitik bezeichnet werden kann, leitete weiterhin die restriktiven Gesetze der 1990er Jahre (z. B. das Ausländergesetz von 1991 und die Grundgesetzänderung auf Asyl im „Asylkompromiss“ von 1993) ein, die bis heute als Grundlage für migrationspolitische Reformen in Deutschland gelten (vgl. Butterwegge 2009, S. 137). Darüber hinaus wurden die wichtigsten Reformprojekte der Bundesregierung seit den 1990er Jahren als „unvollständige“ Paradigmenwechsel gekennzeichnet (Schönwälder 2006, S. 10). Fünftens: Mit dem Asylkompromiss von 1993 versuchte die Bundesrepublik eine gemeinsame Asylpolitik im Europäisierungsprozess. Es wird daraus rechtlich anhand institutioneller Verordnungen eine regulierte Normierung auf EU-Ebene dargestellt. Sechstens: Die Vetomacht von 
Deutschland wird insbesondere im Bereich legale Migration bzw. Arbeitsmigration weiterhin berücksichtigt, wobei eine Blockade Deutschlands gegen die zunehmende Europäisierung ebenso wirksam ist (vgl. hierzu Kapitel III.2.8). In diesem Zusammenhang ist für die Bundesrepublik das Aufrechterhalten der Einstimmigkeit im EU-Entscheidungsverfahren noch von großer Bedeutung (vgl. Kapitel III.3.1.1). Mit der Beibehaltung der Einstimmigkeit in der Migrationspolitik wollte und will die Bundesrepublik europaweiten Regelungen entgegenwirken, die sich vor allem auf den Bereich der Arbeitsmigration (z. B. die europäischen Familiennachzugesregelungen) beziehen, wobei Deutschland als zentral wichtiger Mitgliedstaat u. a. die Position des Blockieres einnahm (vgl. hierzu Kapitel III.3.2.2). Die Möglichkeit „legaler Zuwanderung“ außerhalb sehr spezifischer Gruppen und der „Integration“ finden hierbei genauso wie der Gesichtspunkt „Asyl und Flüchtlinge“ nur geringfügig Beachtung. Siebtens: Die Verschärfung der migrationsorientierten „Sicherheitspolitik“ wurde besonders durch Anstrengungen seitens Deutschland beobachtet, welches sich bislang durch sein hohes Niveau der Vergemeinschaftung auf EU-Ebene ausgezeichnet hatte (vgl. Kapitel IV. 1.1.2). Dabei spielte das Bundesministerium des Innern (BMI) als Teilakteur der Bundesregierung eine zentrale Rolle und verfolgte seine akteursspezifischen Eigeninteressen auf europäischer Ebene mit großem Erfolg. So wird der Schaffung einer europäischen Grenzpolizei EUROPOL 1995/99 (vgl. Kapitel III.3.1.2) und der Einführung eines EUVisuminformationssystems (VIS) im Jahr 2004 sowie der Einrichtung der europäischen Grenzschutzagentur FRONTEX im Jahr 2005 (vgl. Kapitel III.2.8) durch das BMI bis heute eine hohe politische Priorität im Kontext der Europäisierung beigemessen. Achtens: Die deutschen Akteure streben im 21. Jahrhundert im Vergleich zu den 1990er Jahren allenfalls ein niedriges Niveau der Vergemeinschaftung der Migrationspolitik auf EU-Ebene an. Neuntens: Im Zusammenhang mit der Europäisierung werden die deutschen Interessen von den deutschen Akteuren insbesondere im Hinblick auf nationalstaatliche Souveränität, Sicherheit und wirtschaftliche Nützlichkeit bzw. arbeitsmarktorientierte Migrationssteuerung wahrgenommen. Zehntens: Bei der Anpassung an EU-Vorgaben wurde teilweise nur eine Option bezüglich der deutschen Interessen bzw. der Europastrategien deutscher Akteure berücksichtigt, wie im EURichtlinienumsetzungsgesetz von 2007 aufgeführt ist. Elftens: Die Zusammenarbeit auf europäischer Ebene lenkt schließlich den Blick auf ein Legitimationsproblem. Von besonderer Bedeutung ist dabei die demokratische Legitimation europäischer Entscheidungen, im Fall der Bundesrepublik Deutschland gekennzeichnet durch das 
„Föderalismusprinzip“ ${ }^{1215}$ zwischen Bund, Ländern und Kommunen (vgl. Kapitel IV.1.3). Bezogen auf den Europäisierungsprozess haben die Bundesländer damit im Vergleich zum Bundestag größeren Einfluss auf die Entscheidung, da „die Länderexekutiven formelle und informelle Wege direkter Beteiligung auf europäischer Ebene“"1216 besitzen. Hier ist vor allem der im deutschen Migrationssystem begründeten Existenz von institutionellen Vetopunkten besondere Aufmerksamkeit zu schenken. Solche Vetopunkte geben den Akteuren die Möglichkeit, die Implementation europäischer Vorgaben zu blockieren und zu beeinflussen. Es wird somit einerseits das „Drohpotenzial der subnationalen Ebene“ ${ }^{1217}$ im Hinblick auf die demokratische Legitimation der Europäisierung deutscher Migrationspolitik, aber andererseits als ein Aspekt des Europäisierungsprozesses in Bezug auf die Einbindung des deutschen Föderalismus in das europäische Mehrebenensystem betrachtet.

\section{E. Ergebnisse in Kapitel IV. 2}

Im Hinblick auf die Fragen der deutschen Interessen im Euopäisierungsprozess der „hochqualifizierten Arbeitsmigration“ können folgende Antworten formuliert werden.

Erstens: Die Untersuchung der bestehenden Zuwanderungsmöglichkeiten nach Deutschland zeigt ein bislang noch ungenügendes Vorhandensein von Steuerungsinstrumenten für den Zuzug qualifizierter Arbeitskräfte und den Bedarf einer Verbesserung durch ergänzende Maßnahmen. Die Analyse der in Kapitel IV.2 beschriebenen Zuzugsdaten lässt die Auslegung $\mathrm{zu}$, dass Deutschland in den vergangenen Jahren trotz der Hinwendung zu einer arbeitsmarktorientierten Steuerung relativ wenige hochqualifizierte Zuwanderer anhaltend gewinnen konnte. Das bisher gescheiterte und humankapitalorientierte „Punktesystem“ mit Zulassungskriterien, das bereits von der Süssmuth-Kommission im Jahr 2001 vorgelegt wurde, wird weiterhin als Steuerungsinstrument betrachtet. Jedoch hat dieses Instrument angesichts der wirtschaftlichen Rezession und der hohen Arbeitslosigkeit immer noch keine politische Mehrheit gefunden. Zweitens: Das Punktesystem zeigt jedoch eine Interessenslogik, die zwischen Leistungsträgern und Nutzlosen, die keinen Gewinn erbringen, deutlich

1215 Tomei, Verónica 2001: Europäisierung nationaler Migrationspolitik: a.a.O., S. 155.

1216 Tomei, Verónica 2001: Europäisierung nationaler Migrationspolitik: a.a.O., S. 156.

1217 Tomei, Verónica 2001: Europäisierung nationaler Migrationspolitik: a.a.O., S. 156. 
unterscheidet. Drittens: Es muss festgehalten werden, dass neben der Gestaltung des Rechtssystems für die Zuwanderung auch weitere Aspekte wie beispielsweise das Lohnniveau sowie Sprachbarrieren auf die Attraktivität Deutschlands als Zielland für qualifizierte ausländische Arbeitsnehmer Einfluss nehmen können. Viertens: Die Anerkennung von Qualifikationen (z. B. ausländische Bildungs- und Berufsabschlüsse) ist als eine begleitende Maßnahme für die Wettbewerbsfähigkeit Deutschlands in der Konkurrenz um hochqualifizierte Zuwanderer vorgesehen. Fünftens: Die Untersuchung der EU-weiten Einführung einer „Blue Card“ für hochqualifizierte Einwanderer aus Drittstaaten zeigt, dass die durch die EU-Kommission vorbereitete Blue-Card-Regelung bisher als ungenügend betrachtet werden muss, um den großen und weiter wachsenden Bedarf der EU an hochqualifizierten Arbeitskräften zu decken. Bei der im Jahr 2009 von den Mitgliedstaaten verabschiedeten „Blue-Card-Richtlinie“ (gültig für alle Mitgliedstaaten, abgesehen von Dänemark, Irland und Großbritannien) fehlt dabei folgender zentrale Punkt: Die europäische Blue Card gewährt vor allem keinen freien Zugang zum gesamten EU-Arbeitsmarkt, sondern ist nur in Verbindung mit einer konkreten Stelle gültig. Ebenso erfolgt die konkrete Ausstellung einer EU Blue Card weiterhin in den einzelnen Mitgliedstaaten. Demzufolge wird in der Blue-Card Regelung keine automatische EU-weite Zulassung vorgenommen und somit nicht im Kontext europäisierter EU-Vorgaben betrachtet. Des Weiteren ist eine Überarbeitung der Blue-Card-Regelung indes nicht abzusehen, da die politische Debatte stagniert. Ein Grund ist darin $\mathrm{zu}$ sehen, dass die EU-Kommission ein wichtiges Anliegen vieler Mitgliedstaaten vernachlässigt hat: die Intention, inländische Arbeitsmarktpotenziale besser ausschöpfen zu können. Vorschläge der EU-Kommission fokussierten ausschließlich auf die Anwerbung neuer Arbeitskräfte aus Drittstaaten. Allerdings hat die EU-Kommission dabei mit ihren Vorschlägen zur Förderung der Zuwanderung von Hochqualifizierten keine hinlänglichen Lösungsvorschläge bezüglich der Integrationsdefizite angeboten. Sechstens: Diesbezüglich sind zumindest aktuelle Politiktendenzen erkennbar: Arbeitsmarktprüfungen für Hochqualifizierte bzw. qualifizierte Arbeitskräfte stufenweise abzuschaffen und stattdessen Kriterienkataloge einzuführen. Hierfür bieten einige Länder Systeme an, welche auf Quoten (z. B. Italien) und Punkten (z. B. die Niederlande und Großbritannien) basieren. Auch wird in vielen Ländern die Entwicklung neuer temporärer Zuwanderungsmöglichkeiten vorgenommen, wie etwa die sogenannte „Greencard“ in Irland. Ebenso werden spezielle Anwerbeprogramme für Arbeitsmarktbereiche, in denen ein besonderer Bedarf besteht, geschaffen. Eine weitere Tendenz ist der Versuch, ausländische Studenten, die ihr Studium absolviert haben, mithilfe von Angeboten hinsichtlich eines 
Arbeitsmarktzuganges im Land $\mathrm{zu}$ halten. Auch an dieser Stelle hat das deutsche Zuwanderungsgesetz bereits eine erkennbare Öffnung bewirkt. Außerdem ist eine Tendenz zur Verfahrensbeschleunigung und Vereinfachung der Regelungen für Arbeitskräfte zu beobachten. Siebtens: Analysiert man, welches Niveau der Vergemeinschaftung auf EU-Ebene von Deutschland angestrebt wird, so beweist Deutschland insgesamt das niedrigste Niveau betreffend der Europäisierung im Bereich der Arbeitsmigration. Das heißt, die Entwicklungen der deutschen Interessen im Europäisierungsprozess der Hochqualifizierten können als sehr gering oder sogar als blockierend betrachtet werden, wie sich beispielsweise im Europäisierungsprozess der EU-weiten „Blue-Card-Richtlinie“ gezeigt hat. Achtens: Schließlich lässt sich ein Politikwandel im Bereich Arbeitsmigration beobachten. Die rechtlichen Regelungen für die Zuwanderung von gut qualifizierten Personen aus Drittstaaten wurden angesichts der Entwicklung in den 1970er Jahren, d. h. Ölkrise und Anwerbestopp mit vergleichbar geringerer Nachfrage an Geringqualifizierten und dem heutigen Bedarf an Hochqualifizierten (nach $\S 19$ AufenthG für Hochqualifizierte) entworfen. Einwanderung wird somit nur dann positiv bewertet, wenn sie Vorteile, d. h. etwa positive Effekte für den deutschen Arbeitsmarkt bringt, wie dies auch in anderen EUMitgliedstaaten betont wird.

\section{F. Zusammenfassung der dargestellten Ergebnisse in Kapitel IV}

Die hier dargestellten Ergebnisse des migrationspolitischen Europäisierungsprozesses innerhalb der Migrationspolitik Deutschlands in Kapitel IV sind schließlich folgendermaßen zusammenzufassen: Erstens: Die deutsche Migrationspolitik kann tatsächlich als eine Form der Interessenpolitik durch die Akteure im deutschen Migrationssystem betrachtet werden. Hierbei sind durchgängig historisch die Bundesregierung und Bundeskanzler(in) als Hauptakteure auf dem Politikfeld Migration zu sehen sowie das Bundesministerium des Innern (BMI) als Teilakteuer der Bundesregierung mit entscheidendem Einfluss auf EU-Ebene. Während des Europäisierungsprozesses werden die deutschen Interessen von den deutschen Akteuren in Bezug auf nationalstaatliche Souveränität, Sicherheit und die wirtschaftliche Nützlichkeit bzw. auf die arbeitsmarktorientierte Migrationssteuerung betrachtet. 
Zweitens: Die hauptsächlichen politischen Veränderungen deutscher Migrationspolitik seit den 1990er Jahren sind einerseits von der restriktiven Migrationspolitik und andererseits eindeutig durch die zunehmende Verrechtlichung geprägt. Drittens: Die politische Abwehrhaltung gegenüber geringer qualifizierten und daher „nicht wllkommenen“ MigrantInnen wie etwa Flüchtlinge, Asylsuchende und Illegalisierte ist in erster Linie in dem wirtschaftlich motivierten Eigeninteresse mit dem Ziel der „Begrenzung“ der Migration (vgl. das im Jahr 2005 in Kraft getretene Zuwanderungsgesetz) deutlich $\mathrm{zu}$ ersehen. Viertens: Die richtungsweisenden ersten Schritte der deutschen Migrationspolitik wurden mit dem Anwerbestopp von 1973 berücksichtigt, der zugleich als „Pfad der Restriktion“ deutscher Migrationspolitik gekennzeichnet ist. Dieser Pfad leitete weiterhin die restriktiven Gesetze der 1990er Jahre (z. B. das Ausländergesetz von 1991 und die Grundgesetzänderung auf Asyl im „Asylkompromiss“ von 1993) ein, die bis heute als Grundlage für migrationspolitische Reformen in Deutschland gelten. Darüber hinaus werden die wichtigsten Reformprojekte der Bundesregierung seit den 1990er Jahren als „unvollständige“ Paradigmenwechsel berücksichtigt. Diesbezüglich entwickelt sich tatsächlich ein neuer Fokus bezüglich der qualifizierten Migration, der Schwächung der polititschen Asylidee. Fünftens: Die deutsche Migrationspolitik kann anhand der Gegensätze, nämlich dem nationalstaatlichen Souveränitätsbeharren einerseits und dem Kooperationsbedarf andererseits seit den 1990er Jahren dem Kontinuum von Intergouvernementalität und Supranationalität zugeordnet werden. In Bezug auf die Europäisierung wurde besonders auf die legale Migration bzw. Arbeitsmigration der Mitgliedstaaten, allen voran auf dem deutschen Akteursfeld, als nationales Vorrecht hingewiesen. Dabei ist das Aufrechterhalten des Einstimmigkeitsprinzips im Abstimmungsverfahren der EU von großer Bedeutung für die Bundesrepublik. Mit diesem Einstimmigkeitsprinzip bleibt die Vetomacht von Deutschland in dem Bereich Arbeitsmigration weiterhin erhalten und ist als Blockade Deutschlands gegen eine zunehmende Europäisierung auch ebenso wirksam. Des Weiteren wurde eine Verschärfung der Sicherheitspolitik durch Anstrengungen seitens Deutschlands beobachtet. Insbesondere spielte hier das BMI die wichtigste Rolle. Es entsteht somit das hohe Niveau der Vergemeinschaftung auf EU-Ebene auf diesem Politikfeld (z. B. die Schaffung von EUROPOL, VIS und FRONTEX). Sechstens: Allerdings ist bei der von den deutschen Akteuren vorangetriebenen migrationspolitischen Vergemeinschaftung auf EU-Ebene im 21. Jahrhundert ein niedrigeres Niveau im Vergleich zu den 1990er Jahren deutlich zu erkennen. Siebtens: Die demokratische Legitimation europäischer Entscheidungen wird im deutschen Fall besonders durch das 
„Föderalismusprinzip“ zwischen Bund, Ländern und Kommunen geprägt. So kann einerseits das „Drohpotenzial der subnationalen Ebene“ im Hinblick auf die demokratische Legitimation der Europäisierung deutscher Migrationspolitik und andererseits auch als ein Aspekt des Europäisierungsprozesses, begünstigt durch die Einbindung des deutschen Föderalismus in das europäische Mehrebenensystem, betrachtet werden. 1218 Achtens: Die Untersuchung der bestehenden Zuwanderungsmöglichkeiten nach Deutschland zeigt ein ungenügendes Vorhandensein von Steuerungsinstrumenten für den Zuzug von qualifizierten und hochqualifizierten Arbeitskräften. Deutschland und auch einige EU-Länder haben bereits bezüglich der Zuwanderungsmöglichkeit eine Perspektive vorgestellt, bei der die Kriterienkataloge auf Quoten (z. B. Italien) und Punkten (beispielsweise die Niederlande und Großbritannien) anstatt auf Arbeitsmarktprüfungen bzw. Vorrangprüfung für Hochqualifizierte beruhen. Daraufhin wurde die „EU-Blue-Card-Regelung“ als Steuerungsinstrument für die Förderung der Zuwanderung von Hochqualifizierten nicht als eine befriedigende Lösung empfunden. Insbesondere gewährt die europäische Blue Card keinen freien Zugang zum gesamten EU-Arbeitsmarkt, sondern ist nur in Verbindung mit einer konkreten Stelle gültig. Ebenso sind für die Ausstellung einer Blue Card auch die einzelnen Mitgliedstaaten zuständig. Demzufolge wird in diesem Verfahren keine automatische EU-weite Zulassung vorgenommen und diese somit nicht im Kontext europäisierter EU-Vorgaben betrachtet. Neuntens: Von zentraler Bedeutung ist dagegen, dass in Deutschland, wie in einigen anderen EU-Mitgliedstaaten, allerdings eine Tendenz zu verstärkter Zuwanderung von qualifizierten Arbeitskräften im Bereich der Arbeitsmigration beobachtet werden kann. Diese hatte sich schon zwischen 2000 und 2004 mittels der deutschen „Greencard“ zur Anwerbung von IT-Fachkräften bestätigt, wobei Deutschland heute noch mehr Zuwanderung von Hochqualifizierten in diesem Bereich benötigt. Angesichts dieser Tendenz könnte künftig die Verwendbarkeit des „Punktesystems“ auf dem Arbeitsmarkt Deutschlands aufgrund seiner wirtschaftlichen und integrationspolitischen Bedeutung weiterhin berücksichtigt werden. Zehntens: Zugleich zeigt das Punktesystem jedoch eine Interessenslogik, die zwischen Leistungsträgern und Ungeeigneten, die keinen Gewinn erbringen, deutlich unterscheidet.

1218 Vgl. Tomei, Verónica 2001: Europäisierung nationaler Migrationspolitik: a.a.O., S. 155-156. 


\subsection{Diskussion von Europäisierungsprozessen im Politikfeld Migration}

Vor dem Hintergrund der oben zusammengefassten Betrachtungen wird nun die Frage erörtert, welchen Beitrag die hier dargestellten Ergebnisse zur Diskussion von Europäisierungsprozessen leisten können. Darüber hinaus werden im Anschluss die Bestätigungen der in der Einleitung entwickelten Arbeitshypothesen zusammengefasst.

Als Ergebnis der Analyse ist zuerst zu nennen, dass einige Merkmale des Europäisierungstrends bezüglich der wachsenden Institutionalisierung in beiden Ebenen bestehen: So lassen sich einerseits in Deutschland, also in nationalstaatlicher Ebene, „Anpassungen“ der migrationspolitischen Instrumente in „Reaktion auf supranationalen Druck“ 1219 ablesen. Andererseits ist es in beiden Ebenen zu einer „Form der Parallelförderung“ gekommen. Des Weiteren haben sich ungeahnte Auswirkungen der EU-Beihilfenkontrolle ergeben. Außerdem liegt die hauptsächliche Verantwortung für die Anpassungen der Instrumente in erster Linie im Bereich der nationalstaatlichen Migrationspolitik. Diesbezüglich hat die EU die Möglichkeiten, die Mitgliedsländer zu einer Anpassung ihrer Politikinstrumente oder $\mathrm{zu}$ Veränderungen in deren Politikgestaltung aufzufordern. ${ }^{1220}$ Die Veränderungen der nationalstaatlichen Migrationspolitik dagegen resultieren eindeutig nicht einfach aus einem europäischen Anpassungsdruck und auch nicht aus einer Annäherung an die EU-Vorgabe. Angesichts dieser Überlegungen wird in der Arbeit die Ausgestaltung europäisierter Migrationspolitik in Deutschland erfasst. Hierbei wurde im Hinblick auf die vorab genannten Ergebnisse des Europäisierungsprozesses deutlich, dass keine migrationspolitischen „Entwicklungen unabhängig von den jeweiligen Handlungsstrategien der mitgliedstaatlichen Akteure“1221 gesehen werden können.

Diesbezüglich zeigt sich, dass Deutschland durch die Europäisierung eindeutig eine nationalstaatliche Strategie gegenüber der supranationalen EU-Ebene beibehält. Hier kann die „Selbstbehauptung“ von Akteuren als „die erfolgreiche Repräsentation deutscher Interessen auf der EU-Ebene“61222 erörtert werden. In diesem Sinne hat die

\footnotetext{
1219 Conzelmann, Thomas 2002: Große Räume, kleine Räume: Europäisierte Regionalpolitik in Deutschland und Großbritannien. Baden-Baden, S. 254.

1220 Vgl. Conzelmann, Thomas 2002: Große Räume, kleine Räume: a.a.O., S. 254.

1221 Conzelmann, Thomas 2002: Große Räume, kleine Räume: a.a.O., S. 254.

1222 Knodt, Michèle 2000: Europäisierung: Eine Strategie der Selbstbehauptung?. In: Knodt, Michèle / Kohler-Koch, Beate (Hrsg.) 2000: Deutschland zwischen Europäisierung und Selbstbehauptung. Frankfurt a. M., S. 35.
} 
Untersuchung darauf hingewiesen, dass die deutschen Akteure in der EU als „Ideengebers“ oder als „Impulsgeber“ bezüglich der Entwicklung eigener Problemlösungen agieren. ${ }^{1223}$ Insbesondere in den 1990er Jahren konnten die eigenen Anregungen oder Konzepte als deutsche hegemoniale Einflussnahme wahrgenommen werden, während die Bundesrepublik im 21. Jahhundert (bis Mitte 2012) jedoch ein relativ „,niedriges Niveau der Vergemeinschaftung“"1224 auf EU-Ebene betrieb (wie sich z. B. im Bereich der Arbeitsmigration zeigte). Es wird somit deutlich, dass der Europäisierungsprozess durchaus im Verständnis einer nationalstaatlichen Selbstbehauptung steht und auch in einer „Form aktiver Interessenpolitik“ 1225 beobachtet werden kann. Die in der Einleitung entwickelte Arbeitshypothese ging dabei davon aus, dass die parallele institutionelle Einbindung den aktuell herausragendsten Aspekt des Europäisierungsprozesses zwischen EU und Deutschland darstellt. Aus dieser Perspektive bedeutet Europäisierung stets „die institutionalisierte Wechselwirkung zwischen europäischer und nationaler Ebene.“" ${ }^{1226}$ Hinsichtlich dieser Arbeitshypothese wird weiterhin ein zentrales Ergebnis bestätigt, nämlich, dass die Europäisierung nationaler Migrationspolitik nicht mit dem einfachen Prozess eines „Anpassungsdrucks“ vonseiten der EU zu verstehen ist. Die Besonderheit der Europäisierung im Politikfeld Migration liegt erkennbar nicht in einer allmählichen Transformation der mitgliedstaatlichen Migrationspolitik, sondern in einem Prozess der schrittweisen Überlagerung und Ergänzung dieser Politik durch die beschriebene These „paralleler Institutionalisierung“ der gemeinschaftlichen Interessen. Das Besondere daran ist jedoch, dass dabei der Kernbereich nationalstaatlicher Souveränität durch die supranationale Institutionalisierung noch nicht penetriert wird. Des Weiteren wird anstatt größerer Offenheit innerhalb der Migrationspolitik ein Transparenz- und zu guter Letzt ein Legitimationsdefizit ersichtlich, angesichts dessen eine weitere Vergemeinschaftung wenigstens klar angezweifelt werden muss. Europäisierung besteht hier allerdings nicht in einer Übernahme von EU-Kompetenzen in das mitgliedstaatliche Politikgefüge mit einer daraus resultierenden Anpassung der mitgliedstaatlichen Politik. Anstelle dessen zeigt sich die Europäische Union als ein zusätzlicher migrationspolitischer Akteur, der selbst zur Allokation von Werten innerhalb der politischen Systeme der Mitgliedstaaten, hier im Migrationssystem Deutschlands, einen Beitrag zu leisten vermag.

\footnotetext{
1223 Knodt, Michèle 2000: Europäisierung: Eine Strategie der Selbstbehauptung?. a.a.O., S. 35.

${ }^{1224}$ Parusel, Bernd 2010: Abschottungs- und Anwerbungsstrategien: a.a.O., S. 158.

1225 Kohler-Koch, Beate 2000: Europäisierung: Plädoyer für eine Horizonterweiterung. In: Knodt, Michèle / Kohler-Koch, Beate (Hrsg.) 2000: a.a.O., S. 11.

1226 Tomei, Verónica 2001: Europäisierung nationaler Migrationspolitik: a.a.O., S. 134.
} 


\section{Einordnung der Ergebnisse in die drei Ansätze des Neo-Institutionalismus (NI)}

Die Ergebnisse der vorliegenden Arbeit können zunächst als Bestätigung jener drei Ansätze des Neo-Institutionalismus (NI) betrachtet werden, die in den Nationalstaaten und in der Europäischen Union eine wechselseitige Abhängigkeit von Institutionen sehen, wobei hier eher das Verhältnis von Akteur und Handlung, d. h. ein Brückenschlag zwischen Handlungs- und Strukturebene, gemeint ist. Der Europäisierungsprozess hängt somit in hohem Maße von den beteiligten Akteuren, den auf der Tagesordnung stehenden Themen und vor allem den Institutionen ab, die den Prozess strukturieren. Die drei Ansätze des Neo-Institutionalismus (NI), also Rational Choice-Institutionalismus (RC: Logik der Konsequenz), soziologischer Institutionalismus (SI: Logik der Angemessenheit) und historischer Institutionalismus (HI: Logik der Sequenz) zeigen damit, ,warum politische Akteure sich verhalten, wie sie es tun, welche Wahlhandlungen sie treffen, und insbesondere wie diese Wahlhandlungen von Institutionen beeinflusst oder bestimmt werden. “1227 Hinsichtlich der Kooperation im Mehrebenensystem der EU erklären NI-Ansätze weiterhin, wie belegt werden kann, dass das institutionelle Design das Policy-Output (d. h. migrationspolitische Entscheidungen: z. B. Gesetze, Verträge, Programme, politischadministrative Maßnahmen) und auch das Policy-Outcome (d. h. Implementation der Maßnahmen und Auswirkungen auf die MigrantInnen) faktisch beeinflusst. ${ }^{1228}$ Dies ermöglichte zunächst die Frage, in welcher Weise institutionelle Faktoren zu unterschiedlichen Politikergebnissen beitragen können. Hier zeigte die vorliegende Arbeit Hinweise auf den institutionellen Wandel. So gab es z. B. im Vergleich zum Maastrichter Vertrag die Verschiebung der EU-Migrationspolitik von der „dritten Säule“ zur „ersten Säule“ im Amsterdamer Vertrag. D. h., dass der Amsterdamer Vertrag die EU-Migrationspolitik von der „intergouvernementalen Säule“ in die „vergemeinschaftete“ erste Säule überleitete (siehe hierzu Kapitel III.2.4 u. 2.5). ${ }^{1229}$ Allerdings mussten bezüglich des Vergemeinschaftungsschubs Beschlüsse in diesem Politikbereich nur vom (Minister-)Rat einstimmig gefasst werden. ${ }^{1230}$ Das

\footnotetext{
1227 Van Waarden, Frans 2009: Institutionen zur Zentralisierung und Kontrolle politischer Macht. In: Schubert, Klaus / Bandelow, Nils C. (Hrsg.) 2009: Lehrbuch der Politikfeldanalyse 2.0. S. 283.

1228 Vgl. Jann, Werner / Wegrich, Kai 2009: Phasenmodelle und Politikprozesse: Der Policy Cycle. In: Schubert, Klaus / Bandelow, Nils C. (Hrsg.) 2009: Lehrbuch der Politikfeldanalyse 2.0. S. 82-83.

1229 Vgl. Birsl, Ursula 2005: Migration und Migrationspolitik im Prozess der europäischen Integration?. Opladen, S. 115, 117.; vgl. auch Parusel, Bernd 2010: Abschottungs- und Anwerbungsstrategien: EU-Institutionen und Arbeitsmigration. Wiesbaden, S. 142.

${ }^{1230}$ Vgl. Parusel, Bernd 2010: Abschottungs- und Anwerbungsstrategien: a.a.O., S. 142.
} 
Einstimmigkeitsprinzip im EU-Entscheidungsverfahren, unter anderem die vorrangige Vetomacht des EU-Ministerrats, werden als Vetopunkt bzw. Vetospieler in der EUMigrationspolitik berücksichtigt. Auch das deutsche Föderalismusprinzip zwischen verschiedenen politischen Ebenen (Bund, Länder und Kommunen), u. a. der Bundesrat, kann als Vetopunkt bzw. Vetospieler festgelegt werden. Diese Entscheidungsstrukturen des deutschen Föderalismussystems sowie des EU-Mehrebenensystems verfügen über hohe Einfluss- und auch Blockademöglichkeiten innerhalb der migrationspolitischen Entscheidungsprozesse. Insbesondere mit Bezug auf die „Pfadabhängigkeit“"1231 (d. h. „frühere Wahlhandlungen bestimmen spätere““1232) werden somit die grundlegenden migrationspolitischen Veränderungen durch diese institutionellen Rahmenbedingungen teilweise blockiert bzw. verzögert. ${ }^{1233}$ So wird z. B. aufgrund des Einstimmigkeitsprinzips eine Vergemeinschaftung über die Frage der Arbeitsmigration aus Drittstaaten bis heute als undurchführbar bezeichnet.

Zur Erklärung der „Europäisierung deutscher Migrationspolitik“ ist es nun angebracht, folgende drei Richtungen der NI-Ansätze genauer zu unterscheiden:

\subsection{Europäisierung als rational-akteurszentrierter Prozess (RC)}

Gemäß dem Rational-Choice-Ansatz (RC), der in seinen Ursprüngen auf mikroökonomischen Hypothesen sowie auf der rationalen Kosten-Nutzen-Variante basiert, besteht das Interesse der Bundesrepublik Deutschland darin, mit anderen EUStaaten in migrationspolitischen Kontexten zusammenzuarbeiten, in welchen durch zunehmende Nutzung der EU-Ebene im Vergleich zu nationaler Autonomie ein höherer Grad der Zweckmäßigkeit erwartet wird. Ziel deutscher Akteure ist demgemäß eine Maximierung der Eigeninteressen, wobei diese ihre Bestrebungen auf eine rationale Art verwirklichen. Die Akteure schöpfen daraus alternative Wahlmöglichkeiten und wählen

\footnotetext{
1231 Der Begriff der Pfadabhängigkeit stellt dar, ,dass die zu historischen Zeitpunkten getroffenen Festlegungen von Grundregeln einer institutionellen Ordnung Weichenstellungen markieren, die die weitere Entwicklung prägen." In: Benz, Arthur 2009: Politik in Mehrebenensystemen. S. 39.

1232 Van Waarden, Frans 2009: Institutionen zur Zentralisierung und Kontrolle politischer Macht. In: Schubert, Klaus / Bandelow, Nils C. (Hrsg.) 2009: Lehrbuch der Politikfeldanalyse 2.0. S. 287.

1233 Vgl. Blum, Sonja / Schubert, Klaus 2009: Politikfeldanalyse. Wiesbaden, S. 78.
} 
jene aus, die ihnen den „maximalen Nutzen bei minimalen Kosten“ ${ }^{1234}$ bringt. Diesbezüglich ist vor allem das Einstimmigkeitsprinzip in EU-Entscheidungsverfahren von Bedeutung. So setzte zum Beispiel Bundeskanzler Helmut Kohl bereits auf dem Amsterdamer Gipfel gegen die Abschaffung des Einstimmigkeitsprinzips im Bereich Asyl mit Erfolg die Regelung der Einstimmigkeit durch. Dies gilt bis heute ebenso hinsichtlich der Regelung der Arbeitsmigration; in dieser Hinsicht bleibt vor allem eine Blockade der deutschen Vetomacht gegen eine zunehmende Europäisierung weiterhin wirkungsvoll. Die Einstimmigkeitsregel schützt somit Akteure davor, eine Maßnahme mittragen zu müssen, die nicht in ihrem rationalen Interesse liegt. Das RC-Modell setzt in diesem Sinn voraus, dass politische Akteure ihren Interessen und Präferenzen folgen, weil sie es so wollen. ${ }^{1235}$

An dieser Stelle beinhaltet die Europäisierung als Einbindung in vielseitige Kooperationen und Institutionen mannigfache Möglichkeiten der Selbstbehauptung der unterschiedlichen Akteure. Dabei bleibt zu beachten, dass die Handlungspräferenzen der einzelnen Akteure exogen, also von außen vorgegeben sind, d. h. die Form und der Wandel der Institutionen ist als das Resultat individueller Entscheidungen vorgegeben und somit nicht von sozialer Interaktion abhängig. Im Rahmen dieser Auffasung stellen individuelle Akteure Insitutionen dar, da durch jene bestimmte Funktionen erfüllt werden, die für die Umsetzung von Handlungsplänen und das Erreichen von Zielen erforderlich sind. Auch diesbezüglich haben die Kriege im ehemaligen Jugoslawien in den 1990er Jahren als externer Faktor, also als externer Schock für die institutionelle Systementwicklung der EU und zur Herausbildung neuer Problemlösungsstrategien auf europäischer Ebene beigetragen. Darüber hinaus erfolgte vor allem durch die Reaktionen deutscher Akteure während der vertraglichen Verhandlungen in den 1990er Jahren eine hohe Interdependenz im Politikfeld Migration. ${ }^{1236}$ Des Weiteren ist als ein wichtiger Befund anzusehen, dass sich die Machtgewichte in der institutionellen Dreiecksstruktur (Ministerrat, Kommission und Parlament) bezüglich der EUKompetenzverteilung in den untersuchten Politikfeldern Migration immer deutlicher in Richtung des Rates bzw. der Mitgliedstaaten verschieben, d. h., es wird in dieser Hinsicht der Kurs eines Kosten-Nutzen-Kalküls verfolgt.

\footnotetext{
1234 Schubert, Klaus / Bandelow, Nils C. 2009: Lehrbuch der Politikfeldanalyse 2.0. Oldenbourg, S. 284.

1235 Van Waarden, Frans 2009: Institutionen zur Zentralisierung und Kontrolle politischer Macht. S. 290.

1236 Vgl. Moravcsik, Andrew / Nicolaidis, Kalypso 1999: Explaining the Treaty of Amsterdam: Interests, Influence, Institutions. In: Journal of Common Market Studies (JCMS). Volume 37. No. 1: March 1999. S. 59-85, hier S. 62-63.
} 


\subsection{Europäisierung als sozialer Prozess (SI)}

Nach dem Ansatz des soziologischen Institutionalismus (SI) wird das Verhältnis von Akteuren und Institutionen als integrativ betrachtet: Handlungen von Akteuren werden von Institutionen geprägt oder beeinflusst. ${ }^{1237}$ So formen Institutionen die Akteure. Dies wird im Rahmen eines normativen Zusammenhangs bewirkt (,von kollektiven Erwartungen an das angemessene Verhalten von Akteuren mit einer vorgegebenen Identität") oder für signifikante kollektive Identitäten (etwa verschiedenartiger Aufbau von Staatlichkeit). ${ }^{1238}$ Spezifisch für Identität und Normen sind zwei Auswirkungen: Sie setzen Akteure ein und beeinflussen ihre Interessen und beschränken sich somit auf Akteurspräferenzen. ${ }^{1239}$ Die „Wirkung von Institutionen auf Akteursinteressen beruht nicht nur auf Nutzenkalkül, sondern auch auf der bewussten oder unbewussten Befolgung von Normen." ${ }^{1240}$ Folglich wird jede Entscheidung eines Akteurs immer in einem institutionellen Rahmen gefällt. Die politischen Handlungsoptionen können somit nicht nur über den Rechtsweg vermittelt werden, sondern parallel anhand eines Prozesses der sozialen Anerkennung Verbreitung finden.

Auf der Grundlage der hier durchgeführten SI-Analyse ist im Hinblick auf die Veränderung des Regierens in Deutschland und auch in der EU auf das Folgende hinzuweisen: Bezüglich der Zusammenarbeit auf europäischer Ebene wird dabei, wie die Ergebnisse in Kapitel III und IV gezeigt haben, ein Legitimationsproblem im deutschen Migrationssystem deutlich. So ist der im deutschen Föderalismusprinzip begründeten Existenz von institutionellen Vetopunkten besondere Beachtung zu schenken. Diese Vetopunkte im deutschen Föderalismus geben den Akteuren die Möglichkeit, die Implementation europäischer Vorgaben $\mathrm{zu}$ blockieren und $\mathrm{zu}$ beeinflussen. Die Rolle der deutschen Bundesländer im Europäisierungsprozess nationaler Migrationspolitik ist somit mit großer Aufmerksamkeit zu betrachten (vgl. hierzu Kapitel IV.1.3 und 1.4). Aus diesem Blickwinkel heraus hat Deutschland eine nationale „kollektive Identität“" entwickelt. ${ }^{1241}$ Vor allem wird damit, als ein Aspekt des Europäisierungsprozesses, die Einbindung des deutschen Föderalismus in das

\footnotetext{
1237 Parusel, Bernd 2010: Abschottungs- und Anwerbungsstrategien: a.a.O., S. 58.

1238 Katzenstein, Peter J. 2000: Gezähmte Macht: Deutschland in Europa. In: Knodt, Michèle / KohlerKoch, Beate (Hrsg) 2000: Deutschland zwischen Europäisierung und Selbstbehauptung. Frankfurt a. M., S. 57-84, hier S. 58.

1239 Katzenstein, Peter J. 2000: Gezähmte Macht: Deutschland in Europa. a.a.O., S. 58.

1240 Parusel, Bernd 2010: Abschottungs- und Anwerbungsstrategien: a.a.O., S. 58.

1241 Katzenstein, Peter J. 2000: Gezähmte Macht: Deutschland in Europa. a.a.O., S. 59.
} 
europäische Mehrebenensystem beobachtet. Des Weiteren sind beispielsweise auch die parlamentarische Oppositionsrolle oder die Rollenerwartungen an die gesellschaftlichen Interessengruppen und Verbände in migrationspolitischen Arrangements zu nennen. Zudem fördert auch das Solidaritätsprinzip die Ausweitung der europäischen migrationspolitischen Agenda. Der Gedanke kann auf politische Programme versinnbildlicht übertragen werden, durch die desgleichen bestimmten Akteuren bestimmte Rollen zugeschrieben werden; eine im Rahmen dieser Arbeit aufschlussreiche Rollenzuweisung erging beispielsweise an die Nichtregierungsorganisationen (NGOs), an nationale und europäische Akteure, als wichtige Mitspieler in Europäisierungsprozessen. Die ,Antidiskriminierungsrichtlinie 2000/43/EG' war somit das Produkt einiger von NGOs vorangetriebenen Policy-Ideen, die im Kontext eines institutionellen Umfelds erfolgt sind (vgl. Kapitel III.3.2.1). Das institutionelle Umfeld, in dem NGOs agieren, wird hierbei durch den SI-Ansatz als ausschlaggebend für die Rechtfertigung ihrer Aktivitäten betrachtet. ${ }^{1242}$ Quintessenz der soziologischen-institutionalistischen Antworten in Bezug auf die Frage nach politischem Einfluss von NGOs ist somit die Erklärung, dass Handlungschancen, Handlungsmöglichkeiten und Einflussoptionen von NGOs vorwiegend durch die strukturellen Eigenschaften der Nationalstaaten und der EU bestimmt werden. Zusammenfassend ist insbesondere die Anschlussfähigkeit der Präferenzen und Positionen der NGOs ausschlaggebend und bestimmt ihren Erfolg bei den Institutionen maßgeblich mit. Diese Beispiele zeigen schließlich, dass solche Rollen nicht alleine Handlungsrestriktionen auferlegen, sondern Akteure mit spezifischen Aufgaben und Rechten innerhalb eines sozialen Zusammenhangs ausstatten können. Insofern zeichnet die Migrationspolitik neben den strukturellen Faktoren auch durch soziale Verhaltensorientierung und kognitive Prozesse ein sehr viel umfassenderes Bild von Europäisierung auf nationaler- und europäischer Ebene.

${ }^{1242}$ Vgl. Groenleer, Martijn L.P. / Van Schaik, Louise G. 2007: United We Stand? The European Union's International Actorness in the Cases of the International Criminal Court and the Kyoto Protocol. In: Journal of Common Market Studies (JCMS). Volume 45. Number 5: December 2007. S. 969-998, hier S. 983. 


\subsection{Europäisierung als historischer Prozess (HI)}

Der historische Institutionalismus (HI), dessen zentrale Gewichtung auf der Geschichte und der Vergangenheit liegt, unterstreicht vor allem die „Pfadabhängigkeit“ (d. h. „frühere Wahlhandlungen beeinflussen spätere“). ${ }^{1243}$ Hinsichtlich der migrationspolitischen Entscheidungsfindung erklärt der HI-Ansatz zunächst, warum Akteure der Tradition folgen. Diesbezüglich werden die Akteure erläutern: „Ich handle, weil ich es immer so getan habe, weil Veränderung teuer ist. “' ${ }^{1244}$ Die Akteure hängen insofern der Tradition an, wobei Institutionen diese Tradition repräsentieren. In dieser Hinsicht lässt sich somit eindeutig erkennen, dass die Veränderungen in Kosten-NutzenRelationen zu teuer sein kann oder mit den geltenden Normen nicht im Einklang stehen. ${ }^{1245}$ Vor diesem Hintergrund bezieht sich der HI-Ansatz auf die „Zeitdimension“ oder die „historische Prozesshaftigkeit des Verhältnisses zwischen Insitutionen und Akteuren“. ${ }^{1246}$ Hierbei wird betont, dass die sogenannte Pfadabhängigkeit insbesondere für die Entwicklung von Institutionen bedeutend ist. Bestehende politische Insitutionen wirken somit auf nachfolgende Wahlhandlungen ein, wobei dies auch die Wahl umfasst, diese Insitutionen $\mathrm{zu}$ verändern. ${ }^{1247}$ Nach diesem Verständnis fällt es den politischen Akteuren schwer, sich von den einmal entwickelten Modellen und Regeln freizumachen und gegebenfalls einen neuen Pfad einzubinden. ${ }^{1248}$

Ausgehend von diesen HI-Überlegungen ist in der Untersuchung vor allem auf Folgendes hingewiesen worden: Es wurde zum Beispiel gezeigt, dass eine einmal gefasste vertragliche Grundlage, etwa die zentralen Meilensteine der völkerrechtlichen Schengener Übereinkommen 1985/1990 sowie die intergouvernementale Zusammenarbeit nach dem Maastrichter Vertrag 1993 und die Vergemeinschaftung seit dem Amsterdamer Vertrag 1999, eine umfassende restriktive Migrationspolitik für die EU zu entwickeln, lange vorhält und auch nach über zehn Jahren trotz großer Schwierigkeiten und Interessensgegensätzen nicht aufgehoben wurde. Ein Abweichen von solchen Pfaden wird somit immer schwieriger, je stärker ein Ziel im Politikfeld Migration institutionalisiert wird. Im Einklang mit diesem Ansatz des historischen Institutionalismus lässt sich weiterhin argumentieren, dass die restriktive EU-

\footnotetext{
1243 Van Waarden, Frans 2009: Institutionen zur Zentralisierung und Kontrolle politischer Macht. S. 287.

1244 Van Waarden, Frans 2009: Institutionen zur Zentralisierung und Kontrolle politischer Macht. S. 287.

1245 Van Waarden, Frans 2009: Institutionen zur Zentralisierung und Kontrolle politischer Macht. S. 287 f.

1246 Parusel, Bernd 2010: Abschottungs- und Anwerbungsstrategien: a.a.O., S. 58.

1247 Van Waarden, Frans 2009: Institutionen zur Zentralisierung und Kontrolle politischer Macht. S. 287.

1248 Parusel, Bernd 2010: Abschottungs- und Anwerbungsstrategien: a.a.O., S. 58.
} 
Migrationspolitik als Folge solcher vorangegangener Lernprozesse gesehen werden kann. Zum anderen ermöglicht das „, Einstimmigkeitsprinzip“ bei Ratentscheidungen im Bereich der legalen Migration, wie bereits an anderer Stelle dargestellt worden ist, dass ein Mitgliedstaat allein einen Vorschlag ins Wanken bringen kann. ${ }^{1249}$ Das heißt, dass ein EU-Mitgliedstaat aufgrund der bis zum Inkrafttreten des Vertrags von Lissabon (2009) fortbestehenden Einstimmigkeitsregelung allein eine Einigung verhindern kann. Umgekehrt bedeutet dies, dass die einmal erreichten Verhandlungsergebnisse potenziell von lang anhaltender Wirksamkeit sind, und dass sie infolge des Einstimmigkeitserfordernisses nur schwer zu ändern sind. Für die Länder, die eine Vervielfachung der Einwandererzahlen durch unerwünschte Einwanderung befürchten, bedeutet das geltende Einstimmigkeitsprinzip daher ihrerseits selbstverständlich eine indirekte Aufforderung, ein Veto einzulegen. Außerdem ist seitens der Mitgliedstaaten eine weitgehend kritische Haltung bezüglich einer weiteren Vergemeinschaftung der Politik zur Steuerung der legalen (Wirtschafts-)Migration und auch der Integrationspolitik zu beobachten. EU-Mitgliedstaaten, allen voran Deutschland, weisen mit Blick auf dieses EU-Entscheidungsverfahren durchgängig ein niedriges Niveau der Vergemeinschaftung im Politikfeld Arbeitsmigration auf (vgl. hierzu Kapitel III.2.8). Das Einstimmigkeitsprinzip kann nun zugleich sowohl im EU-System als auch innerhalb von nationalen Akteuren sehr stabil sein und darum eine „Pfadabhängigkeit“" wecken.

Vor allem durch diesen HI-Ansatz erklärt sich der weitaus restriktive Politikprozess der Bundesrepublik Deutschland im Bereich Asyl- und Flüchtlingspolitk. Die deutsche Grundgesetzänderung von 1993 (der sogenannte „Asylkompromiss“) bildet bislang die Grundlage für asylpolitische Reformen. Diese wurde damals jedoch als ein großzügiges „Asylrecht“ im Vergleich zu anderen EU-Staaten anerkannt, und die Bundesregierung beabsichtigte daraufhin auf EU-Ebene eine Europäisierung des restriktiven Asylrechts. Alles in allem zeigte und zeigt die Migrationspolitik auf beiden Ebenen EU und Deutschland schließlich, dass im Rahmen des HI-Ansatzes häufig von einer „Pfadabhängigkeit“ ausgegangen wird. Diese führte und führt deshalb, wie bereits erwähnt, nicht zum generösen Politikwandel, sondern lediglich zum partiellen Politikwandel oder teilweise nur zum Perspektivenwechsel bezüglich der Europäisierung im Bereich Migrationspolitik.

1249 Vgl. Parusel, Bernd 2010: Abschottungs- und Anwerbungsstrategien: a.a.O., S. 244. 


\section{Schlussbetrachtung}

Die vorliegende Arbeit hat zu dem Ergebnis geführt, dass die deutsche Migrationspolitik seit den neunziger Jahren nicht unabhängig von nationaler Exekutive, Legislative und Judikative gestaltet wird, sondern zunehmend transnational im EU-Verbund. Angesichts dessen haben die Bedingungen deutscher Migrationspolitik nur im Rahmen des Kernbereichs der nationalstaatlichen Souveränität zur Veränderung geführt. Auf diese Weise bildete sich in Deutschland ein Modus der Politikgestaltung heraus, der gezielt die Institutionalisierung von Politik und das Entstehen entsprechender Vergemeinschaftung zwischen Deutschland und der EU unterstützen wollte und will. Mit diesem Verständnis hat sich der Handlungsrahmen migrationspolitischer Akteure über nationale Grenzen hinweg ausgedehnt. Auch den jeweils vorgefundenen Mustern institutioneller Anpassung in den unterschiedlichen Politikfeldern wird sich unter Anwendung einer institutionalistischen Perspektive angenähert. Die Auswirkungen der Einbindung deutscher Migrationspolitik in das europäische Mehrebenensystem im Kontext der EU-Migrationspolitik haben demgemäß in der vorliegenden Untersuchung allenfalls zur teilweisen nationalstaatlichen Anpassung an europäische Vorgaben bzw. Politikinstrumente und auch zum Entstehen einer Parallelförderung sowie zu ungewöhnlichen Effekten der EU-Beihilfenkontrolle geführt. Das Augenmerk der Bundesrepublik bezüglich ihrer Strategien im Politikfeld Migration war in diesem Zusammenhang in erster Linie auf eine Gewährleistung der Maximierung des politischen Einflusses in der EU gerichtet, wobei auch die defensive Haltung der Gemeinschaftsaufgabe zunehmend als ein zentrales Anliegen gesehen wurde. Das Verhalten der Bundesrepublik Deutschland kann hierbei nur erklärt werden, wenn man es aus den theoriegeleiteten Ausführungen des sogenannten „Neo-Institutionalismus (NI)“ versteht. Gemäß diesen hat die institutionelle Umgebung, in der Politik entsteht, entscheidenden Einfluss auf die Entwicklung politischer Prozesse.

Im Zusammenhang des Europäisierungsprozesses geht es im Politikfeld Migration erkennbar nicht um ein Lernen von der EU oder um eine graduelle Anpassung der mitgliedstaatlichen Migrationspolitik an europäische Vorgaben auf Druck der supranationalen Organe. Es haben sich vielmehr die Rollenzuweisungen etabliert, die im europäischen Politikparadigma gefestigt sind. Derartige Rollenzuweisungen beinhalten in erster Linie das Prinzip der „Solidarität“, wobei eine Vielzahl von Akteuren als anerkannte Mitspieler in der Migrationspolitik aufgeführt werden. 
Dementsprechend wird nunmehr auch die Rolle der einzelnen institutionellen Akteure stärker in den Vordergrund gerückt. Wie die vorliegende Untersuchung gezeigt hat, bedeutet „Europäisierung“ in diesem Kontext, dass mitgliedstaatliche Kompetenzen auf EU-Ebene übertragen werden (hierbei wurde die Bottom-up-Perspektive eingenommen, etwa in der Analyse des Einflusses der Mitgliedstaaten, wie im Fall der Bundesrepublik Deutschland, auf die europäische Regulierung und Politikgestaltung) und die supranationale Ebene gegenüber den Mitgliedstaaten aufgewertet wird (die Top-downBeziehung). Der Begriff der Europäisierung ist real dadurch miteinander verbunden, dass unterschiedliche Europäisierungsprozesse in Mischformen auftreten. Gleichzeitig wurde deutlich, dass es nicht $\mathrm{zu}$ einer allmählichen Angleichung deutscher Migrationspolitik an das supranationale Muster kommt, sondern eher zur realen Entkopplung der deutschen und supranationalen Politik kommt sowie als ein mögliches Ergebnis der Institutionalisierung der Migrationspolitik zur Ausformung ,zweier weitgehend unverbunden nebeneinander“ existierender „paralleler“ politischer Gefüge. $^{1250}$

Die vorliegende Arbeit hat schließlich aufgezeigt, dass die Dynamik der Entfaltung deutscher Migrationspolitik als ein komplexes, interdependentes Zusammenspiel von Europäisierung und nationalen Interessen vonstatten ging, das von einer Fülle von Faktoren beeinflusst wurde, die teils gleichgerichtete, teils gegenläufige Auswirkungen zeigten. Dabei werden insbesondere die deutschen Interessen der Akteure in strategischer- und institutionell strukturierter Weise in Bezug auf nationalstaatliche Souveränität, Sicherheit und die wirtschaftliche Nützlichkeit bzw. auf die arbeitsmarktorientierte Migrationssteuerung verfolgt. Im Hinblick auf diese deutsche nationalstaatlichen Interessen wird auch anhand der Komplexität sowie der Vielzahl von Mitgliedstaaten offenkundig, wo die Schwierigkeiten bei dem Aufbau einer gemeinsamen Migrationspolitik zu finden sind. Möglicherweise ist von einer Einigung auf eine gemeinsame europäische Migrationspolitik nur dann auszugehen, wenn ungeachtet verbindlicher Rahmenbedingungen weiterhin genügend Freiräume erhalten bleiben, die die Bundesrepublik Deutschland und auch die EU-Mitgliedstaaten gemäß ihrer nationalen Interessen verwalten können. Inwiefern die dargelegten Thesen und die Analyse in diesem Politikfeld Migration zum Tragen kommen, ist eine Frage für künftige Forschungen hinsichtlich der Europäisierung nationaler Migrationspolitik.

1250 Conzelmann, Thomas 2002: Große Räume, kleine Räume: Europäisierte Regionalpolitik in Deutschland und Großbritannien. Baden-Baden, S. 270. 
Anhang 


\section{Übersicht 1}

Neo-Institutionalism: Main features of the three institutionalist approaches ${ }^{1251}$

\begin{tabular}{|c|c|c|c|}
\hline & $\begin{array}{l}\text { Soziologischer } \\
\text { Institutionalismus }\end{array}$ & $\begin{array}{l}\text { Historischer } \\
\text { Institutionalismus }\end{array}$ & $\begin{array}{l}\text { Rationalistischer } \\
\text { Institutionalismus }\end{array}$ \\
\hline Scientific world view & $\begin{array}{l}\text { Holism, } \\
\text { constructivism; } \\
\text { group identity; } \\
\text { shared past/common } \\
\text { experience }\end{array}$ & $\begin{array}{l}\text { Modified egoism; } \\
\text { agency constrained } \\
\text { or structured by } \\
\text { common agreement }\end{array}$ & $\begin{array}{l}\text { Methodological } \\
\text { individualism; } \\
\text { optimizing and } \\
\text { strategic behavior }\end{array}$ \\
\hline $\begin{array}{l}\text { Typical research } \\
\text { design }\end{array}$ & $\begin{array}{l}\text { Case studies of } \\
\text { cultural, cognitive } \\
\text { links. }\end{array}$ & $\begin{array}{l}\text { Historical sociology, } \\
\text { case studies }\end{array}$ & $\begin{array}{l}\text { Casual illustrations } \\
\text { of hypotheses, } \\
\text { macroquantitative tests }\end{array}$ \\
\hline Time horizon & Long term & Long term & Short term \\
\hline $\begin{array}{l}\text { Definition of } \\
\text { institutions }\end{array}$ & Norms, rules, culture & $\begin{array}{l}\text { Informal and formal } \\
\text { rules }\end{array}$ & Rules, procedures \\
\hline $\begin{array}{l}\text { Role of institutions } \\
\text { for human action }\end{array}$ & $\begin{array}{l}\text { Major independent } \\
\text { variable; cultural } \\
\text { constraint. }\end{array}$ & $\begin{array}{l}\text { Intervening variable. } \\
\text { Grown constraint } \\
\text { and opportunity }\end{array}$ & $\begin{array}{l}\text { Intervening variable. } \\
\text { Situative constraint } \\
\text { and opportunity }\end{array}$ \\
\hline Preference formation & $\begin{array}{l}\text { Constitution of } \\
\text { actors through } \\
\text { institutions; } \\
\text { endogeneous process }\end{array}$ & $\begin{array}{l}\text { Endogenous. } \\
\text { Creation of } \\
\text { institutions affects } \\
\text { preferences. }\end{array}$ & $\begin{array}{l}\text { Exogeneous to the } \\
\text { model or decision- } \\
\text { theoretic explanation }\end{array}$ \\
\hline $\begin{array}{l}\text { Creation of } \\
\text { Institutions }\end{array}$ & $\begin{array}{l}\text { Evolutionary; } \\
\text { occasional abrupt } \\
\text { changes caused by } \\
\text { new events or } \\
\text { reinterpretations. }\end{array}$ & $\begin{array}{l}\text { Delegation; self- } \\
\text { maintaining and } \\
\text { potentially expansive }\end{array}$ & $\begin{array}{l}\text { Distributional } \\
\text { conflict, reduction of } \\
\text { transaction costs or } \\
\text { collective dilemma } \\
\text { as driving force }\end{array}$ \\
\hline $\begin{array}{l}\text { Evolution of } \\
\text { institutions }\end{array}$ & $\begin{array}{l}\text { Cognitive/memory - } \\
\text { process of mythologizing } \\
\text { common events. }\end{array}$ & $\begin{array}{l}\text { Contingent processes } \\
\text { with path dependency } \\
\text { and unintended conseque }\end{array}$ & $\begin{array}{l}\text { Barganing process, } \\
\text { evolutionary selection }\end{array}$ \\
\hline
\end{tabular}

${ }^{1251}$ Aspinwall, Mark D. / Schneider, Gerald 2000: Same menu, separate tables: The institutionalist turn in political science and the study of European integration. In: European Journal of Political Research, Volume 38, No. 1 (August 2000). Netherlands, S. 1-36, hier S. 7. 


\section{Übersicht 2: ,Ebenen der Migrationsanalyse' von Thomas Faist}

\begin{tabular}{|c|c|c|}
\hline $\begin{array}{l}\text { Makroebene: strukturell } \\
\text { Opportunitätsstrukturen } \\
\text { (politisch-ökonomisch-kulturelle Struktur) }\end{array}$ & $\begin{array}{l}\text { Meso-Bindeglied: relational } \\
\text { Kollektive und Netzwerke } \\
\text { (soziale Beziehungen) }\end{array}$ & $\begin{array}{l}\text { Mikroebene: individuell } \\
\text { Werte, Erwartungen und } \\
\text { Ressourcen } \\
\text { (Grade individueller Autonomie) }\end{array}$ \\
\hline $\begin{array}{l}\text { Ökonomie: } \\
\text { - Unterschiede im Einkommen und in Bezug auf } \\
\text { verfügbare Arbeitsplätze; } \\
\text { Zugriff auf ökonomisches Kapital } \\
\text { Politik: } \\
\text { - Regulierung geographischer Mobilität } \\
\text { (Nationalstaaten und internationale Regime); } \\
\text { - politische Repression, } \\
\text { ethnische und religiöse Konflikte; } \\
\text { - Interdependenzen von Staaten } \\
\text { im Rahmen des internationalen Systems }\end{array}$ & $\begin{array}{l}\text { soziale Bindungen: } \\
\text { - starke Bindungen: Familien } \\
\text { und Haushalte; } \\
\text { - schwache Bindungen: } \\
\text { Netzwerke potentieller } \\
\text { Migranten und Makler; } \\
\text { - symbolische Bindungen: } \\
\text { ethnische und religiöse } \\
\text { Organisationen } \\
\text { soziales Kapital: } \\
\text { - verfügbare Ressourcen } \\
\text { potentieller Migranten durch } \\
\text { Partizipation in Netzwerken } \\
\text { und Kollektiven mittels } \\
\text { starker, schwacher und } \\
\text { symbolischer sozialer Bindungen }\end{array}$ & $\begin{array}{l}\text { individuelle Präferenzen } \\
\text { (Ziele, Werte) und Erwartungen: } \\
\text { Sicherung des Überlebens, } \\
\text { Steigerung des Lebensstandards, } \\
\text { Status, Komfort, Anregung, } \\
\text { Autonomie, Zugehörigkeit und } \\
\text { Moralität } \\
\text { individuelle Ressourcen, z.B.: } \\
\text { - ökonomisches Kapital } \\
\text { - Humankapital }\end{array}$ \\
\hline
\end{tabular}

Quelle: Faist, Thomas 1997: Migration und der Transfer sozialen Kapitals oder: Warum gibt es relativ wenige internationale Migranten?. In: Pries, Ludger (Hrsg.) 1997: Transnationale Migration. BadenBaden (Soziale Welt: Sonderband. 12), S. 63-83, hier S. 73. 


\section{Übersicht 3: ‘A General Typology of Migration' nach William Petersen}

\begin{tabular}{|c|c|c|c|c|}
\hline \multirow{2}{*}{ Relation } & Migratory Force & Class of & \multicolumn{2}{|c|}{ Type of migration } \\
\cline { 3 - 5 } & & Migration & Conservative & Innovating \\
\hline Nature and man & Ecological push & Primitive & Wandering & Flight from \\
the land
\end{tabular}

Quelle: Petersen, William 1958: A General Typology of Migration. In: American Sociological Review (ASR), Vol. 23 (1/1958), S. 266.; vgl. auch Petersen, William 1996: A General Typology of Migration. In: Cohen, Robin (Ed.) 1996: Theories of Migration. Cheltenham/Brookfield, S. 3-13, hier S. 13. 


\section{Übersicht 4 : Elf-EU-Richtlinien ${ }^{1252}$}

- Richtlinie 2003/86/EG des Rates vom 22.9.2003 betreffend das Recht auf Familienzusammenführung („Familiennachzugsrichtlinie“, ABl. EU Nr. L251 S. 12.),

- Richtlinie 2003/109/EG des Rates vom 25.11.2003 betreffend die Rechtsstellung der langfristig aufenthaltsberechtigten Drittstaatsangehörigen („Daueraufenthaltsrichtlinie“, ABl. EU Nr. L16 S. 44.),

- Richtlinie 2004/81/EG vom 29.4.2004 über die Erteilung von Aufenthaltstiteln für Drittstaatsangehörige, die Opfer des Menschenhandels sind oder denen Beihilfe zur illegalen Einwanderung geleistet wurde und die mit den zuständigen Behörden kooperieren („Opferschutzrichtlinie“, AB1. EU Nr. L261 S. 19.),

- Richtlinie 2002/90/EG des Rates vom 28.11.2002 zur Definition der Beihilfe zur unerlaubten Ein- und Durchreise und zum unerlaubten Aufenthalt (AB1. EG Nr. L328 S. 17.),

- Richtlinie 2003/110/EG des Rates vom 25.11.2003 über die Unterstützung bei der Durchbeförderung im Rahmen von Rückführungsmaßnahmen auf dem Luftweg („Durchbeförderungsrichtlinie“, AB1. EU Nr. L321 S. 26; 2004 Nr. L236 S. 18).

- Richtlinie 2004/114/EG des Rates vom 13.12.2004 über die Bedingungen für die Zulassung von Drittstaatsangehörigen zwecks Absolvierung eines Studiums oder Teilnahme an einem Schüleraustausch, einer unbezahlten Ausbildungsmaßnahme oder einem Freiwilligendienst („Studentenrichtlinie“, AB1. EU Nr. L375 S. 12.),

- Richtlinie 2005/71/EG des Rates vom 12.10.2005 über ein besonderes Zulassungsverfahren für Drittstaatsangehörige zum Zwecke der wissenschaftlichen Forschung („Forscherrichtlinie“, AB1. EU Nr. L289 S. 15.),

- Richtlinie 2004/38/EG des Europäischen Parlaments und des Rates vom 29.4.2004 über das Recht der Unionsbürger und ihrer Familienangehörigen, sich im Hoheitsgebiet der Mitgliedstaaten frei zu bewegen und aufzuhalten, zur Änderung der Verordnung (EWG) Nr. 1612/68 und zur Aufhebung weiterer

1252 Maaßen, Hans-Georg 2006: Zum Stand der Umsetzung von elf aufenthalts- und asylrechtlichen Richtlinien der Europäischen Union. In: Zeitschrift für Ausländerrecht und Ausländerpolitik (ZAR) 5-6/2006, 26. Jahrgang. S. 161-167 hier, S. 162.; vgl. auch im Internet: http://www.abgeordnetenwatch.de/aufenthalts_und_asylrecht-636-120.html (Stand: 14.06.2007). 
Richtlinien („Freizügigkeitsrichtlinie“, AB1. EU Nr. L229 S. 35 - bereinigte Fassung.),

- Richtlinie 2004/83/EG des Rates vom 29.4.2004 über Mindestnormen für die Anerkennung und den Status von Drittstaatsangehörigen oder Staatenlosen als Flüchtlinge oder als Personen, die anderweitig internationalen Schutz benötigen, und über den Inhalt des zu gewährenden Schutzes („AsylQualifikationsrichtlinie“, ABl. EU Nr. L304 S. 12.),

- Richtlinie 2005/85/EG des Rates vom 1.12.2005 über Mindestnormen für Verfahren in den Mitgliedstaaten zur Zuerkennung und Aberkennung der Flüchtlingseigenschaft („Asyl-Verfahrensrichtlinie“, AB1. EU Nr. L326 S. 13.),

- Richtlinie 2003/9/EG des Rates vom 27.1.2003 zur Festlegung von Mindestnormen für die Aufnahme von Asylbewerbern in den Mitgliedstaaten (,Richtlinie Aufnahmebedingungen“, AB1. EU Nr. L31 S. 18.). 


\section{Übersicht 5 : Die Zehn Prioritäten des Haager Programms ${ }^{1253}$}

- Grundrechte und Unionsbürgerschaft: Der Schutz der Grundrechte soll umfassend gewährleistet werden. Die vorgeschlagene Gründung einer Agentur der Grundrechte wird ein wichtiger Beitrag sein. Auch die Antidiskriminierungsmaßnahmen fallen unter diesen ersten Punkt und sollen effektiv umgesetzt werden.

- Bekämpfung des Terrorismus: Es soll ein globales Konzept zur Abwehr des internationalen Terrorismus ausgearbeitet werden. Dabei soll eine Konzentration auf Prävention und präventives Krisenmanagements stattfinden. Im Kampf gegen den Terrorismus soll die externe Kooperation mit weiteren Staaten intensiviert werden.

- Ein gemeinsamer Asylraum: Die Einführung eines effizienten und unionsweiten Verfahrens im Einklang mit den Werten und der humanitären Tradition der EU.

- Steuerung von Migrationsströmen: Es soll ein umfassendes Konzept entwickelt werden um mit der Migration und auch der illegalen Einwanderung, dem Schleusertum und Menschenhandel besser umgehen zu können. Hierunter fallen auch die Regelungen über Rückführungsverfahren und die Kooperation mit Drittstaaten.

- Integration: Maximierung der positiven Auswirkungen der Migration in Gesellschaft und Wirtschaft. Mit Blick auf den demographischen Wandel sollen insbesondere die positiven Effekte der Migration hervorgehoben werden, um ein breiteres Verständnis innerhalb der Bevölkerung $\mathrm{zu}$ wecken. Insbesondere Isolation, die Schaffung von „Parallelgesellschaften“ und die soziale Ausgrenzung sollen angegangen werden. Hierzu gehören auch Maßnahmen in den Bereichen Bildung, Ausbildung, Fortbildung und Beschäftigung.

- Binnengrenzen, Außengrenzen und Visa: Das Haager Programm dient der Schaffung eines integrierten Schutzes an den Außengrenzen sowie der vollständigen Abschaffung der Personenkontrollen an den Binnengrenzen. Konkret soll hierzu ein Visa-Informationssystem ausgearbeitet werden, um eine effiziente Visapolitik zu ermöglichen.

- Datenschutz und Sicherheit beim Informationsaustausch: Ziel ist die

1253 Vgl. KOM/2005/184 endg.: Mitteilung der Kommission an den Rat und das EP vom Mai 2005: Das Haager Programm: Zehn Prioritäten für die nächsten fünf Jahre, S. 8-9.; http://www.europa.eu.int/smartapi/cgi/sga_doc?smartapi!celexplus!prod!DocNumber\&lg=de\&type $\mathrm{doc}=$ COMfinal\&an_doc $=2005 \& n u \_d o c=184$ (Stand: 23.03.2006). 
Herstellung einer in der europäischen Bürgergesellschaft anerkannten Balance zwischen den Bedürfnissen des Datenschutzes und der inneren Sicherheit, um einen erfolgreichen Datenaustausch in Strafverfolgungs- und Justizverfahren zu gewährleisten.

- Organisierte Kriminalität: Zur Bekämpfung dieses Phänomens soll ein strategisches Konzept ausgearbeitet und danach umgesetzt werden.

- Zivil- und Strafjustiz. In diesem Bereich geht es um die schrittweise Schaffung eines leistungsfähigen, europäischen Rechtsraumes.

- Verantwortung und Solidarität gemeinsam ausüben: Hierzu sollen drei Rahmenprogramme ausgearbeitet werden, um die politischen und finanziellen Instrumente zur Umsetzung des Haager Programms zur Verfügung zu stellen. 


\section{Übersicht 6 : Der Strategische Plan zur legalen Einwanderung ${ }^{1254}$}

- Der Vorschlag für eine Richtlinie über die Bedingung für die Einreise und den Aufenthalt hoch qualifizierter Arbeitnehmer (mit Ausnahme von Forschern)

- Der Vorschlag für eine Richtlinie über die Bedingungen für die Einreise und den Aufenthalt von Saisonarbeitern

- Der Vorschlag für eine Richtlinie über Verfahren zur Regelung der Einreise, des befristeten Aufenthalts und der Wohnsitznahme von innerbetrieblich versetzten Arbeitnehmern

- Der Vorschlag für eine Richtlinie über die Bedingung für die Einreise und den Aufenthalt von bezahlten Auszubildenden

1254 Europäische Kommission (KOM) 2005: Mitteilung der Kommission vom 21.12.2005: Der Strategische Plan zur legalen Einwanderung, KOM/2005/669 endgültig. Brüssel, S. 8-9.; http://europa.eu.int/eur-lex/lex/LexUriServ/site/de/com/2005/com2005_0669de01.pdf (Stand: 21.02.2006). 


\section{Übersicht 7 : Aufbau des Primärrechts entsprechend dem Vertrag von Lissabon}

\begin{tabular}{|c|c|c|c|}
\hline \multicolumn{4}{|c|}{ Vertrag von Lissabon (2007/2009) } \\
\hline \multicolumn{2}{|c|}{$\begin{array}{l}\text { Vertrag über die Europäische Union - } \\
\text { EUV }\end{array}$} & \multicolumn{2}{|c|}{$\begin{array}{l}\text { Vertrag über die Arbeitsweise der } \\
\text { Europäischen Union - AEUV }\end{array}$} \\
\hline Titel I & $\begin{array}{l}\text { Gemeinsame } \\
\text { Bestimmungen }\end{array}$ & Erster Teil & Grundsätze \\
\hline Titel II & $\begin{array}{l}\text { Bestimmungen über } \\
\text { die demokratischen } \\
\text { Grundsätze }\end{array}$ & Zweiter Teil & $\begin{array}{l}\text { Nicht- } \\
\text { Diskriminierung und } \\
\text { Unionsbürgerschaft }\end{array}$ \\
\hline Titel III & $\begin{array}{l}\text { Bestimmungen über } \\
\text { die Organe }\end{array}$ & Dritter Teil & $\begin{array}{l}\text { Die internen Politiken } \\
\text { und Maßnahmen der } \\
\text { Union }\end{array}$ \\
\hline Titel IV & $\begin{array}{l}\text { Bestimmungen über } \\
\text { eine verstärkte } \\
\text { Zusammenarbeit }\end{array}$ & Vierter Teil & $\begin{array}{l}\text { Die Assoziierung der } \\
\text { überseeischen Länder } \\
\text { und Hoheitsgebiete }\end{array}$ \\
\hline Titel V & $\begin{array}{l}\text { Allgemeine } \\
\text { Bestimmungen über das } \\
\text { auswärtige Handeln der } \\
\text { Union und besondere } \\
\text { Bestimmungen über die } \\
\text { Gemeinsame Außen- } \\
\text { und Sicherheitspolitik }\end{array}$ & Fünfter Teil & $\begin{array}{l}\text { Das auswärtige } \\
\text { Handeln der Union }\end{array}$ \\
\hline Titel VI & Schlussbestimmungen & Sechster Teil & $\begin{array}{l}\text { Institutionelle } \\
\text { Bestimmungen }\end{array}$ \\
\hline & & Siebter Teil & $\begin{array}{l}\text { Und } \\
\text { Finanzvorschriften } \\
\text { Allgemeine und } \\
\text { Schlussbestimmungen }\end{array}$ \\
\hline
\end{tabular}

Quelle: Hofmann, Andreas / Wessels, Wolfgang 2009: Eine dauerhafte Verfassung für Europa? Die Beantwortung konstitutioneller Grundfragen durch den Vertrag von Lissabon. In: Decker, Frank (Hrsg.) 2009: Die Verfassung Europas: Perspektiven des Integrationsprojekts. Wiesbaden, S. 72. 


\section{Übersicht 8 : Bestimmungen über die qualifizierte Mehrheit nach Nizza und Lissabon}

\begin{tabular}{|c|c|c|}
\hline & Vertrag von Nizza (EU 27) & Vertrag von Lissabon (EU 27) \\
\hline $\begin{array}{c}\text { Neuordnung } \\
\text { des Abstimmungsverfahrens }\end{array}$ & - & $\begin{array}{c}\text { „Doppelte Mehrheit“ im (Minister-)Rat } \\
\text { der EU, Art. 238. Abs. 3a. AEUV / } \\
\text { Art. } 16 \text { Abs. } 4 \text { EUV }\end{array}$ \\
\hline Rechtliche Grundlage & $\begin{array}{l}\text { Art. } 205 \text { EGV, Art. } 3 \text { des Protokolls über } \\
\text { die Erweiterung der Europäischen Union } \\
\text { und Art. } 12 \text { der Beitrittsakte }\end{array}$ & Art. 16 Abs. 4 EUV \\
\hline Vorschlagsrecht & Kommission & $\begin{array}{l}\text { Kommission od. Hoher Vertreter der } \\
\text { Union für Außen- und Sicherheitspolitik }\end{array}$ \\
\hline Zahl der Mitgliedstaaten & $\begin{array}{l}\text { Mehrheit der Mitgliedstaaten } \\
\qquad(14 \mathrm{MS})\end{array}$ & $\begin{array}{c}\text { Mindestens } 55 \% \text { der } \\
\text { Mitgliedstaaten (min. } 15 \mathrm{MS} \text { ) }\end{array}$ \\
\hline $\begin{array}{l}\text { Anzahl/Anteil der gowogenen } \\
\text { Stimmen }^{1255}\end{array}$ & $\begin{array}{l}255 \text { der insgesamt } 345 \\
\text { gewogenen Stimmen } \\
\text { (ca. } 74 \% \text { ) }\end{array}$ & entfällt \\
\hline $\begin{array}{c}\text { Anteil an der Bevölkerung der } \\
\text { Union }\end{array}$ & $\begin{array}{c}62 \% \text { der Gesamtbevölkerung } \\
\text { der Union (Prüfung auf Antrag } \\
\text { eines Mitgliedstaats) }\end{array}$ & Mindestens 65 \% der Bevölkerung \\
\hline Sperrminorität & - & Mindestens 4 Mitgliedstaaten \\
\hline \multicolumn{3}{|c|}{$\begin{array}{l}\text { Zur besonderen qualifizierten Mehrheit wird folgendes gezählt: } \\
\text { Die qualifizierte Mehrheit mit } 72 \% \text { der Mitgliedstaaten und } 65 \% \text { Bevölkerungsanteil, wenn Entscheidungen nicht auf } \\
\text { Vorschlag der Kommission oder des Außenministers gefällt werden (Art. } 238 \text { Abs. } 2 \text { AEUV). }\end{array}$} \\
\hline
\end{tabular}

Quellen: Zusammenstellung aus Hofmann, Andreas / Wessels, Wolfgang 2009: Eine dauerhafte Verfassung für Europa? Die Beantwortung konstitutioneller Grundfragen durch den Vertrag von Lissabon. In: Decker, Frank (Hrsg.) 2009: Die Verfassung Europas: Perspektiven des Integrationsprojekts. Wiesbaden, S. 85, 87. und Weidenfeld, Werner / Wessels, Wolfgang (Hrsg.) 2009: Europa von A bis Z: Taschenbuch der europäischen Integration. Bonn, S. 123. sowie Wessls, Wolfgang 2008: Das politische System der Europäischen Union. Wiesbaden. S. 203.; vgl. auch Oppelland, Torsten 2010: Institutionelle Neuordnung und Demokratisierung. In: Leiße, Olaf (Hrsg.) 2010: Die Europäische Union nach dem Vertrag von Lissabon. Wiesbaden, S. 85.

1255 Das Prinzip der gewogenen Stimmen teilt jedem Mitgliedstaat eine bestimmte Anzahl von Stimmen $\mathrm{zu}$, die die Größe des Staates repräsentieren soll. Die Verteilung verläuft degressiv proportional von 29 (z.B. Deutschland und Frankreich) bis 3 (Malta) Stimmen. 
Übersicht 9 : Stimmenverteilung im Rat (Ministerrat) und Sitze im EP

\begin{tabular}{|c|c|c|c|}
\hline $\begin{array}{l}\text { EU-27 Mitgliedstaaten } \\
\text { (Stand: 2008) }\end{array}$ & $\begin{array}{c}\text { Stimmenverteilung } \\
\text { im Rat }\end{array}$ & Sitze im EP & $\begin{array}{c}\text { Bevölkerung } \\
\text { in Mio. }\end{array}$ \\
\hline Deutschland (DE) & 29 & 99 & 82,3 \\
\hline Frankreich (FR) & 29 & 78 & 63,4 \\
\hline Großbritannien (UK) & 29 & 78 & 60,9 \\
\hline Italien (IT) & 29 & 78 & 59,1 \\
\hline Spanien (ES) & 27 & 54 & 44,5 \\
\hline Polen (PL) & 27 & 54 & 38,1 \\
\hline Rumänien (RO) & 14 & 35 & 21,6 \\
\hline Niederlande (NL) & 13 & 27 & 16,4 \\
\hline Griechenland (EL) & 12 & 24 & 11,2 \\
\hline Belgien (BE) & 12 & 24 & 10,6 \\
\hline Portugal (PT) & 12 & 24 & 10,6 \\
\hline Tschechische Republik (CZ) & 12 & 24 & 10,3 \\
\hline Ungarn (HU) & 12 & 24 & 10,1 \\
\hline Schweden (SE) & 10 & 19 & 9,1 \\
\hline Österreich (AT) & 10 & 18 & 8,3 \\
\hline Bulgarien (BG) & 10 & 18 & 7,7 \\
\hline Dänemark (DK) & 7 & 14 & 5,4 \\
\hline Slowakei (SK) & 7 & 14 & 5,4 \\
\hline Finnland (FI) & 7 & 14 & 5,3 \\
\hline Irland (IE) & 7 & 13 & 4,3 \\
\hline Litauen (LT) & 7 & 13 & 3,4 \\
\hline Lettland (LV) & 4 & 9 & 2,3 \\
\hline Slowenien (SI) & 4 & 7 & 2,0 \\
\hline Estland (EE) & 4 & 6 & 1,3 \\
\hline Zypern (CY) & 4 & 6 & 0,8 \\
\hline Luxemburg (LU) & 4 & 6 & 0,5 \\
\hline Malta (MT) & 3 & 5 & 0,4 \\
\hline EU-27: Insgesamt & 345 & 785 & 495,1 \\
\hline
\end{tabular}

Quellen: Amt für amtliche Veröffentlichungen der Europäischen Gemeinschaften 2008: Die vielen Gesichter des Europäischen Parlaments 2007-2009. Luxemburg, S. 9.; hierzu „Der Rat der Europäischen Union“ unter http://www.consilium.europa.eu; vgl. Pollak, Johannes / Slominski, Peter 2006: Das poitische System der EU. Wien, S. 76, 89.; Statistisches Bundesamt 2008: Datenreport 2008: Ein Sozialbericht für die Bundesrepublik Deutschland. Bonn, S. 421. Abrufbar unter: http://www.destatis.de 


\section{Übersicht 10 : Der Europäische Pakt zu Einwanderung und Asyl ${ }^{1256}$}

1. Steuerung legaler Einwanderung und Integration: Die Gemeinschaft will ihre Attraktivität für hoch qualifizierte Arbeitnehmer, etwa Ingenieure oder Programmierer, in der weltweiten Konkurrenz mit klassischen Einwanderungsländern wie den USA, Kanada oder Australien erhöhen. Hierfür wurde die so genannte „Blue Card“ geschaffen - eine europäische Arbeitserlaubnis.

2. Umgang mit illegaler Einwanderung: Die EU-Mitgliedstaaten, die EU-Kommission sowie Herkunfts- und Transitländer sollen enger bei der Bekämpfung der illegalen Migration zusammenarbeiten. Geplant ist der Abschluss weiterer Rückübernahmeabkommen. Für Abschiebungen werden EU-weite Sammelflüge angeregt. In Einzelfällen soll es jedoch für undokumentierte Einwanderer möglich sein, einen legalen Aufenthaltsstatus zu erhalten. Massenlegalisierungen sollen ausgeschlossen werden.

3. Verstärkung der Grenzkontrollen: Die Mitgliedstaaten verpflichten sich, alle verfügbaren Ressourcen zu mobilisieren, um die Luft-, See- und Landgrenzen besser zu sichern. Geplant ist die EU-weite Einführung biometrischer Visa spätestens bis Januar 2012. Weiter soll die europäische Grenzschutz-Agentur FRONTEX mehr Geld bekommen.

4. Asylpolitik: Da zwischen den einzelnen Mitgliedstaaten weiterhin erhebliche Unterschiede im Asylrecht bestehen, soll bis spätestens 2012 ein einheitliches Asylverfahren für Flüchtlinge geschaffen werden. In Krisenfällen sollen künftig auf ,freiwilliger und koordinierter Basis“ schutzbedürftige Flüchtlinge zwischen den Mitgliedstaaten umverteilt werden können. Vor allem Malta, Griechenland, Spanien und Italien hatten wiederholt mehr Solidarität der EU beim Umgang mit Ankömmlingen aus Drittstaaten gefordert

5. Beziehung zu Drittstaaten: Die Zusammenarbeit mit den Herkunfts- und Transitländern soll ausgebaut werden. Legale Zuwanderungsmöglichkeiten sollen geschaffen werden, die zugleich die Abwanderung von gut ausgebildeten Arbeitskräften verhindern (Braindrain). Im Gegenzug sollen sich die Drittstaaten an der Bekämpfung illegaler Einwanderung beteiligen. Das Instrument der ,zirkulären Migration“ soll schneller eingeführt werden, d.h. Einwanderer aus Entwicklungsländern erhalten eine befristete Arbeitserlaubnis, um mit dem erworbenen Wissen anschließend in ihren Herkunftsländern zu einer besseren Entwicklung beizutragen.

1256 Rat der Europäischen Union 2008: Europäischer Pakt zu Einwanderung und Asyl. Brüssel, den 24. September 2008, Dok.-Nr. 13440/08.; vgl. auch Newsletter ,Migration und Bevölkerung' 2008: EU: Pakt $\mathrm{zu}$ Einwanderung und Asyl angenommen. http://www.migrationinfo.de/mub_artikel.php?Id=080904 (Ausgabe 09/08).; vgl. Rat der Europäischen Union 2009: Das Stockholmer Programm - Ein offenes und sicheres Europa im Dienste und zum Schutz der Bürger. Brüssel, den 2. Dezember 2009 (04.12), 17024/09., S. 60. 


\section{Übersicht 11 : Die Bundeskanzlerwahlen der Bundesrepublik Deutschland seit 1949 ${ }^{1257}$}

\begin{tabular}{|c|c|c|c|c|c|c|}
\hline Bundeskanzler & Partei & Amtszeit & $\begin{array}{c}\text { Tag der Wahl/ } \\
\text { Anlass der Wahl }\end{array}$ & Regierungskoalition & \multicolumn{2}{|c|}{$\begin{array}{c}\text { Parlamentarische } \\
\text { Mehrheit } \\
\text { Mandate }\end{array}$} \\
\hline Konrad Adenauer & CDU & $1949-1953$ & $14.8 .1949 /$ Bundestagswahl & CDU/CSU;FDP;DP & 212 & 51,7 \\
\hline Konrad Adenauer & CDU & $1953-1957$ & $6.9 .1953 /$ Bundestagswahl & CDU/CSU & 345 & 67,8 \\
& & & & FDP;DP;GB/BHE & & \\
\hline Konrad Adenauer & CDU & $1957-1961$ & $15.9 .1957 /$ Bundestagswahl & CDU/CSU;DP & 295 & 56,8 \\
\hline Konrad Adenauer & CDU & $1961-1963$ & $17.9 .1961 /$ Bundestagswahl & CDU/CSU;FDP & 318 & 61,0 \\
\hline Ludwig Erhard & CDU & $1963-1965$ & $16.10 .1963 /$ Kanzlerwechsel & & & \\
\hline Ludwig Erhard & CDU & $1965-1966$ & $19.9 .1965 /$ Bundestagswahl & CDU/CSU;FDP & 301 & 58,1 \\
\hline Kurt Georg Kiesinger & CDU & $1966-1969$ & $1.12 .1966 /$ Koalitionswechsel & CDU/CSU;SPD & 468 & 90,3 \\
\hline Willy Brandt & SPD & $1969-1972$ & $28.9 .1969 /$ Bundestagswahl & SPD;FDP & 268 & 51,7 \\
\hline Willy Brandt & SPD & $1972-1974$ & $19.11 .1972 /$ Bundestagswahl & SPD;FDP & 284 & 54,8 \\
\hline Helmut Schmidt & SPD & $1974-1976$ & $16.5 .1974 /$ Kanzlerwechsel & & & \\
\hline Helmut Schmidt & SPD & $1976-1980$ & $3.10 .1976 /$ Bundestagswahl & SPD;FDP & 264 & 51,0 \\
\hline Helmut Schmidt & SPD & $1980-1982$ & $5.10 .1980 /$ Bundestagswahl & SPD;FDP & 282 & 54,3 \\
\hline Helmut Kohl & CDU & $1982-1983$ & $4.10 .1982 /$ Misstrauensvotum & CDU/CSU;FDP & 291 & 56,1 \\
\hline Helmut Kohl & CDU & $1983-1987$ & $6.3 .1983 /$ Vorgezogene Wahl & CDU/CSU;FDP & 290 & 55,8 \\
\hline Helmut Kohl & CDU & $1987-1990$ & $25.1 .1987 /$ Bundestagswahl & CDU/CSU;FDP & 282 & 54,3 \\
\hline Helmut Kohl & CDU & $1990-1994$ & $2.12 .1990 /$ Bundestagswahl & CDU/CSU;FDP & 398 & 60,1 \\
\hline Helmut Kohl & CDU & $1994-1998$ & $16.10 .1994 /$ Bundestagswahl & CDU/CSU;FDP & 341 & 50,7 \\
\hline Gerhard Schröder & SPD & $1998-2002$ & $27.9 .1998 /$ Bundestagswahl & SPD;B'90/GRÜNE & 345 & 51,6 \\
\hline Gerhard Schröder & SPD & $2002-2005$ & $22.9 .2002 /$ Bundestagswahl & SPD;B'90/GRÜNE & 306 & 50,7 \\
\hline Angela Merkel & CDU & $2005-2009$ & $18.9 .2005 /$ Vorgezogene Wahl & CDU/CSU;SPD & k. A. & 64,7 \\
\hline & & & & & & \\
\hline
\end{tabular}

Quellen: Schmidt, Manfred G. 2007: Das politische System Deutschlands: Institutionen, Willensbildung und Politikfelder. München, S. 168-169.; Ismayr, Wolfgang 2006: Das politische System Deutschlands. In: Ismayr, Wolfgang (Hrsg.) 2006: Die politischen Systeme Westeuropas. S. 457.; Kropp, Sabine 2005: Regieren: Akteure, Strukturen, Prozesse. In: Gabriel, Oscar W. / Holtmann, Everhard (Hrsg.) 2005: Politisches System der Bundesrepublik Deutschland. München, S. 154.

1257 Vgl. auch im Internet: www.bundeswahlleiter.de (Bundeswahlleitung, Informationen zu sämtlichen Wahlen in Deutschland) / www.bundeskanzleramt.de (Bundeskanzleramt) / www.bundesregierung.de (Bundesregierung). 


\section{Übersicht 12}

\section{EU-Abstimmungsregeln für den „Raum der Freiheit, der Sicherheit und des Rechts“}

Einige Vorschriften über Visa werden bereits seit dem Inkrafttreten des Amsterdamer Vertrags vom Rat mit qualifizierter Mehrheit auf Vorschlag der Kommission und nach Anhörung des Europäischen Parlaments beschlossen (Art. 62 (2 b, i und iii) in Verbindung mit Art. 67 (3)).

Nach Ablauf einer im Amsterdamer Vertrag vereinbarten Übergangsfrist von fünf Jahren hat der Rat Anfang 2005 nach einstimmigem Beschluss die Bereiche Visa, Grenzschutz und illegale Einwanderung in das Verfahren der Mitentscheidung überführt. Zuvor galt ein Sonderfall in der Verfahrenstypologie: Nach dieser „unvollständigen Gemeinschaftsmethode“ kann der Rat einstimmig auf Vorschlag der Kommission oder auf Initiative eines Mitgliedstaats und nach Anhörung des Europäischen Parlaments Rechtsakte beschließen. Der Bereich der legalen Einwanderung verbleibt jedoch nach wie vor in der Einstimmigkeit.

Seit dem Vertrag von Nizza ist schließlich auch für einen Großteil des Bereichs Asyl (Art. 63 (1) und (2 a) in Verbindung mit Art. 67 (5)) das Verfahren der Mitentscheidung vorgesehen. Gleiches gilt für den Bereich der ziviljustiziellen Zusammenarbeit (Art. 65 EGV), jedoch mit Ausnahme des Bereichs Familienrecht, der nach wie vor der Einstimmigkeit im Rat unterliegt.

Quelle: Wessls, Wolfgang 2008: Das politische System der Europäischen Union. Wiesbaden. S. 420-421. 


\section{Übersicht 13 : Vorschlag Punktesystem (UKZU), Maximum 100 Punkte}

- Alter: 1 Punkt für jedes Lebensjahr unter 45, jedoch maximal 20 Punkte

- Höchster erreichter Ausbildungsabschluss: bis 30 Punkte

- Hochschul- oder Fachhochschulabschluss: 20 Punkte

- Qualifizierter Berufsabschluss, je nach Ausbildungsdauer: 5 bis 20 Punkte

- Bonuspunkte: bis 10 Punkte

- Besondere Nachfrage des Ausbildungsabschlusses am Arbeitsmarkt

- Abschluss nach deutschem Bildungssystem

- Promotion

- Abschluss einer besonders renommierten Ausbildungseinrichtung

- Berufserfahrung und Zusatzqualifikation: bis 15 Punkte

- Erfahrung (maximal 5 Jahre) im erlernten Beruf (bis 10 Punkte)

- EDV-Kenntnisse

- Fremdsprachenkenntnisse (Drittsprachen)

- Führungserfahrung

- Gute Deutschkenntnisse: bis 20 Punkte

- Weitere Kriterien für gute Anpassungsfähigkeit: bis 15 Punkte

- Qualifikation des Ehepartners (bis 5 Punkte)

- Pro Kind 2 Punkte (bis 5 Punkte)

- Arbeitsplatz(angebot) (5 Punkte)

- Frühere oder derzeitige Aufenthalte in Deutschland (bis 5 Punkte)

- Eventuell: Wachsender Punktebonus für Personen aus EU-Beitrittsländern bis zur vollen Verwirklichung der Freiheiten des Binnenmarktes.

Quelle: Unabhängige Kommission Zuwanderung (UKZU) 2001: Zuwanderung gestalten, Integration fördern. op. cit, 94. Berlin. http://www.zuwanderung.de/downloads/Zuwanderungsbericht_kurz.pdf; vgl. Angenendt, Steffen 2008: Die Steuerung der Arbeitsmigration in Deutschland: Reformbedarf und Handlungsmöglichkeiten. Bonn, S. 52. http://www.library.fes.de/pdf-files/wiso/05705.pdf (WISO Diskurs, Stand: September 2008).; vgl. auch Newsletter ,Migration und Bevölkerung' 2001: Deutschland: Bericht der Süssmuth-Kommission. http://www.migration-info.de/mub_artikel.php?Id=010401(Ausgabe 04/01). 
Literaturverzeichnis 


\section{Literaturverzeichnis}

ABL (Amtsblatt der Europäischen Union) 1992: ABL. 1992. EG Nr. C 191. S. 1 ff.

ABL (Amtsblatt der Europäischen Union) 1993: ABL. 1993. EG Nr. L 293. S. 61.

ABL (Amtsblatt der Europäischen Union) 1995: EG Nr. L 234, 1 vom 03.10.1995.

ABL (Amtsblatt der Europäischen Union) 1995: C 316 vom 27.11.1995. S. 2-32; Übereinkommen über die Errichtung eines Europäischen Polizeiamts (EPKEuropolkonvention).

ABL (Amtsblatt der Europäischen Union) 1995: EG Nr. C 262, vom 07.10.1995, S. 1 f. (Entschließung des Rates vom 25. September 1995 zur Lastenverteilung hinsichtlich der Aufnahme und des vorübergehenden Aufenthalts von Vertriebenen).

ABL (Amtsblatt der Europäischen Union) 1996: EG Nr. L 63, vom 13.03.1996 (Beschluß zum Warnsystem und Dringlichkeitsverfahren bei der Lastenverteilung hinsichtlich der Aufnahme und des vorübergehenden Aufenthalts von Vertriebenen).

ABL (Amtsblatt der Europäischen Union) 1997: EG Nr. L 147, v. 05.06.1997, S. 3 f. (Beschluß des Rates vom 26.05.1997 über den Informationsaustausch betreffend die Hilfen für die freiwillige Rückkehr von Drittstaatsangehörigen).

ABL (Amtsblatt der Europäischen Union) 1997: EG Nr. C 340/1ff vom 10.11.1997.

ABL (Amtsblatt der Europäischen Union) 1998: EG Nr. L 138, v. 09.05.1998, S. 6 f.

ABL (Amtsblatt der Europäischen Union) 2000: Nr. L 180/22 vom 19.07.2000.

ABL (Amtsblatt der Europäischen Union) 2001: EU 2001 Nr. C 80/85.

ABL (Amtsblatt der Europäischen Union) 2003: L 50/1, 25.02.2003. Hierzu auch im Internet: http://europa.eu/legislation_summaries/justice_freedom_security/free_movement_of_person s_asylum_immigration/133153_de.htm (Stand: 24.06 .2009$)$.

$\mathrm{ABL}^{-}$(Amtsblatt der Europäischen Union) 2003: L 251 vom 03.10.2003. S. 12 (Richtlinie 2003/86/EG des Rates vom 22.9.2003 betreffend das Recht auf Familienzusammenführung).

ABL (Amtsblatt der Europäischen Union) 2003: L 16, 23.01.2004, S. 44-53 (Richtlinie 2003/109/EG des Rates vom 25. November 2003 betreffend die Rechtsstellung der langfristig aufenthaltsberechtigten Drittstaatsangehörigen).

ABL (Amtsblatt der Europäischen Union) 2004: L vom 28.12.2004, S. 52 (Entscheidung 2004/904/EG des Rates vom 02.12.2004 über die Errichtung des Europäischen Flüchtlingsfonds für den Zeitraum 2005-2010).

ABL (Amtsblatt der Europäischen Union) 2009: L 155 vom 18.06.2009 (Richtlinie 2009/50/EG des Rates vom 25. Mai 2009 über die Bedingungen für die Einreise und den Aufenthalt von Drittstaatsangehörigen zur Ausübung einer hochqualifizierten Beschäftigung). S. 17-29; http://www.aufenthaltstitel.de/rl_2009_50_eg.html

Achermann, Alberto / Bieber, Roland / Epiney, Astrid / Wehner, Ruth (Hrsg.) 1995: Schengen und die Folgen: Der Abbau der Grenzkontrollen in Europa. Bern u. a.

Ad-hoc-Gruppe Einwanderung (AHE) 1991: Bericht der für Einwanderungsfragen zuständigen Minister an den Europäischen Rat (Maastricht) über die Einwanderungs- und Asylpolitik. Brüssel, WGI 930. S. 13.

Albrecht, Günther 1972: Soziologie der geographischen Mobilität. Zugleich ein Beitrag zur Soziologie des sozialen Wandels. Stuttgart, S. 29.

Amt für amtliche Veröffentlichungen der Europäischen Gemeinschaften 2006: Europäische Union: Konsolidierte Verträge. Luxemburg, S. 136.

Andreae, Lisette / Kaiser, Karl 1998: Die ,Außenpolitik' der Fachministerien. In: Eberwein, Wolf-Dieter / Kaiser, Karl 1998: Deutschlands neue Außenpolitik. Bd. 4: Institutionen und Ressourcen. München, S. 41. 
Angenendt, Steffen (Ed.) 1999: Asylum and Migration Policies in the European Union. Berlin, S. 27, 29, 177.

Angenendt, Steffen 2002: Einwanderungspolitik und Einwanderungsgesetzgebung in Deutschland 2000-2001. In: Migrationsreport 2002: Fakten-Analysen-Perspektiven. Frankfurt a. Main, S. 35-49.

Angenendt, Steffen 2008: Die Steuerung der Arbeitsmigration in Deutschland: Reformbedarf und Handlungsmöglichkeiten. Bonn, S. 4, 8, 12, 42-59. Online verfügbar unter: http://www.library.fes.de/pdf-files/wiso/05705.pdf (WISO Diskurs / Stand: September 2008).

Angenendt, Steffen / Parkes, Roderick 2009: EU-Migrationspolitik nach Lissabon und Stockholm: Neue Kompetenzen, bessere Politik?. In: SWP-Aktuell 71, Dezember 2009. Berlin, S. 1-4; http://www.swp-berlin.org/common/get_document.php?asset_id=6676

Angenendt, Steffen / Parkes, Roderick 2010: Blue Card - (noch) kein Erfolg?: Perspektiven der EU-Migrationspolitik für hochqualifizierte Arbeitskräfte. In: SWP-Aktuell 34, April 2010. Berlin, S. 1-2.

Angenendt, Steffen / Parkes, Roderick 2010: Wanderer, kommst du nach Europa?: Strategien zur Anwerbung Hochqualifizierter in der EU. In: Internationale Politik (IP), Juli/August 2010. Nr. 4., 65 Jahrgang. Berlin, S. 74-78; http://www.internationalepolitik.de

Ardittis, Solon/Lewis, Richard/Manchip, Colin 2005: From Rome to The Hague. European Union Policy-Making on Asylum. London: Institute for Public Policy Research. S. $15 \mathrm{f}$.

Aspinwall, Mark D. / Schneider, Gerald 2000: Same menu, separate tables: The institutionalist turn in political science and the study of European integration. In: European Journal of Political Research, Volume 38, No. 1 (August 2000). Netherlands, S. 1-36, hier S. 7.

Bade, Klaus. J. 1990: Ausländer, Aussiedler, Asyl in der Bundesrepublik Deutschland. Niedersächsische Landeszentrale für politische Bildung, S. 15.

Bade, Klaus J. / Emmer, Pieter C. / Lucassen, Leo / Oltmer, Jochen (Hrsg.) 2008: Enzyklopädie: Migration in Europa: Vom 17. Jahrhundert bis zur Gegenwart. Paderborn, S. 157-162.

Bade, Klaus J. / Emmer, Pieter C. / Lucassen, Leo / Oltmer, Jochen (Hrsg.) 2010: Enzyklopädie: Migration in Europa: Vom 17. Jahrhundert bis zur Gegenwart. Paderborn.

Bade, Klaus J. / Oltmer, Jochen 2010: Deutschland. In: Bade, Klaus J. / Emmer, Pieter C. / Lucassen, Leo / Oltmer, Jochen (Hrsg.) 2010: Enzyklopädie: Migration in Europa: Vom 17. Jahrhundert bis zur Gegenwart. Paderborn, S. 168-169.

Bagshaw, Simon 1997: Benchmarks or Deutschmarks? Determining the Criteria for the Repatriation of Refugees to Bosnia and Herzegovina. EUI Working Papers. No. 23. Florence, S. 33.

Baldwin-Edwards, Martin 1991: Immigration after 1992. In: Policy and Politics, 19. Nr. 3/1991, S. 199-211.

Baldwin-Edwards, Martin 1997: The Emerging European Immigration Regime: Some Reflections on Implications for Southern Europe. In: Journal of Common Market Studies (JCMS) 1997. Vol. 35, No. 4. December 1997, S. 497-519, hier S. 497.

Baringhorst, Sigrid 2009: Nationaler Zusammenhalt versus kulturelle Vielfalt: Die britische Einwanderungs- und Integrationspolitik zwischen globalem Wettbewerb und nationaler Identität. In: Butterwegge, Christoph / Hentges, Gudrun (Hrsg.) 2009: a.a.O., S. 177-179.

Barth, Christian / Mentler, Michael 1998: Länderpositionen für die Innen- und Rechtspolitik der Europäischen Union. In: Borkenhagen, Franz H. U. (Hrsg.) 1998: Europapolitik der deutschen Länder: Bilanz und Perspektiven nach dem Gipfel von Amsterdam. Opladen, S. $87 \mathrm{ff}$.

Bauböck, Rainer 1996: Nation, Migration und Staatsbürgerschaft. In: Beyme, Klaus von / Offe, Claus (Hrsg.) 1996: Politische Theorien in der Ära der Transformation. PVS-Sonderheft Nr. 26/1995. Opladen, S. 325-348, hier S. 330-332.

Baumann, Mechthild 2006: Der deutsche Fingerabdruck: Die Rolle der deutschen Bundesregierung bei der Europäisierung der Grenzpolitik. Baden-Baden, S. 37, 47, 141. 
Baumann, Mechthild 2008: Der Einfluss des Bundeskanzleramts und des Bundesministeriums des Innern auf die Entwicklung einer europäischen Grenzpolitik. In: Hunger, Uwe / Aybek, Can M. / Ette, Andreas / Michalowski, Ines (Hrsg.) 2008: Migrations- und Integrationsprozesse in Europa: Vergemeinschaftung oder nationalstaatliche Lösungswege?. Wiesbaden, S. 19-23, 28.

Beauftragte der Bundesregierung für Ausländerfragen 2002: Bericht der Beauftragten der Bundesregierung für Ausländerfragen über die Lage der Ausländer in der Bundesrepublik Deutschland. Berlin und Bonn, S. 169.

Beck, Marieluise 2001: Ihr Inderlein kommet. In: Blätter für deutsche und internationale Politik, Jahrgang 46/2001, Heft 1. Bonn, S. 7.

Bendel, Petra 2004: Migrationspolitik der Europäischen Union: Kompetenzen, Inhalte, Prognosen. In: Werz, Nikolaus / Nuthmann, Reinhard (Hrsg.) 2004: Abwanderung und Migration in Mecklenburg und Vorpommern. Wiesbaden, S. 257.

Bendel, Petra 2005a: Immigration Policy in the European Union. Still bringing up the walls for Fortress Europe?. In: Migration Letters 2. 1: S. 20-31.

Bendel, Petra 2005b: Migration. Dritte Phase: Migrationspolitik als echte Gemeinschaftsaufgabe (seit 1999): Online verfügbar unter http://www.bpb.de/themen/812ACX,0,0,Dritte_Phase:_Migrationspolitik_als_echte_Gemein schaftsaufgabe_(seit_1999).html (Stand: 30.11.2007).

Bendel, Petra 2006: Migrations- und Integrationspolitik der Europäischen Union: Widersprüchliche Trends und ihre Hintergründe. In: Baringhorst, Sigrid / Hunger, Uwe / Schönwälder, Karen (Hrsg.) 2006: Politische Steuerung von Integrationsprozessen: Intentionen und Wirkungen. Wiesbaden, S. 95-106, 116.

Bendel, Petra 2006: Neue Chancen für die EU-Migrationspolitik? Die Europäische Union im Spagat zwischen Sicherheits- Entwicklungs- und Außenpolitik. In: Butterwegge, Christioph / Hentges, Gudrun (Hrsg.) 2006: Zuwanderung im Zeichen der Globalisierung: Migrations-, Integrations- und Minderheitenpolitik. Wiesbaden, S. 128.

Bendel, Petra 2008: Migration und Integration in Europa: Geschichte der europäischen Migrationspolitik; http:/www.bpb.de/themen/K9YHTK.html (Stand: 29.01.2008).

Bendel, Petra / Haase, Marianne 2008: Integrationspolitik der Europäischen Union; http://www.bpb.de/themen/A3OEJX,2,0,Integrationspolitik_der_Europ\%E4ischen_Union.ht $\mathrm{ml}$ (Stand: 27.01.2008).

Bendel, Petra / Haase, Marianne 2008: Integrationspolitik der Europäischen Union: Antidiskriminierungs- und Antirassismus-Richtlinien. S. 7-8. Online verfügbar unter http://www.bpb.de/themen/A30EJX.html (Stand: 27.01.2008).

Bendel, Petra / Haase, Marianne 2008: Migration und Integration in der EU: Warum überhaupt Europa?; http://www.bpb.de/themen/MOPDNW.html (Stand: 29.01.2008).

Bendel, Petra 2009: Die Migrationspolitik der Europäischen Union: Inhalte, Institutionen und Integrationsperspektiven. In: Butterwegge, Christioph / Hentges, Gudrun (Hrsg.) 2009: Zuwanderung im Zeichen der Globalisierung: Migrations-, Integrations- und Minderheitenpolitik. Wiesbaden, S. 131-133.

Bendiek, Annegret 2004: Der Konflikt im ehemaligen Jugoslawien und die Europäische Integration: eine Analyse ausgewählter Politikfelder. Wiesbaden, S. 77-78, 80-97, 101-105, 141, 207-208, 247.

Benyon, John et al. 1993: Police Co-Operation in Europe: An Investigation. Leicester, S. 159160.

Benz, Arthur 2009: Politik in Mehrebenensystemen. S. 39.

Berg-Schlosser, Dirk / Quenter, Sven (Hrsg.) 1999: Literaturführer Politikwissenschaft: Eine kritische Einführung in Standardwerke und „Klassiker“ der Gegenwart. Stuttgart, S. $152 \mathrm{f}$.

Bericht der Unabhängigen Kommission Zuwanderung 2001: Zuwanderung gestalten Integration fördern, 04.07.2001. Berlin, S. 36. 
Beschluss des Bundesausschusses der CDU Deutschlands 2001: Zuwanderung steuern und begrenzen. Integration fördern, 07.06.2001. Berlin, S. 7.

Beschluss der Programmkommission (SPD) 2007: Soziale Demokratie im 21. Jahrhundert: Grundsatzprogramm der Sozialdemokratischen Partei Deutschlands. Empfehlungen zum „Bremer Entwurf“ für ein neues Grundsatzprogramm der SPD. 22. September 2007, Punkt 42 f., S. 19-20.

Bethlehem, Siegfried 1982: Heimatvertreibung, DDR-Flucht, Gastarbeiterzuwanderung: Wanderungsströme und Wanderungs-politik in der Bundesrepublik Deutschland. Stuttgart, S. 30 .

Beutler, Bengt / Bieber, Roland / Pipkorn, Jörn / Streil, Jochen 2001: Die Europäische Union. Rechtsordnung und Politik. Baden-Baden, S. 460.

Beyme, Klaus von 1984: Parteien in westlichen Demokratien. München, S. 25.

BGBl (Bundesgesetzblatt) II. 1992: S. 1253.

BGBl (Bundesgesetzblatt) II. 1993: S. 1947.

BGBl (Bundesgesetzblatt) II 1994: Abkommen zwischen der Regierung der Bundesrepublik Deutschland und der Regierung der Französischen Republik über den schrittweisen Abbau der Kontrollen an der deutsch-französischen Grenze vom 13. Juli 1984. S. 768 ff.

BGBl (Bundesgesetzblatt) II 1994: Dubliner Asylrechtsübereinkommen vom 15.06.1990, S. 792.

BGBl (Bundesgesetzblatt) II 1995: Gesetz zu dem Protokoll vom 26.04.1994 zu den Konsequenzen des Inkrafttretens des Dubliner Abkommens für einige Bestimmungen des Durchführungsübereinkommens zum Schengener Übereinkommen vom 11.09.1995 (sog. „Bonner Protokoll“). S. 738.

BGBl (Bundesgesetzblatt) II. 1998: S. 2930.

Bielefeldt, Heiner / Follmar-Otto, Petra 2005: Diskriminierungsschutz in der politischen Diskussion. Berlin: Deutsches Institut für Menschenrechte, S. $8 \mathrm{f}$.

Birg, Herwig 2003: Dynamik der demographischen Alterung, Bevölkerungsschrumpfung und Zuwanderung in Deutschland. In: Aus Politik und Zeitgeschichte (APuZ) 2003/53. Jg., B20/2003. S. 7, 11-12.

Birg, Herwig 2004: Bevölkerungsentwicklung: Zur aktuellen Lage der Weltbevölkerung: Sonderfall Deutschland. In: Informationen zur politischen Bildung, Nr. 282/2004. Bonn, S. 20-21; www.bpb.de/publikationen/70Z856.html.

Birg, Herwig 2009: Integration und Migration im Spiegel harter Daten, FAZ vom 9. April. 2009. S. 37.

Birgelen, Georg 1998: Europapolitische Meinungsbildung in Deutschland. In: Weidenfeld, Werner (Hrsg.) 1998: Deutsche Europapolitik: Optionen wirksamer Interessenvertretung. Bonn, S. 105.

Birsl, Ursula 2003: Deutschland. In: Gieler, Wolfgang (Hrsg.) 2003: Handbuch der Ausländerund Zuwanderungspolitik: Von Afghanistan bis Zypern. Hamburg, S. 129-147.

Birsl, Ursula et. al. 2003: Migration und Interkulturalität in Großbritannien, Deutschland und Spanien: Fallstudien aus der Arbeitswelt. Opladen, S. 20.

Birsl, Ursula 2005: Migration und Migrationspolitik im Prozess der europäischen Integration?. Opladen, S. 15, 19, 33, 35-39, 81-85, 92 f., 112-118, 201-205, 323.

Blaschke, Jochen 1997: Migration-Ein Bericht über den Forschungsstand unter besonderer Berücksichtigung internationaler Publikationen zur Arbeitsmigration seit 1991 (Materialien zur Bewölkerungswissenschaft, Sonderheft 28). Wiesbaden, S. 11.

Bleek, Wilhelm 2003: PDS-SED. In: Woyke, Wichard / Andersen, Uwe (Hrsg.) 2003: Handwörterbuch des politischen Systems der Bundesrepublik Deutschland. Opladen, S. 475-480.

Blum, Sonja / Schubert, Klaus 2009: Politikfeldanalyse. Wiesbaden, S. 19, 78.

Boeles, Pieter 2001: Directive on Family Reunification: Are the Dilemmas Resolved?. In: European Journal of Migration and Law (EJML) 2001, 4. 3., S. $61 \mathrm{ff}$. 
Boeri, Tito / Hanson, Gordon / McCormick, Barry (Ed.) 2002: Immigration Policy and the Welfare System. Oxford, S. 10-12.

Bommes, Michael 2006: Integration durch Sprache als politisches Konzept. In: In: Davy, Ulrike / Weber, Albrecht (Hrsg.) 2006: Paradigmenwechsel in Einwanderungsfragen?: Überlegungen zum neuen Zuwanderungsgesetz. Baden-Baden, S. 61.

Bommes, Michael / Schiffauer, Werner 2006: Migrationsreport 2006: Fakten-AnalysenPerspektiven. Frankfurt am Main, S. 253.

Bommes, Michael 2008: „Integration findet vor Ort statt“ - über die Neugestaltung kommunaler Integrationspolitik. In: Bommes, Michael / Krüger-Potratz, Marianne (Hrsg.) 2008: Migrationsreport 2008: Fakten-Analysen-Perspektiven. Frankfurt a. M., S. 165.

Bommes, Michael / Krüger-Potratz, Marianne (Hrsg.) 2008: Migrationsreport 2008: FaktenAnalysen-Perspektiven. Frankfurt a. M., S. 239-240, 246, 250, 262, 279-280, 290-292.

Boswell, Christina 2007: Migration Control in Europe After 9/11: Explaining the Absence of Securitization. In: Journal of Common Market Studies (JCMS) 2007: Septemebr, Volume 45. Number 3., S. 589-610, hier S. 596, 601.

Bourdieu, Pierre 1983: Ökonomisches Kapital, kulturelles Kapital, soziales Kapital. In: Kreckel, Reinhard (Hrsg.) 1983: Soziale Ungleichheiten (Soziale Welt, Sonderband 2). Göttingen, S. 183-198.

Böhret, Carl / Jann, Werner / Kronenwett, Eva 1988: Innenpolitik und politische Theorie. Opladen, S. 7.

Börzel, Tanja A. 1999: Institutional Adaptation to Europeanization in Germany and Spain. In: Journal of Common Market Studies (JCMS), 37 (4), 1999, S. 573-596. hier S. 574.

Börzel, Tanja A. / Risse, Thomas 2000: When Europe Hits Home: Europeanization and Domestic Change. In: European Integration Online Papers (EIoP), Vol. 4 (2000) N ${ }^{0} 15$, S. 310; http://www.eiop.or.at/eiop/texte/2000-015.htm (Stand: 29.11.2000).

Bösch, Frank 2002: Bereit für den Wechsel? Die strategische und inhaltliche Positionierung von CDU/CSU und FDP vor der Bundestagswahl 2002. In: Aus Politik und Zeitgeschichte (APuZ) B21/2002. S. 13-21, hier S. 17.

Braun, Wilfried 1996: Asylpolitik in der Europäischen Union. In: Müller-Graff, Peter-Christian (Hrsg.) 1996: Europäische Zusammenarbeit in den Bereichen Justiz und Inneres: Der dritte Pfeiler der Europäischen Union. Baden-Baden, S. 78-81.

Brok, Elmar 1997: Der Amsterdamer Vertrag: Etappen auf dem Weg zur europäischen Einigung. In: Integration 4/1997. S. 211-218.

Brubaker, Rogers 1992: Citizenship and Nationhood in France and Germany. Cambridge MA.

Brubaker, Rosers 1994: Staats-Bürger: Deutschland und Frankreich im historischen Vergleich. Hamburg (amerikanische Originalausgabe von 1992), S. 57, 79.

Bulmer, Simon / Jeffery, Charlie / Paterson, William E. 1998: Deutschlands europäische Diplomatie: die Entwicklung des regionalen Milieus. In: Weidenfeld, Werner (Hrsg.) 1998: Deutsche Europapolitik. Optionen wirksamer Interessenvertrettung. Bonn, S. 35-36.

Bundesamt für Bauwesen und Raumordnung 2000: Raumordnungsbericht 2000. Bonn, S. 12.

Bundesamt für die Anerkennung ausländischer Flüchtlinge (BAFI) 2003: Migration und Asyl in Zahlen. Nürnberg, S. 38.

Bundesamt für Migration und Flüchtlinge (BAMF) 2007: Dublin II Verordnung: Der Umfang des Bundesamtes für Migration und Flüchtlinge mit dem Dublinverfahren. Fachtagung am Montag, 17. Dezember 2007 in Mainz. S. 5.; http://www.diakonie-hessennasssau.de/DWHN/rathilfe/Seiten/Migration/Dublin2/BAMF1Praesentation.pdf (Stand: 07.10.2009).

Bundesamt für Migration und Flüchtlinge (BAMF) 2009: Ausländerzahlen 2009. S. 5-13; www.bamf.de.

Bundesamt für Migration und Flüchtlinge (BAMF) 2010: Die deutschen Interessen bei der Europäisierung des Zuwanderungs- und Flüchtlingsrechts (Rede von BMI-Staatssekretär 
Klaus-Dieter Fritsche bei den 2. Nürnberger Tagen zum Asyl- und Ausländerrecht am 23. September 2010). S. 2-8.; http://www.bamf.de/cln_092/nn_442764/DE/DasBAMF/HomeTeaser/nuernberger-tage-asyl-2010-dokumentation.html (Stand: 21.10.2010).

Bundesamt für Migration und Flüchtlinge (BAMF) 2010: Schutz und Hilfe außerhalb Europas die externe Dimension der europäischen Flüchtlingspolitik (Rede vom Koordinator der Intergovernmental Consultations on Migration, Asylum and Refugees Herrn Friedrich Löper in Nürnberg). S. 2-6; http://www.bamf.de/cln_092/nn_442764/DE/DasBAMF/HomeTeaser/nuernberger-tage-asyl-2010 dokumentation.html (Stand: 21.10.2010).

Bundesministerium des Innern (Hrsg.) 1997: Aufzeichnung zur Ausländerpolitik und zum Ausländerrecht in der Bundesrepublik Deutschland. Bonn, S. 118.

Bundesministerium des Innern (Hrsg.) 1998: Ausländer und Ausländerpolitik in der Bundesrepublik Deutschland. Bonn, S. 148.

Bundesministerium des Innneren (Hrsg.) 2000: Ausländerpolitik und Ausländerrecht in Deutschland. Berlin, S. $54 \mathrm{ff}$.

Bundesministerium des Innern (Hrsg.) 2001: Ausländerpolitik und Ausländerrecht in Deutschland. Berlin.

Bundesministerium des Innern (Hrsg.) 2006: Zuwanderungsrecht und Zuwanderungspolitik. S. $3,10,28,76 f ., 89$.

Bundesministerium des Innern (Hrsg.) 2008: Migration und Integration: Aufenthaltsrecht, Migrations- und Integrationspolitik in Deutschland. Berlin, S. 17, 49, 63-68, 82, 110-111.

Bundesministerium des Innern (Hrsg.) 2009: Europäische Harmonisierung des Flüchtlings- und Migrationsrechts;

http://www.bmi.bund.de/nn_161630/Internet/Content/Themen/Auslaender_Fluechtlinge_As yl_Zuwanderung/DatenundFakten/Europaeische_Harmonisierung_des_Id_94202_de.html (Stand: 30.11.2009).

Bundesrat 1995: Drucksachen: BR-Drs. 169/95 (Beschluss) vom 31.03.1995.

Bundesrat 1995: Drucksachen: BR-Drs. 667/95 (Beschluss) vom 15.12.1995.

Bundesrat 2003: Pressemitteilungen: Nr. 102/2003: Bundesrat lehnt Zuwanderungsgesetz ab.

Bundesrat 2007: Pressemitteilungen: Nr. 197/2007: Stellungnahme zur EU Blue Card.

Bundesrat 2008: Pressemitteilungen: Nr. 20/2008: Bundesrat würdigt Vertrag von Lissabon.

Bundestag 2010: Die Rolle des Bundestages nach Lissabon. Online verfügbar unter: http://www.bundestag.de/dokumente/textarchiv/2010/30212544_kw24_europa_union/index .html (Stand: 25.06.2010).

Bundeszentrale für politische Bildung (Hrsg) 2007: Hintergrund aktuell: Fünf Jahre HartzReformen; http://www.bpb.de/themen/70CALY,0,0,F\%FCnf-Jahre_HartzReformen.html.

Bundeszentrale für politische Bildung 2009: Der Lissabonner Vertrag auf einen Blick. S. 2-3; http://www.bpb.de/files/634ZGY.pdf (Stand: 20.02.2010).

Bundeszentrale für politische Bildung (Hrsg.) 2010: Mitgliedstaaten der Europäischen Union. Online verfügbar unter: http://www.bpb.de/themen/R7H216.html

Butterwegge, Carolin 2009: Fit für die Globalisierung? Deutschland auf dem Weg zur Modernisierung seiner Migrations- und Integrationspolitik. In: Butterwegge, Christoph / Hentges, Gudrun (Hrsg.) 2009: Zuwanderung im Zeichen der Globalisierung: Migrations-, Integrations- und Minderheitenpolitik. Wiesbaden, S. 137-165.

Butterwegge, Christoph 2005: Krise und Zukunft des Sozialstaates. Wiesbaden, S. 184-189.

Büdenbender, Martin 2004: Das Verhältnis des Europäischen Gerichtshofs zum Bundesverfassungsgericht (Diss. Uni Bonn). Bonn, S. 151.

BÜNDNIS 90/DIE GRÜNEN (Hrsg.) 2009: Europawahlprogramm 2009: Für ein besseres Europa. Berlin, S. 79, 116-120. Im Internet: http://www.gruene.de (Stand: 07.06.2009).

Calic, Marie-Janine 1993: Jugoslawienpolitik am Wendepunkt. In: Aus Politik und Zeitgeschichte (APuZ) 1993, B 37/93, S. 11-20, hier S. 11.

Caporaso, James / Cowles, Maria Green / Risse, Thomas 2001: Europeanization and Domestic 
Change: Introduction. In: Cowles, Maria Green / Caporaso, James / Risse, Thomas (Hrsg.) 2001: Transforming Europe. Europeanization and Domestic Change. Ithaca: Cornell University Press, S. 3.

Castles, Stephen / Miller, Mark J. 1998: The Age of Migration. International Population Movements in the Modern World. London, S. 3-8 f.

Geddes, Andrew 2003: The EU Migration Regime's Effects on European Welfare States. In: Lavenex, Sandra / Ucarer, Emek M. (Ed.) 2003: Migration and the Externalities of European Integration. New York, S. 201-202.

Checkel, Jeffrey T. 2001: The Europeanization of Citizenship? In: James A. Caporaso, Maria Green Cowles und Thomas Risse (Hrsg.) 2001: Transforming Europe. Europeanization and Domestic Change. Ithaca, NY: Cornell University Press, S. 180-197.

Cholewinski, Ryszard 2001: Family Reunification and Conditions Placed on Family Members: Dismantling a Fundamental Human Right. In: European Journal of Migration and Law (EJML) 2001, 4. 3., S. 271-290.

Conzelmann, Thomas 2002: Große Räume, kleine Räume: Europäisierte Regionalpolitik in Deutschland und Großbritannien. Baden-Baden, S. 32, 35, 48-51, 254, 270.

Cram, Laura 1996: Integration theory and the study of the European policy process. In: Richardson, Jeremy J. (Ed.) 1996: European Union: power and policy-making. London, S. 40-58, hier S. 46-47.

Currle, Edda 2004: Migration in Europa - Daten und Hintergründe. Stuttgart, S. 18-20.

Frankfurter Allgemeine Zeitung (FAZ) 2000: Ruf nach fairer Lastenverteilung. Die Harmonisierung der Asyl- und Flüchtlingspolitik in der Europäischen Union, FAZ vom 01.12.2001, S. 3.

Davy, Ulrike / Cinar, Dilek 2001: Deutschland. In: Davy, Ulrike (Hrsg.) 2001: Die Integration von Einwanderern: Rechtliche Regelungen im europäischen Vergleich. Wien, S. 351.

Das Bundesverfassungsgericht (Hrsg.) 2010: Entscheidungen des Bundesverfassungsgerichts. Nr. 9. Urtiel des Zweiten Senats vom 30. Juni 2009. Vertrag von Lissabon. Tübingen, S. 267-268.

Der Spiegel 1995: „Nur wer schweigt, ist sicher“, Interview mit Justizministerin Sabine Leutheusser-Schnarrenberger (FDP) über die Abschiebung von Kurden. In: Der Spielgel vom 13.3.1995 (Nr. 11/1995). S. 25.

Deutscher Bundestag 1985: Drucksachen: BT-Drs. 10/4555 vom 12.12.1985, 11/3594 vom 07. 05.1990 .

Deutscher Bundestag 1995: Drucksachen: BT-Drs. 12/2453 vom 12.12.1995, S. 91, 93; 12/6485 (Anlage 2) vom 07.05.1995.

Deutscher Bundestag 1996: Drucksachen: BT-Drs. 13/3247 vom 06.12.1995, 13/4534 vom 07.05.1996.

Deutscher Bundestag 2000: Drucksachen: BT-Drs. 14/4357: Unterrichtung durch die Bundesregierung: Sechster Familienbericht: Familien ausländischer Herkunft in Deutschland: Leistungen-Belastungen-Herausforderungen und Stellungnahme der Bundesregierung. S. 40-45; www.bundestag.de.

Deutscher Bundestag 2002: Schlussbericht der Enquéte-Kommission „Demographischer Wandel - Herausforderungen unserer älter werdenden Gesellschaft an den Einzelnen und die Politik“. S. 36.

Die Linke 2008: Pressemitteilung vom 08. Juli 2008. Im Internet: http://die-linke.de/nc/presse

Die Linke 2009: Bundestagswahlprogramm der Partei DIE LINKE: Konsequent sozial. Für Demokratie und Frieden (Leitantrag des Parteivorstandes an den Bundestags-Wahlparteitag 2009 der Partei DIE LINKE am 20./21. Juni in Berlin), S. 20-34; http://die-linke.de

Die Welt 2000: Schily provoziert rot-grünen Asyl-Streit, Die Welt vom 13.07.2000. S. 2.

Die Welt 2000: Zuwanderungskommission: Süßmuth pfeift Fücks zurück, Die Welt vom 18.10.2000. S. 4. 
Die Zeit 2000: Offensiver Rückzug: Wie sich die CDU die Leitkultur als Leitbild verordnet, Die Zeit vom 09.11.2000. S. 4.

DiMaggio, Paul J. / Powell,Walter W. 1983: The Iron Cage Revisited: Institutional Isomorphism and Collective Rationality in Organization Fields. In: American Sociological Review 48. S. 147-160.

Dittberner, Jürgen 2005: Die FDP. Geschichte, Personen, Organisation, Perspektiven. Eine Einführung. Wiesbaden.

Dürr, Tobias 2002: Die Linke nach dem Sog der Mitte. In: Aus Politik und Zeitgeschichte (APuZ) B21/2002. S. 5-12, hier S. 10.

Eder, Klaus 1998: Warum ist Migration ein soziales Problem? Von einer politischen Ökonomie zu einer politischen Soziologie der Migration. In: Bommes, Michael / Halfmann, Jost (Hrsg.) 1998: Migration in nationalen Wohlfahrtsstaaten: Theoretische und vergleichende Untersuchungen. IMIS-Schriften Bd. 6. Osnabrück, S. 64.

EG/2000/2725: Verordnung des Rates vom 11. Dezember 2000 über die Einrichtung von „Eurodac" für den Vergleich von Fingerabdrücken zum Zwecke der effektiven Anwendung des Dubliner Übereinkommens. Im Internet:

http://europa.eu.int/smartapi/cgi/sga doc?smartapi!prod!CELEXnumdoc\&1g=DE\&numdoc $=32000 \mathrm{R} 2725 \&$ model $=$ guichett (Stand: 13.02.2006).

Egle, Christoph 2007: In der Regierung erstarrt? Die Entwicklung von Bündnis 90/Die Grünen von 2002 bis 2005. In: Egle, Christoph / Zohlnhöfer, Reimut (Hrsg.) 2007: Ende des rotgrünen Projektes: Eine Bilanz der Regierung Schröder 2002-2005. Wiesbaden, S. 114-115.

Eigmüller, Monika 2007: Grenzsicherungspolitik: Funktion und Wirkung der europäischen Außengrenze. Wiesbaden, S. 55, 59.

Elmar, Brok 2001: Der Vertrag von Nizza: Wird die EU handlungsfähig?. In: Frankfurter Allgemeine Zeitung vom 13. Januar 2001, S. 11.

Emmanouilidis, Janis. A. 2009: Deutschland in der EU. In: Weidenfeld, Werner / Wessels, Wolfgang (Hrsg.) 2009: Europa von A bis Z: Taschenbuch der europäischen Integration. Bonn, S. 112, 114.

Epiney, Astrid 1995: Das zweite Schengener Abkommen: Entstehung, Konzept und Einbettung in die Europäische Union. In: Achermann, Alberto / Bieber, Roland / Epiney, Astrid / Wehner, Ruth (Hrsg.) 1995: Schengen und die Folgen: Der Abbau der Grenzkontrollen in Europa. Bern u. a., S. 24-29.

Erklärung von Bundesaußenminister Fischer zu den Ergebnissen der Tagung des Europäischen Rates vor dem Deutschen Bundestag. Berlin, 11.11.2004 (Auszug). Abrufbar im Internet: http://www.auswaertiges-amt.de/diplo/de/Inforservice/Presse/Reden/Archiv/2004 (Stand: 05.05.2009).

Erklärung von Bundesaußenminister Steinmeier vor dem Europäischen Parlament zum Europäischen Rat am 21./22.06.2007 und zur Vertragsreform. Im Internet: http://www.auswaertiges-amt.de/diplo/de/Inforservice/Presse/Reden/2007/070607-MiniEPZsfsgEU-Praes.html

Erler, Petra 1998: Die institutionelle Reform und die Interessen der Länder. In: Borkenhagen, Franz H. U. (Hrsg.) 1998: Europapolitik der deutschen Länder: Bilanz und Perspektiven nach dem Gipfel von Amsterdam. Opladen, S. 208.

Esping-Andersen, Gosta 1987: The Comparison of Policy Regimes: An Introduction. In: Rein, Martin / Esping-Andersen, Gosta / Rainwater, Lee (Hrsg.) 1987: Stagnation and Renewal. The Rise and Fall of Policy Regimes. Armonk/New York, S. 3-13, hier S. 6.

Esping-Andersen, Gosta 1993: The Three Worlds of Welfare Capitalism. Princeton, S. 21f.

Esser, Hartmut 1980: Aspekte der Wanderungssoziologie. Assimilation und Integration von Wanderern, ethnischen Gruppen und Minderheiten. Eine handlungstheoretische Analyse. Darmstadt/Neuwied, S. 20, 25.

Ette, Andreas / Kreienbrink, Axel 2008: Kooperation statt Harmonisierung: Konsequenzen 
europäischer Governance für die Europäisierung der deutschen Rückkehr- und Abschiebungspolitik. In: Hunger, Uwe / Aybek, Can M. / Ette, Andreas / Michalowski, Ines (Hrsg.) 2008: Migrations- und Integrationsprozesse in Europa: Vergemeinschaftung oder nationalstaatliche Lösungswege?. Wiesbaden, S. 51-74.

Europa-Archiv (EA) 1991: 46 Jahrgang:1991, Folge 21/1991, S. D 537-539.

Europäische Kommission 1995: Finanzieller Beitrag der Europäischen Union zum Wiederaufbau im ehemaligen Jugoslawien. KOM (1995) 581 endg. 18.12.1995. Brüssel.

Europäische Kommission 2009: Die Rolle der NRO und Gewerkschaften bei der Bekämpfung der Diskriminierung. Luxemburg; http://ec.europa.eu/social/main.jsp?catId=649\&langId=de. S. 4-6.

Europäisches Parlament (Hrsg.) 2000: Arbeitsvorlage: Asyl in den EU-Mitgliedstaaten. Generaldirektion Wissenschaft. PE 285.899. Januar 2000. S. 31.

Europäischer Rat 1992: Erklärung zu den Grundsätzen für die externen Aspekte der Einwanderungspolitik, Schlussfolgerungen des Vorsitz Teil A, Anlage 5. In: EG-Nachrichten. Bericht und Informationen - Dokumentationen Nr. 15 vom 21. Dezember 1992, S. 25 ff.

Europäischer Rat 1999: Schlussfolgerungen des Vorsitzes in Tampere, 15. und 16. Oktober 1999; http://www.consilium.europa.eu/ueDocs/cms_Data/docs/pressData/de/ec/00200rl.d9.htm (SN 200/99).

Europolice 2009: ECLN Statement zum „Stockholm Programm“ der EU; http://www.stockholm.noblogs.org/post2009/04/15/ecln-statement-zum-stockholmProgramm-der-eu (Stand: 15.04.2009).

Eurostat Pressestelle (Hrsg.) 2009: Asylentscheidungen in der EU27, 2008: Die EUMitgliedstaaten erkannten 76.300 Asylbewerber als schutzberechtigt an. In: Eurostat Pressemitteilungen. Nr. 175/2009 - 8. Dezember 2009.; http://ec.europa.eu/eurostat

Eurostat (Hrsg.) 2010: Europa in Zahlen: Eurostat Jahrbuch 2010. Luxemburg, S. 161-181.

Eurostat-Pressestelle (Hrsg.) 2011: Ausländische Staatsangehörige machten 6,5\% der EU27 Bevölkerung im Jahr 2010 aus. In: Eurostat-Pressemitteilung, 105/2011-14.Juli. 2011. Online verfügbar unter: http://ec.europa.eu/eurostat

Everling, Ulrich 2009: Rechtsschutz in der Europäischen Union nach dem Vertrag von Lissabon. In: Schwarze, Jürgen / Hatje, Armin (Hrsg.) 2009: Europarecht (EuR): Der Reformvertrag von Lissabon. EuR-Beiheft 1/2009. Baden-Baden, S. 79, 85.

Ewers, Ruth 1931: Die soziologische und ökonomische Bedeutung der Einwanderung. Untersucht am Beispiel der Vereinigten Staaten von Nord-Amerika. Heidelberg, S. 39.

Fairchild, Henry Pratt 1925: Immigration: A World Movement and its American Significance. New York:Macmillan, S. 13 ff.

Faist, Thomas 1997: Migration und der Transfer sozialen Kapitals oder: Warum gibt es relativ wenige internationale Migranten?. In: Pries, Ludger (Hrsg.) 1997: Transnationale Migration. Baden-Baden (Soziale Welt;Sonderband. 12), S. 63-83.

Faist, Thomas 1998: Immigration, Integration und Wohlfahrtsstaaten. Die Bundesrepublik Deutschland in vergleichender Perspektive. In: Bommes, Michael und Halfmann, Jost (Hrsg.) 1998: Migration in nationalen Wohlfahrtsstaaten: Theoretische und vergleichende Untersuchungen. Osnabrück, S. 147, 152, 170.

Fassmann, Heinz / Münz, Rainer 1996: Europäische Migration - ein Überblick. In: Fassmann, Heinz / Münz, Rainer (Hrsg.) 1996: Migration in Europa. Historische Entwicklung, aktuelle Trends, politische Reaktionen. Frankfurt a. M., S. 13-52.

Fassmann, Heinz / Münz, Rainer (Hrsg.) 1996: Migration in Europa: Historische Entwicklung, aktuelle Trends und politische Reaktionen. Frankfurt a.M, S. 28-30.

Fawcett, James T. 1989: Networks, Linkages, and Migration Systems. In: International Migration Review (IMR) 1989, Volume 23, No. 3. New York, S. 671-680.

FDP-Bundestagsfraktion 2007: Pressemitteilung vom 23. Oktober 2007. Berlin.

FDP-Bundestagsfraktion 2008: Presseinformation vom 27.08.2008. Nr. 1083; http://www.fdp- 
fraktion.de

FDP 2009: Beschluss: Die Mitte stärken. Deutschlandprogramm der Freien Demokratischen Partei. 60. Ord. Bundesparteitags der FDP in Hannover, 15.-17. Mai 2009. S. 36-37.

Feithen, Rosemarie 1985: Arbeitskräftewanderungen in der Europäischen Gemeinschaft. Bestimmungsgründe und regionalpolitische Implikationen. Frankfurt/New York, S. 53.

Fellmer, Simon 2008: Europäische Migrationspolitik gegenüber Drittstaatsangehörigen. Ein klubtheoretischer Deutungsansatz zum Vergemeinschaftungswillen der Nationalstaaten. In: Hunger, Uwe / Aybek, Can M. / Ette, Andreas / Michalowski, Ines (Hrsg.) 2008: Migrationsund Integrationsprozesse in Europa: Vergemeinschaftung oder nationalstaatliche Lösungswege?. Wiesbaden, S. 104-105.

Fijnaut, Cyrille 1993: The „Communitization“ of Police Cooperation in Western Europe. In: Schermers, Henry G. et al. (Ed.) 1993: Free Movement of Persons in Europe. Legal Problems and Experiences. Dordrecht u. a., S. 81.

Fischer, Klemens H. 2003: Der Vertrag von Nizza. Text und Kommentar. Baden-Baden, S. 357358; http://europa.eu.int/comm/nice_treaty/index_en.htm

Fischer, Thomas 2007: Bundesländer und Bundesrat. In: Schmidt, Siegmar / Hellmann, Gunther / Wolf, Reinhard (Hrsg.) 2007: Handbuch zur deutschen Außenpolitik. Wiesbaden, S. 194 f., 197.

Flam, Helena (Hrsg.) 2007: Migranten in Deutschland. Statistiken - Fakten - Diskurse. Konstanz, S. 293-296.

Foerster, Viktor 1996: Rechtliche Grundlagen des Schengener Abkommen. In: Heckmann, Friedrich / Tomei, Verònica (Hrsg.) 1996: Freizügigkeit in Europa: Migrations- und europapolitische Aspekte des Schengen-Vertrages. Bonn, S. 25-28.

Frankfurter Allgemeine Zeitung (FAZ) 1994: „Koalition streitet über Abschiebestop für Kurden“, FAZ vom 16.12.1994.

Frankfurter Allgemeine Zeitung (FAZ) 1997: Die Gewinner von Amsterdam, FAZ vom 27.06.1997.

Frankfurter Allgemeine Zeitung (FAZ) 2004: „Einwanderungsgesetz tritt am 1. Januar 2005 in Kraft", FAZ vom 10.07.2004.

Franz, Mariella 2006: Familienzusammenführung in der Einwanderungspolitik der Europäischen Union. Rechtsfragen aus dem Europa- und Völkerrecht. IMIS-Beiträge, Heft 30/2006. Osnabrück: Institut für Migrtionsforschung und interkulturelle Studien. S. 45-68.

Gallagher, Stephen 2002: Towards a Common European Asylum System: Fortress Europe redesigns the ramparts. In: International Journal. Bd. 57. Summer 2002. Toronto, S. 385.

Geddes, Andrew 2000: Immigration and European Integration. Towards Fortress Europe?. Mancester/New York:Manchester University Press. S. 95.

Geddes, Andrew 2003/2005: The Politics of Migration and immigration in Europe. London:Sage, S. 132, 137.

Geddes, Andrew / Guiraudon, Virginie 2004: Britain, France, and EU Anti-Discrimination Policy. The Emergence of an EU Policy Paradigm. In: West European Politics, Vol. 27, Nr. 2 (March), S. 334.

Geiger, Rudolf 2004: EUV/EGV: Vertrag über die Europäische Union und Vertrag zur Gründung der Europäischen Gemeinschaft. München, S. 370.

Geiß, Bernd 2001: Die Ausländerbeauftragten der Bundesregierung in der ausländerpolitischen

Diskussion. In: Currle, Edda / Wunderlich, Tanja (Hrsg.) 2001: Deutschland - ein Einwanderungsland? Rückblick, Bilanz und neue Fragen. Stuttgart, S. 128.

Giersch, Carsten 1998: Konfliktregulierung in Jugoslawien 1991-1995: Die Rolle von OSZE, EU, UNO und NATO. Baden-Baden, S. 111, 134-136.

Giesecke, Johannes / Groß, Martin 2005: Arbeitsmarktreformen und Ungleichheit. In: Aus Politik und Zeitgeschichte (APuZ), 55. Jahrgang, 16/2005. Bonn, S. 27.

Glaab, Manuela / Gros, Jürgen / Korte, Karl-Rudolf / Wagner, Peter M. 1998: Wertgrundlagen 
und Belastungsgrenzen deutscher Europaplitik. In: Weidenfeld, Werner (Hrsg.) 1998: Deutsche Europapolitik: Optionen wirksamer Interessenvertretung. Bonn, S. 174.

Gomolla, Mechtild / Radtke, Frank-Olaf 2007: Institutionelle Diskriminierung. Die Herstellung ethnischer Differenz in der Schule. Wiesbaden.

Gormsen, Erdmann 1993: Internationale Migration. Begriffe - Hintergründe - Folgen. Ein weltweiter Vergleich. In: Gormsen, Erdmann / Thimm, Andreas (Hrsg.) 1993: Migration in der Dritten Welt. Mainz, S. 11 f.

Göhler, Gerhard 1997: Wie verändern sich Institutionen? Revolutionärer und schleichender Institutionenwandel. In: Göhler, Gerhard (Hrsg.) 1997: Institutionenwandel. Leviathan, Sonderheft 16/1997. Opladen, S. 21-56, hier S. 29.

Groeben, Hans von der / Thiesing, Jochen / Ehlermann, Claus-Dieter (Hrsg.) 1997: Kommentar zum EU-/EG-Vertrag. Band 5. Baden-Baden, S. 1013.

Groenleer, Martijn L.P. / Van Schaik, Louise G. 2007: United We Stand? The European Union's International Actorness in the Cases of the International Criminal Court and the Kyoto Protocol. In: Journal of Common Market Studies (JCMS). Volume 45. Number 5: December 2007. S. 969-998, hier S. 983.

Große Hüttmann, Martin / Knodt, Michéle 2000: Die Europäisierung des deutschen Föderalismus. In: Aus Politik und Zeitgeschichte (APuZ), B 52-53/2000. Bonn, S. 32.

Große Hüttmann, Martin 2005: Vom abstrakten zum konkreten Systemgestalter: Die Rolle des Europäischen Parlaments in den Regierungskonferenzen bis Nizza. In: Maurer, Andreas / Nickel, Dietmar (Hrsg.) 2005: Das Europäische Parlament: Supranationalität, Repräsentation und Legitimation. Baden-Baden, S. 42-45.

Grünhage, Jan 2007: Entscheidungsprozesse in der Europapolitik Deutschlands: Von Konrad Adenauer bis Gerhard Schröder (Diss., Bonn). Baden-Baden, S. 311.

Haack, Stefan 2010: Der Raum der Freiheit, der Sicherheit und des Rechts im Vertrag von Lissabon - Rhetorik oder Integrationsschub?. In: Leiße, Olaf (Hrsg.) 2010: Die Europäische Union nach dem Vertrag von Lissabon. Wiesbaden, S. 220-233, hier S. 232.

Haas, Ernst Bernard 1958: The Uniting of Europe: political, social, and economic forces 19501957. London.

Haase, Marianne / Jugl, Jan C. 2007: Asyl- und Flüchtlingspolitik der EU: Vergemeinschaftung der Asyl- und Migrationspolitik im neuen Jahrtausend. Online verfügbar unter http://www.bpb.de/themen/7H6FAJ,2,0,Asyl_und_F1\%FCchtlingspolitik_der_EU.html\#art2 (Stand: 27.11.2007).

Haftendorn, Helga 1994: Gulliver in der mitte Europas. Internationale Verflechtung und nationale Handlungsmöglichkeiten. In: Kaiser, Karl / Maul, Hanns W. (Hrsg.) 1994: Deutschlands neue Außenpolitik. Band 1: Grundlagen. Oldenbourg, S. 141.

Hailbronner, Kai 1995: Ausländerrecht: Kommentar. Heidelberg, D1.

Hailbronner, Kay 1995: Die europäische Asylrechtsharmonisierung nach dem Vertrag von Maastricht. In: Zeitschrift für Ausländerrecht und Ausländerpolitik (ZAR). Bd. 15. 1995. Baden-Baden. S. 3.

Hailbronner, Kay / Thiery, Claus 1997: Schengen II und Dublin - Der zuständige Asylstaat in Europa. In: Zeitschrift für Ausländerrecht und Ausländerpolitik (ZAR). Bd. 17. 1997. Baden-Baden. S. 55.

Hailbronner, Kay 1998: European Immigration and Asylum Law under the Amsterdam Treaty. In: Common Market Law Review (CMLR) 35. S. 1047-1067.

Hailbronner, Kay / Thiery, Claus 1998: Amsterdam-Vergemeinschaftung der Sachbereiche Freier Personenverkehr, Asyl und Einwanderung sowie Überführung des SchengenBesitzstands auf EU-Ebene. In: Europarecht, Heft 5, 33. Jahrgang 1998, September-Oktober 1998. S. 585.

Hailbronner, Kay 2000: Immigration and Asylum Law and Policy of the European Union. Hague u.a., S. 383. 
Hailbronner, Kay 2002: Migrationspolitik und Rechte der Drittstaatsangehörigen in der Europäischen Union. In: Zeitschrift für Ausländerrecht und Ausländerpolitik (ZAR), 3.2002, S. 86.

Hall, Peter 1993: Policy Paradigms, Social Learning and the State: The Case of Economic Policymaking in Britain. In:Comparative Politics, 25 (3). Jg., S. 275-296.

Hall, Peter A. / Taylor, Rosemary C. R. 1996: Poitical Science and the Three New Institutionalism. In: Political Studies 44 (5), S. 936-957.

Hammar, Tomas / Brochmann, Grete / Tamas, Kristof / Faist, Thomas (Ed.) 1997: International Migration Immobility and Development. A Multidisciplinary Perspective. Oxford:Berg.

Han, Petrus 2005: Soziologie der Migration: Erklärungsmodelle. Fakten. Politische Konsequenzen. Perspektiven. Stuttgart, S. 7, 12-17, 26-28, 34, 42-43, 59-64, 194, 200-204.

Hanschmann, Felix 2009: Die Ewigkeit dauert lange, besonders gegen Ende“ - eine rechtliche (Neu-) Bewertung des kommunalen Wahlrechts für Drittstaatsangehörige. In: Zeitschrift für Parlamentsfragen (ZParl) 40. Jahrgang, Heft 1/2009. Baden-Baden, S. 74-85, hier S. 75.

Hansen, Georg / Wennig, Norbert 1991: Migration in Vergangenheit und Zukunft. Hagen, S. 17.

Harmsen, Robert 2000: Europeanzation and Governance: A New Institutionalist Perspektive. In: Harmsen, Robert / Wilson, Thomas M. (Ed.) 2000: Europeanization: Institution, Identities and Citizenship. Amsterdam-Atlanta, S. 51-81.

Harmsen, Robert / Wilson, Thomas M. (Ed.) 2000: Europeanization: Institution, Identities and Citizenship. Amsterdam, S. 19-20.

Hauchler, Ingomar / Messner, Dirk / Nuscheler, Franz (Hrsg.) 1997: Globale Trends 1998. Fakten-Analysen-Prognossen. Frankfurt a. M., S. 108.

Häußermann, Hartmut / Kapphan, Andreas 2008: Integrationspolitik der Städte - ein Paradigmenwechsel. In: Bommes, Michael / Krüger-Potratz, Marianne (Hrsg.) 2008: Migrationsreport 2008: Fakten-Analysen-Perspektiven. Frankfurt a. M., S. 32-34.

Heinelt, Hubert (Hrsg.) 1994: Zuwanderungspolitik in Europa. Nationale Politiken. Gemeinsamkeiten und Unterschiede. Opladen.

Heinz, Wolfgang S. 2007: Menschenrechtspolitik. In: Schmidt, Siegmar / Hellmann, Gunther / Wolf, Reinhard (Hrsg.) 2007: Handbuch zur deutschen Außenpolitik. Wiesbaden, S. 692693.

Hemingway, Bernd / Beckers, Hans 2003: Förderung der freiwilligen Rückkehr ausländischer Mitbürger. In: Bundesamt für die Anerkennung ausländischer Flüchtlinge 2003. S. 131-159.

Henkel, Hans-Olaf 2001: Perspektiven der Zuwanderungspolitik. In: Klemmer, Paul 2001: Migration in Europa, Beihefte der Konjunkturpolitik, H. 52. Berlin, S. 10.

Herbert, Ulrich 2001: Geschichte der Ausländerpolitik in Deutschland: Saisonarbeiter, Zwangsarbeiter, Gastarbeiter, Flüchtlinge. München, S. 193-213, 225, 238-256, 263, $274-$ 276, 287-289, 319-322, 332-333.

Herdegen, Matthias 2006: Europarecht. München, S. 55.

Heß, Barbara 2009: Zuwanderung von Hochqualifizierten aus Drittstaaten nach Deutschland: Ergebnisse einer schriftlichen Befragung. In: Working Paper 28 der Forschungsgruppe des BAMF. Nürnberg, S. 11 (Fn. 1); http://www.bamf.de (erschienen 2009).

Heß, Barbara / Sauer, Leonore 2007: Migration von hoch Qualifizierten und hochrangig Beschäftigten aus Drittstaaten nach Deutschland. Working Paper Nr. 9, Nürnberg: Bundesamt für Migration und Flüchtlinge (BAMF), S. 32.

Hildebrandt, Achim 1996: Das Visumregime im Schengener Vertragswerk. In: Heckmann, Friedrich / Tomei, Verònica (Hrsg.) 1996: Freizügigkeit in Europa: Migrations- und europapolitische Aspekte des Schengen-Vertrages. Bonn, S. 47.

Hitzel-Cassagnes, Tanja 2000: Der Europäische Gerichtshof: Ein europäisches „Verfassungsgericht“"? In: Aus Politik und Zeitgeschichte (APuZ), B 52-53/2000. Bonn, S. 23.

Hofmann, Andreas / Wessels, Wolfgang 2009: Eine dauerhafte Verfassung für Europa? Die 
Beantwortung konstitutioneller Grundfragen durch den Vertrag von Lissabon. In: Decker, Frank (Hrsg.) 2009: Die Verfassung Europas: Perspektiven des Integrationsprojekts. Wiesbaden, S. 71-72, 79-81.

Hoffmann, Holger 2006: „One-Stop-Government“ - Was bedeuten die neuen Aufenthaltstitel? In: Davy, Ulrike / Weber, Albrecht (Hrsg.) 2006: Paradigmenwechsel in Einwanderungsfragen?: Überlegungen zum neuen Zuwanderungsgesetz. Baden-Baden, S. 42-58.

Hoffmann-Nowotny, Hans-Joachim 1970: Migration. Ein Beitrag zu einer soziologischen Erklärung. Stuttgart (Diss.), S. 60-64.

Hoffmann-Nowotny, Hans-Joachim 1973: Soziologie des Fremdarbeiterproblems: Eine theoretische und empirische Analyse am Beispiel der Schweiz. Stuttgart, S. 21.

Hofmann, Rainer / Donath, Philipp B. 2008: Die Asylverfahrensrichtlinie unter besonderer Berücksichtigung völkerrechtlicher Standards. In: Hofmann, Rainer / Löhr, Tillmann (Hrsg.) 2008: Europäisches Flüchtlings- und Einwanderungsrecht: Eine kritische Zwischenbilanz. Baden-Baden, S. 19-45.

Holzinger, Katharina 2005: Institutionen und Entscheidungsprozesse der EU. In: Lauth, HansJoachim / Zimmerling, Ruth (Hrsg.) 2005: Die Europäische Union: Theorien und Analysekonzepte. Paderborn, S. 107-108, 117.

Hörich, Carsten 2010: Die Sanktionsrichtlinie-Zündstoff zwischen EuGH und BVerfG? In: Zeitschrift für Ausländerrecht und Ausländerpolitik (ZAR), 30. Jahrgang, 2/2010. BadenBaden, S. 51.

Huber, Bertold 1998: Das Dubliner Übereinkommen. In: Neue Zeitschrift für Verwaltungsrecht (NVwZ). Bd. 17. 1998, Heft 2. München. S. 150.

Huysmans, Jef 2000: The European Union and the Securitization of Migration. In: Journal of Common Market Studies (JCMS), Vol. 38, No. 5. December 2000, S. 751-777.

Immergut, Ellen 1998: The Theoretical Core of the New Institutionalism. In: Politics and Society 26 (1), S. 5-34.

Ingram, Helen / Schneider, Anne 1990: Improving Implementation Through Framing Smarter Statutes. Journal of Public Policy 10, S. 67-88.

Internationale Politik (IP) 2010: „Für Deutschland wird die Blue Card nicht viel verändern.“ In: Internationale Politik (IP), Juli/August 2010. Nr. 4., 65. Jahrgang. Berlin, S. 80-81; http://www.internationalepolitik.de

Ipsen, Knut 1999: Völkerrecht: Ein Studienbuch. München, S. 291-295.

Ismayr, Wolfgang 2006: Das politische System Deutschlands. In: Ismayr, Wolfgang (Hrsg.) 2006: Die politischen Systeme Westeuropas. Wiesbaden, S. 471, 477-478.

Ismayr, Wolfgang 2007: Bundestag. In: Schmidt, Siegmar / Hellmann, Gunther / Wolf, Reinhard (Hrsg.) 2007: Handbuch zur deutschen Außenpolitik. Wiesbaden, S. 176, 187.

Jacobmeyer, Wolfgang 1992: Ortslos am Ende des Grauens: „Displaced Persons“ in der Nachkriegszeit. In: Bade, Klaus (Hrsg.) 1992: Deutsche im Ausland - Fremde in Deutschland. Migration in Geschichte und Gegenwart. München, S. 368.

Jahn, Daniela / Maurer, Andreas / Oetzmann, Verena / Riesch, Andrea 2006: Asyl- und Migrationspolitik der EU: Ein Kräftespiel zwischen Freiheit, Recht und Sicherheit. In: Diskussionspapier der FG 1, 2006 / 09, Juli 2006 SWP Berlin. Berlin, S. 25-26, 44-45.; http://www.swp-berlin.org (Stand: 30.11.2007).

Jann, Werner / Wegrich, Kai 2009: Phasenmodelle und Politikprozesse: Der Policy Cycle. In: Schubert, Klaus / Bandelow, Nils C. (Hrsg.) 2009: Lehrbuch der Politikfeldanalyse 2.0. S. $76,82-83$.

Jorry, Héléne 2007: Construction of a European Institutional Model for Managing Operational Cooperation at the EU's External Borders: Is the FRONTEX Agency a decisive step forward?. In: CEPS Challenge Liberty \& Security, Research Paper 6: http://www.ceps.be 
(Stand: 09.10.2008).

Kaiser, Karl / Angenendt, Steffen 2002: Asyl- und Migrationspolitik der Europäischen Union: Strukturen, Prozesse und Inhalte im Spannungsfeld nationalstaatlicher, intergouvernementaler, supranationaler und internationaler Regulierung. Eine Studie zur Dynamik des Regierens in einem postnationalen Mehrebenensystem, Forschungsprojekte der DGAP. Berlin, S. 15; http://www.aicgs.org.

Katzenstein, Peter J. 1987: Policy and Politics in West Germany. The Growth of a Semisovereign State. Philadelphia.

Katzenstein, Peter J. 2000: Gezähmte Macht: Deutschland in Europa. In: Knodt, Michèle / Kohler-Koch, Beate (Hrsg) 2000: Deutschland zwischen Europäisierung und Selbstbehauptung. Frankfurt a. M., S. 57-84, hier S. 58.

Keskin, Hakki 2005: Deutschland als neue Heimat: Eine Bilanz der Integrationspolitik. S. 152153, 163-164.

Klaus, Henning 1996: Die deutschen Bundesländer und die Europäische Union: Die Mitwirkung der Länder am EU-Integrationsprozess seit dem Vertrag von Maastricht. Vierow, S. 92.

Klos, Christian 1999: Eine Reise von Rom nach Amsterdam: Die Entwicklung des europäischen Einwanderungsrechts. In: Wolter, Achim (Hrsg.) 1999: Migration in Europa: Neue Dimensionen, neue Fragen, neue Antworten. Baden-Baden, S. 19, 24-33.

Kluth, Winfried 2009: Vertrauen ist gut, Kontrolle ist besser: Zur Bedeutung der Entscheidung des Bundesverfassungsgerichts zum Vertrag von Lissabon für das Ausländer- und Staatsangehörigkeitsrecht. In: Zeitschrift für Ausländerrecht und Ausländerpolitik (ZAR), 29. Jahrgang, 10/2009. Baden-Baden, S. 329.

Knelangen, Wilhelm 2001: Das Politikfeld innere Sicherheit im Integrationsprozess: Die Entstehung einer europäischen Politik der inneren Sicherheit. Opladen, S. 207, 239, 250.

Knill, Christoph / Lehmkuhl, Dirk 1999: How Europe Matters. Different Mechanisms of Europeanization. In: European Integration Online Papers (EIoP) Vol. 3 (1999) $\mathrm{N}^{0}$ 7, bes. S. 1-4; http:/www.eiop.or.at/eiop/texte/1999-007.htm (Stand: 15.06.1999).

Knill, Christoph / Lehmkuhl, Dirk 2002: The National Impact of European Union Regulatory Policy: Three Europeanization Mechanisms. In: European Journal of Political Research 41, S. 255-280.

Knill, Christoph 2005: Die EU und die Mitgliedstaaten. In: Holzinger, Katharina / Knill, Christoph / Peters, Dirk / Rittberger, Berthold / Schimmelfennig, Frank / Wagner, Wolfgang 2005: Die europäische Union: Theorien und Analysekonzepte. Paderborn, S. 153-159, 164166.

Knodt, Michèle 2000: Europäisierung: Eine Strategie der Selbstbehauptung?. In: Knodt, Michèle / Kohler-Koch, Beate (Hrsg.) 2000: Deutschland zwischen Europäisierung und Selbstbehauptung. Frankfurt a. M., S. 35.

Kohler-Koch, Beate 1998: Europäisierung der Regionen: Institutioneller Wandel als sozialer Prozeß. In: Kohler-Koch, Beate, u. a. (Hrsg.) 1998: Interaktive Politik in Europa. Regionen im Netzwerk der Integration. Opladen, S. 13-31.

Kohler-Koch, Beate 2000: Europäisierung: Plädoyer für eine Horizonterweiterung. In: Knodt, Michéle / Kohler-Koch, Beate (Hrsg.) 2000: Deutschland zwischen Europäisierung und Selbstbehauptung. Frankfurt a. M., S. 11, 19-27, 28 f (Fn. 17).

Kohler-Koch, Beate / Conzelmann, Thomas / Knodt, Michéle 2004: Europäische Integration Europäisches Regieren. Wiesbaden, S. 110, 134-138, 171, 177, 183.

Kohler-Koch, Beate / Edler, Jakob 1998: Ideendiskurs und Vergemeinschaftung: Erschließung transnationaler Räume durch europäisches Regieren. In: Kohler-Koch, Beate (Hrsg.) 1998: Regieren in entgrenzten Räumen. PVS-Sonderheft 29/1998. Opladen, S. 169-206.

KOM (Kommission der Europäischen Union) 1994: Mitteilung Zuwanderungs- und Asylpolitik, KOM (94) 23 endg. Brüssel. 
KOM (Kommission der Europäischen Union) 1999: 638 endg. vom 1. Dez. 1999 (Erster Vorschlag Familiennachzugs-RL), ABIEG 2000/C 116E/15, S. 66.

KOM (Kommission der Europäischen Union) 2000: 624 endg. vom 10. Okt. 2000 (Zweiter Vorschlag der Familiennachzugs-RL), ABIEG C 62E, S. 99.

KOM (Kommission der Europäischen Union) 2001: Vorschlag für eine Richtlinie des Rates über die Bedingungen für die Einreise und den Aufenthalt von Drittstaatsangehörigen zur Ausübung einer unselbstständigen oder selbstständigen Erwerbstätigkeit, Dok.-Nr. KOM (2001) 386 endgültig. Brüssel, 11. Juli 2001.

KOM (Kommission der Europäischen Union) 2002: 225 endg. vom 2. Mai 2002 (Dritter Vorschlag der Familiennachzugs-RL), ABlEG C 203, S. 136.

KOM (Kommission der Europäischen Union) 2005: Mitteilung der Kommission an den Rat und das EP vom Mai 2005: Das Haager Programm: Zehn Prioritäten für die nächsten fünf Jahre, $\operatorname{KOM}(2005) 184$ endg., S. 8-9.

http://www.europa.eu.int/smartapi/cgi/sga_doc?smartapi!celexplus!prod!DocNumber\&lg=d e\&type_doc $=$ COMfinal\&an_doc $=2005 \& n u \_d o c=184$ (Stand: 23.03.2006).

KOM (Kommission der Europäischen Union) 2005: Mitteilung der Kommission vom 21.12.2005: Der Strategische Plan zur legalen Einwanderung, $\mathrm{KOM(2005)} 669$ endgültig. Brüssel, S. 8-9; (Stand: 21.02.2006). http://europa.eu.int/eur-lex/lex/LexUriServ/site/de/com/2005/com2005_0669de01.pdf

KOM (Kommission der Europäischen Union) 2007: Vorschlag für eine Richtlinie des Rates über ein einheitliches Antragsverfahren für eine kombinierte Erlaubnis für Drittstaatsangehörige zum Aufenthalt und zur Arbeit im Gebiet eines Mitgliedstaates und über ein gemeinsames Bündel von Rechten für Drittstaatsangehörige, die sich rechtmäßig in einem Mitgliedstaat aufhalten, Dok.-Nr. KOM (2007) 638 endgültig, Brüssel, 23. Oktober 2007. S. 2.

KOM (Kommission der Europäischen Union) 2010: Mitteilung der Kommission an das europäische Parlament, den Rat, den europäischen Wirtschafts- und Sozialausschuss und den Ausschuss der Regionen: Ein Raum der Freiheit, der Sicherheit und des Rechts für die Bürger Europas: Aktionsplan zur Umsetzung des Stockholmer Programms. KOM (2010) 171 endgültig. Brüssel, S. 55.

Korte, Karl-Rudolf 2007: Der Pragmatiker des Augenblicks: Das Politikmanagement von Bundeskanzler Gerhard Schröder 2002-2005. In: Egle, Christoph / Zohlnhöfer, Reimut (Hrsg.) 2007: Ende des rot-grünen Projektes: Eine Bilanz der Regierung Schröder 20022005. Wiesbaden, S. 173, 189.

König, Christian / Pechstein, Matthias 1995: Die Europäische Union - Der Vertrag von Maastricht. Tübingen. S. 114, 118.

König, Thomas / Rieger, Elmar / Schmitt, Hermann (Hrsg.) 1996: Das europäische Mehrebenensystem. Frankfurt a. M., S. 21.

Kövel, Svea 2000: Die Mitwirkung des Deutschen Bundestages in Angelegenheiten der Europäischen Union - Unter besonderer Berücksichtigung der Mitwirkung am und der Veränderung durch den Vertrag von Amsterdam. München, S. 169.

Kreckel, Reinhard (Hrsg.) 1983: Soziale Ungleichheiten. Göttingen (Soziale Welt: Sonderband 2), S. 183-198, hier S. 191.

Kreienbrink, Axel 2004: Einwanderungsland Spanien: Migrationspolitik zwischen Europäisierung und nationalen Interessen. Frankfurt a. M., S. 20 (Fn 26), 21 (Fn 29).

Kropp, Sabine 2005: Regieren: Akteure, Strukturen, Prozesse. In: Gabriel, Oscar W. / Holtmann, Everhard (Hrsg.) 2005: Handbuch Politisches System der Bundesrepublik Deutschland. München, S. 129, 131.

Kröhnert, Steffen 2011: Zur demografischen Lage der Nation. In: Bundeszentrale für politischen Bildung (Hrsg.) 2011: Demografischer Wandel in Deutschland. Online verfügbar unter: http://www.bpb.de/themen/WM0Z6D.html 
Kuhn, Marco 2000: Humanitäre Hilfe der Europäischen Gemeinschaft. Entwicklung, System und primärrechtlicher Rahmen. Berlin, S. $249 \mathrm{ff}$.

Kühne, Peter / Rüßler, Harald 2000: Die Lebensverhältnisse der Flüchtlinge in Deutschland. Frankfurt a. M., S. 22.

Kürsat-Ahlers, Elcin 2002: Die Vorreiterrolle der Europäischen Union bei der Etablierung einer Antidiskriminierungsgesetzgebung in der Bundesrepublik Deutschland - Lernen von anderen Ländern. In: Treichler, Andreas (Hrsg.) 2002: Wohlfahrtsstaat, Einwanderung und ethnische Minderheiten. Wiesbaden, S. 261.

Ladrech, Robert 1994: Europeanization of Domestic Politics and Institutions: The Case of France. In: Journal of Common Market Studies (JCMS), 32 (1), 1994, S. 69-88. hier S. 69.

Lavenex, Sandra 2001: The Europeanisation of Refugee Policies: Between human rights and internal security. Aldershot u. a., S. 96-97.

Lavenex, Sandra 2001/2002: The Europeanisation of Refugee Policies. Between human rights and Internal security. Aldershot, S. 16, 39.

Lavenex, Sandra / Ucarer, Emek M. 2003: Introduction: The Emergent EU Migration Regime and Its External Impact. In: Lavenex, Sandra / Ucarer, Emek M. (eds.) 2003: Migration and the Externalities of European Integration. Lanham, S. 7.

Läufer, Thomas (Hrsg.) 1998: Vertrag von Amsterdam: Texte des EU-Vertrages und des EGVertrages. Bonn, S. 9, 81 f., 83; http://europa.eu.int/en/agenda/igc-home/amst.htm

Lee, Everett S. 1966: A Theory of Migration. In: Demography. Vol. 3, 1966/I. Washington, S. 47-57.

Lee, Everett S. 1972: Eine Theorie der Wanderung. In: Szèll, György (Hrsg.) 1972: Regionale Mobilität. Elf Aufsätze. München, S. 115-129..

Lee, Everett S. 1996: A Theory of Migration. In: Cohen, Robin (Ed.) 1996: Theories of Migration. Cheltenham/Brookfield, S. 16, 47-57.

Lehr, Ursula 2003: Die Jugend von gestern - und die Senioren von morgen. In: Aus Politik und Zeitgeschichte (APuZ) 2003/53. Jg., B 20/2003. Bonn, S. 3.

Leiße, Olaf (Hrsg.) 2010: Die Europäische Union nach dem Vertrag von Lissabon. Wiesbaden, S. 232.

Lepsius, M. Rainer 1995: Institutionenanalyse und Institutionenpolitik. In: Nedelmann, Birgitta (Hrsg.) 1995: Politische Institutionen im Wandel. Kölner Zeitschrift für Soziologie und Sozialphychologie (KZfSS), Sonderheft 35, Opladen, S. 392-403.

Link, Werner 2002: Deutschland als europäische Macht. In: Weidenfeld, Werner (Hrsg.) 2002: Europa-Handbuch. Gütersloh, S. 611-612.

Loeffelholz, Hans-Dietrich / Köpp, Günter 1998: Ökonomische Auswrikungen der Zuwanderung nach Deutschland. Essen, S. 83.

Loescher, Gil 1992: Refugee Movements and International Security. Adelphi Papers 268. London:Brassey's, S. 18.

Lösche, Peter 2003: SPD - Sozialdemokratische Partei Deutschlands. In: Andersen, Uwe / Woyke, Wichard (Hrsg.) 2003: Handwörterbuch des politischen Systems der Bundesrepublik Deutschland. Opladen, S. 572-577.

Luft, Stefan 2009: Staat und Migration: Zur Stuerbarkeit von Zuwanderung und Integration. Frankfurt a. M., S. 36, 59-60.

Maaßen, Hans-Georg 2006: Zum Stand der Umsetzung von elf aufenthalts- und asylrechtlichen Richtlinien der Europäischen Union. In: Zeitschrift für Ausländerrecht und Ausländerpolitik (ZAR) 5-6/2006, 26. Jahrgang. S. 162.

Mahnig, Hans 2001: „Ist Deutschland wirklich anders?“ Die deutsche Integrationspolitik im europäischen Vergleich. In: Currle, Edda / Wunderlich, Tanja (Hrsg.) 2001: Deutschland ein Einwanderungsland? Rückblick, Bilanz und neue Fragen. Stuttgart, S. 175-177.

March, James G. / Olsen, Johan P. 1989: Rediscovering Institutions: The Organizational Basis of Politics. New York. 
March, James G / Olsen, Johan P. 1998: The Institutional Dynamics of International Political Orders. International Organization 52 (4), S. 943-969.

Marinho, Clotilde / Heinonen, Matti 1998: Dublin after Schengen: Allocating Responsibility for Examining Asylum Applications in Practice. In: Institut Européene d'Administration Publique: EIPASCOPE, No. 1998/3. S. 7.

Marshall, Barbara 2000: Closer Integration or Re-Nationalization? Recent Trends in EU Migration and Asylum Policies: The Case of Germany. In: European Integration 22 (2000), 4. S. 425.

Martínez Soria, José 1998: Die polizeiliche Zusammenarbeit in Europa und der Rechtsschutz des Bürgers. In: Verwaltungsarchiv - Zeitschrift für Verwaltungslehre, Verwaltungsrecht und Verwaltungspolitik 89/1998, S. 418.

Märker, Alfredo 2005: Europäische Zuwanderungspolitik und globale Gerechtigkeit: Über die normative Dimension der Vergemeinschaftung zuwanderungspolitischer Maßnahmen in der Europäischen Union. Baden-Baden, S. 42.

Maurer, Andreas / Wessels, Wolfgang 2003: Das Europäische Parlament nach Amsterdam und Nizza: Akteur, Arena oder Alibi?. Baden-Baden, S. $14 \mathrm{ff}$.

Maurer, Andreas / Parkes, Roderick 2006: Asylum Policy and Democracy in the European Union from Amsterdam towards the Hague Programme. In: Diskussionspapier der FG 1, 2006 / 16. November 2006 SWP Berlin. Berlin, S. 25; http:/www.swpberlin.org/en/common/get_document.php?asset_id=2730\&PHPSESSID=7b23d71b9deec5ce b9c8e90c7ec9807f (Stand: 30.11.2007)

Maurer, Andreas 2007: Vertrag von Nizza. In: Weidenfeld, Werner / Wessels, Wolfgang (Hrsg.) 2007: Europa von A bis Z. Baden-Baden, S. 369-373.

Maurer, Daniel 2002: Europäische Sicherheit: Konfliktmanagement am Beispiel "ExJugoslawien”. In: Spillmann, Kurt R. / Wenger, Andreas (Hrsg.) 2002: Zürcher Beiträge: zur Sicherheitspolitik und Konfliktforschung Nr. 59. Forschungsstelle für Sicherheitspolitik und Konfliktanalyse der ETH Zürich, S. 79.

Meier-Braun, Karl-Heinz 2007: Der lange Weg ins Einwanderungsland Deutschland. In: Frech, Siegfried / Meier-Braun, Karl-Heinz (Hrsg.) 2007: Die offene Gesellschaft: Zuwanderung und Integration. Baden-Württemberg, S. 21-39.

Menzel, Jörg / Pierlings, Tobias / Hoffmann, Jeannine (Hrsg.) 2005: Völkerrechtsprechung. Tübingen, S. 465-466.

Meyer, Thomas 2002: Sozialstruktur und Migration - Die soziale Lage der Arbeitsmigranten in Deutschland. In: Treichler, Andreas (Hrsg.) 2002: Wohlfahrtsstaat, Einwanderung und ethnische Minderheiten: Probleme, Entwicklungen, Perspektiven. Wiesbaden, S. 70-71.

Mintzel, Alf 1997: Multikulturelle Gesellschaften in Europa und Nordamerika: Konzepte, Streitfragen, Analysen, Befunde. Passau, S. 470-474.

Moravcsik, Andrew / Nicolaidis, Kalypso 1999: Explaining the Treaty of Amsterdam: Interests, Influence, Institutions. In: Journal of Common Market Studies (JCMS). Volume 37. No. 1: March 1999. S. 59-85, hier S. 62-63, 79.

Motte, Jan / Ohliger, Rainer / Von Oswald, Anne (Hrsg.) 1999: 50 Jahre Bundesrepublik-50 Jahre Einwanderung: Nachkriegsgeschichte als Migrationsgeschichte. Frankfurt a. M.

Mühlum, Albert 1993: Armutswanderung, Asyl und Abwehrverhalten: Globale und nationale Dilemmata. In: Aus Politik und Zeitgeschichte (APuZ), 43 Jahrgang, B7/1993, S. 5.

Müller-Graff, Peter-Christian 1994: The legal Bases of the third Pillar and its Position in the Framework of the Union Treaty. In: Common Market Law Review(CMLR) 31. S. 493-498 f.

Müller-Graff, Peter-Christian 1997: Justiz und Inneres nach Amsterdam - Die Neuerungen in erster und dritter Säule. In: Integration, Jg. 20 (1997), S. 280.

Müller-Graff, Peter-Christian 2009: Der Raum der Freiheit, der Sicherheit und des Rechts in der Lissabonner Reform. In: Schwarze, Jürgen / Hatje, Armin (Hrsg.) 2009: Europarecht (EuR): Der Reformvertrag von Lissabon. EuR-Beiheft 1/2009. Baden-Baden, S. 115, 119. 
Müller, Doreen 2010: Flucht und Asyl in europäischen Migrationsregimen: Metamorphosen einer umkämpften Kategorie am Beispiel der EU, Deutschlands und Polens. Göttingen, S. 208-209.

Münscher, Alice 1979: Ausländische Familien in der Bundesrepublik Deutschland: Familiennachzug und generatives Verhalten. München, S. 36.

Münz, Rainer 1997: Phasen und Formen der europäischen Migration. In: Angenendt, Steffen 1997: Migration und Flucht: Aufgabe und Strategien für Deutschland, Europa und die internationale Gemeinschaft. S. 34-47.

Münz, Rainer / Seifert, Wolfgang / Ulrich, Ralf (Hrsg.) 1997: Zuwanderung nach Deutschland: Strukturen, Wirkungen, Perspektiven. Frankfurt a. M./New York, S. 36-41.

Münz, Rainer / Ulrich, Ralf 2000: Migration und zukünftige Bevölkerungsentwicklung in Deutschland. In: Bade, Klaus / Münz, Rainer 2000: Migrationsreport 2000. S. 39 ff., 56.

Nadoll, Jörg 2000: Die Europäische Union und die Konfliktbearbeitung in Ex-Jugoslawien 1991-1998 - Mühl- oder Meilenstein?. In: Schubert, Klaus / Müller-Brandeck-Bocquet, Gisela (Hrsg.) 2000: Die Europäische Union als Akteur der Weltpolitik. Opladen, S. 83-91.

Neisser, Heinrich / Verschraegen, Bea 2001: Die Europäische Union. Anspruch und Wirklichkeit. Wien, S. 22-23.

Newsletter ,Migration und Bevölkerung' 2000: Deutschland: Nach Green Card nun Blue Card; http://www.migration-info.de/mub_artikel.php?Id=000604 (Ausgabe 06/00).

Newsletter ,Migration und Bevölkerung' 2003: EU: Antidiskriminierungs-Richtlinie kaum umgesetzt; http://www.migration-info.de/mub_artikel.php?Id=030706 (Ausgabe 07/03).

Newsletter ,Migration und Bevölkerung' 2003: Deutschland: Zukunft des Zuwanderungsgesetzes weiter ungewiss; http://www.migrationinfo.de/mub_artikel.php?Id=031002 (Ausgabe 10/03).

Newsletter ,Migration und Bevölkerung' 2004: Deutschland: Einigung auf ein Zuwanderungsgesetz; http://www.migration-info.de/mub_artikel.php?Id=040501 (Ausgabe 05/04).

Newsletter ,Migration und Bevölkerung' 2005: Deutschland: Wahlprogramm im Vergleich. Im Internet: http://www.migration-info.de/mub_artikel.php?Id=050702 (Ausgabe 07/05).

Newsletter ,Migration und Bevölkerung' 2006: Deutschland: Verschärfung des Ausländerrechts durch Umsetzung von EU-Richtlinien; http://www.migrationinfo.de/mub_artikel.php?Id=060105 (Ausgabe 01/06).

Newsletter ,Migration und Bevölkerung' 2006: EU: Einheitliche Asylregelungen, mehr Befugnisse für EUROPOL; http://www.migration-info.de/mub_artikel.php?Id=060112 (Ausgabe 01/06).

Newsletter ,Migration und Bevölkerung' 2006: Deutschland: Antidiskriminierungsgesetz. Im Internet: http://www.migration-info.de/mub_artikel.php?Id=060302 (Ausgabe 03/06).

Newsletter ,Migration und Bevölkerung' 2006: Deutschland: Neue Einbürgerungsrichtlinien. Im Internet: http://www.migration-info.de/mub_artikel.php?Id=060503 (Ausgabe 05/06).

Newsletter ,Migration und Bevölkerung' 2006: Deutschland: Verschärfung des Ausländerrechts geplant; http://www.migration-info.de/mub_artikel.php?Id=060901 (Ausgabe 09/06).

Newsletter ,Migration und Bevölkerung' 2007: Deutschland: Debatte um Zuwanderungsgesetz im Bundestag; http://www.migration-info.de/mub artikel.php?Id=070408 (Ausgabe 04/07).

Newsletter ,Migration und Bevölkerung' 2007: Deutschland: Novellierung des Zuwanderungsrechts; http://www.migration-info.de/mub_artikel.php?Id=070601 (Ausgabe 06/07).

Newsletter ,Migration und Bevölkerung' 2007: Deutschland: Nationaler Integrationsplan Verabschiedet, http://www.migration-info.de/mub_artikel.php?Id=070602 (Ausgabe 06/07).

Newsletter ,Migration und Bevölkerung' 2007: EU-Kommission schlägt „Blue Card“ für Einwanderer vor; http://www.migration-info.de/mub_artikel.php?Id=070802 (Ausgabe 08/07). 
Newsletter ,Migration und Bevölkerung' 2007: Frankreich: Einwanderungsgesetz erschwert Familiennachzug; http://www.migration-info.de/mub_artikel.php?Id=070801 (Ausgabe 08/07).

Newsletter ,Migration und Bevölkerung' 2008: Deutschland: Integrationsmonitoring beschlossen; http://www.migration-info.de/mub_artikel.php?Id=080401 (Ausgabe 04/08).

Newsletter ,Migration und Bevölkerung' 2008: Deutschland: NRW: Erweitertes Kopftuchverbot; http://www.migration-info.de/mub_artikel.php?Id=080403 (Ausgabe 04/08).

Newsletter ,Migration und Bevölkerung' 2008: EU/Deutschland: Antidiskriminierung; http://www.migration-info.de/mub_artikel.php?Id=080508 (Ausgabe 05/08).

Newsletter ,Migration und Bevölkerung' 2008: Deutschland: Bundeseinheitlicher Einbürgerungstest; $\quad$ http://www.migration-info.de/mub artikel.php?Id=080601(Ausgabe 06/08).

Newsletter ,Migration und Bevölkerung' 2008: EU: Pakt zu Einwanderung und Asyl angenommen; http://www.migration-info.de/mub_artikel.php?Id=080904 (Ausgabe 09/08).

Newsletter ,Migration und Bevölkerung' 2008: Vereinigtes Königreich: Einwanderung erreicht Höchststand; http://www.migration-info.de/mub_artikel.php?Id=081011 (Ausgabe 10/08).

Newsletter ,Migration und Bevölkerung' 2009: Deutschland: Einbürgerungstest wird fast immer bestanden. Im Internet: http://www.migration-info.de/mub_artikel.php?Id=090101 (Ausgabe 01/09).

Newsletter ,Migration und Bevölkerung' 2009: Deutschland: SPD will „moderne Migrationspolitik“; http://www.migration-info.de/mub_artikel.php?Id=090402 (Ausgabe 04/09).

Newsletter ,Migration und Bevölkerung' 2009: Frankreich: Strenge Umsetzung des Einwandrungsgesetzes; $\quad$ http://www.migration-info.de/mub artikel.php?Id=090409 (Ausgabe 04/09).

Newsletter ,Migration und Bevölkerung' 2009: Deutschland: Zuwanderungs- und Integrationspolitik im Koalitionsvertrag. Im Internet: http://www.migrationinfo.de/mub_artikel.php?Id=090901 (Ausgabe 09/09).

Newsletter ,Migration und Bevölkerung' 2009: Deutschland: Diskussion um Integrationsvertrag. Im Internet: http://www.migration-info.de/mub_artikel.php?Id=091003 (Ausgabe 10/09).

Newsletter ,Migration und Bevölkerung' 2010: Vereinigtes Königreich: Einwanderungspolitik im Wahlkampf. In: http://www.migration-info.de/mub_artikel.php?Id=100405 (Ausgabe 04/10).

Newsletter ,Migration und Bevölkerung' 2010: Schweiz: Kontingente für Nicht-EUArbeitskräfte; http://www.migration-info.de/mub_artikel.php?Id=100510 (Ausgabe 05/10).

Newsletter ,Migration und Bevölkerung' 2010: Deutschland: Diskussion um Fachkräftemangel. In: http://www.migration-info.de/mub artikel.php?Id=100704 (Ausgabe 07/10).

Newsletter ,Migration und Bevölkerung' 2010: Vereinigtes Königreich: Einwanderungsquote in der Kritik. In: http://www.migration-info.de/mub_artikel.php?Id=100806 (Ausgabe 08/10).

Newsletter ,Migration und Bevölkerung' 2010: Dänemark: Strenges Punktesystem; http://www.migration-info.de/mub_artikel.php?Id=100907 (Ausgabe 09/10).

Newsletter ,Migration und Bevölkerung' 2010: Deutschland: FDP entfacht neue Debatte um ein Punktesystem; http://www.migration-info.de/mub_artikel.php?Id=100903 (Ausgabe 09/10).

Newsletter ,Migration und Bevölkerung' 2010: Deutschland: Fortsetzung der Debatte über Fachkräftemangel; http://www.migration-info.de/mub_artikel.php?Id=101003 (Ausgabe 10/10).

Newsletter ,Migration und Bevölkerung' 2011: Kurzmeldungen-Deutschland: Abschaffung der Optionspflicht gescheitert; http://www.migration-info.de/mub_artikel.php?Id=110905 (Ausgabe 09/11).

Newsletter ,Migration und Bevölkerung' 2011: Deutschland: Arbeitsmarkt offen. 
Im Internet: http://www.migration-info.de/mub_artikel.php?Id=110504 (Ausgabe 05/11).

Newsletter ,Migration und Bevölkerung' 2011: Deutschland: Einführung der „EU Blue Card“ für Hochqualifizierte. http://www.migration-info.de/mub_artikel.php?Id=110902 (Ausgabe 09/11).

Newsletter ,Migration und Bevölkerung' 2012: Deutschland: Bericht zu Integrationsmonitoring. Im Internet: http://www.migration-info.de/mub_artikel.php?Id=120103 (Ausgabe 01/12).

Newsletter ,Migration und Bevölkerung' 2012: Deutschland: Beschluss der Innenminister zum Bleiberecht. http://www.migration-info.de/mub_artikel.php?Id=120105 (Ausgabe 01/12).

Newsletter ,Migration und Bevölkerung' 2012: Deutschland: Bundesrat begrüßt Blue Card; http://www.migration-info.de/mub_artikel.php?Id=120205 (Ausgabe 02/12).

Newsletter ,Migration und Bevölkerung' 2012: Deutschland: Integrationspolitik soll verbindlicher werden. http://www.migration-info.de/mub_artikel.php?Id=120201 (Ausgabe $02 / 12$ ).

Niclauß, Karlheinz 1995: Das Parteiensystem der Bundesrepublik Deutschland: eine Einführung. S. 11.

Niclauß, Karlheinz 2004: Kanzlerdemokratie: Regierungsführung von Konrad Adenauer bis Gerhard Schröder. Paderborn, S. 337-339.

Niessen, Jan 2002: Zwischen Harmonisierung und kleinstem gemeinsamen Nenner: Einwanderungs-politik auf europäischer Ebene. In: Bade, Klaus J. / Münz, Rainer (Hrsg.) 2002: Migrationsreport 2002: Fakten, Analysen, Perspektiven. Frankfurt a. M., S. 207, 214.

Nohl, Arnd-Michael / Schittenhelm, Karin / Schmidtke, Oliver / Weiß, Anja 2010: Zur Einführung: Migration, kulturelles Kapital und Statuspassagen in den Arbeitsmarkt. In: Nohl, Arnd-Michael / Schittenhelm, Karin / Schmidtke, Oliver / Weiß, Anja (Hrsg.): Kuturelles Kapital in der Migration: Hochqualifizierte Einwanderer und Einwanderinnen auf dem Arbeitsmarkt. Wiesbaden, S. 9-10.

Nuscheler, Franz 2004: Internationale Migration: Flucht und Asyl. Wiesbaden, S. 137-190.

Nuttall, Simon J. 1995: The Commission and foreign policy-making. In: Edwards, Geoffrey / Spence, David (Ed.) 1995: The European Commission. London, S. 287-302.

Oberpenning, Hannelore 1999: Das ,Modell Espelkamp': Zur Geschichte der sozialen und kulturellen Eingliederung von Flüchtlingen, Vertriebenen und Aussiedlern. In: Motte, Jan / Ohliger, Rainer / Von Oswald, Anne (Hrsg.) 1999: 50 Jahre Bundesrepublik-50 Jahre Einwanderung: Nachkriegsgeschichte als Migrationsgeschichte. Frankfurt a. M., S. 31.

OECD: SOPEMI 1994: Continuous reporting system on migration. Jahresberichte 1989-1994. Paris, S. 188.

O'Keeffe, David 1995: Recasting the Third Pillar. In: Common Market Law Review (CMLR) 32. S. $893,898,901$.

Olsen, Johan P. 2002: The Many Faces of Europeanization. In: JCMS, 40 (5), S. 921-952 (ARENA Working Paper, WP 01/2); http://www.arena.uio.no/publications/wp01_2.htm (Stand: 23.08.2002).

Oltmer, Jochen 2010: Migration im 19. und 20. Jahrhundert. München, S. 45, 52-53.

Oppermann, Thomas 1999: Europarecht. München, S. 204 ff., 285 ff., 630 ff.

Oswald, Ingrid 2007: Migrationssoziologie. Konstanz, S. 66-67, 71-73.

Parusel, Bernd 2010: Abschottungs- und Anwerbungsstrategien: EU-Institutionen und Arbeitsmigration. (Dissertation Universität Osnabrück). Wiesbaden, S. 58, 142, 158, 225, 244-245.

Parusel, Bernd / Schneider, Jan 2010: Deckung des Arbeitskräftebedarfs durch Zuwanderung: Studie der deutschen Kontaktstelle für das Europäische Migrationsnetzwerk (EMN), Working Paper 32 der Forschungsgruppe des BAMF. Nürnberg, S. 20, 27, 55 (Fn. 41), 56, 61, 71-72; http://www.bamf.de (Stand: Juni 2010).

Paulsen, Thomas 1999: Die deutsche Rolle in Europa. In: Weidenfeld, Werner (Hrsg.) 1999: Europa-Handbuch. Gütersloh, S. 539-551 hier S. 543. 
Pechstein, Matthias / König, Christian 1998: Die Europäische Union. Die Verträge von Maastricht und Amsterdam. Tübingen. S. 180, 192-197, 288 ( Anhang), 308-319 (Anhang).

Peek, Jan / Hoefman, Merle 1993: The Dutch Perspective on Internationalization of Police Cooperation in Western Europe. In: Fijnaut, Cyrille (Ed.) 1993: The Internationalization of Police Cooperation in Western Europe. Deventer, Boston, S. 110.

Pehle, Heinrich / Sturm, Roland 2005: Die Europäisierung des politischen Systems. In: Gabriel, Oscar W. / Holtmann, Everhard (Hrsg.) 2005: Handbuch Politisches System der Bundesrepublik Deutschland. München, S. 885.

Petersen, William 1958: A General Typology of Migration. In: American Sociological Review (ASR), Vol. 23 (1/1958), S. 257, 266.

Petersen, William 1972: Eine allgemeine Typologie der Wanderung. In: Szèll, György (Hrsg.) 1972: Regionale Mobilität. Elf Aufsätze. München, S. 95-97, 109 (englisches Original von 1958).

Petri, Thomas Bernhard 2001: Europol - Grenzüberschreitende polizeiliche Tätigkeit in Europa. Frankfurt a. M., S. 25.

Pierson, Paul 2000: Increasing Returns, Path Dependence, and the Study of Politics. In: American Political Science Review 94 (2), S. 251-267.

Piotrowicz, Ryszard 2003: Dublin II und zukünftige Perspektiven eines gemeinsamen europäischen Asylsystems. In: Zeitschrift für Ausländerrecht und Ausländerpolitik (ZAR). Bd. 23. 2003. Baden-Baden, S. 386.

Poguntke, Thomas 2005: Politische Parteien. In: Gabriel, Oscar W. / Holtmann, Everhard (Hrsg.) 2005: Handbuch Politisches System der Bundesrepublik Deutschland. (S. 623-652), S. 628 .

Portes, Alejandro / Böröcz, József 1996: Contemporary Immigration: Theoretical Perspectives on its Determinants and Modes of Incorporation. In: Cohen, Robin (Ed.) 1996: Theories of Migration. Cheltenham/Brookfield, S. 156-180.

Pöttering, Hans-Gert 2009: Von Rom nach Lissabon. Die europäische Perspektive. In: Decker, Frank (Hrsg.) 2009: Die Verfassung Europas: Perspektiven des Integrationsprojekts. Wiesbaden, S. 25-27.

Presse- und Informationsamt der Bundesregierung 1991: Deutschlands Einheit vollenden. Die Einheit Europas gestalten. Dem Frieden der Welt dienen: Regierungspolitik 1991-1994 (Regierungserklärung von Bundeskanzler Dr. Helmut Kohl vor dem Deutschen Bundestag am 30. Januar 1991). S. 80-83.

Presse- und Informationsamt der Bundesregierung 1998: Die Regierungserklärung von Bundeskanzler Gerhard Schröder. Bonn, S. 34.

Presse- und Informationsamt der Bundesregierung 1999: Vor wichtigen Aufgaben: Das Arbeitsprogramm 1999 der Bundesregierung. Bonn, S. 16.

Presse- und Informationsamt der Bundesregierung 2002: Gerechtigkeit im Zeitalter der Globalisierung: Regierungserklärung von Bundeskanzler Gerhard Schröder vor dem Deutschen Bundestag. Berlin, S. 19-21.

Presse- und Informationsamt der Bundesregierung 2005: Bundeskanzler Gerhard Schröder: Reden Januar 2003-Dezember 2004. Paderborn, S. 22.

Presse- und Informationsamt der Bundesregierung 2005: Regierungserklärung von Bundeskanzlerin Angela Merkel vor dem Deutschen Bundestag. Berlin, S. 23-26, 41-42.

Presse- und Informationsamt der Bundesregierung 2007: Der Nationale Integraionsplan: Neue Wege-Neue Chancen. Berlin, S. 8-11.

Presse- und Informationsamt der Bundesregierung 2007: Eine neue Grundlage für Europa: Der Vertrag von Lissabon. Berlin, S. 3, 5, 13.

Preuß, Ulrich 1993: Zum verfassungstheoretischen Begriff des Staatsbürgers in der modernen Gesellschaft. In: Preuß, Ulrich (Hrsg.) 1993: Staatsbürgerschaft und Zuwanderung. Bremen: Zentrum für Europäische Rechtspolitik. S. 23. 
Pries, Ludger 1997: Neue Migration im transnationalen Raum. In: Pries, Ludger (Hrsg.) 1997: Transnationale Migration. Baden-Baden (Soziale Welt; Sonderband. 12), S 17.

Pries, Ludger 2001: Internationale Migration. Bielefeld.

Pro Asyl 2000: Offenes Europa oder Abschottungsgemeinschaft? Die Union auf dem Weg zu einem gemeinsamen Asylrecht. Frankfurt a. M.

Pro Asyl 2012: Presseerklärung: Bilanz: Ein Jahr Kampagne „Jetzt erst Recht(e) für Flüchtlingskinder!“; http://www.proasyl.de/de/presse/detail/news (Stand: 04.06.2012).

Pro Asyl 2012: Presseerklärung: PRO ASYL fordert Ende des deutschen Rückübernahmeabkommens mit Syrien; http://www.proasyl.de/de/presse/detail/news (Stand: 04.06.2012).

Prümm, Kathrin / Alscher, Stefan 2007: From Model to Average Student: the Europeanization of Migration Policy and Politics in Germany. In: Faist, Thomas / Ette, Andreas (Hrsg.) 2007: The Europeanization of National Policies and Politics of Immigration. Between Autonomy and the European Union. Basingstoke, S. 73-92.

Radaelli, Claudio M. 2000: Whither Europeanization? Concept Stretching and Substantive Change. In: European Integration Online Papers (EIoP) Vol. 4 (2000) $\mathrm{N}^{0}$ 8, S. 3-4.; http://www.eiop.or.at/eiop/texte/2000-008.htm (Stand: 17.07.2000).

Radaelli, Claudio M. 2003: The Europeanization of Public Policy. In: Featherstone, Kevin / Radaelli, Claudio M. (Hrsg.) 2003: The Politics of Europeanization. Oxford, S. 27-56.

Radaelli, Claudio M. / Exadaktylos, Theofanis 2009: Research Design in European Studies: The Case of Europeanization. In: Jounal of Common Market Studies (JCMS) 2009, Volume 47. Number 3: June 2009, S. 507-530.

Rat der Europäischen Union (Innen und Justiz) 1998: Presseerklärung Nr. 11282/98 (Presse 302), vom 24.09.1998.

Rat der Europäischen Union (Innen und Justiz) 1999: Aktionsplan des Rates und der Kommission zur bestmöglichen Umsetzung der Bestimmungen des Amsterdamer Vertrags über den Aufbau eines Raums der Freiheit, der Sicherheit und des Rechts, vom 3.12.98, ABL. EG Nr C 19/1 vom 23.01.1999.

Rat der Europäischen Union 2008: Europäischer Pakt zu Einwanderung und Asyl. Brüssel, den 24. September 2008, Dok.-Nr. 13440/08.

Rat der Europäischen Union 2009: Das Stockholmer Programm - Ein offenes und sicheres Europa im Dienste und zum Schutz der Bürger. Brüssel, den 2. Dezember 2009 (04.12), 17024/09, S. 58-73.

Ratsdokument im Bereich Migration und Rückkehr (MIGR) 2003: 6912/03 MIGR 16 (Einigung Familiennachzugs-RL).

Ravenstein, Ernest George 1972: Die Gesetze der Wanderung I und II. In: Szèll, György (Hrsg.) 1972: Regionale Mobilität. Elf Aufsätze, München, S. 41-94 (deutsche Übersetzungen der englischen Texte von 1885 und 1889).

Reißlandt, Carolin 2005: Von der „Gastarbeiter“-Anwerbung zum Zuwanderungsgesetz: Migrationsgeschehen und Zuwanderungspolitik in der Bundesrepublik. S. 6-9; http:/www.bpb.de/themen/6XDUPY.html (Stand: 15.03.2005).

Reißlandt, Carolin 2007: Arbeitsmarktinitiativen. S. 6. Im Internet: http://www.bpb.de/themen/4007ZM.html (Stand: 16.05.2007).

Reißlandt, Carolin 2007: Neue Zuwanderungs- und Integrationspolitik seit 2005. Im Internet: http://www.bpb.de/themen/0MOQFQ.html (Stand: 20.07.2007).

Reißlandt, Carolin / Schneider, Jan 2007: Regelungen der Arbeitsmigration bis 2004; http://www.bpb.de/themen/U189VO.html (Stand: 16.05.2007).

Rinsche, Günter / Friedrich, Ingo (Hrsg.) 1997: Europa als Auftrag: ,Der dritte Pfeiler des Maastrichter Vertrags - zwischenstaatliche Zusammenarbeit oder gemeinschaftliches Handeln'. Köln.

Rometsch, Dietrich 1999: Die Rolle und Funktionsweise der Europäischen Kommission. 
Frankfurt a. M.

Rosenau, James N. (Hrsg.) 1969: Linkage Politics. Essays on the Convergence of National and international Systems. New York/London, S. 65.

Rosenow, Kerstin 2008: Die Entstehung einer integrationspolitischen Agenda auf der Ebene der Europäischen Union. In: Hunger, Uwe / Aybek, Can M. / Ette, Andreas / Michalowski, Ines (Hrsg.) 2008: Migrations- und Integrationsprozesse in Europa: Vergemeinschaftung oder nationalstaatliche Lösungswege?. Wiesbaden, S. 123-142, hier S. 133.

Rudolph, Hedwig 1996: Die Dynamik der Einwanderung im Nichteinwanderungsland Deutschland. In: Fassmann, Heinz / Münz, Rainer (Hrsg.) 1996: Migration in Europa: Historische Entwicklung, aktuelle Trends und politische Reaktionen. Frankfurt a.M, S. 163, 168-173.

Salt, John 2005: Current trends in international migration in Europe. Evolution actuelle des migrations internationales en Europe. Strasbourg: Council of Europe Publ. (Migration collection), S. 11.

Santel, Bernhard 1995: Migration in und nach Europa: Erfahrungen. Strukturen. Politik. Opladen, S. 17-27, 57, 63, 71, 177 ff., 181.

Santel, Bernhard / Weber, Albrecht 2000: Zwischen Ausländerpolitik und Einwanderungspolitik: Migrations- und Ausländerrecht in Deutschland. In: Bade, Klaus J. / Münz, Rainer (Hrsg.) 2000: Migrationsreport 2000. Frankfurt a. M., S. 123.

Sassen, Saskia 1996: Migranten, Siedler, Flüchtlinge. Von der Massenauswanderung zur Festung Europa. Frankfurt a. M.

Scharpf, Fritz 1994: Autonomieschonend und gemeinschaftsverträglich. Zur Logik einer europäischen Mehrebenenpolitik. In: Scharpf, Fritz 1994: Optionen des Föderalismus in Deutschland und Europa. Frankfurt a. M., S. 131-155.

Scharpf, Fritz W. 2000: Interaktionsformen: Akteurzentrierter Institutionalismus in der Politikforschung. Opladen, S. 128.

Schelter, Kurt 1996: Innenpolitische Zusammenarbeit in Europa zwischen Maastricht und Regierungskonferenz 1996. In: Aus Politik und Zeitgeschichte (APuZ) B 1-2, S. 25.

Schieffer, Martin 1998: Die Zusammenarbeit der EU-Mitgliedstaaten in den Bereichen Asyl und Einwanderung. Baden-Baden, S. 63, 74.

Schmalz-Jacobsen, C. / Hinte, H. / Tsapanos, G., 1993: Einwanderung - und dann? München, S. 28.

Schmid, Christian / Bartels, Romy 2001: Handbuch zum Dubliner Übereinkommen. BadenBaden.

Schmid, Christian / Frank, Michaela 2001: Europäisches Asylrecht. Wien. S. 17.

Schmidt, Manfred G. 1999: Die Europäisierung der öffentlichen Ausgaben. In: Ellwein, Thomas / Holtmann, Everhard (Hrsg.) 1999: 50 Jahre Bundesrepublik Deutschland: Rahmenbedingungen, Entwicklungen, Perspektiven. Opladen, S. 385-394.

Schmidt, Manfred G. 2007: Das politische System Deutschlands: Institutionen, Willensbildung und Politikfelder. München, S. 85-86, 94-95, 163, 225, 230.

Schmidt-Nothen, Rainer 1987: Der lange Marsch durch viele Konferenzen. Es gibt noch viel zu tun - Verträge und Abkommen, die dem Kampf gegen das Verbrechen dienen. In: Kriminalistik 41, S. 411.

Schmidt, Susanne K. / Blauberger, Michael / van den Nouland, Wendelmoet 2008: Jenseits von Implementierung und Compliance - Die Europäisierung der Mitgliedstaaten. In: Tömmel, Ingeborg (Hrsg.) 2008: Die Europäische Union: Governance und Policy-Making. PVSSonderheft 40/2007. Wiesbaden, S. 277, 292-293.

Schmidt, Vivien A. 2001: Europeanization and the Mechanics of Economic Policy Adjustment. In: European Integration Online Papers (EIoP) 5(6); http://eiop.or.at/eiop/texte/2001006a.htm

Schneider, Jan 2007: Die Novellierung des Zuwanderungsgesetzes 2007. S. 1-4.; 
http://www.bpb.de/themen/OGZA5T.html (Stand: 15.05.2007).

Schneider, Jan 2007: Rückblick: Zuwanderungsgesetz 2005. S. 6; http://www.bpb.de/themen/TLG91N.html (Stand: 15.05.2007).

Schneider, Jens-Peter 1994: Effektiver Rechtsschutz Privater gegen EG-Richtlinien nach dem Maastricht-Urteil des Bundesverfassungsgerichts, AöR 119 (1994), S. 294-320.

Schoenemann, Peter 1994: Das Asylrecht in europäischen Staaten. Eine vergleichende Betrachtung. In: Heinelt, Hubert (Hrsg.) 1994: Zuwanderungspolitik in Europa: Nationale Politiken - Gemeinsamkeiten und Unterschiede. Opladen, S. 68-69.

Schoo, Johann 2009: Das neue institutionelle Gefüge der EU. In: Schwarze, Jürgen / Hatje, Armin (Hrsg.) 2009: Europarecht (EuR): Der Reformvertrag von Lissabon. EuR-Beiheft 1/2009. Baden-Baden, S. 55-57.

Schönwälder, Karen 1999: „Ist nur Liberalisierung Fortschritt?“: Zur Entstehung des ersten Ausländergesetzes der Bundesrepublik. In: Motte, Jan / Ohliger, Rainer / Von Oswald, Anne (Hrsg.) 1999: 50 Jahre Bundesrepublik-50 Jahre Einwanderung: Nachkriegsgeschichte als Migrationsgeschichte. Frankfurt a. M., S. 128.

Schönwälder, Karen 2004: Kleine Schritte, verpasste Gelegenheiten, neue Konflikte:

Zuwanderungsgesetz und Migrationspolitik. In: Blätter für deutsche und internationale Politik, Jahrgang 49/2004, Heft 2. Bonn, S. 1205, 1206 (Fn. 1), 1207, 1214.

Schönwälder, Karen 2006: Politikwandel in der (bundes-) deutschen Migrationspolitik. In: Davy, Ulrike / Weber, Albrecht (Hrsg.) 2006: Paradigmenwechsel in Einwanderungsfragen?: Überlegungen zum neuen Zuwanderungsgesetz. Baden-Baden, S. 8-22.

Schröder, Tim 2006: Die Fördermöglichkeiten bei der Rückkehr von Ausländern mit Finanzinstrumenten der EU. In: Zeitschrift für Ausländerrecht und Ausländerpolitik (ZAR). 26. Jahrgang 2006. S. 8-14.

Schubert, Klaus / Bandelow, Nils C. 2009: Lehrbuch der Politikfeldanalyse 2.0. Oldenbourg, S. $5,284$.

Schulte, Axel / Treichler, Andreas 2010: Integration und Antidiskriminierung: Eine interdisziplinäre Einführung. München, S. 7, 17-29, 38-40.

Schultz-Süchting, Nikolaus 2000: Kirchenasyl: zeitgeschichtliche und rechtliche Aspekte. Berlin (Humboldt-Univ. Diss.).

Schulze, Hagen 1994: Staat und Nation in der europäischen Geschichte. München.

Schwarze, Jürgen 2009: Der Reformvertrag von Lissabon - Wesentliche Elemente des Reformvertrages. In: Schwarze, Jürgen / Hatje, Armin (Hrsg.) 2009: Europarecht (EuR): Der Reformvertrag von Lissabon. EuR-Beiheft 1/2009. Baden-Baden, S. 12-19.

Schwentker, Björn / Vaupel, James W. 2011: Eine neue Kultur des Wandels. In: Aus Politik und Zeitgeschichte (APuZ) 2011/61. Jg., B 10-11/2011. Bonn, S. 3.

Scott, W. Richard 1995: Institutions and Organizations. Thousand Oaks, S. 33.

Seidel, Eberhard 2001: Grenzverläufe des Zumutbaren: Einsichten und Absichten deutscher Einwanderungspolitik. In: Blätter für deutsche und internationale Politik. 46/2001, Heft 2. S. 857-862, hier S. 860. auch im Internet: www.blaetter.de

Seifer, Kerstin 2009: Governance als Einfluss-System: Der politische Einfluss von NGOs in asymmetrisch strukturierten Interaktionsarrangements. Illustriert am Beispiel der Harmonisierung der Asylpolitik der Europäischen Union. Wiesbaden, S. 169.

Seifert, Wolfgang 2000: Geschlossene Grenzen - offene Gesellschaften?: Migrations- und Integrationsprozesse in westlichen Industrienationen. Frankfurt/New York, S. 27-46, 117.

Seifert, Hartmut 2005: Was bringen die Hartz-Gesetze? In: Aus Politik und Zeitgeschichte (APuZ), 55. Jahrgang, 16/2005. Bonn, S. 17 (Fn 1)., 17-23.

Senge, Konstanze / Hellmann, Kai-Uwe (Hrsg.) 2006: Einführung in den NeoInstitutionalismus: Mit einem Beitrag von W. Richard Scott. Wiesbaden.

Sieveking, Klaus 2001: Einwanderungs- und Flüchtlingspolitik: neue Perspektiven nach ‘Amsterdam'. In: Friedrich-Ebert-Stiftung (Hrsg.) 2001: Europäische Einwanderungs- und 
Flüchtlingspolitik. Gesprächskreis Arbeit und Soziales 97. Bonn, S. 21-46.

Sjaastad, Larry A. 1962: The costs and returns of human migration. In: The Journal of Political Economy (70/1962), Volume LXX, Number 5, Part 2. Chicago, S. 80-93.

Sodan, Helge 2009: Grundgesetz: Beck'scher Kompakt-Kommentar. München, S. 243.

Sontheimer, Kurt / Bleek, Wilhelm 2003: Grundzüge des politischen Systems Deutschlands. S. $276,317,343,355-361$.

Sontheimer, Kurt / Bleek, Wilhelm / Gawrich, Andrea 2007: Grundzüge des politischen Systems Deutschlands. München, S. 235-243, 352.

SPD-Bundestagsfraktion: Pressemitteilung vom 04.03.2009. Nr. 177/2009; www.spdfraktion.de

Statistisches Bundesamt (Hrsg.) 2002: Statistisches Jahrbuch 2002: Für die Bundesrepublik Deutschland. Wiesbaden, S. 44, 65.

Statistisches Bundesamt (Hrsg.) 2002: Statistisches Jahrbuch 2002: Für die Bundesrepublik Deutschland. Wiesbaden, S. 44, 65.

Statistisches Bundesamt (Hrsg) 2003: Bevölkerung Deutschlands bis 2050 - 10. koordinierte Bevölkerungsvorausberechnung. Wiesbaden, S. 10 ff., 31, 33, 65.

Statistisches Bundesamt (Hrsg) 2004: Statistisches Jahrbuch 2004. S. 26, 47.

Statistisches Bundesamt (Hrsg) 2005: Statistisches Jahrbuch 2005. S. 34, 48.

Statistisches Bundesamt (Hrsg) 2006: Statistisches Jahrbuch 2006: S. 34, 48.

Statistisches Bundesamt (Hrsg) 2007: Statistisches Jahrbuch 2007: S. 34, 48.

Statistisches Bundesamt (Hrsg) 2008: Statistisches Jahrbuch 2008: S. 34, 47.

Statistisches Bundesamt (Hrsg) 2009: Statistisches Jahrbuch 2009: S. 34, 51.

Statistisches Bundesamt (Hrsg.) 2010: Statistisches Jahrbuch 2010: Für die Bundesrepublik

Deutschland mit „Internationalen Übersichten“. Wiesbaden, S. 19, 21, 27, 31, 34, 42, 48-50, 52; www.destatis.de.

Stein, Otti 1992: Asylpoltik, Unionsbürgerschaft und Innere Sicherheit. In: Borkenhagen, Franz H. U. / Bruns-Klöss, Christian / Memminger, Gerhard / Stein, Otti (Hrsg.) 1992: Die deutschen Länder in Europa: Politische Union und Wirtschafts- und Währungsunion. Baden-Baden, S. 75-88., hier S. 82.

Storbeck, Jürgen 1997: Aufgaben und Perspektiven von Europol. In: Theobald, Volkmar (Hrsg.) 1997: Von der Europäischen Union zur Europäischen Sicherheitsunion. Berlin, S. 110.

Storz, Henning / Wilmes, Bernhard 2007: Wahlrecht und Einwanderung. Im Internet: http://www.bpb.de/themen/R8AQSN,0,0,Wahlrecht_und_Einwanderung.html (15.05.2007).

Straubhaar, Thomas / Wolter, Achim 1999: Migration in Europa - Neue Dimensionen, neue Fragen, neue Antworten In: Wolter, Achim (Hrsg.) 1999: Migration in Europa: Neue Dimensionen, neue Fragen, neue Antworten. Baden-Baden, S. 12.

Streinz, Rudolf 1999: Europarecht. Heidelberg, S. 49.

Streinz, Rudolf 2008: Der europäische Verfassungsprozess: Grundlagen, Werte und Perspektiven nach dem Scheitern des Verfassungsvertrags und nach dem Vertrag von Lissabon. München, S. 5, 20-22 (Fn. 11).

Streinz, Rudolf / Ohler, Christoph / Herrmann, Christoph 2008: Der Vertrag von Lissabon zur Reform der EU: Einführung mit Synopse. München, S. 133 f, 138, 143.

Sturm, Roland / Pehle, Heinrich 2001: Das neue deutsche Regierungssystem. Die Europäisierung von Institutionen, Entscheidungsprozessen und Politikfeldern in der Bundesrepublik Deutschland. Opladen.

Süddeutsche Zeitung (SZ) 1999: Luftkrieg gegen Jugoslawien verstärkt, SZ vom 27.04.1999.

Süddeutsche Zeitung (SZ) 1999: EU-Minister für besseren Schutz der Flüchtlinge, SZ vom 28.05.1999.

Süddeutsche Zeitung (SZ) 2001: Schily zu Entgegenkommen bereit. S. 8., SZ vom 06.12.2001.

Süddeutsche Zeitung (SZ) 2002: Koalition macht der Union Zugeständnisse. Senkung des Nachzugsalters für Kinder auf zwölf Jahre soll Unionsländern die Zustimmung ermöglichen. S. 1, SZ vom 26.02.2002: 
Süddeutsche Zeitung (SZ) 2003: Wenn die Babyboomer in Ruhestand gehen: Während auf Deutschland riesige Probleme bei der Bevölkerungsentwicklung zukommen, stehen die USA dank Zwanderung gut da, SZ vom 20.10.2003. S. 2.

Szèll, György (Hrsg.) 1972: Regionale Mobilität. Elf Aufsätze. München, S. 41-94.

Thränhardt, Dietrich 1995: Ausländer und Asyl. In: Andersen, Uwe / Woyke, Wichard (Hrsg.) 1995: Handwörterbuch des politischen Systems der Bundesrepublik Deutschland. Opladen, S. 14.

Thränhardt, Dietrich 1997: Zuwanderungspolitik im europäischen Vergleich. In: Angenendt, Steffen (Hrsg.) 1997: Migration und Flucht: Aufgaben und Strategien für Deutschland, Europa und die internationale Gemeinschaft. Bonn, S. 147.

Thym, Daniel 2008: Europäische Einwanderungspolitik: Grundlagen, Gegenstand und Grenzen. In: Hoffmann, Rainer / Löhr, Tillmann (Hrsg.) 2008: Europäisches Flüchtlings- und Einwanderungsrecht: Eine kritische Zwischenbilanz. Baden-Baden, S. 186.

Thym, Daniel 2010: Migrationsverwaltungsrecht. (Berlin, Humboldt-Univ., Habil. Schr.). Tübingen, S. 282-283.

Tietze, Klaudia 2008: Migration von Hochqualifizierten im Kontext der Entwicklung der Einwanderungskonzepte deutscher Parteien. In: Hunger, Uwe / Aybek, Can M. / Ette, Andreas / Michalowski, Ines (Hrsg.) 2008: Migrations- und Integrationsprozesse in Europa: Vergemeinschaftung oder nationalstaatliche Lösungswege?. Wiesbaden, S. 47.

Tomei, Verònica 1996: Migrationspolitische und europapolitische Perspektiven des Schengener Abkommens. In: Heckmann, Friedrich / Tomei, Verònica (Hrsg.) 1996: Freizügigkeit in Europa: Migrations- und europapolitische Aspekte des Schengen-Vertrages. Bonn, S. 92-98.

Tomei, Verónica 1997: Europäische Migrationspolitik: zwischen Kooperationszwang und Souveränitätsansprüchen. Bonn, S. 13, 17, 24-29, 36, 53 f., 59.

Tomei, Verónica 2001: Das Einwanderungsland Deutschland und die Europäisierung. In: Currle, Edda / Wunderlich, Tanja (Hrsg.) 2001: Deutschland - ein Einwanderungsland? Rückblick, Bilanz und neue Fragen. Stuttgart, S. 141.

Tomei, Verónica 2001: Europäisierung nationaler Migrationspolitik: Eine Studie zur Veränderung von Regieren in Europa. Stuttgart, S. 14, 20, 24, 40-46, 52 f., 55-57, 61, 67, 75-76, 82 (Fn 117), 83 (Fn. 118), 84-87, 134, 155-156, 179-182.

Tomei, Verònica / Heckmann, Friedrich 1999: Europäisierung und nationalstaatliche Souveränität - Das Beispiel Migrationspolitik. In: Wenzel, Heinz-Dieter (Hrsg.) 1999: Integration und Transformation in Europa. Forschungsform Heft 9/1999. Berichte aus der Otto-Friedrich-Universität Bamberg, S. 117.

Tömmel, Ingeborg 2008: Governance und Policy-Making im Mehrebenensystem der EU. In: Tömmel, Ingeborg (Hrsg.) 2008: Die europäische Union: Governance und Policy-Making. Wiesbaden, S. 20-31.

Tömmel, Ingeborg (Hrsg.) 2008: Die Europäische Union: Governance und Policy-Making. S. 15.

Treibel, Annette 2001: Von der Anwerbestoppausnahme-Verordnung zur Green Card: Reflexion und Kritik der Migrationspolitik. In: Currle, Edda / Wunderlich, Tanja (Hrsg.) 2001: Deutschland - ein Einwanderungsland? Rückblick, Bilanz und neue Fragen. Stuttgart, S. 114-117.

Treibel, Annette 2003: Migration in modernen Gesellschaften: Soziale Folgen von Einwanderung, Gastarbeit und Flucht. München, S. 17-27, 40, 55-63, 68, 72-73, 157-165, 177-178.

Treichler, Andreas 2002: Einwanderung und Europäisierung. Postnationale Arbeitsmärkte ohne wohlfahrtspolitische Verfassung?. In: Treichler, Andreas (Hrsg.) 2002: Wohlfahrtsstaat, Einwanderung und ethnische Minderheiten: Probleme, Entwicklungen, Perspektiven. Wiesbaden, S. 116-117.

Uhl, Hans-Peter / Grindel, Reinhard 2008: Zuwanderung: Punktesystem führt zu ungesteuerter 
Zuwanderung; http://www.cdu.de/archiv/2370_24547.htm (Stand: 14.10.2008).

Unabhängige Kommission Zuwanderung (UKZU) 2001: Zuwanderung gestalten, Integration fördern. Berlin. S. 87 ff.;

In: http://www.zuwanderung.de/downloads/Zuwanderungsbericht_kurz.pdf.

UNHCR 2000/2001: Zur Lage der Flüchtlinge in der Welt. 50 Jahre Humanitärer Einsatz. Bonn, S. 247.

UNHCR 2006: Anmerkungen zur Mitteilung der Europäischen Kommission an den Rat und das Europäische Parlament über Regionale Schutzprogramme: http://www.unhcr.at/pdf/1474.pdf (Stand: 28.06.2006).

UNHCR 2006: The Dublin II Regulation - A UNHCR Discussion Paper: Auszugsweise Übersetzung der UNHCR-Studie vom April 2006. S. 2-4. Im Internet: http://www.unhcr.de/fileadmin/unhcr data/pdfs/rechtsinformationen/2 EU/2 EUAsyl/B.01_Dubliner_Uebereinkommen/B.1.07.UNHCR-DublinII.pdf (Stand : 05.10.2009).

Van Waarden, Frans 2009: Institutionen zur Zentralisierung und Kontrolle politischer Macht. In: Schubert, Klaus / Bandelow, Nils C. (Hrsg.) 2009: Lehrbuch der Politikfeldanalyse 2.0. S. 283-291.

Vasileva, Katya 2010: Foreigners living in the EU are diverse and largely younger than the nationals of the EU Member States. In: Eurostat (Hrsg.) 2010: Statistics in focus, 45/2010. Catalogue number: KS-SF-10-045-EN-N. Luxembourg, S. 3. Online verfügbar unter: http://epp.eurostat.ec.europa.eu/portal/page/portal/population/publications/migrationasylum

Vogel, Wolfram 2010: Die Migration im Hintergrund: Strukturen der Integrationspolitik in Deutschland. In: Baasner, Frank (Hg.) 2010: Migration und Integration in Europa. BadenBaden, S 45.

Von Loeffelholz, Hans Dietrich 2011: Demografischer Wandel und Migration als Megatrends. In: Aus Politik und Zeitgeschichte (APuZ) 2011/61. Jg., B 10-11/2011. Bonn, S. 34-40.

Wachinger, Hans-Albrecht 1979: Erklärungen und Vorausschätzungen von Wanderungen: Entscheidungs- und systemtheoretische Ansätze und Analysen. Göttingen, S. 16-18.

Wahl, Rainer 2001: Das Bundesverfassungsgericht im europäischen und internationalen Umfeld. In : Aus Politik und Zeitgeschichte (APuZ) B 37-38/2001. Bonn, S. 45-54, hier S. 52.

Wallace, Helen 1990: Making Multilateral Negotiations Work. In: Wallace, William (Hrsg.) 1990: The Dynamics of European Integration. London, S. $223 \mathrm{f}$.

Wallace, Paul 1999: Altersbeben. Wie wir die demographische Erschütterung in Wirtschaft und Gesellschaft meistern werden. Frankfurt a. M./New York, S. 187.

Walter, Peter 2001: Die Darstellung der Europäischen Integrationspolitik des Bundeskanzlers Helmut Kohl in ausgewählten deutschen Printmedien (Diss., Gießen). Gießen, S. 11.

Walter, Anne 2003: Familiennachzug - ein Mittel zur Integration? In: Sahlfeld, Konrad u. a. (Hrsg.) 2003: 43. Assistententagung Öffentliches Recht. Luzern, S. 181-196.

Weber, Albrecht 1993: Einwanderungs- und Asylpolitik nach Maastricht. In: Zeitschrift für Ausländerrecht und Ausländerpolitik (ZAR). Bd. 13. 1993. Baden-Baden. S. 13.

Weber, Albrecht / Walter, Anne 2003: The Right of Protection of Family for Migrants in Europe: Access and Integration of Family Reunion. In: von Hoffmann, B. (Hrsg.) 2003: Towards a Common European Immigration Policy. Frankfurt a. M., S. 227 ff.

Weber, Max 1988 (Erstausgabe: 1918): Parlament und Regierung im neugeordneten Deutschland. Zur politischen Kritik des Beamtentums und Parteiwesens. In: Weber, Max: Gesammelte Politische Schriften, hg. v. Johannes Winkelmann. Tübingen, S. 324.

Weidenfeld, Werner / Wessels, Wolfgang (Hrsg.) 2007: Europa von A bis Z. Baden-Baden, S. 35-37.

Weidenfeld, Werner (Hrsg.) 2008: Die Europäische Union: Politisches System und Politikbereiche. Bonn, S. 825 (Anhang).

Weidenfeld, Werner / Wessels, Wolfgang (Hrsg.) 2009: Europa A bis Z: Taschenbuch der europäischen Integration. Berlin, S. 445. 
Weinzierl, Ruth 2009: Der Asylkompromiss 1993 auf dem Prüfstand. Deutsches Institut für Menschenrechte, Berlin, Juli 2009. Im Internet: http://www.institut-fuermenschenrechte.de/fileadmin/user_upload/PDF-

Dateien/Ergebnispapiere_Zusammenfassungen_Hintergrundpapiere/zusammenfassung_studie der_asylkompromiss_1993_auf_dem_pruefstand.pdf

Weizsäcker, Esther 2005: Vom „Inlandslegitimierungszwang“ zum „Zuwanderungsgesetz“: Zur rechtlichen Regulierung der Arbeitsmigration in Deutschland. In: Geisen, Thomas (Hrsg.) 2005: Arbeitsmigration: WanderarbeiterInnen auf dem Weltmarkt für Arbeitskraft. Frankfurt a. M., S. 189 f., 192-193.

Weizsäcker, Jakob 2010: Die enge Pforte: Prioritäten für die europäische Migrationspolitik. In: Baasner, Frank (Hrsg.) 2010: Migration und Integration in Europa. Baden-Baden, S. 236.

Welsch, Johann 2000: Green Cards für die New Economy. Eine erste Bilanz. In: Blätter für deutsche und internationale Politik. Jahrgang 45/2000, Heft 12. Bonn, S. 1476, 1480-1482.

Wessel, Wolfgang 1997: Der Amsterdamer Vertrag - Durch Stückwerksreformen zu einer effizienteren, erweiterten und föderalen Union?. In: Integration, Jg. 20. 3/1997. S. 122.

Wessels, Wolfgang 1999: Das politische System der EU. In: Weidenfeld, Werner (Hrsg.) 1999: Europa-Handbuch. Gütersloh, S. 344.

Wessels, Wolfgang 2008: Das politische System der Europäischen Union. Wiesbaden, S. 89, 97 , 101, 201-202, 441.

Widgren, Jonas 1999: Rückkehr nach Bosnien-Herzegowina: Lektionen für eine europäische Migrationspolitik. In: Internationale Politik (IP). 54. Jahrgang/April 1999. Band 1. Nr. 4. S. 32-38.

Wilp, Markus 2007: Die Arbeitsmarktintegration von Zuwanderern in Deutschland und den Niederlanden: Hintergründe, aktuelle Entwicklungen und politische Maßnahmen. Münster, S. 72.

Winchie, Diana B. / Carment, David W. 1989: Migration and Motivation: The Migrant's Perspective. In: International Migration Review (IMR) 1989, Volume 23, No. 1. New York, S. 96-104.

Winkler, Beate 2001: Bestrebungen zur Bekämpfung von Rassismus und Fremdenfeindlichkeit in der Europäischen Union. In: Arnim, Gabriele von u. a. (Hrsg.) 2001: Jahrbuch Menschenrechte 2002. Frankfurt a. M., S. 262-270.

Wolfram 2010: Die Migration im Hintergrund: Strukturen der Integrationspolitik in Deutschland. In: Bassner, Frank (Hrsg.) 2010: Migration und Integration in Europa. S. 43.

Wolter, Achim 1999: Von der unternehmensinternen zur unternehmensinduzierten Migration Höherqualifizierter in Europa. In: Wolter, Achim (Hrsg.) 1999: Migration in Europa: Neue Dimensionen, neue Fragen, neue Antworten. Baden-Baden, S. 38-55.

Woyke, Wichard 2000: Deutsch-französische Beziehungen seit der Wiedervereinigung: Das Tandem faßt wieder Tritt. Opladen, S. 56, 70-71.

Würz, Karl 1997: Das Schengener Durchführungsübereinkommen: Einführung. Erläuterungen. Vorschriften. Stuttgart u. a., S. 29, 49-50, 163-223.

Zolberg, Aristide R. 1981: International Migrations in Political Perspektive. In: Kritz, Mary M. / Keely, Charles B. / Tomasi, Silvano M. (Ed.) 1981: Global Trends in Migration. Theory and Research on International Population Movements. New York:Center for Migration Studies, S. 3-27, hier S. 7. 
Erklärung

„Ich versichere, dass ich die eingereichte Dissertation Europäisierung deutscher Migrationspolitik selbständig und ohne unerlaubte Hilfsmittel verfasst habe. Anderer als der von mir angegebenen Hilfsmittel und Schriften habe ich mich nicht bedient. Alle wörtlich oder sinngemäß den Schriften anderer Autoren entnommenen Stellen habe ich kenntlich gemacht.“

Nam-Eun Lee, 2012 


\section{Lebenslauf (Curriculum vitae)}

Name : Lee, Nam-Eun

Geburt : am 20. Januar 1968 in Tanyang, Korea

Eltern : Lee, Hang-Gu und Cho, Yang-Hyung

\section{Staatsangehörigkeit : koreanisch}

\section{Schulbesuch}

März 1974 - Feb. 1980 : Grundschule „Tanyang“ in Tanyang

März 1980 - Feb. 1983 : Mädchenmittelschule „Tanyang“ in Tanyang

März 1983 - Feb. 1986 : Mädchenoberschule „Chungbuk“ in Chongju

\section{Studium}

März 1986 - Feb. 1990 : An der Chongju-Universität in Chongju, Korea

(Germanistik für Bachelor of Art)

\section{Berufliche Tätigkeit}

Juni 1990 - Feb. 1998 : Angestellte bei einer Firma in Seoul, Korea

\section{Auslandsstudium}

Okt. 1998 - Juli. 1999 Sprachkursbesuch am Deutschen Lektorat an der Georg-August-Universität Göttingen

Okt. 1999 - Feb. 2001 Grundstudium für Politikwissenschaft, Medien- u. Kommunikationswissenschaft, Soziologie an der Georg-August-Universität Göttingen

Juli 2001 - Sep. 2001 Zwischenprüfung für Politikwissenschaft (Hauptfach), Medien- u. Kommunikationswissenschaft (1. Nebenfach), Soziologie (2. Nebenfach)

Okt. 2001 - Feb. 2003 Hauptstudium für Politikwissenschaft, Medien- u. Kommunikationswissenschaft und Soziologie an der Georg-August-Universität Göttingen

März 2003 - Nov. 2004 Magisterprüfung für Politikwissenschaft (Hauptfach), Medien- u. Kommunikationswissenschaft (1. Nebenfach), Soziologie (2. Nebenfach)

17. Nov. 2004 Abschluss : Magistra Artium Magisterarbeit zum Thema: „Die Politik der Bundesregierung zur Vereinigung der beiden deutschen Staaten (BRD und DDR) 1989-1991“

Sep. 2005 - Okt. 2011 Promotion zum Thema: „Europäisierung deutscher Migrationspolitik“, Georg-August-Universität Göttingen 